\title{
Regulation der Synthese der Glukosamin-6-Phosphat Synthase GImS in Escherichia coli durch das neuartige Protein YhbJ
}

\author{
Dissertation \\ zur Erlangung des Doktorgrades \\ der Mathematisch-Naturwissenschaftlichen Fakultäten \\ der Georg-August-Universität zu Göttingen
}

vorgelegt von

Falk Kalamorz

aus

Bad Lauterberg

Göttingen 2008 
D7

Referent: $\quad$ Prof. Dr. Jörg Stülke

Korreferent: Dr. Michael Hoppert

Tag der mündlichen Prüfung: 19.01.2009 
Goodbye, old friend, goodbye.

Good night.

I'tl move on,

you'll call it fate,

I'll call it Karma.

We had our time,

it was fun while it lasted.

I'tl look 6ack

with honour and no regrets.

I won't be mad,

won't feel $6 a d$,

these memories will never leave me.

Don't be sad,

because life goes on,

life goes on.

It's getting too late,

tomorrow is here.

Silverstein - Call it karma 


\section{Danksagung}

Bevor ich hier in die Details gehe möchte ich erstmal allen danken.

Jedem Einzelnen, der mich in den letzten Jahren (oder überhaupt einmal) in dem unterstützt hat, was ich gemacht habe.

Nicht nur im Labor, sondern insgesamt.

Es gibt so viele Leute, die hier nicht persönlich erwähnt werden, die aber trotzdem auf die eine oder andere Art dazu beigetragen haben, dass ich heute an diesem Punkt angelangt bin.

Das hier geht an alle, die an mich geglaubt haben.

An alle, die mir offen begegnet sind.

An alle, die mir gesagt haben, das sie gut finden, was ich mache.

Euch allen sei hiermit gesagt:

Danke für alles!

So, nach dieser allgemeinen Ansage nun zu den Einzelheiten:

An erster Stelle danke ich natürlich Professor Jörg Stülke, in dessen Abteilung ich meine Doktorarbeit anfertigen durfte und Dr. Boris Görke für das interessante Projekt und die Unterstützung meiner Arbeiten.

Dr. Michael Hoppert gebührt mein herzlicher Dank für die Übernahme des Korreferats dieser Arbeit.

Slawomir Milewski hat uns glücklicherweise FMDP überlassen, und von Bernard Badet erhielten wir die Antikörper gegen GlmS. Karin Schnetz danke ich nicht nur für die wiederholte Versorgung mit Stämmen und Plasmiden, sondern auch für die freundliche Betreuung während meines Aufenthalts in Köln. Jörg Vogel möchte ich für die Möglichkeit danken, dass ich mehrere Wochen in Berlin arbeiten durfte, in denen ich sehr viel gelernt und Neues kennengelernt habe. Kai Papenfort hat mich in dieser Zeit sehr gut in meiner Arbeit unterstützt und war immer da, wenn es mal brannte.

Natürlich bedanke ich mich auch bei allen aktuellen und ehemaligen Mitgliedern der AG Görke für die Zusammenarbeit. Ganz besonders erwähnen möchte ich hier Ricarda, Antje und Sabine, und es hat viel Spaß gemacht, mit euch zu arbeiten. Und natürlich Maria, die sich immer bemüht hat, eine angenehme Arbeitsatmosphäre zu schaffen. 
Sabine Lentes hat mich nicht nur äußerst kompetent in meiner Arbeit unterstützt, sondern auch immer Rücksicht genommen, wenn ich mal einen sehr schlechten Tag hatte. Danke, dass du dir diese Mühe gemacht hast. Du hast mir sehr geholfen.

So, jetzt bin ich schon beim Rest der Abteilung. Christina Herzberg und Julia Busse halfen mir immer mit Rat und Tat, wenn es nötig war. Ebenso waren alle Kollegen immer eine große Hilfe (nicht nur im Labor) und es war toll, in diesem Umfeld zu arbeiten. Und natürlich ein herzliches Dankeschön an all die guten Geister des Instituts, die immer alles am Laufen halten: Bärbel, Nicole, Olaf, Patrick und Gerd.

Ein kurzes Gedenken an die, die von uns gegangen sind...

Die AG Mascher hat mir verdammt gefehlt in der letzten Zeit, und damit meine ich nicht nur die Kaffeemaschine!

Thorsten, nochmals: Danke für alles.

Sina, du warst immer für mich da, und hast auch mein ständiges Jammern auf hohen Niveau ertragen. Ich wünsch dir alles Gute für deine Zukunft (ohne Labor?!?).

Jessi, was hätte ich ohne dich nicht alles verpasst $;$. Danke, dass du mich immer mal wieder für ein paar Stunden aus meiner kleinen (Labor-) Welt geholt hast, und für ein paar ziemlich coole Aktionen.

Sebastian, wenn es nicht das Schicksal war, das uns beide zusammengeführt hat, muss es der Teufel gewesen sein $\odot$. Wird schwer nach so langer Zeit ohne dich klar kommen zu müssen.

Meiner Familie kann ich nur dasselbe sagen wie immer: Danke für alles, was ihr je für mich getan habt. Ich weiß, dass ihr immer an mich geglaubt habt, und jetzt bin ich da, wo ich sein wollte. Ihr habt mich immer unterstützt und all meine Spinnereien ertragen. Ich liebe euch!

Gudrun, ich liebe dich! Du bist mein Antrieb, mein Halt und mein Schutz.

Du bist das Einzige auf dieser Welt, das ich nie mehr missen möchte.

Sometimes Ifeel like I'm still dreaming... 


\section{Inhaltsverzeichnis}

Inhaltsverzeichnis

$\begin{array}{ll}\text { Abkürzungsverzeichnis } & \text { VI }\end{array}$

1. Zusammenfassung 1

$\begin{array}{lr}\text { 2. Einleitung } & 2\end{array}$

2.1. E. coli als Modellorganismus 2

2.2. Regulation der Genexpression 2

2.3. Das rpoN-Operon 3

2.3.1. rpoN 4

2.3.2. $h p f \quad 6$

2.3.3. ptsN und $n p r \quad 6$

2.3.4. $y h b J$

2.3.5. Die Deletion von $y h b J$ führt zu einer Akkumulation von GlmS 9

2.4. Aminozucker-Metabolismus 11

2.4.1 Die Glukosamin-6-Phosphat Synthase GlmS 11

2.4.2. Kataboler Abbau von Glukosamin-6-P 13

$\begin{array}{ll}\text { 2.4.3. Regulation des glmUS-Operons durch NagC } & 14\end{array}$

2.4.4. Regulation von GlmS in B. subtilis und in Eukaryoten 15

2.4.5. YhbJ-abhängige Regulation der $g \operatorname{lm} S$-Expression durch

$\begin{array}{ll}\text { Stabilisierung einer } g \operatorname{lm} S \text {-spezifischen mRNA } & 17\end{array}$

2.5. Fragestellung der Arbeit 20

3. Material und Methoden 21

3.1. Stämme, Plasmide und Oligonukleotide 21

3.2. Medien und Antibiotika 21

3.2.1. Luria Bertani (LB) -Medium 21

3.2.2. M9-Minimalmedium 21

3.2.3. SOB/SOC-Medium 22

3.2.4. McConkey/Lac-Plattenmedium 23

3.2.5. Antibiotika 23

3.2.6. Weitere Medienzusätze 23 
3.3. Mikrobiologische Methoden

3.3.1. Anzucht und Konservierung von Bakterien

3.3.2. Herstellung chemisch kompetenter E. coli

3.3.3. Transformation von E. coli 25

3.3.4. $\beta$-Galaktosidase-Assay 25

$\begin{array}{ll}\text { 3.3.5. Transposonmutagenese } & 27\end{array}$

3.4. Präparation und Nachweis von DNA 28

3.4.1. Präparation chromosomaler DNA 28

3.4.2. Fällung von DNA 28

3.4.3. Isolation und Aufreinigung von Plasmid-DNA 29

3.4.4. Reinigung von DNA und Gelelution $\quad 29$

3.4.5. Agarose-Gelelektrophorese von DNA 30

3.5. Allgemeine Klonierungstechniken und Enzymreaktionen mit DNA 31

3.5.1. Polymerasekettenreaktion (Polymerase chain reaction, PCR 31

3.5.2. Semi-random two-step PCR (ST-PCR) 31

3.5.3. Generierung von Gen-Deletionen 33

3.5.3.1 Vorbereitung der Stämme 34

3.5.3.2. Amplifikation der Resistenzkassette mit homologen

Bereichen zu den flankierenden Sequenzen des Zielgens 34

3.5.3.3. Herstellung elektrokompetenter Zellen 35

3.5.3.4. Elektroporation $\quad 35$

3.5.3.5. Entfernen der Kassette 36

3.5.4. Restriktion von DNA 36

3.5.5. Dephosphorylierung 37

$\begin{array}{ll}\text { 3.5.6. Ligation } & 37\end{array}$

3.5.7. Sequenzierung nach der Kettenabbruchmethode 38

3.6. Präparation, Synthese und Nachweis von RNA 38

3.6.1. Präparation von Gesamt-RNA 38

3.6.2. Fällung von RNA 39

3.6.3. In vitro Transkription T7 39

3.6.4. Nachweis von RNA 40

3.6.5. Herstellung DIG-markierter RNA-Sonden für Northern Blot Analysen 41

3.6.6. Herstellung ${ }^{32} \mathrm{P}$-markierter Sonden für Northern Blot Analysen 42

3.6.7. Northern Blot Analyse (für Detektion mit DIG-markierten Sonden) 43

3.6.8. Slot Blot Analyse (für Detektion mit DIG-markierten Sonden) 44 
3.6.9. Hybridisierung mit DIG-markierten Sonden und Detektion4

3.6.10. Northern Blot Analyse (für Detektion mit

${ }^{32} \mathrm{P}$-markierten Sonden)

3.6.11. Hybridisierung mit ${ }^{32} \mathrm{P}$-markierten Sonden und Detektion $\quad 48$

3.6.12. Präparation und Markierung von RNA für MicroArray-Analysen 48

3.6.13. MicroArray-Analysen $\quad 50$

3.6.14. Markierung von RNA mittels ${ }^{32} \mathrm{P}-\gamma$-ATP für EMSA $\quad 50$

3.7. Präparation und Nachweis von Proteinen 52

3.7.1. Präparation cytoplasmatischer Proteine aus E. coli

3.7.2. Optimierung der Expression heterologer Proteine in E. coli 54

3.7.3. Aufreinigung von His-Tag-tragenden Proteinen mittels

$\mathrm{Ni}^{2+}$-NTA-Säulen $\quad 55$

3.7.4. Dialyse von Proteinen $\quad 55$

3.7.5. Proteinmengenbestimmung 56

3.7.6. Denaturierende Proteingelelektrophorese 57

3.7.6.1. Vorbereitung der Proben 57

3.7.6.2. Herstellung denaturierender SDS-Polyacrylamid-Gele 58

3.7.6.3. Gelelektrophorese $\quad 59$

3.7.6.4. Färbung mittels Coomassie Brilliant Blue R 59

3.7.7 Western Blot Analyse $\quad 60$

3.7.7.1. Herstellung polyklonaler Antikörper 60

3.7.7.2. Aufreinigung des Antikörpers 60

3.7.7.3. Transfer und Detektion 61

3.8. Electrophoretic Mobility Shift Assay (EMSA) 63

3.8.1. EMSA mit nicht-markierter RNA 63

3.8.1.1. Native Polyacrylamid-Gele 63

3.8.1.2. Vorbereitung der Proben 63

3.8.1.3. Gelelektrophorese $\quad 64$

3.8.2. EMSA mit ${ }^{32} \mathrm{P}$-markierter RNA 65

3.8.2.1. Native Polyacrylamid-Gele für EMSA mit ${ }^{32} \mathrm{P}$-markierter RNA 65

3.8.2.2. Vorbereitung der Proben 65

3.8.2.3. Gelelektrophorese 66

3.9. Computergestützte Datenanalyse von DNA- und

Proteinsequenzen und Literaturrecherche $\quad 66$ 


\section{Ergebnisse}

4.1. Die Regulation der glmS-Expression in Escherichia coli 68

4.1.1. Transposonmutagenese und Charakterisierung der Mutanten 68

4.1.2. Untersuchung der Rolle von GlmZ 72

4.1.3. Die Expression von $g \operatorname{lmZ}$ ist nicht durch YhbJ beeinflusst oder autoreguliert

4.1.4 Die Rolle von Hfq in der Regulation der $g \operatorname{lm} S$-Expression77

4.1.5. Die Rolle von RNase E in der Regulation der $g \operatorname{lm} S$-Expression 78

4.2. Identifikation des Signals

4.2.1. Die Inaktivierung von GlmS führt zu einer verstärkten

Aktivität der glmS-lacZ-Reporterfusion

4.2.2. Identifikation des Signal-Metabolits

4.2.3. Die Rolle von GlmZ in der metabolitengesteuerten

Regulation der $g \operatorname{lm} S$-Expression

4.3. Charakterisierung von YhbJ

4.3.1. Analyse mittels ClustalW und MEME

4.3.2. Phylogenetische Analyse

4.3.3. Identifikation einer potenziellen RNA-Bindedomäne

4.3.4. Mutationsanalyse konservierter Reste und Motive in YhbJ100

4.4. Untersuchungen zur Interaktion von YhbJ mit GlmY/GlmZ

4.4.1. Überexpression His(10)-YhbJ

4.4.2. Electrophoretic Mobility Shift Assay (EMSA)

4.5. Expression des rpoN-Operons

4.5.1. Untersuchung zur Expression des rpoN-Operons mittels lacZ-Reporterfusionen

4.5.2. Einfluss des Aminozucker-Metabolismus auf die

Expression des rpoN-Operons

4.5.3. Einfluss von GlmY und GlmZ auf die Expression des rpoN-Operons

4.6. Untersuchung der Auswirkungen einer yhbJ-Deletion

mittels MicroArray Analysen

\section{Diskussion}


5.2. Die Funktion von YhbJ

5.3. MicroArray Analysen eines $\Delta y h b J$-Stammes im Vergleich zum Wildtyp

5.3.1. Chaperone und Proteasen der Stressantwort

5.3.2. Enzyme der Pyrimidinsynthese

5.3.3. Komponenten von Transportkomplexen

5.3.4. Gene regulatorischer Proteine mit erhöhter Expression im

$\Delta y h b J$-Hintergrund

5.3.5. Das Kälteschockprotein CspA

5.3.6. Gene der Lipopolysaccharid-Kernsynthese

5.3.7. Gene regulatorischer Proteine mit erniedrigter Expression im $\Delta y h b J$-Hintergrund

5.4. Vergleich der Auswirkungen einer yhbJ-Deletion mit der

Überexpression von GlmY und GlmZ in MicroArray Analysen

\section{Literaturverzeichnis}

7. Anhang

$\begin{array}{ll}\text { 7.1. Stämme } & 174\end{array}$

$\begin{array}{ll}\text { 7.2. Plasmide } & 176\end{array}$

$\begin{array}{lr}\text { 7.3. Oligonukleotide } & 179\end{array}$

7.4. Zusätzlich verwendete Materialien 184

7.4.1. Chemikalien 184

7.4.2. Antikörper, Enzyme und Oligonukleotide 185

7.4.3. Hilfsmittel 185

7.4.4. Geräte 186

$\begin{array}{ll}\text { 7.4.5. Computerprogramme } & 187\end{array}$

$\begin{array}{ll}\text { 7.5. Rohdaten der } \beta \text {-Galaktosidase-Messungen } & 187\end{array}$

7.6. Rohdaten zur Charakterisierung von YhbJ 193

7.6.1. Verwendete Proteinsequenzen 193

7.6.2. Clustal W-Analyse 200

$\begin{array}{ll}\text { 7.6.3. RNABindR-Vorhersagen } & 208\end{array}$

7.7. Rohdaten der MicroArray Analyse 212 


\section{Abkürzungsverzeichnis}

\begin{tabular}{|c|c|}
\hline$\%(\mathrm{v} / \mathrm{v})$ & Volumenprozent \\
\hline$\%(\mathrm{w} / \mathrm{v})$ & Massenprozent \\
\hline Abb. & Abbildung \\
\hline $\mathrm{ABC}$ & ATP-binding cassette, ATP-bindende Kassette \\
\hline APS & Ammoniumperoxodisulfat \\
\hline ATP & Adenosintriphosphat \\
\hline B. & Bacillus \\
\hline bidest. & deionisiert \\
\hline CTP & Cytosintriphosphat \\
\hline dest. & destilliert \\
\hline DIG & Dioxigenin \\
\hline DMSO & Dimethylsulfoxid \\
\hline DNA & Desoxyribonucleic acid, Desoxyribonukleinsäure \\
\hline DTT & Dithiothreitol \\
\hline$E$ & Escherichia \\
\hline EI & Enzym I des PTS \\
\hline EII & Enzym II des PTS \\
\hline EDTA & Ethylendiamintetraacetat \\
\hline EtOH & Ethanol \\
\hline Fa. & Firma \\
\hline FMDP & N3-(4-methoxyfumaroyl)-L-2,3-diaminopropanol-Säure \\
\hline fwd & Vorwärtsprimer \\
\hline GlcN & Glukosamin \\
\hline GlcNAc & N-Acetylglukosamin \\
\hline GTP & Guanosintriphosphat \\
\hline HEPES & 2-(4-(2-Hydroxyethyl)-1-piperazinyl)-ethansulfonsäure \\
\hline His & Aminosäure Histidin \\
\hline $\mathrm{K}^{+}$ & Kalium-Ion \\
\hline IPTG & Isopropyl- $\beta$-D-Thiogalactopyranosid \\
\hline LB & Luria Bertani (Medium) \\
\hline mRNA & Messenger RNA, Boten-Ribonukleinsäure \\
\hline MOPS & 3-(n-Morpholino)-Propansulfonsäure \\
\hline MW & Molecular weight, Molekulargewicht \\
\hline $\mathrm{OD}_{\mathrm{x}}$ & Optische Dichte bei einer Wellenlänge von x nm \\
\hline ONPG & $o$-Nitrophenyl- $\beta$-Galactopyranosid \\
\hline $\mathrm{P}$ & Promotor \\
\hline$-\mathrm{P}$ & Phosphat \\
\hline PAGE & Polyacrylamid-Gelelektrophorese \\
\hline PAP I & Poly(a)-Polymerase I \\
\hline $\mathrm{P}: \mathrm{C}: \mathrm{I}$ & Phenol:Chloroform:Isoamylalkohol \\
\hline PCR & Polymerase chain reaction, Polymerasekettenreaktion \\
\hline PIPES & Piperazin-N,N'-bis(2-ethansulfonsäure) \\
\hline PTS & Phosphoenolpyruvat:Zucker-Phosphotransferasesystem \\
\hline PVDF & Polyvinylidendiflourid \\
\hline RNA & Ribonucleic acid, Ribonukleinsäure \\
\hline rev & reverser Primer \\
\hline $\mathrm{rpm}$ & Rounds per minute, Umdrehungen pro Minute \\
\hline SDS & Sodiumdodecysulfate, Natriumdodecylsulfat \\
\hline sRNA & kleine, nicht-kodierende RNA \\
\hline ST-PCR & Semi-random two-step PCR, halb-gerichtete, zweistufige PCR \\
\hline Tab. & Tabelle \\
\hline TBE & Tris-Borsäure-EDTA-Puffer \\
\hline TEMED & $\mathrm{N}, \mathrm{N}, \mathrm{N}^{\prime}, \mathrm{N}^{\prime}-\mathrm{Tetramethylethylendiamin}$ \\
\hline Tris & Tris-(hydroxymethyl)-Aminomethan \\
\hline tRNA & transfer-RNA, Transfer-Ribonukleinsäure \\
\hline UDP & Uridin-5'-diphosphat \\
\hline UV & Ultraviolett \\
\hline ZAP & Zellaufschlußpuffer \\
\hline
\end{tabular}




\section{Zusammenfassung}

Aminozucker sind essentielle Bausteine des Lebens, die in Bakterien vorallem als Vorläufer der Zellwandbiosynthese dienen. Ihre de novo-Synthese beginnt mit der Umsetzung von Fruktose-6-Phosphat und Glutamin zu Glukosamin-6-Phosphat und Glutamin. Diese Reaktion wird durch die Glukosamin-6-Phosphat Synthase GlmS katalysiert. Escherichia coli ist in der Lage, externe Aminozuckerquellen zu verwerten, und unter diesen Bedingungen ist die Aktivität von GlmS nicht essentiell.

Für eukaryotische Organismen und Gram-positive Bakterien sind Mechanismen beschrieben, die die Expression oder Enzymaktivität von GlmS an die Verfügbarkeit des eigenen Produktes oder von Metaboliten stromabwärts davon in der Zellwandbiosynthese koppeln. In E. coli war eine derartige Regulation bislang unbekannt.

Die Beobachtung, dass Stämme mit einer Deletion des Gens yhbJ eine starke Erhöhung der intrazellulären GlmS-Menge aufweisen, gab eine ersten Ansatzpunkt für die Suche nach einer Kontrolle der Aktivität dieses Enzyms in E. coli.

In dieser Arbeit konnte gezeigt werden, dass die spezifische Expression von $g \operatorname{lm} S$ einer posttranskriptionellen Kontrolle unterliegt. Mittels Transposonmutagenese konnte die kleine, nicht-kodierende RNA GlmZ als notwendiger Faktor für diese Regulation identifiziert und ein Einfluß von Rnase E und Hfq beschrieben werden. Diese Regulation stellt einen der ersten beschriebenen Fälle dar, in denen eine kleine RNA die Transkription eines Gens innerhalb eines Operons positiv beeinflusst.

Des Weiteren konnte die intrazelluläre Verfügbarkeit von Glukosamin-6-Phosphat als Signal für dieses Regulation identifiziert werden. Somit erfolgt die Kontrolle der $\mathrm{glmS}$ spezifischen Expression durch einen negativen Feedback-Mechanismus.

Zudem wurde das Protein YhbJ analysiert und mehrere konservierte Motive in der Aminosäuresequenz identifiziert. Anschließend wurde der Einfluß von Mutationen dieser Reste untersucht. Es wurde gezeigt, dass YhbJ in vitro an RNA binden kann. Ausserdem wurde die globale Auswirkung einer $y h b J$-Deletion auf die Transkription mittels MicroArray Analysen untersucht. 


\section{Einleitung}

\subsection{E. coli als Modellorganismus}

Prokaryoten stellen, neben Archaea und Eukaryoten, eine der drei Domänen des Lebens dar und umfassen alle Organismen, deren DNA nicht durch eine Kompartimentierung vom Cytoplasma der Zelle getrennt ist und deren Ribosomen aus einer 50S und einer 30S-Untereinheit aufgebaut sind. Erstmals beobachtet wurden Prokaryoten im Jahr 1676 durch Antoni van Leeuwenhoek, und in den nachfolgenden 300 Jahren wurden über 5000 Arten beschrieben (Madigan et al. 2003).

Escherichia coli (E. coli) ist ein stäbchenförmiges, Gram-negatives Bakterium. Systematisch gehört es zur Klasse der Gamma-Proteobacteria und zur Familie der Enterobacteriaceae. Sein natürliches Habitat ist der Intestinaltrakt von Menschen und Tieren. 1885 wurde es durch Theodor Escherich erstmals beschrieben (Madigan et al. 2003).

In den über 100 Jahren seit seiner Entdeckung hat sich E. coli zu einem der am besten untersuchten Organismen der Welt entwickelt, und stellt ein wichtiges Modell für die zelluläre Grundlagenforschung dar. Zudem wurde das Genom von E. coli, welches etwa 4400 Gene in 4,64 × $10^{6}$ Basenpaaren umfasst, als eines der ersten vollständig sequenziert (Blattner et al. 1997; Serres et al. 2001). E. coli ist genetisch leicht zugänglich und kann sowohl über Transformation, Konjugation als auch Transduktion manipuliert werden (Madigan et al. 2003).

Auch in der Industrie ist E. coli ein wichtiger Organismus, beispielsweise für die Produktion von Insulin (Goeddel et al. 1979) und Vitamin K (Bentley und Meganathan 1982).

\subsection{Regulation der Genexpression}

Um auf äußere Reize und Veränderungen ihrer Umgebung reagieren zu können, besitzen bakterielle Zellen Rezeptoren, die essentielle Parameter wahrnehmen (Seshasayee et al. 2006). Ein Beispiel für ein derartiges Sensorsystem sind Zweikomponentensysteme. Diese bestehen aus einer meist membranständigen SensorKinase und einem cytoplasmatischen Response Regulator. Wenn ein Reiz detektiert wird, kommt es zunächst zur Autophosphorylierung der Sensor-Kinase unter ATP- 
Verbrauch und nachfolgend zur Übertragung der Phosphatgruppe auf den zugehörigen Response Regulator. Dieser wird dadurch aktiviert und ist nun in der Lage, an regulatorische Elemente in der DNA zu binden und die Transkription von Zielgenen zu beeinflussen (Parkinson 1993). Eine weitere Möglichkeit, auf veränderte Umwelteinflüsse zu reagieren, ist die Verwendung alternativer $\sigma$-Faktoren. Diese sind in der Lage, eine Promotorspezifität des RNA-Polymerase-Holoenzyms zu vermitteln, so dass je nach assoziierten $\sigma$-Faktor ein spezielles Set an Genen aktiviert wird (Helmann 2002; Raivio 2005).

Diese beiden Systeme wirken auf der Ebene der Transkription. Neben dieser kann eine Antwort auf veränderte Lebensbedingung auch durch Veränderung der Translation oder Regulation der enzymatischen Aktivität von Enzymen vermittelt werden.

Die Translation kann durch Stabilisierung beziehungsweise Destabilisierung der entsprechenden mRNA beeinflusst werden (Condon 2003). Hierzu gibt es eine Vielzahl verschiedener Mechanismen: Schutz vor Abbau der mRNA durch verstärkte Translation (Deana und Belasco 2005), Modifikation des 5'-terminalen Phosphorylierungsstatus (Celesnik et al. 2007), 3'-Polyadenylierung (Joanny et al. 2007), Ausbildung von Sekundärstrukturen (Kozak 2005) oder Interaktion mit Proteinfaktoren und ribosomale Initiationskomplexen (Sharp und Bechhofer 2003). Ein weiterer wichtiger Mechanismus zur Beeinflussung der mRNA-Stabilität sind die in trans wirkenden kleinen, nichtkodierenden RNAs (Gottesman et al. 2006).

Die enzymatische Aktivität von Proteinen kann beispielsweise durch FeedbackHemmung durch das Produkt einer Synthesereaktion beeinflusst werden (Madigan et al. 2003) oder durch die Verfügbarkeit eines Ko-Faktors (Holliday et al. 2007).

\subsection{Das rpoN-Operon}

Das rpoN-Operon besteht aus den 5 Gene $r p o N$, $h p f$ (vormals $y h b H$ ), pts $N$, yhbJ und $n p r$ (vormals ptsO) ((GOA et al. 2001), siehe Abbildung 1.1.). Es umfasst etwa 5300 Basenpaare und wird von einem $\sigma^{70}$-abhängigen Promotor vor $r p o N$ aus exprimiert. Die Termination erfolgt Rho-abhängig stromabwärts von $n p r$ (Jones et al. 1994). Die Expression von diesem Promotor aus ist konstitutiv (Castano und Bastarrachea 1984) und die Anzahl an $\sigma^{54}$-Molekülen in der Zelle unterliegt nur vernachlässigbaren Schwankungen (Jishage et al. 1996).

Angrenzend befinden sich stromaufwärts das lptAB-Operon, welches unter Kontrolle eines $\sigma^{\mathrm{E}}$-abhängigen Promotors steht und für Proteine kodiert, die am Export von 
Bestandteilen der Lipopolysaccharide der äußeren Membran beteiligt sind (Sperandeo et al. 2006; Sperandeo et al. 2007). Stromabwärts befindet sich das monocistronische yrbL-Operon. Die Funktion des korrespondierenden Genproduktes ist nicht näher charakterisiert, jedoch steht das Operon unter der Magnesium-abhängigen Kontrolle des PhoPQ-Systems (Minagawa et al. 2003) und des EvgAS-Systems (Eguchi et al. 2004). Neben einem Transkript, welches das gesamte Operon umfasst, wurde auch ein Transkript nachgewiesen, das auf einem Durchlesen ausgehend vom lptB-Promotor beruht und somit zusätzlich zum $r p o N$-Operon auch $\operatorname{lptB}$ und Bereiche stromaufwärts von dessen Startpunkt umfasst (Rhodius et al. 2006).

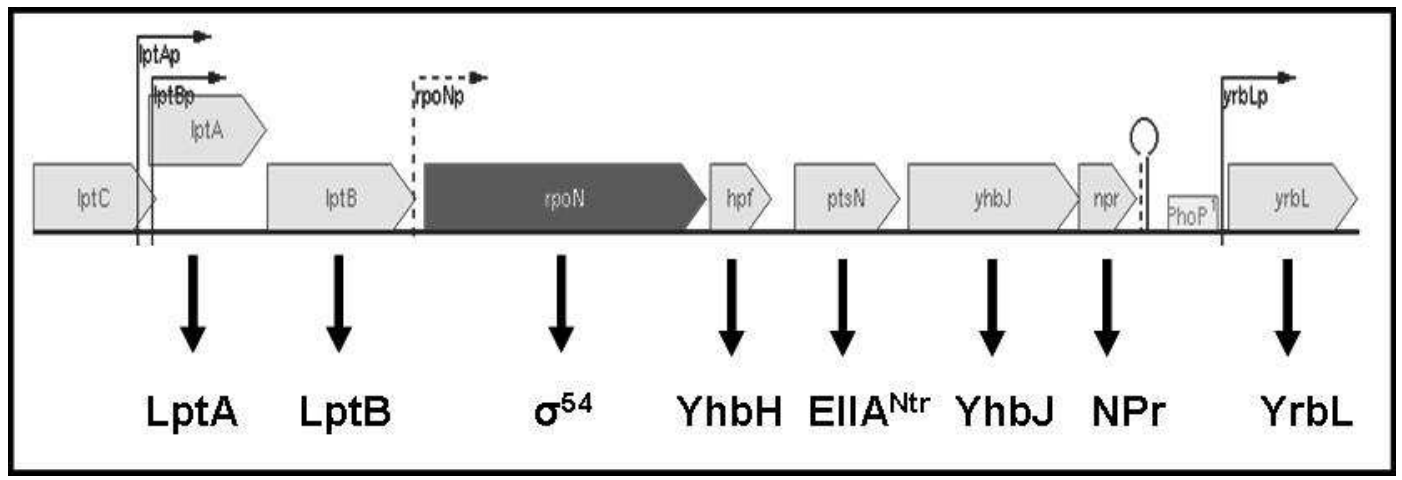

Abb. 2.1.: Das rpoN-Operon in E. coli

Schematische Darstellung des rpoN-Operons sowie der flankierenden genetischen Elemente. Promotoren sind durch rechtwinklige Pfeile dargestellt, Terminatoren durch Haarnadeln. Das rpoN-Operon besteht aus den fünf Genen $r p o N$, hpf, pts $N$, yhbJ und $n p r$. Die Expression erfolgt von einem $\sigma^{70}$-abhängigen Promotor stromaufwärts von rpoN aus und endet an einem Rhoabhängigen Terminator hinter dem Gen npr. Stromaufwärts befindet sich das IptAB-Operon, dessen Genprodukte in den Transport von Lipopolysacchariden involviert sind, stromabwärts das monocistronische yrbL, ein Gen unbekannter Funktion. Unter der Darstellung der Gene sind die Bezeichnungen der entsprechenden Genprodukte angegeben.

Abbildung modifiziert nach EcoCyc (siehe 2.9.)

\subsection{1. rpoN}

Das erste Gen im Operon, rpoN, codiert für den alternativen Sigma-Faktor $\sigma^{54}$. SigmaFaktoren sind Teil des RNA-Polymerase-Holoenzyms und beeinflussen das Muster der Genexpression, indem sie die RNA-Polymerase zu spezifischen Promotoren rekrutieren (Helmann und Chamberlin 1988; Wosten 1998). Die Anzahl an $\sigma$-Faktoren in einem bakteriellen Genom reicht von 1 in Mycoplasma genitalium bis zu 63 in Streptomyces coelicolor (Gruber und Gross 2003). Neben der Vermittlung von Promotorspezifität haben $\sigma$-Faktoren weitere wichtige Aufgaben: Sie dienen als Interaktionspartner für Trankriptionsregulatoren, erleichtern das Aufschmelzen der DNA-Helix und beeinflussen die frühe Phase der Elongation sowie das Pausieren der Transkription hinter dem Promotor (Gruber und Gross 2003). 
In $E$. coli wurden bislang sieben unterschiedliche Sigma-Faktoren identifiziert, darunter der allgemeine oder primäre Sigma-Faktor $\sigma^{70}$ sowie zum Beispiel Sigma-Faktoren, die die Antwort auf Stress durch Hitzeschock oder fehlgefaltete periplasmatische Proteine vermitteln (Madigan et al. 2003). $\sigma^{54}$ ist der einzige Sigma-Faktor in E. coli, der nicht homolog $\mathrm{zu} \sigma^{70}$ ist und deshalb einige einzigartige Eigenschaften besitzt (Merrick 1993). Seine Aktivität ist strikt von einem zusätzlichen Aktivatorprotein abhängig, welches ATP hydrolysiert und so die Energie für den Übergang des RNA-PolymeraseHoloenzyms von der geschlossenen zur offenen Konformation liefert. Dadurch kann $\sigma^{54}$-abhängige Genexpression vollständig abgeschaltet werden. Zudem unterliegen die Position und Orientierung der Aktivatorbindestelle an der DNA keinen bekannten Regeln, jedoch befindet sich keine der bislang identifizierten Bindestellen innerhalb eines Gens (Buck et al. 2000; Reitzer und Schneider 2001). Sie kann jedoch bis zu 3000 Basenpaare vom Transkriptionsstartpunkt entfernt liegen (Reitzer und Magasanik 1986), und in B. subtilis liegt die Aktivatorbindestelle in mindestens einem Fall stromabwärts des durch sie kontrollierten Gens (Belitsky und Sonenshein 1999).

Häufig wird $\sigma^{54}$ ausschließlich als Sigma-Faktor zur Expression der Gene des Stickstoff-Stoffwechsels der Zelle angesehen, jedoch ist etwa die Hälfte der bekannten oder vermuteten Zielgene von $\sigma^{54}$ nicht mit der Assimilation von Stickstoff assoziiert (Studholme und Buck 2000) und vermittelt unter Anderem die Antwort auf Phagenschock und alkalische $\mathrm{pH}$-Werte oder kodieren für Proteine des Fettsäurestoffwechsels (Reitzer 2003). Die zugehörigen von $\sigma^{54}$ kontrollierten Promotoren werden jedoch allgemein als Stickstoff-Promotoren bezeichnet und zeichnen sich in $E$. coli durch folgende Konsensus-Sequenz aus: aa- $\mathrm{N}_{3}-\mathrm{TGGCAc-}_{6}$ TGCNNt. Große Buchstaben bedeuten keine Abweichung in den 17 bekannten $\sigma^{54}$ abhängigen Promotoren, kleine Buchstaben 2-5 Abweichungen (Reitzer und Schneider 2001). In jüngster Zeit konnte gezeigt werden, dass die Expression von lytischen und strukturellen Genen einiger Bakteriophagen von $\sigma^{54}$ abhängig ist (Ceyssens et al. 2008). Untersuchungen der Struktur von $\sigma^{54}$ mittels scanning force microscopy (Rippe et al. 1997) und Röntgen-Streuungsmikroskopie (Svergun et al. 2000) zeigten trotz des Mangels an Sequenz-Homologie eine weitgehende Übereinstimmung zwischen den Strukturen von $\sigma^{54}$ und dem allgemeinen Sigma-Faktor $\sigma^{70}$. Beide interagieren auf dieselbe Art mit der RNA-Polymerase (Wigneshweraraj et al. 2008), nämlich über eine Region aus sich wiederholenden sauren, hydrophoben Aminosäuren. Die Bindung von $\sigma^{54}$ an die Promotor-DNA erfolgt über ein ,Helix-turn-helix“-Motiv am Carboxy- 
terminalen Ende (Sasse-Dwight und Gralla 1990; Wong et al. 1994) und führt zu starken Konformationsänderungen im Protein (Ray et al. 2005).

Im Gegensatz zur $\sigma^{70}$-abhängigen Genexpression erfolgt in RNA-PolymeraseHoloenzymen mit $\sigma^{54}$-Untereinheit kein spontaner Übergang in die für die Transkription notwendige offene Konformation. Die Initiation der Transkription $\sigma^{54}$-abhängiger Promotoren ist strikt von $\mathrm{AAA}^{+}$-Aktivatoren (ㅅTPases associated with various cellular activities / ATPasen verbunden mit unterschiedlichen zellulären Aktivitäten) abhängig (Buck et al. 2000). Diese Proteine bilden polymere Ringe, in denen Teile zweier nebeneinander liegender Protomere gemeinsam ein aktives Zentrum der ATPaseAktivität bilden (Schumacher und Brennan 2002; Zhang et al. 2002). Als Reaktion auf sensorische Reize werden sie aktiviert und binden Enhancer-Sequenzen auf der DNA nahe des Promotors. Die durch die ATP-Hydrolyse gewonnene Energie wird in mechanische Kraft umgesetzt, durch die die Isomerisierung des geschlossenen $\sigma^{54} /$ RNA-Polymerase-Komplexes in die offene Konfiguration stimuliert wird, und somit die Transkription ermöglicht (Schumacher et al. 2007).

\subsection{2. $h p f$}

$h p f$ ist ein verhältnismäßig kurzes Gen mit nur 288 Basenpaaren und liegt direkt stromabwärts von rpoN. Die Funktion des Genproduktes YhbH ist unbekannt. Es ist homolog zu YfiA in E. coli und beide Proteine zeigen in der exponentiellen Wachstumsphase eine schwache Assoziation mit 70S-Ribosomen. In der stationären Phase hingegen interagiert YfiA stark mit den 70S-Ribosomen, während YhbH an Dimere der 100S-Ribosomen bindet (Maki et al. 2000).

Abweichend von der beschriebenen Expression des rpoN-Operons wurde eine Regulation beschrieben, in der das „,quorum sensing“-Pheromon AI-2 eine verstärkte Expression des Gens $h p f$ bewirkt (DeLisa et al. 2001).

\subsection{3. ptsN und $n p r$}

Die beiden Gene $p t s N$ und $n p r$ kodieren für Proteine, die Homologien zu Bestandteilen des kanonischen Phosphoenolpyruvat:Zucker-Phosphotransferasesystems (PTS) zeigen (Powell et al. 1995). 
Die Aufgabe des kanonischen PTS ist die koordinierte Aufnahme von Zuckern in die Zelle. Als eine Besonderheit dieses Systems wird das Substrat während des Transports über die Zellmembran phosphoryliert, was eine direkte Einspeisung in die Glykolyse ermöglicht. Das kanonische PTS besteht aus Enzym I (EI) und HPr sowie aus verschiedenen Enzym IIs (EII), welche den eigentlichen zuckerspezifischen Transport des Substrats übernehmen und aus mehreren Domänen bestehen (Postma et al. 1993).

Für die Zuckeraufnahme wird zunächst ein Phosphatrest über eine Phosphorylierungskaskade von Phosphoenolpyruvat über EI auf HPr übertragen und anschließend auf die EIIA-Domäne der Permease. Von hier wird er auf die B-Domäne übertragen, welche den Zucker phosphoryliert, der über die C-Domäne aufgenommen wird.

Neben der eigentlichen Aufgabe, dem Import von Zuckern, üben die Bestandteile der Phosphorylierungskaskade weitergehende regulatorische Funktionen aus (Deutscher et al. 2006; Görke und Stülke 2008). Der Phosphorylierungszustand der PTSKomponenten gibt dem regulatorischen Netz der Zelle Auskunft über die Verfügbarkeit von Kohlenstoffquellen.

NPr stellt ein Homolog von HPr dar (Powell et al. 1995). Es kann durch das Protein $\mathrm{EI}^{\mathrm{Ntr}}$ (kodiert durch das Gen ptsP, siehe Abb. 2.2.B) phosphoryliert werden (Rabus et al. 1999). Zusammen mit ptsP ist rppH in diesem Operon lokalisiert. Das korrespondierende Genprodukt ist vermutlich ein Nudix-Protein, welches DinukleotidOligophosphate hydrolysiert (Bessman et al. 2001). Diese Verbindungen wirken als sogenannte Alarmone (Kisselev et al. 1998) und in diesem Fall vermitteln sie eine Antwort auf Sekretionsstress (Hand und Silhavy 2003).

Das durch $p t s N$ kodierte Protein ist ein Homolog der Enzym IIA-Domäne des Fruktosespezifischen Transportkomplexes und wird als EIIA ${ }^{\text {Ntr }}$ bezeichnet (Reizer et al. 1992). Es wird analog zur Phosphorylierungskaskade des kanonischen PTS durch NPr phosphoryliert (siehe Abb. 2.2.A). Aufgrund der Ko-Lokalisation mit $\sigma^{54}$ wird diese Kaskade als „Stickstoff-PTS“ bezeichnet (Ntr = ,nitrogen related“). Der Phosphattransfer von $\mathrm{EI}^{\mathrm{Ntr}}$ über NPr zu EIIA ${ }^{\mathrm{Ntr}}$ findet mit hoher Affinität der Komponenten zueinander statt (Rabus et al. 1999), jedoch wurden nennenswerte Kreuzreaktionen mit Proteinen des kanonischen PTS in vitro und in vivo beschrieben (Rabus et al. 1999).

Es ist bekannt, dass die nicht-phosphorylierte Form des EIIA ${ }^{\mathrm{Ntr}}$ notwendig für die Aufhebung der Repression des ilvBN-Operons ist, dessen Genprodukte den initialen 
Schritt der Synthese verzweigtkettiger Aminosäuren katalysieren (Lee et al. 2005). Zudem zeigt eine ptsN-Mutante einen Wachstumsdefekt mit Intermediaten des Citratzyklus als Kohlenstoffquelle, wenn ihr gleichzeitig nur Alanin als Stickstoffquelle zur Verfügung steht (Powell et al. 1995).

Die dephosphorylierte Form von EIIA ${ }^{\mathrm{Ntr}}$ interagiert ferner mit TrkA, einem Transporter für Kaliumionen, und hemmt dessen Aktivität. Umgekehrt ist der Kalium-Import in einer $p t s N$-Deletion stark erhöht, wodurch die Expression des $i l v B N$-Operons inhibiert wird, in welchem die Acetohydroxysäure-Synthase I (AHAS I) kodiert ist (Lee et al. 2007). Dieses Enzym katalysiert den ersten Schritt der Biosynthese verzweigtkettiger Aminosäuren, und seine stark verringerte Expression ist der Grund für den Wachstumsdefekt eines $\Delta p t s N$-Stammes in Anwesenheit von leucinhaltigen Peptiden (Lee et al. 2005). Da ein $\Delta p t s N \Delta t r k A-S t a m m$ diesen Defekt nicht mehr aufweist, kann er direkt auf die Erhöhung des $\mathrm{K}^{+}$-Spiegels in der Zelle zurückgeführt werden. Die Interaktion zwischen EIIA ${ }^{\mathrm{Ntr}}$ und TrkA ähnelt der Kontrolle von Zuckerpermeasen, die nicht zum PTS gehören, durch EIIA ${ }^{\text {Glc }}$ (Lee et al. 2007).

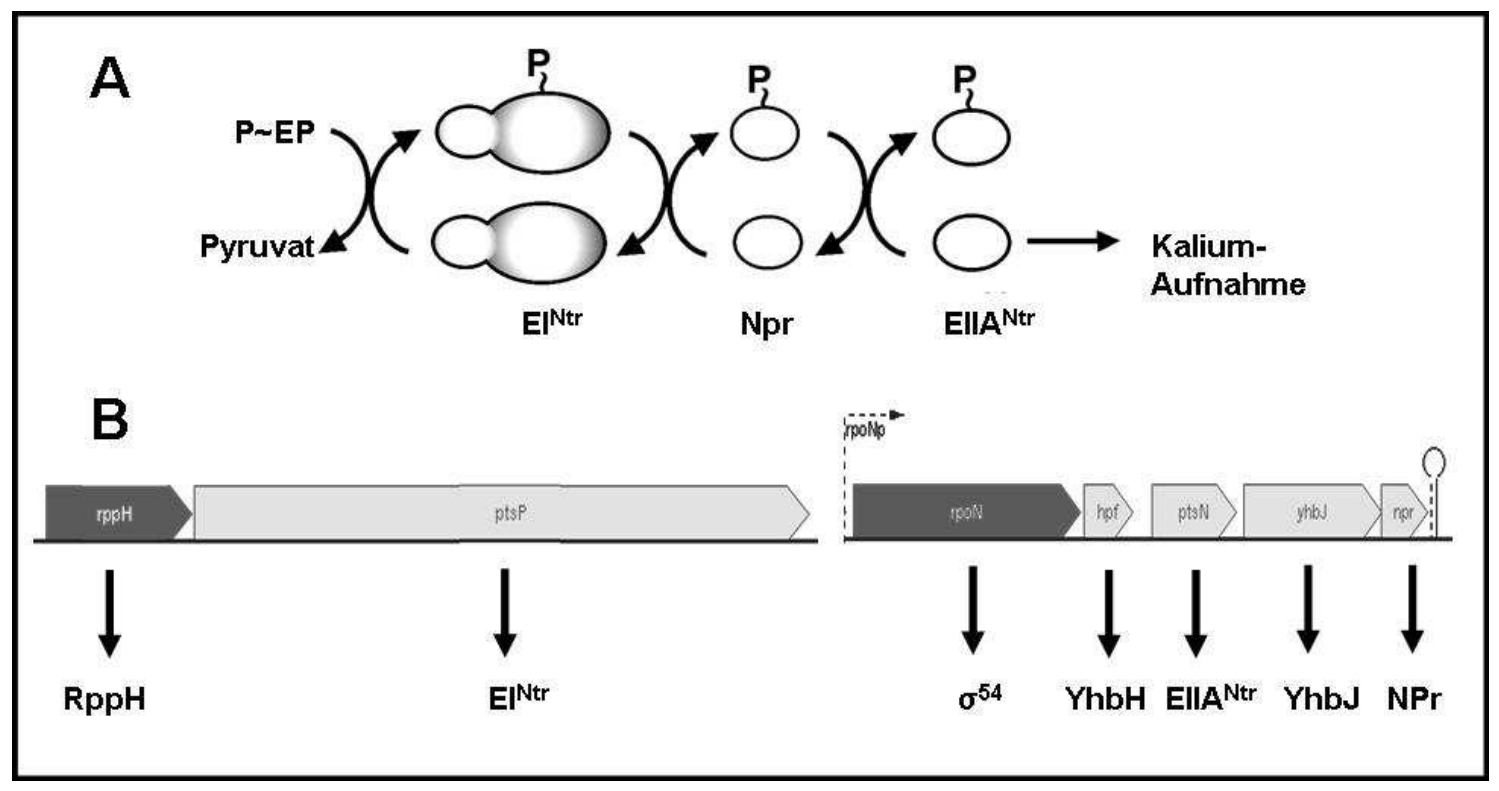

Abb. 2.2.: Das „Stickstoff“"-PTS in E. coli

(A) Schema der durch das "Stickstoff“-PTS gebildeten Phosphorylierungskaskade. Von Phosphoenolpyruvat $(P \sim E P)$ wird ein Phosphatrest auf $\mathrm{El}^{\mathrm{Ntr}}$ übertragen, wodurch Pyruvat entsteht. Von EI ${ }^{\mathrm{Ntr}}$ wird der Phosphatrest über NPr auf ElIA ${ }^{\mathrm{Ntr}}$ übertragen. Es ist kein terminaler Akzeptor für den Phosphatrest bekannt, jedoch hat der Phosphorylierungsstatus von EllA $A^{\mathrm{Ntr}}$ auf die Kaliumaufnahme (siehe 2.3.3. für Details).

(B) Lokalisierung der Gene der Komponenten des "Stickstoff“-PTS. Pfeile symbolisieren Translation und führen zur Bezeichnung des korrespondierenden Genprodukts. Das Gen pts $P$, welches für El ${ }^{\mathrm{Ntr}}$ kodiert, bildet zusammen mit $r p H$ ein Operon, während $n p r$ und das für Ell/ ${ }^{\mathrm{Nir}}$ kodierende $p t s N$ Bestandteile des rpoN-Operons sind. 
Bislang konnte kein terminaler Akzeptor der Phosphorylgruppe von EIIA ${ }^{\mathrm{Ntr}}$ identifiziert werden, und auch das Fehlen von spezifischen EIIB- und EIIC-Domänen weisen darauf hin, dass es sich bei dieser Signalkaskade um einen rein regulatorischen Vorgang handelt. Hierzu passen auch die Beobachtungen, dass die Unterbrechung des pts $N$-Gens die letalen Effekte einer Deletion des Gens era aufhebt, welches für eine GTPase unbekannter Funktion codiert (Powell et al. 1995) sowie die zuvor beschriebene Regulation des $\mathrm{K}^{+}$-Imports. Ferner kann die Überexpression von $p t s N$ die Letalität einer $\sigma^{\mathrm{E}}$-Deletion supprimieren, wofür die phosphorylierte Form von EIIA ${ }^{\mathrm{Ntr}}$ benötigt wird (Hayden und Ades 2008).

\subsection{4. yhbJ}

Das durch yhbJ kodierte Protein wurde als ATPase mit einer P-Loop-Domäne annotiert. Seine gemeinsame Lokalisation mit Komponenten des PTS ist in einem weiten Feld von Prokaryoten konserviert. In vielen Gram-negativen wie E. coli, Klebsiella pneumoniae und Pseudomonas putida ist $y h b J$ zwischen $p t s N$ und $n p r$ lokalisiert und in diesem Kontext konserviert (Deutscher et al. 2006). In Gram-positivem, die keine Homologe von EIIA ${ }^{\mathrm{Ntr}}$ und NPr besitzen, ist bemerkenswerter Weise die Lokalisation von $y h b J$ (hier als $y v c J$ bezeichnet) mit dem Gen eines anderen Homologs von HPr, crh, konserviert (Boël et al. 2003). Analysen der Funktion des entsprechenden yvcIJKL-crh$y v c N$-Operon zeigten, dass B. subtilis $\Delta y v c K$-Stämme eine anormale Zellmorphologie aufweisen, sowie Defekte in der Verwertung bestimmter Kohlenstoff-Quellen (Görke $e t$ al. 2005).

Die genauere Analyse der Funktion YhbJ ist Bestandteil dieser Arbeit.

\subsubsection{Die Deletion von $y h b J$ führt zu einer Akkumulation von GlmS}

In vorangegangen Arbeiten durch B. Görke, deren Ziel ursprünglich die Untersuchung der Funktion von $p t s N$ und $n p r$ war, wurde ein Stamm generiert, der eine Deletion der Gene $p t s N$, yhbJ und $n p r$ trägt. Eine Analyse von Gesamtzellextrakten mittels SDSPolyacrylamid-Gelelektrophorese (SDS-PAGE, siehe 3.7.6.) zeigte, dass in diesem Stamm eine starke Proteinbande mit einer Größe von etwa $65 \mathrm{kDa}$ zusätzlich auftrat (Abb. 2.3. Spalte 1 und 5). Eine nachfolgende Komplementation der [ptsN-npr]Deletion mit Plasmiden, die die drei Genen in allen möglichen Kombinationen tragen, zeigte dass einzig die Abwesenheit von $y h b J$ notwendige und hinreichende Bedingung 
für das Erscheinen dieser Bande war. Weder die Komplementation mit ptsN (Spalte 7) oder npr (Spalte 9) noch mit einer Kombination aus beiden (Spalte 11) verhinderte das Auftreten der Bande. Im Gegensatz dazu war die Bande nicht mehr detektierbar, wenn mit einem yhbJ-exprimierenden Plasmid komplementiert wurde (Spalte 8, 10 und 12)

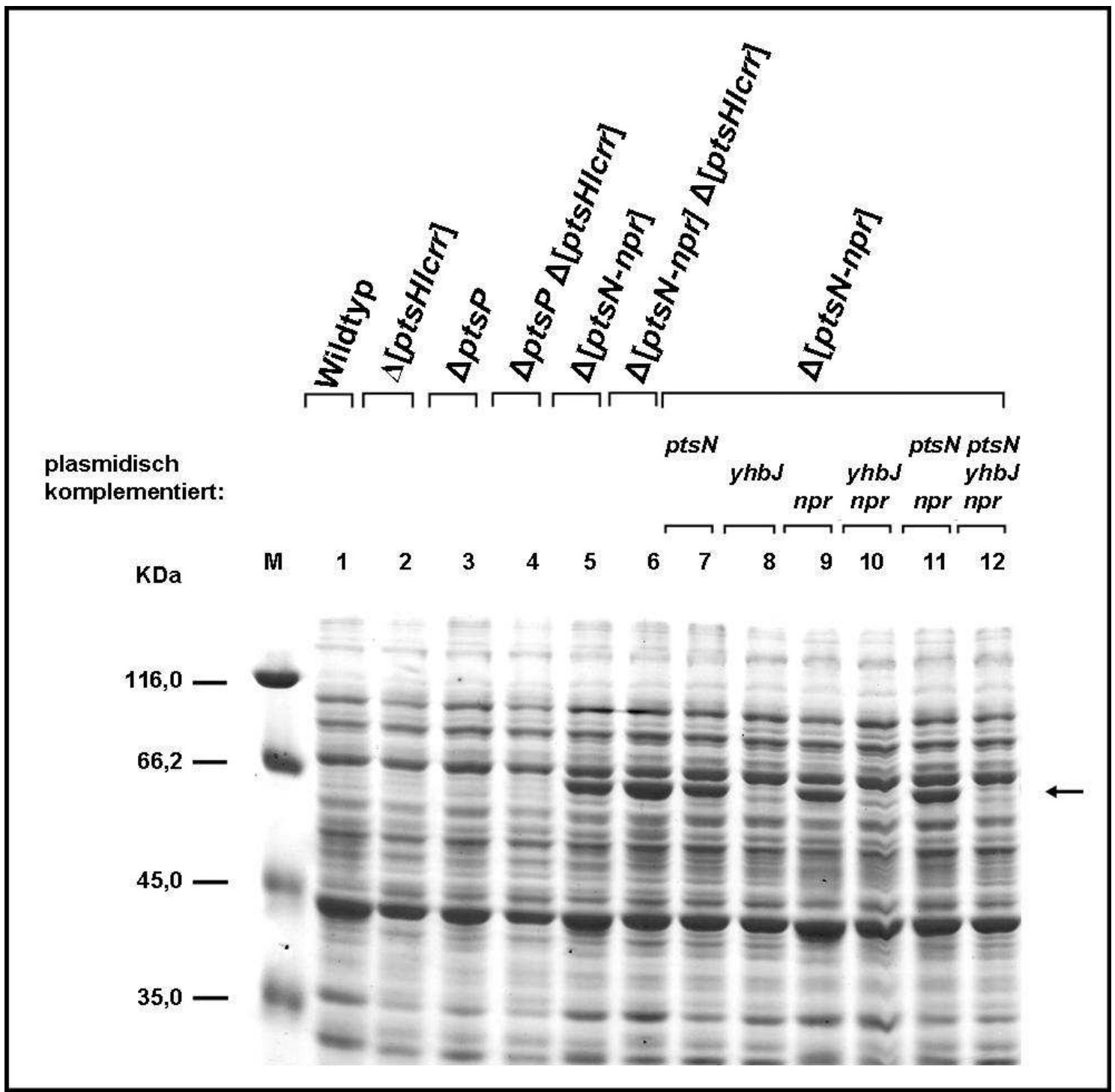

Abb. 2.3.: Deletionsanalyse der Gene ptsN, yhbJ und npr in E. coli

Gesamtzellextrakte des Wildtyps R1279 sowie der Stämme $\Delta[$ ptsHIcrr] (R2260), $\Delta$ ptsP (R2404), $\Delta$ ptsP $\Delta[p t s H / c r r]$ (R2409), $\Delta[p t s N-n p r]$ (R2413), $\Delta[p t s H / c r r] \Delta[p t s N-n p r]$ (R2415) sowie $\Delta[p t s N-n p r]$ transformiert mit den plasmidständigen ptsN (pFDX4294), yhbJ (pFDX4324), $n p r$ (pFDX4292), [yhbJ,npr] (pFDX4320), [ptsN,npr] (pFDX4322) und [ptsN,yhbJ,npr] (pFDX4296) wurden mittels SDS-PAGE analysiert. $M=$ Unstained molecular weight marker.

Der Pfeil an der rechten Seite markiert eine Proteinbande von etwa $65 \mathrm{KDa}$, die nur in Abwesenheit von yhbJ detektierbar ist und nachfolgend als GlmS identifiziert wurde.

Abbildung nach (Kalamorz et al. 2007).

Desweiteren trat die Bande weder in einer Deletion der Komponenten des kanonischen PTS auf (Spalte 2), noch in einer $\mathrm{EI}^{\mathrm{Ntr}}$-Deletion (Spalte 3) oder einer Kombination dieser Deletionen (Spalte 4). In Kombination mit der Deletion des kanonischen PTS verhält sich die [ptsN-npr]-Deletion dominant (Spalte 5). 
Somit konnte festgestellt werden, dass weder die Bestandteile des kanonischen PTS noch die des „Stickstoff“-PTS einen Einfluss auf das Erscheinen dieser Proteinbande haben, und dieses einzig von der Abwesenheit von yhbJ abhängt (Kalamorz et al. 2007).

Das korrespondierende Protein wurde extrahiert und mittels massenspektrometrischer Analyse als Glukosamin-6-Phosphat- Synthase GlmS identifiziert.

\subsection{Aminozucker-Metabolismus}

\subsubsection{Die Glukosamin-6-Phosphat Synthase GlmS}

Aminozucker sind essentielle Bausteine für die Synthese des Peptidoglykans der Zellhülle und der Lipopolysaccharide der äußeren Membran.

Der anabole und katabole Metabolismus von Aminozuckern ist in Abbildung 2.4. dargestellt. Das zentrale Intermediat dieses Stoffwechselweges ist Uridin-5' -diphospho$\mathrm{N}$-Acetylglukosamin (UDP-GlcNAc). In E. coli ist der erste und geschwindigkeitsbestimmende Schritt der de novo-Synthese von UDP-GlcNAc die Generierung von Glukosamin-6-Phosphat (GlcN-6-P) aus Glutamin und Fruktose-6-Phosphat, wobei als Nebenprodukt Glutamat entsteht (Milewski 2002; Teplyakov et al. 2002). Dieser Schritt wird durch die Glukosamin-6-Phosphat Synthase GlmS katalysiert und besteht aus zwei gekoppelten enzymatischen Reaktionen: Der Hydrolyse von Glutamin zu Glutamat und Ammonium (welches nachfolgend auf das Fruktose-6-Phosphat übertragen wird), sowie die Isomerisierung von Fruktose-6-Phosphat von einer Ketose in eine Aldose (Milewski 2002). GlcN-6-P wird im Folgenden durch die Phosphoglukosamin-Mutase GlmM in D-Glukosamin-1-Phosphat umgewandelt, welches dann von der bifunktionalen NAcetylglukosamin-1-Phosphat Uridyltransferase / Glukosamin-1-Posphat Acetyltransferase GlmU zu UDP-GlcNAc umgesetzt wird (Mengin-Lecreulx und van Heijenoort 1993; Mengin-Lecreulx und van Heijenoort 1994; Mengin-Lecreulx und van Heijenoort 1996). 


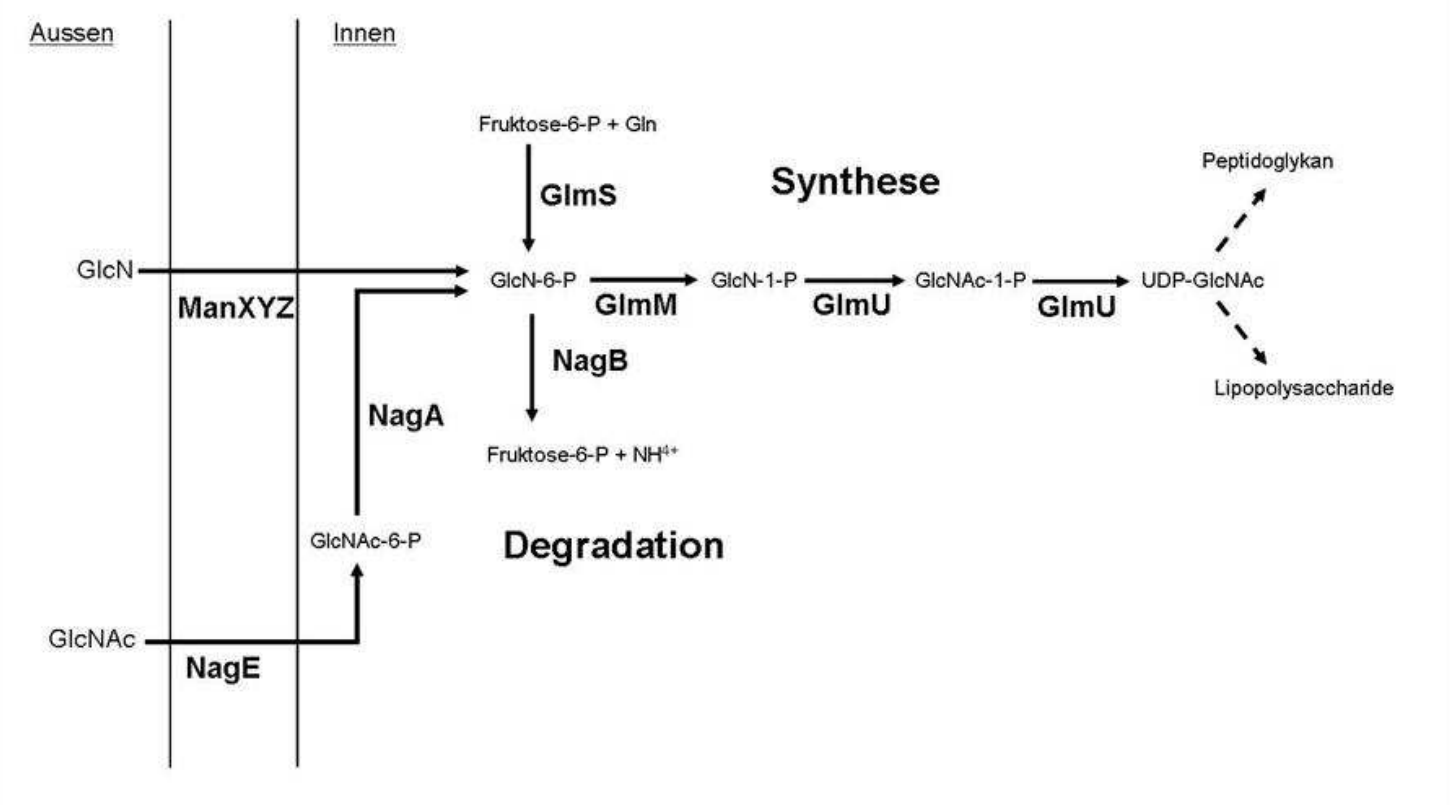

Abb. 2.4.: Aminozucker-Metabolismus in E. coli

Die beiden Linien links symbolisieren die Zellmembran. „Innen“ bezeichnet das Cytoplasma, „Aussen“ die Umgebung jenseits der Zellhülle. Glukosamin (GlcN) und N-Acetylglukosamin (GlcNAc) können über die Transporter ManXYZ und NagE aufgenommen werden, wobei das Substrat phosphoryliert wird. N-Acetylglukosamin-6-Phosphat (GlcNAc-6-P) wird nachfolgend durch NagA zu Glukosamin-6-Phosphat (GlcN-6-P) umgesetzt. Dieses wird entweder zur Synthese von Peptidoglykan oder Lipopolysacchariden verwendet oder als Kohlenstoffquelle verstoffwechselt. In diesem Fall wird es durch NagB in Ammonium und Fruktose-6-P gespalten, welches in der Glykolyse abgebaut werden kann.

Falls keine externe Quelle für Aminozucker zur Verfügung steht, ist $E$. coli in der Lage, GlcN-6$P$ mittels GlmS aus Fruktose-6-P und Glutamat zu synthetisieren.

GlcN-1-P= Glukosamin-1-Phosphat, GlcNAc-1-P= N-Acetylglukosamin-1-Phosphat, UDPGlcNAc= Uridin-5'-diphospho-N-Acetylglukosamin.

Abbildung nach (Plumbridge 1995).

Die Gene $g \operatorname{lm} M$ und $g \operatorname{lm} U$ sind essentiell für E. coli, während $g \operatorname{lm} S$ nur dann notwendig für das Überleben der Zelle ist, wenn keine externe Quelle für Aminozucker verfügbar ist. N-Acetylglukosamin (GlcNAc), Glukosamin (GlcN) und weitere Aminozucker wie Chitobiose und Sialinsäure können von der Zelle aufgenommen und zu GlcN-6-P umgewandelt werden, wodurch der von GlmS katalysierte Syntheseschritt umgangen werden kann (Plumbridge und Vimr 1999).

GlmS besteht aus einer N-terminalen Glutaminase-Domäne und einer C-terminalen Isomerase-Domäne, und bildet Homodimere (Badet et al. 1987). Der Mechanismus der Glc-6-P-Synthese ist beschrieben (Teplyakov et al. 2002; Mouilleron et al. 2006) und die Kristallstrukturen des Proteins sowie von Protein-Substrat-Komplexen sind aufgeklärt (Isupov et al. 1996; Teplyakov et al. 1998; Teplyakov et al. 2001). Es sind mehrere Inhibitoren von GlmS bekannt, darunter Bacilysin (Kenig und Abraham 1976; Chmara et al. 1984), FMDP (Marshall et al. 2003) und reaktive Intermediat-Analoga (Bearne und Blouin 2000). Ebenso wurde eine Inhibition der enzymatischen Aktivität 
von GlmS durch Glukosamin und GlcN-6-P in vitro beschrieben (White 1968; Teplyakov et al. 2001), jedoch sind die benötigten Konzentrationen sehr hoch und die physiologische Bedeutung dieses Effektes wird angezweifelt, da GlcN-6-P in der Zelle sehr schnell zu GlcN-1-P umgesetzt wird (Milewski 2002). Da die Menge des durch GlmS synthetisierten GlcN-6-P pro Generationszeit lediglich 2-3fach höher ist als die für die Peptidoglykanherstellung benötigte Menge, ist GlmS ein attraktives Ziel für die Entwicklung antimikrobieller Wirkstoffe (Teplyakov et al. 2002).

\subsubsection{Kataboler Abbau von Glukosamin-6-P}

Sollte E. coli eine externe Quelle für Aminozucker angeboten werden, so ist es in der Lage, diese Verbindungen aufzunehmen und als Kohlenstoffquelle zu verstoffwechseln (siehe Abb. 1.4.). Hierbei wird das Substrat über PTS-Transporter aufgenommen und phosphoryliert (Postma et al. 1993). Der Transport von Glukosamin erfolgt durch den ManXYZ-Komplex, während GlcNAc durch das Protein NagE, einem EnzymIIABCProtein des PTS, importiert wird. Das so entstehende N-Acetyl-Glukosamin-6-Phosphat (GlcNAc-6-P) wird zunächst durch die GlcNAc-6-P Deacetylase NagA in GlcN-6-P umgesetzt. Nachfolgend wird dieses durch Isomerisation und Deaminierung, katalysiert durch die GlcN-6-P Deaminase NagB, in Fruktose-6-Phosphat umgewandelt (AlvarezAnorve et al. 2005). Die hierzu notwendigen Proteine sind im divergenten nagEnagBACD-Operon codiert, dessen Expression unter Kontrolle des Regulators NagC steht. NagC wirkt als Repressor der nagE-nagBACD-Expression, indem es an OperatorSequenzen bindet, die mit den Promotoren der beiden Operons überlappen (Plumbridge 1991). Diese Bindung induziert die Ausbildung einer Schleife in der DNA, wodurch die Transkription der Gene verhindert wird (Plumbridge et al. 1993). In Anwesenheit einer externen Aminozuckerquelle wird GlcNAc-6-P gebildet, welches als Effektor an NagC binden kann und die DNA-Bindefähigkeit des Proteins aufhebt. Die Repression der nag-Gene wird aufgehoben und der katabole Metabolismus für Aminozucker wird aktiviert. Zusätzlich dient GlcNAc-6-P als allosterischer Aktivator der NagB-Aktivität (Midelfort und Rose 1977).

Zusätzlich reprimiert NagC die Expression des $\operatorname{ch} b B C A R F G$-Operons, dessen Produkte den Abbau von Chitobiose katalysieren, einem Disaccharid aus zwei GlcNAc-Einheiten (Plumbridge und Pellegrini 2004). 


\subsubsection{Regulation des glmUS-Operons durch NagC}

Da in E. coli ein anaboler und ein kataboler Metabolismus für Aminozucker besteht, muss deren Aktivität präzise ausbalanciert sein, so dass keine nutzlosen Zyklen aus Synthese und Degradation entstehen, die als „Kurzschluß“-Reaktion der Zelle Energie entziehen. Einer der einfachsten Wege, eine solche Kontrolle auszuüben ist die Einrichtung eines „Schalters“, der immer nur die Aktivität eines der beiden Wege zulässt, also einen der Wege aktiviert und/oder den anderen inhibiert.

Die Gene für zwei der Enzyme des UDP-GlcNAc-Syntheseweges, GlmS und GlmU, sind zusammen in einem Operon codiert, welches von zwei Promotoren vor $g \operatorname{lm} U$ aus exprimiert wird. Diese beiden Promotoren (P1 und P2) stehen unter Kontrolle des DNA-bindenden Proteins NagC (Plumbridge 1995), welches ebenfalls die Expression des nag- und chb-Operons reguliert, die für die Proteine des katabolen Abbaus von Aminozuckern codieren (siehe 2.4.2.), sowie in E. coli auch die Expression von galP, welches die Galactose-Permease kodiert (El Qaidi et al. 2008).

Die Regulation der beiden $g \operatorname{lm} U$-Promotoren durch NagC ist komplex: Der Regulator bindet an zwei Operator-Sequenzen stromaufwärts der Promotoren und wirkt dort als Aktivator von P1, jedoch zur selben Zeit als Repressor für P2. Dies resultiert in einer lediglich 3-fach höheren Expression wenn NagC an die Operator-Sequenzen gebunden ist, verglichen mit einem Faktor von 40 in der NagC-abhängigen Regulation des nagBACD-Operons (Plumbridge et al. 1993; Plumbridge 1995). Im Gegensatz zu diesen Genen ist zumindest $\operatorname{glm} U$ ein unter allen Wachstumsbedingungen essentielles Gen in E. coli, was eine Erklärung für eine hohe Expression auch unter nicht-aktivierenden Bedingungen ist. Die Aktivität von NagC ist durch GlcNAc-6-P reguliert: Als Effektor ist es in der Lage, an NagC zu binden und moduliert dessen Fähigkeit zur DNABindung (Plumbridge et al. 1993). Dadurch wird die Synthese der anabolen und katabolen Proteine des Aminozucker-Metabolismus an die Verfügbarkeit einer externen Quelle gekoppelt: Bei Anwesenheit von Aminozuckern in der Umgebung werden diese über NagE aufgenommen und in GlcNAc-6-P umgesetzt. Dieses interagiert mit NagC und inhibiert dessen Fähigkeit zur Bindung an die Operatorsequenzen (siehe Abb. 2.5.B). Dadurch wird gleichzeitig die Repression des nagBACD-Operons aufgehoben und der aktivierende Einfluss von NagC auf die $g \operatorname{lm} U$-Promotoren beendet (Plumbridge 1995). Sollten keine externen Aminozucker mehr verfügbar sein, so kann NagC wieder an die DNA binden, wodurch die Expression der katabolen Proteine wieder reprimiert 
wird. Zusätzlich wird die Expression der Enzyme zur de novo-Synthese verstärkt (siehe Abb. 2.5.A).

A

Kein externer Aminozucker verfügbar

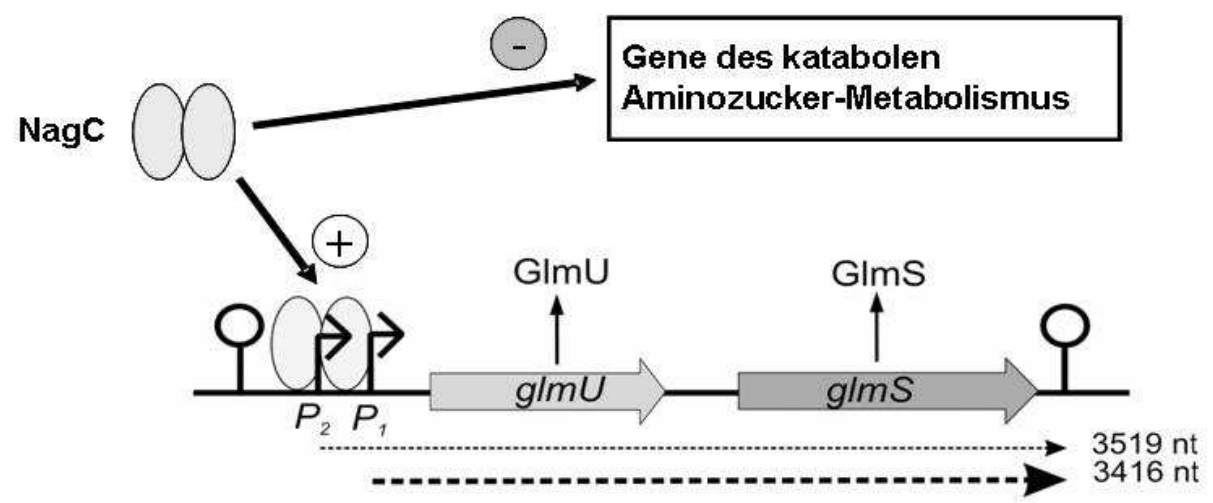

B

\section{Externer Aminozucker verfügbar}

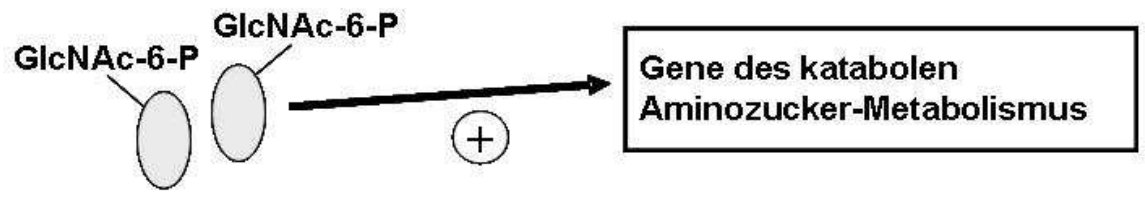

$\mathrm{NagC}$

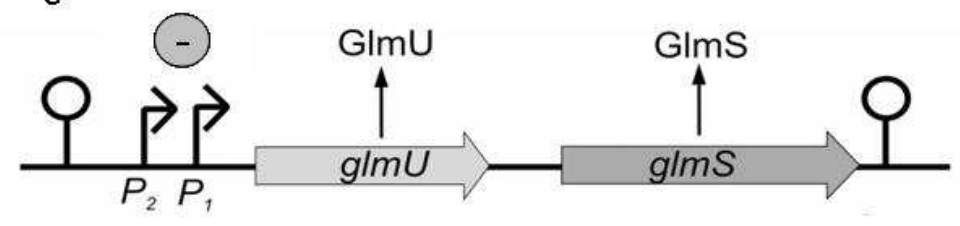

Abb. 2.5.: NagC-abhängige Regulation der Expression kataboler und anaboler Gene des Aminozucker-Metabolismus in $E$. coli

(A) Wenn keine externe Quelle für Aminozucker zur Verfügung steht, bindet NagC an seine Operatorsequenzen. Hier wirkt es als Repressor der Expression der Gene des katabolen Aminozucker-Metabolismus, während es die Expression der anabolen Gene glmU und $\mathrm{g} / \mathrm{mS}$ aktiviert.

(B) Sobald eine externe Quelle für Aminozucker verfügbar wird, interagiert GlcNAc-6-P mit NagC und dieses verliert seine Fähigkeit zur Bindung an die DNA. Dadurch wird der aktivierende Effekt auf die gImUS-Expression aufgehoben, ebenso wie die Repression der Expression der Gene des katabolen Aminozuckermetabolismus

\subsubsection{Regulation von GlmS in B. subtilis und in Eukaryoten}

Das glmUS-Operon kodiert sowohl die essentielle N-Acetylglukosamin-1-Phosphat Uridyltransferase / Glukosamin-1-Posphat Acetyltransferase GlmU, die unter allen Wachstumsbedingungen für die Umwandlung von Glukosamin-1-Phosphat zu UDP- 
GlcNAc notwendig ist, sowie die Glukosamin-6-Phosphat Synthase GlmS, die die de novo-Synthese von GlcN-6-P aus Fructose-6-Phosphat und Glutamin katalysiert, ein Schritt, der nur notwendig ist, wenn keine externe Quelle für Aminozucker zur Verfügung steht. Dies führt zu der Frage, ob die Synthese oder Aktivität von GlmS einer weiteren Regulation unterliegt, da eine synchrone Expression mit GlmU unter bestimmten Umständen dazu führen würde, dass trotz einer ausreichenden Versorgung durch externe Aminozucker die de novo-Syntheserate von GlcN-6-P erhöht wird. Dies würde der Zelle jedoch unnötig die zentralen Stoffwechselprodukte Fruktose-6Phosphat und Glutamin entziehen.

In eukaryotischen Organismen unterliegt die Aktivität von GlmS einer starken allosterischen Hemmung durch UDP-GlcNAc, dem zentralen Intermediat stromabwärts im Syntheseweg (Milewski 2002). Ebenso wurde eine starke Hemmung des menschlichen Homologs GFAT1 durch Glukosamin-6-Phosphat (Broschat et al. 2002) beobachtet.

Darüber hinaus ist bekannt, dass die Translation des glmS-Transkripts in Grampositiven Organismen wie Bacillus subtilis von einem Ribozym kontrolliert wird. Dieses ist ein in cis-wirkendes regulatorisches RNA-Element in der nicht-translatierten 5'-Region des glmS-Transkriptes. Das glmS-Ribozym ist bislang einzigartig: Im Gegensatz ähnlichen regulatorischen Elementen handelt es sich bei diesem Mechanismus nicht um eine Attenuationskontrolle der Translation, sondern um eine Metaboliten-vermittelte Selbstspaltung der RNA (Winkler et al. 2004). Hierbei bindet GlcN-6-P an die Sekundärstruktur nahe der Spaltstelle (Jansen et al. 2006) und dient als Koenzym der Spaltung (McCarthy et al. 2005). Im Gegensatz zu Riboswitches kommt es bei dem glmS-Ribozym bei Bindung des Substrates nicht zu dramatischen Änderungen der Sekundärstruktur, sondern diese löst lediglich die Spaltung des Primärtranskriptes aus (Tinsley et al. 2007). Die Spaltung durch das Ribozym generiert RNA-Produkte mit einem zyklischen 2'-3'-Phosphat und einer 5'-Hydroxylgruppe (Cochrane und Strobel 2008). Die Stabilität des $\mathrm{glmS}$-spezifischen Spaltproduktes ist gegenüber dem Primärtranskript herabgesetzt, und es wurde gezeigt, das RNA mit 5'Hydroxylgruppen spezifisch durch RNase J1 abgebaut wird (Collins et al. 2007).

In $E$. coli ist RNase E verantwortlich für den mRNA-Abbau, jedoch fehlt B. subtilis ein entsprechendes Homolog. Interessanterweise zeigt diese ein der RNase J1 entgegengesetztes Verhalten: RNAse E-abhängige Degradation zeigt gegenüber RNAs mit 5’-Hydroxylgruppe die geringste Affinität (Celesnik et al. 2007). 
Demnach wird die Aktivität der Glukosamin-6-Phosphat Synthase sowohl in Eukaryoten wie auch in Gram-positiven Mikroorganismen direkt oder indirekt durch stromabwärts gelegenen Intermediate des Syntheseweges inhibiert.

In E. coli ist zwar in vitro ein inhibierender Effekt von Glukosamin und GlcN-6-P beschrieben, jedoch findet dieser nur bei Konzentrationen statt, die außerhalb des physiologisch zu erwartenden Bereiches im Inneren der Zell liegen, und der zugrunde liegende Mechanismus ist unklar (Milewski 2002).

2.4.5. YhbJ-abhängige Regulation der $g \operatorname{lm} S$-Expression durch Stabilisierung einer $g \operatorname{lm} S$ spezifischen mRNA

Um die Hypothese eines regulatorischen Ereignisses stromabwärts der bekannten Promotoren vor $g \operatorname{lm} U \mathrm{zu}$ untersuchen, wurden Northern Blot Analysen von GesamtRNA-Proben des Wildtyps (R1279) und eines $\Delta[p t s N-n p r]-S t a m m e s$ (R2413), sowie des $\Delta[p t s N$-npr $]$-Stammes transformiert mit einem $y h b J$-tragenden Plasmid (pFDX4324) durchgeführt (siehe 3.6.7), bei denen Sonden gegen $g \operatorname{lm} U$ und $\operatorname{glm} S$ verwendet wurden (siehe Abb. 2.6., Arbeiten von B. Reichenbach in (Kalamorz et al. 2007)).

Mit der Sonde gegen $g \operatorname{lm} U$ konnte ein schwaches Signal mit einer Größe von 3,5 kB detektiert werden, welches einem Transkript des gesamten glmUS-Operons entspricht. Es konnten keine signifikanten Unterschiede zwischen den verwendeten Stämmen und der Transformante beobachtet werden (Abb 2.6., Spur 1-3). Die geringe Menge an glmUS-Transkript beruht auf einer hohen Instabilität der mRNA (Joanny et al. 2007). Dies erklärt auch das undeutliche Signal unter der Bande des Transkriptes, welches auf Abbauprodukten der mRNA zurückzuführen ist.

Im Gegensatz hierzu ist mit einer gegen $g \operatorname{lm} S$ gerichteten Sonde in der [ptsN-npr]Deletion ein auffälliges und sehr starkes Signal für eine RNA mit einer Größe von etwa $2 \mathrm{kB}$ detektierbar (Abb. 2.6., Spur 5), das im Wildtyp nicht vorhanden ist (Abb. 2.6., Spur 4). Wird die [ptsN-npr]-Deletion mit yhbJ auf einem Plasmid komplementiert, ist das zusätzliche Transkript ebenfalls nicht detektierbar (Abb. 2.6., Spur 6). Hieraus lässt sich schlussfolgern, dass in Abwesenheit von YhbJ die Menge eines $g \operatorname{lmS}$-spezifischen Transkriptes stark ansteigt. Vergleicht man die Größe des $g \operatorname{lm} S$-spezifischen Signals mit der Operon-Struktur, so ist anzunehmen, dass das korrespondierende Transkript seinen Startpunkt im 3'-Bereich des $g \operatorname{lm} U$-Gens oder im 5'-Bereich des intergenischen Bereiches zwischen $g \operatorname{lm} U$ und $g \operatorname{lm} S$ hat. 


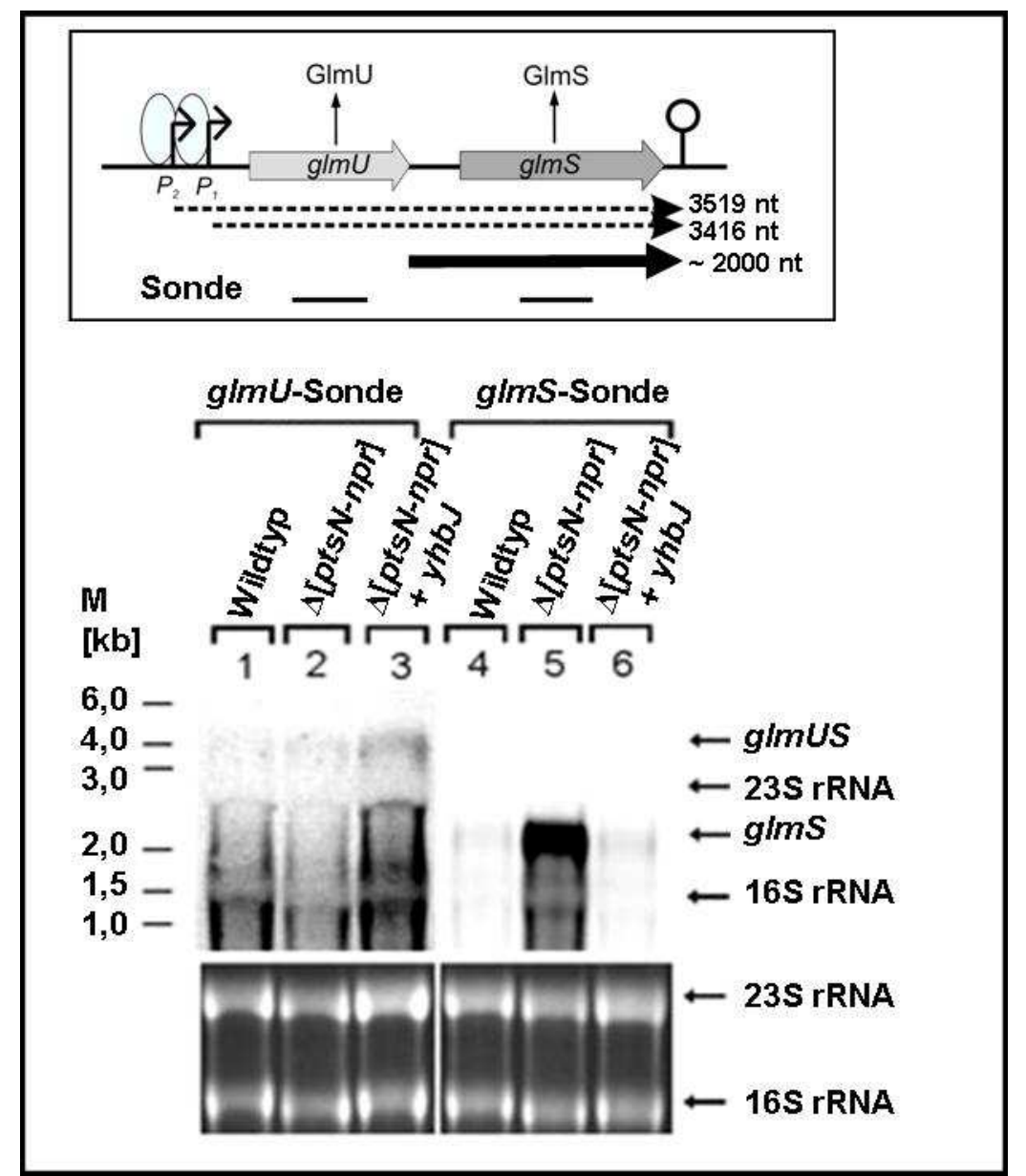

Abb. 2.6.: Northern Blot Analysen mit Sonden gegen $g / m U$ und $g / m S$

(A) Schematische Darstellung des glmUS-Operons. Pfeile symbolisieren die in der Northern Blot Analyse detektierten Transkripte. Die beiden Balken markieren die Bereiche, zu denen die Sonden komplementär sind.

(B) Ergebnisse der Northern Blot Analysen. Gesamt-RNA des Wildtyps (R1279), eines $\Delta[p t s N$ $n p r]-S t a m m e s$ (R2413) sowie des [ptsN-npr]-Stammes transformiert mit einem Plasmid, das yhbJ unter $\mathrm{P}_{\text {tac }}$-Kontrolle trägt ( $\mathrm{pFDX} 4324$ ) wurde präpariert und in einer Northern Blot Analyse (siehe 3.6.7.) eingesetzt. Die Spuren 1-3 zeigen die detektierten Signale bei Verwendung einer gegen $\mathrm{g} / \mathrm{mU}$ gerichteten Sonde. Es ist kein signifikanter Unterschied zwischen den verwendeten Stämmen erkennbar.

In den Spuren 4-6, in denen eine gegen glmS gerichtete Sonde verwendet wurde, ist ein zusätzliches Transkript einer Größe von etwa 2000 Basen detektierbar. Dieses tritt nur in dem [pts $N$-npr]-Deletionsstamm auf, und verschwindet bei Komplementation mit plasmidständigen yhbJ.

$\mathrm{Zu}$ beachten ist in diesem Zusammenhang, dass die gegen glmS gerichtete Sonde in einer $10 f a c h$ niedrigeren Konzentration eingesetzt wurde als die gegen glmU gerichtete, weshalb das Primärtranskript von 3500 Basen nicht detektiert werden kann.

Aus diesen Beobachtungen lässt sich schließen, dass die erhöhte GlmS-Menge in Abwesenheit von yhbJ auf dem Auftreten eines zusätzlichen, glmS-spezifischen Transkriptes beruht.

Abbildung nach (Kalamorz et al. 2007).

Dies konnte durch Messungen der $\beta$-Galaktosidase-Aktivität (siehe 3.3.4.) mit plasmidischen $g \operatorname{lm} U$-, glmUS- und glmS-lacZ-Reporterfusionen bestätigt werden. Die Anwesenheit von YhbJ hat keinen Effekt auf eine glmU-lacZ-Reporterfusion. Sobald jedoch der intergenische Bereich zwischen $\operatorname{glm} U$ und $g \operatorname{lm} S$ in der Reporterfusion vorhanden ist, zeigt diese eine erhöhte Aktivität in Abwesenheit von YhbJ (vergleiche Abb. 4.1. und (Kalamorz et al. 2007)). 
Um den Startpunkt des $g l m S$-spezifischen Transkriptes zu lokalisieren wurden Primer Extension-Experimente durchgeführt (Arbeiten von Walter März und Bodo Rak in (Kalamorz et al. 2007). Hierbei wurde festgestellt, dass das 5'-Ende des glmSspezifischen Transkriptes mit dem $\mathrm{G}$ beziehungsweise A des Stop-Codons von $\operatorname{glm} U$ übereinstimmt (siehe Abb. 2.7). Dieses Transkript war auch hier ausschließlich in Abwesenheit von YhbJ zu beobachten. Interessanterweise ergab eine Analyse der direkt stromaufwärts gelegenen DNA-Sequenz keinerlei Hinweise auf einen zusätzlichen Promotor.

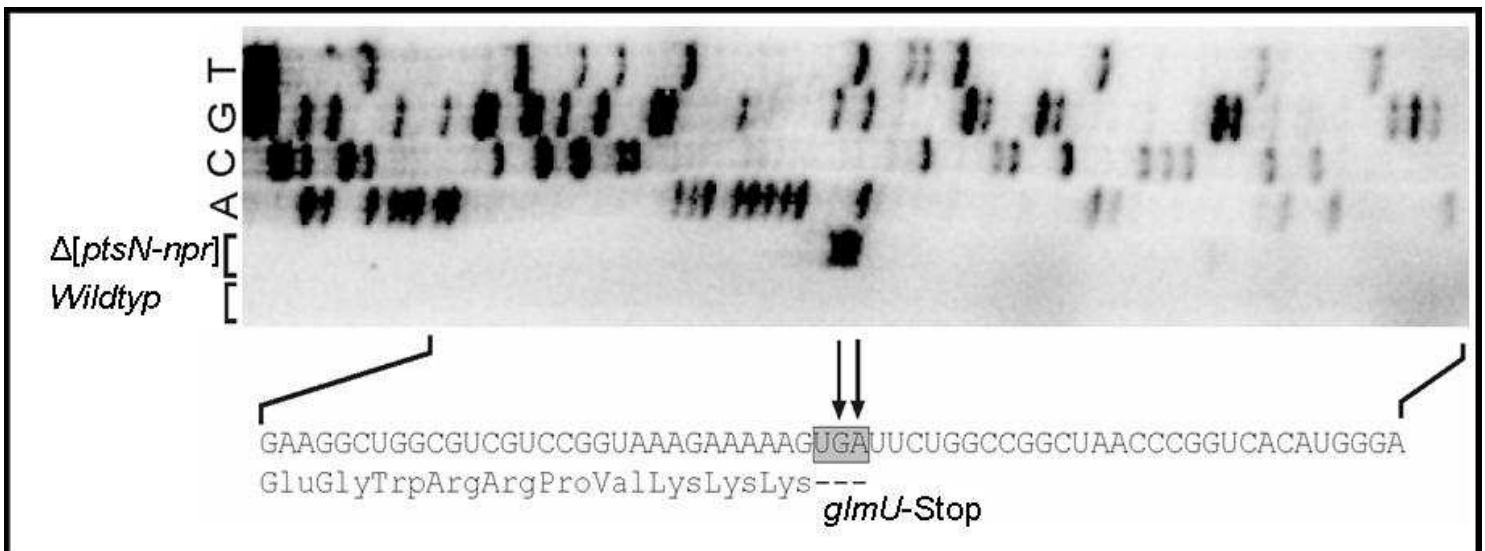

Abb. 2.7.: Primer Extension-Experiment zur Lokalisation des Startpunktes des glmsspezifischen Transkriptes in E. coli.

Gesamt-RNA des Wildtyps (R1279) und eines $\Delta[p t s N-n p r]-S t a m m e s$ (R2413) wurde präpariert und für Primer Extension-Experimente eingesetzt. Es wurde hierbei ein Oligonukleotid verwendet, das komplementär zu einer Sequenz stromaufwärts vom glmS-Startpunkt ist. Die Reaktionsprodukte wurden zusammen mit einer Sequenzierungsleiter (A, C, G, T), welche unter Verwendung desselben Oligonukleotids generiert wurde, in einem Harnstoff/Polyacrylamid-Gel aufgetrennt und analysiert.

Es ist kein Signal im Wildtyp-Stamm detektierbar. Im Gegensatz dazu treten im $\Delta[p t s N-n p r]-$ Stamm zwei deutliche Signale auf. Die Startpunkte dieser glmS-spezifischen Transkripte stimmen mit dem $\mathrm{G}$ beziehungsweise A des Stopcodons des Gens glmU überein.

Abbildung nach (Kalamorz et al. 2007).

Ein vergleichbares Auftreten eines $g \operatorname{lm} S$-spezifischen Transkriptes wurde für Stämme beschrieben, in denen das Gen $p c n B$ deletiert ist, welches für die Poly(A)-Polymerase PAP I codiert. In diesem Fall konnte gezeigt werden, dass dieses $g \operatorname{lm} S$-spezifische Transkript durch eine RNase E-abhängige Prozessierung des glmUS-Primärtranskriptes entsteht (Joanny et al. 2007). 


\subsection{Fragestellung der Arbeit}

Nachdem gezeigt werden konnte, dass die verstärkte Expression von $g \operatorname{lm} S$ in Abwesenheit von YhbJ auf der Akkumulation eines glmS-spezifischen Transkriptes beruht, sollte nun zunächst mittels Transposon-Mutagenese nach weiteren Genen gesucht werden, deren Produkte an dieser Regulation beteiligt sind. Falls solche zusätzlichen Komponenten identifiziert werden können, soll ihre Funktion in der Regulation nachfolgend näher untersucht werden.

Die Akkumulation der $g \operatorname{lm} S$-spezifischen mRNA konnte bislang nur in der artifiziellen Situation eines $y h b J$-Deletionsstammes beobachtet werden. Um die physiologische Rolle des regulatorischen Ereignisses aufzuklären soll das Signal identifiziert werden, welches diesen Mechanismus im Wildtyp aktiviert.

Aufgrund der zentralen Rolle von YhbJ in der Kontrolle der glmS-Expression soll dieses Protein näher charakterisiert werden. Hierzu soll die Expression von $y h b J$ als Teil des rpoN-Operons untersucht, Mutanten von YhbJ durch Aminosäure-Austausche und Deletionen generiert und analysiert sowie ein möglicher globaler Einfluss einer $y \mathrm{hbJ}$ Deletion durch MicroArray Analysen bestimmt werden.

Sollten in der oben genannten Transposon-Mutagenese weitere Komponenten des Regulationsmechanismus identifiziert werden, so soll eine mögliche Interaktion mit YhbJ untersucht werden. 


\section{Material und Methoden}

\subsection{Stämme, Plasmide und Oligonukleotide}

Die in dieser Arbeit verwendeten Stämme, Plasmide und Oligonukleotide sind im Anhang in den Tabellen 7.1., 7.2. und 7.3. aufgeführt.

\subsection{Medien und Antibiotika}

Puffer, Lösungen und Medien wurden, soweit nicht anders angegeben, mit $\mathrm{H}_{2} \mathrm{O}$ (bidest) angesetzt und $20 \mathrm{~min}$ bei $121^{\circ} \mathrm{C}$ und 2 bar autoklaviert. Thermolabile Substanzen wurden gelöst und mittels FP 30/0,2 CA-S Filtern (Fa. Schleicher \& Schuell, Dassel) sterilfiltriert.

\subsubsection{Luria Bertani (LB) -Medium}

LB-Medium:

$\begin{array}{ll}\text { Trypton } & 10 \mathrm{~g} \\ \text { Hefeextrakt } & 5 \mathrm{~g} \\ \mathrm{NaCl} & 5 \mathrm{~g} \\ \mathrm{H}_{2} \mathrm{O} \text { (dest) } & \mathrm{ad} 1.000 \mathrm{ml}\end{array}$

Dem Grundmedium wurde bei der Herstellung von Plattenmedien zur Verfestigung $15 \mathrm{~g} / \mathrm{l}$ Agar zugesetzt.

\section{$\underline{\text { 3.2.2. M9-Minimalmedium }}$}

M9 $(20 \times)$ :

$\begin{array}{ll}\mathrm{Na}_{2} \mathrm{HPO}_{4} & 140 \mathrm{~g} \\ \mathrm{KH}_{2} \mathrm{PO}_{4} & 60 \mathrm{~g} \\ \mathrm{NH}_{4} \mathrm{Cl} & 20 \mathrm{~g} \\ \mathrm{H}_{2} \mathrm{O} \text { (dest) } & \text { ad } 1.000 \mathrm{ml}\end{array}$


M9-Medium (Minimal-Medium):

$\begin{array}{lll}\text { M9 } & (20 \times) & 50 \mathrm{ml} \\ \mathrm{MgSO}_{4} & {[1 \mathrm{M}]} & 1 \mathrm{ml} \\ \mathrm{CaCl}_{2} & {[0.1 \mathrm{M}]} & 1 \mathrm{ml} \\ \mathrm{FeCl}_{3} & {[1 \mathrm{mM}]} & 0.5 \mathrm{ml} \\ \mathrm{L}-\text { Prolin } & {[4 \mathrm{mg} / \mathrm{ml}]} & 10 \mathrm{ml} \\ \text { Thiamindichlorid } & {[1 \mathrm{mg} / \mathrm{ml}]} & 1 \mathrm{ml} \\ \text { Kohlenstoffquelle } & & 1 \%[\mathrm{w} / \mathrm{v}] \\ \mathrm{H}_{2} \mathrm{O} \text { (dest) } & & \text { ad } 1.000 \mathrm{ml}\end{array}$

M9-Minimalmedium wurde aus sterilen Lösungen angesetzt und nicht autoklaviert.

Zur Herstellung von M9-Plattenmedium wurde zunächst 3\% (w/v) Bacto-Agar in einem Volumen entsprechend der Hälfte des gewünschten Endvolumens autoklaviert und nach dem Abkühlen auf $60^{\circ} \mathrm{C}$ mit den oben genannten Bestandteilen des M9-Mediums komplementiert und zum gewünschten Endvolumen aufgefüllt.

\subsubsection{SOB/SOC - Medium}

SOB-Medium:

$\begin{array}{ll}\text { Trypton } & 20 \mathrm{~g} \\ \text { Hefeextrakt } & 5 \mathrm{~g} \\ \mathrm{NaCl} & 0,5 \mathrm{~g} \\ \mathrm{KCl}(3 \mathrm{M}) & 834 \mu \mathrm{l} \\ \mathrm{H}_{2} \mathrm{O} \text { (dest) } & \text { ad } 1.000 \mathrm{ml} \\ \mathrm{pH} 7,0 \text { einstellen mit } \mathrm{HCl}\end{array}$

Nach dem autoklavieren $2 \mathrm{ml} \mathrm{MgCl}_{2}(1 \mathrm{M})$ zugeben.

SOC-Medium:

SOC-Medium wurde zunächst wie SOB angesetzt, jedoch nach dem autoklavieren zusätzlich mit 19,8 ml Glukose (10\% (w/v)) pro Liter supplementiert 
3.2.4. McConkey/Lac - Plattenmedium

$\begin{array}{ll}\text { McConkey-Agar } & 40 \mathrm{~g} \\ \text { Lactose } & 10 \mathrm{~g} \\ \mathrm{H}_{2} \mathrm{O} \text { (dest) } & \text { ad } 1.000 \mathrm{ml}\end{array}$

\subsubsection{Antibiotika}

Die verwendeten Antibiotika wurden als 1.000fach konzentrierte Stammlösungen angesetzt. Nva-FMDP, Ampicillin und Kanamycin wurden dazu in $\mathrm{H}_{2} \mathrm{O}$ (bidest) gelöst, Tetracyclin, Chloramphenicol und Fosfomycin in $70 \%$ Ethanol (reinst), NEthylmaleimid in $20 \%$ DMSO. Alle Lösungen wurden steril filtriert und bei $-20^{\circ} \mathrm{C}$ oder $4^{\circ} \mathrm{C}$ bewahrt.

Die Antibiotika wurden den Medien entweder nach dem Abkühlen auf etwa $50^{\circ} \mathrm{C}$ oder direkt vor Gebrauch zu den angegebenen Endkonzentrationen zugegeben.

Selektionskonzentration für E. coli:

$\begin{array}{ll}\text { Ampicillin } & 100 \mu \mathrm{g} / \mathrm{ml} \\ \text { Chloramphenicol } & 15 \mu \mathrm{g} / \mathrm{ml} \\ \text { Kanamycin } & 30 \mu \mathrm{g} / \mathrm{ml} \\ \text { Tetracyclin } & 12,5 \mu \mathrm{g} / \mathrm{ml}\end{array}$

\subsubsection{Weitere Medienzusätze}

Neben Antibiotika wurden ebenfalls folgende Chemikalien zur Komplementation von Medien eingesetzt:

$\begin{array}{ll}\text { X-Gal } & 50 \mu \mathrm{g} / \mathrm{ml} \\ \text { IPTG } & 0,1-1 \mathrm{mM} \\ \text { L-Arabinose } & 20 \mathrm{mM} \text { oder } 0,2 \%(\mathrm{w} / \mathrm{v})\end{array}$




\subsection{Mikrobiologische Methoden}

\subsubsection{Anzucht und Konservierung von Bakterien}

E. coli wurde, wenn nicht anders erwähnt, in LB-Medium (siehe 3.2.1.) bei $37^{\circ} \mathrm{C}$ und 180 rpm auf einem Horizontalschüttler in Reagenzgläsern oder Erlenmeyerkolben kultiviert. Die Inokulation erfolgte mit Einzelkolonien von frischen Vereinzelungsplatten oder aus Übernachtkulturen auf eine $\mathrm{OD}_{600}$ von 0,1 . Das Wachstum wurde durch Messung der optischen Dichte bei $600 \mathrm{~nm}$ mit Hilfe eines V530 UV/VIS Spectrophotometers (Fa. Jasco, Gotha) oder einem Ultrospec 2100 proPhotometers (Fa. Amersham, Freiburg) verfolgt.

Zur langfristigen Lagerung wurden Kulturen bei $-70^{\circ} \mathrm{C}$ aufbewahrt. Hierzu wurde $1 \mathrm{ml}$ einer spätlogarithmischen oder stationären Kultur mit $80 \mu \mathrm{l}$ DMSO versetzt und in flüssigem Stickstoff schockgefroren.

\subsubsection{Herstellung chemisch kompetenter E. coli (Hanahan 1983)}

Kompetente E. coli-Zellen wurden mittels der Calciumchlorid-Methode hergestellt. Hierzu wurden $25 \mathrm{ml}$ LB-Medium (siehe 3.2.1.) in einem $300 \mathrm{ml}$-Erlenmeyerkolben aus einer Übernacht-Kultur zu einer $\mathrm{OD}_{600}$ von 0,1 inokuliert und bei $37^{\circ} \mathrm{C}$ auf einem Horizontalschüttler bei $180 \mathrm{rpm}$ bis zum Erreichen einer $\mathrm{OD}_{600}$ von 0,3 inkubiert. Dann folgte eine Zentrifugation für $15 \mathrm{~min}$ bei $4^{\circ} \mathrm{C}$ und $4.000 \mathrm{rpm}$ in einem Heraeus \#75007590-Rotor (Kendro Laboratory Products, Langenselbold). Das Pellet wurde in $10 \mathrm{ml} 0,1 \mathrm{M} \mathrm{CaCl} 2$ resuspendiert und für $20 \mathrm{~min}$ auf Eis inkubiert, bevor die beschriebene Zentrifugation wiederholt wurde. Das Pellet wurde in $500 \mu 10,1 \mathrm{M} \mathrm{CaCl}_{2}$ aufgenommen und zur Transformation eingesetzt.

Alternativ wurden sogenannte super-kompetente Zellen hergestellt. Hierzu wurden zunächst $5 \mathrm{ml}$ LB-Medium (siehe 3.2.1.) mit dem gewünschten Stamm inokuliert und über Nacht bei $37^{\circ} \mathrm{C}$ auf einem Horizontalschüttler inkubiert. Mit dieser Vorkultur wurden dann $250 \mathrm{ml}$ SOB-Medium (siehe 3.2.3.) in einem 1 1-Schikanekolben inokuliert und in einem Wasserbad bei $18^{\circ} \mathrm{C}$ unter Agitation inkubiert, bis eine $\mathrm{OD}_{600}$ von 0,6 erreicht wurde (etwa 24 h). Die Kultur wurde für 10 min auf Eis abgekühlt und die Zellen anschließend bei $4.000 \mathrm{rpm}$ und $4^{\circ} \mathrm{C}$ für $10 \mathrm{~min}$ pelletiert. Der Überstand wurde verworfen und das Pellet in $80 \mathrm{ml}$ TB aufgenommen. Es folgte eine Inkubation 
für $10 \mathrm{~min}$ auf Eis, danach wurden die Zellen wiederum bei $4.000 \mathrm{rpm}$ und $4^{\circ} \mathrm{C}$ für 10 min pelletiert und der Überstand verworfen. Das Pellet wurde in $20 \mathrm{ml}$ TB resuspendiert und auf Eis gelagert. Nach Zugabe von 1,5 ml DMSO wurde der Ansatz zu je $200 \mu \mathrm{l}$ in vorgekühlte 1,5 ml-Reaktionsgefäße aliquotiert, die dann in Flüssigstickstoff schockgefroren und bis zur Verwendung bei $-70^{\circ} \mathrm{C}$ gelagert wurden.

TB :

$\begin{array}{ll}\text { PIPES } & 10 \mathrm{mM} \\ \mathrm{CaCl}_{2} & 15 \mathrm{mM} \\ \mathrm{KCl} & 250 \mathrm{mM} \\ \mathrm{pH} 6,7 \text { einstellen mit } \mathrm{HCl} & \end{array}$

Nach dem Autoklavieren sterilfiltriertes $\mathrm{MnCl}_{2}$ zu einer Konzentration von $45 \mathrm{mM}$ zugeben.

\subsubsection{Transformation von E. coli}

Für die Transformation wurden $100 \mu \mathrm{l}$ kompetente Zellen auf Eis mit 10-100 ng Plasmid in $50 \mu \mathrm{l}$ TEN-Puffer in einem 1,5 ml-Reaktionsgefäß gemischt und der Ansatz für 20 min auf Eis inkubiert. Danach wurde das Gemisch für 90 Sekunden bei $42^{\circ} \mathrm{C}$ einem Hitzeschock ausgesetzt und nach Zugabe von $1 \mathrm{ml}$ LB-Medium zunächst für 1 min auf Eis gekühlt und anschließend in ein steriles Reagenzglas überführt. Dieses wurde für $60 \mathrm{~min}$ bei $37^{\circ} \mathrm{C}$ auf einem Schüttler inkubiert. Von den Transformationsansätzen wurden jeweils $100 \mu \mathrm{l}$ und der abzentrifugierte Rest auf entsprechenden LB-Selektionsagar ausplattiert.

TEN pH 8,0:

$\begin{array}{ll}\text { Tris- } \mathrm{HCl} & 20 \mathrm{mM} \\ \text { EDTA } & 1 \mathrm{mM} \\ \mathrm{NaCl} & 50 \mathrm{mM}\end{array}$

3.3.4. $\beta$-Galaktosidase-Assay (Miller 1972)

Die Bestimmung der $\beta$-Galaktosidase-Aktivität ist ein klassisches Reportergen-Assay, das zur indirekten Bestimmung der Expressionsstärke beziehungsweise Translationseffizienz eines Genes verwendet wird. Die Messung beruht auf der 
enzymatischen Umwandlung von $\underline{o}$-Nitrophenyl- $\beta$-D-Galaktopyranosid (ONPG) in Galaktose und $o$-Nitrophenol durch die $\beta$-Galaktosidase (siehe Abb. 3.1.). $o$ Nitrophenol ist ein gelber Farbstoff und kann photometrisch bei einer Wellenlänge von $420 \mathrm{~nm}$ quantitativ bestimmt werden.

Der zu testende Stamm oder die zu testende Transformante wurde zunächst über Nacht in $5 \mathrm{ml}$ des Testmediums auf dem Horizontalschüttler bei $37^{\circ} \mathrm{C}$ inkubiert. Aus dieser Vorkultur wurden $10 \mathrm{ml}$ des Testmediums zu einer $\mathrm{OD}_{600}$ von 0,1 inokuliert und auf dem Horizontalschüttler oder im Wasserbad inkubiert, bis eine $\mathrm{OD}_{600}$ von 0,5 bis 0,8 erreicht wurde (exponentielle Wachstumsphase). Die OD $_{600}$ zum Zeitpunkt der Ernte wurde protokolliert und $1 \mathrm{ml}$ der Kultur für $1 \mathrm{~min}$ bei $4^{\circ} \mathrm{C}$ und $13000 \mathrm{rpm}$ pelletiert. Der Überstand wurde möglichst vollständig entfernt und das Pellet bis zur weiteren Verwendung bei $-20^{\circ} \mathrm{C}$ gelagert.

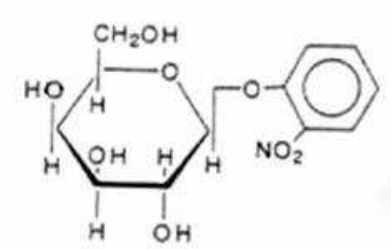

ONPG

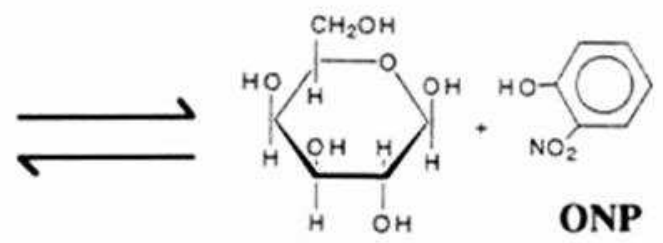

Galactose

Abb. 3.1.: Prinzip des $\beta$-Galaktosidase Assays.

o-Nitrophenyl- $\beta$-D-Galactopyranosid (ONPG) wird durch die $\beta$-Galaktosidase LacZ enzymatisch zu Galactose und dem gelben Farbstoff o-Nitrophenol (ONP) umgesetzt. Dieser kann über die Bestimmung der Absorption bei $420 \mathrm{~nm}$ quantifiziert werden.

Für den $\beta$-Galaktosidase-Assay wurde das Pellet auf Eis aufgetaut und in $1 \mathrm{ml} \mathrm{Z}$ Arbeitspuffer aufgenommen. In 2 ml-Reaktionsgefäßen wurden geeignete Verdünnungen der Probe in einem Endvolumen von $1 \mathrm{ml}$ auf Eis angelegt sowie eine Referenzprobe mit $1 \mathrm{ml}$ Z-Puffer, die nachfolgend wie die Probenverdünnungen behandelt wurde. Um die Zellen permeabel zu machen, wurden jedem Ansatz 2 Tropfen Chloroform sowie 1 Tropfen $0,1 \%$ (w/v) SDS zugesetzt und die Proben gründlich gemischt. Es folgte eine Vorinkubation für $5 \mathrm{~min}$ bei $28^{\circ} \mathrm{C}$, dann wurde die Enzymreaktion durch Zugabe von $200 \mu$ l ONPG-Lösung gestartet und die Probe nochmals gut durchmischt, bevor sie für 30 min bei $28^{\circ} \mathrm{C}$ inkubiert wurde. Nach Ablauf der Zeit wurden dem Ansatz $500 \mu 11 \mathrm{M} \mathrm{Na}_{2} \mathrm{CO}_{3}$ zugesetzt und wiederum gründlich gemischt, um die Reaktion zu stoppen. Der Ansatz wurde für $12 \mathrm{~min}$ bei 
Raumtemperatur und 13000 rpm zentrifugiert und $1 \mathrm{ml}$ des Überstandes in eine Küvette überführt. Es wurde die Absorption der Probe bei $420 \mathrm{~nm}$ photometrisch bestimmt.

Eine Einheit $\beta$-Galaktosidase, die von einer $\mathrm{OD}_{600}$ Zellen pro Minute freigesetzt wird, berechnet sich durch:

1 Miller unit $=\quad\left(\mathrm{OD}_{420} \times \mathrm{V} \times 1000\right) /\left(\mathrm{t} \times \mathrm{OD}_{600}\right)$,

wobei V der Verdünnungsfaktor und t die Reaktionszeit (in Minuten) ist.

$0,1 \%$ SDS

$1 \mathrm{M} \mathrm{Na}_{2} \mathrm{CO}_{3}$

Z-Puffer (pH 7,0):

$\begin{array}{ll}\mathrm{Na}_{2} \mathrm{HPO}_{4} & 60 \mathrm{mM} \\ \mathrm{NaH}_{2} \mathrm{PO}_{4} & 40 \mathrm{mM} \\ \mathrm{KCl} & 10 \mathrm{mM} \\ \mathrm{MgSO}_{4} & 1 \mathrm{mM}\end{array}$

Z-Arbeitspuffer:

$\begin{array}{ll}\text { B-Mercaptoethanol } & 20 \mathrm{mM} \\ \text { Chloramphenicol } & 10 \mathrm{mg} \\ \text { Z-Puffer (pH 7,0) } & \text { ad } 100 \mathrm{ml}\end{array}$

ONPG-Lösung:

$\begin{array}{ll}\mathrm{Na}_{2} \mathrm{HPO}_{4} & 60 \mathrm{mM} \\ \mathrm{NaH}_{2} \mathrm{PO}_{4} & 40 \mathrm{mM} \\ \text { ONPG } & 4 \mathrm{mg} / \mathrm{ml}\end{array}$

3.3.5. Transposonmutagenese (Madhusudan et al. 2005)

Die Zielstämme mit einer lacZ-Reporterfusion wurden mit dem Plasmid pKESK18 transformiert (siehe 3.3.3.). Aufgrund des temperatursensitiven Replikationsursprunges dieses Plasmids wurden die Ansätze nach dem Hitzeschock bei $30^{\circ} \mathrm{C}$ inkubiert, ebenso wie die ausplattierten Ansätze auf LB-Selektionsplatten (mit Kanamycin und Chloramphenicol).

$100 \mathrm{ml}$ LB-Medium (siehe 3.2.1.) mit Kanamycin und Chloramphenicol wurden mit einer Einzelkolonie der Transformante inokuliert und bei $30^{\circ} \mathrm{C}$ über Nacht oder bis zum 
Erreichen der gewünschten $\mathrm{OD}_{600}$ inkubiert. Dann wurden Verdünnungen von $10^{-3}$ bis $10^{-6}$ auf M9-Minimalmedium-Platten mit Glukose als Kohlenstoffquelle und supplementiert mit X-Gal (siehe 3.2.2.), sowie auf McConkey-Lac-Platten (siehe 3.2.4.) jeweils unter Selektion auf Chloramphenicol ausplattiert und über Nacht bei $42^{\circ} \mathrm{C}$ inkubiert. In diesem Schritt wird einerseits die Replikation des Plamides unterbrochen, während gleichzeitig die Expression der Transposase aktiviert wird. Dadurch kommt es zu einer Integration des mTn10-Transposons in das Genom des Zielstammes.

Zusätzlich wurden Verdünnungen von $10^{-4}$ bis $10^{-7}$ auf M9-Minimalplatten mit Glukose und X-Gal und auf McConkey-Lac-Platten unter Selektion auf Kanamycin-Resistenz für die Lebendzellzahlbestimmung plattiert und bei $30^{\circ} \mathrm{C}$ inkubiert.

Am folgenden Tag wurden die Zellzahlen auf allen Platten durch Zählung bestimmt. Kolonien mit dem gewünschten Phänotyp wurden auf M9-Minimalplatten mit Chloramphenicol und X-Gal vereinzelt, um diesen zu verifizieren. Anschließend wurde die Insertionsstelle des Transposons mittels ST-PCR (siehe 3.5.2.) bestimmt sowie die Aktivität der Reporterfusion im Vergleich zu den Ursprungsstämmen im $\beta$ Galaktosidase-Assay (siehe 3.3.4) bestimmt.

\subsection{Präparation und Nachweis von DNA}

\subsubsection{Präparation chromosomaler DNA}

Für die Isolation chromosomaler DNA aus E. coli wurde das DNeasy Tissue Kit (Fa. Quiagen, Hilden) gemäß Herstellerangaben verwendet. Für die Elution wurden zunächst $90 \mu 1 \mathrm{H}_{2} \mathrm{O}$ (vorgewärmt auf $70^{\circ} \mathrm{C}$ ) auf die Säule gegeben und diese für 5 min bei $70^{\circ} \mathrm{C}$ inkubiert. Es folgte eine Zentrifugation für $1 \mathrm{~min}$ bei $8.000 \mathrm{rpm}$ und Raumtemperatur. Anschließend wurden nochmals $90 \mu \mathrm{l}$ auf $70^{\circ} \mathrm{C}$ vorgewärmtes $\mathrm{H}_{2} \mathrm{O}$ auf die Säule gegeben und diese für 3 min bei Raumtemperatur inkubiert, bevor die beschriebene Zentrifugation wiederholt wurde.

\subsubsection{Fällung von DNA}

Zur Fällung von DNA wurde die Probe zunächst mit $\mathrm{H}_{2} \mathrm{O}$ auf ein Volumen von $100 \mu \mathrm{l}$ aufgefüllt. Dann wurden zunächst 1/10 Volumen Ammonium-Acetat (3 M, pH 5,2) zugegeben und gemischt, gefolgt von 2,5 Volumen Ethanol (100\% reinst). Der Ansatz wurde nochmals gut gemischt und in Flüssigstickstoff schockgefroren. Es folgte eine 
Inkubation bei $-20^{\circ} \mathrm{C}$ für $30 \mathrm{~min}$, in denen die Probe wieder auftaute. Anschließend wurde der Ansatz für 20 min bei $4^{\circ} \mathrm{C}$ und $13.000 \mathrm{rpm}$ zentrifugiert, bevor der Überstand vorsichtig entfernt wurde. Das Pellet wurde mit $500 \mu$ Ethanol (80\% reinst) gewaschen. Es folgte eine weitere Zentrifugation für $5 \mathrm{~min}$ bei $4^{\circ} \mathrm{C}$ und $13.000 \mathrm{rpm}$. Der Überstand wurde abermals verworfen und das Pellet über Nacht getrocknet, bis das Ethanol vollständig verdampft war. Anschließend konnte die DNA im gewünschten Volumen $\mathrm{H}_{2} \mathrm{O}$ resuspendiert werden.

\subsubsection{Isolation und Aufreinigung von Plasmid-DNA}

Die Plasmidisolation wurde mittels dem auf alkalischer Lyse und spezifischer Bindung von DNA an ein Silica-basierendes Anionentauscher-Material beruhenden Nucleospin Plasmid-Kit (Fa. Macherey-Nagel, Düren) gemäß Herstellerangaben durchgeführt. Für die Isolation wurden $4 \mathrm{ml}$ einer über Nacht inkubierten Kultur eingesetzt.

Midi-Präparationen von Plasmiden wurden mit Hilfe des NucleoBond PC100-Kit (Fa. Macherey-Nagel, Düren) gemäß Herstellerangaben durchgeführt. Dieses Kit beruht ebenfalls auf der Freisetzung von DNA durch alkalische Lyse und deren spezifische Bindung an ein Silica-basierendes Anionentauscher-Material. Für die Präparation wurden $50 \mathrm{ml}$ Kultur mit einer $\mathrm{OD}_{600}$ von 3,5 eingesetzt. Die abschließende Elution erfolgte zur Erhöhung der Ausbeute mit $200 \mu 1 \mathrm{H}_{2} \mathrm{O}$ (bidest).

Maxi-Präparationen von Plasmiden wurden mittels Wizard Plus Maxipreps DNA Purification System (Fa. Promega, Mannheim) nach Herstellerangaben durchgeführt.

\subsubsection{Reinigung von DNA und Gelelution}

Die Produkte aus Enzymreaktionen mit DNA wurden mit dem QIAquick PCR Purification Kit (Fa. Qiagen, Hilden) nach Herstellerangaben gereinigt. Die Funktionsweise des Kits beruht auf der spezifischen Bindung von DNA an eine SilicaMembran in Anwesenheit hoher Salzkonzentrationen.

Das QIAquick Gel Extraction Kit (Fa. Qiagen, Hilden) erlaubt die Elution von DNA aus analytischen Agarosegelen (siehe 2.4.5.). Hierzu wurden die entsprechenden Banden bei UV-Licht der Wellenlänge 365 nm mit Hilfe einer UV Kontaktlampe Chroma 41 (Fa. 
Laborgeräte Vetter, Wiesloch) sichtbar gemacht, ausgeschnitten und gemäß Herstellerangaben aufgereinigt.

\subsubsection{Agarose-Gelelektrophorese von DNA}

DNA-Moleküle können in einem elektrischen Feld durch Gelelektrophorese gemäß ihrer Größe aufgetrennt werden, da DNA über ein negativ geladenes Grundgerüst verfügt.

Hierzu wurden Gele aus $60^{\circ} \mathrm{C}$ warmer Agarose-Lösung mit Ethidiumbromid in einer horizontalen Elektrophorese-Kammer des Typs PerfectBlue Gelsystem Mini M (Fa. PeqLab, Erlangen) gegossen. Die Polymerisation der Agarose erfolgte durch Abkühlen auf Raumtemperatur. Anschließend wurden die Gele mit 1x TAE-Puffer überschichtet. Sofern nicht anders angegeben wurden 1,5\% Agarose-Gele verwendet.

DNA-Proben wurden mit 6x Ladepuffer versetzt und in die Taschen des Gels aufgetragen. Zur Größenbestimmung wurde des Weiteren ein Marker mit DNAFragmenten bekannter Größe aufgetragen, soweit nicht anders vermerkt GeneRuler $1 \mathrm{~kb}$ DNA Ladder (Fa. Fermentas, St. Leon-Rot). Die Elektrophorese erfolgte bei 100-170 Volt bis die Bromphenolblau-Bande des Ladepuffers im unteren Viertel des Gels angelangte. Anschließend wurden die Gele direkt unter UV-Licht einer Wellenlänge von 254 nm mittels einer Gel Doc 2.000-Anlage (Fa. Bio-Rad, München) betrachtet und dokumentiert.

EDTA-Stammlösung (pH 8,0)

Ethidiumbromid-Stammlösung

50x TAE (pH 8,3):

Tris $800 \mathrm{mM}$

Essigsäure (100\%) $950 \mathrm{mM}$

EDTA (pH 8,0) $\quad 50 \mathrm{mM}$

Agarosegel:
$500 \mathrm{mM}$ EDTA

$10 \mathrm{mg} / \mathrm{ml}$ 
6x Ladepuffer:

$\begin{array}{ll}\text { Glycerin } & 5 \mathrm{ml} \\ \text { 50x TAE-Puffer } & 200 \mu \mathrm{l} \\ \text { Bromphenolblau } & 0,01 \mathrm{~g} \\ \text { Xylencyanol } & 0,01 \mathrm{~g} \\ \mathrm{H}_{2} \mathrm{O} \text { (bidest) } & 4,5 \mathrm{ml}\end{array}$

\subsection{Allgemeine Klonierungstechniken und Enzymreaktionen mit DNA}

\subsubsection{Polymerasekettenreaktion (Polymerase chain reaction, PCR (Mullis et al. 1986)}

Bei der Polymerasekettenreaktion wird ein durch zwei als Primer eingesetzte Oligonukleotide definiertes Stück DNA enzymatisch in vitro vervielfältigt. Die verwendeten Oligonukleotide sind in Tabelle 7.3.. zusammengefasst. Alle Reaktionsansätze und Thermocycler-Programme wurden gemäß den HerstellerAngaben und mittels der mitgelieferten Puffer und Lösungen erstellt. Alle Reaktionen fanden in Geräten des Typs Tpersonal combi (Fa. Biometra, Göttingen) oder Mastercycler gradient (Fa. Eppendorf, Hamburg) statt.

Es wurden für verschiedene Aufgaben unterschiedliche Polymerasen verwendet:

Taq (Fa. Fermentas, St. Leon-Rot und aus eigener Produktion) als Polymerasen ohne Korrekturlese-Aktivität, $P f u$ (Fa. Fermentas, St. Leon-Rot) als Polymerase mit Korrekturlese-Aktivität und sowie TripleMaster-Polymerase (Fa. Roche, Mannheim).

Als Matrize für die Amplifikation wurde entweder chromosomale DNA oder Plasmide verwendet.

\subsubsection{Semi-random two-step PCR (ST-PCR; (Madhusudan et al. 2005))}

Die ST-PCR stellt eine Methode zur Bestimmung von Transposon-Insertionsstellen (in diesem Fall $\mathrm{m} T n 10$, vergleiche 3.3.5.) dar. Hierzu wurden zwei aufeinander folgende PCR-Schritte durchgeführt. Im ersten Schritt wurde ein Oligopaar als Primer eingesetzt, von denen eines mit der stromaufwärts gerichteten Flanke des Transposons hybridisiert (BG84), während das andere (BG 80) eine definierte Sequenz aus 20 Nukleotiden am 5'-Ende besitzt, gefolgt von einer degenerierten Sequenz aus 10 Nukleotiden und einer GATC-Sequenz am 3'-Ende (vgl. Abb. 3.2.). Dieses Oligonukleotid hybridisiert 
statistisch alle 300 bis 400 Basenpaare einmal im Genom, so dass ein DNA-Fragment amplifiziert werden kann, das den das Transposon flankierenden Bereich umfasst.

Für die erste PCR wurde folgendes Cyclerprogramm verwendet:

$\begin{array}{lll}94^{\circ} \mathrm{C} & 2 \mathrm{~min} & \\ 94^{\circ} \mathrm{C} & 30 \mathrm{sec} & \\ 42^{\circ} \mathrm{C} & 30 \mathrm{sec} & -1^{\circ} \mathrm{C} \text { pro Zyklus } \\ 72^{\circ} \mathrm{C} & 3 \mathrm{~min} & 5 \text { Wiederholungen } \\ & \\ 94^{\circ} \mathrm{C} & \\ 65^{\circ} \mathrm{C} & 30 \mathrm{sec} & \\ 72^{\circ} \mathrm{C} & 30 \mathrm{sec} & \\ & 3 \mathrm{~min} & 24 \text { Wiederholungen } \\ 4{ }^{\circ} \mathrm{C} & \text { Pause }\end{array}$

Das Produkt dieser ersten PCR wurde mit einem vierfachen Volumen $\mathrm{H}_{2} \mathrm{O}$ verdünnt und als Matrize in einer zweiten PCR-Reaktion eingesetzt. Hierbei wurden Oligonukleotide als Primer eingesetzt, von denen einer (BG81) mit dem definierten Bereich des Oligonukleotide BG80 hybridisiert, während der andere komplementär zu einem Abschnitt des Transposons ist, der durch das Oligonukleotidpaar der ersten Reaktion umfasst wird (BG85). Das Produkt dieser zweiten Reaktion wurde mittels Gelelution (siehe 3.4.4.) aufgereinigt und anschließend sequenziert (siehe 3.5.7.). Für die zweite PCR wurde folgendes Cyclerprogramm verwendet:

\begin{tabular}{|c|c|c|}
\hline $94^{\circ} \mathrm{C}$ & $2 \min$ & \\
\hline $65^{\circ} \mathrm{C}$ & $30 \mathrm{sec}$ & \\
\hline $72^{\circ} \mathrm{C}$ & $3 \min$ & 29 Wiederholungen \\
\hline
\end{tabular}


Um die Bereiche zu amplifizieren, die das Transposon stromabwärts flankieren, wurde eine analoge Methode unter Verwendung der Oligopaare BG82 und BG80 (für die erste PCR) respektive BG 81 und BG83 (zweite PCR) angewandt.

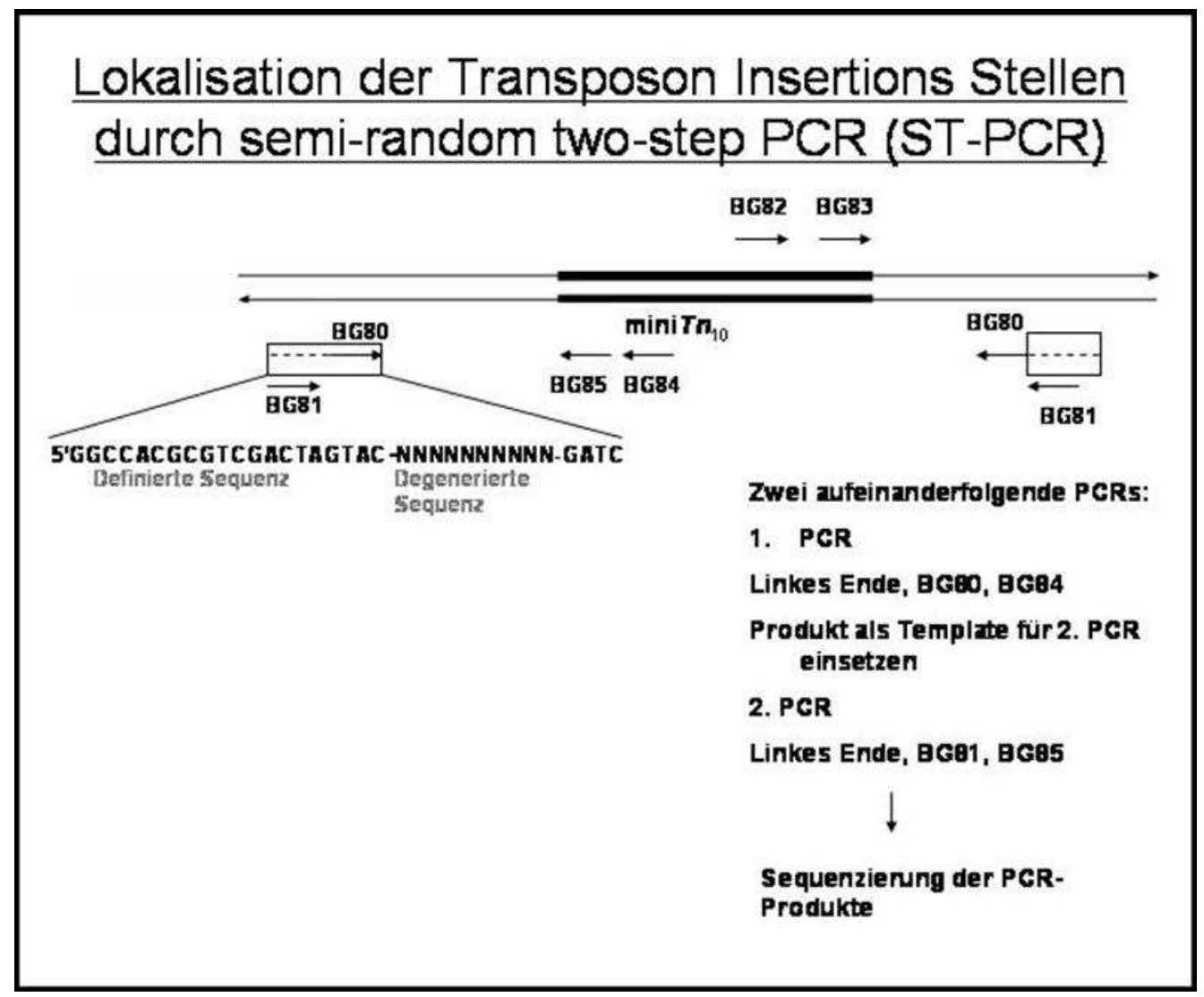

Abb. 3.2.: Schematische Darstellung der Semi-random two-step PCR (ST-PCR).

Das Oligonukleotid BG80 hybridisiert statistisch alle 300-400 bp im Genom und ermöglicht so gepaart mit BG84 die Amplifikation des Bereiches stromaufwärts des Transposons (,linkes Ende“). Das Produkt dieser ersten PCR (siehe 3.6.1.) wurde als Matrize für eine weitere PCR eingesetzt. Bei dieser zweiten Reaktion hybridisiert der Primer BG81 an der durch BG80 definierten Sequenz, während das Oligonukleotid BG85 im mTn10 hybridisiert, jedoch innerhalb des durch das Paar BG80/BG84 umfassten Bereich.

Die Produkte der zweiten PCR wurden in einem analytischen Agarose-Gel kontrolliert. War eine dominante Bande vorhanden, so wurde das Produkt der zweiten PCR nochmals auf ein präperatives Agarosegel aufgetragen und die Bande aus dem Gel eluiert (siehe 3.5.4.) und anschließend sequenziert (siehe 3.5.7.).

Die Identifizierung der stromabwärts des Transposons gelegenen Sequenzen (,rechtes Ende") verlief analog unter Verwendung der Primer BG82 + BG80 für die erste PCR, und BG 81 und BG 83 für die zweite PCR.

\subsubsection{Generierung von Gen-Deletionen (Datsenko und Wanner 2000)}

Bei dieser Methode zur Generierung von chromosomalen Gen-Disruptionen und -Deletionen werden PCR-Produkte genutzt, bei denen eine Resistenzkassette von Sequenzen flankiert wird, die homolog zu den flankierenden Sequenzen des Zielgens sind und somit eine Rekombination ermöglichen. Desweiteren tragen diese Inserts 
sogenannte FRT-Sequenzen (FLP recognition targets), die es erlauben, die integrierte Resistenzkassette wieder aus dem Genom zu entfernen, wodurch lediglich eine „Narbe“ entsteht, die sowohl Stop-Codons in allen sechs Leserastern trägt, als auch eine optimale Ribosomenbindestelle zur Expression stromabwärts gelegener Gene generiert. Hierdurch können markerlose Gen-Deletionen generiert werden, die das Risiko polarer Effekte auf die Expression benachbarter Gene minimieren. Für die homologe Rekombination wird ein temperatursensitives Helferplasmid (pKD46, siehe Tabelle 7.2.) genutzt, welches die Rekombinase $\operatorname{Red}(\gamma \beta$ exo) des Phagen $\lambda$ unter Kontrolle eines Arabinose-induzierbaren Promotors trägt. Zum Entfernen der Resistenzkassette wird das Helferplasmid pCP20 (siehe Tabelle 7.2.) verwendet, welches eine temperaturabhängige Expression von FLP ermöglicht.

\subsubsection{Vorbereitung der Stämme}

Der Zielstamm wurde zunächst chemisch kompetent gemacht (siehe 3.3.2) und wie unter 3.3.3. beschrieben mit dem temperatursensitiven Helferplasmid pKD46 transformiert. Die Transformanten wurden auf LB+Ampicillin-Platten (siehe 3.2.1.) bei $30^{\circ} \mathrm{C}$ selektiert.

\subsubsection{Amplifikation der Resistenzkassette mit homologen Bereichen zu den} flankierenden Sequenzen des Zielgens

Oligonukleotide, die als Primer zur Generierung des DNA-Fragmentes für die Elektroporation verwendet wurden, bestehen aus 40 bis 45 Basen die einerseits homolog zu den Bereichen direkt stromaufwärts beziehungsweise -abwärts des Zielgens sind andererseits $\mathrm{zu}$ Bereichen der flankierenden Regionen der ChloramphenicolResistenzkassette auf dem Plasmid pKD3 (im Fall des Vorwärts-Primers: GTGTAGGCTGGAGCTGCTTCG; für den Rückwärts-Primer: CATATGAAT ATCCTCCTTAGTTCCTATTCC). Die PCR wurde wie unter 3.5.1. beschrieben durchgeführt und das resultierende Fragment mittels Gel-Elution aufgereinigt (siehe 3.4.4.). Die Konzentration sollte mindestens $100 \mathrm{ng} / \mu \mathrm{l}$ betragen, gegebenenfalls muss das PCR-Produkt mittels Ethanol-Fällung (siehe 3.4.2.) aufkonzentriert werden. 


\subsubsection{Herstellung elektrokompetenter Zellen ( $Y u$ und Court 1998)}

Der mit pKD46 transformierte Zielstamm wurde in $5 \mathrm{ml} \mathrm{SOB}$ (siehe 3.2.3.) mit Ampicillin und $20 \mathrm{mM}$ L-Arabinose (zur Induktion des $\gamma$-RED Systems) bei $30^{\circ} \mathrm{C}$ auf dem Horizontalschüttler über Nacht inkubiert. Aus dieser Vorkultur wurden $50 \mathrm{ml}$ desselben Mediums zu einer $\mathrm{OD}_{600}$ von 0,1 inokuliert und auf dem Horizontalschüttler bei $30^{\circ} \mathrm{C}$ inkubiert, bis eine $\mathrm{OD}_{600}$ von 0,6 erreicht wurde. Die Kultur wird in ein auf $4^{\circ} \mathrm{C}$ vorgekühltes $50 \mathrm{ml}$ Plastikröhrchen überführt und 1 Stunde auf Eis inkubiert.

Es folgen eine Reihe von Wasch- und Zentrifugationsschritten:

- Zentrifugation für $15 \mathrm{~min}$ bei $4^{\circ} \mathrm{C}$ und $3.000 \mathrm{rpm}$

- Überstand verwerfen, Pellet in $50 \mathrm{ml}$ eiskaltem $\mathrm{H}_{2} \mathrm{O}$ resuspendieren

- Zentrifugation für $15 \mathrm{~min}$ bei $4^{\circ} \mathrm{C}$ und $3.000 \mathrm{rpm}$

- Überstand verwerfen, Pellet in $25 \mathrm{ml}$ eiskaltem $\mathrm{H}_{2} \mathrm{O}$ resuspendieren

- Zentrifugation für $15 \mathrm{~min}$ bei $4^{\circ} \mathrm{C}$ und $3.000 \mathrm{rpm}$

- Überstand verwerfen, Pellet in $2 \mathrm{ml}$ eiskaltem Glycerol 10\% (v/v) resuspendieren

- Zentrifugation für $15 \mathrm{~min}$ bei $4^{\circ} \mathrm{C}$ und $3.000 \mathrm{rpm}$

Anschließend wird das Pellet in $200 \mu$ l eiskaltem Glycerol 10\% (v/v) aufgenommen und für die Elektroporation eingesetzt

\subsubsection{Elektroporation (Yu und Court 1998)}

$2 \mathrm{~mm}$-Elektroporationsküvetten (Fa. Biozym, Hessisch Oldendorf) wurden auf Eis vorgekühlt. $100 \mathrm{ng}$ DNA-Fragment (in einem maximalen Volumen von $10 \mu \mathrm{l}$ ) wurden mit $40 \mu$ l elektrokompetenten Zellen in einem vorgekühlten 1,5 ml-Reaktionsgefäß gemischt und $10 \mathrm{~min}$ auf Eis inkubiert. Danach wurde der Ansatz in eine Elektroporationsküvette überführt und es erfolgte ein Elektroschock für 3 sec bei 1,8 $\mathrm{kV}, 25 \mu \mathrm{F}$ und $200 \Omega$. Sofort nach dem Schock wurde $1 \mathrm{ml}$ SOC-Medium (siehe 3.2.3.) zugegeben und der Ansatz in ein 1,5 ml-Reaktionsgefäß überführt. Nach einer Inkubation für 60 min auf dem Horizontalschüttler bei $37^{\circ} \mathrm{C}$ wurden den $500 \mu \mathrm{des}$ Ansatzes auf LB-Selektionsplatten (siehe 3.2.1) ausplattiert und bei $37^{\circ} \mathrm{C}$ über Nacht inkubiert. Der restliche Ansatz wurde für 24 h bei Raumtemperatur inkubiert, auf LBSelektionsplatten ausplattiert und ebenfalls über Nacht bei $37^{\circ} \mathrm{C}$ inkubiert. Transformanten wurden mittels PCR unter Verwendung umfassender und Resistenzkassetten-spezifischer Oligonukleotide als Primer auf Integration der 
Resistenzkassette und durch Plattieren auf LB-Selektionsplatten mit Ampicillin auf Verlust des temperatursensitiven Plasmids pKD46 überprüft.

\subsubsection{Entfernen der Kassette}

Um eine markerfreie Deletion des Zielgens $\mathrm{zu}$ erhalten, muss die eingebrachte Resistenzkassette wieder aus dem Genom entfernt werden. Hierzu wurde ein Rekombinase-System genutzt, dass die die Resistenzkassette flankierenden FRTSequenzen erkennt und den dazwischen liegenden DNA-Bereich entfernt. Hierzu wurde der Zielstamm zunächst chemisch kompetent gemacht (siehe 3.3.2) und dann mittels Hitzeschock mit dem Plasmid pCP20 transformiert (siehe 3.3.3.). Die Inkubation nach dem Hitzeschock sowie die Inkubation der LB-Selektionplatten (siehe 3.2.1.) über Nacht erfolgte bei $30^{\circ} \mathrm{C}$, da das Plasmid pCP20 über einen temperatursensitiven Replikationsursprung verfügt.

Transformanten wurden vereinzelt und bei $37^{\circ} \mathrm{C}$ in $5 \mathrm{ml} \mathrm{LB}$-Medium über Nacht auf einem Horizontalschüttler inkubiert. Anschließend wurden sie auf LB-Platten sowie LB-Selektionsplatten mit Chloramphenicol oder Ampicillin plattiert und bei $37^{\circ} \mathrm{C}$ über Nacht inkubiert, um den Verlust der Resistenzkassette sowie des Helferplasmides zu prüfen. Der Deletionsstamm ohne Resistenz wurden nachfolgend mittels PCR (siehe 3.5.1.) überprüft.

\subsubsection{Restriktion von DNA}

DNA-Fragmente und Plasmide wurden mit Hilfe von unterschiedlichen Restriktionsendonukleasen (Fa. Fermentas, St. Leon-Rot) geschnitten. Die verwendeten Enzyme sind an den entsprechenden Stellen vermerkt. Alle Reaktionsansätze wurden gemäß den Herstellerangaben erstellt. Pro Restriktionsreaktion wurden 500-700 ng DNA eingesetzt.

Um die benötigte Menge an Enzym zu berechnen, wurde folgende Formel verwendet :

$$
\frac{\operatorname{MW}(\lambda)}{\operatorname{MW}(x)} * \frac{\mathrm{n}(x)}{\mathrm{n}(\lambda)}=\frac{\mathrm{u}(\text { Enzym })}{\mu \mathrm{g}(x)}
$$

mit $\lambda \quad$ Referenz-DNA (Phage $\lambda$ )

$\mathrm{x} \quad \mathrm{zu}$ verdauende DNA 
MW Molekulargewicht

n Anzahl der Schnittstellen

Als Referenz diente die DNA des Phagen $\lambda$. Für die Reaktionen wurde das 1,5fache der errechneten Enzymmenge eingesetzt.

Restriktionsansätze wurden für $2 \mathrm{~h}$ bei $37^{\circ} \mathrm{C}$ inkubiert. Anschließend wurden sie mittels QIAquick PCR Purification Kit wie unter 3.4.4. beschrieben aufgereinigt und mittels Agarose-Gelelektrophorese (siehe 3.4.5.) überprüft. Die Bestimmung der Konzentration erfolgte mittels eines Nanodrop ND-1000 Spectrophotometers (Fa. Peqlab Biotechnologie GmbH, Erlangen).

\subsubsection{Dephosphorylierung}

Mittels Restriktionsenzymen geschnittene Vektoren wurden dephosphoryliert, um die Wahrscheinlichkeit einer Religation in der anschließenden Ligationsreaktion zu minimieren. Shrimp Alkaline Phosphatase bzw. Calf Intestine Alkaline Phosphatase (Fa. Fermentas, St. Leon-Rot) entfernt die 5'-Phosphatgruppe der DNA hydrolytisch, so dass das Plasmid nur dann wieder eine zirkuläre Form annehmen kann, wenn ein phosphoryliertes DNA-Fragment während der Ligation integriert wird. Für die Dephosphorylierung wurde den Vektor-Restriktionsansätzen nach der Inkubation 1,5 $\mu 1$ der alkalischen Phosphatase zugegeben und diese für weitere $60 \mathrm{~min}$ bei $37^{\circ} \mathrm{C}$ inkubiert. Anschließend wurden die Ansätze wie unter 3.4.4. beschrieben gereinigt und mittels Agarose-Gelelektrophorese (siehe 3.4.5.) überprüft. Auch hier erfolgte die Bestimmung der Konzentration erfolgte mittels eines Nanodrop ND-1000 Spectrophotometers (Fa. Peqlab Biotechnologie GmbH, Erlangen).

\subsubsection{Ligation}

Die T4-Ligase katalysiert die Bildung einer Phosphodiester-Bindung zwischen der 5'Phosphatgruppe und der 3'-Hydroxylgruppe von DNA-Molekülen.

Diese Reaktion wurde mit Hilfe von T4 DNA Ligase (Fa. Fermentas, St. Leon-Rot) gemäß Herstellerangaben und unter Verwendung der mitgelieferten Lösungen durchgeführt. Es wurden pro Ligationsreaktion 50-100 ng Vektor-DNA und der 1,53fache molare Überschuss an Fragment verwendet. Der Ansatz wurde für $3 \mathrm{~h}$ bei 
Raumtemperatur oder über Nacht bei $16^{\circ} \mathrm{C}$ inkubiert und direkt zur Transformation (siehe 3.2.3) eingesetzt.

\subsubsection{Sequenzierung nach der Kettenabbruchmethode (Sanger et al. 1977)}

Plasmide und andere manipulierte DNA-Sequenzen wurden durch Sequenzierung relevanter DNA-Abschnitte überprüft. Alle Sequenzierungsreaktionen wurden vom GenoMIK-Network (Göttingen) durchgeführt. Hierzu wurden 200 ng DNA und 5 pMol Oligonukleotid als Primer in $5 \mu \mathrm{H}_{2} \mathrm{O}$ (bidest) Endvolumen verwendet. Die erhaltenen Sequenzen wurden anschließend mittels der Programme CHROMAS und Vector NTI analysiert (siehe 3.9.).

\subsection{Präparation, Synthese und Nachweis von RNA}

\subsubsection{Präparation von Gesamt-RNA}

Gesamt-RNA wurde mittels des Rneasy Mini Kit (Fa. Quiagen, Hilden) präpariert. Hierzu wurde eine Kulturmenge äquivalent zu einer $\mathrm{OD}_{600}$ von 1 verwendet und nach Herstellerangabe behandelt. Nach der Präparation wurde die RNA wie unter 3.6.2. beschrieben gefällt.

Alternativ wurde RNA für Northern Blot Analysen mit radioaktiv-markierten Sonden

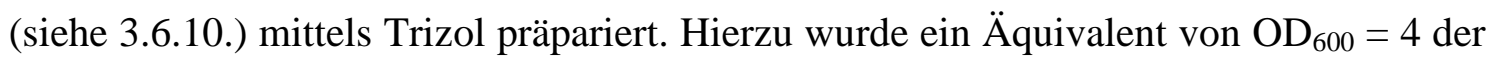
Kultur von Interesse abgenommen, mit 1/5 Volumen Stop-Lösung gemischt und in Flüssigstickstoff gefroren. Anschließend wurden die Proben auf Eis aufgetaut und durch Zentrifugation für $10 \mathrm{~min}$ bei $8.000 \mathrm{rpm}$ und $4^{\circ} \mathrm{C}$ pelletiert. Der Überstand wurde verworfen und eine weitere Zentrifugation für $5 \mathrm{~min}$ bei $8.000 \mathrm{rpm}$ und $4^{\circ} \mathrm{C}$ durchgeführt. Der Überstand wurde möglichst vollständig entfernt und das Pellet in 1 ml Trizol (Fa. Invitrogen, Karlsruhe) gelöst. Anschließend wurden $400 \mu$ l Chloroform zugegeben und der Ansatz durch Invertieren gründlich gemischt. Er wurde dann in ein PLG-Röhrchen (Phase Lock Gel, Fa. 5 PRIME, Hamburg) überführt und nach einer Inkubation für 2 bis 5 min bei Raumtemperatur für $15 \mathrm{~min}$ bei $13.000 \mathrm{rpm}$ und $15^{\circ} \mathrm{C}$ zentrifugiert. Die obere, wässrige Phase wurde danach in ein frisches $1,5 \mathrm{ml}$ Reaktionsgefäß überführt und mit $450 \mu$ I Isopropanol versetzt. Nach gründlichem Mischen durch Invertieren folgte eine Inkubation für 30 min bei Raumtemperatur. Der 
Ansatz wurde für $30 \mathrm{~min}$ bei $13.000 \mathrm{rpm}$ und Raumtemperatur zentrifugiert und der Überstand verworfen. Das Pellet wurde mit $350 \mu \mathrm{l} \mathrm{EtOH} 70 \%$ (reinst.) gewaschen und nochmals für 15 min bei $13.000 \mathrm{rpm}$ und Raumtemperatur zentrifugiert. Anschließend wurde der Überstand abgenommen und das Pellet getrocknet. Die RNAwurde in $30 \mu 1$ $\mathrm{H}_{2} \mathrm{O}$ (RNase-frei) aufgenommen und die Konzentration mittels eines Nanodrop ND1000 Spectrophotometers (Fa. Peqlab Biotechnologie GmbH, Erlangen) bestimmt und die Qualität der Präparation wie unter 2.6.4. beschrieben überprüft.

Stop-Lösung:

$\begin{array}{ll}\text { Phenol } & 5 \%(\mathrm{v} / \mathrm{v}) \\ \text { Ethanol } & 95 \%(\mathrm{v} / \mathrm{v})\end{array}$

\subsubsection{Fällung von RNA}

Zur Fällung von RNA wurde das Volumen der Probe zunächst mit $\mathrm{H}_{2} \mathrm{O}$ (RNase-frei) auf $100 \mu$ l eingestellt. Es folgte die Zugabe von $5 \mu 1$ 0,5 M EDTA (pH 8,0) und 12,5 $\mu 1$ $4 \mathrm{M} \mathrm{LiCl}$. Der Ansatz wurde anschließend mit eiskaltem $375 \mu$ l Ethanol (100\% reinst) gemischt und über Nacht bei $-20^{\circ} \mathrm{C}$ inkubiert. Anschließend erfolgte eine Zentrifugation für $30 \mathrm{~min}$ bei $4^{\circ} \mathrm{C}$ und $13.000 \mathrm{rpm}$. Der Überstand wurde entfernt und das Pellet mit $500 \mu$ l eiskaltem Ethanol (70\% reinst) gewaschen. Es folgte eine weitere Zentrifugation für $20 \mathrm{~min}$ bei $4^{\circ} \mathrm{C}$ und $13.000 \mathrm{rpm}$, bevor der Überstand vorsichtig und möglichst vollständig abgenommen wurde. Nach einem weiteren Zentrifugationsschritt für $10 \mathrm{~min}$ bei $4^{\circ} \mathrm{C}$ und $13000 \mathrm{rpm}$ wurde der Rest des Überstandes abgenommen und das Pellet bei Raumtemperatur getrocknet. Anschließend konnte die RNA im gewünschten Volumen $\mathrm{H}_{2} \mathrm{O}$ (RNase-frei) aufgenommen werden.

\subsubsection{In vitro Transkription $\mathrm{T} 7$}

Zur in vitro Transkription von RNA wurden Komponenten des DIG-RNA labeling Kits (Fa. Roche, Mannheim) oder alternativ das MEGAScript T7 Kit (Fa. Amersham, Freiburg) verwendet, welche beide auf der in vitro Transkription definierter Bereiche von DNA-Matrizen aus basiert. Hierzu wurde zunächst mittels PCR (siehe 3.5.1.) Matrizen-DNA mit einer T7-Promotorsequenz generiert und mittels Gel-Elution (siehe 3.4.5.) aufgereinigt. In der in vitro Transkription wurden 500-1000 ng DNA eingesetzt. 
Die Vorbereitung der Ansätze erfolgte gemäß der Herstellerangaben in einem Endvolumen von $100 \mu \mathrm{l}$. Nach einer Inkubation über Nacht bei $37^{\circ} \mathrm{C}$ erfolgte eine Behandlung der Transkriptionsansätze mit dem „DNA-free Kit“ (Fa. Ambion, Austin) zur Entfernung der Matrizen-DNA gemäß Herstellerangaben. Anschließend wurde die RNA wie unter 3.6.2. beschrieben gefällt, das Pellet in $50 \mu \mathrm{H}_{2} \mathrm{O}$ (RNase-frei) aufgenommen und mittels eines Nanodrop ND-1000 Spectrophotometers (Fa. Peqlab Biotechnologie $\mathrm{GmbH}$, Erlangen) quantifiziert. Zusätzlich wurde die RNA wie unter 3.6.4 beschrieben durch Gelelektrophorese überprüft.

\subsubsection{Nachweis von RNA}

RNA-Moleküle können, wie auch DNA, in einem elektrischen Feld durch Gelelektrophorese gemäß ihrer Größe aufgetrennt werden, da RNA ebenfalls über ein negativ geladenes Grundgerüst verfügt.

Zum Nachweis von RNA wurden 1\% Agarose-Gele mit Formaldehyd verwendet. Hierzu wurde zunächst $1 \mathrm{~g}$ Agarose in $72 \mathrm{ml} \mathrm{H}_{2} \mathrm{O}$ durch Erhitzen gelöst und anschließend im Wasserbad auf $65^{\circ} \mathrm{C}$ temperiert. Anschließend wurden unter einem Abzug $10 \mathrm{ml}$ 10x MOPS und $18 \mathrm{ml}$ Formaldehyd (37\%) zugesetzt, bevor das Gel in einer horizontalen Elektrophorese-Kammer des Typs PerfectBlue Gelsystem Mini M (Fa. PeqLab, Erlangen) gegossen wurde. Die Polymerisation der Agarose erfolgte durch Abkühlen auf Raumtemperatur. Anschließend wurden die Gele mit 1x MOPS überschichtet.

RNA-Proben wurden mit $\mathrm{H}_{2} \mathrm{O}$ (RNase-frei) auf ein Volumen von $10 \mu$ l gebracht, mit 5 $\mu 1$ RNA-Ladepuffer versetzt und für $10 \mathrm{~min}$ bei $65^{\circ} \mathrm{C}$ denaturiert. Nach einem raschen Abkühlen auf Eis wurden sie in die Taschen des Gels aufgetragen. Zur Größenbestimmung wurde des Weiteren ein Marker mit RNA-Fragmenten bekannter Größe aufgetragen, die RiboRuler low range RNA Ladder (Fa. Fermentas, St. LeonRot). Die Elektrophorese erfolgte bei 100 Volt bis die Bromphenolblau-Bande des Ladepuffers im unteren Viertel des Gels angelangt war. Anschließend wurden die Gele direkt unter UV-Licht einer Wellenlänge von $254 \mathrm{~nm}$ mittels einer Gel Doc 2.000Anlage (Fa. Bio-Rad, München) dokumentiert und gegebenenfalls für Northern BlotAnalysen (siehe 3.6.6) eingesetzt. 
10x MOPS

$\begin{array}{ll}\text { MOPS } & 200 \mathrm{mM} \\ \text { Natriumacetat } & 50 \mathrm{mM} \\ \text { EDTA } & 10 \mathrm{mM} \\ \mathrm{H}_{2} \mathrm{O} \text { (dest) } & \text { ad } 1.000 \mathrm{ml} \\ \text { pH 7,0 einstellen mit NaOH } & \end{array}$

MOPS muss auf eine besondere Weise autoklaviert werden: Es darf maximal $10 \mathrm{~min}$ lang in einem Dampfkochtopf sterilisiert werden. Nach dem Autoklavieren sollte die Lösung leicht gelb sein.

\subsubsection{Herstellung DIG-markierter RNA-Sonden für Northern Blot Analysen}

Um RNA-Sonden für Northern Blot Analysen zu generieren, wurde in einer in vitroTranskription eine DIG-markierte RNA hergestellt, die der revers-komplementären Sequenz der Ziel-RNA entsprach. Hierzu wurde wie unter 3.6.3. das DIG-RNA labeling Kits (Fa. Roche, Mannheim) verwendet, jedoch statt des rNTP-Mixes der DIG RNAlabelling Mix 10x desselben Herstellers verwendet. Die RNA wurde gefällt (siehe 3.6.2.) und in einem Volumen von $100 \mu \mathrm{H}_{2} \mathrm{O}$ (RNase-frei) mit $1 \mu 1$ RNase-Inhibitor für $2 \mathrm{~h}$ bei $37^{\circ} \mathrm{C}$ gelöst.

Um die Qualität der DIG-Markierung zu überprüfen wurden Verdünnungen der Sonde von $10^{0}$ bis $10^{-4}$ angelegt und je $1 \mu$ dieser Verdünnungen auf eine Nylonmembran aufgetropft. Die Membran wurde luftgetrocknet und die RNA anschließend durch Bestrahlung mit UV-Licht einer Wellenlänge von $254 \mathrm{~nm}$ für $3 \mathrm{~min}$ fixiert. Anschließend wurde die Membran für $5 \mathrm{~min}$ in Puffer I inkubiert. Dieser und alle nachfolgenden Inkubationsschritte erfolgten bei Raumtemperatur auf einem Horizontalschüttler. Es folgte eine Inkubation für 30 min in Puffer II, gefolgt von einer Inkubation für $30 \mathrm{~min}$ in Puffer II gemischt 10.000:1 mit Anti-Digoxigenin-AP fragments (Fa. Roche, Mannheim). Anschließend wurde die Membran drei Mal für je 10 min in Puffer I gewaschen und abschließend für 10 min in Puffer III inkubiert. Die Membran wurde in $1 \mathrm{ml}$ Puffer III mit $5 \mu$ l CDP-Star (Fa. Roche, Mannheim) gewendet, in eine Klarsichtfolie überführt und 10 min im Dunkeln inkubiert. Die Signalstärke wurde anschließend über einen Zeitraum von $5 \mathrm{~min}$ in einem Chemi-Smart 5.000 Chemilumineszenz-System (Fa. PeqLab, Erlangen) unter Verwendung der zugehörigen ChemiCapt 11.07-Software dokumentiert. 
10\% Blocking Reagenz:

$\begin{array}{ll}\text { Blocking Reagenz } & 10 \mathrm{~g} \\ 1 \mathrm{x} \text { Puffer I } & \text { ad } 100 \mathrm{ml}\end{array}$

5x Puffer I:

$\begin{array}{ll}\text { Maleinsäure } & 500 \mathrm{mM} \\ \mathrm{NaCl} & 750 \mathrm{mM} \\ \text { Tween20 } & 0.3 \% \\ \mathrm{NaOH} & 900 \mathrm{mM} \\ \mathrm{pH} 7,5 \text { einstellen mit } \mathrm{NaOH} & \end{array}$

Puffer II:

$\begin{array}{ll}5 x \text { Puffer I } & 40 \mathrm{ml} \\ 10 \% \text { Bocking Reagenz } & 20 \mathrm{ml} \\ \mathrm{H}_{2} \mathrm{O} \text { (dest) } & \text { ad } 200 \mathrm{ml}\end{array}$

Puffer III (pH 9,5):

$\begin{array}{ll}\text { Diethanolamin } & 9.63 \mathrm{ml} \\ \mathrm{H}_{2} \mathrm{O} \text { (dest) } & \text { ad } 200 \mathrm{ml}\end{array}$

3.6.6. Herstellung ${ }^{32} \mathrm{P}$-markierter Sonden für Northern Blot Analysen

Für diese Art der Northern Blot-Analyse wurden als Sonde Oligonukleotide verwendet, die komplementär zur Sequenz der zu detektierenden RNA sind. Diese Oligonukleotide wurden durch T4-Polynukleotid Kinase (PNK, Fa. Fermentas, St. Leon-Rot) mit ${ }^{32} \mathrm{P}$ markiert.

Die Reaktionsansätze für die Markierung waren wie folgt zusammengesetzt:

$\begin{array}{ll}\text { Oligonukleotid (10 nM) } & 1 \mu \mathrm{l} \\ \text { 10x PNK-Puffer } & 2 \mu \mathrm{l} \\ { }^{32} \mathrm{P}-\gamma \text {-ATP } & 5 \mu \mathrm{l} \\ \text { PNK } & 1 \mu \mathrm{l} \\ \mathrm{H}_{2} \mathrm{O} \text { (RNase-frei) } & 11 \mu \mathrm{l}\end{array}$


Diese Ansätze wurden für $1 \mathrm{~h}$ bei $37^{\circ} \mathrm{C}$ inkubiert.

Anschließend wurden verbliebene freie Nukleotide unter Verwendung von G-25-Säulen (Fa. GE Healthcare, Freiburg) nach Herstellerangaben entfernt.

Die so generierten ${ }^{32} \mathrm{P}$-markierten Oligonukleotide wurden wie unter 3.6.10 beschrieben als Sonde in Northern Blot Analysen eingesetzt.

\subsubsection{Northern Blot Analyse (für Detektion mit DIG-markierten Sonden)}

Für den Vakuum-Transfer mittels des VacuGene XL-Systems (Fa. Amersham, Freiburg) wurden positiv geladene Nylonmembranen (Fa. Roche, Mannheim) in Größe des Gels ausgeschnitten und in 20x SSC äquilibriert. Anschließend wurde die Membran auf mit $\mathrm{H}_{2} \mathrm{O}$ (dest) befeuchtete Trägerplatte aufgelegt und mit einer Plastikmaske abgedichtet. Das Agarosegel wurde auf die Membran und die Plastikmaske aufgelegt, wodurch die Apparatur luftdicht verschlossen wurde. Der Transfer erfolgte bei einem Vakuum von 60 mBar. Das Gel wurde während des Transfers mit den folgenden Lösungen überschichtet:

$\begin{array}{ll}\text { Denaturierungslösung } & 5 \mathrm{~min} \\ \text { Neutralisierungslösung } & 5 \mathrm{~min} \\ \text { 20x SSC } & 4-5 \mathrm{~h}\end{array}$

Beim Wechsel der Lösungen wurden Reste der vorherigen Lösung durch abgießen entfernt. Nach Beendigung des Transfers wurde die RNA mittels Bestrahlung mit UVLicht (3 min, $254 \mathrm{~nm}$ ) an der Membran fixiert. Anschließend wurden die Membranen luftgetrocknet und unter UV-Licht die Banden des RNA-Standards auf der Membran markiert Die Membran wurde in ein Hybridisierungsröhrchen überführt und für $2 \mathrm{~h}$ bei $68^{\circ} \mathrm{C}$ in einem OV2-Hybridisierungsofen (Fa. Biometra, Göttingen) in $15 \mathrm{ml}$ PräHybridisierungslösung unter Rotation inkubiert. Die Hybridisierung mit der Sonde und die Detektion der Signale erfolgten wie unter 3.6.9. beschrieben.

Denaturierungslösung:

$\begin{array}{ll}\mathrm{NaOH} & 50 \mathrm{mM} \\ \mathrm{NaCl} & 10 \mathrm{mM}\end{array}$


Neutralisierungslösung:

Tris

$100 \mathrm{mM}$

$\mathrm{pH}$ 7,4 einstellen mit $\mathrm{HCl}$

10\% Blocking Reagenz:

$\begin{array}{ll}\text { Blocking Reagenz } & 10 \mathrm{~g} \\ \text { 1x Puffer I } & \text { ad } 100 \mathrm{ml}\end{array}$

Prä-Hybridisierungslösung:

$\begin{array}{ll}\text { Formamid } & 25 \mathrm{ml} \\ \text { 20x SSC } & 12,5 \mathrm{ml} \\ \text { Blocking Reagenz 10\% } & 10 \mathrm{ml} \\ \text { N-Lauroylsarcosin 10\% } & 500 \mu \mathrm{l} \\ \text { SDS 10\% } & 100 \mu \mathrm{l}\end{array}$

5x Puffer I:

$\begin{array}{ll}\text { Maleinsäure } & 500 \mathrm{mM} \\ \mathrm{NaCl} & 750 \mathrm{mM} \\ \text { Tween20 } & 0.3 \% \\ \mathrm{NaOH} & 900 \mathrm{mM} \\ \mathrm{pH} 7,5 \text { einstellen mit } \mathrm{NaOH} & \end{array}$

20x SSC

$\begin{array}{ll}\mathrm{NaCl} & 3 \mathrm{M} \\ \text { Natriumcitrat } & 0.3 \mathrm{M} \\ \mathrm{pH} \mathrm{7,0} \mathrm{einstellen} \mathrm{mit} \mathrm{HCl} & \end{array}$

\subsubsection{Slot Blot Analyse (für Detektion mit DIG-markierten Sonden)}

In einer Slot Blot Analyse wird RNA nicht durch Gelelektrophorese nach Größe aufgetrennt, sondern direkt auf eine Nylonmembran transferiert. Dadurch sind Slot Blot Analysen zwar in der Lage, eine Aussage über die Gesamtmenge einer bestimmten RNA zu liefern, jedoch nicht über Größe oder unterschiedliche Spezies selbiger.

Die Proben wurden auf zunächst eine RNA-Menge von $2 \mu \mathrm{g}, 1 \mu \mathrm{g}, 0,5 \mu \mathrm{g}$ und 0,25 $\mu \mathrm{g}$ in $100 \mu \mathrm{l}$ eingestellt. Die positiv geladene Nylonmembran (Fa. Roche, Mannheim) 
wurde in 10x SSC gewässert und anschließend in eine PR648 Slot Blot-Apparatur (Fa. Hoefer, San Francisco) eingelegt. Der Transfer der RNA auf die Membran erfolgte durch Anlegen eines Unterdruckes mittels einer VacuGene XL-Pumpe (Fa. Amersham, Freiburg). Nach dem vollständigen Transfer wurde die Membran der Apparatur entnommen und luftgetrocknet, bevor die RNA durch Bestrahlung mit UV-Licht einer Wellenlänge von $254 \mathrm{~nm}$ für 3 min fixiert wurde.

Die Membran wurde in ein Hybridisierungsröhrchen überführt und für $2 \mathrm{~h}$ bei $68^{\circ} \mathrm{C}$ in einem OV2-Hybridisierungsofen (Fa. Biometra, Göttingen) in $15 \mathrm{ml}$ PräHybridisierungslösung unter Rotation inkubiert. Die Hybridisierung mit der Sonde und die Detektion der Signale erfolgten wie unter 3.6.9. beschrieben.

Prä-Hybridisierungslösung:

$\begin{array}{ll}\text { Formamid } & 25 \mathrm{ml} \\ \text { 20x SSC } & 12,5 \mathrm{ml} \\ \text { Blocking Reagenz 10\% } & 10 \mathrm{ml} \\ \text { N-Lauroylsarcosin 10\% } & 500 \mu \mathrm{l} \\ \text { SDS 10\% } & 100 \mu \mathrm{l}\end{array}$

10\% Blocking Reagenz:

$\begin{array}{ll}\text { Blocking Reagenz } & 10 \mathrm{~g} \\ \text { 1x Puffer I } & \text { ad } 100 \mathrm{ml}\end{array}$

20x SSC

$\begin{array}{ll}\mathrm{NaCl} & 3 \mathrm{M} \\ \text { Natriumcitrat } & 0.3 \mathrm{M} \\ \mathrm{pH} \mathrm{7,0} \text { einstellen mit } \mathrm{HCl} & \end{array}$

5x Puffer I:

$\begin{array}{ll}\text { Maleinsäure } & 500 \mathrm{mM} \\ \mathrm{NaCl} & 750 \mathrm{mM} \\ \text { Tween20 } & 0.3 \% \\ \mathrm{NaOH} & 900 \mathrm{mM} \\ \text { pH 7,5 einstellen mit } \mathrm{NaOH} & \end{array}$




\subsubsection{Hybridisierung mit DIG-markierten Sonden und Detektion}

Für die Sondenlösung wurden $5 \mathrm{ml}$ Prä-Hybridisierungslösung mit $15 \mu \mathrm{l}$ der DIGmarkierten Sonde versetzt und für $15 \mathrm{~min}$ in kochendem Wasser denaturiert und anschließend rasch auf Eis abgekühlt.

Nach der Inkubation der Membran in Prä-Hybridisierungslösung (siehe 3.6.6. beziehungsweise 3.6.7.) wurde diese gegen die Sondenlösung ausgetauscht und die Membran über Nacht bei $68^{\circ} \mathrm{C}$ im OV2-Hybridisierungsofen (Fa. Biometra, Göttingen) unter Rotation inkubiert.

Nach dieser Inkubation wurde die Sondenlösung in ein steriles 15 ml-Plastikröhrchen gegossen und bis zu fünf Mal wiederverwendet (Lagerung bei $-20^{\circ} \mathrm{C}$ ).

Die Membran wurde zunächst zwei Mal für 5 min bei Raumtemperatur in $5 \mathrm{ml}$ Waschlösung I inkubiert und dabei per Hand gerollt. Anschließend erfolgten drei Waschschritte für $20 \mathrm{~min}$ mit je $5 \mathrm{ml}$ Waschlösung II im Hybridisierungsofen bei $68^{\circ} \mathrm{C}$ und Rotation, bevor die Membran in eine saubere Plastikschale überführt wurde. Alle weiteren Inkubationsschritte erfolgten bei Raumtemperatur auf einem Horizontalschüttler. Zunächst wurde die Membran für $5 \mathrm{~min}$ in $20 \mathrm{ml}$ Puffer I inkubiert, danach für $30 \mathrm{~min}$ in $20 \mathrm{ml}$ Puffer II. Es folgte die Bindung des sekundären Antikörpers AntiDigoxigenin-AP fragments (Fa. Roche, Mannheim), welcher 1:10.000 in Puffer II verdünnt wurde $(2,5 \mu \mathrm{l}$ auf $25 \mathrm{ml})$, bevor die Membran für weitere $30 \mathrm{~min}$ darin geschwenkt wurde. Nach der Bindung des Antikörpers folgten drei Waschschritte für jeweils 10 min mit $20 \mathrm{ml}$ Puffer I, bevor die Membran für $10 \mathrm{~min}$ in $10 \mathrm{ml}$ Puffer III geschwenkt wurde.

Anschließend wurde die Membran in eine frische Schale überführt und in $1 \mathrm{ml}$ Puffer III mit $5 \mu 1$ des Chemilumineszenz-Substrates CDP-Star (Fa. Roche, Mannheim) für 15 min im Dunkeln inkubiert. Die Membran wurde dann in eine frische durchsichtige Plastikfolie gelegt und die Lumineszenz über einen Zeitraum von $20 \mathrm{~min}$ und $45 \mathrm{~min}$ in einem Chemi-Smart 5.000 Chemilumineszenz-System (Fa. PeqLab, Erlangen) unter Verwendung der zugehörigen ChemiCapt 11.07-Software dokumentiert.

10\% Blocking Reagenz:

$\begin{array}{ll}\text { Blocking Reagenz } & 10 \mathrm{~g} \\ \text { 1x Puffer I } & \text { ad } 100 \mathrm{ml}\end{array}$


5x Puffer I:

$\begin{array}{ll}\text { Maleinsäure } & 500 \mathrm{mM} \\ \mathrm{NaCl} & 750 \mathrm{mM} \\ \text { Tween20 } & 0.3 \% \\ \mathrm{NaOH} & 900 \mathrm{mM} \\ \mathrm{pH} \mathrm{7,5} \mathrm{einstellen} \mathrm{mit} \mathrm{NaOH} & \end{array}$

Puffer II:

$\begin{array}{ll}5 x \text { Puffer I } & 40 \mathrm{ml} \\ 10 \% \text { Bocking Reagenz } & 20 \mathrm{ml} \\ \mathrm{H}_{2} \mathrm{O} \text { (dest) } & \text { ad } 200 \mathrm{ml}\end{array}$

Puffer III ( $\mathrm{pH} 9,5)$ :
Diethanolamin
$9.63 \mathrm{ml}$
$\mathrm{H}_{2} \mathrm{O}$ (dest) ad $200 \mathrm{ml}$

Waschpuffer I:

2x SSC

$0.1 \%$ SDS

Waschpuffer II:

$$
\begin{aligned}
& 0.1 \times \mathrm{SSC} \\
& 1 \% \mathrm{SDS}
\end{aligned}
$$

\subsubsection{Northern Blot Analyse (für Detektion mit ${ }^{32} \mathrm{P}$-markierten Sonden)}

$5 \mu \mathrm{g}$ RNA in einem Volumen von $5 \mu \mathrm{l}$ wurden wie unter 3.6.4. beschrieben in einem 6\% Polyacrylamid-Gel (7M Harnstoff, TBE) bei 300 Volt in einer SE 600 Vertical Unit (Fa. Hoefer, San Francisco, USA) für 2 h aufgetrennt. Als Marker wurde in diesem Fall ${ }^{32} \mathrm{P}$-markierte pUC8-DNA verwendet.

Nach dem Gellauf wurde die RNA in einer Trans-Blot Plus cell (Fa. Bio-Rad, München) auf eine Hypobond XL-Membran (Fa. Amersham, Freiburg) für $1 \mathrm{~h}$ bei 50 Volt übertragen und die RNA anschließend durch Bestrahlung mit 120 Joule UV-Licht fixiert. 
3.6.11. Hybridisierung mit ${ }^{32} \mathrm{P}$-markierten Sonden und Detektion

Membranen für die Detektion mit ${ }^{32} \mathrm{P}$-markierten Sonden (siehe 3.6.9.) wurden einer Prähybridisierung für $1 \mathrm{~h}$ in $15 \mathrm{ml}$ Rapid-hyb-Puffer (Fa. GE Healthcare, Freiburg) bei $42^{\circ} \mathrm{C}$ in einem Hybridisierungsofen unterzogen. Anschießend wurden $5 \mu$ l einer ${ }^{32} \mathrm{P}$ markierten Sonde (siehe 3.6.6.) zugegeben und für $2 \mathrm{~h}$ bei $42^{\circ} \mathrm{C}$ hybridisiert.

Die Membran wurde getrocknet und danach für $15 \mathrm{~min}$ in $5 \mathrm{x}$ SSC $+0,1 \%$ SDS gewaschen, anschließend für ebenfalls je $15 \mathrm{~min}$ in $1 \mathrm{x} \mathrm{SSC}+0,1 \% \mathrm{SDS}$ beziehungsweise 0,5x SSC + 0,1\% SDS. Nach dem Trocknen der Membran wurde diese für $2 \mathrm{~h}$ auf einen Molecular dynamics GP Storage Phosphor-Schirm (Fa. GE Healthcare, Freiburg) aufgelegt und die Strahlung der radioaktiv-markierten Sonden und des Markers mittels eines FujiImager BAS (Fa. Fuji, Düsseldorf) beziehungsweise eines Molecular dynamics STORM-BSO (Fa. GE Healthcare, Freiburg) ausgewertet.

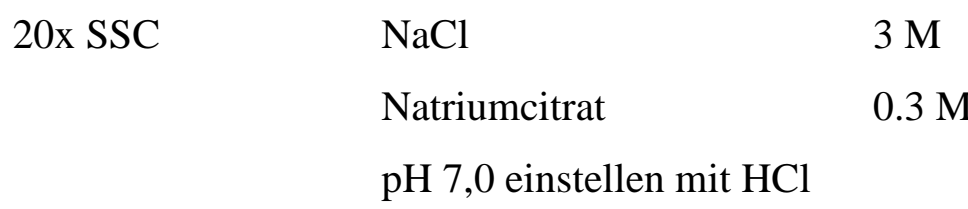

\subsubsection{Präparation und Markierung von RNA für MicroArray-Analysen}

Die gewünschten Stämme wurden in $5 \mathrm{ml} \mathrm{LB}$-Medium (siehe 3.2.1.) bei $37^{\circ} \mathrm{C}$ unter Agitation inkubiert. Aus diesen Vorkulturen wurden $20 \mathrm{ml}$ LB-Medium der Hauptkultur auf eine $\mathrm{OD}_{600}$ von 0,1 inokuliert und bei $37^{\circ} \mathrm{C}$ unter Agitation inkubiert, bis eine $\mathrm{OD}_{600}$ von 2 erreicht wurde. Ein Äquivalent von $4 \mathrm{OD}_{600}$-Einheiten wurde abgenommen und mit $400 \mu 1$ Stop-Lösung gemischt. Anschließend wurden die Pellets bis zur weiteren Verwendung in Flüssigstickstoff gelagert.

Die Pellets wurden auf Eis aufgetaut und durch Zentrifugation für 2 min bei $4.000 \mathrm{rpm}$ und $4^{\circ} \mathrm{C}$ pelletiert. Der Überstand wurde verworfen und das Pellet in $100 \mu 1 \mathrm{H}_{2} \mathrm{O}$ (RNase-frei) mit $50 \mathrm{mg} / \mathrm{ml}$ Lysozym aufgenommen und 4 min bei Raumtemperatur inkubiert. Die Probe wurde in ein frisches 1,5 ml-Reaktionsgefäß überführt, und mittels PureYield RNA Midi-Prep Kit (Fa. Promega, Mannheim) weiter behandelt. Zunächst wurden $75 \mu 1$ Lysis agent zugegeben und durch invertieren gemischt. Es folgte eine Inkubation für $3 \mathrm{~min}$ bei $70^{\circ} \mathrm{C}$, bevor die Probe für $10 \mathrm{~min}$ bei $13.000 \mathrm{rpm}$ und Raumtemperatur zentrifugiert wurde. 
Der Überstand wurde möglichst vollständig in ein frisches 1,5 ml-Reaktionsgefäß überführt und mit $200 \mu \mathrm{l} \mathrm{EtOH} \mathrm{100 \%} \mathrm{(reinst)} \mathrm{gemischt.} \mathrm{Der} \mathrm{Ansatz} \mathrm{wurde} \mathrm{in} \mathrm{eine} \mathrm{Spin}$ Column gefüllt und für $1 \mathrm{~min}$ bei $13.000 \mathrm{rpm}$ und Raumtemperatur zentrifugiert. Der Durchlauf wurde verworfen und $600 \mu 1$ Waschpuffer auf die Säule gegeben, bevor der beschriebene Zentrifugationsschritt wiederholt wurde. Der Durchlauf wurde wiederum verworfen, dann wurden $50 \mu$ l Dnase-Mix $\left(5 \mu \mathrm{MnCl}_{2}(90 \mathrm{mM}), 40 \mu \mathrm{l}\right.$ Yellow Dnase core buffer (Fa. Promega, Mannheim), 5 ul DnaseI (Fa. Promega, Mannheim)) auf die Säule gegeben und diese 15 min bei Raumtemperatur inkubiert. Danach wurden $200 \mu 1$ Dnase stop mix zugegeben und nochmals wie beschrieben zentrifugiert. Der Durchlauf wurde verworfen, bevor $600 \mu \mathrm{l}$ Waschpuffer auf die Säule gegeben wurden und wie beschrieben zentrifugiert. Dieser Waschschritt wurde nochmals mit $250 \mu$ l Waschpuffer wiederholt.

Danach wurde die Säule in ein frisches 1,5 ml-Reaktionsgefäß überführt und die RNA eluiert, indem $100 \mu \mathrm{l} \mathrm{H}_{2} \mathrm{O}$ (RNase-frei) auf die Säule gegeben und nach $1 \mathrm{~min}$ Inkubation bei Raumtemperatur für $2 \mathrm{~min}$ bei $13.000 \mathrm{rpm}$ und Raumtemperatur abzentrifugiert wurde.

Die Konzentration der präparierten RNA wurde mittels mittels eines Nanodrop ND1000 Spectrophotometers (Fa. Peqlab Biotechnologie GmbH, Erlangen) bestimmt und die Proben bis zur weiteren Verwendung bei $-20^{\circ} \mathrm{C}$ gelagert.

Für das Umschreiben der RNA in markierte cDNA für die MicroArray-Analyse wurde das Amersham CyScribe Microarray labeling Kit (Fa. GE Healthcare, Freiburg ) verwendet. Der erste Schritt war das Primer annealing. Hierzu wurden Ansätze aus 5 $\mu \mathrm{g}$ RNA, $1 \mu \mathrm{l}$ random nonamers und $\mathrm{H}_{2} \mathrm{O}$ (RNase-frei) bis zu einem Gesamtvolumen von $11 \mu 1$ pipettiert, die dann für 5 min bei $70^{\circ} \mathrm{C}$ inkubiert wurden. Die Ansätze wurden dann für 10 min auf Raumtemperatur abgekühlt, dann folgte eine Zentrifugation für 30 sec bei 13.000 rpm und Raumtemperatur. Als Nächstes folgte die reverse Transkription in der extension reaction. Hierzu wurden folgende Bestandteile zu dem RNA-Eluat zugegeben:

$\begin{array}{ll}4 \mu \mathrm{l} & \text { 5x CyScript buffer } \\ 2 \mu \mathrm{l} & 0,1 \mathrm{M} \text { DTT } \\ 1 \mu \mathrm{l} & \text { dCTP nucleotide mix } \\ 1 \mu \mathrm{l} & \text { dCTP CyDye-labelled nucleotides } \\ 1 \mu \mathrm{l} & \text { CyScript reverse transcriptase }\end{array}$


Jede RNA wurde sowohl mit dem Cy3- als auch mit dem Cy5-Farbstoff markiert.

Die Ansätze wurden durch vortexen gemischt und für $30 \mathrm{sec}$ bei $13.000 \mathrm{rpm}$ und Raumtemperatur abzentrifugiert, bevor sie für 90 min bei $42^{\circ} \mathrm{C}$ inkubiert wurden. Anschließend wurden sie bis zur Aufreinigung auf Eis gelagert.

Zur Aufreinigung wurde zunächst die RNA in der Probe abgebaut. Hierzu wurden $2 \mu 1$ $\mathrm{NaOH}(2,5 \mathrm{M})$ zugegeben und die Proben nach kurzem vortexen für $30 \mathrm{sec}$ bei 13.000 rpm und Raumtemperatur zentrifugiert, bevor eine Inkubation für 15 min bei $37^{\circ} \mathrm{C}$ folgte. Danach wurden $10 \mu$ l HEPES (2M) zugegeben und nach gründlichem Mischen wiederum wie beschrieben zentrifugiert.

Die eigentliche Aufreinigung erfolgte mittels des CyScribe GFx Purification Kits (Fa. GE Healthcare, Freiburg ) nach Herstellerangaben. Anschließend wurde die cDNAKonzentration und die Markierungseffizienz mittels eines Nanodrop ND-1000 Spectrophotometers (Fa. Peqlab Biotechnologie GmbH, Erlangen) überprüft.

Stop-Lösung:

$\begin{array}{ll}\text { Phenol } & 5 \%(\mathrm{v} / \mathrm{v}) \\ \text { Ethanol } & 95 \%(\mathrm{v} / \mathrm{v})\end{array}$

\subsubsection{MicroArray-Analysen}

Die MicroArray-Analysen wurden durch die MicroArray Core Facility des Max-PlanckInstitutes für Infektionsbiologie, Berlin, durchgeführt und durch Kai Papenfort, AG RNA-Biologie des Max-Planck-Institutes für Infektionsbiologie, Berlin, ausgewertet.

\subsubsection{Markierung von RNA mittels ${ }^{32} \mathrm{P}-\gamma$-ATP für EMSA}

RNA wurde mittels in vitro-Transkription (siehe 3.6.3) generiert und mittels eines Nanodrop ND-1000 Spectrophotometers (Fa. Peqlab Biotechnologie GmbH, Erlangen) quantifiziert. 20 pMol RNA wurden mit $\mathrm{H}_{2} \mathrm{O}$ (RNase-frei) auf ein Volumen von $17 \mu \mathrm{l}$ gebracht und für 1 min bei $95^{\circ} \mathrm{C}$ denaturiert. Nach einem Abkühlen auf Eis für 5 min wurden $2 \mu$ l B7003-S-Puffer (Fa. New England Biolabs, Frankfurt am Main) sowie $1 \mu 1$ CIP (Fa. New England Biolabs, Frankfurt am Main) zugegeben und der Ansatz für $1 \mathrm{~h}$ bei $37^{\circ} \mathrm{C}$ inkubiert. Anschließend folgte die Zugabe von $90 \mu 1 \mathrm{H}_{2} \mathrm{O}$ (RNase-frei) sowie $160 \mu 1$ P:C:I-Lösung. Der Ansatz wurde kurz gevortext und dann in ein PLG-Röhrchen (Phase Lock Gel, Fa. 5 PRIME, Hamburg) überführt. Nach einer Zentrifugation für 12 
min bei $13.000 \mathrm{rpm}$ und $15^{\circ} \mathrm{C}$ wurde die obere Phase der Probe in ein frisches $1,5 \mathrm{ml}$ Reaktionsgefäß überführt und mit 1,1 $\mu$ l GlycoBlue $15 \mathrm{mg} / \mathrm{ml}$ (Fa. Ambion, Austin) versetzt. Nach Zugabe von $5 \mu \mathrm{l} 3 \mathrm{M}$ Natriumacetat und $300 \mu \mathrm{l}$ EtOH 100\% (reinst) erfolgte eine Inkubation bei $-20^{\circ} \mathrm{C}$ über Nacht zum Fällen der RNA.

Es folgte eine Zentrifugation für $30 \mathrm{~min}$ bei $13.000 \mathrm{rpm}$ und $4^{\circ} \mathrm{C}$, dann wurde der Überstand abgenommen und das Pellet mit $100 \mu \mathrm{l}$ eiskaltem EtOH 70\% (reinst) gewaschen. Nach einer weiteren Zentrifugation für $10 \mathrm{~min}$ bi $13.000 \mathrm{rpm}$ und $4^{\circ} \mathrm{C}$ wurde der Überstand möglichst vollständig abgenommen und das Pellet getrocknet.

Anschließend wurde die RNA in $16 \mu \mathrm{H}_{2} \mathrm{O}$ (RNase-frei) aufgenommen und für $5 \mathrm{~min}$ bei $65^{\circ} \mathrm{C}$ gelöst. Es folgte eine Bestimmung der Konzentration mittels eines Nanodrop ND-1000 Spectrophotometers (Fa. Peqlab Biotechnologie GmbH, Erlangen). Die dephosphorylierte RNA wurde bis zur weiteren Verwendung bei $-20^{\circ} \mathrm{C}$ gelagert.

Für die Markierung mit ${ }^{32} \mathrm{P}$ wurden die CIP-behandelten RNAs auf Eis aufgetaut und für 1 min bei $95^{\circ} \mathrm{C}$ denaturiert. Nach einem Abkühlen auf Eis für 10 min wurden dem Ansatz $2 \mu 1{ }^{32} \mathrm{P}-\gamma$-ATP, $10 \mu \mathrm{l}$ PNK-Puffer (Fa. Fermentas, St. Leon-Rot) und $1 \mu 1 \mathrm{~T} 4-$ Polynukleotid Kinase (PNK, Fa. Fermentas, St. Leon-Rot) zugesetzt und für $1 \mathrm{~h}$ bei $37^{\circ} \mathrm{C}$ inkubiert. Anschließend wurde der Ansatz mit $20 \mu \mathrm{l}$ Ladepuffer II versetzt und in einem 6\% Polyacrylamid-Gel (7 M Harnstoff, TBE) bei 300 Volt aufgetrennt.

Die gewünschte Bande wurde aus dem Gel ausgeschnitten und in $750 \mu 1$ RNAElutionspuffer über Nacht bei $4^{\circ} \mathrm{C}$ gelöst.

Der Ansatz wurde für $1 \mathrm{~min}$ bei $13.000 \mathrm{rpm}$ und Raumtemperatur zentrifugiert und der Überstand in einem frischem 1,5 ml-Reaktionsgefäß mit $750 \mu 1$ P:C:I gemischt. Anschließend wurde der Ansatz in ein PLG-Röhrchen (Fa. 5 PRIME, Hamburg) überführt und für $12 \mathrm{~min}$ bei $13.000 \mathrm{rpm}$ und $15^{\circ} \mathrm{C}$ zentrifugiert. Die obere Phase wurde auf zwei 1,5 ml-Reaktionsgefäße aufgeteilt und jede Probe mit $1 \mathrm{ml}$ EtOH 100\% (reinst) gemischt und über Nacht bei $-20^{\circ} \mathrm{C}$ inkubiert.

Nach einer weiteren Zentrifugation für $30 \mathrm{~min}$ bei $13.000 \mathrm{rpm}$ und $4^{\circ} \mathrm{C}$ wurde der Überstand entfernt und das Pellet getrocknet. Abschließend wurde die RNA in $25 \mu 1$ $\mathrm{H}_{2} \mathrm{O}$ (RNase-frei) aufgenommen und für $5 \mathrm{~min}$ bei $65^{\circ} \mathrm{C}$ gelöst. Die Konzentration wurde mittels eines Nanodrop ND-1000 Spectrophotometers (Fa. Peqlab Biotechnologie GmbH, Erlangen) bestimmt. Die so generierten RNAs wurden in EMSA (siehe 3.8.2.) verwendet 
$\mathrm{P}: \mathrm{C}: \mathrm{I}$ :

$\begin{array}{ll}\text { Phenol } & 50 \% \\ \text { Chloroform } & 48 \% \\ \text { Isoamylalkohol } & 2 \%\end{array}$

Ladepuffer II:

$\begin{array}{ll}\text { Formamid } & 95 \% \\ \text { SDS } & 0,025 \% \\ \text { EDTA } & 18 \mathrm{mM} \\ \text { Bromphenolblau } & 0,01 \%\end{array}$

RNA-Elutionspuffer:

$\begin{array}{ll}\text { Natriumacetat } & 0,1 \mathrm{M} \\ \text { SDS } & 0,1 \% \\ \text { EDTA } & 10 \mathrm{mM}\end{array}$

\subsection{Präparation und Nachweis von Proteinen}

\subsubsection{Präparation cytoplasmatischer Proteine aus E. coli}

Die entsprechenden Stämme wurden in $5 \mathrm{ml}$ des gewünschten Mediums über Nacht bei $37^{\circ} \mathrm{C}$ und $180 \mathrm{rpm}$ auf einem Horizontalschüttler inkubiert. Aus diesen Vorkulturen wurde das gewünschte Volumen Medium der Hauptkultur auf eine $\mathrm{OD}_{600}$ von 0,1 inokuliert und bei $37^{\circ} \mathrm{C}$ und $180 \mathrm{rpm}$ unter Agitation inkubiert, bis die gewünschte $\mathrm{OD}_{600}$ erreicht wurde.

Für vergleichende SDS-PAGE (siehe 2.7.6.) wurden Äquivalente zu einer $\mathrm{OD}_{600}$ von 1 durch Zentrifugation für 2 min bei $13.000 \mathrm{rpm}$ und $4^{\circ} \mathrm{C}$ pelletiert. Der Überstand wurde möglichst vollständig abgenommen und die Pellets bis zur Verwendung bei $-20^{\circ} \mathrm{C}$ gelagert. Für die SDS-PAGE wurden diese Pellets in $200 \mu \mathrm{l} 1 \mathrm{x}$ SDS-Ladepuffer aufgenommen.

Für den Aufschluss per Ultraschall, beispielsweise für die Überprüfung der Löslichkeit eines heterolog überexprimierten Proteins (siehe 3.7.2.), wurden die Proben wie zuvor beschrieben geerntet und in ZAP aufgenommen. Der Aufschluss erfolgte in einem UP 
200s Ultraschallprozessor (Fa. Dr. Hielscher, Stuttgart) für 10 Sekunden bei 80 Watt mit einem Intervall von 0,5 sec. Diese Behandlung wurde vier Mal wiederholt. Zwischen den einzelnen Durchgängen wurde die Probe jeweils für 1 Minute in Eiswasser abgekühlt. Zum Abtrennen der Zelltrümmer wurde die Suspension für 30 min bei $4{ }^{\circ} \mathrm{C}$ und $13.000 \mathrm{rpm}$ in einem Heraeus \#75003328-Rotor (Fa. Kendro Laboratory Products, Langenselbold) zentrifugiert.

Um Rohzellextrakte für die Aufreinigung His-Tag-tragender Proteine zu erhalten, wurde die entsprechende Transformante in $50 \mathrm{ml}$ LB-Medium (siehe 2.2.1.) über Nacht bei $37^{\circ} \mathrm{C}$ und $180 \mathrm{rpm}$ auf einem Horizontalschüttler inkubiert. Aus diesen Vorkulturen wurde $11 \mathrm{LB}-M e d i u m$ der auf eine $\mathrm{OD}_{600}$ von 0,1 inokuliert und bei $37^{\circ} \mathrm{C}$ und $180 \mathrm{rpm}$ unter Agitation inkubiert, bis eine $\mathrm{OD}_{600}$ von 0,5 - 0,6 erreicht wurde. Die Expression des His-Tag-tragenden Proteins wurde dann durch Zugabe von 0,1 - 1 mM IPTG induziert und die Inkubation für $1 \mathrm{~h}$ fortgeführt. Es folgte die Ernte der Kultur durch Zentrifugation für $15 \mathrm{~min}$ bei $5.000 \mathrm{rpm}$ und $4^{\circ} \mathrm{C}$. Der Überstand wurde verworfen und die Zellen in $50 \mathrm{ml}$ ZAP aufgenommen. Es folgte eine weitere Zentrifugation für $15 \mathrm{~min}$ bei $5.000 \mathrm{rpm}$ und $4^{\circ} \mathrm{C}$. Der Überstand wurde wiederum verworfen und das Pellet bis zur weiteren Verwendung bei $-20^{\circ} \mathrm{C}$ gelagert.

Für den Zellaufschluß mittels French Press wurden diese Pellets in $10 \mathrm{ml}$ ZAP aufgenommen. Es folgten zwei Durchgänge in einer SLM Aminco 2-FA-078-E1 French Press (Fa. G. Heinemann, Schwäbisch Gmünd) in einer Standardzelle (20 ml) bei 1.000 psi. Zur Entfernung von Zelltrümmern erfolgte eine Zentrifugation für 30 min bei $4^{\circ} \mathrm{C}$ und $5.000 \mathrm{rpm}$ in einem Heraeus \#75007590-Rotor (Fa. Kendro Laboratory Products, Langenselbold), gefolgt von einer Ultrazentrifugation für $60 \mathrm{~min}$ bei $40.000 \mathrm{rpm}$ und $4^{\circ} \mathrm{C}$ in einer Sorvall Ultra pro 80 (Fa. Beckman, München) oder in einer Sorvall OTD 50B (Fa. Beckman, München) in einem Ti60-Rotor.

ZAP (pH 7,4):

$\begin{array}{ll}\text { Tris } & 10 \mathrm{mM} \\ \mathrm{NaCl} & 200 \mathrm{mM} \\ \mathrm{H}_{2} \mathrm{O} \text { (bidest) } & \text { ad } 500 \mathrm{ml}\end{array}$


5x SDS-Ladepuffer:

$\begin{array}{ll}\beta \text {-Mercaptoethanol } & 16 \%(\mathrm{v} / \mathrm{v}) \\ \text { SDS } & 5 \%(\mathrm{w} / \mathrm{v}) \\ \text { Bromphenolblau } & 0,2 \%(\mathrm{w} / \mathrm{v}) \\ \text { Tris- } \mathrm{HCl}(\mathrm{pH} 6,8) & 200 \mathrm{mM} \\ \text { Glycerin } & 50 \%(\mathrm{v} / \mathrm{v})\end{array}$

\subsubsection{Optimierung der Expression heterologer Proteine in E. coli}

Um die optimalen Bedingungen für die Expression des Proteins zu ermitteln, wurde das Expressionsniveau von Kulturen überprüft, die unter unterschiedlichen Bedingungen inkubiert wurden. Für die Optimierung der exprimierten Proteinmenge wurden Kulturen für unterschiedliche Zeiträume und mit unterschiedlichen Mengen IPTG induziert. Hierbei wurde als Induktionszeitpunkt das Erreichen einer $\mathrm{OD}_{600}$ von 0,6 gewählt. Getestet wurden IPTG-Endkonzentrationen von $0,1 \mathrm{mM}, 1 \mathrm{mM}$ und $10 \mathrm{mM}$. Des Weiteren wurde die Expression der heterologen Proteine über die Zeit verfolgt, um zu überprüfen, ob sich das exprimierte Protein in der Zelle anreichert oder eventuell einer Degradation unterliegt. Hierzu wurden die Expressionsniveau 30 min, 1 h und 3 h nach Induktion verglichen. Abschließend wurde überprüft, ob das heterolog exprimierte Protein in einer löslichen Form oder als inclusion bodies vorliegt. Hierzu wurden die Proben auf eine Zellzahl normalisiert, die der in $1 \mathrm{ml}$ Kultur bei OD $_{600}$ 0,6 entspricht. Dies geschah über die Formel:

$$
\frac{\mathrm{OD}_{600}}{0,6} * 1000 \mu l=x \mu l
$$

Um lösliches und unlösliches Protein unterscheiden zu können, wurden zwei Proben genommen, von denen eine dem errechneten normalisierten Probenvolumen entsprach, die andere dem doppelten errechneten normalisierten Probenvolumen. Die erste Probe wurde direkt abzentrifugiert und das Pellet in $50 \mu 1$ 5x SDS-Ladepuffer aufgenommen, während letztere in $100 \mu \mathrm{l}$ ZAP aufgenommen wurde und per Ultraschall aufgeschlossen wurde (siehe 3.7.1.), um nur die lösliche Fraktion der Proteine zu präparieren. 
5x SDS-Ladepuffer:

$\begin{array}{ll}\beta \text {-Mercaptoethanol } & 16 \%(\mathrm{v} / \mathrm{v}) \\ \text { SDS } & 5 \%(\mathrm{w} / \mathrm{v}) \\ \text { Bromphenolblau } & 0,2 \%(\mathrm{w} / \mathrm{v}) \\ \text { Tris- } \mathrm{HCl}(\mathrm{pH} 6,8) & 200 \mathrm{mM} \\ \text { Glycerin } & 50 \%(\mathrm{v} / \mathrm{v})\end{array}$

\subsubsection{Aufreinigung von His-Tag-tragenden Proteinen mittels $\mathrm{Ni}^{2+}$-NTA-Säulen}

Zur Aufreinigung von Proteinen mit einem Decahistidin-Sequenz wurden Poly-PrepChromatographie-Säulchen (Fa. Bio-Rad, München) verwendet. Dabei wurde die Säule zunächst mit $6 \mathrm{ml} \mathrm{Ni}{ }^{2+}$-NTA Superflow (Fa. Qiagen, Hilden) beladen und mit ZAP äquilibriert. Dann wurden $20 \mathrm{ml}$ Proteinrohextrakt (siehe 3.7.1.) auf die Säule geladen. Es folgten Waschschritte mit zweimal $10 \mathrm{ml}$ ZAP $+50 \mathrm{mM}$ Imidazol und einmal $10 \mathrm{ml}$ ZAP(+100 mM Imidazol, um unspezifisch gebundene Proteine von der Säule zu waschen.

Die Elution der His-Tag-tragenden Proteine von der Säule erfolgte mit je $6 \mathrm{ml}$ ZAP steigender Imidazolkonzentrationen $(200 \mathrm{mM}, 300 \mathrm{mM}$ und $500 \mathrm{mM})$. Die dadurch erhaltenen Fraktionen wurden mittels denaturierender Proteingelelektrophorese auf Zusammensetzung und Reinheit überprüft (siehe 3.7.5.). Die aufgereinigten His-Tagtragenden Proteine wurden anschließend einer Dialyse unterzogen (siehe 3.7.4.).

ZAP (pH 7,4):

$\begin{array}{ll}\text { Tris } & 10 \mathrm{mM} \\ \mathrm{NaCl} & 200 \mathrm{mM} \\ \mathrm{H}_{2} \mathrm{O} \text { (bidest) } & \text { ad } 500 \mathrm{ml}\end{array}$

\subsubsection{Dialyse von Proteinen}

Bei der Aufreinigung eines Proteins über eine N-terminale Decahistidin-Sequenz ist Imidazol zum Ablösen des an die Säule gebundenen Proteins notwendig, welches weitere Versuche mit dem aufgereinigten Protein negativ beeinflussen kann. Um diese Stoffe aus der Proben zu entfernen, wurden die Elutionsfraktionen in einem MembraCell Dialyseschlauch mit einer Ausschlussgröße von 12-14 kDa (Fa. Serva, Heidelberg) 
gegen Glycerinpuffer mit DTT dialysiert. Der Dialyseschlauch wurde vor dem Beladen mit Protein zweimal in $500 \mathrm{ml} \mathrm{H}_{2} \mathrm{O}$ (bidest) mit $500 \mu 1$ 0,5 M EDTA aufgekocht.

Das Volumen des Dialysepuffers betrug mindestens das 500fache der zu dialysierenden Proteinlösung und jede Dialyse wurde für mindestens $16 \mathrm{~h}$ bei $4^{\circ} \mathrm{C}$ unter Rühren durchgeführt.

Glycerinpuffer:

$\begin{array}{ll}\text { Glycerin } & 25 \%(\mathrm{v} / \mathrm{v}) \\ \mathrm{KCl} & 100 \mathrm{mM} \\ \text { Tris } & 10 \mathrm{mM} \\ \mathrm{MgCl}_{2} & 10 \mathrm{mM} \\ \text { DTT } & 5 \mathrm{mM}\end{array}$

$\mathrm{ZAP}(\mathrm{pH} 7,4)$ :

$\begin{array}{ll}\text { Tris } & 10 \mathrm{mM} \\ \mathrm{NaCl} & 200 \mathrm{mM} \\ \mathrm{H}_{2} \mathrm{O} \text { (bidest) } & \text { ad } 500 \mathrm{ml}\end{array}$

\subsubsection{Proteinmengenbestimmung (Bradford 1976)}

Diese Methode zur Bestimmung von Proteinkonzentrationen beruht auf der Bindung des Farbstoffes Coomassie Brilliant Blue an basische und aromatische Seitenketten der Aminosäuren eines Proteins im sauren Milieu. Hierbei verschiebt sich das Absorptionsmaximum des Farbstoffes von 465 nm (vor der Bindung an ein Protein) zu $595 \mathrm{~nm}$ (nach der Bindung an ein Protein). Abb. 3.3. zeigt ein Schema dieser Reaktion. Für die Proteinbestimmung wurde Roti-Quant-Lösung (Fa. Roth, Karlsruhe) verwendet. Für jede Probe wurden $780 \mu \mathrm{l}, 790 \mu \mathrm{l}$ und $795 \mu \mathrm{l} \mathrm{H}_{2} \mathrm{O}$ (bidest) in einem 1,5 mlReaktionsgefäß vorgelegt und mit der zu bestimmenden Proteinlösung auf $800 \mu 1$ aufgefüllt. Als Referenz diente ein Ansatz mit $800 \mu \mathrm{H}_{2} \mathrm{O}$ (bidest) ohne Protein. Anschließend wurden $200 \mu$ l Roti-Quant-Lösung hinzugegeben, die Ansätze gründlich gemischt und unter gelegentlichen Schütteln für 15 Minuten bei Raumtemperatur inkubiert. Dann wurde die Absorption bei einer Wellenlänge von $595 \mathrm{~nm}$ mit Hilfe eines Ultrospec 2100 pro-Photometers (Fa. Amersham, Freiburg) oder eines V-530 UV/VIS Spectrophotometers (Fa. Jasco, Gotha) gemessen. 


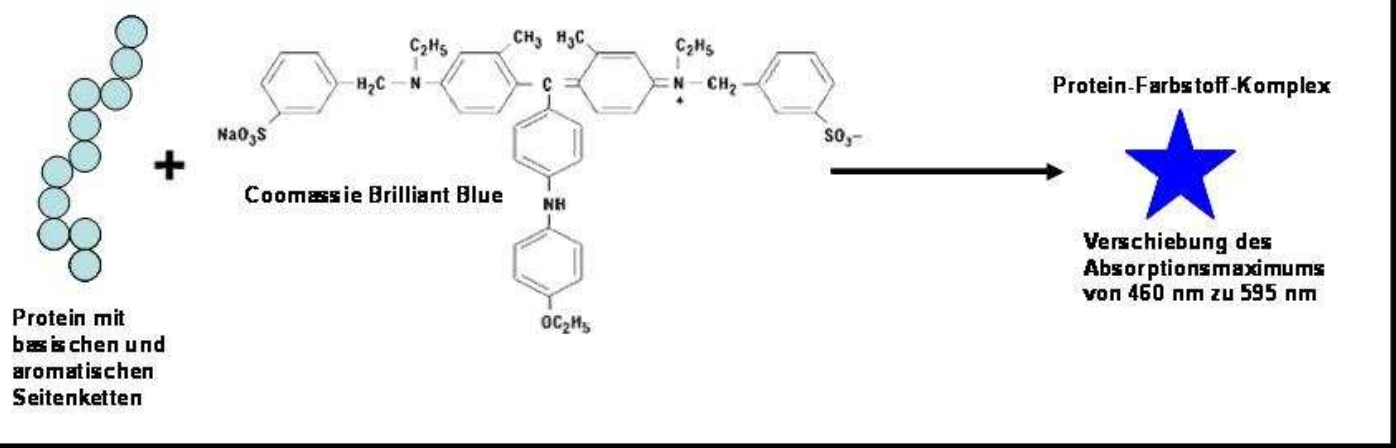

Abb. 3.3.: Schema der Bestimmung von Proteinkonzentrationen nach Bradford

In saurer Umgebung interagiert der der Farbstoff Coomassie Brilliant Blue mit basischen und aromatischen Seitenketten bestimmter Aminosäuren. Durch diese Interaktion kommt es zu einer Verschiebung des Absorptionsmaximums des Stoffes von $480 \mathrm{~nm}$ zu $595 \mathrm{~nm}$. Diese Verschiebung ist direkt proportional zur Konzentration der entsprechenden Aminosäuren und somit auch zum Proteingehalt der Probe

Anhand einer mit definierten Mengen Rinderserum-Albumin erstellten Eichkurve wurde folgende Formel für die Berechnung der Proteinkonzentration aufgestellt :

$$
\frac{(A 595 * 0,0536 \mu g)}{\mu l \text { Probe }}=c
$$

mit A595 Absorption bei $595 \mathrm{~nm}$

c Proteinkonzentration in $\mu \mathrm{g} / \mu \mathrm{l}$

\subsubsection{Denaturierende Proteingelelektrophorese}

\subsubsection{Vorbereitung der Proben}

Zellextrakte wurden mittels Proteinmengenbestimmung nach Bradford quantifiziert (siehe 3.7.5.) und äquivalente Proteinmengen in $\mathrm{H}_{2} \mathrm{O}$ (bidest) mit 5x SDS-Ladepuffer gemischt. Alternativ wurden übereinstimmende $\mathrm{OD}_{600}$-Einheiten verwendet (siehe 3.7.1.). Anschließend wurden die Proben für $15 \mathrm{~min}$ bei $94^{\circ} \mathrm{C}$ denaturiert. Die verwendeten Proteinmengen sind an entsprechender Stellen vermerkt. Zur Größenbestimmung wurden $10 \mu \mathrm{l}$ Unstained Protein Molecular Weight Marker oder Prestained Protein Molecular Weight Marker (Fa. Fermentas, St. Leon-Rot) verwendet, der ebenso denaturiert wurde. Nicht durch Proben belegte Taschen wurden mit dem Probenvolumen entsprechenden Mengen 1x SDS-Ladepuffer gefüllt. 
5x SDS-Ladepuffer:

$\begin{array}{ll}\beta \text {-Mercaptoethanol } & 16 \%(\mathrm{v} / \mathrm{v}) \\ \text { SDS } & 5 \%(\mathrm{w} / \mathrm{v}) \\ \text { Bromphenolblau } & 0,2 \%(\mathrm{w} / \mathrm{v}) \\ \text { Tris- } \mathrm{HCl}(\mathrm{pH} 6,8) & 200 \mathrm{mM} \\ \text { Glycerin } & 50 \%(\mathrm{v} / \mathrm{v})\end{array}$

\subsubsection{Herstellung denaturierender SDS-Polyacrylamid-Gele}

Denaturierende SDS-Polyacrylamid-Gele wurden wie unten angegeben angesetzt. Nach Mischen der Bestandteile wurde zunächst das Trenngel in den vorbereiteten Gießständen der verwendeten Laufapparatur gegossen und mit Isobutanol überschichtet, um eine waagerechte Fläche zu erhalten. Nachdem das Trenngel ausgehärtet war, wurde das Isobutanol entfernt, das $\mathrm{Gel}$ mit $\mathrm{H}_{2} \mathrm{O}$ (bidest) gespült und die Oberfläche vorsichtig getrocknet.

Dann wurde das Sammelgel angesetzt, gegossen und ein Kamm eingesetzt. Mini-Gele mit einer Höhe von 7,3 cm und einer Breite von $8 \mathrm{~cm}$ wurden in Mini-PROTEAN 3 Cell-Apparaturen (Fa. Bio-Rad, München) gegossen, große Gele mit einer Höhe und Breite von $16 \mathrm{~cm}$ in einer SE 400 oder SE 600 Vertical Unit (Fa. Hoefer, San Francisco, USA).

Sofern nicht anders angegeben wurden 12,5\%ige Trenngele und 5\%ige Sammelgele verwendet.

Für 15 ml Sammelgel:

$\begin{array}{ll}1 \mathrm{M} \text { Tris/HCl pH6.8 } & 1.8 \mathrm{ml} \\ \text { AA/Bis 29:1 (40\%) } & 1.875 \mathrm{ml} \\ \mathrm{H}_{2} 0 & 11.18 \mathrm{ml} \\ 10 \% \text { SDS } & 150 \mu \mathrm{l} \\ \text { Ammoniumpersulfat }(10 \%) & 150 \mu \mathrm{l} \\ \text { TEMED } & 15 \mu \mathrm{l}\end{array}$


Für 25 ml Trenngel:

$\begin{array}{ll}1.5 \mathrm{M} \text { Tris/HCl } \mathrm{pH} 8.7 & 6.25 \mathrm{ml} \\ \text { AA/Bis 29:1 (40\%) } & 7.81 \mathrm{ml} \\ \mathrm{H}_{2} \mathrm{O} & 10.69 \mathrm{ml} \\ 10 \% \mathrm{SDS} & 250 \mu \mathrm{l} \\ \text { Ammoniumpersulfat }(10 \%) & 250 \mu \mathrm{l} \\ \text { TEMED } & 25 \mu \mathrm{l}\end{array}$

Bei Verwendung von Mini-PROTEAN 3 Cell-Apparaturen (Fa. Bio-Rad, München) wurden die verwendeten Mengen halbiert (ausreichend für 2 Mini-Gele).

\subsubsection{Gelelektrophorese}

Die Gelelektrophorese wurde in Mini-PROTEAN 3 Cell-Apparaturen (Fa. Bio-Rad, München) bzw. SE 400 oder SE 600 Vertical Unit (Fa. Hoefer, San Francisco, USA) bei 120-180 Volt in 1x SDS-Laufpuffer durchgeführt, bis die Bromphenolblau-Bande des Ladepuffers das untere Ende des Gels erreichte.

5x Laufpuffer:

$\begin{array}{ll}\text { Tris } & 25 \mathrm{mM} \\ \mathrm{NaCl} & 250 \mathrm{mM} \\ \mathrm{SDS} & 0,1 \%(\mathrm{w} / \mathrm{v})\end{array}$

\subsubsection{Färbung mittels Coomassie Brilliant Blue R}

Nach dem Lauf wurden die Gele aus den Apparaturen entnommen und für mindestens 30 min in Coomassie-Färbelösung auf dem Horizontalschüttler bei Raumtemperatur gefärbt. Anschließend wurden die Gele kurz mit $\mathrm{H}_{2} \mathrm{O}$ (bidest) gespült und für 30 min in Entfärber I auf dem Horizontalschüttler bei Raumtemperatur inkubiert. Anschließend wurden sie in Entfärber II auf die selbe Art inkubiert, bis sie ausreichend entfärbt waren. Gele wurden mittels eines CanoScan 5.000F-Scanners (Fa. Canon, Krefeld) dokumentiert und gegebenenfalls getrocknet. Hierzu wurde das Gel auf zwei Lagen mit $\mathrm{H}_{2} \mathrm{O}$ (bidest) gewässerten Whatman-Papier transferiert und mit befeuchteter „Alba 
Einmach-Haut“ (Fa. Gehring \& Neiweiser, Bielefeld) abgedeckt. Anschließend wurde das Gel für $2 \mathrm{~h}$ in einem Model 583 gel dryer (Fa. Bio-Rad, München) getrocknet.

Coomassie-Färbelösung:

$\begin{array}{ll}\text { Ethanol } & 40 \%(\mathrm{v} / \mathrm{v}) \\ \text { Essigsäure } & 10 \%(\mathrm{v} / \mathrm{v}) \\ \text { Coomassie Brilliant Blue R } & 0,25 \%(\mathrm{w} / \mathrm{v})\end{array}$

Entfärber I:

$\begin{array}{ll}\text { Ethanol } & 40 \%(\mathrm{v} / \mathrm{v}) \\ \text { Essigsäure } & 10 \%(\mathrm{v} / \mathrm{v})\end{array}$

Entfärber II:

$\begin{array}{ll}\text { Ethanol } & 20 \%(\mathrm{v} / \mathrm{v}) \\ \text { Essigsäure } & 5 \%(\mathrm{v} / \mathrm{v})\end{array}$

\subsubsection{Western Blot Analyse}

\subsubsection{Herstellung polyklonaler Antikörper}

Polyklonale Antikörper aus Kaninchen gegen His(10)-YhbJ wurden von der Firma SeqLab (Göttingen) hergestellt. Es wurde ein erweitertes Immunisierungsschema mit vier Boost-Schritten angewendet. Hierbei wurde dem Tier zunächst vor der ersten Injektion $5 \mathrm{ml}$ Präimmun-Serum zur Untersuchung auf Kreuzreaktionen abgenommen. Danach erfolgte die erste Injektion des Antigens, welche nach 21, 49 und 65 Tagen wiederholt wurde. Für jede Antigen-Injektion wurden $400 \mu \mathrm{g}$ His(10)-YhbJ in ZAP verwendet. Blutentnahmen fanden an den Tagen 35, 53 und 70 nach der ersten AntigenInjektion statt. Die Entblutung des Tieres erfolgte am Tag 82 nach der ersten AntigenInjektion. Die Blutproben wurden bis zur Verwendung bei $-20^{\circ} \mathrm{C}$ gelagert.

\subsubsection{Aufreinigung des Antikörpers}

Um das Vorkommen von Kreuzreaktionen zu minimieren, wurde eine Aufreinigung des Antikörpers vorgenommen. Bei dieser sollen nicht YhbJ-spezifische Antikörper durch 
Bindung an Proteine in Lösung titriert werden, um ihre Reaktion mit an der PVDFMembran gebundenen Proteinen zu verhindern.

Hierzu wurden 11 LB-Medium aus einer Vorkultur des yhbJ-Deletionsstammes Z37 (siehe Tabelle 7.1.) zu einer $\mathrm{OD}_{600}$ von 0,1 inokuliert und bis zum Erreichen einer $\mathrm{OD}_{600}$ von 1 bei $37^{\circ} \mathrm{C}$ unter Agitation in einem 2 1-Schikanekolben inkubiert. Das Äquivalent $\mathrm{zu} 100 \mathrm{OD}_{600}$-Einheiten wurde durch Zentrifugation $\left(10 \mathrm{~min}, 5.000 \mathrm{rpm}, 4^{\circ} \mathrm{C}\right)$ geerntet und der Überstand verworfen. Das Pellet wurde in $10 \mathrm{ml}$ ZAP (pH 7,4) aufgenommen und die Zellen mittels Sonifizierung (5x 30 Pulse á 1 sec, vergleiche auch 3.7.1.) aufgeschlossen. Durch eine weitere Zentrifugation wie beschrieben wurden Zelltrümmer pelletiert. Der Überstand wurde in ein steriles Plastikröhrchen überführt, mit $100 \mu \mathrm{l}$ primären Antikörper $(\alpha-Y h b J)$ gemischt und $3 \mathrm{~h}$ bei Raumtemperatur inkubiert. Anschließend wurde der Ansatz bis zur Nutzung bei $4^{\circ} \mathrm{C}$ gelagert. In Western Blot Analysen wurde der aufgereinigte Antikörper 1:100 in Blotto verdünnt eingesetzt (siehe 3.7.7.3.)

\subsubsection{Transfer und Detektion}

Für Western Blot Analysen wurden die Proteinproben zunächst per denaturierender Proteingelelektrophorese wie unter 3.7.6. beschrieben aufgetrennt. Die Übertragung der Proteine auf eine Immun-Blot PVDF-Membran (Fa. Bio-Rad, München) erfolgte in einer Semiphor Transpher Unit (Fa. Amersham, Freiburg) oder eine Semi-dry Blotting Apparatur Fa. Waase-Tech, Göttingen).

Die Nitrocellulose-Membran wurde kurz in $100 \%$ Methanol aktiviert und die Polyacrylamid-Gele in Transferpuffer gewaschen, und die Elektroden der Apparatur wurden mit $\mathrm{H}_{2} \mathrm{O}$ (bidest) befeuchtet. Auf drei Lagen entsprechend zugeschnittenem und mit Transferpuffer befeuchteten Whatman-Papiers wurde zunächst die aktivierte Nitrocellulose-Membran und dann das Polyacrylamid-Gel gelegt, welches mit drei weiteren Lagen befeuchteten Whatman-Papiers abgedeckt wurde. Der Transfer der Proteine vom Polyacrylamid-Gel auf die Membran erfolgte für $1 \mathrm{~h}$ bei $60 \mathrm{~mA}$.

Anschließend wurde die Membran in eine Plastikschale mit Blotto überführt, in der sie über Nacht auf einem Horizontalschüttler bei $40 \mathrm{rpm}$ inkubiert wurde. Die Polyacrylamid-Gele wurden zur Kontrolle der Vollständigkeit des Transfers wie unter 3.7.6.4. beschrieben einer Coomassie-Färbung unterzogen.

Die Membranen wurden dann für $3 \mathrm{~h}$ in Blotto mit primären Antikörper beziehungsweise Präimmun-Serum (10.000:1) oder Blotto mit dem Ansatz zur 
Aufreinigung der Antikörper (siehe 3.7.7.2., 100:1) auf einem Horizontalschüttler mit 40 rpm inkubiert und anschließend drei Mal für 30 Minuten in Blotto gewaschen.

Daraufhin wurde die Membran für weitere $30 \mathrm{~min}$ in Blotto mit dem sekundären Antikörper Anti Rabbit IgG (FC) AP Conjugate (Fa. Promega, Mannheim) im Verhältnis 100.000:1 auf einem Horizontalschüttler mit $40 \mathrm{rpm}$ inkubiert und anschließend drei Mal für 20 min in Blotto gewaschen.

Die Membran wurde mit $\mathrm{H}_{2} \mathrm{O}$ (bidest) abgespült und für $5 \mathrm{~min}$ in Puffer III gewaschen, bevor sie für 5 Minuten in Puffer III mit dem Chemilumineszenz-Substrat CDP Star (Fa. Roche, Mannheim) im Verhältnis 100:1 inkubiert wurde.

Die Lumineszenz wurde dann über einen Zeitraum von $20 \mathrm{~min}$ und $45 \mathrm{~min}$ in einem Chemi-Smart 5.000 Chemilumineszenz-System (Fa. PeqLab, Erlangen) unter Verwendung der zugehörigen ChemiCapt 11.07-Software dokumentiert.

Transferpuffer:

$\begin{array}{ll}\text { Tris } & 25 \mathrm{mM} \\ \text { Glycin } & 192 \mathrm{mM} \\ \text { Methanol } & 15 \%\end{array}$

10x TBS (pH 7,6):

$\begin{array}{ll}\text { Tris } & 500 \mathrm{mM} \\ \mathrm{NaCl} & 1,5 \mathrm{M}\end{array}$

Blotto:

$\begin{array}{ll}\text { 10x TBS } & 1 \mathrm{x} \\ \text { Tween } 20 & 0,1 \% \\ \text { Magermilchpulver } & 2,5 \%(\mathrm{w} / \mathrm{v})\end{array}$

Puffer III (pH 9,5):

$\begin{array}{ll}\text { Tris } & 100 \mathrm{mM} \\ \mathrm{NaCl} & 100 \mathrm{mM}\end{array}$




\subsection{Electrophoretic Mobility Shift Assay (EMSA) (Garner und Revzin 1981)}

Der EMSA ist eine Methode, bei der die Interaktion zwischen Polynukleotiden (sowohl RNA wie auch DNA) und Proteinen untereinander bestimmt werden kann. Hierzu werden Ansätze mit unterschiedlichen Verhältnissen der potenziellen Interaktionpartner inkubiert und anschließend mittels nativer, also nicht-denaturierender, Gelelektrophorese aufgetrennt. Falls die Komponenten miteinander interagieren, so ist ihr Laufverhalten im Komplex deutlich vom Laufverhalten der einzelnen Komponenten zu unterscheiden.

\subsubsection{EMSA mit nicht-markierter RNA}

\subsubsection{Native Polyacrylamid-Gele}

Die Gele für EMSA wurden in Mini-PROTEAN 3 Cell-Apparaturen (Fa. Bio-Rad, München) gegossen. Es gibt im Gegensatz zur SDS-PAGE (siehe 3.7.6.) keine unterschiedlichen Sammel- und Trenngele.

Ansatz für $20 \mathrm{ml}$ :

$\begin{array}{ll}\text { 10x TBE } & 2 \mathrm{ml} \\ \text { AA/Bis 19:1 (40\%) } & 3 \mathrm{ml} \\ \mathrm{H}_{2} \mathrm{O} & 15 \mathrm{ml} \\ \text { Ammoniumpersulfat }(10 \%) & 200 \mu \mathrm{l} \\ \text { TEMED } & 20 \mu \mathrm{l}\end{array}$

10x TBE:

$\begin{array}{ll}\text { Tris } & 900 \mathrm{mM} \\ \text { Borsäure } & 890 \mathrm{mM} \\ \text { EDTA } & 25 \mathrm{mM}\end{array}$

\subsubsection{Vorbereitung der Proben}

Zunächst wurde das Molekulargewicht der verwendeten RNAs errechnet, wobei davon ausgegangen wurde, dass ein kb einzelsträngiger RNA ein Gewicht von $3,4 \times 10^{5}$ Da hat. Anschließend wurde ein 12x-Mastermix für $30 \mathrm{pMol}$ beziehungsweise $50 \mathrm{pMol}$ 
RNA in 2x Strukturpuffer und einem Gesamtvolumen von $96 \mu 1$ mit $\mathrm{H}_{2} \mathrm{O}$ (RNase-frei) angelegt. Diese Ansätze wurden für 10 min bei $95^{\circ} \mathrm{C}$ denaturiert und anschließend auf Eis abgekühlt.

Währenddessen wurden aufsteigende Konzentrationen von $\mathrm{His}(10)-\mathrm{YhbJ}$ in $\mathrm{H}_{2} \mathrm{O}$ (RNase-frei) mit einem Gesamtvolumen von $8 \mu \mathrm{l}$ vorgelegt, im Bereich von 0 pMol bis $40 \mathrm{pMol}$ Protein, wenn $30 \mathrm{pMol}$ RNA pro Ansatz verwendet wurde, und von $0 \mathrm{pMol}$ bis 150 pMol Protein, wenn 50 pMol RNA eingesetzt wurden.

Nach dem Abkühlen der denaturierten RNA auf Eis wurden $8 \mu$ l des RNA-Mastermix zu jeder vorgelegten Protein-Konzentration gegeben, und die Ansätze für $30 \mathrm{~min}$ bei Raumtemperatur inkubiert.

Anschließend wurden $4 \mu \mathrm{l} 50 \%$ Glycerin (in $\mathrm{H}_{2} \mathrm{O}$ (RNase-frei)) zu den Ansätzen gegeben und diese vorsichtig auf ein natives Polyacrylamid-Gel geladen (siehe 3.8.1.1.) und wie unter 3.8.1.3. beschrieben aufgetrennt und analysiert.

Strukturpuffer:

$\begin{array}{ll}\text { Tris-HCl }(\mathrm{pH} 7) & 100 \mathrm{mM} \\ \mathrm{KCl} & 1 \mathrm{M} \\ \mathrm{MgCl}_{2} & 100 \mathrm{mM}\end{array}$

3.8.1.3. Gelelektrophorese

Die Gelelektrophorese erfolgte in Mini-PROTEAN 3 Cell-Apparaturen (Fa. Bio-Rad, München). Die Gele wurden mit 1x TBE überschichtet und es erfolgte ein Vorlauf für 15 min bei 50 Volt, um die Gele zu äquilibrieren.

Nach dem Beladen der Gele mit EMSA-Proben (siehe 2.8.1.2.) erfolgte ein Lauf der Gele für 2-3 h bei 50 Volt und Raumtemperatur.

Anschließend wurden die Gele aus der Apparatur entnommen, für 2-3 min in einem Ethidiumbromid-Wasserbad gefärbt, kurz in $\mathrm{H}_{2} \mathrm{O}$ gespült und mittels direkt unter UVLicht einer Wellenlänge von $254 \mathrm{~nm}$ in einer Gel Doc 2.000-Anlage (Fa. Bio-Rad, München) dokumentiert.

10x TBE:

$\begin{array}{ll}\text { Tris } & 900 \mathrm{mM} \\ \text { Borsäure } & 890 \mathrm{mM} \\ \text { EDTA } & 25 \mathrm{mM}\end{array}$


3.8.2. EMSA mit ${ }^{32} \mathrm{P}$-markierter RNA

\subsubsection{Native Polyacrylamid-Gele für EMSA mit ${ }^{32} P$-markierter $R N A$}

Die Gele für EMSA mit ${ }^{32} \mathrm{P}$-markierter RNA wurden in einer SE 600 Vertical Unit (Fa. Hoefer, San Francisco) gegossen. Es gibt im Gegensatz zur SDS-PAGE (siehe 3.7.6.) keine unterschiedlichen Sammel- und Trenngele.

Ansatz für $100 \mathrm{ml}$ :

$\begin{array}{ll}\text { 10x TBE } & 10 \mathrm{ml} \\ \text { AA/Bis 19:1 (40\%) } & 15 \mathrm{ml} \\ \mathrm{H}_{2} \mathrm{O} & 75 \mathrm{ml} \\ \text { Ammoniumpersulfat }(10 \%) & 1 \mathrm{ml} \\ \text { TEMED } & 100 \mu \mathrm{l}\end{array}$

10x TBE:

$\begin{array}{ll}\text { Tris } & 900 \mathrm{mM} \\ \text { Borsäure } & 890 \mathrm{mM} \\ \text { EDTA } & 25 \mathrm{mM}\end{array}$

\subsubsection{Vorbereitung der Proben}

Zunächst wurde ein $4 \mathrm{x}$ upper mix mit je $4 \mathrm{nM}{ }^{32} \mathrm{P}$-markierter RNA sowie $100 \mathrm{nM}$ HefetRNA pro Ansatz in einem Volumen von $18 \mu \mathrm{l}$ mit $\mathrm{H}_{2} \mathrm{O}$ (RNase-frei) angelegt, für 1 min bei $95^{\circ} \mathrm{C}$ denaturiert und auf Eis abgekühlt, bevor $2 \mu 1$ 10x Strukturpuffer (Fa. Ambion, Austin) zugesetzt wurden.

Es wurden zudem drei unterschiedliche lower mixes in jeweils $5 \mu$ l Volumen angesetzt: Zunächst 1x Strukturpuffer ohne Protein, dann 4 nM His(10)-YhbJ in 1x Strukturpuffer und schließlich $40 \mathrm{nM}$ His(10)-YhbJ in 1x Strukturpuffer.

Je $5 \mu \mathrm{l}$ des 4x upper mix wurden zu einem der lower mix-Ansätze gegeben und für 30 $\min$ bei $37^{\circ} \mathrm{C}$ inkubiert. 
Strukturpuffer:

$\begin{array}{ll}\text { Tris-HCl (pH 7) } & 100 \mathrm{mM} \\ \mathrm{KCl} & 1 \mathrm{M} \\ \mathrm{MgCl}_{2} & 100 \mathrm{mM}\end{array}$

\subsubsection{Gelelektrophorese}

Die Gelelektrophorese erfolgte in einer SE 600 Vertical Unit (Fa. Hoefer, San Francisco). Die Gele wurden mit 1x TBE überschichtet und es erfolgte ein Vorlauf für 30 min bei 300 Volt und $120 \mathrm{~A}$, um die Gele zu äquilibrieren.

Die Proben wurden nach Ablauf der unter 3.8.2.2. beschriebenen Inkubation mit $3 \mu 1$ nativem Ladepuffer gemischt und unter Spannung aufgetragen. Der Lauf der Gele erfolgte für $2 \mathrm{~h}$ bei 300 Volt, $120 \mathrm{~A}$ und $4^{\circ} \mathrm{C}$.

Anschließend wurden die Gele aus der Apparatur entnommen, für $1 \mathrm{~h}$ mittels eines Model 583 gel dryer (Fa. Bio-Rad, München) getrocknet (vergleiche 2.7.6.4.) und für 2 h auf einen Molecular dynamics GP Storage Phosphor-Schirm (Fa. GE Healthcare, Freiburg) aufgelegt und die Strahlung der radioaktiv-markierten Sonden und des Markers mittels eines FujiImager BAS (Fa. Fuji, Düsseldorf) ausgewertet.

10x TBE:

$\begin{array}{ll}\text { Tris } & 900 \mathrm{mM} \\ \text { Borsäure } & 890 \mathrm{mM} \\ \text { EDTA } & 25 \mathrm{mM}\end{array}$

\subsection{Computergestützte Datenanalyse von DNA- und Proteinsequenzen und Literaturrecherche}

Für E. coli wurde die Genomdatenbank EcoCyc unter http://www.ecocyc.org genutzt. Die Analyse von Aminosäure-Sequenzen wurden mit Hilfe des Basic Local Alignment Search Tool BLAST (Altschul et al. 1990) unter http://www.ncbi.nlm.nih.gov/blast/ und des Simple Modular Architecture Research Tool SMART (Schultz et al. 1998) unter http://smart.embl-heidelberg.de/ durchgeführt. Konservierte Motive wurden mittels MEME version 3.5.7. ermittelt (Bailey et al. 2006). 
RNA-Bindedomänen wurden mittels RNABindR vorhergesagt (Terribilini et al. 2007). Für phylogenetische Analysen wurde ebenfalls die Datenbank MicrobesOnline unter http://www.microbesonline.org genutzt.

Desweiteren wurden die Programme ClustalW (Thompson et al. 1994; Larkin et al. 2007) unter http://www.ebi.ac.uk/clustalw/ und WebLogo (Crooks et al. 2004) unter http://weblogo.berkeley.edu/logo.cgi verwendet sowie BioEdit Sequence Alignment Editor (Hall 1999) und TreeView 1.6.6. (Copyright R.D.M Page 2001) .

Die Verarbeitung von DNA-Sequenzen wurde mit Hilfe des Programmes CHROMAS (Conor MacCarthy, Southport) durchgeführt, virtuelle Klonierungen und Sequenzanalysen mittels VectorNTI (Fa. Invitrogen, Karlsruhe) verwendet.

Für die Literaturrecherche wurde PubMed (National Institutes of Health, Bethesda, USA) unter http://www.ncbi.nlm.nih.gov/entrez/query.fcgi?db=PubMed sowie die Datenbank EcoCyc (siehe oben) genutzt. 


\section{Ergebnisse}

\subsection{Die Regulation der glmS-Expression in Escherichia coli}

Vorherige Analysen zeigten, dass eine Deletion von $y h b J$ zu einer starken Überexpression des Gens der Glukosamin-6-Phosphat-Synthase GlmS führt sowie zu einer Akkumulation einer $g \operatorname{lm} S$-spezifischen mRNA.

\subsubsection{Transposonmutagenese und Charakterisierung der Mutanten}

Um weitere an der Regulation der $g \operatorname{lm} S$-Expression beteiligte Faktoren zu identifizieren, wurde eine Transposon-Mutagenese unter Verwendung des Transposons mTn10 durchgeführt (siehe 2.3.5.). Diese beruht auf der Transposition des plasmidständigen Transposons und der zufälligen Integration des Elementes in das Genom der Zelle.

Für diese Analysen wurden der Wildtyp Z8 und der $y h b J$-Deletionsstamm Z28 verwendet (siehe Tabelle 7.1.). Diese tragen beide eine $g l m S$-lacZ-Reporterfusion, die in das Chromosom integriert ist. Wie in Abb. 4.1. dargestellt handelt es sich hierbei um ein Konstrukt, in dem die Expression von $g \operatorname{lm} S$ und des stromaufwärts gelegenen intergenischen Bereiches vom konstitutiven Promotor des aadA-Resistenzgens aus erfolgt. Diese Resistenzkassette besitzt zwar einen schwachen Terminator, jedoch kommt es dennoch zu einer signifikanten Expression der Reporterfusion. Dadurch eignet sich dieses Konstrukt besonders zur Untersuchung der posttranskriptionellen Regulation von $\operatorname{glm} S$.

Um Messungen mittels $\beta$-Galaktosidase-Assay zu ermöglichen, ist in diesen Stämmen zudem das authentische, chromosomale lac-Operons deletiert, und das Gen des LacRespressor, $l a c Y$, wurde nachträglich über das F-Plasmid wieder eingefügt.

In Abb. 4.1. ist die im Wildtyp und in einem $\Delta y h b J$-Stamm gemessene $\beta$-GalaktosidaseAktivität dargestellt. Der Wildtyp-Stamm weist für die hier verwendete chromosomale glmS-lacZ-Fusion eine geringe Aktivität von 3 Miller units auf, während die Aktivität in Abwesenheit von yhbJ um einen Faktor 35 höher ist (106 Miller units, vergleiche auch Abb. 4.3.). 
A

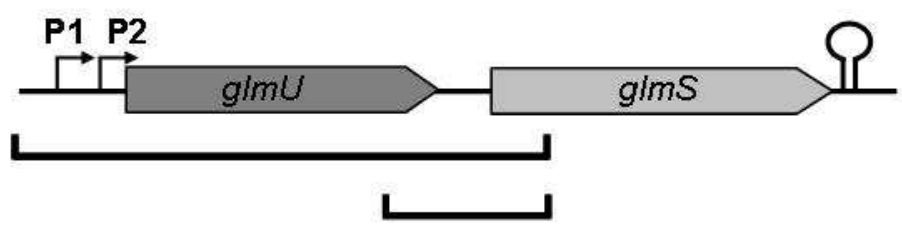

B

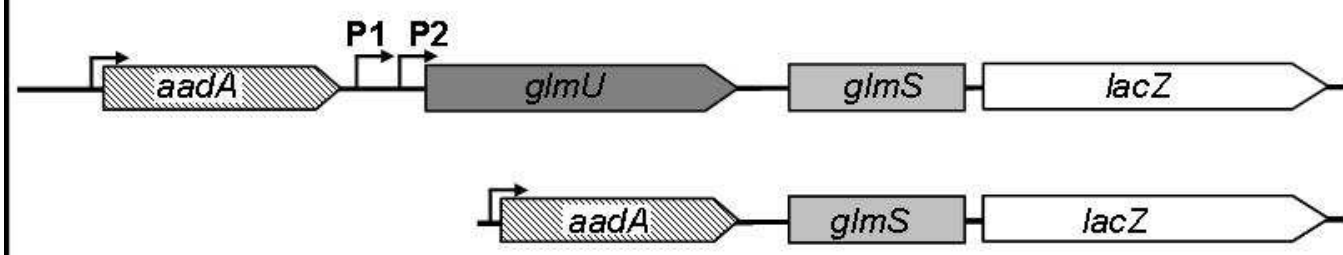

C

\begin{tabular}{|l|c|c|c|c|}
\hline \multirow{2}{*}{$\begin{array}{l}\text { Reporter- } \\
\text { fusion }\end{array}$} & \multicolumn{2}{|l|}{ plasmidständig } & \multicolumn{2}{l|}{ chromosomal } \\
& Wildtyp & $\Delta[p t s N-n p r]$ & Wildtyp & $\Delta[p t s N-n p r]$ \\
\hline glmUS-lacZ & 3.250 & 32.510 & 363 & 4.378 \\
\hline glmS-lacZ & 110 & 940 & 3 & 106 \\
\hline
\end{tabular}

Abb. 4.1.: Reporterfusionen zur Untersuchung der glmS-spezifischen Expression in $E$. coli

(A) Schematische Darstellung des gImUS-Operons in E. coli. P1 und P2 bezeichnen die beiden Promotoren, das Haarnadel-Symbol den Terminator des Operons (vergleiche 2.1.). Die Klammern unter der Abbildung markieren die an lacZ fusionierten Bereiche.

(B) Schematische Darstellung der glmUS'-lacZ-Reporterfusion und der glmS'-lacZReporterfusion. Vor den Fusionen befindet sich die aadA-Resistenzkassette.

(C) $\beta$-Galaktosidase-Aktivität der glmUS-lacZ- und glmS-lacZ-Reporterfusionen (in Miller units). Es wurden der Wildtyp (R1279) und ein [ptsN-npr]-Deletionsstamm (R2413) mit Plasmiden, die die Reporterfusionen tragen (pBGG16 und pBGG17) transformiert, als auch Wildtyp (Z8 beziehungsweise $\mathrm{Z9}$ ) und ein [ptsN-npr]-Deletionsstamm ( $\mathrm{Z} 5$ beziehungsweise $\mathrm{Z6}$ ) verwendet, bei denen die Reporterfusionen in das Chromosom integriert sind (siehe Tab. 7.2). Die Stämme und Transformanten wurde in LB-Medium bei $37^{\circ} \mathrm{C}$ auf einem Horizontalschüttler inkubiert, bis eine $\mathrm{OD}_{600}$ von 0,6 erreicht wurde und anschließend die $\beta$-Galaktosidase-Aktivität bestimmt (siehe 3.3.4.).

Beide Reporterfusionen zeigen sowohl plasmidständig als auch integriert in das Chromosom eine stark erhöhte $\beta$-Galaktosidase-Aktivität in Abwesenheit von yhbJ.

Der Wildtyp-Stamm Z8 wurde eingesetzt, um nach Transposonmutanten zu suchen, in denen die $\beta$-Galaktosidase-Aktivität deutlich erhöht ist. In diesen Mutanten wurde durch die Transposition ein genetisches Element inaktiviert, dass sich negativ auf die glmSspezifische Expression, und somit auf die Aktivität der glmS-lacZ-Reporterfusion, auswirkt (reprimierender Faktor).

Im Stamm Z28 ist die $g l m S$-spezifische Expression aufgrund der Deletion von $y h b J$ entkoppelt (vergleiche 2.3.), was sich in der hohen $\beta$-Galaktosidase-Aktivität 
wiederspiegelt. In diesem Stamm wurde nach Transposonmutanten gesucht, deren $\beta$ Galaktosidase-Aktivität deutlich niedriger als im Ausgangsstamm ist. In diesen Mutanten wurde ein genetisches Element inaktiviert, dass sich positiv auf die $g \operatorname{lm} S$ spezifische Expression, und somit auch auf die glmS-lacZ-Reporterfusion, auswirkt (aktivierender Faktor).

Um eine große Zahl Transposonmutanten mit hohem Durchsatz untersuchen zu können, wurden die Transposonmutanten auf M9-Minimalmedium mit Glukose (siehe 3.2.2.) mit X-Gal plattiert. X-Gal (5-Brom-4-chlor-3-indoxyl- $\beta$-D-galactopyranosid) wird durch die $\beta$-Galaktosidase gespalten, hiebei entstehen Galaktose und ein blauer Farbstoff (5,5'-Dibrom-4,4'-dichlor-Indigo) (Sambrooke 2001). Alternativ wurde McConkey-Agar (siehe 2.2.3) verwendet. Dieser enthält Neutralrot als pH-Indikator, der eine Verwertung von Laktose durch einen Farbumschlag anzeigt (Sambrooke 2001). In beiden Fällen ist es möglich, entweder gefärbte Kolonien mit einer erhöhten $\beta$ Galaktosidase-Aktivität vor einem Hintergrund ungefärbter Kolonien zu selektieren (Suche nach reprimierenden Faktoren), oder ungefärbte Kolonien mit einer erniedrigten $\beta$-Galaktosidase-Aktivität vor einem Hintergrund gefärbter Kolonien zu suchen (Suche nach aktivierenden Faktoren).

Die Zielstämme wurden mit dem Plasmid pKESK18 transformiert (siehe 3.3.3.). Dieses trägt einen temperatursensitiven Replikationsursprung, der keine Replikation des Plasmids bei Temperaturen über $30^{\circ} \mathrm{C}$ zulässt, sowie ein Transposase-Gen unter Kontrolle eines ebenfalls temperaturabhängigen Promotors. Dadurch ist die Expression der Transposase nur bei einer Temperatur von $42^{\circ} \mathrm{C}$ möglich. Somit können Transformanten bei $30^{\circ} \mathrm{C}$ inkubieren werden, um eine Replikation des Plasmides zu gewährleisten, während eine Temperaturerhöhung diese verhindert, jedoch die Transposition aktiviert. Durch dieses System werden unerwünschte mehrfache Insertionen in das Genom verhindert.

Die transformierten Zielstämme wurden zunächst bei $30^{\circ} \mathrm{C}$ in LB-Medium (siehe 3.2.1.) mit Selektion auf Kanamycin- und Chloramphenicol-Resistenz (siehe 3.2.5.) inkubiert und in der exponentiellen Wachstumsphase $\left(\mathrm{OD}_{600}\right.$ von 0,5 bis 0,8$)$ in Verdünnungen von $10^{-3}$ bis $10^{-6}$ auf M9-Minimalplatten mit Glukose (siehe 3.2.2.) und X-Gal sowie auf McConkey-Lac-Platten (siehe 3.2.3.) jeweils unter Selektion auf ChloramphenicolResistenz ausplattiert und über Nacht bei $42^{\circ} \mathrm{C}$ inkubiert. 
Zusätzlich wurden Verdünnungen von $10^{-4}$ bis $10^{-7}$ auf M9-Minimalplatten mit Glukose und X-Gal und auf McConkey-Lac-Platten unter Selektion auf Kanamycin-Resistenz für die Lebendzellzahlbestimmung plattiert und bei $30^{\circ} \mathrm{C}$ inkubiert.

Wie beschrieben wurde im Wildtyp-Stamm Z8 nach Transposonmutanten gesucht, in denen die Insertion des Transposons in das Chromosom zu einer erhöhten $\beta$ Galaktosidase-Aktivität führt. Hierzu wurden Kolonien untersucht, die im Gegensatz zum unbehandelten Wildtyp eine deutliche Färbung auf M9-Minimalmedium mit Glukose und X-Gal beziehungsweise McConkey-Agar aufwiesen.

Umgekehrt wurde im $\Delta y h b J-S t a m m$ Z28 nach Mutanten gesucht, in denen die $\beta$ Galaktosidase-Aktivität der Reporterfusion herabgesetzt ist, so dass entsprechende Kolonien auf M9-Minimalmedium mit Glukose und X-Gal oder McConkey-Agar keine oder eine deutlich schwächere Färbung aufweisen als der Ausgangsstamm Z28.

Entsprechende Kolonien wurden auf M9-Minimalplatten mit Chloramphenicol vereinzelt, um den Phänotyp zu verifizieren. Anschließend wurde die Insertionsstelle des Transposons mittels ST-PCR (siehe 3.5.2.) bestimmt sowie die Aktivität der Reporterfusion im Vergleich zu den Ursprungsstämmen im $\beta$-Galaktosidase-Assay (siehe 3.3.4.) bestimmt.

Im Wildtyp wurden auf der Suche nach reprimierenden Faktoren der glmS-Expression etwa 240.000 Transposonmutanten untersucht. Die Mutagenese in diesem Stamm resultierte in 27 Mutanten, die reproduzierbar eine deutlich erhöhte $\beta$-GalaktosidaseAktivität der Reporterfusion aufwiesen. In einem Großteil der Mutanten war der Anstieg der Aktivität jedoch durch eine Integrationen des Plasmides in die Reporterfusion bedingt und für drei weitere Mutanten konnte die Insertionsstelle nicht bestimmt werden, da es sich Integrationen des gesamten pKESK18-Plasmides in das Genom handelte.

Tabelle 4.1: Transposonmutanten im Wildtyp (Z8)

\begin{tabular}{|c|c|c|c|}
\hline Stamm & Genotyp & Richtung & Bemerkungen \\
\hline Z8 TM 1 & $\mathrm{Z} 8 \mathrm{~g} \operatorname{lm} S:: \mathrm{m} T n 10$ (cat) & $\rightarrow \rightarrow \rightarrow$ & Insertion an Position -7 \\
\hline Z8 TM 2 & $\mathrm{Z} 8 \mathrm{~g} \operatorname{lm} S:: \mathrm{m} T n 10$ (cat) & $\rightarrow \rightarrow \rightarrow$ & Insertion an Position +5 \\
\hline Z8 TM 3 & $\mathrm{Z} 8 \mathrm{~g} \operatorname{lm} S:: \mathrm{m} T n 10(\mathrm{cat})$ & $\rightarrow \rightarrow \rightarrow$ & Insertion an Position -63 \\
\hline Z8 TM 7 & Z8 yhbJ::mTn10 (cat) & $\rightarrow \leftarrow \rightarrow$ & Insertion an Position +678 \\
\hline Z8 TM 8 & $\mathrm{Z} 8$ yhbJ::mTn10 (cat) & $\rightarrow \rightarrow \rightarrow$ & $\begin{array}{l}\text { Insertion an Position }-6,3 \text { unabhängge } \\
\text { Mutanten gefunden }\end{array}$ \\
\hline Z8 TM 9 & $\mathrm{Z8}$ yhbJ::mTn10 (cat) & $\rightarrow \rightarrow \rightarrow$ & Insertion an Position +756 \\
\hline Z8 TM 11 & $\mathrm{Z} 8$ yhbJ::mTn10 (cat) & $\rightarrow \rightarrow \rightarrow$ & Insertion an Position (+716) \\
\hline
\end{tabular}

Die verbliebenen Transposonmutanten sind in Tabelle 4.1. aufgeführt. Sechs von ihnen trugen Insertionen des Transposons in $y h b J$, die sich auf vier unterschiedliche 
Insertionstellen verteilen und die den bekannten Effekt einer Inaktivierung von $y h b J$ auf die $g \operatorname{lm} S$-Expression wiederspiegeln.

Die restlichen drei Transposonmutanten trugen Insertionen in oder nahe $g \operatorname{lm} S$ selbst.

Tabelle 4.2: Transposonmutanten im $\Delta y h b J$-Hintergrund (Z28)

\begin{tabular}{|c|c|c|c|}
\hline Stamm & Genotyp & Richtung & Bemerkungen \\
\hline Z28 TM1 & $\mathrm{Z} 28$ glmZ::mTn10 (cat) & $\rightarrow \rightarrow \rightarrow$ & $\begin{array}{l}\text { Insertion an Position }+10,2 \text { unabhängige } \\
\text { Mutanten gefunden }\end{array}$ \\
\hline Z28 TM2 & Z28 glmZ::mTn10 (cat) & $\rightarrow \rightarrow \rightarrow$ & Insertion an Position +6 \\
\hline Z28 TM3 & $\mathrm{Z} 28$ dgoT::mTn10 (cat) & $\longleftarrow \longrightarrow$ & Insertion an Position +26 \\
\hline Z28 TM4 & $\mathrm{Z} 28$ glmZ::mTn10 (cat) & $\rightarrow \leftarrow \rightarrow$ & Insertion an Position +12 \\
\hline Z28 TM5 & $\mathrm{Z} 28$ glmZ::mTn10 (cat) & $\rightarrow \leftarrow \rightarrow$ & Insertion an Position +84 \\
\hline Z28 TM6 & $\mathrm{Z} 28$ glmZ::mTn10 (cat) & $\rightarrow \longleftarrow \rightarrow$ & Insertion an Position +16 \\
\hline Z28 TM7 & $\mathrm{Z} 28$ glmZ::mTn10 (cat) & $\rightarrow \rightarrow \rightarrow$ & Insertion an Position +74 \\
\hline Z28 TM8 & Z28 yjiR::mTn10 (cat) & $\leftarrow \longleftarrow \leftarrow$ & Insertion an Position -166 \\
\hline Z28 TM9 & $\mathrm{Z} 28$ glmZ::mTn10 (cat) & $\rightarrow \longleftarrow \rightarrow$ & Insertion an Position -59 \\
\hline Z28 TM10 & $\mathrm{Z} 28$ glmZ::mTn10 (cat) & $\rightarrow \leftarrow \rightarrow$ & $\begin{array}{l}\text { Insertion an Position }+30,3 \text { unabhängige } \\
\text { Mutanten gefunden }\end{array}$ \\
\hline Z28 TM11 & Z28 hemY::mTn10 (cat) & $\leftarrow \longrightarrow$ & Insertion an Position +1067 \\
\hline Z28 TM12 & $\mathrm{Z} 28$ glmZ::mTn10 (cat) & $\rightarrow \leftarrow \rightarrow$ & Insertion an Position -88 \\
\hline Z28 TM13 & $\mathrm{Z} 28$ glmZ::mTn10 (cat) & $\rightarrow \rightarrow \rightarrow$ & $\begin{array}{l}\text { Insertion an Position }+83,2 \text { unabhängige } \\
\text { Mutanten gefunden }\end{array}$ \\
\hline Z28 TM15 & Z28 glmZ::mTn10 (cat) & $\rightarrow \rightarrow \rightarrow$ & Insertion an Position -1 \\
\hline
\end{tabular}

Die Suche nach aktivierenden Faktoren der Expression im $\Delta y h b J$-Stamm Z28 resultierte in 26 Kolonien aus etwa 75.000 untersuchten Mutanten, die reproduzierbar eine deutlich geringere $\beta$-Galaktosidase-Aktivität der Reporterfusion aufwiesen. Acht dieser Transposonmutanten trugen eine Insertion im lacZ-Gen der Reporterfusion.

Zwei weitere Transposonmutanten trugen Insertionen in $d g o T$ beziehungsweise im Gen $y j i R$. Für beide Gene wurden Deletionsstämme mittels der unter 3.5.3. Methode generiert (resultierend in den Stämmen Z88 und Z90 sowie Z92 und Z94, siehe Tab. 7.1.), in denen jedoch kein Einfluß der Deletionen auf die $g \operatorname{lm} S$-Expression nachgewiesen werden konnte (Daten nicht gezeigt).

Der größte Anteil der Transposonmutanten jedoch trug Insertionen in oder nahe dem Gen $\operatorname{glm} Z$ (vormals sraJ), die sich auf 11 unterschiedliche Insertionsstellen verteilen (siehe Tabelle 4.2.).

\subsubsection{Untersuchung der Rolle von GlmZ}

Das Gen $\operatorname{glm} Z$ liegt als monocistronische Einheit zwischen aslA, welches für eine Arylsulfatase kodiert (Murooka et al. 1978), und dem hemCDXY-Operon, welches für Proteine der Tetrapyrrol-Synthese kodiert ((GOA et al. 2001), siehe Abb. 4.2.) . 


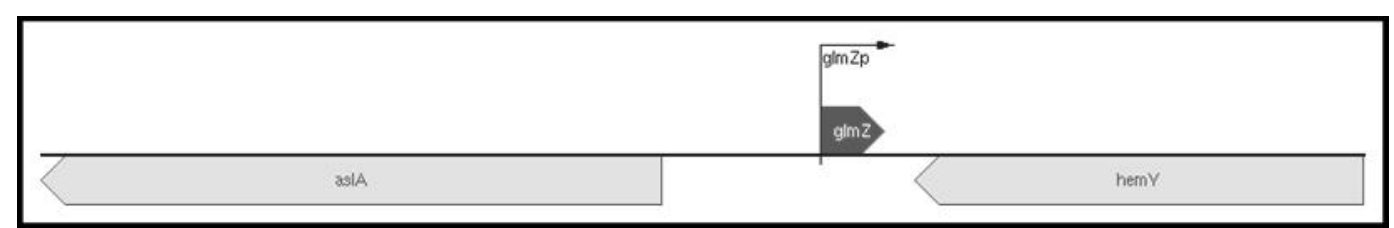

Abb. 4.2.: Position des gImZ im E. coli-Genom

Das Gen $g / m Z$ ist zwischen dem Gen für eine Arysulfatase, aslA, und dem letzten Gen des hemCDXY-Operons lokalisiert.

Das korrespondierende Genprodukt ist die kleine, nichtcodierende RNA GlmZ, von welcher aus früheren Untersuchungen lediglich bekannt war, dass sie von Hfq (host factor required for phage $Q \beta$ RNA replication, oder auch Host factor 1) gebunden wird und dass auch eine stabile prozessierte Form in der Zelle vorliegt (Argaman et al. 2001; Rivas et al. 2001; Wassarman et al. 2001). Diese Prozessierung wurde als RNase IIIabhängig beschrieben (Argaman et al. 2001).

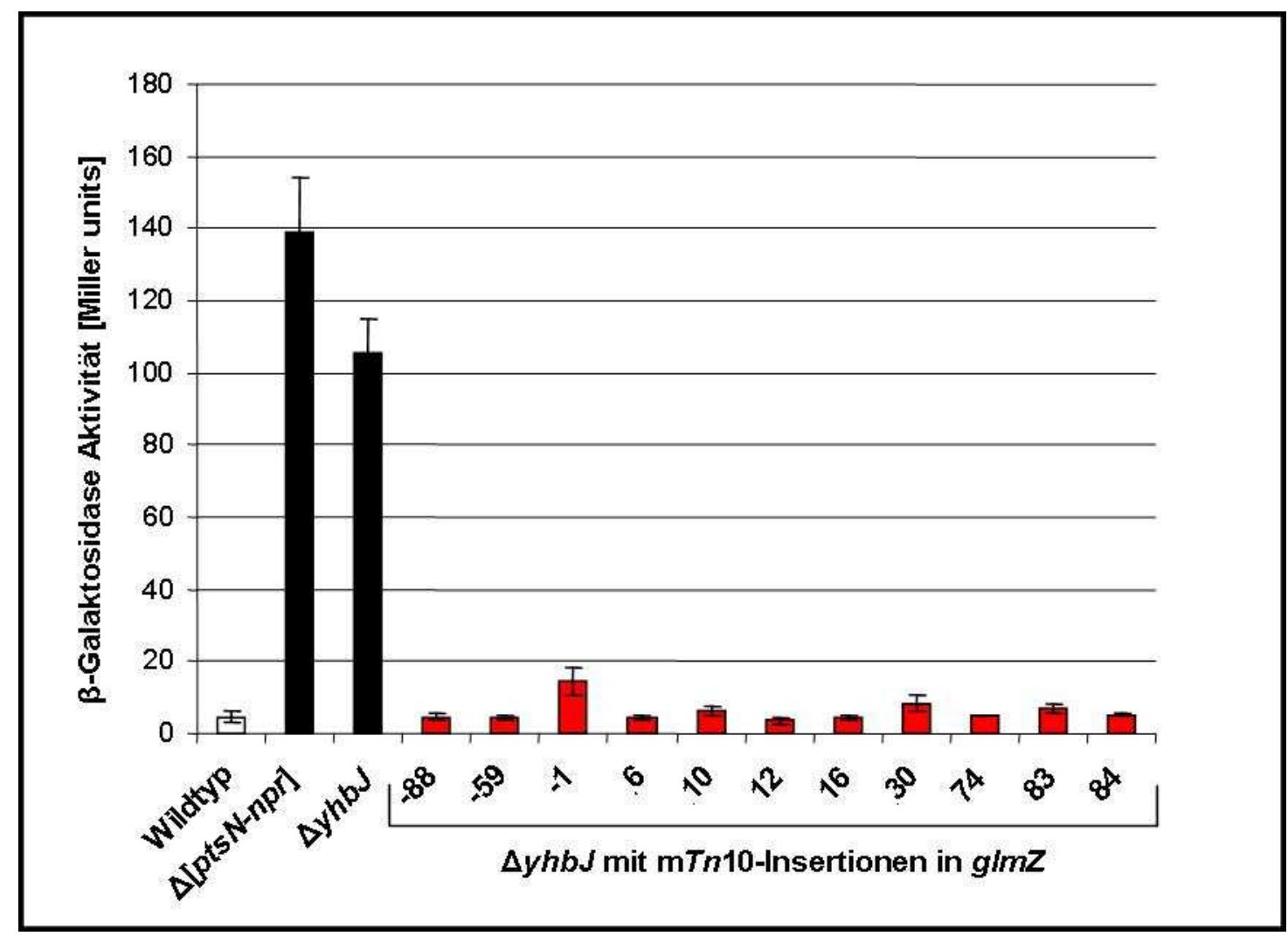

Abb. 4.3.: Transposon-Insertionen im Gen $g / m Z$ verhindern die Überexpression von $g / m S$ in einem yhbJ-Deletionsstamm

Transposonmutanten aus der Mutagense unter Verwendung des $\Delta y h b J-S t a m m ~ m i t$ chromosomaler glmS-lacZ-Reporterfusion (Z28) mit einer Insertionen des Transposons in oder nahe des Gens $g / m Z$ wurden, ebenso wie der Ausgangsstamm Z28, eine [ptsN-npr]-Deletion (Z5) und der korrespondierende Wildtyp (Z8), in LB-Medium inkubiert, bis eine $\mathrm{OD}_{600}$ von 0,6 erreicht wurde. Anschließend wurde die $\beta$-Galaktosidase-Aktivität wie unter 3.3.4. beschrieben bestimmt.

Die Insertion des Transoposon in oder nahe des Gens glmZ verhindert die erhöhte Reporteraktivität in Abwesenheit von yhbJ.

Die Positionen der Insertion sind relativ zur ersten Base des glmZ-Gens angegeben. 
Die Mutanten, bei denen das Transposon in oder nahe $g \operatorname{lm} Z$ integrierte, wiesen im $\beta$ Galaktosidase-Assay eine stark verringerte Aktivität der $g \operatorname{lmS}$-lacZ-Reporterfusion auf, obwohl das $y h b J$-Gen deletiert ist. In den meisten Fällen war diese Aktivität auf einem ähnlichen Niveau wie die des Wildtyp-Stammes Z8 (vergleiche Abb. 4.3.).

Daraufhin wurde eine markerlose Deletion von $g \operatorname{lm} Z$ sowohl im Wildtyp als auch im $\Delta y h b J$-Hintergrund generiert (siehe 3.5.3.) und diese Stämme mittels Western Blot Analyse (siehe 3.7.7.) mit polyklonalen Anti-Körpern gegen GlmS untersucht. Hierbei wiesen Stämme mit einer Deletion von $y h b J$ deutlich höhere Mengen an GlmS als der Wildtyp auf (vergleiche Abb. 4.4. Spur 1 mit Spur 2 beziehungsweise 3). In einem $\Delta g \operatorname{lmZ}$ - sowie einem $\Delta g \operatorname{lm} Z \Delta[p t s N$-npr]-Hintergrund war die GlmS-Menge jedoch geringer als im Wildtyp (vergleiche Abb. 4.4. Spur 4 und 5 mit Spur 1). Hieraus lässt sich schließen, dass $g \operatorname{lm} Z$ für die Akkumulation von GlmS in Abwesenheit von YhbJ erforderlich ist und somit einen essentiellen Bestandteil des hier untersuchten Regulationsmechanismus zur Expression von $g \operatorname{lm} S$ darstellt.

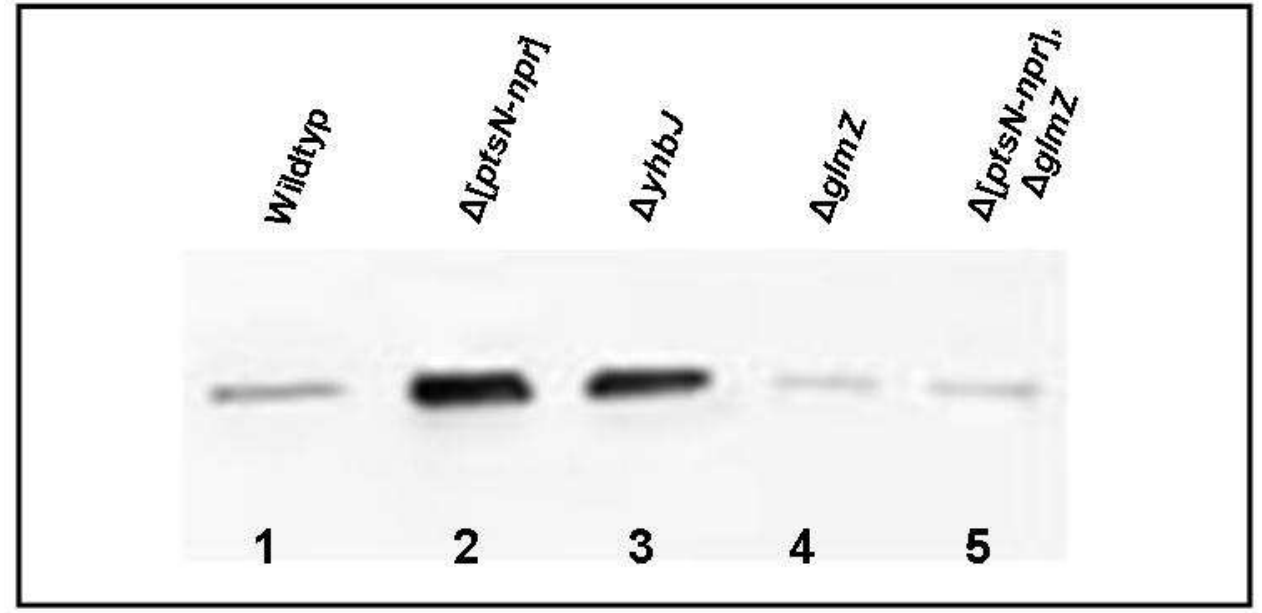

Abb. 4.4.: Analyse der GImS-Menge in Abhängigkeit von GImZ.

Der Wildtyp R1279 sowie die Stämme $\Delta[p t s N-n p r]$ (R2413), $\Delta y h b J(Z 24), \Delta g / m Z$ (Z44) und $\Delta[p t s N-n p r] \Delta g I m Z(Z 46)$ wurden in LB-Medium inkubiert bis eine $\mathrm{OD}_{600}$ von 0,6 erreicht wurde. Anschließend wurden Gesamtzellextrakte hergestellt (siehe 3.7.1.) und wie unter 3.7.7. beschrieben eine Western Blot Analyse unter Verwendung polyklonaler Antikörper gegen GlmS durchgeführt.

Es ist eine deutliche Erhöhung der GlmS-Menge in Abwesenheit von yhbJ erkennbar. Eine Deletion von $g / m Z$ verhindert die Überexpression von GlmS, sogar in Abwesenheit von yhbJ.

Dies wird bestätigt durch Komplementationsexperimente, in denen $g \operatorname{lm} Z$ plasmidisch in den Wildtyp und eine $\Delta g \operatorname{lmZ} \Delta[p t s N$-npr]-Deletion eingebracht und überexprimiert wurde. Wie aus Abb. 4.5. ersichtlich ist in Abwesenheit von glmZ keine verstärkte Expression der glmS-lacZ-Reporterfusion erkennbar, selbst wenn $y h b J$ deletiert ist (vergleiche Abb. 4.5 Balken 1 und 4). Wird glmZ jedoch von einem Plasmid aus stark 
exprimiert, zeigt sich in $\operatorname{der} \Delta g \operatorname{lm} Z \quad \Delta[p t s N$-npr]-Deletion eine vollständige

Komplementation und Wiederherstellung der verstärkten $g \operatorname{lmS}$-Expression, was auch in einer erhöhten Aktivität der glmS'-lacZ-Reporterfusion resultiert (vergleiche Abb. 4.5. Balken 4 und 6). Erstaunlicherweise führt eine plasmidische Expression von $g \operatorname{lmZ} \mathrm{im}$ Wildtyp ebenfalls zu einer erhöhten Aktivität der $g \operatorname{lm} S$ '-lacZ-Reporterfusion (vergleiche Abb. 4.5. Balken 1 und 3). Daraus kann geschlossen werden, dass $g \operatorname{lm} Z$ im Regulationsmechanismus stromabwärts von YhbJ agiert.

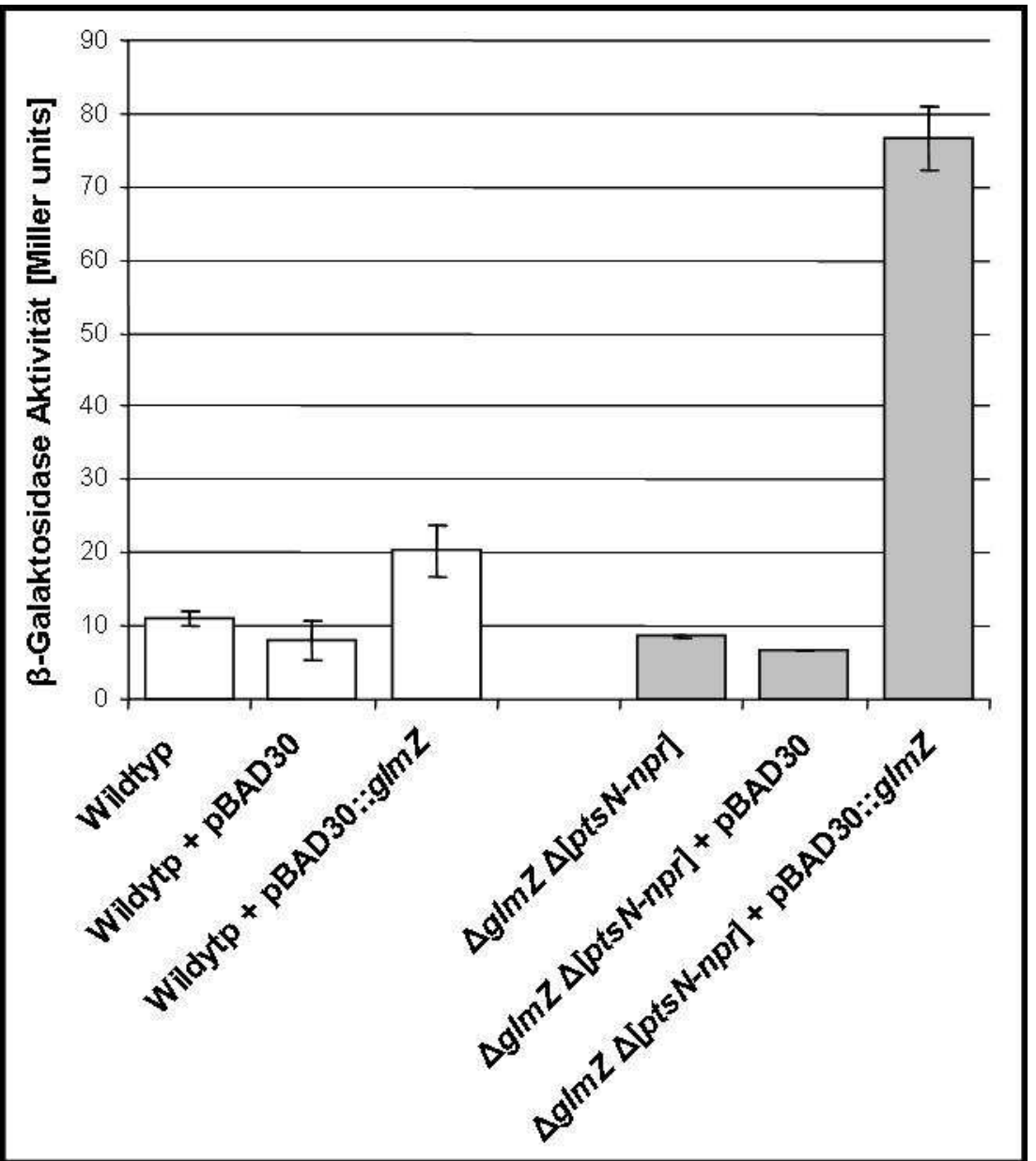

Abbildung 4.5.: Ein $\Delta g / m Z$-Stamm kann durch plasmidisch exprimiertes $g / m Z$ komplementiert werden.

Ein g/mZ-Deletionsstamm (Z40) und ein $\Delta g / m Z \Delta[p t s N-O]$-Stamm (Z43) mit chromosomaler glmS-lacZ-Reporterfusion wurden mit einem Plasmid transformiert, welches $g / m Z$ unter Kontrolle des induzierbaren $\mathrm{P}_{\text {Ara }}$-Promotors trägt (pBGG 84). Die Transformanten wurden unter Induktion mit $0,2 \%(\mathrm{w} / \mathrm{v})$ L-Arabinose in LB-Medium (siehe 3.2.1.) bei $37 \mathrm{C}^{\circ}$ auf einem Horizontalschüttler inkubiert, bis eine $\mathrm{OD}_{600}$ von 0,6 erreicht wurde und die Aktivität der Reporterfusion wurde wie unter 3.3.4. beschrieben bestimmt.

Die Expression des plasmidständigen $\mathrm{g} / \mathrm{m} Z$ komplementiert die Deletion des chromosomalen $g / m Z$ vollständig und rekonstituiert die hohe Reporteraktivität im $\Delta g \operatorname{lm} Z \Delta[p t s N-O]$-Hintergrund. Zugleich induziert die glmZ-Expression vom Plasmid aus auch im Wildtyp eine leicht erhöhte Reporteraktivität in Anwesenheit von yhbJ. 
4.1.3. Die Expression von $g \operatorname{lm} Z$ ist nicht durch YhbJ beeinflusst oder autoreguliert

Um das Verhältnis von GlmZ und YhbJ weiter zu klären, wurde der Einfluß von YhbJ auf die Expression von glmZ sowie eine mögliche Autoregulation von GlmZ untersucht. Hierzu wurde eine plasmidständige $g \operatorname{lm} Z^{\prime}$-lacZ-Reporterfusion generiert (pBGG59, siehe Tabelle 7.2.) und ihre Aktivität in entsprechenden Deletionsstämmen untersucht (siehe Abb. 4.6.).

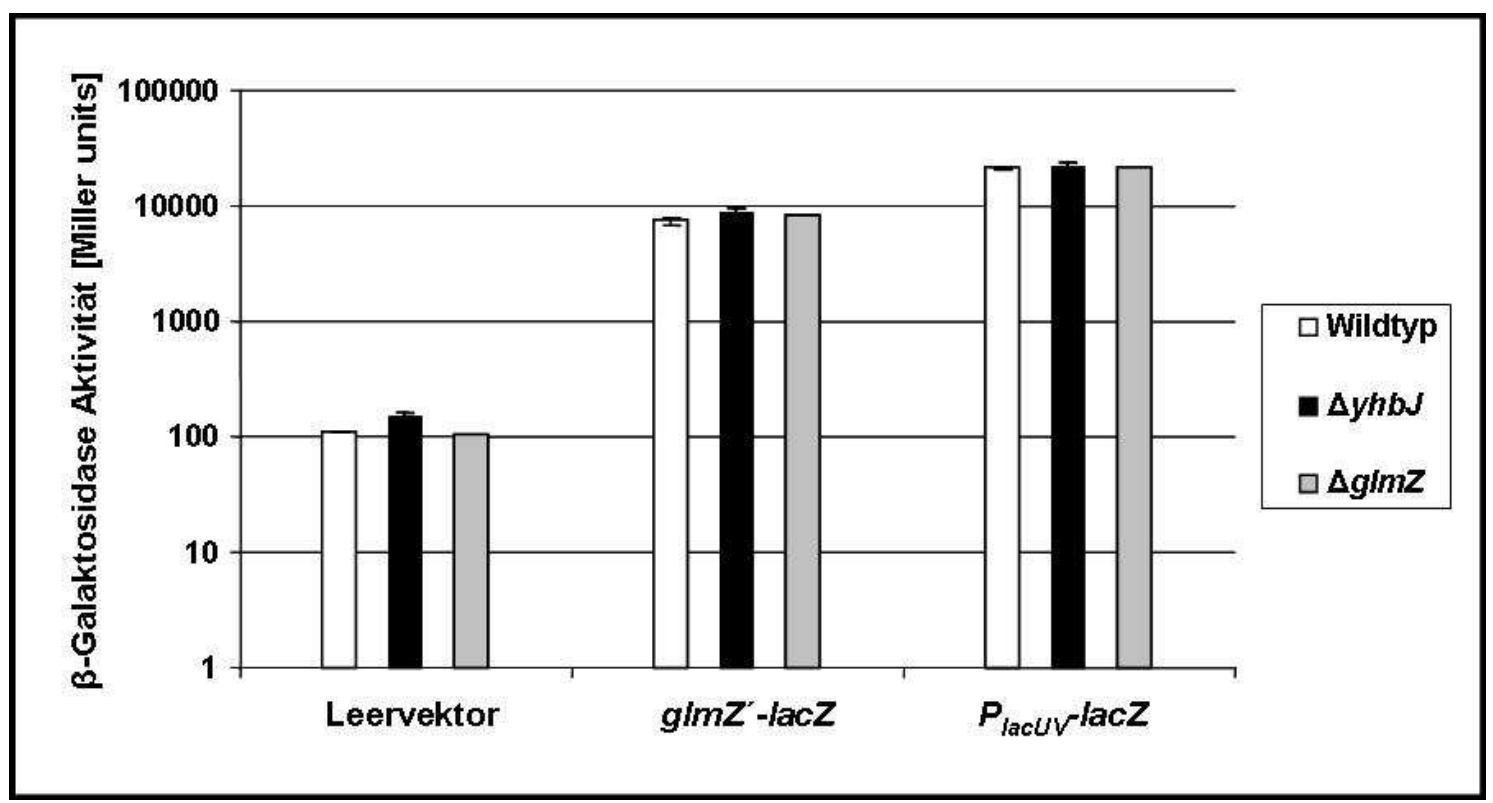

Abb. 4.6.: Untersuchung zur Expression von $g / m Z$

Der Wildtyp R1279 sowie die Stämme $\Delta y h b J$ (Z37) und $\Delta g / m Z$ (Z45) wurden mit den Leervektor (pKEM04, Negativkontrolle), einem PlacuvlacZ-tragenden Plasmid (pKEM99, Positivkontrolle) und einem Plasmid mit der glmZ'-lacZ-Reporterfusion (pBGG59) transfomiert und in LBMedium inkubiert, bis eine $\mathrm{OD}_{600}$ von 0,6 erreicht wurde. Anschließend wurde die $\beta$ Galaktosidase-Aktivität bestimmt (siehe 3.3.4.).

Es ist keinerlei Effekt einer Deletion von yhbJ oder $g / m Z$ selbst auf die Akivität der glmZ'-lacZReporterfusion messbar.

Vergleicht man die Werte der glmZ'-lacZ-Aktivität in Wildtyp mit dem $\Delta y h b J$ - und $\Delta g \operatorname{lmZ}$-Hintergrund, so zeigt sich keinerlei Effekt der Deletionen auf die Expression der glmZ'-lacZ-Reporterfusion.

Somit kann ausgeschlossen werden, dass die Wirkung von YhbJ auf die Regulation der GlmS-Expression auf einer Beeinflussung der Expression von $g \operatorname{lm} Z$ beruht.

Ebenso kann eine Autoregulation der Expression durch GlmZ ausgeschlossen werden. 


\subsubsection{Die Rolle von Hfq in der Regulation der $g \operatorname{lm} S$-Expression}

Für die kleine, nicht-kodierende RNA GlmZ ist beschrieben, dass sie mit dem Protein Hfq interagieren kann (Wassarman et al. 2001). Hfq bindet bevorzugt an U/A-reiche, einzelsträngige RNA-Sequenzen in der Nähe von Haarnadelstrukturen. Zudem ist es ein wichtiger Faktor in der posttranskriptionellen Regulation der Genexpression: Es bindet sRNAs und stabilisiert deren Interaktion mit ihren Ziel-mRNAs (Brennan und Link 2007). Somit stellte sich die Frage, ob Hfq einen Einfluss auf die Regulation der glmSExpression durch GlmZ hat.

Hierzu wurden Western Blot-Analysen (siehe 2.7.7.) mit Antikörpern gegen GlmS durchgeführt, in denen ein $h f q$-defekter Stamm ( $h f q-1)$ (Tsui et al. 1994)in An- und Abwesenheit von $y h b J$ untersucht wurden (siehe Abb. 4.7.) In diesen Stämmen ist das Gen für Hfq durch Insertion einer Resistenzkassette inaktiviert. Da $h f q$ das erste Gen im hfq-hflYCK-Operon ist (GOA et al. 2001), könnte diese Insertion zu polaren Effekten auf die stromabwärts gelegenen Gene führen. Deshalb wurden parallel Stämme mit dem $h f q$-2-Allel verwendet, in dem die Resistenzkassette am 3' -Ende des $h f q$-Gens inseriert ist. Dadurch kann ein funktionales Hfq-Protein hergestellt werden, jedoch wirken dieselben möglichen polaren Effekte auf die stromabwärts gelegenen Gene wie im $h f q$ 1-Allel. So kann überprüft werden, ob die beobachteten Effekte auschließlich auf der Inaktivierung von $h f q$ beruhen .

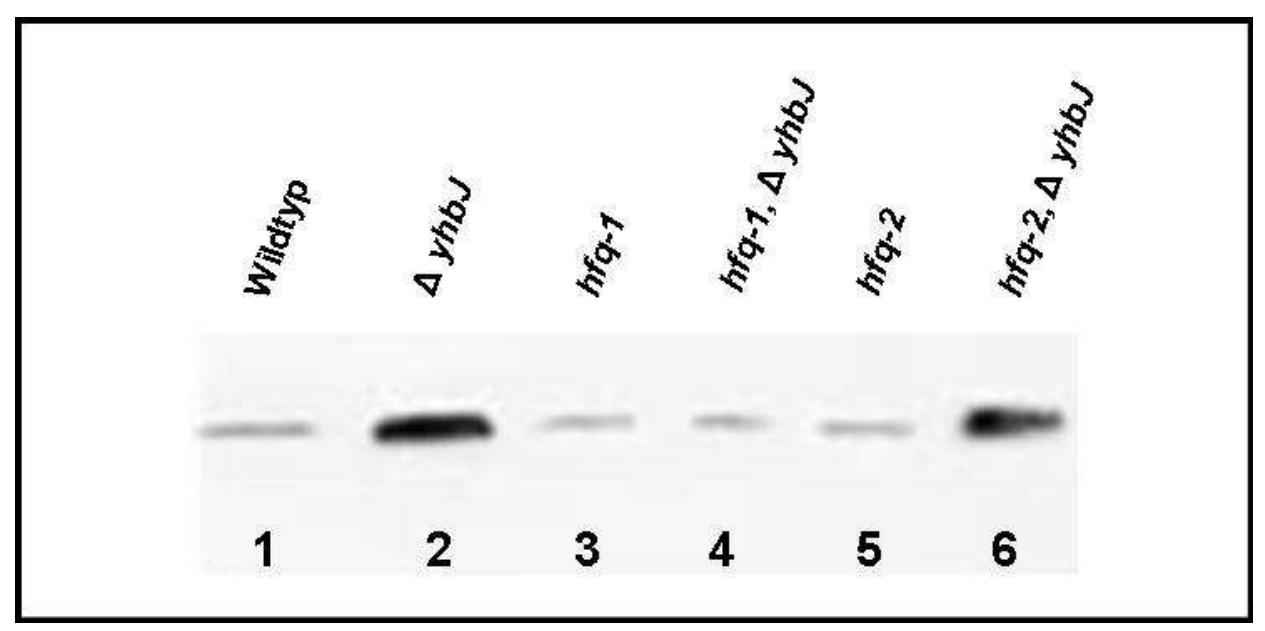

Abb. 4.7.: Analyse der GImS-Menge in Abhängigkeit von Hfq.

Der Wildtyp R1279 und die Stämme $\Delta y h b J$ (Z24), hfq-1 (Z60), $\Delta y h b J ~ h f q-1$ (Z61), hfq-2 (Z62) und $\Delta y h b J$ hfq-2 (Z63) wurden in LB-Medium inkubiert bis eine $O_{600}$ von 0,6 erreicht wurde. Anschließend wurden Gesamtzellextrakte hergestellt (siehe 3.7.1.) und wie unter 3.7.7. beschrieben eine Western Blot Analyse unter Verwendung polyklonaler Antikörper gegen GImS durchgeführt.

Während sich die Kontrollstämme mit $h f q-2-A l l e l$ wie der Wildtyp verhalten und in Abwesenheit von yhbJ eine deutlich erhöhte GlmS-Menge aufweist, ist in den Stämmen mit dem inaktiven hfq-1-Allel selbst in Abwesenheit von yhbJ keine erhöhte GImS-Expression zu beobachten. 
In Abb. 4.7. ist im Vergleich von Spur 1 und 2 die Akkumulation von GlmS in Abwesenheit von YhbJ erkennbar. Die Kontrollstämme $h f q-2$ und $h f q-2 \Delta y h b J$ zeigen dasselbe Verhalten wie der Wildtyp und ein $\Delta y h b J$-Stamm (vergleiche Abb. 4.7. Spur 1 und 2 mit Spur 5 und 6). Im Stamm $h f q-1$, in dem $h f q$ durch Insertion der Resistenzkassette inaktiviert wurde, ist die intrazelluläre Menge von GlmS mit der des Wildtyps vergleichbar (vergleiche Spur 1 und 3). Eine Deletion von $y h b J$ im $h f q-2-$ Stamm zeigt jedoch keine Erhöhung der GlmS-Menge in der Zelle, die Stärke des detektierbaren Signals entspricht ebenfalls der des Wildtyps.

Dies zeigt, dass funktionales $\mathrm{Hfq}$ für die verstärkte glmS-Expression in E. coli erforderlich ist. Ein wahrscheinlicher Mechanismus an dieser Stelle ist die Stabilisierung der sRNA/mRNA-Interaktion durch Hfq.

\subsubsection{Die Rolle von RNase E in der Regulation der $g \operatorname{lmS}$-Expression}

Vorherige Analysen des $g l m S$-spezifischen Transkriptes durch Primer-Extension zeigten, dass der Startpunkt des Transkriptes mit dem Stopcodon von glmU übereinstimmt (siehe 1.3.5.). Zudem wurde beschrieben, dass in einer Deletion des Genes $p c n B$, welches für die Poly(A)-Polymerase PAP I kodiert, ebenfalls ein glmSspezifisches Transkript akkumuliert, welches durch die Prozessierung des ursprünglichen glmUS-Transkriptes am 3'-Ende von $g \operatorname{lm} U$ durch RNase E ensteht (Joanny et al. 2007).

Um nun zu untersuchen, ob die hier beobachtete spezifische Prozessierung des primären glmUS-Transkriptes sowie die daraus resultierende Erhöhung der GlmS-Menge in der Zelle in Abwesenheit von YhbJ ebenfalls von RNase E abhängig ist, wurden Western Blot-Analysen (siehe 3.7.7.) mit Antikörpern gegen GlmS durchgeführt (siehe Abbildung 4.8). Da RNase E in E. coli ein essentielles Gen darstellt (Gerdes et al. 2003), wurde auf einen Stamm mit dem temperatursensitiven rne3071(ts)-Allel und dem Kontroll-Allel $r n e^{+}$(Goldblum und Apririon 1981) zurückgegriffen. Das Allel rne3071(ts) kodiert für eine Variante der RNase E, die durch eine Erhöhung der Temperatur auf der Protein-Ebene inaktiviert wird. Im Gegensatz zur temperatursensitiven Kontrolle der Transkription, bei der die Zellen nach der Erhöhung langsam an dem entsprechenden Genprodukt verarmen, handelt es sich hierbei um ein sofortiges und vollständiges Ausschalten der RNase E-Aktivität.

Die Stämme wurden bei $30^{\circ} \mathrm{C}$ in LB-Medium (siehe 2.2.1.) inkubiert, bis eine $\mathrm{OD}_{600}$ von 0,3 erreicht wurde. Daraufhin wurden die Kulturen geteilt: Eine Hälfte wurde 
weiterhin bei $30^{\circ} \mathrm{C}$ inkubiert, was eine fortlaufende Aktivität der temperatursensitiven RNase E erlaubte, während die andere Hälfte bei der in dieser Hinsicht restriktiven Temperatur von $44^{\circ} \mathrm{C}$ inkubiert wurde.

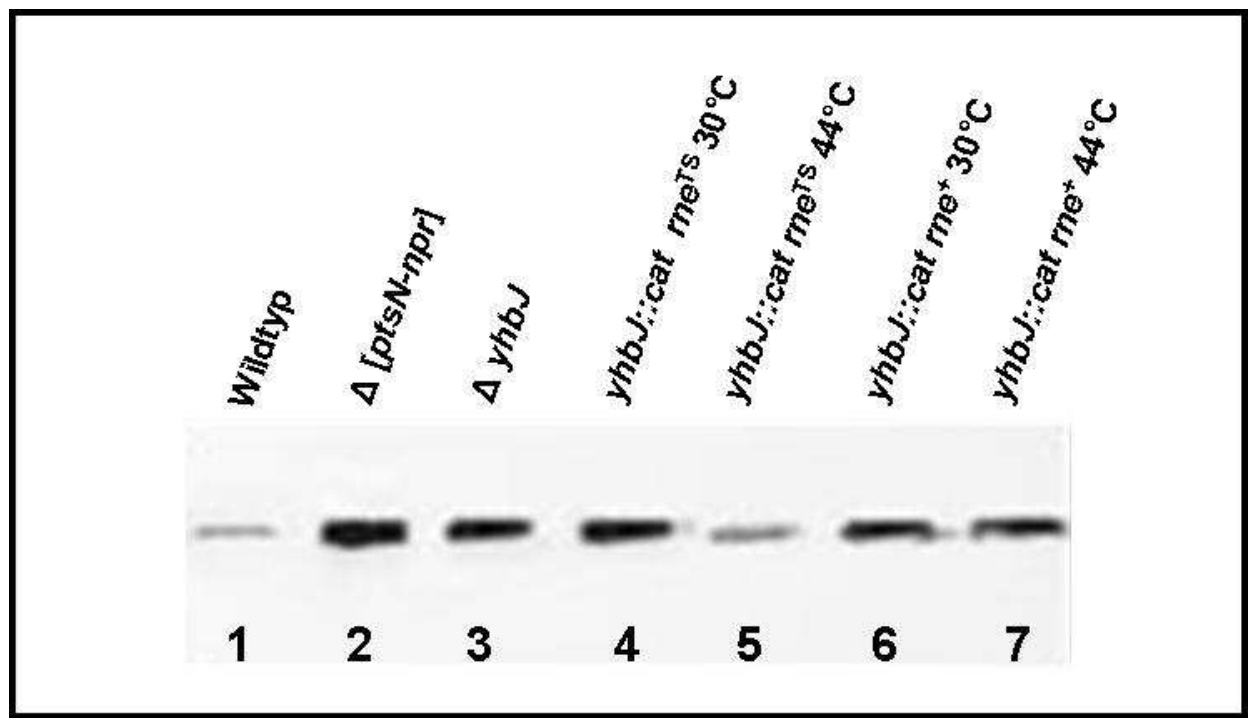

Abb 4.8: Analyse der glmS-Expression in Abhängigkeit von Rnase $\mathrm{E}$

Der Wildtyp (R1279) sowie die Stäme $\Delta[p t s N-n p r]$ (R2413), $\Delta y h b J(Z 24), r n e^{T S}$ yhbJ::cat (Z52) und $r n e^{+}$yhbJ::cat (Z53) wurden wie unter 4.1.5. beschrieben in LB-Medium inkubiert. Anschließend wurden Gesamtzellextrakte hergestellt (siehe 3.7.1.) und wie unter 3.7.7. beschrieben eine Western Blot Analyse unter Verwendung polyklonaler Antikörper gegen GlmS durchgeführt.

Während sich die Kontrollstämme mit $r n e^{+}$-Allel wie der Wildtyp verhalten und in Abwesenheit von yhbJ eine deutlich erhöhte GlmS-Menge aufweist, ist in den Stämmen mit dem temperatursensitiven $r n e^{T S}$-Allel bei restriktiver Temperatur eine deutlich geringere GlmSExpression zu beobachten.

Wie in Abb. 4.8. Spur 1 bis $3 \mathrm{zu}$ sehen, weisen auch hier der $\Delta y h b J$ - beziehungsweise $\Delta[p t s N-O]$-Deletionsstamm eine deutlich höhere GlmS-Menge auf als der Wildtyp. Der Kontrollstamm mit einer $y h b J$-Deletion und dem $r n e^{+}$-Allel verhält sich wie eine $y h b J$ Deletion im Wildtyp mit dem nativem rne-Allel, und zwar sowohl bei $30^{\circ} \mathrm{C}$ wie auch bei $44^{\circ} \mathrm{C}$ (vergleiche Spur 2 mit 6 und 7).

Ein Stamm mit dem rne3071(ts)-Allel im $\Delta y h b J$-Hintergrund verhält sich bei der nichtrestriktiven Temperatur von $30^{\circ} \mathrm{C}$ ebenfalls wie eine $y h b J$-Deletion mit dem nativen rne-Allel. Nach einer Erhöhung der Temperatur auf $44^{\circ} \mathrm{C}$ hingegen, wenn eine weitere Aktivität von RNase E verhindert wird, zeigt sich eine deutliche Abnahme der GlmSMenge im Vergleich zur Inkubation bei $30^{\circ} \mathrm{C}$ (vergleiche Spur 4 und 5) sowie auch im Vergleich zur yhbJ-Deletion mit nativer RNase E oder dem $r n e^{+}$-Allel (vergleiche Spur 5 mit 2 respektive 6 und 7). Zudem kann unter diesen Umständen ein weiteres Signal in einer Northern Blot Analyse mit einer Sonde gegen $\operatorname{glmS}$ detektiert werden, dessen Größe mit dem glmUS-Primärtranskript korrespondiert (Kalamorz et al. 2007). 
Demnach ist die erhöhte GlmS-Menge in einem $\Delta y h b J$-Hintergrund zurückzuführen auf die Akkumulation eines $g \operatorname{lm} S$-spezifischen Transkriptes, welches durch die Prozessierung der primären $g \operatorname{lm} U S$-mRNA durch RNase E generiert wird.

\subsection{Identifikation des Signals}

Bislang konnte gezeigt werden, dass die Expression von $\operatorname{glm} S$ durch einen Prozess reguliert wird, an dem neben Hfq und RNase E vor allem die sRNA GlmZ und das Protein YhbJ beteiligt sind. Die stark erhöhte GlmS-Expression konnte aber bis zu diesem Punkt exklusiv in der artifiziellen Situation der vollständigen Abwesenheit eines funktionalen $y h b J$-Gens gezeigt werden. Es stellt sich somit die Frage, welche natürlich vorkommenden Bedingungen $\mathrm{zu}$ einer Aktivierung dieses Regulationsmechansimus führen und welches Signal zu diesem Zweck detektiert wird.

\subsubsection{Die Inaktivierung von GlmS führt zu einer verstärkten Aktivität der glmS-lacZ-}

\section{$\underline{\text { Reporterfusion }}$}

Wie bereits unter 4.1.1. beschrieben resultierte die Transposonmutagenese im WildtypStamm Z8 unter Anderem in drei Mutanten, die Insertionen in oder nahe des glmS-Gens trugen. Eine Messung der Aktivität der glmS-lacZ-Reporterfusion in diesen Stämmen ergab eine erhöhte Aktivität, die etwa $20-45 \%$ der Aktivität einer $y h b J$-Deletion ausmachte (vergleiche Abb. 4.9.A Balken 1 und 2 mit Balken 3 bis 5).

Die anschließende Analyse der in der Zelle vorhandenen Menge an GlmS mittels Western Blot Analyse (siehe 3.7.7.) zeigte, dass die Transposonmutanten in der Lage sind, GlmS zu synthetisieren, jedoch in deutlich geringeren Mengen als der Wildtyp (vergleiche Abb. 4.9.B Spur 1 mit 3, 4 und 5).

Aus diesen Beobachtungen lässt sich folgern, dass die Insertion der Transposons nahe dem Startpunkt von $g \operatorname{lm} S$ die Menge an Protein in der Zelle herabsetzt, was im Gegenzug eine Aktivierung der Expression der glmS-lacZ-Reporterfusion nach sich zieht. 


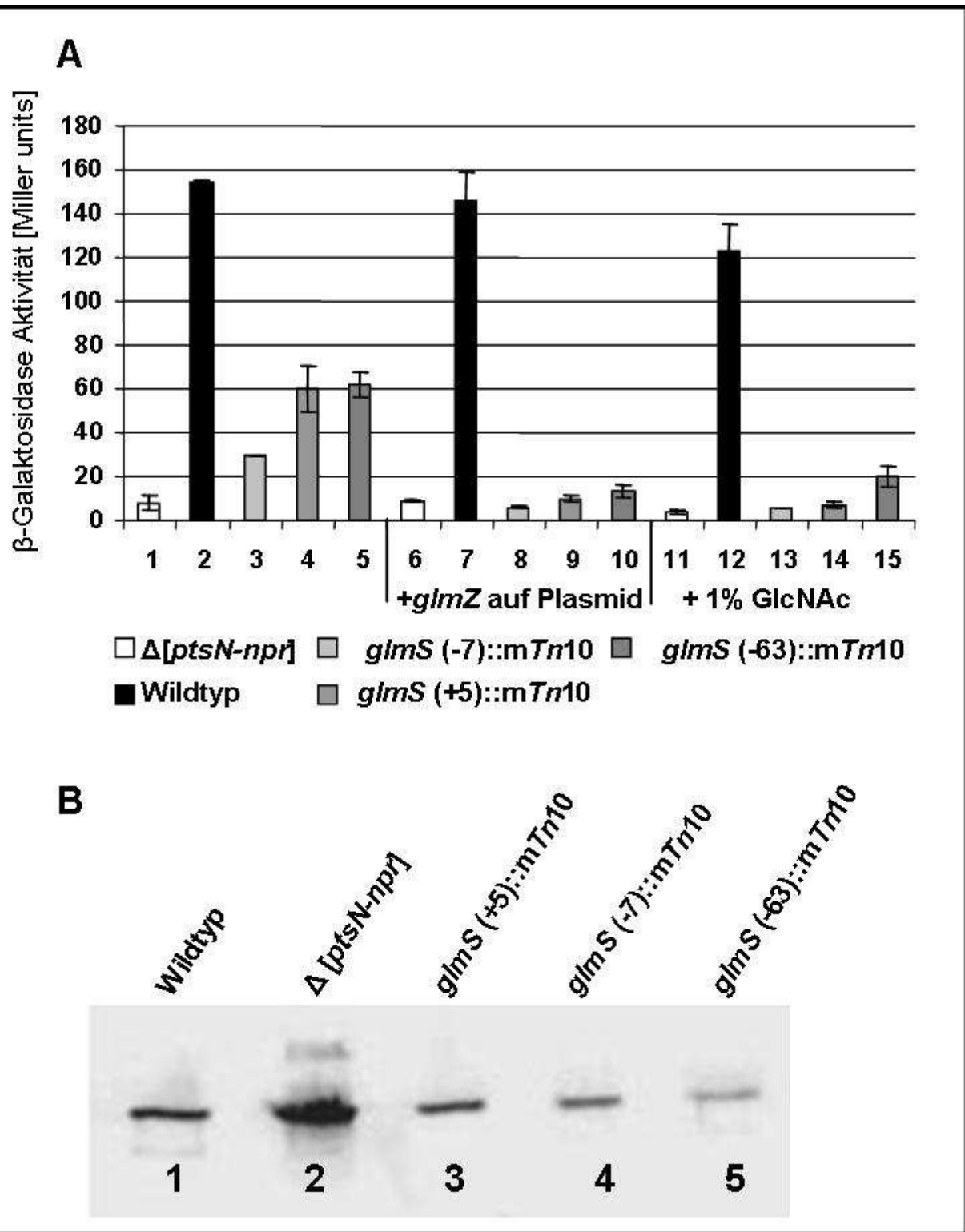

Abb. 4.9.: Eine Reduktion der GImS-Synthese erhöht die Aktivität der gImS-lacZ-Reporterfusion.

(A) Der Wildtyp mit chromosomaler glmS'-lacZ-Reporterfusion (Z8), ein korrespondierender $\Delta[$ pts N-npr]-Stamm (Z5) sowie die drei Transposonmutanten mit Insertionen in oder nahe glmS (Z8 TM1, Z8 TM2 und Z8 TM3, siehe Tab.4.1.) wurden in LB-Medium bei $37^{\circ} \mathrm{C}$ auf einem Horizontalschüttler inkubiert, bis eine $\mathrm{OD}_{600}$ von 0,6 erreicht wurde. Ausserdem wurden die Stämme mit einem Plasmid transformiert, welches $\mathrm{g} / \mathrm{mZ}$ unter Kontrolle des induzierbaren $\mathrm{P}_{\text {tac }^{-}}$ Promotors trägt und wie beschrieben in LB-Medium mit $1 \mathrm{mM}$ IPTG inkubiert.

Zusätzlich wurden die genannten Stämme in LB-Medium mit 1\% (w/v) GlcNAc inkubiert.

Die $\beta$-Galaktosidase-Aktivität der glmS-lacZ-Reporterfusionen unter diesen Bedingungen wurde wie unter 3.3.4. beschrieben bestimmt.

Die erhöhte Aktivität der Reporterfusion in den Transposonmutanten kann sowohl durch g/mZExpression von einem Plasmid aus als auch durch die Zugabe von GlcNAc aufgehoben werden.

(B) Western Blot Analyse (siehe 2.7.7.) unter Verwendung polyklonaler Antikörper gegen GlmS. Es wurden Rohzellextrakte der oben genannten Stämme und Mutanten verwendet, die unter den gleichen Bedingungen inkubiert wurden. Eine [pts $N$-npr]-Deletion führt zu einer stark erhöhten GlmS-Menge in der Zelle. Im Gegensatz hierzu ist die Proteinkonzentration in den Transposonmutanten geringer als im Wildtyp. Die Insertionen reduzieren demnach die Expression des chromosomal kodierten glmS, machen sie aber nicht unmöglich. 
Um zu prüfen, ob die verringerte Menge an GlmS in der Zelle die Ursache für die Erhöhung der Reporteraktivität ist, wurden die Transposonmutanten mit plasmidisch kodierten $g \operatorname{lm} S$ (pBGG56, siehe Tabelle 7.2.) komplementiert. Dies resultierte in einer deutlichen Absenkung der Reporteraktivität auf Werte nahe denen des Wildtyps (vergleiche Abb. 4.9.A Balken 8-10 mit Balken 3-5 sowie mit Balken 7).

Dies lässt zwei Alternativen zu: Entweder ist die direkte Präsenz einer bestimmten Menge GlmS in der Zelle erforderlich, um die eigene Expression zu reprimieren (beispielsweise durch direkte Interaktion mit einem anderen an der Regulation beteiligten Faktor), oder die enzymatische Aktivität (und somit in Konsequenz die Menge an Glukosamin-6-Phosphat oder eines Metabolites stromabwärts davon) ist ausschlaggebend für die Stärke der Expression. Um dies zu prüfen wurden die Transposonmutanten in Medium inkubiert, welchem 1\% (w/v) GlcNAc zugesetzt wurde. Dieses kann über NagE und den ManXYZ-Transporter in die Zelle aufgenommen und auf der Ebene von GlcN-6-P in den Syntheseweg der ZellwandVorläufer eingespeist werden (Alvarez-Anorve et al. 2005), wodurch die Aktivität von GlmS überflüssig wird (siehe 2.3.1.).

Unter diesen Bedingungen zeigten die Transposonmutanten eine vollständige Reprimierung der Reporteraktivität auf das Niveau des Wildtyps (vergleich Abb. 4.8.A Balken 13-15 mit Balken 3-5 beziehungsweise mit 2 und 12).

Um die Abhängigkeit der erhöhten Aktivität der glmS-lacZ-Reporterfusion von einer verringerten enzymatischen GlmS-Aktivität zu bestätigen, wurden ein $\Delta g \operatorname{lm} S$-Stamm (IBPC750) und sowie der korrespondierende Wildtyp IBPC5321 ((Plumbridge und Vimr 1999), siehe Tabelle 7.1.) verwendet. Unter den meisten Bedingungen ist die Aktivität von GlmS essentiell für die Zelle, und eine Mutation von $g \operatorname{lm} S$ wirkt letal. Da E. coli jedoch in der Lage ist, Aminozucker aus dem Medium aufzunehmen und zu verwerten (siehe 2.3.), kann eine Zugabe von $1 \%$ (w/v) GlcNAc die Letalität einer glmS-Deletion aufheben.

Die beiden Stämme wurden mit einer plasmidständigen Version der glmS-lacZReporterfusion (pBGG16, siehe Tabelle 7.2.) transformiert (siehe 3.3.3.) und in LBMedium mit $1 \%$ GlcNAc inkubiert, bis eine $\mathrm{OD}_{600}$ von 0,3 erreicht wurde. $\mathrm{Zu}$ diesem Zeitpunkt $\left(\mathrm{t}_{0}\right)$ wurden die Kulturen aufgeteilt, für 5 Minuten bei Raumtemperatur und $5000 \mathrm{rpm}$ zentrifugiert und die Pellets in ZAP gewaschen. Nach einer weiteren Zentrifugation wie zuvor wurden die Pellets entweder in LB-Medium oder in LBMedium mit $1 \%$ Glukosamin gelöst und die $\mathrm{OD}_{600}$ bestimmt. Die so geteilten Kulturen 
wurden weiter bei $37^{\circ} \mathrm{C}$ auf dem Horizontalschüttler inkubiert und stündlich die $\mathrm{OD}_{600}$ bestimmt sowie Proben für $\beta$-Galaktosidase Assays entnommen (siehe 3.3.4.). Die Ergebnisse sind in Abb. 4.10. dargestellt.

Der $\Delta g l m S$-Stamm zeigt beim Wachstum in LB-Medium mit $1 \%$ GlcNAc keinerlei Beeinträchtigung gegenüber dem Wildtyp. In Medium ohne eine externe Aminozuckerquelle hingegen verlangsamt sich das Wachstum nach $2 \mathrm{~h}$ deutlich (siehe Abb. 4.10. Zeitpunkt 2), und nach $3 \mathrm{~h}$ kommt es zu einer Verringerung der $\mathrm{OD}_{600}$ durch Absterben der Bakterien (siehe Abb. 4.10. Zeitpunkt 3). Parallel zur Abnahme der $\mathrm{OD}_{600}$ ist eine starke Expression der $g \operatorname{lmS}$-lacZ-Reporterfusion zu beobachten, die schließlich einen neunfach höheren Wert im Vergleich zum Wildtyp oder der glmSDeletion in LB mit 1\% GlcNAc erreicht (siehe Abb. 4.10. Zeitpunkt 6).

Zusammenfassend zeigt dies, dass die verringerte enzymatische Aktivität von GlmS und die dadurch verursachte Verarmung an Metaboliten der Zellwand-Vorläufer eine erhöhte Aktivität der glmS-lacZ-Reporterfusion bedingt.

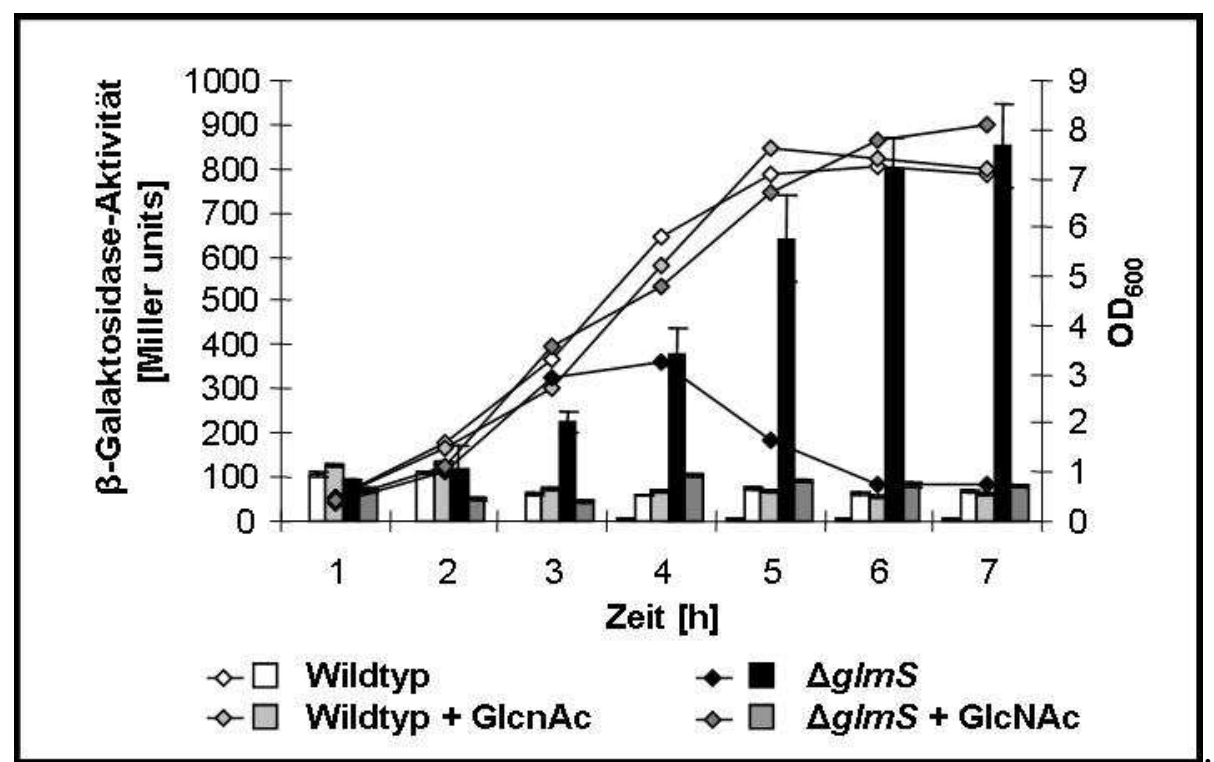

Abb. 4.10.: Verarmung von GImS führt zu verstärkter Aktivität der glmS'-lacZReporterfusion

Ein $\Delta g / m S$-Stamm (IBPC750) und der korrespondierende Wildtyp (IBPC5321) wurden mit dem Plasmid pBGG16 transformiert, welches eine glmS'-lacZ-Reporterfusion trägt. Die Transformanten wurden in LB-Medium mit $1 \%(\mathrm{w} / \mathrm{v})$ GlcNAc inkubiert, bis sie eine $\mathrm{OD}_{600}$ von 0,3 erreichten. Die Kulturen wurden geteilt und in An- und Abwesenheit von GlcNAc inkubiert. Nach diesem Zeitpunkt $t_{0}$ wurde stündlich die optische Dichte bestimmt sowie Proben für die Messung der $\beta$-Galaktosidase-Aktivität (siehe 3.3.4.) genommen.

Während der Wildtyp und die Mutante in Medium mit GlcNAc weder eine erhöhte Reporteraktivität noch einen Wachstumsedefekt aufweisen, kommt es im $\Delta g / m S$-Stamm bei Entzug der externen Aminozuckerquelle zu einem starken Anstieg der Aktivität der glmS'-lacZReporterfusion und nach $3 \mathrm{~h}$ zu einer Abnahme der Zelldichte. 
Weder die plasmidische Expression von GlmS noch der Zusatz von GlcNAc zum Medium hat einen Einfluß auf die Aktivität der glmS-lacZ-Reporterfusion in Abwesenheit von $y h b J$ (vergleiche Abb. 4.9.A Balken 1, 6 und 11), was darauf hinweist, dass YhbJ stromabwärts des Signal-detektierenden Faktors wirkt.

\subsubsection{Identifikation des Signal-Metabolits}

Nachdem gezeigt werden konnte, dass die Verarmung eines Metaboliten im Sytheseweg der Zellwand-Vorläufer zu einer erhöhten $g \operatorname{lm} S$-Expression führt, musste nun die entsprechende Verbindung identifiziert werden.

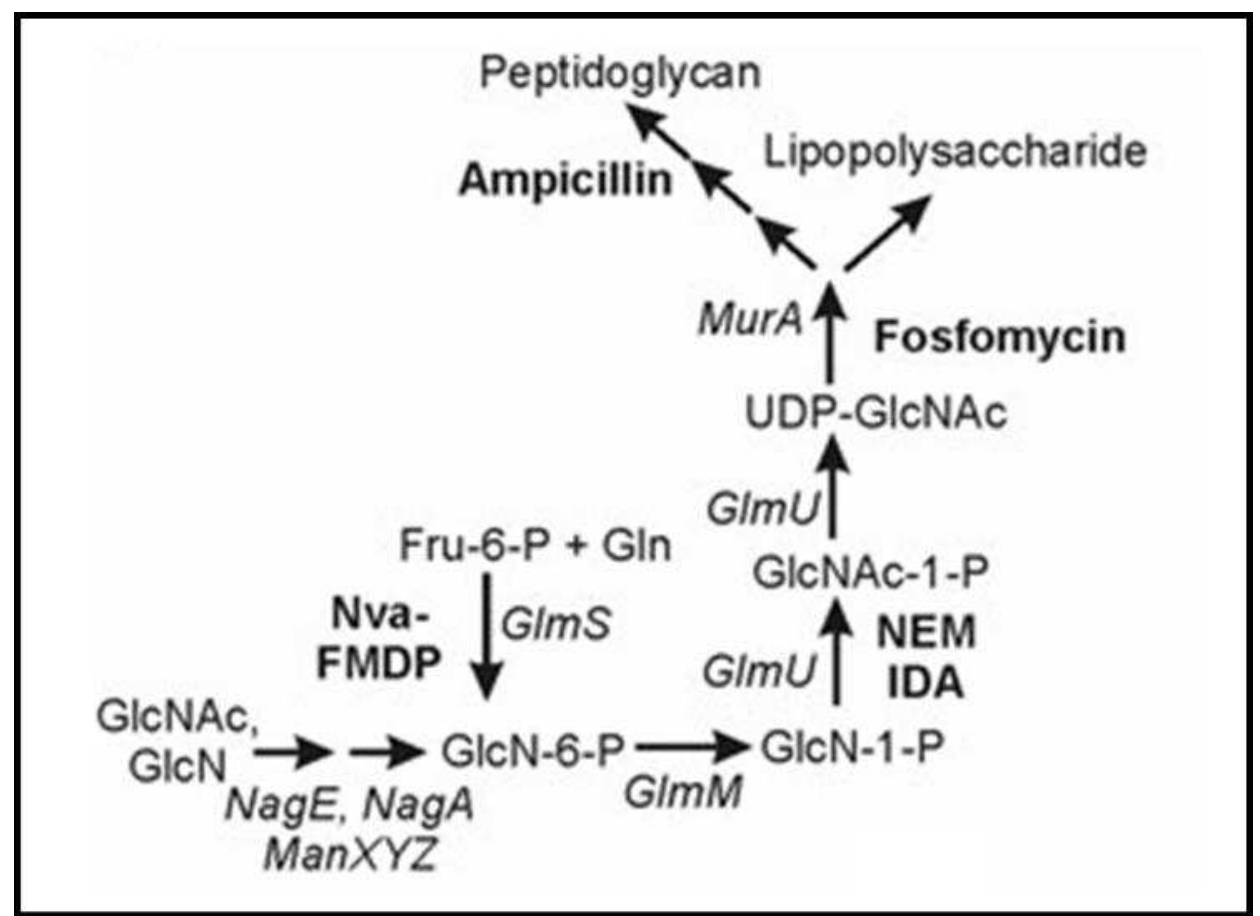

Abb. 4.11.: Anaboler Aminozuckermetabolismus in E.coli

GlcN-6-P kann entweder durch Aufnahme externer Aminozucker oder die de novo-Synthese über GlmS generiert werden. Es wird durch GlmM und GImU zu UDP-GlcNAc umgesetzt, welches der zentrale Vorläufer für den Aufbau von Peptidoglykan und Lipopolysacchariden ist. Die Enzyme, die die dargestellten Schritte katalysieren, sind kursiv gedruckt, Inhbitoren bestimmter Schritte fett.

GlcN= Glukosamin, GlcNAc= N-Acetylglukosamin, GlcN-6-P= Glukosamin-6-Phosphat, GlcN-1$\mathrm{P}=$ Glukosamin-1-Phosphat, GlcNAc-1-P=N-Acetylglukosamin-1-Phosphat, UDP-GlcNac= Uridin-5'-diphospho-N-Acetylglukosamin.

Hierzu wurden Inhibitoren verschiedener enzymatischer Schritte des Syntheseweges von Peptidoglycan eingesetzt (siehe Abb. 4.11). Nva-FMDP ist ein Derivat der N3-(4methoxyfumaroyl)-L-2,3-diaminopropanol-Säure (FMDP) und stellt einen spezifischen Inhibitor der Glukosamin-6-Phosphat Synthase GlmS und somit des initialen Schrittes 
der de novo-Synthese von Zellwand-Vorläufern dar (Marshall et al. 2003). Iodacetamid (IDA) und N-Ethylmaleimid (NEM) wirken auf die N-Acetyl-glukosamin-1-Phosphat Uridyltransferase / Glukosamin-1-Posphat Acetyltransferase GlmU und verhindert die Umwandlung von Glukosamin-1-Phosphat zu N-Acetyl-Glukosamin-1-Phosphat und weiter zu UDP-GlcNAc, welches einen der letzten gemeinsamen Vorläufer von Peptidoglycan und Lipopolysacchariden darstellt (Burton et al. 2006). Direkt stromabwärts von UDP-GlcNAc wirkt Fosfomycin durch Inhibition der UDP-GlcNAcenol-Pyruvattransferase MurA (Kahan et al. 1974). Das Enzym eines der letzten Schritte der Peptidoglycan-Synthese, die Transpeptidase, wird durch das $\beta$-LactamAntibiotikum Ampicillin inhibiert (Nguyen-Disteche et al. 1974).

Zunächst mussten subinhibitorische Konzentrationen dieser Stoffe ermittelt werden. Hierzu wurden Wachstumskurven des Wildtyps mit chromosomaler glmUS-lacZReporterfusion (Z9) aufgenommen. Der Stamm wurde mit aufsteigenden Konzentrationen der Wirkstoffe inkubiert (siehe Abb. 4.12.).
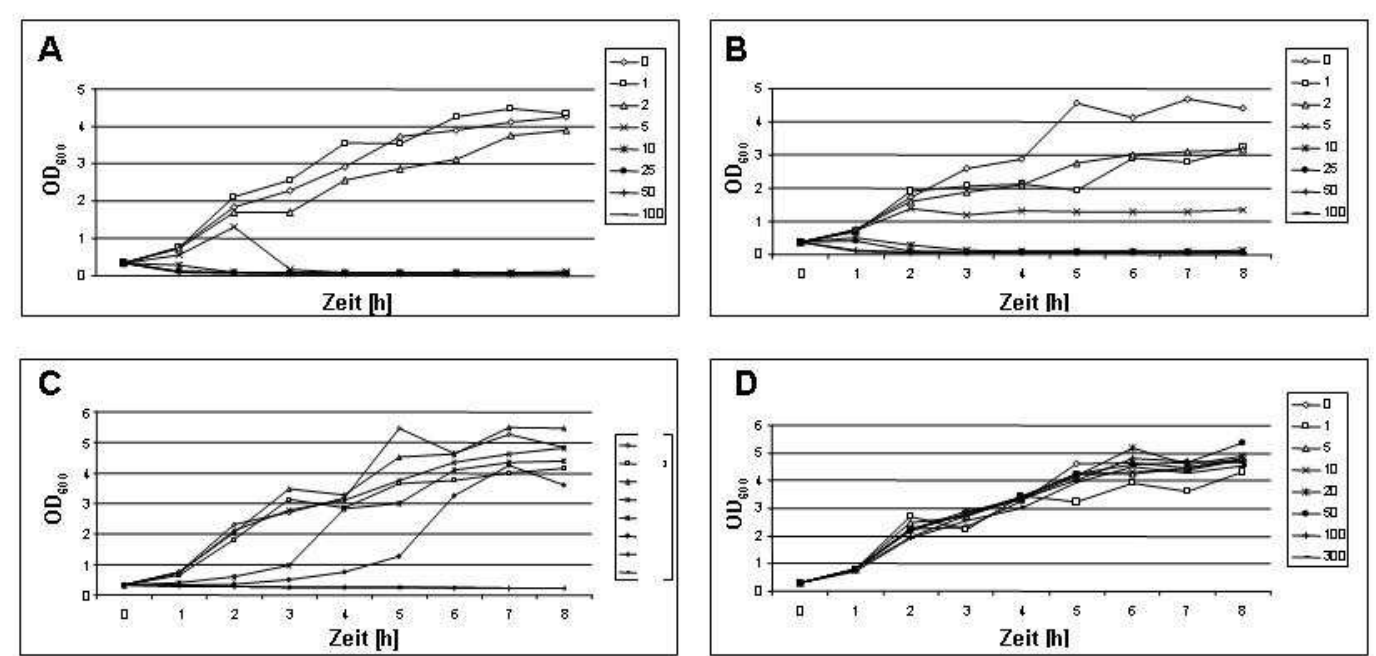

Abb. 4.12.: Wachstumskurven zur Bestimmung subinhibitorischer Konzentrationen von Inhibitoren des anabolen Aminozuckermetabolismus in E. coli

Der Wildtypstamm mit chromosomaler gImUS-lacZ-Reporterfusion (Z9) wurde in LB-Medium inkubiert, bis er eine $\mathrm{OD}_{600}$ von 0,3 erreichte. Die Kultur wurde daraufhin aufgeteilt und mit aufsteigenden Konzentrationen der Wirkstoffe versetzt. Die Inkubation wurde fortgesetzt und stündlich die optische Dichte der Kultur bestimmt.

(A) Fosfomycin, (B) Ampicillin, (C) N-Ethylmaleimid, (D) Nva-FMDP.

Die so ermittelten subinhibitorischen Konzentrationen, die zwar das Wachstum des Stammes deutlich beeinträchtigen, jedoch nicht letal wirken, sind: Fosfomycin $2 \mu \mathrm{g} / \mathrm{ml}$ (siehe 4.12.A), Ampicillin $2 \mu \mathrm{g} / \mathrm{ml}$ (siehe 4.12.B), N-Ethylmaleimid $10 \mu \mathrm{g} / \mathrm{ml}$ (siehe 4.12.C). Für Nva-FMDP konnte kein inhibitorischer Effekt auf das Wachstum des $E$. 
coli-Stammes Z9 festgestellt werden, selbst für eine Konzentrationen von $300 \mu \mathrm{g} / \mathrm{ml}$ (siehe 4.12.D). Übereinstimmende Wachstumskurven wurden auch für den Wildtypstamm Z8 aufgenommen, welcher eine $g \operatorname{lm} S-5$ '-lacZ-Reporterfusion trägt (Daten nicht gezeigt). Zur Untersuchung der Wirkung dieser Inhibitoren sollte nun die Aktivität der glmUS-lacZ-Reporterfusion in Anwesenheit dieser Stoffe untersucht werden. Der Stamm Z9 wurde in LB-Medium bei $37^{\circ} \mathrm{C}$ auf einem Horizontalschüttler inkubiert, bis die Kulturen eine $\mathrm{OD}_{600}$ von 0,3 erreichten. Daraufhin wurden die Kulturen aufgeteilt und sowohl den ermittelten subinhibitorischen wie auch inhibitorischen Konzentrationen der genannten Wirkstoffe ausgesetzt. Zusätzlich wurden äquivalente Mengen DMSO und EtOH verwendet, da diese Stoffe als Lösungsmittel für einen Teil der Antibiotika dienten und ein Effekt dieser Verbindungen ausgeschlossen werden sollte. Es erfolgte eine Inkubation für weitere $5 \mathrm{~h}$ bei $37^{\circ} \mathrm{C}$ auf dem Horizontalschüttler. Stündlich wurde die $\mathrm{OD}_{600}$ der Kulturen überprüft. Zusätzlich wurden zum Zeitpunkt der Aufteilung $\left(t_{0}\right)$ sowie $1 \mathrm{~h}\left(\mathrm{t}_{1}\right), 3 \mathrm{~h}\left(\mathrm{t}_{3}\right)$ und $5 \mathrm{~h}\left(\mathrm{t}_{5}\right)$ nach der Aufteilung Proben für $\beta$-Galaktosidase-Aktivitätsmessungen entnommen (siehe 3.3.4.). Die Ergebnisse sind in Abbildung 4.12. dargestellt.

Zunächst ist zu beobachten, dass die als subinhibitorisch bestimmten Konzentrationen von Fosfomycin und NEM bereits ein deutlich verringertes Wachstum gegenüber der unbehandelten Kultur oder den subinhibitorischen Konzentrationen der anderen Wirkstoffe verursachen (siehe Abb. 4.13.B.). Da die Kulturen jedoch weiterhin Wachstum zeigten und eine niedrigere $\mathrm{OD}_{600}$ in der Auswertung der $\beta$-GalaktosidaseAktivitätsmessung normalisiert wird, ist dieser Effekt für das Experiment vernachlässigbar. 

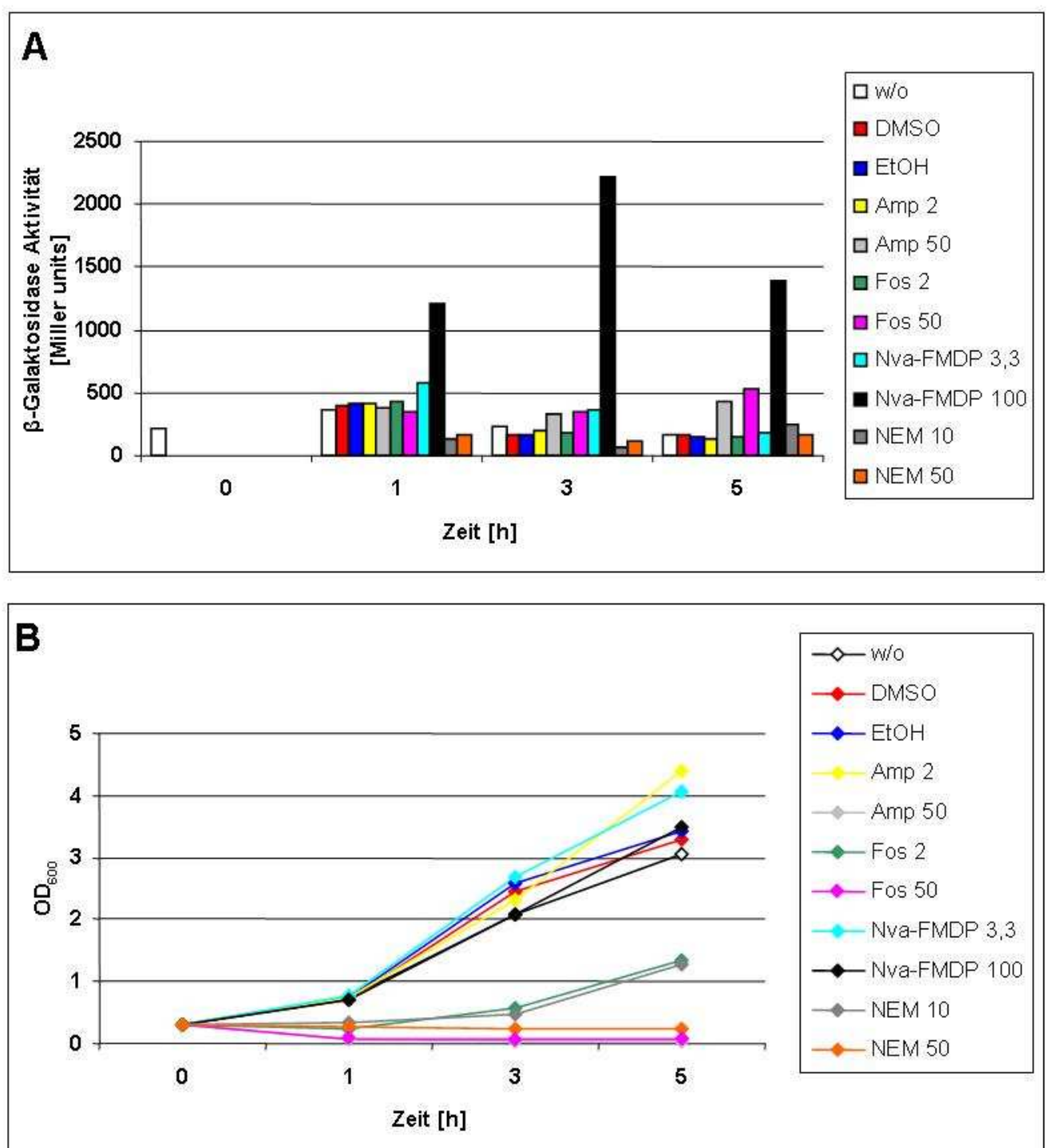

Abb. 4.13.: Effekt der Inhibition von Schritten des anabolen Aminozuckermetabolismus auf die Aktivität der glmUS-lacZ-Reporterfusion

Der Wildtyp mit chromosomaler gImUS-lacZ-Reporterfusion (Z9) wurde in LB-Medium inkubiert, bis eine $\mathrm{OD}_{600}$ von 0,3 erreicht wurde. Die Kultur wurde aufgeteilt und in Anwesenheit inhibitorischer und subinhibitorischer Konzentrationen der Wirkstoffe weiter inkubiert. Die optische Dichte wurde stündlich bestimmt. 1h, 3h und $5 \mathrm{~h}$ nach Zugabe der Wirkstoffe wurden zudem Proben zur Bestimmung der $\beta$-Galaktosidase-Aktivität genommen.

(A) Ergebnisse der $\beta$-Galaktosidase Assays. Lediglich die Zugabe hoher Konzentrationen NvaFMDP hat einen Effekt auf die Reporterfusion und führt zu einer stark erhöhten Aktivität.

(B) Wachstumskurven der Kulturen. Während NEM und Fosfomycin selbst in geringer Konzentration einen negativen Effekt auf die Wachstumsrate der Kultur haben, ist das Wachstum in Anwesenheit hoher Konzentrationen von Nva-FMDP nicht von dem einer unbehandelten Kultur zu unterscheiden.

$\mathrm{w} / \mathrm{o}=$ ohne Zugabe, $\mathrm{DMSO}=20 \% \mathrm{DMSO}, \mathrm{EtOH}=70 \%$ Ethanol, $\mathrm{Amp}=$ Ampicillin, Fos= Fosfomycin, NEM= N-Ethylmaleimid. 
Auf der anderen Seite ist anzumerken, dass selbst eine Nva-FMDP-Konzentration von $100 \mu \mathrm{g} / \mathrm{ml}$, was deutlich über der beobachteten MIC (Minimal inhibitory $\underline{\text { concentration, }}$ minimale inhibitorische Konzentration) für Candida albicans von 0,2 $\mu \mathrm{g} / \mathrm{ml}$ liegt (Milewski et al. 1991), keinen Effekt auf das Wachstum des Stammes Z9 hat (vergleiche Abb. 4.13.B.).

Weiterhin ist zu beobachten, dass die Antibiotika Fosfomycin und Ampicillin, welche Schritte stromabwärts der Generierung von UDP-GlcNAc (und somit auch stromabwärts der enzymatischen Aktivität von GlmU) inhibieren, weder in subinhibitorischer noch in inhibitorischer Konzentrationen einen Effekt auf die Expression der Reportergenfusion haben. Dasselbe Ergebnis zeigt die Bestimmung der $\beta$-Galaktosidase-Aktivität der mit NEM induzierten Kultur (vergleiche Abb. 4.13.A). Im Gegensatz dazu hat eine Behandlung der Kultur mit hohen Konzentrationen an NvaFMDP einen starken Effekt auf die Expression der Reporterfusion und führt zu einer um einen Faktor 10 erhöhten $\beta$-Galaktosidase-Aktivität (2200 Miller units gegenüber 237 Miller units in der unbehandelten Kultur zum Zeitpunkt $t_{3}$, siehe Abb. 4.13.A.).

Um den Effekt von Nva-FMDP auf die Expression der glmUS-lacZ-Reporterfusion weiter $\mathrm{zu}$ charakterisieren, wurden Kulturen des Wildtyps Z9 mit aufsteigenden Konzentrationen dieses Stoffes inkubiert (siehe Abbildung 4.14.).

Wiederum zeigt keine der eingesetzten Konzentrationen von Nva-FMDP einen inhibitorischen Effekt auf das Wachstum von Z9, jedoch ist bei der Bestimmung der $\beta$ Galaktosidase-Aktivität (siehe 3.3.4.) ein klarer Dosis-abhängiger Effekt erkennbar. 


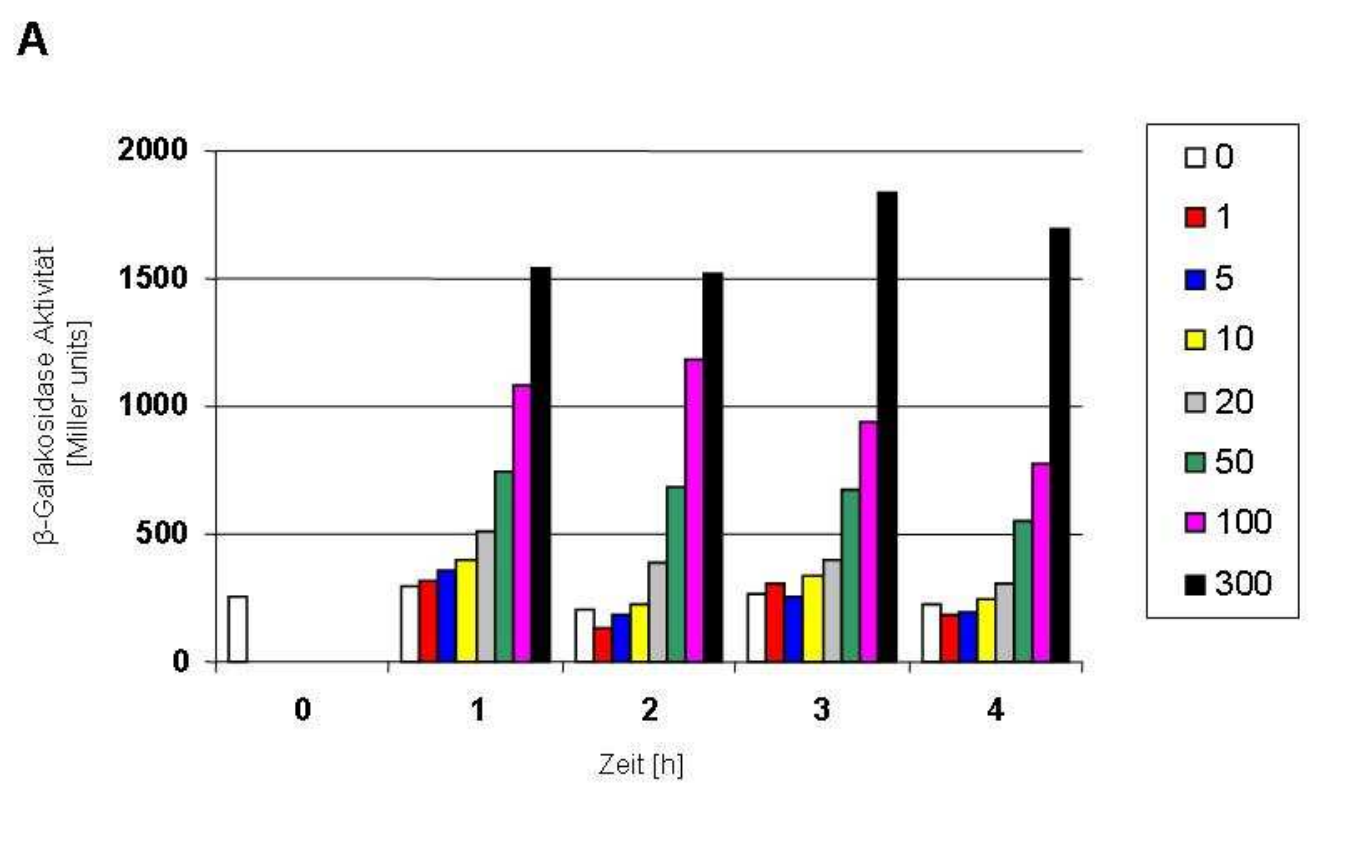

B

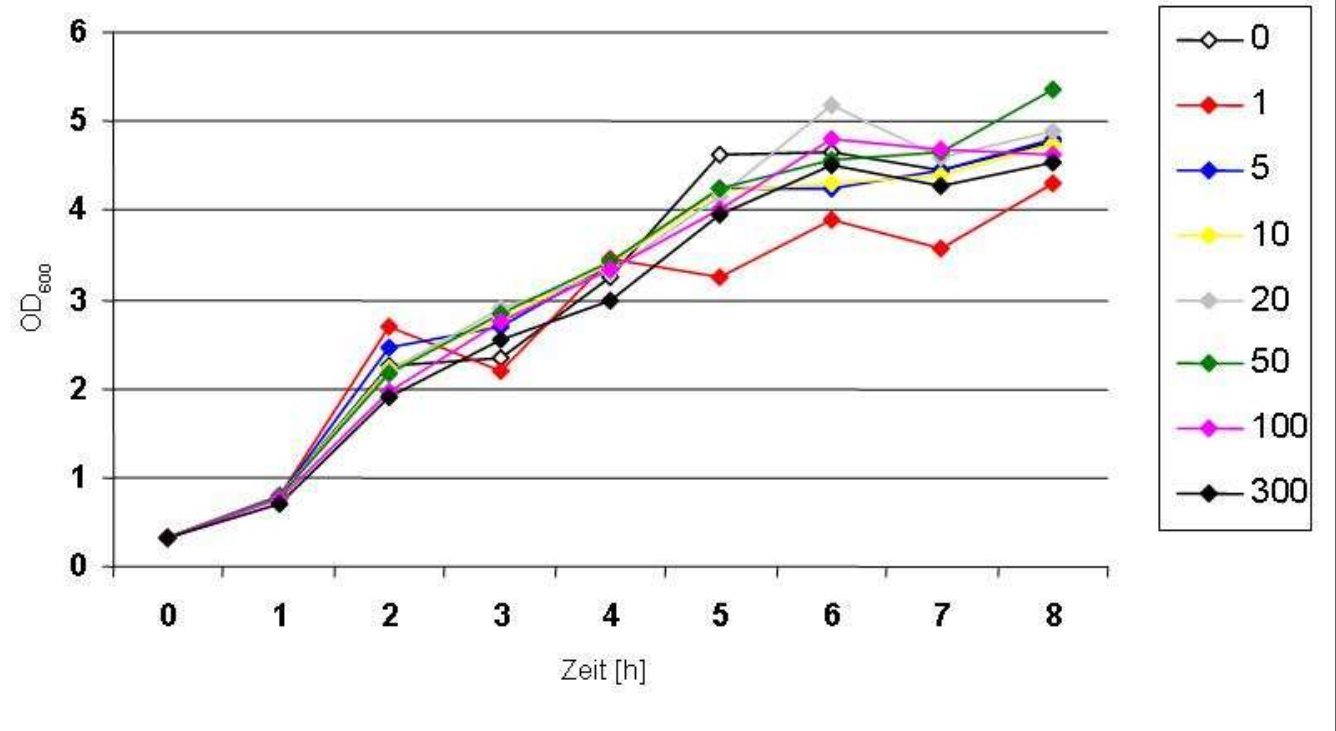

Abb. 4.14.: Dosisabhängiger Effekt von Nva-FMDP auf die Aktivität der gImUS-lacZReporterfusion

Der Wildtyp mit chromosomaler gImUS-lacZ-Reporterfusion (Z9) wurde in LB-Medium inkubiert bis er eine $\mathrm{OD}_{600}$ von 0,3 erreichte. Die Kultur wurde aufgeteilt und in Anwesenheit aufsteigender Konzentrationen von Nva-FMDP (von $0 \mathrm{mg} / \mathrm{ml}$ bis $300 \mathrm{mg} / \mathrm{ml}$ ) weiter inkubiert. Stündlich wurde die optische Dichte bestimmt und Proben zur Bestimmung der $\beta$ Galaktosidase-Aktivität (siehe 3.3.4.) genommen.

(A) Ergebnisse des $\beta$-Galaktosidase-Aktivität Assays. Zugabe von Nva-FMDP führt zu einer deutlichen und dosisabhängigen Induktion der Reporter-Aktivität.

(B) Wachstumskurven der Kulturen. Das Wachstum in Anwesenheit hoher Konzentrationen von Nva-FMDP ist nicht von dem einer unbehandelten Kultur zu unterscheiden.

Alle Konzentrationen sind in $\mu \mathrm{g} / \mathrm{ml}$ angegeben. 
Die Aktivität von GlmS ist redundant, falls eine externe Quelle für Aminozucker zur Verfügung steht (siehe 3.3.1.).

Demzufolge wurde postuliert, dass eine Zugabe von GlcNAc, welches die enzymatischen Aktivität von GlmS ersetzen kann, den aktivierenden Effekt von NvaFMDP auf die der glmUS-lacZ-Reporterfusion aufhebt. LB-Medium (siehe 2.2.1.) wurde mit dem Wildtypstamm mit chromosomaler glmUS-lacZ-Reporterfusion (Z9) inokuliert und bis zu einer $\mathrm{OD}_{600}$ von 0,3 inkubiert. Dann wurde die Kultur in drei Teile aufgespalten. Ein Teil wurde unverändert weiter inkubiert, ein Teil wie beschrieben mit $100 \mu \mathrm{g} / \mathrm{ml}$ Nva-FMDP induziert, und der dritte Teil mit $100 \mu \mathrm{g} / \mathrm{ml}$ Nva-FMDP induziert und mit 1\% (w/v) GlcNAc komplementiert (siehe Abb. 4.15.). Nach 1 h, 3 h und $5 \mathrm{~h}$ wurden Proben entnommen und die Aktivität der Reporterfusion mittels $\beta$ Galaktosidase-Assay (siehe 3.3.4.) bestimmt.

Die Aktivität des unbehandelten Wildtyp-Stammes Z9 liegt wie zuvor bereits mehrfach beobachtet bei etwa 200 Miller units (siehe Abb. 4.15. weiße Balken), während die Zugabe von Nva-FMDP, ebenfalls wie zuvor beobachtet, zu einer etwa 10fach erhöhten Aktivität nach 3 h führt (2100 Miller units, siehe Abb. 4.15. schwarze Balken).

Wird dem Stamm jedoch parallel zur Induktion mit Nva-FMDP eine externe Aminozuckerquelle in Form von GlcNAc angeboten, so ist lediglich eine $\beta$ Galaktosidase-Aktivität von 130 Miller units zu beobachten (vergleiche Abb. 4.15. graue Balken). Der reprimierende Effkt von GlcNAc gegenüber dem unbehandelten Stamm ist durch die Wirkung von externen Aminozuckerquellen auf die Promotoren vor $g \operatorname{lm} U$ zurückzuführen (vergleiche Abb. 4.15. weiße und graue Balken, siehe auch 2.3.).

Wird dem Stamm jedoch parallel zur Induktion mit Nva-FMDP eine externe Aminozuckerquelle in Form von GlcNAc angeboten, so ist lediglich eine $\beta$ Galaktosidase-Aktivität von 130 Miller units zu beobachten (vergleiche Abb. 4.15. graue Balken Balken). Der reprimierende Effekt von GlcNAc gegenüber dem unbehandelten Stamm ist durch die Wirkung von externen Aminozuckerquellen auf die Promotoren vor $g \operatorname{lm} U$ zurückzuführen (vergleiche Abb. 4.15. weiße und graue Balken, siehe auch 2.3.). 


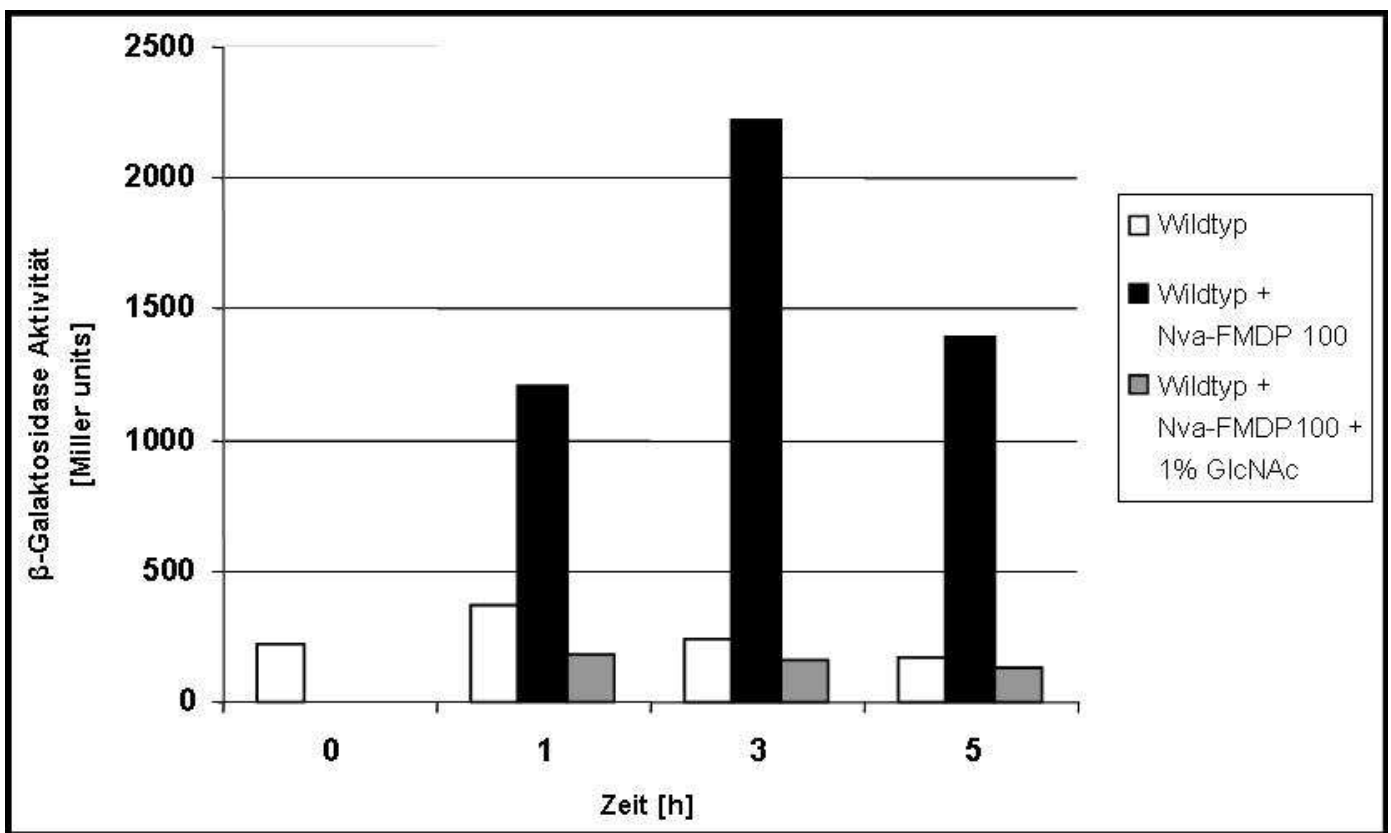

Abb. 4.15.: Die Wirkung von Nva-FMDP auf die Aktivität der gImUS-lacZ-Reporterfusion kann durch eine externe Aminozuckerquelle aufgehoben werden.

Der Wildtyp mit chromosomaler gImUS-lacZ-Reporterfusion (Z9) wurde bis zum Erreichen einer $\mathrm{OD}_{600}$ von 0,3 in LB-Medium inkubiert. Die Kultur wurde aufgespalten: Ein Teil wurde weiterhin in LB-Medium ohne Zusatz inkubiert (weiße Balken), ein Teil mit $100 \mu \mathrm{g} / \mathrm{ml}$ Nva-FMDP induziert (schwarze Balken) und ein Teil mit $100 \mathrm{mg} / \mathrm{ml}$ Nva-FMDP induziert bei gleichzeitiger Zugabe von $1 \%(\mathrm{w} / \mathrm{v})$ GlcNAc (graue Balken). Zum Zeitpunkt des Aufspaltens sowie $1 \mathrm{~h}, 3 \mathrm{~h}$ und $5 \mathrm{~h}$ danach wurden Proben zur Bestimmung der $\beta$-Galaktosidase-Aktivität (siehe 2.3.4.) entnommen.

Die Anwesenheit von 1\% GlcNAc hebt den Effekt des Nva-FMDPs auf die Reporteraktivität vollständig auf.

Somit kann bestätigt werden, dass die aktivierende Wirkung von Nva-FMDP auf die glmUS-lacZ-Reporterfusion auf einer Reduktion des intrazellulären GlcN-6-P-Spiegels aufgrund einer Hemmung der enzymatischen Aktivität von GlmS zurückzuführen ist.

Diese Aussage wird auch durch eine Western Blot Analyse mit einem Antikörper gegen GlmS (siehe 3.7.7.) unter Verwendung von Proteinrohextraken aus dem WildtypStamm R1279 und der [ptsN-npr]-Deletion R2413 unter Induktion mit den zuvor beschriebenen subinhibitorischen Konzentrationen der Wirkstoffe unterstützt (siehe Abb. 4.16.) Hierzu wurden die Stämme in LB-Medium inkubiert, bis sie eine $\mathrm{OD}_{600}$ von 0,3 erreichten. Dann wurden sie mit den genannten subinhibitorischen Wirkstoffkonzentrationen induziert und nach weiteren $3 \mathrm{~h}$ Inkubation geerntet. Während die Induktion des Wildtyps mit Ampicillin, Fosfomycin und NEM keinerlei Effekt auf die GlmS-Menge hat, ist bei Induktion mit Nva-FMDP eine deutliche Verstärkung des GlmS-Signals detektierbar. Dieser Effekt wird wie erwartet durch die Zugabe von 1\% (w/v) GlcNAc aufgehoben. 


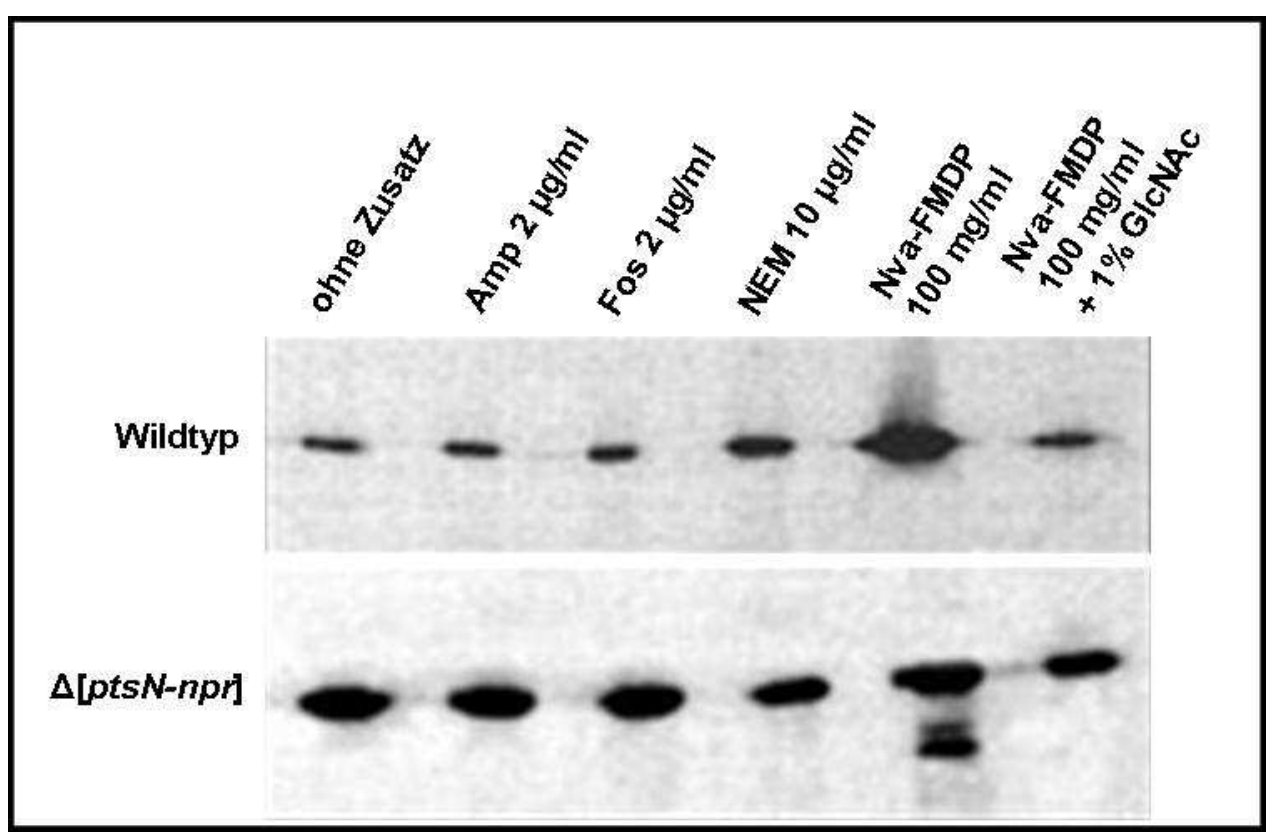

Abb. 4.16: Analyse der GImS-Menge bei Inhibition von Schritten des anabolen Aminozuckermetabolismus

Der Wildtyp (R1279) sowie die Stäme $\Delta[p t s N-n p r]$ (R2413), $\Delta y h b J(Z 24), r^{T S}$ yhbJ::cat (Z52) und $r n e^{+}$yhbJ::cat (Z53) wurden in LB-Medium inkubiert, bis sie eine OD600 von 0,3 erreichten udn dann mit subihibitorischen Konzentrationen der aufgeführten Stoffe induziert. $3 \mathrm{~h}$ danach wurden Zellen geerntet und Gesamtzellextrakte hergestellt (siehe 3.7.1.) und wie unter 3.7.7. beschrieben eine Western Blot Analyse unter Verwendung polyklonaler Antikörper gegen GlmS durchgeführt.

Ampicillin (Amp), Fosfomycin (Fos) und N-Ethylmaleimid (NEM) haben keinen Einfluß auf die intrazelluläre GlmS-Menge. Unter Induktion mit Nva-FMDP hingegen ist ein deutlich verstärktes GlmS-Signal detektierbar. Dieser Effekt kann durch die Zugabe von 1\% (w/v) GlcNAc als externe Aminozuckerquelle aufgehoben werden.

$\mathrm{w} / \mathrm{O}=$ ohne Zugabe, $A m p=$ Ampicillin, Fos= Fosfomycin, $\mathrm{NEM}=\mathrm{N}$-Ethylmaleimid

In einem [ptsN-npr]-Deletionsstamm (R2413) hingegen ist unter allen Bedingungen eine große Menge GlmS detektierbar, welcher nicht durch die Zugabe von Nva-FMDP zusätzlich erhöht werden kann. Die Zugabe von GlcNAc hingegen reduziert die Proteinmenge von GlmS nur leicht. Dies unterstützt die Annahme, dass die Metaboliten-abhängige Regulation der GlmS-Menge strikt von der Anwesenheit von funktionsfähigen YhbJ abhängig ist.

Untersuchungen durch korrespondierende Northern Blot Analysen mit einer DIGmarkierten Sonde gegen $\operatorname{glmS}$, bei denen Gesamt-RNA aus dem Wildtyp R1279 unter Induktion durch subinhibitorische Konzentrationen der Wirkstoffe benutzt wurden, führten ebenfalls zu Ergebnissen, die bestätigen, dass die beobachtete Induktion der GlmS-Synthese auf dem in 4.1. beschriebenen regulatorischen Ereignis beruht (Kalamorz et al. 2007).

Die Aufgabe des regulatorischen Ereignisses, dass in 4.1. untersucht wurde, ist somit Induktion der GlmS-Synthese im Falle eines niedrigen GlcN-6-P-Spiegels. Es handelt 
sich somit um einen klassischen negativen Feedback-Mechanismus, in dem die Expression des Gens eines Enzyms durch dessen Produktmenge kontrolliert wird.

\subsubsection{Die Rolle von GlmZ in der metabolitengesteuerten Regulation der $g \operatorname{lm} S$ -} Expression

Da gezeigt werden konnte, dass die Anpassung der glmS-Expression in Abhängigkeit von der Verfügbarkeit von GlcN-6-P durch das in 4.1. beschriebene regulatorische Ereignis geschieht, sollte nun die Rolle von GlmZ in diesem System untersucht werden. Um näheren Einblick zu erlangen, wurde der Einfluß von Nva-FMDP auf einen $\Delta g \operatorname{lm} Z$ Stamm (Z40, siehe Tabelle 7.1.) getestet. Hierzu wurde LB-Medium mit diesem Stamm bei $37^{\circ} \mathrm{C}$ inkubiert, bis eine $\mathrm{OD}_{600}$ von 0,3 erreicht wurde. Die Kultur wurde nun in vier Teile aufgespalten: Einer wurde ohne Zusatz weiter inkubiert und den anderen entweder $100 \mathrm{mg} / \mathrm{ml}$ Nva-FMDP, 100 mg/ml Nva-FMDP und 1\% (w/v) GlcNAc oder $10 \mu \mathrm{g} / \mathrm{ml}$ NEM zugesetzt (Zeitpunkt $t_{0}$ ). Das Wachstum der Kulturen wurde stündlich protokolliert, und nach $1 \mathrm{~h}, 3 \mathrm{~h}$ und $5 \mathrm{~h}$ Proben für die Bestimmung der $\beta$ Galaktosidase-Aktivität (siehe 3.3.4.) entnommen. Abb. 4.17. gibt die Ergebnisse dieses Versuches wieder. Zunächst ist zu bemerken, dass die Deletion von $g \operatorname{lm} Z$ keinen Einfluß auf das Wachstum hat. Wie der korrespondierende Wildtyp-Stamm Z9 erreicht auch der $\Delta g \operatorname{lmZ}$-Stamm Z40 nach 3 h eine $\mathrm{OD}_{600}$ von 3 (vergleiche Abb. 4.10.).

Der glmZ-Deletionsstamm zeigt jedoch bemerkenswerter Weise ein verringertes Wachstum bei Inkubation in Anwesenheit von Nva-FMDP: Dieses verläuft deutlich langsamer und die Zelldichte erreicht keinen $\mathrm{OD}_{600}$-Wert höher als 2,6 (siehe Abb. 4.17. Zeitpunkt 5). Dieser Defekt kann durch die Zugabe einer externen Aminozuckerquelle aufgehoben werden, in Anwesenheit von 100 mg/ml Nva-FMDP und 1\% (w/v) GlcNAc erreichen Wachstumsrate und Zelldichte die Werte der unbehandelten Kultur.

Desweiteren ist im $\Delta g \operatorname{lmZ}$-Hintergrund keinerlei Reaktion der glmUS-lacZReporterfusion auf die Zugabe von Nva-FMDP messbar, lediglich der bekannte, etwa dreifach reprimierende Effekt des GlcNAc auf die Promotoren vor glmU kann detektiert werden (vergleiche 2.3.). 


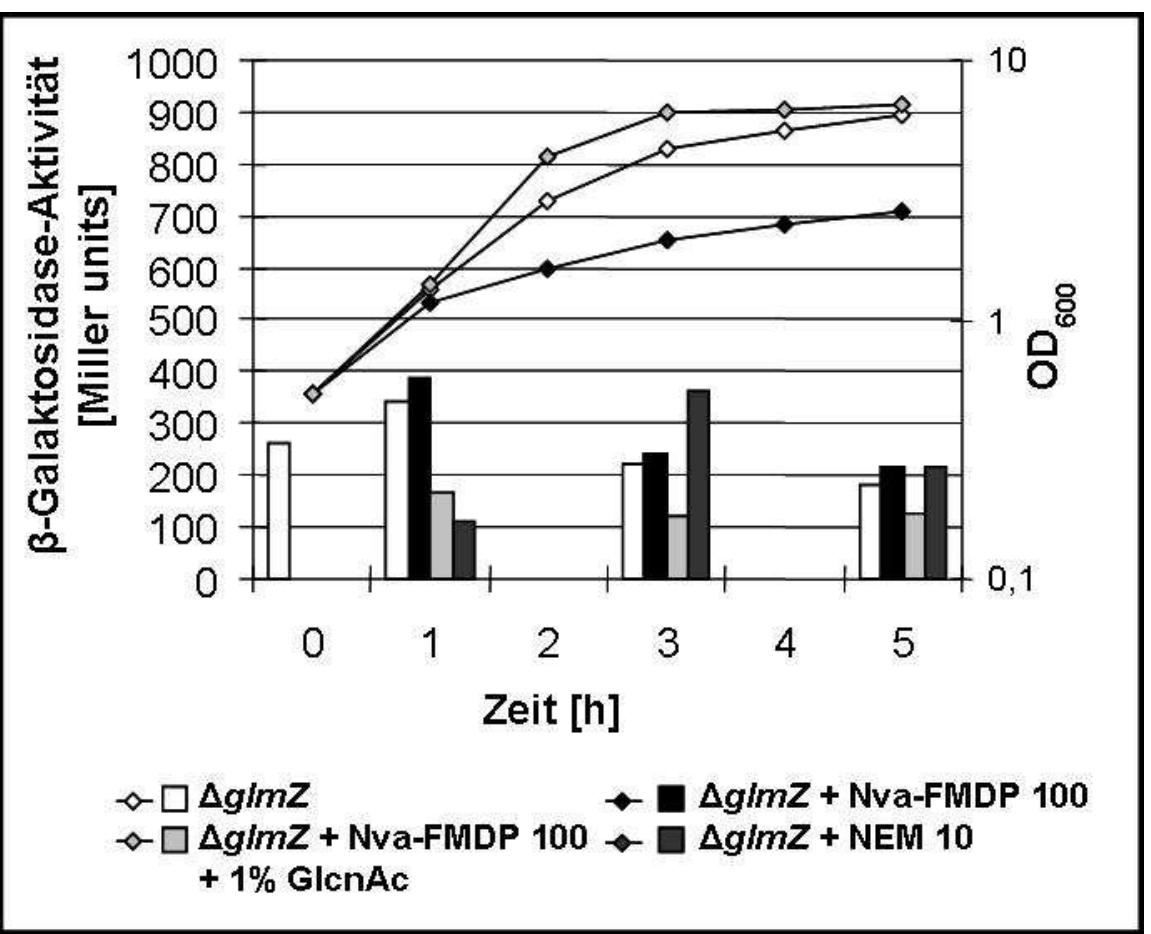

Abb. 4.17.: Die Wirkung von Nva-FMDP auf die Aktivität der glmUS-lacZ-Reporterfusion in Abwesenheit von GImZ.

Der $\Delta g / m Z$ Stamm mit chromosomaler glmUS-lacZ-Reporterfusion (Z40) wurde bis zum Erreichen einer $\mathrm{OD}_{600}$ von 0,3 in LB-Medium inkubiert. Die Kultur wurde aufgespalten: Ein Teil wurde weiterhin in LB-Medium ohne Zusatz inkubiert, ein Teil mit $100 \mathrm{mg} / \mathrm{ml} \mathrm{Nva-FMDP}$ beziehungsweise $40 \mu \mathrm{g} / \mathrm{ml} \mathrm{N}$-Ethylmalemeid induziert und ein Teil mit $100 \mathrm{mg} / \mathrm{ml} \mathrm{Nva-FMDP}$ induziert bei gleichzeitiger Zugabe von 1\% (w/v) GlcNAc. Zum Zeitpunkt des Aufspaltens sowie $1 \mathrm{~h}, 3 \mathrm{~h}$ und $5 \mathrm{~h}$ danach wurden Proben zur Bestimmung der $\beta$-Galaktosidase-Aktivität (siehe 3.3.4.) entnommen.

Der $\Delta g / m Z$-Stamm zeigt keinerlei Wachstumsdefekt und auch die Zugabe von NEM hat keine Auswirkung auf die Wachstumsrate (Daten nicht gezeigt).

Unter Induktion mit Nva-FMDP kommt es zu einer deutlichen Verlangsamung des Wachstums und die $\mathrm{OD}_{600}$ erreicht keinen Wert über 2,6. Dieser hemmende Effekt kann durch die Zugabe von $1 \%(\mathrm{w} / \mathrm{v})$ GlcNAc aufgehoben werden, in diesem Fall ist das Wachstumsverhalten nicht von dem der unbehandelten Kultur zu unterscheiden.

Im Gegensatz zum Wildtypstamm (vergleiche Abb. 3.14.) kommt es in Abwesenheit von $\mathrm{glmZ}$ zu keiner erhöhten Aktivität der Reporterfusion unter Induktion mit Nva-FMDP.

Aus diesen Beobachtungen kann gefolgert werden, dass GlmZ ein essentieller Bestandteil für das regulatorische Ereignis ist, über das die GlmS-Expression an die Verfügbarkeit von intrazellulären GlcN-6-P angepasst wird, und dass ein glmZDeletionsstamm nicht mehr in der Lage ist, dieses Regulationsereignis auszuführen. Zudem erklärt diese Untersuchung die unerwartete hohe Resistenz von E. coli gegenüber FMDP-Derivaten: Falls die enzymatische Aktivität von GlmS durch FMDP inhibiert wird, besteht die Antwort der Zelle aus einer posttranskriptionellen Stabilisierung der $g \operatorname{lm} S$-spezifischen mRNA (Kalamorz et al. 2007), was eine erhöhte GlmS-Synthese bewirkt. So kann der Verlust an enzymatischer Aktivität sehr schnell ausgeglichen werden. Erst durch eine Inaktivierung von GlmZ, beispielsweise durch Deletion des korrespondierenden Gens, wird diese Antwort auf eine geringe 
Verfügbarkeit von GlcNAc-6-P ausgeschaltet, so dass die Zelle nun empfindlich für die Wirkung des FMDPs ist.

Des Weiteren unterliegt diese Antwort einer Kontrolle durch YhbJ, da in Abwesenheit dieses Proteins eine vom GlcN-6-P-Spiegel entkoppelte konstitutive Aktivierung des Mechanismus zu beobachten ist.

\subsection{Charakterisierung von YhbJ}

Aufgrund der zentralen Bedeutung von YhbJ in der Regulation der glmS-Expression wurden verschiedene Datenbank-Analysen durchgeführt, um dieses Protein weitergehend zu charakterisieren.

Zu diesem Zweck wurde zunächst ein Datensatz aus 125 Homologen zusammengestellt, indem das multiple genome alignment von microbesonline.com (siehe 3.9.) sowie BLAST-Suchen (Altschul et al. 1990) gegen YhbJ aus E. coli und dem Homolog YvcJ in B. subtilis (Görke et al. 2005) genutzt wurden. Es wurden Sequenzen berücksichtigt, die eine Homologie von mindestens 50\% aufwiesen. Hierbei ist zu beachten, dass YhbJ aus E. coli und YvcJ aus B. subtilis lediglich eine Übereinstimmung von $39 \%$ aufweisen. Der gesamte Datensatz ist unter 7.6. im Anhang zu finden. Alle Positionsangaben beziehen sich, soweit nicht anders genannt, auf YhbJ aus E. coli.

\subsubsection{Analyse mittels ClustalW und MEME}

Der ClustalW-Algorithmus dient der Identifikation konservierter Aminosäurereste durch Sequenz Alignment (Larkin et al. 2007). Im Falle von YhbJ konnten durch diese Analyse 23 Aminosäuren identifiziert werden, die in allen verwendeten Sequenzen perfekt konserviert sind sowie 26 weitere Aminosäuren, die hinsichtlich Größe und Ladung übereinstimmen (siehe Abb. 3.18.A. und Anhang 7.6.).

Mittels MEME-Anaylse ist es möglich, konservierte Motive in Gruppen verwandter DNA- oder Aminosäuresequenzen zu identifizieren (Bailey et al. 2006). Durch diesen Algorithmus wurden drei Motive gefunden, die in den Sequenzen aller verwendeten Homologe $\mathrm{zu}$ finden sind und die einen Großteil der konservierten Aminosäurereste enthalten (siehe Abb. 4.18.B.). 
A

MVLMIVS $R$ G GKSV LRA EDM YCVD NLPVVLLPDL ARTLADREIS AAVSIDVRNM PESPEIFEQA MSNLPDAFSP QLLFLDADRN TLIRRYSDTR RLHPLSSKNL SLESAIDKES DLLEPLRSRA DLIVDTSEMS VHELAEMLRT RLLGKREREL TMV E FG H IPIDA Y FDVRF PNP WPKL PMTG LDKP AAF D RHTEVHNFIY QTRSYLELWL PMLETNNRSY LTVAICCTCG KHRSVYIAEQ LADYFRSRGK NVQSRHRTLE KRKP

B

Motiv 1
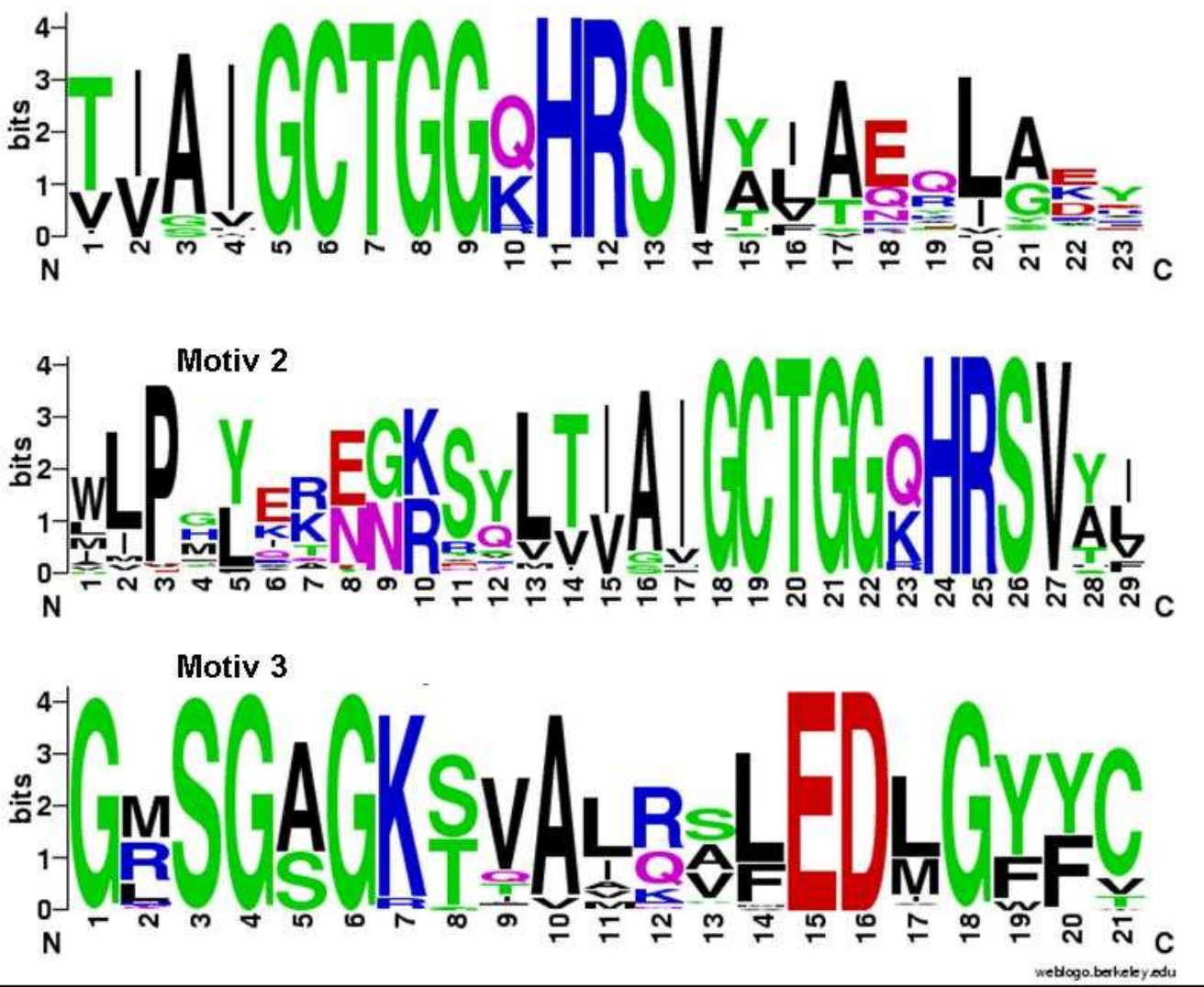

Abb. 4.18.: Sequenzanalyse von YhbJ und Homologen

Es wurden 125 Sequenzen von Homologen des Proteins YhbJ aus E. coli für eine Analyse mittels ClustalW und MEME genutzt.

(A) Sequenz von YhbJ aus E. coli. Rot dargestellte Aminmosäuren sind in allen 125 Sequenzen perfekt konserviert. Orange dargestellte Aminosäuren sind im Kontext von Größe und Ladung konserviert. Das potentielle Walker A-Motiv ist unterstrichen. Motiv 1 aus der MEME-Analyse ist in violett unterlegt, Motiv 2 in grau und Motiv 3 in türkis.

(B) Weblogo-Darstellung der drei mittels MEME gefundenen Motive. Die dargestellte Größe der Buchstaben korreliert zum Grad der Konservierung der jeweiligen Aminosäure.

Motiv 1 umfasst die Aminosäuren 163 bis 212 und beinhaltet 7 perfekt konservierte Aminosäuren und 13 hinsichtlich Größe und Ladung konservierte Aminosäuren.

Motiv 2 befindet sich im C-terminalen Bereich und besteht aus den Aminosäuren 238 bis 256. In ihm sind 6 perfekt konservierte Aminosäuren enthalten, die sich alle in der C-terminalen Hälfte des Motivs befinden, sowie 5 hinsichtlich Größe und Ladung konservierter Aminosäuren, von denen ebenfalls 4 in der C-terminalen Hälfte des Motivs lokalisiert sind. 
Motiv 3 schließlich liegt im N-terminalen Bereich des Proteins und beinhaltet ein Walker A-Motiv mit der Konsensus-Sequenz G-X ${ }_{4}-\mathrm{G}-(\mathrm{K} / \mathrm{T})$ (Walker et al. 1982), welches durch die Aminosäuren 8 bis 15 gebildet wird. Walker A ist in P-loop ATPasen konserviert und ist an der Bindung von ATP und GTP beteiligt (Saraste et al. 1990). Viele Proteine mit einem Walker A-Motiv sind ATPasen (Smirnova et al. 1998) und eine Kinase-Aktivität konnte beispielsweise für die HPr-Kinase HprK aus B. subtilis gezeigt werden (Galinier et al. 2002). Das Motiv 3 in YhbJ umfasst die Aminosäuren 7 bis 28, unter denen sich 4 perfekt konservierte und 7 hinsichtlich Größe und Ladung konservierte Aminosäuren befinden.

Die Motivabfolge 3-1-2 ist konserviert, mit Ausnahme von Desulfotomaculum reducens UPF0042, in welchem das Motiv 3 doppelt vorliegt, was zu der Abfolge 3-3-1-2 führt, sowie Nitrosomas europea NE1849, welches ein doppeltes Motiv 2 aufweist, und zwar in der Abfolge 3-2-1-2.

\subsubsection{Phylogenetische Analyse}

Unter Verwendung der aus der ClustalW-Analyse erhaltenen Daten wurde mittels TreeView (Copyright R.D.M Page 2001) ein phylogenetischer Stammbaum der verwendeten Homologe erstellt (siehe Abb. 4.19) Der Übersichtlichkeit halber wurde in dieser Analyse bei mehreren Vertretern derselben Gattung, die sehr hohe Homologie zueinander aufwiesen, exemplarisch nur eine Sequenz aus diesen Gruppen verwendet. Zudem wurden die Enterobacteriaceae zu der Gruppe „Enterobakteria“ zusammengefasst, deren Position in Abb. 4.19. durch E. coli YhbJ repräsentiert wird und deren Verwandtschaft untereinander in Abb. 4.20. dargestellt ist.

Die weitverbreitete Konservierung des Proteins in Eubakteria ist als starker Hinweis auf eine funktionelle Konservierung anzusehen. 


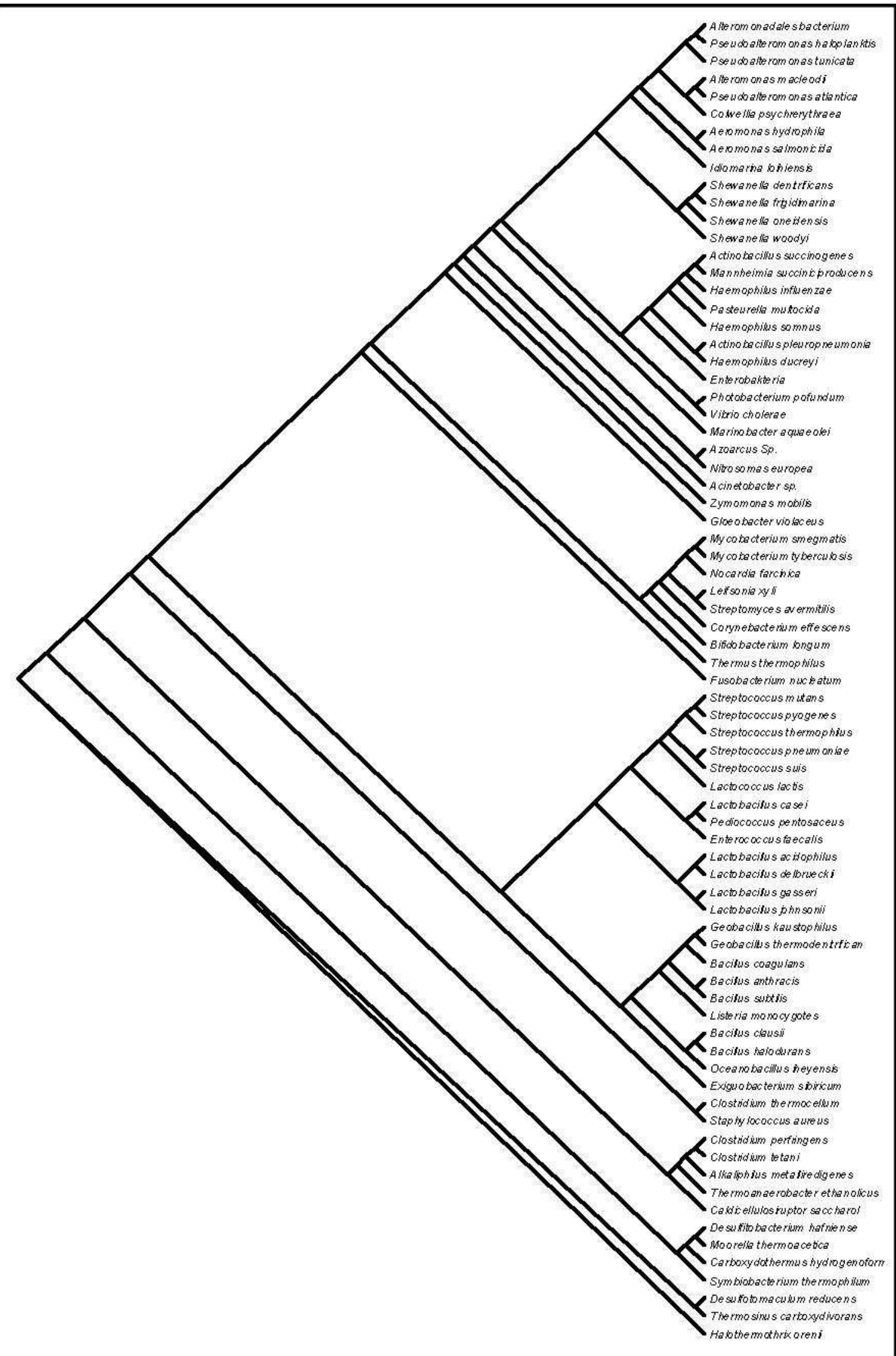

Abb. 4.19.: Phylogenetischer Stammbaum der YhbJ-Homologe

Erstellt aus einer ClustalW-Analyse von Homologen aus 75 Organismen mittels TreeView (siehe 2.9). 


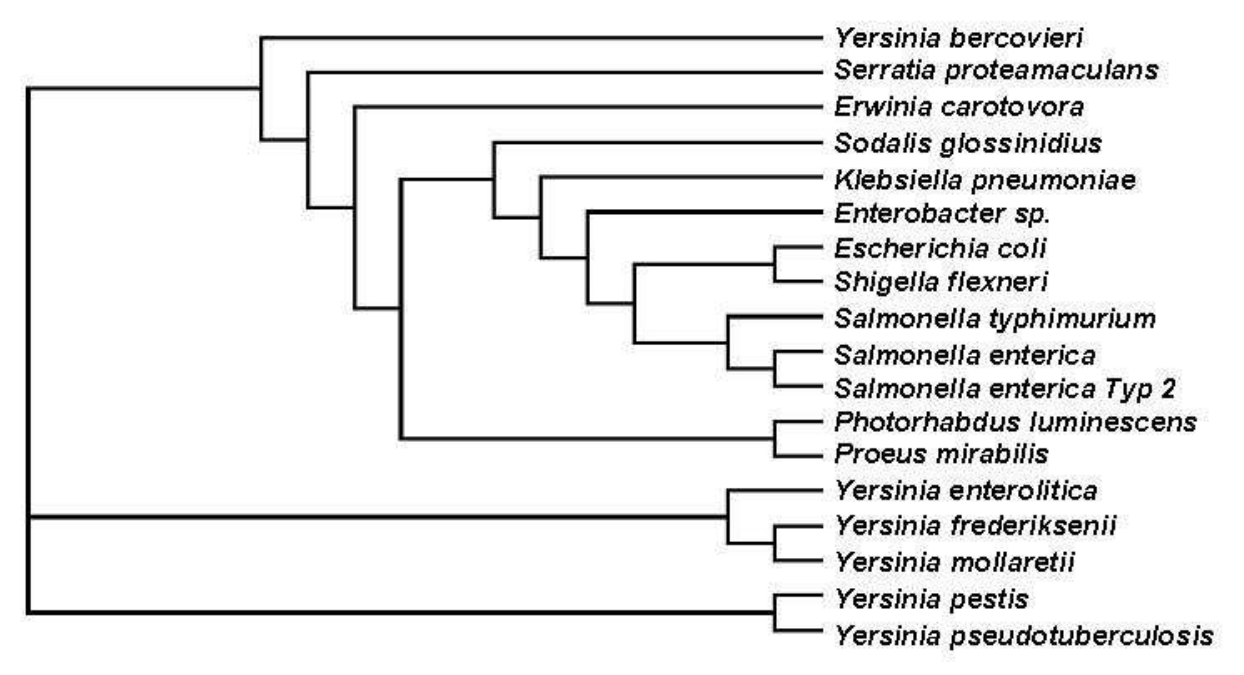

Abb. 4.20.: Phylogenetischer Stammbaum der YhbJ-Homologe in Enterobakterien Erstellt aus ClustalW-Analyse mittels TreeView (siehe 2.9). Dieser Stammbaum repräsentiert die "Gruppe: Enterobacteria“" in Abbildung 3.18.

\subsubsection{Identifikation einer potenziellen RNA-Bindedomäne}

Aufgrund des Einflußes von YhbJ auf die Prozessierung der kleinen RNAs GlmY und GlmZ sollte überprüft werden, ob eine direkte Interaktion zwischen diesen Komponenten möglich ist. Mittels des RNABindR-Algorithmus lassen sich potenzielle RNA-Bindedomänen in Aminosäuresequenzen identifizieren, die an einer potenziellen Bindung von RNA beteiligt sind (Terribilini et al. 2007).

Verwendet man hierzu die Sequenz von YhbJ aus E. coli, so erhält man eine Vorhersage für ein potenzielles RNA-Bindemotiv, welches aus den Aminosäuren 251- 254, 256, 260-271 sowie 273-278 und 281-284 im äussersten C-terminalen Bereich des Proteins gebildet wird (siehe Abb. 4.21.).

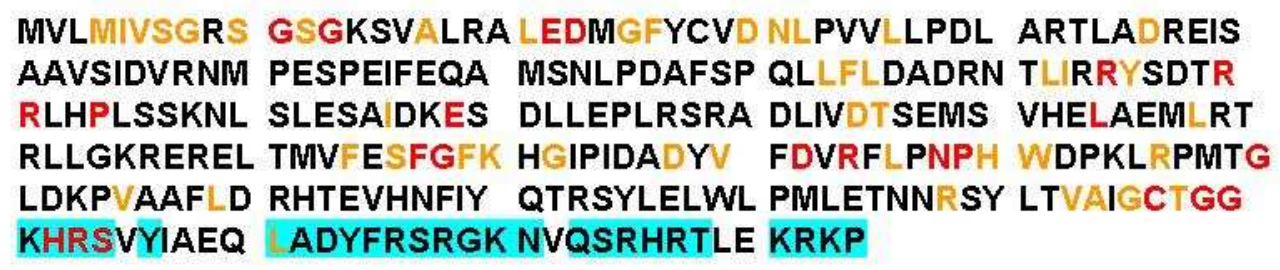

\section{Abb. 4.21.: Potenzielles RNA-Bindemotiv von YhbJ}

Mittels RNA-BindR wurden die in türkis unterlegten Aminosäuren als Teil einer potenziellen RNA-Bindedomäne am C-terminalen Ende des Proteins identifiziert.

Interessanterweise ist dieser Bereich gemäß der ClustalW-Analyse (vergleiche 4.3.1. und 7.6.) nicht stark konserviert, so dass weitere Sequenzen von YhbJ-Homologen 
mittels RNABindR analysiert wurden. Hierbei zeigte sich, dass die am potenziellen RNA-Bindemotiv beteiligten Aminosäuren innerhalb der Gruppe: Enterobakteria (siehe Abb. 4.19. und Abb. 4.20.) vollständig konserviert sind und man für jedes Mitglied dieser Gruppe eine Vorhersage erhält, die mit der für YhbJ aus E. coli übereinstimmt. Im Gegensatz hierzu ergibt eine RNABindR-Analyse der Homologe aus B. subtilis (Motiv aus 13 Aminosäuren), Clostridium perfringens (7 Aminosäuren, die kein zusammenhängendes Motiv bilden), Staphylococcus aureus (3 Aminosäuren) und Vibrio cholerae (2 Aminosäuren) deutlich geringere Wahrscheinlichkeiten für die Anwesenheit eines entsprechenden Bindemotives, während einige andere wie Listeria monocygotes Vorhersagen erhalten, die mit der für E.coli vergleichbar sind (Motiv aus 25 Aminosäuren). Die Vorhersagen sind im Anhang unter 7.6. zusammengefasst.

\subsubsection{Mutationsanalyse konservierter Reste und Motive in YhbJ}

Nachdem durch die in 4.3.1. und 4.3.3. beschriebenen Analysen eine Vielzahl konservierter Aminosäuren und Motive in YhbJ identifiziert werden konnten, wurden nun Mutationsanalysen durchgeführt, um diesen eine funktionelle Bedeutung beizumessen.

Hierzu wurden verschiedene mutierte Versionen von YhbJ unter Kontrolle eines Arabinose-induzuierbaren Promotors in das Plasmid pBAD33 integriert und zur Komplementation einer yhbJ-Mutante (Stamm Z28, siehe Tab. 7.1.) verwendet. Die Effektivität der Komplementation kann über die Aktivität einer im Chromosom verankerten $g \operatorname{lm} S$-lacZ-Reporterfusion bestimmt werden.

Es wurden folgende Mutationen und Deletionen verwendet:

\begin{tabular}{|c|c|}
\hline yhbJ-Gly8Ala & (pBGG63) \\
\hline$y h b J-[\Delta \mathrm{AA} 256-284]$ & (pBGG109) \\
\hline yhbJ-Gly8Ala / [ $\Delta \mathrm{AA} 256-284]$ & (pBGG110) \\
\hline$y h b J-G l y 13 \mathrm{Ala}$ & (pBGG120) \\
\hline$y h b J \Delta \mathrm{AA} 164-212$ & (pBGG121) \\
\hline yhbJ Phe167Ala & (pBGG122) \\
\hline yhbJ Gly168Leu & (pBGG123) \\
\hline$y h b J$ Asn188Ala & (pBGG125) \\
\hline yhbJ Pro189Ala & (pBGG126) \\
\hline yhbJ Gly199Leu & (pBGG127) \\
\hline
\end{tabular}


Die Positionen der einzelnen Mutationen sind in Abb. 4.22. schematisch dargestellt. Als Kontrollen wurden der korrespondierende Wildtyp Z8 (Negativkontrolle), der nichttransformierte Stamm Z28 (Positivkontrolle), die beide eine chromosomale glmS-lacZReporterfusion tragen (vergleiche Abb. 4.1.) sowie Z28 transformiert mit pBAD33 (Leervektor) und mit pBGG119 (authentisches $y h b J$ in pBAD33, vergleiche Tab.7.2.) verwendet.

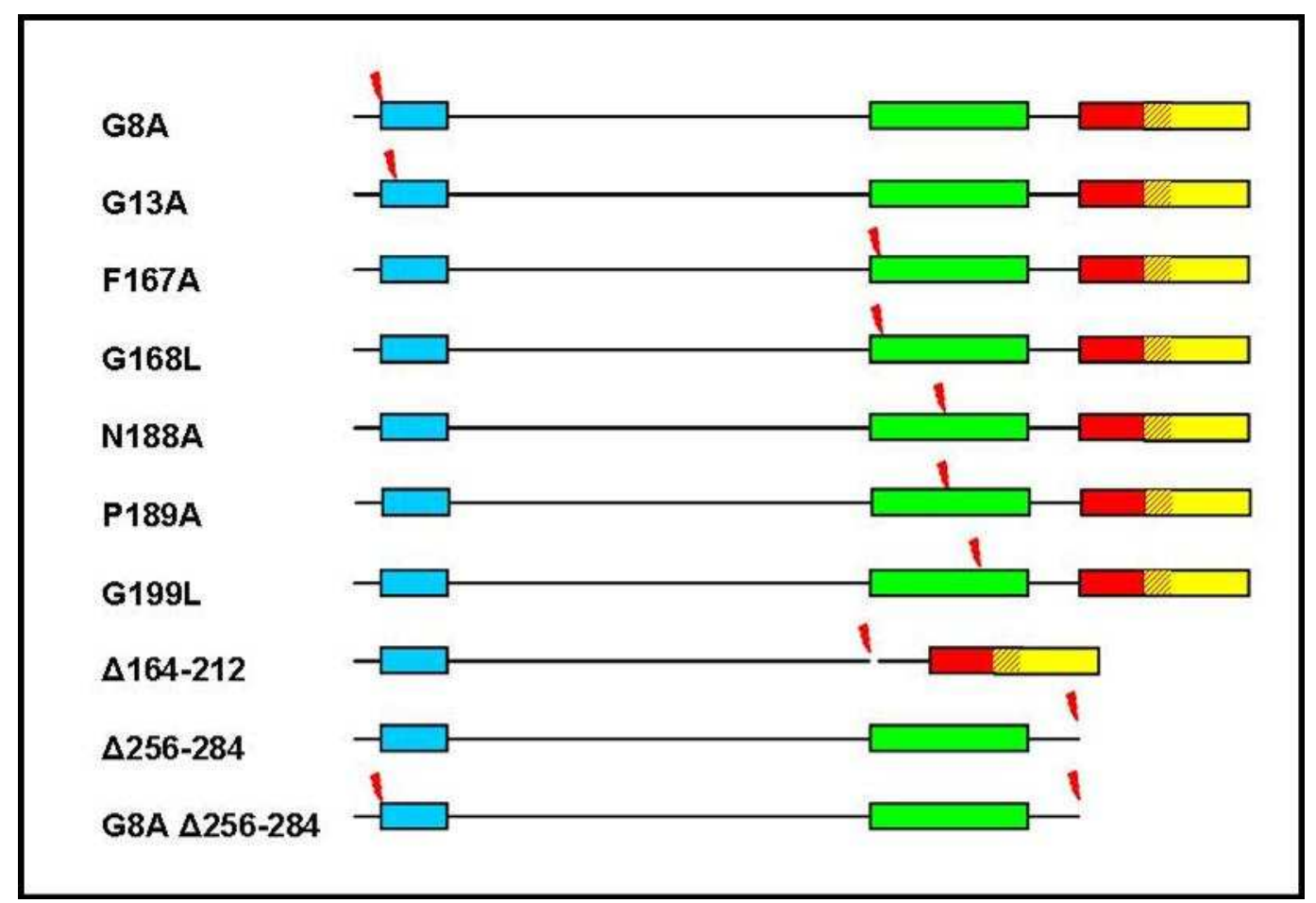

Abb. 4.22.: Lokalisation der Deletionen und Aminosäureaustausche für dei Mutationsanalyse von yhbJ

Maßstabsgerechte schematische Darstellung des yhbJ-Gens. Blaue Box = konserviertes Motiv 1, grüne Box = konserviertes Motiv 2, rote Box = konserviertes Motiv 3, gelbe Box = potenzielles RNA-Bindemotiv. Blitze symbolisieren Mutationen ider Deletionen. Für Details: Siehe 4.3.4.

Der Stamm Z28 wurde mit den Plasmiden, welche für die YhbJ-Mutanten kodieren, transformiert (siehe 3.3.3.) und die Expression der Proteine mittels Western Blot Analyse unter Verwendung von Antikörpern gegen YhbJ (siehe 3.7.7.) überprüft. Wie Abb 4.23. zeigt, werden alle Derivate stabil exprimiert. 


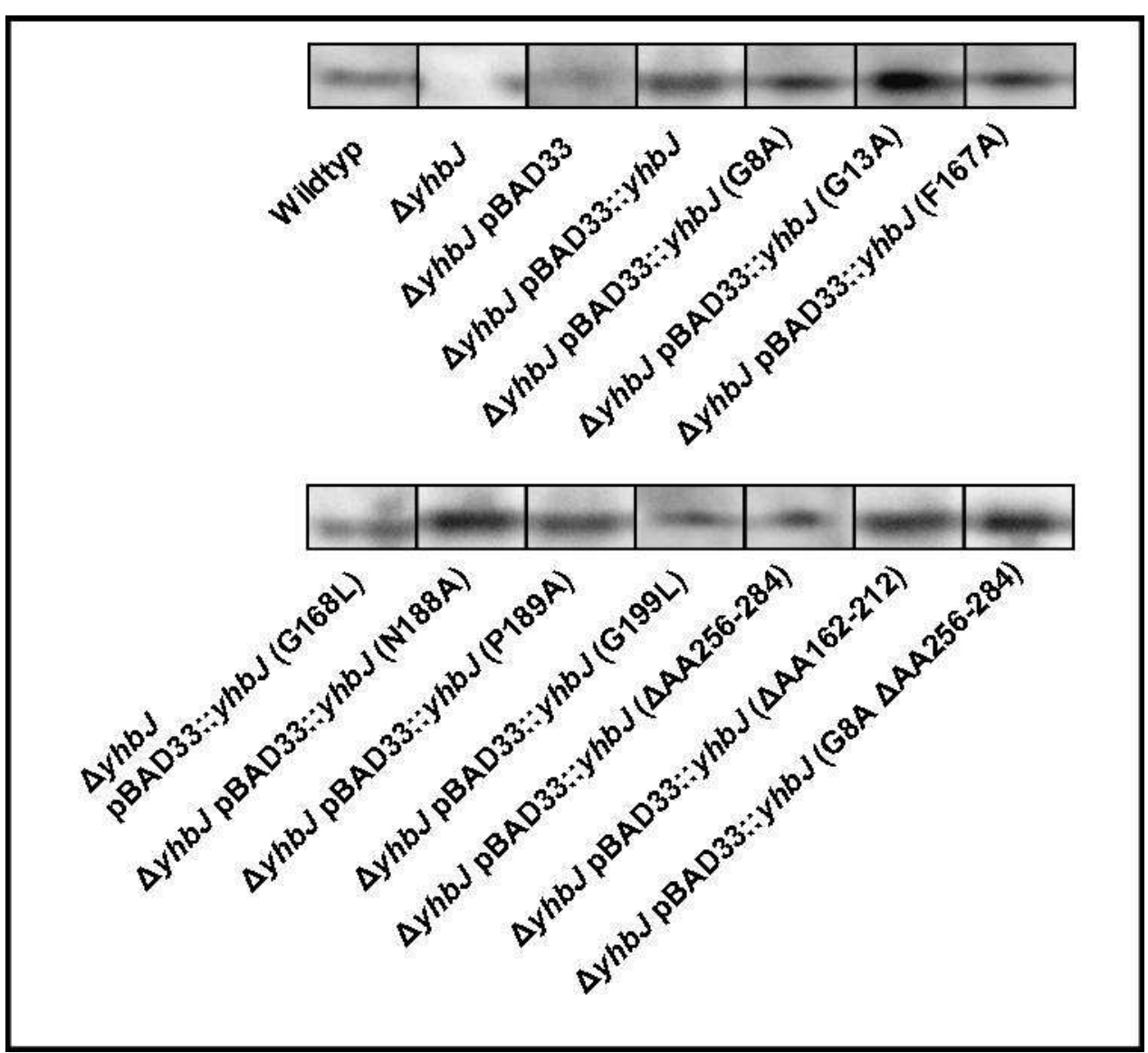

Abb. 4.23.: Western Blot zur Überprufung der stabilen Expression der yhbJ-Mutanten

Der $\Delta y$ hbJ-Stamm Z28 wurde mit den unter 4.3.4. beschriebenen Plasmiden und dem Uprsprungsplasmid (pBAD33) transformiert und die Transformanten sowie der Ausgangsstamm und der korrespondierende Wildtyp (Z8) in LB-Medium mit 0,2\% L-Arabinose inkubiert, bis sie eine $\mathrm{OD}_{600}$ von 0,6 erreichten. Gesamtzellextrakte (siehe 3.7.1.) wurden dann mittels Western Blot Analysen (siehe 3.7.7.) unter Verwendung eines polyklonalen Antikörpers gegen YhbJ analysiert.

Weder in der yhbJ-Deletion noch in der Deletion transformiert mit dem Ausgangsplasmid pBAD33 ist ein Signal detektierbar. In den restlichen Transformanten hingegen sind Signale vorhanden, die mindestens die Stärke des Signals im Wildtyp haben.

Anschließend wurde die $\beta$-Galaktosidase-Aktivität der genannten Stämme und Transformanten bestimmt (siehe 3.3.4.). Die Ergebnisse dieser Analyse sind in Abb. 4.24. grafisch dargestellt. Der $y h b J$-Deletionsstamm Z28 weist erwartungsgemäß eine gegenüber dem Wildtyp stark erhöhte Aktivität auf (70 Miller units zu 8 Miller units). Zudem zeigt die Transformation von Z28 mit dem Leervektor pBAD33 keinen Effekt auf die $\beta$-Galaktosidase-Aktivität. Wird der Deletionsstamm Z28 mit authentischen $y h b J$ komplementiert, so ist die Expression der $g \operatorname{lm} S$-5' -lacZ-Reporterfusion bereits ohne Induktion durch Arabinose stark herabgesetzt, was auf eine basale Expression des plasmidständigen Gens in Abwesenheit des Induktors L-Arabinose zurückzuführen ist. Unter Induktion fällt die Aktivität der Reporterfusion auf das Niveau des Wildtyps zurück. 


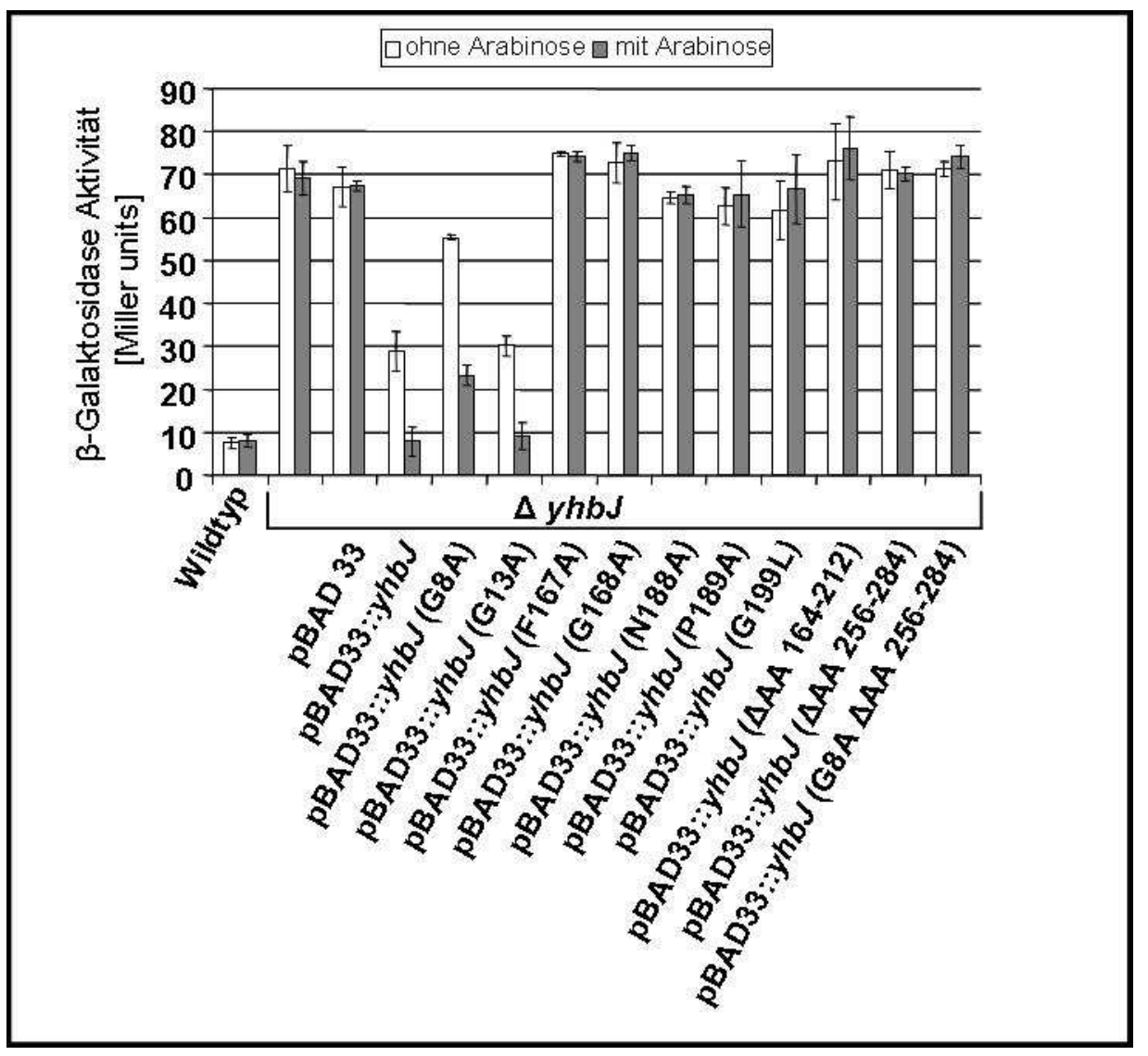

Abb. 4.24.: Komplementation einer yhbJ-Deletion durch mutierte yhbJ-Derivate

Der $\Delta y h b J$-Stamm mit chromosomaler glmS-lacZ-Reporterfusion (Z28) wurde mit den in 4.3.4. genannten Plasmiden transformiert und in LB-Medium mit und ohne Induktion mit $20 \mathrm{mM} \mathrm{L}$ Arabinose inkubiert, bis eine $\mathrm{OD}_{600}$ von 0,6 erreicht wurde. Anschließend wurde die $\beta$ Galaktosidase Aktivität (siehe 3.3.4.) bestimmt.

Mutationen im Walker A-Motiv (G8A und G13A) komplementieren eine yhbJ-Deletion unter Induktion mit Arabinose, während die Expression aller anderen Derivate keinen Effekt auf die $\beta$ Galaktosidase Aktivität hat.

Interessanterweise haben Aminosäure-Austausche innerhalb des Walker A-Motives nur wenig Auswirkung auf die Regulation der $\operatorname{glm} S$-Expression, obwohl diese Reste im Motiv hoch konserviert sind. Bei der Gly13Ala-Mutante ist keinerlei Unterschied zum authentischen YhbJ zu erkennen. Die Transformante des Plasmids mit dem Gly8AlaAustausch weist zwar auch unter Induktion noch eine zweifach erhöhte Expression der Reporterfusion auf, jedoch ist diese Aktivität nur ein Drittel der Aktivität in einer $y h b J$ Deletion. Diese Daten lassen darauf schließen, dass das Walker A-Motiv nur eine untergeordnete Rolle in der Regulation der $g \operatorname{lm} S$-Expression spielt.

Alle weiteren Mutationen und Deletionen sind nicht in der Lage, eine $y h b J$-Deletion zu komplementieren. Die Aktivität der glmS-lacZ-Reporterfusion ist in diesen Transformanten nicht von der Aktivität in einer $y h b J$-Deletion unterscheidbar.

Dies zeigt, dass der Austausch dieser perfekt konservierten Aminosäuren oder die Deletion der konservierten Motive starke Auswirkungen auf die Funktionsfähigkeit von YhbJ hat. 


\subsection{Untersuchungen zur Interaktion von YhbJ mit GImY/GImZ}

Nachdem gezeigt werden konnte, dass zwei kleine RNAs eine wichtige Rolle in der Regulation der glmS-Expression spielen (Kalamorz et al. 2007; Urban et al. 2007; Reichenbach et al. 2008; Urban and Vogel 2008), sollte nun untersucht werden, ob eine direkte Interaktion von GlmY und GlmZ mit YhbJ vorliegt.

\subsection{1. Überexpression His(10)-YhbJ}

Hierzu wurde zunächst Plasmide konstruiert, auf welchen yhbJ mit einem C-terminalen (pBGG161) beziehungsweise N-terminalen (pBGG162) 10x His-Tag unter Kontrolle eines IPTG-induzierbaren Promotors kodiert ist. Diese Fusionsproteine sind in der Lage, eine yhbJ-Deletion vollständig zu komplementieren (siehe Abb. 4.25.).

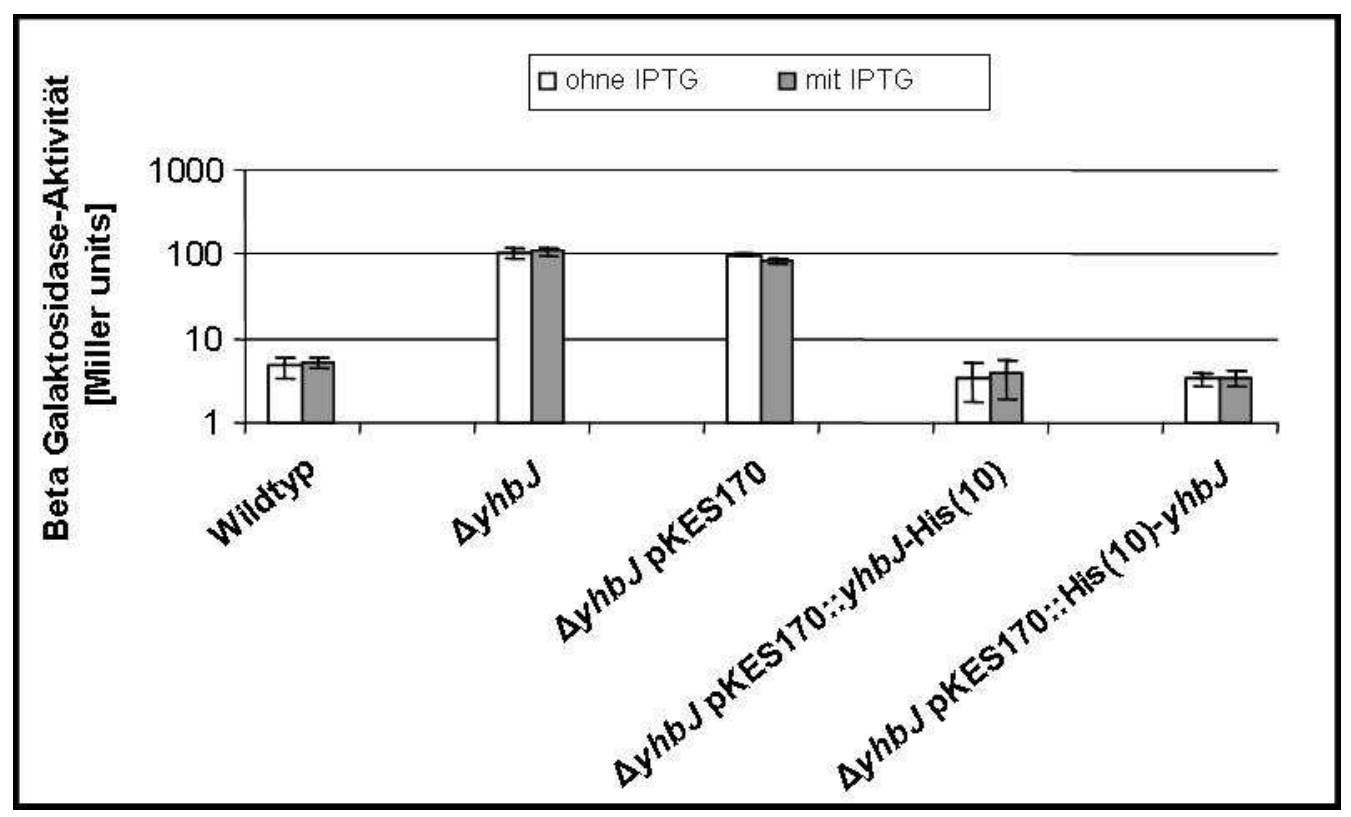

Abb. 4.25.: Komplementation einer yhbJ-Deletion durch His-Tag-Fusionsproteine

Ein $\Delta y$ hbJ-Stamm mit chromosomaler glmS-lacZ-Reporterfusion (Z28) wurde mit Plasmiden transformiert, die das Gen für YhbJ mit einem N-terminalen His(10)-Tag (His(10)-yhbJ, pBGG162) oder mit einem C-terminalen His-Tag (yhbJ-His(10), pBGG161) unter Kontrolle eines IPTG-induzierbaren Promotors tragen. Zusätzlich wurde der Stamm mit dem Ursprungsplasmid pKES170 transformiert. Die Transformanten sowie der nicht transformierten Ausgangsstamm Z28 und der korrespondierenden Wildtyp (Z8) wurden in LB-Medium bei $37^{\circ} \mathrm{C}$ inkubiert, bis eine $\mathrm{OD}_{600}$ erreicht wurde, und die $\beta$-Galaktosidase-Aktivität der Reporterfusion wurde wie unter 3.3.4. beschrieben bestimmt.

Während das Ursprungsplasmid pKES170 keinen Einfluß auf die Aktivität der Reporterfusion hat, komplementieren beide Plasmide, die für Fusionsproteine kodieren, vollständig.

Die stark erniedrigte Reporter-Aktivität in Anwesenheit der Plasmide, die für die Fusionsproteine kodieren, auch ohne Induktion mit IPTG ist auf eine hohe Basalexpression zurückzuführen. 
An dieser Stelle ist zu erwähnen, dass eine Fusion mit einem C-terminalen Tag zwar funktionell sind (also eine yhbJ-Deletion komplementieren kann), jedoch bindet das Fusionsprotein nicht an $\mathrm{Ni}^{2+}$-NTA-Säulen. Dies weist darauf hin, dass C-terminale Tags nicht für die entsprechende Bindung zugänglich sind (Daten nicht gezeigt).

Die Expression des His(10)-YhbJ wurde wie unter 3.7.2. optimiert, wobei eine Induktion bei Erreichen einer $\mathrm{OD}_{600}$ von 0,6 für $1 \mathrm{~h}$ mit $1 \mathrm{mM}$ IPTG als ideal für die Ausbeute bestimmt wurde.

Unter diesen Bedingungen wurde His(10)-YhbJ wie unter 3.7.3. beschrieben aufgereinigt. Abb. 4.25. zeigt exemplarisch die Ergebnisse einer SDS-PAGE zur Überprüfung der Aufreinigung. Anschließend erfolgte eine Dialyse der $300 \mathrm{mM}$ Imidazol-Elutionsfraktion (siehe 3.7.4.).

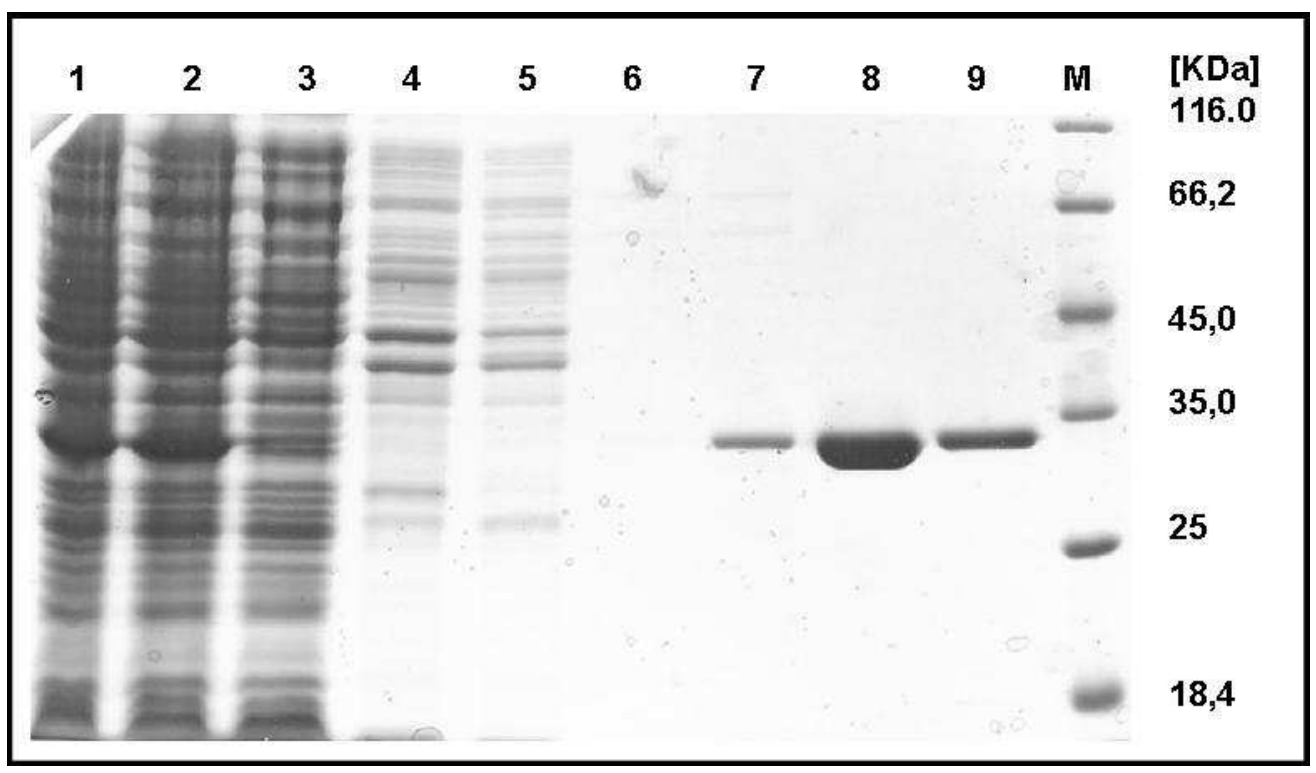

\section{Abb.4.26.: SDS-PAGE der Aufreinigung von His(10)-YhbJ}

Der Stamm DH5a wurde mit einem Plasmid transformiert, das His(10)-YhbJ unter Kontrolle des induzierbaren $\mathrm{P}_{\text {tac }}$-Promotors kodiert. Die Transformante in LB-Medium inkubiert, bis eine $\mathrm{OD}_{600}$ von 0,6 erreicht wurde und dann mit 0,1 mM IPTG für $1 \mathrm{~h}$ induziert. Die Zellen wurden geerntet und die cytosolischen Proteine wie unter 3.7.1. beschrieben präpariert. Es folgte eine Aufreinigung des His(10)-YhbJ über $\mathrm{Ni}^{2+}$-NTA-Säulen aufgereinigt (siehe 3.7.3.).

Es wurden $15 \mu \mathrm{l}$ jeder Fraktion mit $5 \mu \mathrm{l}$ xx SDS-LAdepuffer aufgetragen, und das Gel nach der SDS-PAGE mit Coomassie Brilliant blue gefärbt(siehe 3.7.6.).

$1=$ Rohzellextrakt nach French Press, 2= Überstand nach Ultrazentrifugation, 3= Durchlauf der Säule, 4= Waschschritt $50 \mathrm{mM}$ Imidazol, 5= Waschschritt $50 \mathrm{mM}$ Imidazol, 6= Waschschritt 100 $\mathrm{mM}$ Imidazol, 7= Elutionsschritt $200 \mathrm{mM}$ Imidazol, 8= Elutionsschritt $300 \mathrm{mM}$ Imidazol, 9= Elutionsschritt $500 \mathrm{mM}$ Imidazol, $M=$ Marker. Das Molekulargewicht der Markerbanden ist rechts angegeben.

Das rekombinante Protein eluiert spezifisch im Bereich von $200 \mathrm{mM}$ Imidazol bis $500 \mathrm{mM}$ Imidazol, hauptsächlich in der $300 \mathrm{mM}$ Imidazol-Fraktion. Diese Fraktion wurde für die Dialyse (siehe 3.7.4.) verwendet. 


\subsubsection{Electrophoretic Mobility Shift Assay (EMSA)}

Um eine Bindung zwischen YhbJ und den kleinen RNAs GlmY und GlmZ nachzuweisen wurden Electrophoretic Mobility Shift Assays durchgeführt. Bei diesen EMSAs werden die potenziellen Interaktionspartner in unterschiedlichen Verhältnissen zueinander gemischt und inkubiert, und anschließend in einer nicht-denaturierenden, nativen, Gelelektrophorese, aufgetrennt. Hierbei migrieren Kompexe aus den beiden Interaktionspartnern distinkt von den einzelnen Komponenten, so dass sogenannte Shifts beobachtet werden können, falls es zu einer Komplexbildung kommt (Garner und Revzin 1981).

Für den EMSA wurde zum Einen das aufgereinigte His(10)-YhbJ (vergleiche 4.4.1.) verwendet, zum Anderen RNAs, die wie unter 3.6.3. beschrieben durch in vitro Transkription generiert wurden. Hierbei handelte es sich um die unprozessierte und prozessierte Formen von GlmY und GlmZ, um die sRNA SraC und einem RNA-Stück, das revers-komplementär zu SraC ist $(\mathrm{SraC}$ r/c) ist. Letztere dienten der Untersuchung der Bindespezifität von YhbJ. Die zur Generierung der Matrizen-DNA verwendeten Oligonukleotide sind in Tabelle 7.3. aufgeführt.

In einem ersten Satz Experimente wurden 30 pMol RNA mit aufsteigenden Konzentrationen His(10)-YhbJ von 0 pMol bis 40 pMol inkubiert und anschließend in 6\% -PAA-Gelen mit TBE als Puffer aufgetrennt (siehe 3.8.1.) In diesen Experimenten konnte eine Komplexbildung bei jeder der verwendeten RNAs beobachtet werden (siehe Abb. 4.27.).

Für den EMSA mit His(10)-YhbJ und GlmY (prozessiert) (Abb. 4.27.A.) ist ein konzentrationsabhängiger Shift der RNA sichtbar, der bei einem Verhältnis Protein:RNA von 1:3 einsetzt und bei der Verwendung äquimolarer Mengen oder einem Überschuß an Protein in einen vollständigen Shift übergeht.

Bei dem EMSA mit GlmY (unprozessiert) (Abb. 4.27.B.) ist eine weniger deutliche Interaktion ekennbar. Erst bei Zugabe einer äquimolaren Menge Protein ist ein eindeutiger Shift sichtbar, jedoch ändert sich für einen Großteil der RNA das Laufverhalten nicht.

Die EMSAs mit GlmZ (prozessiert) (Abb. 4.27.C) und GlmZ (unprozessiert) (Abb. 4.27.D) zeigen ein ähnliches Bild wie die EMSAs mit den beiden Formen von GlmY. $\mathrm{Zu}$ beachten ist hier jedoch der zusätzliche zweite Shift bei GlmZ (unprozessiert) unter Verwendung von 40 pMol His(10)-YhbJ. 


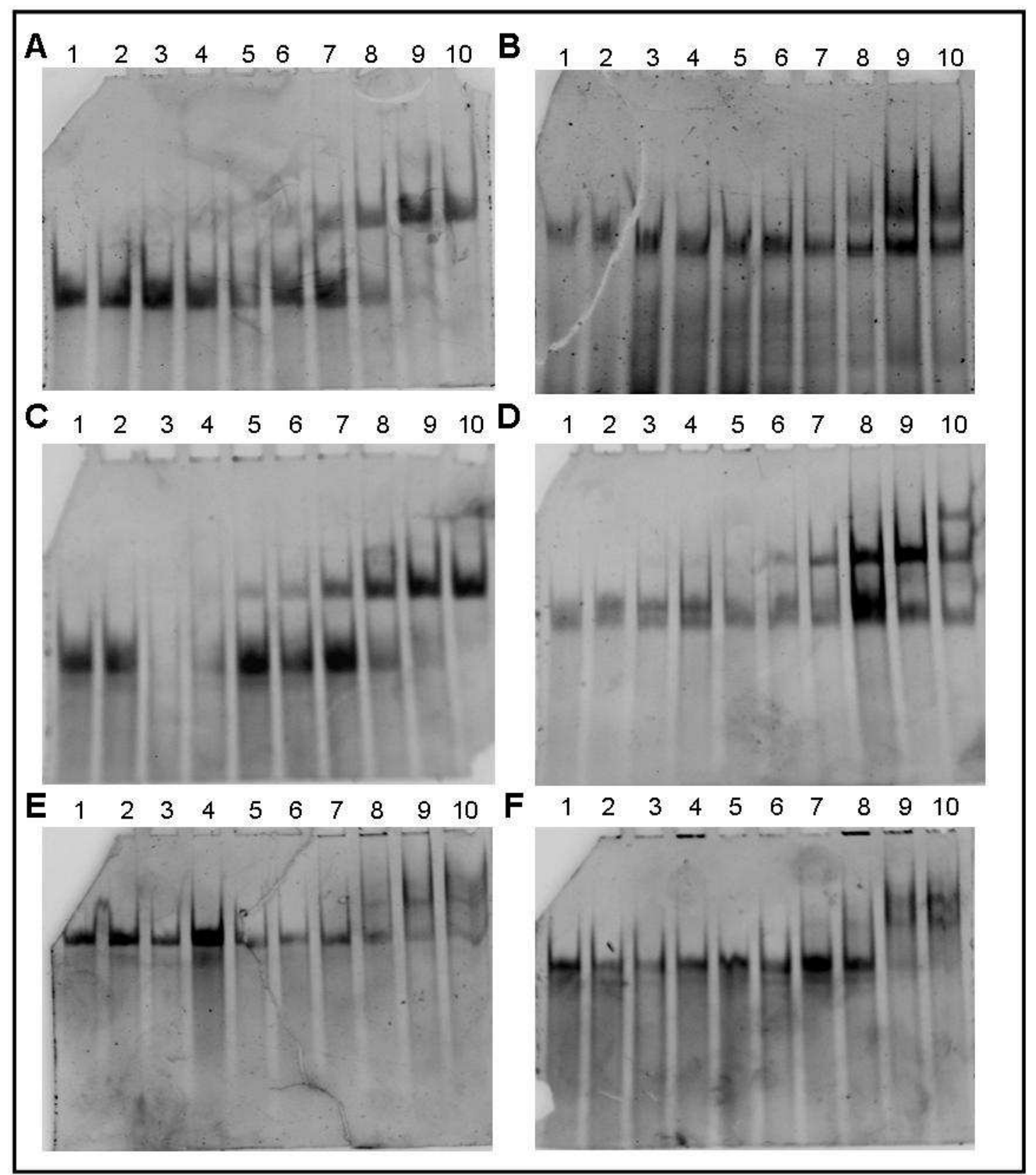

Abb. 4.27.:EMSAs mit His(10)-YhbJ und verschiedenen RNAs

Um eine Interaktion zwischen aufgereinigtem rekombinantem His(10)-YhbJ (siehe 4.6.1.) und durch in vitro-Transkription (siehe 3.6.3.) generierten RNAs zu untersuchen, wurden EMSAs wie unter 3.8.1. beschrieben durchgeführt.

(A) His(10)-YhbJ und GlmY (prozessiert), (B) His(10)-YhbJ und GlmY (unprozessiert), (C) His(10)-YhbJ und GImZ (prozessiert), (D) His(10)-YhbJ und GlmZ (unprozessiert), (E) His(10)YhbJ und SraC, (F) His(10)-YhbJ und SraC (r/c)

$1=30 \mathrm{pMol}$ RNA ohne Protein, $2=30 \mathrm{pMol}$ RNA +1 pMol His(10)-YhbJ, 3=30pMol RNA +2 pMol His(10)-YhbJ, 4= 30pMol RNA + 3 pMol His(10)-YhbJ, 5= 30pMol RNA + 4 pMol His(10)YhbJ, 6= 30pMol RNA + 5 pMol His(10)-YhbJ, 7= 30pMol RNA + 10 pMol His(10)-YhbJ, 8= 30 pol RNA + 20 pMol His(10)-YhbJ, 9=30pMol RNA + 30 pMol His(10)-YhbJ,10=30pMol RNA + 40 pMol His(10)-YhbJ

Es ist für alle verwendeten RNAs ein konzentrationsabhängiger Shift durch His(10)-YhbJ erkennbar.

Um die Spezifität der Interaktion von His(10)-YhbJ mit RNAs zu untersuchen, wurden EMSAs mit in vitro-transkribierter $\mathrm{SraC}$ und einer $\mathrm{zu}$ SraC revers-komplementären Sequenz (SraC r/c) durchgeführt. SraC (Abb. 4.27.E) zeigt eine schwache Interaktion 
mit His(10)-YhbJ bei Verwendung von 20 pMol Protein oder mehr. Diese Interaktion ist in ihrem Muster mit dem Ergebnis des EMSA mit unprozessierten GlmZ vergleichbar, jedoch scheint die Interaktion schwächer zu sein.

$\mathrm{SraC}$ r/c (Abb. 4.27.F) zeigt einen Shift, wenn eine äquimolare Menge His(10)-YhbJ oder mehr eingesetzt wurde.

Zusammenfassend konnte gezeigt werden, dass His(10)-YhbJ in vitro mit RNA interagiert und einen stabilen Kompex bildet. Jedoch ist die Spezifität dieser Interaktion ungeklärt.

Um ein weiteres Spektrum an Mischungsverhältnissen abzudecken, wurden nachfolgend EMSAs mit einer RNA-Menge von 50 pMol und Proteinmengen 0 pMol bis $150 \mathrm{pMol}$ durchgeführt (siehe Abb. 4.28.). Hierbei zeigten sich vergleichbare Ergebnisse wie in dem ersten Satz Experimente. Zusätzlich war nun ein zweistufiger Shift der RNA-Bande sichtbar. Im Falle von GlmY (prozessiert) tritt der erste Shift bereits bei Zugabe geringer Mengen His(10)-YhbJ auf (siehe Abb. 4.28.A Spur 2). Bei Zugabe von 30 pMol Protein oder mehr findet ein vollständiger erster Shift der RNABande statt (siehe Abb. 4.28.A Spur 4 bis 10), während verstärkt der zweite Shift sichtbar wird. Wenn ein mindestens doppelter molarer Überschuß an His(10)-YhbJ zugesetzt wurde (siehe Abb. 4.28.A Spur 8 bis 10) ist ein vollständiger Übergang in den zweiten Shift zu erkennen.

Im Fall von GlmY (unprozessiert) folgt die Bindung einer unterschiedlichen Dynamik (siehe Abb. 4.28.B): Zwar findet auch hier sofort mit Zugabe von His(10)-YhbJ ein erster Shift statt (siehe Abb. 4.28.B. Spur 2), jedoch ist selbst bei sehr hohen Proteinmengen noch immer nicht-komplexierte RNA detektierbar (siehe Abb. 4.28.B. Spur 10). Interessanterweise geht der erste Shift jedoch wie im Fall von GlmY (prozessiert) bei Zugabe von 100 pMol Protein vollständig in den zweiten Shift über. Dies lässt Raum für die Vermutung, dass aus ungeklärter Ursache nicht alle RNAMoleküle in diesem Ansatz für eine Interaktion mit His(10)-YhbJ zugänglich sind.

In einem entsprechenden EMSA mit GlmZ (prozessiert) zeigt dieses ein ähnliches Verhalten wie GlmY (prozessiert) (vergleiche Abb. 4.28.A. und C.). Bereits bei Anwesenheit sehr geringer Proteinmengen kommt es zu einem ersten Shift (siehe Abb. 4.28.C. Spur 2), jedoch findet hier ein vollständiger Übergang der RNA-Bande in den ersten Shift erst bei Proteinmengen größer als 50 pMol statt. Ebenso findet zwar ein von der eingesetzten Proteinmenge abhängiger Übergang in den zweiten Shift statt, jedoch 
tritt dieser erst bei höheren Proteinmengen ein und ist selbst bei Verwendung eines dreifachen molaren Überschußes an His(10)-YhbJ unvollständig.

Aus diesen Beobachtungen lässt sich schließen, dass die prozessierten Formen von GlmY und GlmZ über denselben oder einen sehr ähnlichen Mechanismus mit His(10)YhbJ interagieren, jedoch His(10)-YhbJ eine höhere Affinität zu GlmY (prozessiert) besitzt.

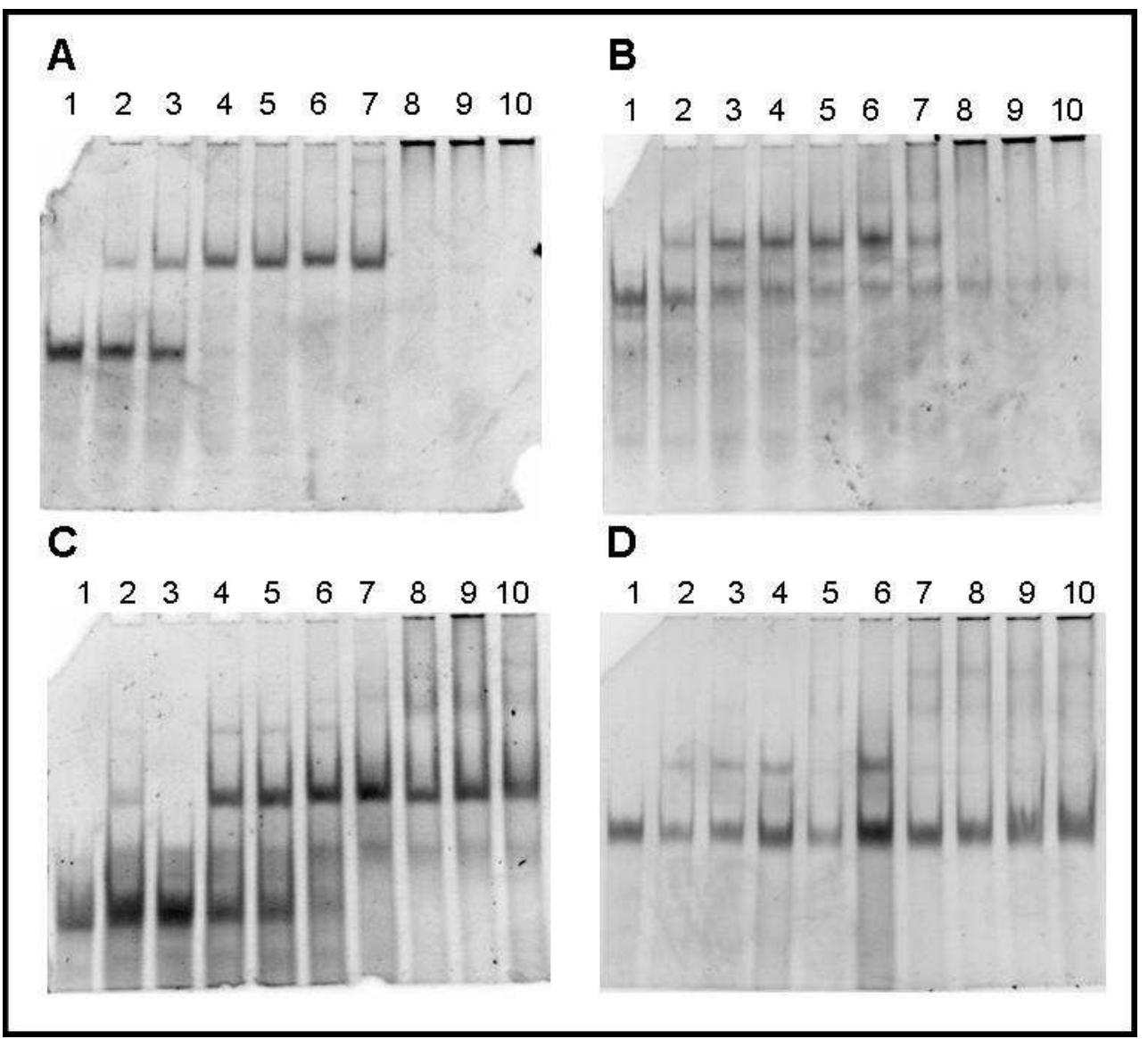

Abb. 4.28.: EMSA mit His(10)-YhbJ und GImY sowie GImY

Um die Interaktion zwischen aufgereinigtem His(10)-YhbJ und der unprozessierten sowie prozessierten Form von GImY beziehungsweise GlmZ näher zu charakterisieren, wurden EMSA s(siehe 2.8.1.) mit 50 pMol RNA und bis zu 150 pMol Protein durchgeführt..

(A) His(10)-YhbJ und GlmY (prozessiert), (B) His(10)-YhbJ und GlmY (unprozessiert), (C) His(10)-YhbJ und GlmZ (prozessiert), (D) His(10)-YhbJ und GlmZ (unprozessiert)

Es ist ein konzentrationsabhängiger Shift der RNA-Bande erkennbar. Details siehe Kapitel 3.6.2.

$1=50 \mathrm{pMol}$ RNA ohne Protein, $2=50 \mathrm{pMol}$ RNA $+10 \mathrm{pMol}$ His(10)-YhbJ, $3=50 \mathrm{pMol}$ RNA +20 pMol His(10)-YhbJ, 4=50pMol RNA +30 pMol His(10)-YhbJ, 5=50pMol RNA +40 pMol His(10)-YhbJ, 6=50pMol RNA $+50 \mathrm{pMol} H$ His(10)-YhbJ, 7=50pMol RNA + 75 pMol His(10)YhbJ, 8= 50pMol RNA + 100 pMol His(10)-YhbJ, 9= 50pMol RNA + 125 pMol His(10)-YhbJ, 10= 50pMol RNA + 150 pMol His(10)-YhbJ.

Neben den bereits in Abb. 4.27. beobachteten Shifts ist nun für alle RNAs ein zweiter Shift bei hohen Proteinkonzentrationen zu beobachten (Einzelheiten siehe Text)

Ein EMSA mit GlmZ (unprozessiert) zeigt ein Bild, welches mit dem bei Verwendung von GlmY (unprozessiert) vergleichbar ist (Abb. 4.28.D.): Es kommt wie bei allen durchgeführten Experimenten zu einem sofortigen ersten Shift, wenn His(10)-YhbJ 
zugesetzt wird, und dieser geht bereits ab einer Proteinkonzentration von mehr als 50 pMol vollständig in den zweiten Shift übergeht. Es sind jedoch auch bei Verwendung eines dreifachen molaren Überschusses noch deutliche Mengen nicht-komplexierter RNA nachweisbar. Demnach scheint es auch hier der Fall zu sein, dass ein Teil der RNA nicht zugänglich für eine Komplexbildung mit His(10)-YhbJ ist.

Somit lässt sich zusammenfassen, dass His(10)-YhbJ in der Lage ist, Komplexe mit RNA-Molekülen zu bilden. Hierbei zeigt sich eine Präferenz zum Einen zu GlmY, zum Anderen zu den prozessierten Formen der RNAs.

Desweiteren bindet His(10)-YhbJ im EMSA jede verwendete RNA, einschließlich die funktionell nicht verwandten sRNA SraC, eine Sequenz, die revers-komplementär zu SraC ist sowie die kleine RNA SraF und ein RNA-Stück, dass 200 bp der lacZ-mRNA repäsentiert (Daten nicht gezeigt).

\subsection{Expression des rpoN-Operons}

Das Muster der Expression des rpoN-Operons ist bislang ungeklärt. Es wurden Transkripte nachgewiesen, die entweder das gesamte Operon umfassen und ihren Startpunkt am $\sigma^{70}$ Promotor vor rpoN haben, sowie Transkripte, die auf einem Durchlesen ausgehend vom lptB-Promotor beruhen und somit zusätzlich zum rpoNOperon auch lptB und Bereiche stromaufwärts von dessen Startpunkt umfasst (Rhodius 2005, vergleiche auch 1.2.). Jedoch ist unklar, zu welchem Maß diese Einzelaktivitäten zur Gesamt-Expression des Operons beitragen.

Zusätzlich gibt es Berichte über eine $\beta$-Galaktosidase-Aktivität, wenn Fragmente stromabwärts des beschriebenen rpoN-Promotors zwischen rpoN und yhbJ an lacZ fusioniert werden(Powell et al. 1995). Zwischen den Genen hpf und ptsN befindet sich ein intergenischer Bereich von 120 bp. Für die korrespondierende mRNA kann mittels mFold (Zuker 2003) eine Haarnadelstruktur in vorhergesagt werden, die die Ribosomenbindestelle von ptsN überdecken würde und welche zudem eine potenzielle Bindestelle für die kleine RNA GlmZ darstellen könnte (B. Görke, persönliche Kommunikation).

Desweiteren ist im 3'-Bereich dieser intergenischen Region eine Sequenz mit Homologie zu der beschriebenen NagC-Bindestelle (El Qaidi et al. 2008) lokalisiert, die mit der letzten Base des $h p f$-Gens überlappt. 
4.5.1. Untersuchung zur Expression des rpoN-Operons mittels lacZ-Reporterfusionen

Um den bekannten Promotoren, die zur Expression des rpoN-Operons beitragen, eine Einzelaktivität zuzuordnen, wurden translationelle lacZ-Fusionen mit unterschiedlichen Bereichen des Operons und der Sequenzen stromaufwärts von rpoN generiert.

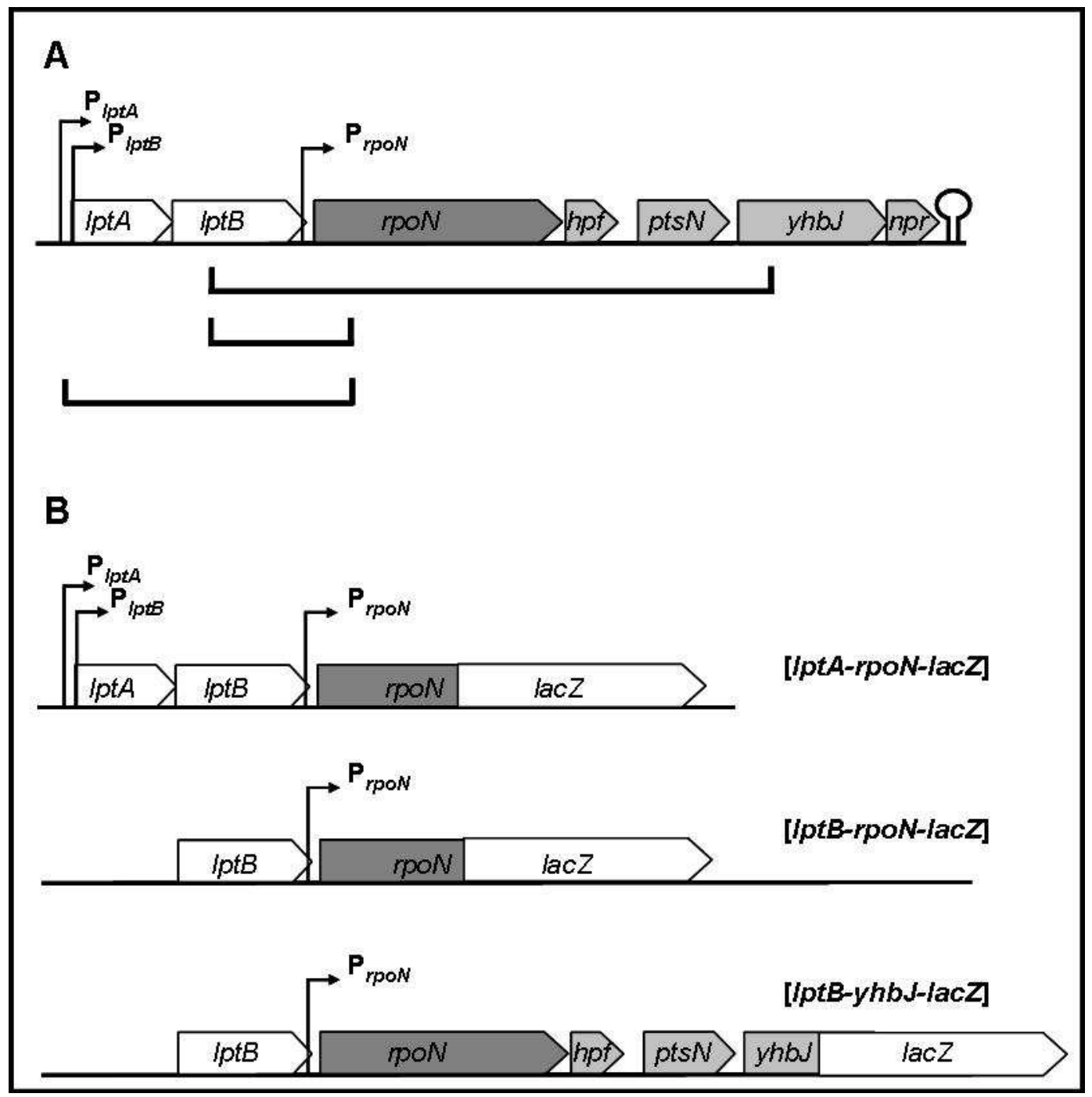

Abb. 4.29.: Reporterfusionen zur Untersuchung der Expression des rpoN-Operons in $E$. coli

(A) Schematische Darstellung des rpoN-Operons in E. coli. rechtwinklige Pfeile symbolisieren Promotoren, das Haarnadel-Symbol den Terminator des Operons. Die Klammern unter der Abbildung markieren die an lacZ fusionierten Bereiche.

(B) Schematische Darstellung der [IptA-rpoN-lacZ]-, [lptB-rpoN-lacZ]- und [lptB-yhbJ-lacZ]Reporterfusion.

Die [lptA-rpoN]-lacZ-Reporterfusion (pBGG165) umfasst die beiden Promotoren des lptAB-Operons sowie den Promotor vor rpoN umfasst (lptA (-152) bis rpoN (+79)) und dient der Bestimmung der Gesamtexpression des rpoN-Operons 
Um die Stärke des Promotors vor rpoN zu bestimmen, wurde in der [lptB-rpoN]-lacZReporterfusion (pBGG166) der Bereich direkt stromaufwärts von rpoN (lptB (+100) bis rpoN (+79)) an lacZ fusioniert

Das letzte Konstrukt, die [lptB-yhbJ]-lacZ-Reporterfusion (pBGG168), trägt eine den gesamten Bereich zwischen den Sequenzen direkt stromaufwärts von $r p o N$ bis zum 5'Bereich von $y h b J$ an $l a c Z$ fusioniert und umfasst somit neben dem Promotor vor rpoN auch den zuvor beschriebenen intergenischen Bereich zwischen hpf und ptsN (lptB $(+100)$ bis $y h b J(+168))$. Mit dieser Fusion kann untersucht werden, ob die Sequenz stromabwärts vom rpoN-Promotor einen Einfluß auf die Transkription oder Translation von yhbJ hat.

Zur Untersuchung der rpoN-Expression wurde der Wildtyp R1279 sowie die Stämme $\Delta$ yhbJ (Z37), $\Delta$ ptsN (Z79) und $\Delta$ rpoN (Z184) mit Plasmiden transformiert, die die in Abb. 4.29.B beschriebenen Reporterfusionen trugen (siehe 3.3.3.). Die Transformanten wurden in LB-Medium bis zum Erreichen einer $\mathrm{OD}_{600}$ von 0,6 inkubiert und anschließend $\beta$-Galaktosidase-Aktivitätsmessungen durchgeführt (siehe 3.3.4.). Die Ergebnisse dieser Analysen sind in Abb. 4.30. dargestellt. In allen Stämmen zeigt sich nur ein schwacher Unterschied zwischen der [lptA-rpoN]- und der [lptB-rpoN]-lacZReporterfusion (siehe Abb. 4.30.). Dies weist darauf hin, dass die Promotoren des lptAB-Operons unter diesen Bedingungen keinen signifikanten Einfluß auf die Expression des rpoN-Operons haben und diese größtenteils vom rpoN-Promotor ausgeht.

Im Gegensatz hierzu weist die Aktivität der [lptB-yhbJ]-lacZ-Reporterfusion eine um einen Faktor von 2,5 geringere Aktivität gegenüber dem der [lptB-rpoN]-lacZ-Fusion auf. Dies ist ein Hinweis darauf, dass ein zusätzliches regulatorisches Ereignis stromabwärts des rpoN-Promotors stattfindet.

In den Stämmen $\Delta y h \mathrm{bJ}(\mathrm{Z} 37), \Delta p t s N(\mathrm{Z79})$ und $\Delta r p o N(\mathrm{Z} 184)$ ist das Verhalten der lacZ-Reporterfusionen nicht von den Messwerten im Wildtyp unterscheidbar. Dies lässt den Schluß zu, dass YhbJ und EIIA ${ }^{\mathrm{Ntr}}$ nicht an der Regulation des rpoN-Operons beteiligt sind. Auch eine Autoregulation der $p t s N$ - beziehungsweise $y h b J$-Expression kann ausgeschlossen werden. Zudem zeigen diese Messungen, dass die Expression des rpoN-Operons weder direkt noch indirekt von der Anwesenheit des durch rpoN kodierten alternativen $\sigma$-Faktor $\sigma^{54}$ abhängig ist. 


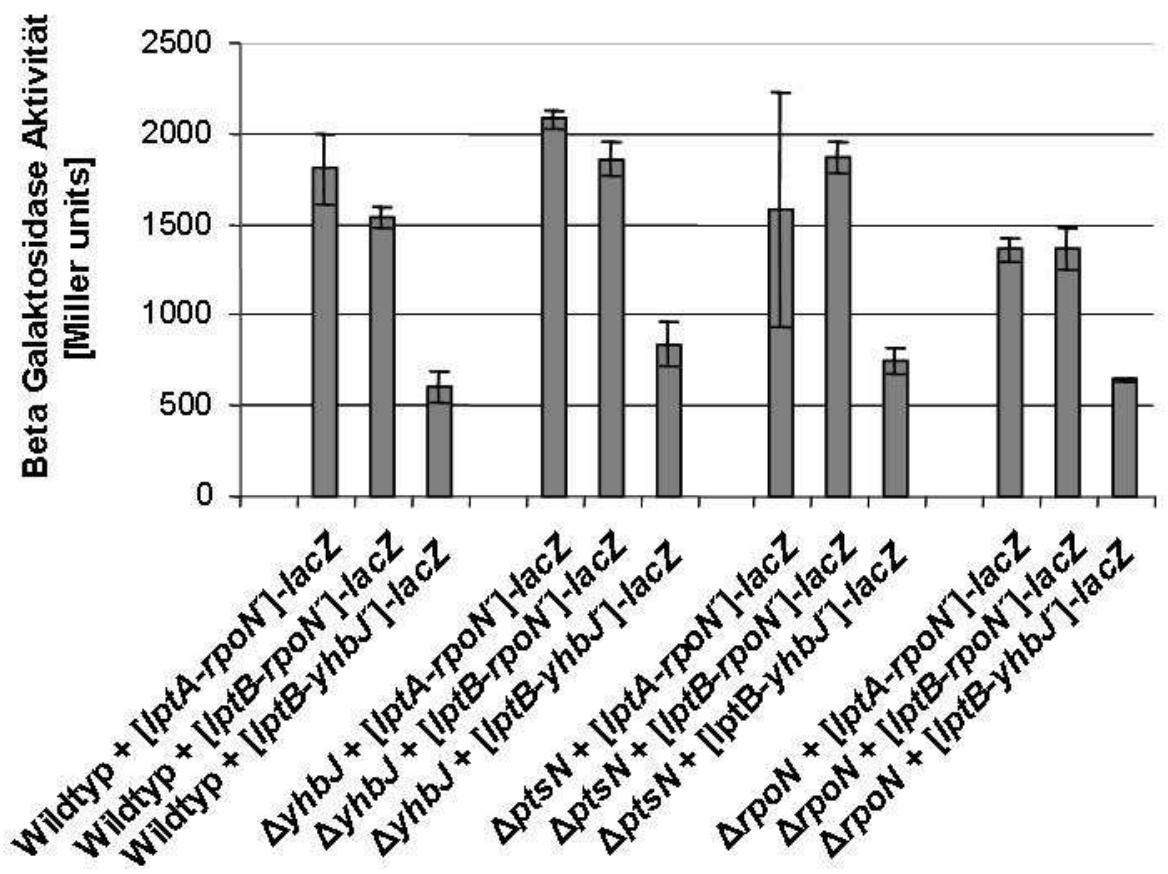

Abb. 4.30.: $\beta$-Galaktosidase Aktivitätsmessung zur Expression des rpoN-Operons.

Der Wildtyp R1279 sowie die Stämme $\Delta y h b J$ (Z37), $\Delta p t s N(Z 79)$ und $\Delta r p o N$ (Z184) wurden mit Plasmiden transformiert, die die Reporterfusionen [/ptA-rpoN]-lacZ (pBGG165), [/ptB-rpoN]-lacZ (pBGG166) und [lptB-yhbJ]-lacZ (pBGG168) tragen. Die Transformanten wurden in LB-Medium inkubiert, bis eine $\mathrm{OD}_{600}$ von 0,6 erreicht wurde. Anschließend wurde die $\beta$-Galaktosidase Aktivität wie unter 3.3.4. beschrieben bestimmt.

Es ist kein signifikanter Unterschied zwischen den verwendeten Stämmen erkennbar.

Um einen Einfluß von YhbJ auf seine eigene Expression auszuchließen, wurde die Aktivität der [lptA-rpoN]-lacZ-, [lptB-rpoN]-lacZ- und [lptB-yhbJ]-lacZ-Reporterfusion zusätzlich bei $y h b J$-Überexpression von einem Plasmid aus (pBGG119, pBAD33::yhbJ) untersucht. Die Messwerte sind in Abbildung 4.31. dargestellt.

Die Anwesenheit des $y h b J$-kodierenden Plasmides führt zu einer erniedrigten Aktivität der Reporterfusionen (Faktor 5, beispielsweise [lptA-rpoN]-lacZ in R1279 = 1805 Miller units, [lptA-rpoN-lacZ] in R1279 mit pBAD33::yhbJ = 342 Miller units), jedoch ist das Verhältnis der Aktivität von [lptA-rpoN]-lacZ-, [lptB-rpoN]-lacZ- und [lptB$y h b J$-lacZ-Reporterfusion zueinander dasselbe wie im Wildtyp (3:2,5:1). Zusätzlich hat die Induktion der Expression von yhbJ durch L-Arabinsoe keinen Effekt auf die Reporteraktivität.

Somit kann aus diesen Daten geschlossen werden, dass YhbJ keinerlei direkten oder indirekten Einfluß auf die Expression des rpoN-Operons hat 


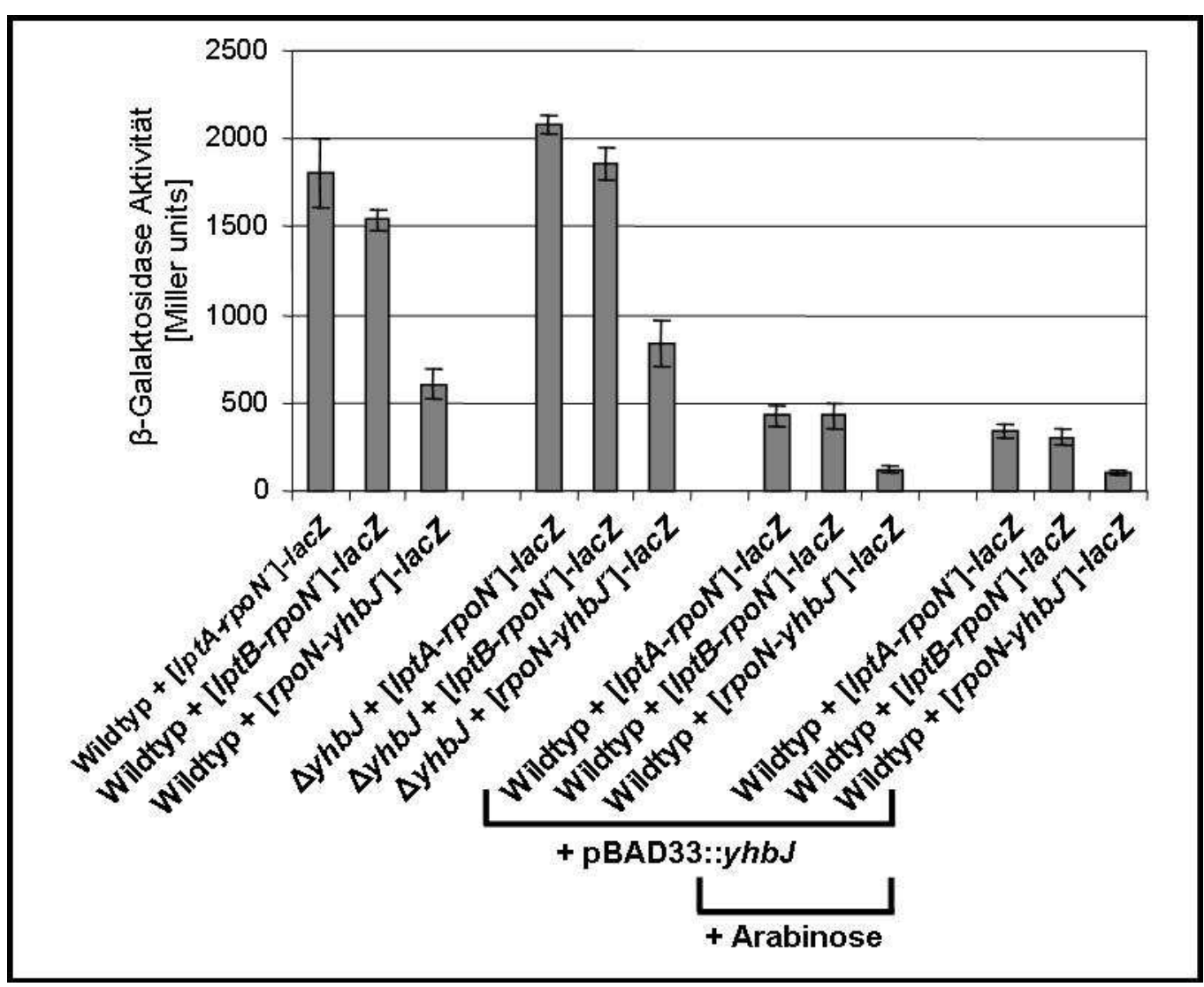

Abb. 4.31.: $\beta$-Galaktosidase Aktivitätsmessung zum Einfluß von YhbJ auf die Expression des rpoN-Operons.

Der Wildtyp (R1279), und ein $\Delta y$ hbJ-Stamm (Z37), sowie der Wildtyp transformiert mit einem Plasmid, das yhbJ unter $P_{a r a}$-Kontrolle kodiert (pBGG119) wurden mit den Plasmiden transformiert, die die [IptA-rpoN]-lacZ-, [lptB-rpoN]-lacZ- und [/ptB-yhbJ-lacZ-Reporterfusion tragen. Die Transformanten wurden in LB-Mediumn inkubiert, bis sie eine ${ } D_{600}$ von 0,6 erreichten und die $\beta$-Galaktosidase Aktivität wie unter 2.3.4. beschrieben bestimmt.

Obwohl die Anwesenheit des yhbJ-kodierenden Plasmids die Aktivität der Reporterfusionen um den Faktor 5 erniedrigt, bleibt das Verhältnis der drei Reporterfusionen zueinander gleich (3:2,5:1). Zusätzlich hat die Induktion der yhbJ-Epression durch Arabinose keinen Effekt auf die Reporteraktivität.

Die Anwesenheit des $y h b J$-kodierenden Plasmides führt zu einer erniedrigten Aktivität der Reporterfusionen (Faktor 5, beispielsweise [lptA-rpoN]-lacZ in R1279 = 1805 Miller units, [lptA-rpoN]-lacZ in R1279 mit pBAD33::yhbJ = 342 Miller units), jedoch ist das Verhältnis der Aktivität der [lptA-rpoN]-, [lptB-rpoN]- und [lptB-yhbJ]-lacZReporterfusionen zueinander dasselbe wie im Wildtyp (3:2,5:1). Zusätzlich hat die Induktion der Expression von $y h b J$ durch L-Arabinose keinen Effekt auf die Reporteraktivität.

Somit kann aus diesen Daten geschlossen werden, dass YhbJ keinerlei direkten oder indirekten Einfluß auf die Expression des rpoN-Operons hat 


\subsubsection{Einfluß des Aminozucker-Metabolismus auf die Expression des $r p o N$-Operons}

Um die Funktion des potenziellen NagC-Bindemotives im 5'-Bereich des intergenischen Bereiches zwischen $h p f$ und $p t s N$ zu untersuchen, wurde die Aktivität der [lptA-rpoN]-, [lptB-rpoN]- und [lptB-yhbJ]-lacZ-Reporterfusionen (vergleiche 4.5.1.) in einem Stamm bestimmt, der eine nagC::tc-Deletion trägt (Z12, siehe Tab. 7.1.). NagC ist der zentrale transkriptionelle Regulator des Aminozucker-Stoffwechsels in E. coli (siehe 2.3.3.). Die Bindung des Regulators an spezifische DNA-Motive ist gut untersucht und beschrieben (El Qaidi et al. 2008). Solange kein externer Aminozucker verfügbar ist, kann das Protein als Dimer an A/T-reiche DNA-Sequenzen binden, die ein konserviertes TT- $\mathrm{X}_{9}-\mathrm{AA}$ beinhalten. Sollte ein entsprechendes AminozuckerMetabolit verfügbar werden, so wird dieser zu GlcNAc-6-P umgesetzt, welches mit NagC interagiert. Dadurch verliert NagC sowohl die Fähigkeit zur Dimerisierung als auch zur Bindung seiner Operatorsequenzen auf der DNA.

Die Aktivität der [lptA-rpoN]-lacZ-, [lptB-rpoN]-lacZ- und [lptB-yhbJ]-lacZReporterfusion ist in Abb. 4.32. dargestellt.

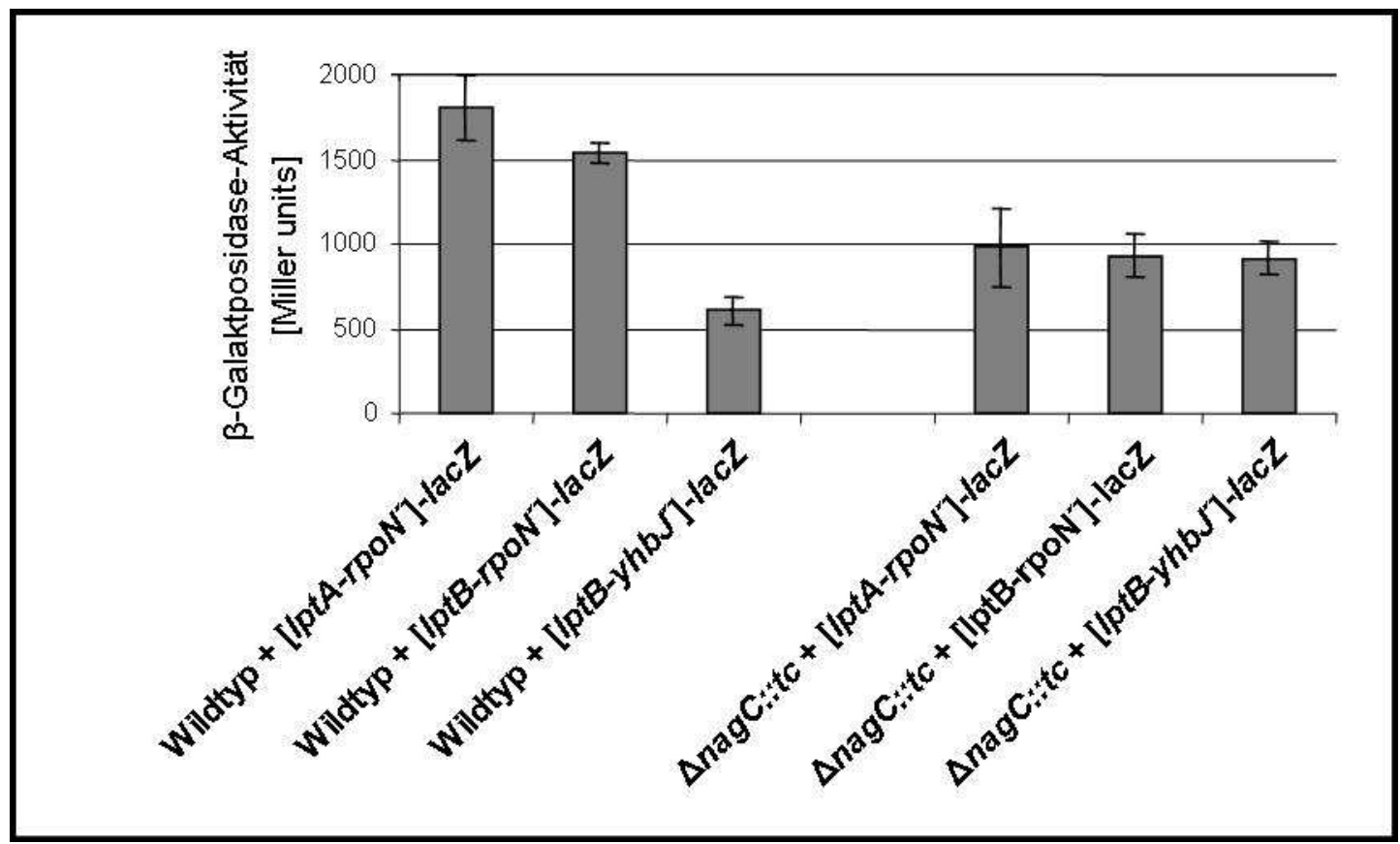

Abb. 4.32.: $\beta$-Galaktosidase Aktivitätsmessung zum Einfluß von NagC auf die Expression des rpoN-Operons.

Der Wildtyp R1279 sowie ein $\triangle$ nagC::tc-Stamm (Z12) wurden mit Plasmiden transformiert, die die [IptA-rpoN]-, [IptB-rpoN]- und [IptB-yhbJ]-lacZ-Reporterfusionen tragen (pBGG165, pBGG166 und pBGG168). Die Transformanten wurden in LB-Medium inkubiert, die eine $\mathrm{OD}_{600}$ von 0,6 erreicht wurde und anschließend die $\beta$-Galaktosidase Aktivität wie unter 3.3.4. beschrieben bestimmt.

Im Gegensatz zum Wildtyp R1279 weist der $\Delta$ nagC::tc-Stamm für alle drei Reporterfusionen eine vergleichbare Aktivität auf. 
Im Wildtypstamm R1279 wurde, wie schon in Abb. 4.30. gezeigt., bei Verwendung der [lptA-rpoN]- und [lptB-rpoN]-lacZ-Reporterfusionen eine $\beta$-Galaktosidase-Aktivität von 1500 und 1800 Miller units gemessen, während die Aktivität bei Verwendung der [lptB$y h b J$-lacZ-Reporterfusion nur 600 Miller units beträgt.

In dem nagC::tc-Deletionsstamm (Z12) hingegen ergab eine Bestimmung der $\beta$ Galaktosidase-Aktivität bei allen drei Reporterfusionen Werte zwischen 900 und 1000 Miller units. Somit ist die Aktivität der [lptA-rpoN]- und [lptB-rpoN]-lacZReporterfusionen (pBGG165 und pBGG166), die die Aktivität des rpoN-Promotors wiederspiegeln, um einen Faktor von 1,5 erniedrigt, während die Aktivität der [lptByhbJ]-lacZ-Fusion ( pBGG168) um denselben Faktor von 1,5 erhöht ist.

Interessanterweise können diese Ergebnisse so gedeutet werden, dass NagC einen leichten aktivierenden Einfluß auf den rpoN-Promotor besitzt, während es gleichzeitig einen gleichstarken reprimierenden Einfluß auf die Expression stromabwärts gelegener Gene nimmt. Diese Theorie weist Ähnlichkeit zur Beeinflussung der beiden Promotoren vor $g \operatorname{lm} U$ durch NagC auf: Hier führt die Bindung von NagC an die DNA im Bereich stromaufwärts des glmU-Startcodons zu einer Aktivierung des Promotors P1 bei gleichzeitiger schwacher Repression des dahinterliegenden Promotors P2 (vergleiche 2.3.3.).

Um einen möglichen Einfluß von NagC weiter zu untersuchen, wurden die Aktivitäten der [lptA-rpoN]-, [lptB-rpoN]- und [lptB-yhbJ]-lacZ-Reporterfusion im Wildtyp R1279 in Anwesenheit von 1\% (w/v) GlcNAc im Medium bestimmt. Durch die Zugabe einer externen Aminozucker-Quelle verliert NagC wie zuvor beschrieben seine Fähigkeit zur Bindung an die DNA. Demnach sollten die Ergebnisse dieser Messungen die Ergebnisse der Messung in der nagC::tc-Deletion wiederspiegeln. Die Aktivität der Reporterfusionen unter diesen Bedingungen ist in Abb. 4.33. dargestellt. 


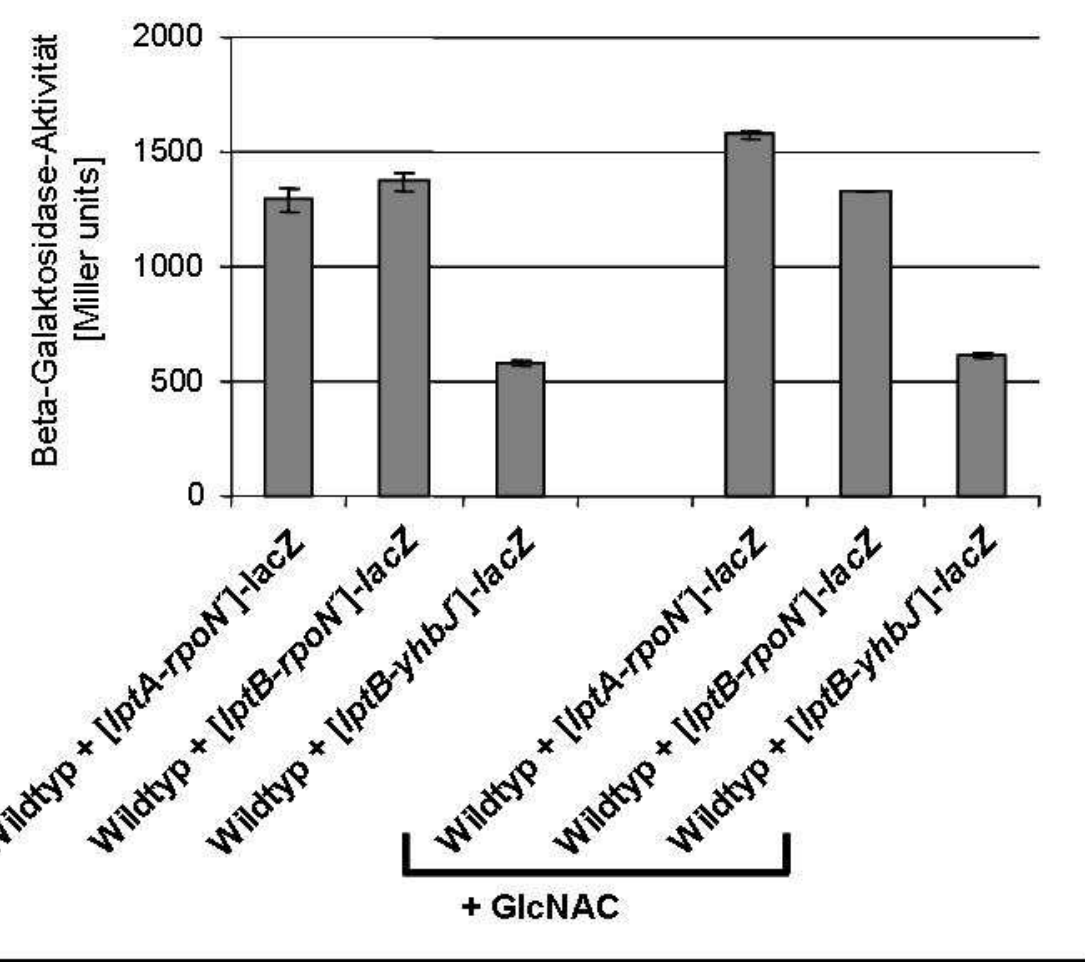

Abb.4.33.: $\beta$-Galaktosidase Aktivitätsmessung zum Einfluß von GIcNAc auf die Expression des rpoN-Operons.

Der Wildtyp R1279 sowie ein $\Delta$ nagC::tc-Stamm (Z12) wurden mit Plasmiden transformiert, die die [IptA-rpoN]-, [IptB-rpoN]- und [IptB-yhbJ]-lacZ-Reporterfusionen tragen (pBGG165, pBGG166 und pBGG168). Die Transformanten wurden in LB-Medium sowie in LB-Medium mit $1 \%(\mathrm{w} / \mathrm{v})$ GlcNAc inkubiert, die eine $\mathrm{OD}_{600}$ von 0,6 erreicht wurde und anschließend die $\beta$ Galaktosidase Aktivität wie unter 2.3.4. beschrieben bestimmt.

Es ist kein signifikanter Unterschied zwischen der Inkubation mit oder ohne 1\% (w/v) GlcNAc erkennbar.

Wie klar erkennbar ist, verhalten sich die drei Reporterfusionen in Anwesenheit von 1\% (w/v) GlcNAc im Medium genau so wie ohne Zugabe einer externen Aminozuckerquelle. Dies widerspricht den in Abb. 4.32. dargestellten Ergebnissen der Aktivitätsbestimmung in einer $\Delta n a g C:$ :tc-Deletion. Da jedoch die Anwesenheit von GlcNAc im Medium die DNA-Bindefähigkeit von NagC aufhebt und somit einen ähnlichen Effekt wie die Deletion von $n a g C$ auf das Expressionsmuster haben sollte, ist es möglich, dass der in Abb. 4.32. beschriebene Effekt ein stammspezifisches Artefakt für diese Deletion ist.

Somit konnte kein Einfluß von Aminozuckern auf die Expression des rpoN-Operons nachgewiesen werden. 


\subsubsection{Einfluß von GlmY und GlmZ auf die Expression des rpoN-Operons}

Parallel zu dieser Arbeit wurde eine zweite sRNA identifiziert, die an der Regulation der glmS-spezifischen Expression beteiligt ist, GlmY (Reichenbach et al. 2008; Urban und Vogel 2008). Es wurden einige Beispiele für kleine RNAs mit multiplen Zielgenen beschrieben (Guillier et al. 2006), weshalb als nächstes ein möglicher Einfluß der beiden kleinen RNAs auf die Expression des rpoN-Operons untersucht wurde. Ein möglicher Mechanismus wäre, dass YhbJ über die Beeinflussung der Aktivität von GlmZ oder GlmY seine eigene Aktivität beeinflusst.

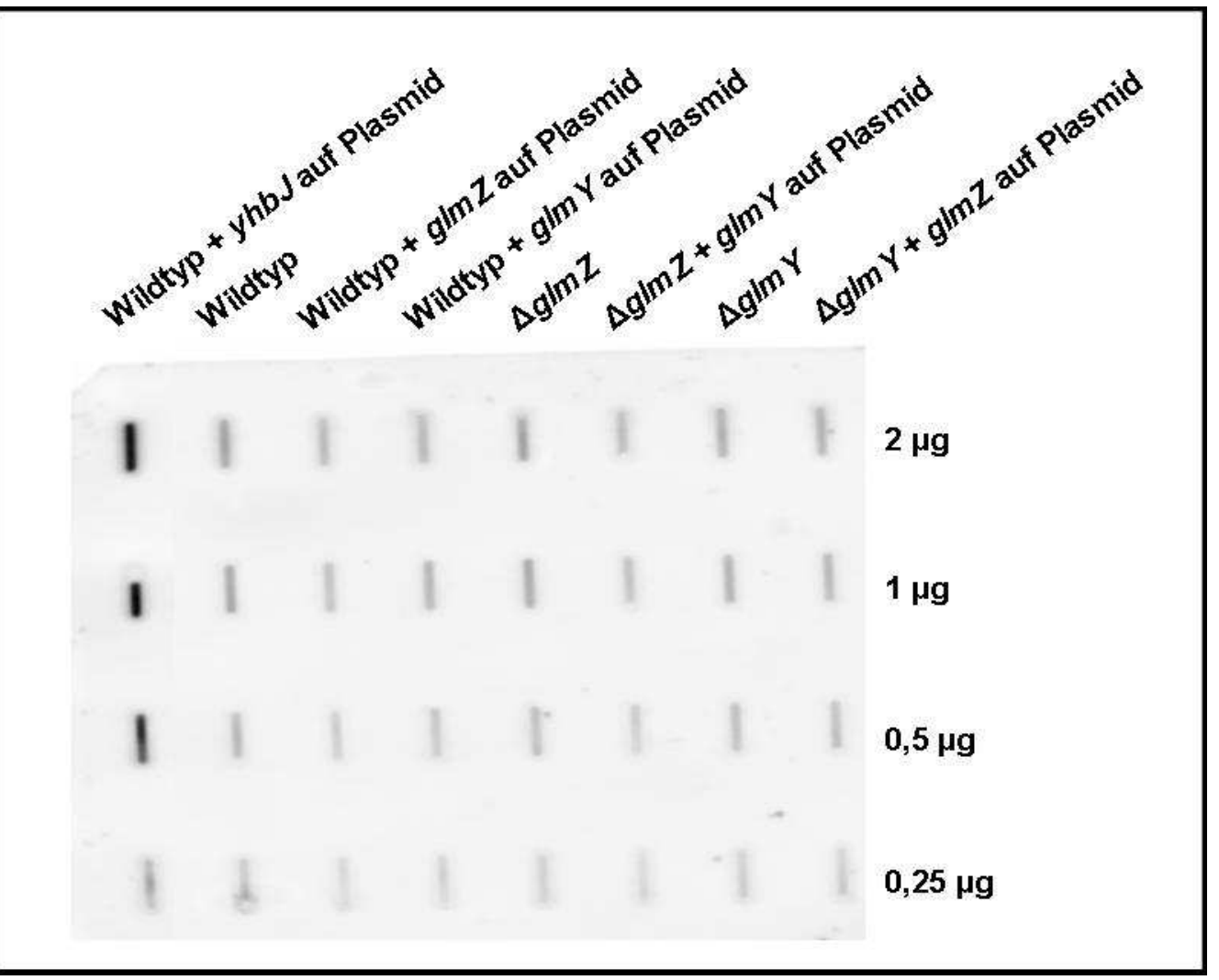

Abb.4.34.: Slot Blot Analyse des Einflußes von GImY und GImZ auf die Expression von yhbJ

Der Wildtyp R1279 sowie die Stämme $\Delta g \operatorname{lmZ}(\mathrm{Z} 45)$ und $\Delta g \operatorname{lm} Y(Z 96)$ und Transformanten des Wildtyps mit einem Plasmid, das yhbJ unter $\mathrm{P}_{\text {tac }}-$ Kontrolle trägt (pBGG119, Positivkontrolle), einem Plasmid mit $g / m Y$ unter $\lambda \mathrm{P}_{\mathrm{L}}$-Kontrolle (pBGG149) und einem Plasmid mitg/mZ unter $\mathrm{P}_{a r a}$ Kontrolle (pBGG84) sowie der Deletionsstämme mit Plasmiden, die die jeweils andere sRNA trugen, wurden in LB-Medium unter Induktion mit $1 \mathrm{mM}$ IPTG beziehungsweise 0,2\% LArabinose inkubiert, bis sie eine $\mathrm{OD}_{600}$ von 1 erreichten. Gesamt-RNA wurde wie unter 3.6.1. beschrieben präpariert und anschließend in einem Slot Blot unter Verwendung einer DIGmarkierten Sonde gegen yhbJ analysiert (siehe 3.6.8.).

Weder die Deletion noch die Überexpression einer der kleinen RNAs hat einen Effekt auf die Transkriptmenge von yhbJ. 
Hierzu wurde der Einfluss von Deletionen als auch der Überexpression der zu den beiden kleinen RNAs korrespondierenden Gene $\operatorname{glm} Z$ und $\operatorname{glm} Y$ auf die Menge des yhbJ-enthaltenden Transkriptes mittels Northern Blot Analyse untersucht.

Der Wildtyp R1279 sowie die Stämme $\Delta g \operatorname{lmZ}$ (Z45) und $\Delta g \operatorname{lm} Y$ (Z96) und Transformanten des Wildtyps mit einem Plasmid, das yhbJ unter $\mathrm{P}_{\text {tac }}$-Kontrolle trägt (pBGG119, Positivkontrolle), einem Plasmid mit $\operatorname{glm} Y$ unter $\lambda \mathrm{P}_{\mathrm{L}}$-Kontrolle (pBGG149) und einem Plasmid mit $g \operatorname{lmZ}$ unter $\mathrm{P}_{a r a}$-Kontrolle (pBGG84) sowie $\Delta g \operatorname{lmZ}$ mit einem Plasmid mit $g \operatorname{lm} Y$ unter $\lambda \mathrm{P}_{\mathrm{L}}$-Kontrolle Plasmiden und $\Delta g \operatorname{lm} Y \operatorname{glmZ}$ unter $\mathrm{P}_{\text {ara }}$-Kontrolle , wurden in LB-Medium unter Induktion mit $1 \mathrm{mM}$ IPTG beziehungsweise 0,2\% LArabinose inkubiert, bis sie eine $\mathrm{OD}_{600}$ von 1 erreichten. Gesamt-RNA wurde wie unter 3.6.1. beschrieben präpariert und anschließend in einem Slot Blot unter Verwendung einer DIG-markierten Sonde gegen $y h b J$ analysiert (siehe 3.6.8.).

Wie klar zu erkennen ist, hat weder eine Deletion noch eine Überexpression einer der beiden sRNAs einen Effekt auf die detektierte Transkriptmenge.

\subsection{Untersuchung der Auswirkungen einer $y h b J$-Deletion mittels MicroArray Analysen}

Um einen möglichen globalen Einfluß einer YhbJ-Deletion auf die Genexpression zu untersuchen, wurden MicroArray Analysen durchgeführt. Hierzu wurde Gesamt-RNA der Stämme JVS-140 (Wildtyp) und JVS-8018 ( $\Delta y h b J)$ wie unter 3.6.12. beschrieben präpariert und mit den Farbstoffen Cy3 und Cy5 markiert. Die MicroArrays wurden dann in der MicroArray Core Facility des Max-Planck-Institutes für Infektionsbiologie, Berlin, durchgeführt und durch Kai Papenfort, AG RNA-Biologie des Max-PlanckInstitutes für Infektionsbiologie, Berlin, ausgewertet. Das Experiment wurde mit sogenannten „Dye-swap“ durchgeführt, das heißt, dass die RNA jedes Stammes sowohl mit Cy3 als auch mit Cy5 markiert und gegeneinander abgeglichen wurden, um eventuelle Unterschiede in der Martkierungseffizienz auszuschließen. Die Ergebnisse sind in den Tabellen 4.3. (erhöhte Expression) und 4.4. (verringerte Expression) aufgeführt, wobei nur Gene berücksichtigt wurden, deren Expression mindestens um einen Faktor von 2,5 verändert war.

Tabelle 4.3.: Gene, deren Expression in einem yhbJ-Deletionsstamm erhöht ist

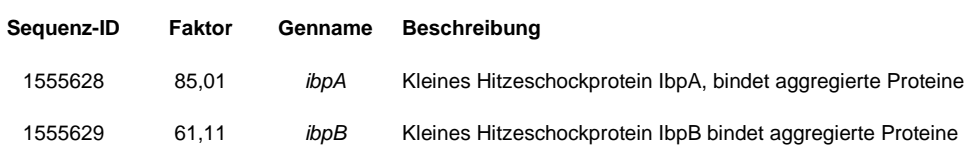




\begin{tabular}{|c|c|c|c|}
\hline 1554953 & 25,82 & pyrB & Katalytische Untereinheit der Aspartat-Carbamoyltransferasease \\
\hline 1554960 & 20,20 & pyrl & Regulatorische Untereinheit der Aspartat-Carbamoyltransferasease \\
\hline 1555678 & 12,25 & $g / m S$ & Glukosamin-6-Phosphat-Synthase \\
\hline 1556250 & 11,90 & carA & Untereinheit der Carbamoyl-Phosphat-Synthase \\
\hline 1555315 & 11,69 & mорА & Untereinheit des GroEL-Chaperones \\
\hline 1555572 & 10,88 & $h s / V$ & Untereinheit der ATPase-Komponente der HsIVU-Protease \\
\hline 1555911 & 10,08 & dnak & Untereinheit des DnaJ/Dank/GrpE-Chaperonkomplexes \\
\hline 1552813 & 10,01 & $y r f G$ & Purin-Nukleotidase der HAD-Familie \\
\hline 1555316 & 9,33 & mopB & Untereinheit des GroES-Regulators \\
\hline 1554517 & 8,67 & $\operatorname{tna} A$ & L-Cystein Desulfhydrase / Tryptophanase \\
\hline 1554518 & 7,67 & tnaB & Tryptophan-Transporter \\
\hline 1554961 & 7,45 & pyrL & Attenuationskontrolle des pyrLBI-Operon \\
\hline 1554501 & 7,18 & thiG & Untereinheit des ThiGH-Thiamin-Biosynthesekomplex \\
\hline 1555272 & 7,12 & $m g l A$ & ATP-bindende Untereinheit des Galaktose ABC-Transporter \\
\hline 1555273 & 7,09 & $m g l B$ & Periplasmatische Bindekomponente des Galaktose ABC-Transporter \\
\hline 1555274 & 6,86 & $m g / C$ & Membranständige Untereinheit des Galaktose ABC-Transporter \\
\hline 1552814 & 6,81 & $y r f H$ & Hitzeschockprotein 15 \\
\hline 1555684 & 6,55 & $g \ln G$ & Aktivator der $\sigma^{54}$-abhängigen Transkription \\
\hline 1556106 & 6,45 & cysH & 3'-Phospho-Adenylylsulfat-Reduktase \\
\hline 1557026 & 6,36 & $a m p D$ & N-Acetyl-Anhydromuramyl-L-Alanin-Amidase \\
\hline 1556197 & 6,30 & $b 4140$ & Protein der inneren Membran, Überexpression verhindert Ausschleusen des Phagen T7 \\
\hline 1555910 & 6,12 & dnaJ & Untereinheit des DnaJ/Dank/GrpE-Chaperonkomplexes \\
\hline 1553230 & 6,05 & yjaB & Potenzielle Acetyltransferase \\
\hline 1552991 & 5,86 & yjcH & Konserviertes Protein der inneren Membran \\
\hline 1555571 & 5,75 & $h s / U$ & Untereinheit der ATPase-Komponente der HsIVU-Protease \\
\hline 1553509 & 5,41 & yhdY & Bestandteil eines potenziellen $\mathrm{ABC}$-Transporter für Aminosäuren \\
\hline 1555460 & 5,27 & lon & Bestandteil der DNA-bindenden Protease La \\
\hline 1556248 & 5,25 & caiF & Transkriptioneller Regulator des anaerober Carnitin-Abbaus \\
\hline 1555858 & 5,02 & frvR & Potenzieller negativer transkriptioneller Regulator eines Zucker-Phosphotransferase-Systems \\
\hline 1556298 & 4,86 & $c l p B$ & ATP-abhängiges molekulares Chaperon \\
\hline 1555888 & 4,68 & fumC & Klasse II Fumarase \\
\hline 1556985 & 4,54 & acs & Acetyl-CoA-Synthetase \\
\hline 1554758 & 4,38 & rhas & Transkriptioneller Aktivator des Rhamnose-Abbaus \\
\hline 1556107 & 4,36 & cysl & Flavi-Reduktase \\
\hline 1555504 & 4,22 & $\operatorname{mcrC}$ & Untereinheit des 5-Methylcytosin-Restriktionssystem \\
\hline 1555139 & 4,07 & $n d k$ & Multifunktionelle Nukleosid-Diphosphat-Kinase \\
\hline 1553071 & 4,05 & yjhH & Potenzielle Lyase/Synthase \\
\hline 1556086 & 4,03 & cycA & Glycin/Serin/Alanin-APC-Transporter \\
\hline 1554111 & 4,00 & ybeY & Protein mit Ähnlichkeit zu Metall-abhängigen Hydrolasen \\
\hline 1556102 & 3,90 & cysC & Adenylylsulfat-Kinase \\
\hline 1555386 & 3,79 & inaA-r & pH-induziertes Protein der Stressantwort \\
\hline 1554955 & 3,77 & pyrD & Dihydroorotat-Oxidase \\
\hline 1552990 & 3,63 & yjcG & Acetat/Glycolat-Permease der SSS-Familie \\
\hline 1554460 & 3,59 & sucC & Succinyl-CoA-Synthetase \\
\hline 1556218 & 3,54 & $b g / F$ & Enzym IIABC des kryptischen $\beta$-Glucosid-PTS-Transporter. \\
\hline 1552815 & 3,53 & yrfl & Hitzeschockprotein 33 \\
\hline 1555250 & 3,48 & menA & 1,4-dihydroxy-2-naphthoat-Octaprenyltransferase \\
\hline 1554112 & 3,45 & ybez & Protein mit potenzieller NTP-Hydrolase-Domäne \\
\hline
\end{tabular}


Ergebnisse

\begin{tabular}{|c|c|c|c|}
\hline 1553798 & 3,40 & $y c j X$ & Konserviertes Protein \\
\hline 1555009 & 3,37 & oppA & ATP-abhängiger Oligopeptid-Transporter der ABC-Superfamilie \\
\hline 1554339 & 3,37 & upp & Uracil-Phosphoribosyltransferase \\
\hline 1555685 & 3,34 & $g / n H$ & Hoch-affiner Glutamin-Transporter der ABC-Superfamilie \\
\hline 1553184 & 3,29 & yigu & Untereinheit des Tat (twin-arginine translocation) -Komplexes \\
\hline 1554319 & 3,25 & $u d h A$ & Lösliche Pyridin-Nukleotid-Transhydrogenase \\
\hline 1556070 & 3,25 & $\operatorname{csp} E$ & multifunktionelles Protein der Kälteschock-Familie \\
\hline 1553892 & 3,25 & yeaD & Konserviertes Protein \\
\hline 1553988 & 3,19 & yceP & Regulator der Biofilmformation \\
\hline 1556347 & 3,12 & isch & Negativer Regulator der iscRSUA-Expression \\
\hline 1555744 & 3,12 & grpE & Untereinheit des DnaJ/Dnak/GrpE-Chaperonkomplexes \\
\hline 1556874 & 3,11 & artP & Untereinheit eines Arginin-Transporter der ABC-Superfamilie \\
\hline 1556193 & 3,08 & $c p x P$ & Negativer Regulator der Cpx-Antwort auf extracytoplasmatische Stress \\
\hline 1556108 & 3,06 & cysJ & Untereinheit des Sulfit-Reduktase Flavoproteins \\
\hline 1555240 & 3,06 & $m d h$ & Malat-Dehydrogenase \\
\hline 1555576 & 3,00 & $h t r A$ & Untereinheit der periplamsatischen Protease Do (DegP) \\
\hline 1555505 & 2,99 & $m c r D$ & konserviertes Protein \\
\hline 1554435 & 2,98 & $y a d D$ & Potenzielle Transposase \\
\hline 1557015 & 2,97 & ald $A$ & Aldehyd-Dehydrogenase A \\
\hline 1555909 & 2,96 & dnaG & DNA-Primase, katalysiert die Synthese von RNA-Primern an einzelsträngiger DNA \\
\hline 1554070 & 2,94 & $y b c U$ & Homolog des Bor-Proteins des Bacteriophagen lambda \\
\hline 1555263 & 2,94 & metF & 5,10-Methylenetetrahydrofolat-Reductase \\
\hline 1556194 & 2,92 & b3914 & Unbekannt \\
\hline 1555241 & 2,92 & $m d h-r$ & Malat-Dehydrogenase \\
\hline 1556987 & 2,90 & add & Deoxyadenosin-Deaminase / Adenosin-Deaminase \\
\hline 1553148 & 2,87 & yid $Y$ & Mitglied der "major facilitator superfamily" (MFS) \\
\hline 1555287 & 2,87 & $\operatorname{mia} A$ & $\delta(2)$-Isopentenylpyrophosphat-tRNA-Adenosin-Transferase \\
\hline 1553958 & 2,87 & $h s p Q$ & Hitzeschockprotein \\
\hline 1553731 & 2,85 & yeic & Pseudouridin-Kinase \\
\hline 1556779 & 2,84 & b1397 & $\beta$-ketoadipyl-CoA-Thiolase des Phenylacetat-Katabolismus \\
\hline 1555432 & 2,80 & $\operatorname{ldh} A$ & D-lactate-Dehydrogenase \\
\hline 1553285 & 2,79 & yhgl & Gerüstprotein für Eisen-Schwefel-Cluster \\
\hline 1556045 & 2,78 & corA & Magnesium-Ionen-Transporter, Mitglied der "Metal Ion Transporter" (MIT)-Familie \\
\hline 1554340 & 2,76 & uraA & Potenzieller hoch-affiner Uracil-Transporter \\
\hline 1553201 & 2,76 & yihR & Potenzielle Aldose-1-Epimerase, involviert in Biofilmbildung \\
\hline 1554950 & 2,76 & putP & Mitglied der SSS-Transporterfamilie \\
\hline 1555086 & 2,75 & phnO & potenzielle Acyltransferase mit Acyl-CoA-N-Acyltransferase-Domäne \\
\hline 1553165 & 2,74 & yifE & konserviertes Protein \\
\hline 1553097 & 2,59 & yjiU & konserviertes Protein \\
\hline 1554110 & 2,58 & ybeX & Potenzieller lonentransporter \\
\hline 1554484 & 2,52 & $t d c D$ & Protein mit Propionat- und Acetat-Kinaseaktivität \\
\hline 1554956 & 2,50 & pyrE & Orotat-Phosphoribosyltransferase \\
\hline 1555164 & 2,50 & $n m p C$ & Mitglied der "General Bacterial Porin" (GBP)-Familie \\
\hline
\end{tabular}

Sequenz-ID= Identifikationsnummer des korrespondierenden Spots auf dem Chip, Faktor= Faktor der Regulation. 
Erwartungsgemäß findet sich hier das Gen $g \operatorname{lm} S$ mit einer der am stärksten erhöhten Expressionen gegenüber dem Wildtyp (Faktor 12), den höchsten Effekt hat eine Deletion von $y h b J$ auf die Expression der Gene $i b p A B$, deren Expression um einen Faktor von 85 beziehungsweise 61 gegenüber dem Wildtyp erhöht ist. Diese Gene kodieren Proteine, die mit der Hitzeschockantwort und der Bildung von sogenannten „,inclusion bodies“ assoziiert sind (Laskowska et al. 1996b). In Tabelle 4.3. findet sich eine Vielzahl weiterer Chaperon- und Protease-kodierende Operone, die in die Antwort auf die Akkumulation fehlgefalteter Proteine, in die Hitzeschockantwort oder andere Stressantworten involviert sind: mopAB (Taguchi 2005), hslUV (Goldberg et al. 1997), dnaJK (Bukau und Horwich 1998), yrfIH (Graf und Jakob 2002), lon (Nishii et al. 2005), clpB (Mogk und Bukau 2004), inaA (White et al. 1992), grpE (Bukau und Horwich 1998), htrA (Seol et al. 1991), cpxP (Danese und Silhavy 1998) und hspQ (Shimuta et al. 2004).

Die Expression von $i b p A B$ wird während der Biofilmbildung erhöht (Ren et al. 2004), enenso wie die Expression von cpxP. Mit yceP ist in der Liste der hochregulierten Gene auch ein Regulator der Biofilm-Bildung enthalten (Beloin et al. 2004; Domka et al. 2006) sowie mit yihR ein weiteres Gen, das in die Biofilm-Bildung involviert ist (Herzberg et al. 2006).

Die Deletion von $y h b J$ hat ebenfalls einen starken Einfluß auf die Expression der Gene pyrB und pyrI. Das Gen pyrB (25fach erhöht) kodiert für die katalytische Untereinheit der Aspartat-Carbamoyltransferase, während das Genprodukt PyrI (20fach erhöht) für die regulatorische Untereinheit desselben Enzyms kodiert (Neidhardt et al. 1996). Die Aspartat-Carbamoyltransferase ist Teil der Pyrmidinsythese und somit der UMPBiosynthese. Beachtenswert ist in diesem Zusammenhang das Gen pyrL, das die Attenuation des gemeinsamen pyrLBI-Operons kontrolliert (Levin und Schachman 1985) und dessen Expression in der $y h b J$-Deletion ebenfalls um einen Faktor von 7,5 erhöht ist. Desweiteren sei auch auf das Gen carA verwiesen, dessen Genprodukt ebenfalls an der Carbamoyl-Synthese beteiligt ist (Thoden et al. 1999), und dessen Expression in einem $\Delta y h b J$-Hintergrund um einen Faktor von 12 erhöht ist.

Die Gene $m g l A B C$ kodieren für einen Galaktose-ABC-Transporter (Wu und MandrandBerthelot 1995) und werden alle in einem $y h b J$-Deletionshintergrund um einen Faktor von 7 verstärkt exprimiert. In Tabelle 4.3. sind einige weitere Bestandteile oder 
vermutete Bestandteile von Transportkomplexen enthalten: yhdY (Saurin et al. 1999), thaB (Edwards und Yudkin 1982), cycA (Robbins und Oxender 1973), yjcG (Gimenez et al. 2003), bglF (Schnetz et al. 1987), oppA(Pearce et al. 1992), glnH (Wu und Mandrand-Berthelot 1995), artP (Linton und Higgins 1998), corA(Smith et al. 1993), putP (Reizer et al. 1994b), ybeX (GOA 2000)und nmpC (Zhai und Saier 2002).

Auffällig in diesem Zusammenhang ist, dass sechs dieser Genen für Bestandteile von Aminosäure-Transportern (tnaB, $y h d Y, c y c A, g \ln H, \operatorname{artP})$ oder Oligopeptide (oppA) kodieren.

Weiterhin beinhaltet die Liste mehrere transkriptionelle Regulatoren, namentlich $\operatorname{gln} G$, welches für NtrC, einen Aktivator der $\sigma^{54}$-abhängigen Genexpression, kodiert (Shiau et al. 1993), sowie caiF (Eichler et al. 1996), frvR (Reizer et al. 1994a), rhaS (Moralejo et al. 1993), iscR (Schwartz et al. 2001) und cpxP (Raivio et al. 1999).

\section{Tabelle 4.4.: Gene, deren Expression in einem yhbJ-Deletionsstamm erniedrigt ist}

\begin{tabular}{|c|c|c|c|}
\hline Sequenz-ID & Faktor & Genname & Beschreibung \\
\hline 1556067 & $-15,31$ & $\operatorname{csp} A$ & RNA-Chaperon, verhindert Bildung von Sekundärstrukturen bei niedrigen Temperaturen \\
\hline 1553461 & $-8,28$ & yhbJ & P-Loop-enthaltendes Protein \\
\hline 1554739 & $-4,74$ & $r f a K$ & Heptosyl-Transferase IV, involviert in die Lipopolysaccharid-Kernbiosynthese \\
\hline 1554481 & $-3,98$ & $t d c A$ & Regulator der LysR-Familie, kontrolliert Gene des Aminosäurekatabolismus \\
\hline 1555519 & $-3,68$ & hepA & Transkriptioneller Aktivator, der die Recyclingrate der RNA-Polymerase erhöht \\
\hline 1553463 & $-3,63$ & yhbM & Lipoprotein, involviert in Zellteilung \\
\hline 1553442 & $-3,56$ & yhaF & $\alpha$-Dehydro- $\beta$-Deoxy- $D$-Glucarat-Aldolase \\
\hline 1556971 & $-3,47$ & aceF & Untereinheit der Pyruvatdehydrogenase \\
\hline 1553455 & $-3,45$ & yhaU & Uncharacterisiertes Mitglied der "major facilitator superfamily" (MFS) \\
\hline 1554745 & $-3,38$ & $r f a Z$ & Protein involviert in die Lipopolysaccharid-Kernbiosynthese \\
\hline 1556476 & $-3,25$ & b2001 & Potenzielles Membranprotein des Prophagen CP4-44 \\
\hline 1553809 & $-3,22$ & $y d a R$ & Potenzieller DNA-bindender transkriptioneller Regulator \\
\hline 1554935 & $-3,19$ & purA & Adenylosuccinat-Synthetase \\
\hline 1554364 & $-3,19$ & $w b b K$ & Protein potenziell involviert in die Lipopolysaccharid-Biosynthese \\
\hline 1555249 & $-3,15$ & melR & Transkriptioneller Aktivator \\
\hline 1554027 & $-2,99$ & $y c h H$ & Potenzielles Protein der inneren Membran \\
\hline 1554440 & $-2,96$ & yadl & Enzym IIA-Domäne des potenziellen $\mathrm{N}$-acetylgalactosamin-PTS \\
\hline 1554744 & $-2,86$ & rfaY & Protein der Lipopolysaccharid-Kernbiosynthese \\
\hline 1553443 & $-2,84$ & yhaG & Galactaratdehydratase \\
\hline 1554012 & $-2,80$ & $y c g E$ & potenzieller DNA-bindender transcriptioneller Regulator \\
\hline 1555109 & $-2,74$ & pmrD & Protein der Polymyxin B Resistenz \\
\hline 1554615 & $-2,67$ & ruvC & Untereinheit des RuvABC-Komplex der Rekombination \\
\hline 1555183 & $-2,66$ & $n t p A$ & Dihydroneopterin-Triphosphat-Pyrophosphohydrolase (DHNTPase) \\
\hline 1552948 & $-2,65$ & yojl & potenzielles Lipoprotein der Thiaminbiosynthese \\
\hline 1555255 & $-2,63$ & menF & Isochorismat-Synthase 2 \\
\hline 1554617 & $-2,61$ & sapA & Untereinheit eines Mitgliedes der ABC-Transporter-Superfamilie \\
\hline 1554422 & $-2,57$ & $y a b O$ & Pseudouridin-Synthase \\
\hline
\end{tabular}




$\begin{array}{llll}1556989 & -2,57 & \text { adhE } & \text { PFL-Deaktivase / Alkoholdehydrogenase / Acetaldehyd-Dehydrogenase } \\ 1555167 & -2,56 & n r d A & \text { B1 Protein der Ribonukleosid-Diphosphat Reduktase } \\ 1553194 & -2,53 & \text { yihK } & \text { Protein potenziell involviert in die Lipopolysachharid-Biosynthese und in Wirtskolonisation } \\ 1552841 & -2,52 & \text { yjjP } & \text { potenzielles Strukturprotein der inneren Membran } \\ 1554847 & -2,50 & \text { rpsC } & \text { S3-Protein der ribosomalen 30S Untereinheit }\end{array}$

Sequenz-ID= Identifikationsnummer des korrespondierenden Spots auf dem Chip, Faktor= Faktor der Regulation (negative Werte geben Erniedrigung an).

Unter den Genen, deren Expression in einem $\Delta y h b J$-Stamm stark verringert ist, weist $\operatorname{csp} A$ den höchsten Effekt auf (Faktor 15). Das korrespondierende Genprodukt ist ein RNA-Chaperon, das die Bildung von Sekundärstrukturen bei niedrigen Temperaturen verhindert (Jiang et al. 1997).

Um einen hohen Faktor von 4,7 ist ebenfalls die Expression von $r f a K$ erniedrigt, dessen Genprodukt an der Lipopolysaccharid-Kern-Biosynthese beteiligt ist (Heinrichs et al. 1998), ebenso zudem finden sich mit rfaYZ zwei weitere Gene des rfaQGPSBIJYZrfaK-Operons in Tabelle 3.4.. Die mit diesen beiden Genen korrespondierenden Proteine sind ebenfalls am Aufbau der Lipopolysaccharide beteiligt (Yethon et al. 1998; Frirdich et al. 2003) genau wie wbbK (GOA et al. 2001) und yihK (Moller et al. 2003). Auch unter den Genen, deren Expression in Abwesenheit von $y h b J$ erniedrigt ist, finden sich solche, die für transkriptionelle Regulatoren kodieren: $t d c A$ (Ganduri et al. 1993), hepA (Sukhodolets et al. 2001), ydaR (Perez-Rueda et al. 2004), melR (Belyaeva et al. 2000) und ycgE (GOA et al. 2001). 


\section{Diskussion}

\subsection{Feedback-Kontrolle der $g l m S$-Expression}

In E. coli sind die Gene $g \operatorname{lm} U$ und $g \operatorname{lm} S$ in einem Operon kolokalisiert, welches von den beiden NagC-kontrollierten Promotoren P1 und P2 vor $\operatorname{glm} U$ aus exprimiert wird. Während GlmU unter allen Bedingungen essentiell für die Synthese von Zellwandvorläufern, und somit für das Überleben der Zelle ist, wird die Glukosamin-6Phosphat Synthase GlmS nur dann benötigt, wenn keine externe Quelle für Aminozucker zur Verfügung steht. Dies warf die Frage auf, wie die Zelle die Aktivität von GlmS steuert, so dass die de novo-Synthese von GlcN-6-P nur dann stattfindet, wenn die Zelle darauf angewiesen ist. Ohne eine derartige Kontrolle würde die konstitutive Aktivität von GlmS auch dann GlcN-6-P synthetisieren, wenn Aminozucker aufgrund eines externen Angebotes als Energiequelle genutzt werden, so dass es zu einer verschwenderischen „Kurzschluss“-Reaktion zwischen GlmS und NagB kommt (vergleiche 2.3.).

In Eukaryoten ist die enzymatische Aktivität von GlmS über eine Feedback-Inhibition durch das zentrale Intermediat stromabwärts im Syntheseweg, UDP-GlcNAc, reguliert (Milewski 2002), oder im Falle des menschlichen Homologs GFAT1, durch das direkte Produkt GlcN-6-P. Im Gram-positiven Bakterium B. subtilis wird die Expression von glmS durch ein Ribozym kontrolliert, welches in Anwesenheit des Produktes GlcN-6-P eine spezifische Spaltung der mRNA katalysiert, was in einer raschen Abbau der mRNA resultiert (Collins et al. 2007).

In dieser Arbeit konnte gezeigt werden, dass die Synthese von GlmS in E. coli ebenfalls einer Feedback-Regulation unterliegt, die auf der posttranskriptionellen Ebene stattfindet: Eine Verarmung von GlcN-6-P, aber keines der stromabwärts gelegenen Intermediate des Syntheseweges, induziert eine stark erhöhte Expression von glmS.

An dieser Regulation sind neben Hfq und RNase E vorallem YhbJ und die kleine RNA GlmZ beteiligt.

In Abwesenheit von $y h b J$ ist die $g \operatorname{lm} S$-Expression stark erhöht. Dies ist strikt abhängig von GlmZ, in einem $\Delta g \operatorname{lmZ}$-Stamm ist der Effekt aufgehoben.

Interaktion von Transkripten mit komplementärer regulatorischer RNA ist ein Modell, dass bereits 1961 als möglicher Kontrollmechanismus der Genexpression vorgeschlagen wurde (Jacob und Monod 1961). Zunächst wurden hauptsächlich antisense-RNAs 
identifiziert, welche in cis mit ihren Zielgenen auf dem Gegenstrang kodiert sind und über perfekte Basenpaarung wirken (Wagner et al. 2002). Es dauerte bis in die 1980er Jahre, bis globale Untersuchungen der RNA einer Zelle Spezies wie Spot42 (Rice et al. 1987) und MicF (Aiba et al. 1987; Andersen et al. 1987) identifizierten, für die eine regulatorische Funktion gezeigt werden konnte und die in trans zu ihren Zielgenen kodiert sind. Im Falle von Spot42 dauerte es noch weitere 15 Jahre, bis eine biologische Rolle zugeordnet werden konnte (Moller et al. 2002). Die Regulation durch kleine, nicht-kodierende RNAs erfolgt meist über einen Mechanismus, in dem die RNA die Ribosomenbindestelle der Ziel-mRNA überdeckt und so die Translation verhindert (Gottesman 2004). Zusätzlich stimuliert diese Interaktion häufig die Degradation der mRNA durch RNase E (Morita et al. 2005).

Die posttranskriptionellen Regulation durch sRNAs ist von Prokaryoten bis hin zu Säugetieren konserviert (Bartel 2004; Gottesman 2005; Storz et al. 2005) und ist vornehmlich in essentielle Vorgänge wie Stressantwort in Bakterien (Gottesman 2004) und zeitlicher Steuerung der Differenzierung Pflanzen (Zhang et al. 2006) beteiligt.

Es wurde gezeigt, dass unter Verarmung der an GlcN-6-P oder in Abwesenheit von YhbJ die unprozessierte, aktive Form von GlmZ in der Zelle akkumuliert (Kalamorz et al. 2007). Die Anwesenheit der unprozessierten Form von GlmZ führt zu einer positiven Kontrolle der Genexpression. Hierbei paart ein Bereich von 15 einzelsträngigen Nukleotiden der sRNA mit dem 5'-Bereich einer Sekundärstruktur an der Ribosomenbindestelle wodurch diese aufgelöst und die Translation der glmS-mRNA ermöglicht wird (siehe Abb.5.1.; (Görke und Vogel 2008; Urban und Vogel 2008)). Diese Interaktion aktiviert nicht nur die Translation, sondern führt auch zu einer signifikanten Stabilisierung des glmS-spezifischen Transkriptes (Kalamorz et al. 2007; Urban und Vogel 2008). Unterstützt wird das beschriebene Modell durch den Umstand, dass nur die unprozessierte Form von GlmZ in der Lage ist, die Akkumulation des glmS-spezifischen Transkriptes zu vermitteln, und dass die Prozessierung der kleinen RNA fast alle an der beschriebenen potenziellen Interaktion beteiligten Basen entfernt (Urban and Vogel 2008).

Eine umgekehrte Regulation, in der ein Verdecken der Ribosomenbindestelle zu einer Destabilisation der mRNA führt, ist für verschiedene sRNAs beschrieben (Morita und Aiba 2006; Prevost et al. 2007).

Einige Beispiele sind bekannt, in denen sRNAs die Translation ihrer Ziel-mRNA stimulieren. Beispielsweise ist die Translation der mRNA des Gens rpoS, kodierend für den alternativen Sigma-Faktor $\sigma^{\mathrm{S}}$, durch eine Haarnadelstruktur an der 
Ribosomenbindestelle stark eingeschränkt. Die Translation kann jedoch durch die sRNAs DsrA und RprA aktiviert werden, deren Basenpaarung mit der rpoS-mRNA die Ausbildung der Sekundärstruktur verhindert (Lease et al. 1998; Majdalani et al. 2002). Parallel hierzu unterliegt die Translation von rpoS einer negativen Kontrolle durch die sRNA OxyS(Zhang et al. 1998).

Die sRNA RhyB kontrolliert Gene des Eisenmetabolismus und ist eines der wenigen Beispiele für eine regulatorische RNA, die sowohl als Repressor wie auch als Aktivator der Translation wirkt. Unter Eisenlimitierung wird eine transkriptionelle Repression des Gens $r h y B$ durch den Hauptregulator des Eisenmetabolismus, Fur, aufgehoben und die sRNA in großen Mengen synthetisiert. Sie bindet daraufhin an spezifische mRNAs, deren Abbau dadurch beschleunigt wird. Zusätzlich zu dieser Wirkung interagiert RhyB mit der shiA-mRNA und aktiviert deren Translation durch Auflösung einer inhibitorischen Sekundärstruktur (Prevost et al. 2007).

Die Interaktion von GadY mit der $g a d X$-mRNA ist der einzige andere beschriebene Fall einer Stabilisierung von mRNA durch sRNA-Bindung. Untypisch ist hier jedoch die Wirkung einer sRNA durch Interaktion mit der 3'-Region der Ziel-mRNA (Opdyke et al. 2004). Somit stellt die Interaktion von GlmZ mit dem $g l m S$-Transkriptes das erste Beispiel für die Stabilisierung der Ziel-mRNA durch Bindung einer sRNA an den nichttranslatierten 5'-Bereich (Kalamorz et al. 2007), siehe Abb. 5.1.).

Die Bindung einer sRNA an ihre Ziel-mRNA ist häufig abhängig von Hfq, welches den RNA:RNA-Komplex stabilisiert. Zudem vermittelt es in vielen Fällen die Degradation des Komplexes (Gottesman 2005; Aiba 2007). Auch im Falle der Kontrolle der glmSExpression durch GlmZ konnte eine starke Abhängigkeit von Hfq gezeigt werden, ein weiterer Hinweis darauf, dass der Mechanismus auf der direkten Interaktion der beiden RNA-Spezies beruht. Hfq hat Homologie zum Protein Sm aus Eukaryoten und Archaea, das ebenfalls in den RNA-Metabolismus involviert ist (Wilusz und Wilusz 2005). Es bildet ringförmige Homo-Hexamere (Møller et al. 2002) und ist ein in großen Mengen vorkommendes Protein: In E. coli liegen etwa 60.000 Proteine dieser Spezies pro Zelle vor (Vassilieva et al. 2002). Es wurde gezeigt, dass Hfq RNA mit hoher Affinität bindet und dass das erkannte Motiv eine kurze A/U-reiche Sequenz gefolgt von einer Haarnadelstruktur ist (Mikulecky et al. 2004). Zusätzlich konnte eine Chaperonaktivität für Hfq gezeigt werden: Die Anwesenheit von Hfq erhöht die Bindung der sRNA DsrA an ihr Ziel rpoS (Arluison et al. 2007). Interessant sind auch Interaktionen von Hfq mit dem RNA-Polymerase-Holoenzym (Sukhodolets und Garges 2003) und mit PNP und 
PAP I (Mohanty et al. 2004), die beide Bestandteil des Degradosoms sind, zumal PAP I ebenfalls eine Rolle in der Regulation der $g \operatorname{lm} S$-spezifischen Expression hat.

Das glmUS-Primärtranskript wird durch RNaseE am Stopcodon von glmU prozessiert. Der Bereich am glmU-Stopcodon stimmt mit den beschriebenen Eigenschaften einer RNase E- Schnittstelle überein: Ein A/U-reicher Bereich in der Nähe einer Haarnadelstruktur (Diwa et al. 2000). Mutationen, die die in Frage kommenden Haarnadelstrukturen auflösen, haben keinen Einfluss auf die Aktivität der glmS'-lacZReporterfusion, jedoch verringert ein Entfernen der gesamten potenziellen RNase ESchnittstelle die Aktivität der Reporterfusion um eine Faktor von 5. Die Aktivität der Reporterfusion ist unter diesen Umständen aber noch immer abhängig von YhbJ und GlmZ. Dies unterstuitzt die Vorhersage, dass GlmZ durch Paarung mit der Region direkt stromaufwärts des $g \operatorname{lm} S$-Startcodons wirkt. Die Prozessierung des glmUS-Primärtranskriptes und die YhbJ/GlmZ-abhängige Regulation der glmS-spezifischen Expression sind demnach zwei unabhängige Ereignisse (Kalamorz et al. 2007), jedoch ist GlmZ für die Stabilisierung des glmS-spezifischen Transkriptes notwendig. In einem $\Delta g \operatorname{lmZ}$-Hintergrund ist YhbJ-abhängige Regulation der $g \operatorname{lmS}$-Expression ausgeschaltet.

Eine weitere sRNA, GlmY, wurde identifiziert, deren Überexpression die $g \operatorname{lm} S$ Expression aktiviert (Reichenbach et al. 2008; Urban und Vogel 2008). GlmY liegt in der Zelle in einer unprozessierten und einer prozessierten Form vor (Wassarman et al. 2001), jedoch ist prozessierte Form stärker vertreten (Reichenbach et al. 2008). Ihre Expression unterliegt vermutlich der Kontrolle eines $\sigma^{54}$-abhängigen Promotors (Urban and Vogel 2008) und die Menge an GlmY in der Zelle ist direkt von der verfügbaren Menge an GlcN-6-P abhängig (Reichenbach et al. 2008). Obwohl GlmY eine hohe Homologie zu GlmZ aufweist, ist der für die Stabilisierung des glmS-Transkriptes verantwortliche Bereich in GlmY nicht konserviert, und GlmY allein ist nicht in der Lage, diese Stabilisierung zu vermitteln (Reichenbach et al. 2008; Urban und Vogel 2008). Über einen noch unbekannten Mechanismus reguliert GlmY jedoch die Menge an unprozessierten GImZ in der Zelle und somit die Stabilisierung des glmSspezifischen Transkriptes. In Abwesenheit von $g \operatorname{lm} Z$ kann GlmY keinen Einfluss auf die $g l m S$-Expression nehmen, während die Wirkung von GlmZ unabhängig von GlmY ist (Reichenbach et al. 2008). 


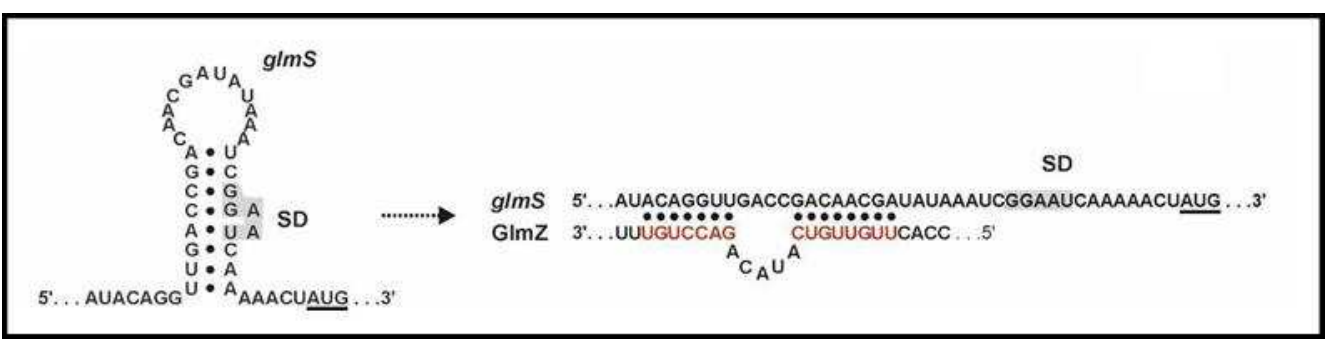

Abb. 5.1.: Interaktion von GImZ mit dem intergenischen Bereich zwischen $g / m U$ und glms

In Abwesenheit von GImZ bildet sich eine stabile Sekundärstruktur, die die Ribosomenbindestelle (SD) von glmS überdeckt und somit die Tanslation verhindert.

Die kleine RNA GlmZ interagiert mit der linken Hälfte dieser Sekundärstruktur, wodurch die Ribosomenbindestelle zugänglich wird.

Abbildung aus (Görke und Vogel 2008)

Neben der Deletion von $y h b J$ führt auch ein Defekt in der Poly-A-Polymerase I (PAP I), kodiert durch $p c n B$, zu einer Akkumulation von GlmS über den GlmZ-kontrollierten Mechanismus (Reichenbach et al. 2008). PAP I fügt Poly-(A)-Sequenzen an das 3'Ende von mRNAs an, wodurch deren Degradation erleichtert wird (Hajnsdorf et al. 1995), besonders bei Transkripten, die aufgrund von Sekundärstrukturen keinen terminalen einzelsträngigen 3'-Bereich aufweisen (Khemici und Carpousis 2004). Es wird vermutet, dass Polyadenylierung die Transkripte für RNasen wie RNase II oder Polynukleotid-Phosphorylase zugänglich macht (Kushner 2007). Es wurde gezeigt, dass PAP I die kleine RNA GlmY polyadenyliert und so destabilisiert. Über die beschriebene Signaltransduktion von GlmY über GlmZ zur $g \operatorname{lmS}$-mRNA nimmt PAP I somit indirekten Einfluss auf die GlmS-Menge in der Zelle (Reichenbach et al. 2008; Urban und Vogel 2008).

Viele Details des Mechanismus der Feedback-Regulation der $\operatorname{glm} S$-Expression sind weiterhin unklar. Es konnte bislang nicht festgestellt werden, welche Komponente initial die Verfügbarkeit von GlcN-6-P wahrnimmt und auf welcher Ebene diese Information an GlmY vermittelt wird. Eine weitere wichtige Frage ist, über welchen Mechanismus GlmY in der Lage ist, die Prozessierung von GlmZ zu kontrollieren. Da in einem $y h b J$-Deletionsstamm die unprozessierte Form von GlmZ akkumuliert, ist eine Wirkung von GlmY stromaufwärts von oder in Kooperation mit YhbJ wahrscheinlich. Eine naheliegende Möglichkeit ist die Kontrolle der YhbJ-Menge in der Zell durch GlmY. Obwohl weder eine plasmidische Überexpression des Gens noch eine Deletion einen Einfluß auf die Transkriptmenge von $y h b J$ hat (siehe 4.5.3.), kann nicht ausgeschlossen werden, dass GlmY über eine posttranskriptionelle Regulation Einfluß auf die YhbJ-Menge nimmt. Zudem konnte gezeigt werden, dass YhbJ in vitro mit 
GlmY interagiert (siehe 4.6.2.). Es ist nicht auszuschließen, dass die Aktivität oder Spezifität von YhbJ durch GlmY gesteuert wird.

Des Weiteren besteht die Möglichkeit einer kompetitiven Interaktion der kleinen RNAs mit YhbJ. Die Untersuchung der in vitro-Bindung von YhbJ an die unterschiedlichen Formen von GlmY und GlmZ zeigt eine Bevorzugung von GlmY gegenüber GlmZ und der prozessierten Form gegenüber einer Volllängen-Form. Interessanterweise ist die prozessierte Form von GlmY dominant in E. coli-Wildtyp-Zellen (Reichenbach et al. 2008). Somit wäre es möglich, dass YhbJ die Prozessierung von GlmZ durch physische Interaktion vermittelt, und dass eine höhere Affinität zu GlmY diese Vermittlung unterdrückt, wenn hohe Mengen dieser RNA vorhanden sind. Vorhersagen der Sekundärstrukturen von GlmZ und GlmY zeigen eine überraschend hohe Übereinstimmung: Beide sRNAs bilden potenziell eine spezifische mittlere Haarnadelstruktur, die sich durch einen konservierten, nicht-paarenden Bereich am Stamm der Haarnadel auszeichnen (Reichenbach et al. 2008; Urban und Vogel 2008) siehe Abb. 5.2.).

Eine Vorhersage der Sekundärstruktur der prozessierten Form von GlmY zeigt lediglich 4 bis 5 ungepaarte Nukleotide am 3'-Ende (Urban et al. 2007). Es wird angenommen, dass dies nicht ausreicht, um die RNA für degradierende Enzyme zugänglich zu machen. Die Polyadenylierung durch PAP I könnte demnach den Abbau der prozessierten sRNA vermitteln. Demnach könnte die Polyadenylierung von GlmY in Abhängigkeit der GlcN-6-P-Konzentration in der Zelle stattfinden. Dies wirft die Frage auf, ob eine weitere Komponente in die Kontrolle der $g l m S$-Expression involviert, die ein entsprechendes Signal vermittelt. Ein derartiger Einfluss von PAP I auf die Aktivität einer regulatorischen RNA ist für RNA I beschrieben. Diese reprimiert die Replikation von ColEI-Plasmiden, und die aktive Form entsteht durch Prozessierung einer Vorläufer-RNA. Die prozessierte Form von RNA I ist instabil und wird durch die Polynukleotid-Phosphorylase abgebaut. In einem pcnB-Deletionsstamm ohne PAP I ist die Menge an aktiver RNA I etwa 10fach erhöht (Xu et al. 1993). Ebenso wird der Abbau der kleinen RNA SraL durch PAP I gesteuert (Viegas et al. 2007). 


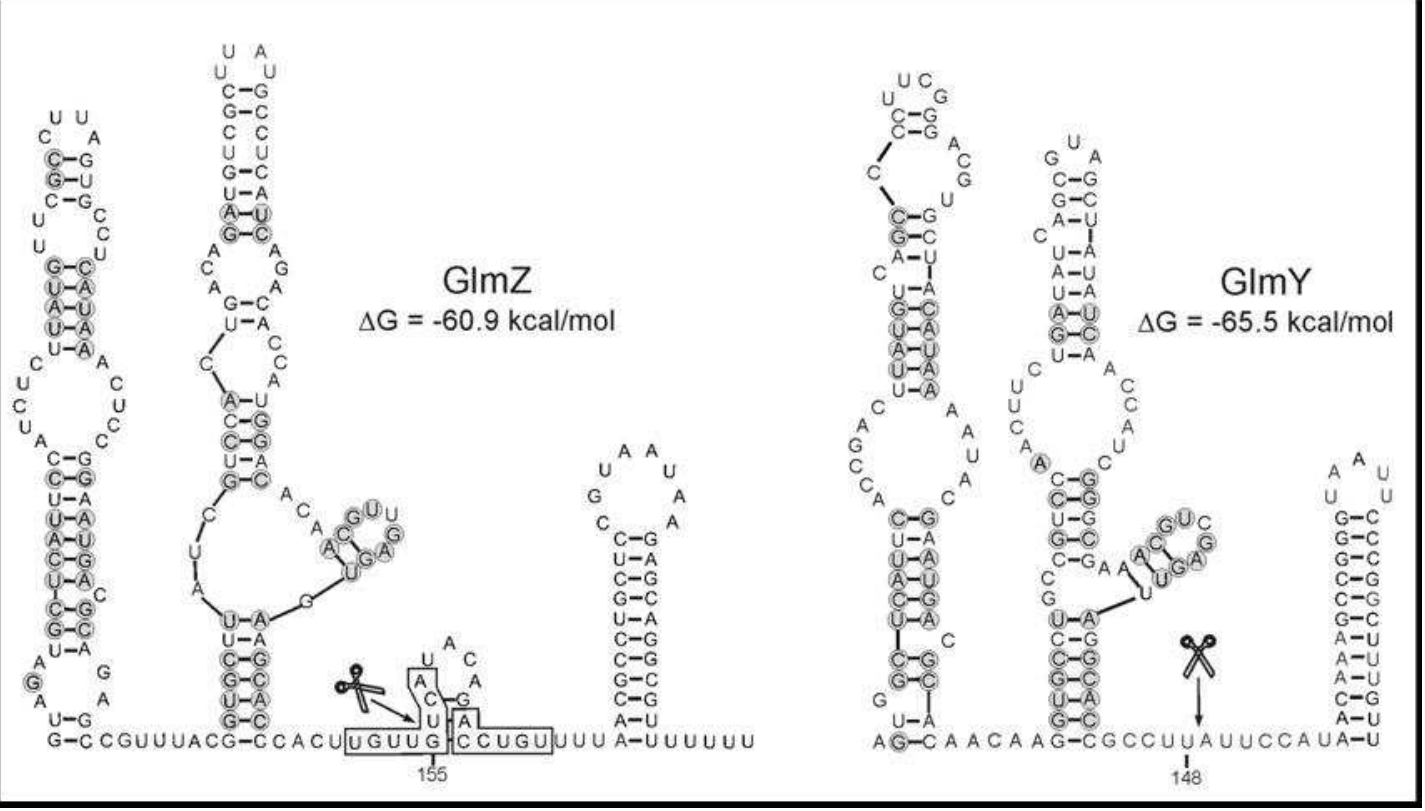

Abb. 5.2.: Potenzielle Sekundärstrukturen von GImZ und GImY

Die Sekundärstruktruren der beiden sRNAs wurden mittels mFold berechnet (siehe 2.8.). Konservierte Reste wurden durch Vergleich der Gensequenzen aus E. coli, Shigella flexneri, Citrobacter koseri, Salmonella enterica subsp. enterica serovar typhi, Salmonella typhimurium, Klebsiella pneumoniae subsp. pneumoniae, Enterobacter sakazakii, Erwinia carotovora subsp. atroseptica, Photorabdus luminescens subsp. laumondii, Serratia marcescens und Yersinia pestis mittels Vector NTI (siehe 2.8.) identifiziert und sind durch graue Kreise hervorgehoben. In GImZ sind die Basen eingerahmt, die an der Interaktion mit dem gImUS-Transkript beteiligt sind. Die Scheren markieren die Prozessierungsstellen der sRNAs.

Die beiden sRNAs weisen eine ungewöhnliche Ausbuchtung in der rechten Hälfte der mittleren Haarnadelstruktur auf.

Abbildung aus (Reichenbach et al. 2008)

Viele Details dieses regulatorischen Ereignissen verbleiben unklar. Neben der elementaren Frage, warum so viele unterschiedlich Faktoren auf verschiedenen Ebenen wirken, um die Adaption der GlmS-Menge an den intrazellulären Spiegel von GlcN-6-P anzupassen, ist vor allem die Frage der Signalwahrnehmung essentiell für das weitere Verständnis dieser Regulation.

Die Komplexität des regulatorischen Ereignisses weist darauf hin, dass dieses nicht exklusiv die verstärkte Expression von $\operatorname{glm} S$ vermittelt, da dies über einen wesentlich einfacheren Mechanismus erreicht werden könnte. Die Involvierung multipler Proteinund sRNA-Faktoren in die Signalkaskade lässt vermuten, dass zusätzliche Determinanten gibt, die das Resultat der Regulation beeinflussen, wie beispielsweise die Verfügbarkeit weiterer Metabolite (die Edukte der von GlmS katalysierten Reaktion, Glutamat und Fruktose-6-Phosphat scheinen hier gute Kandidaten), oder dass die Komponenten der Signalkaskade zusätzliche, bislang nicht identifizierte regulatorische Aufgaben wahrnehmen, so dass die Kontrolle der $g l m S$-Expression nur einen Aspekt eines regulatorischen Netzwerkes darstellt. 


\subsection{Die Funktion von YhbJ}

YhbJ ist ein konserviertes Protein unbekannter Funktion, dass eine P-Loop-ATPaseDomäne enthält. In E. coli ist es Teil des rpoN-Operons, und es ist in einer Vielzahl von Organismen in der Nähe von Homologen des PTS lokalisiert (Boël et al. 2003; Görke et al. 2005) siehe auch 2.2.). YhbJ ist hochkonserviert in verschiedenen Prokaryoten, jedoch konnten keine Homologe in Eukaryoten identifiziert werden. Computergestützte Analysen identifizierten 23 Aminosäuren, die in allen 125 verwendeten Sequenzen von YhbJ-Homologen hinsichtlich Identität und Position perfekt konserviert sind, sowie 26 weitere Aminosäuren, die im Kontext von Größe und Ladung an ihren jeweiligen Positionen übereinstimmen. Diese Aminosäuren befinden sich zum Großteil innerhalb von drei konservierten Sequenzmotiven (siehe Abb. 4.17.).

Es ist bekannt, dass eine Deletion von $y h b J$ das regulatorische Ereignis zur spezifischen Expression des Gens der Glukosamin-6-Phosphat Synthase GlmS entkoppelt, was in einem starken Anstieg der intrazellulären Menge des Proteins resultiert. In diese Regulation sind auch zwei kleine, nicht-kodierende RNAs sowie die Poly(A)Polymerase PAP I involviert, sie wird in 5.1. im Detail diskutiert.

YhbJ enthält ein konserviertes Walker A-Motiv, welches eine ATPase- oder GTPaseAktivität impliziert, ein experimenteller Nachweis steht jedoch noch aus. Das Walker A-Motiv hat die Konsensus-Sequenz G-X $4-G-(K / T)$ (Walker et al. 1982). Mutationen der beiden konservierten Glycin-Rest G8- und G13 weisen einen Einfluss auf die glmSExpression auf, die mit dem von Wildtyp-YhbJ vergleichbar ist (vergleiche Abb. 4.22.). Des Weiteren kann in YhbJ-Homologen in Enterobakterien eine konservierte potenzielle RNA-Bindedomäne vorhergesagt werden (siehe Abb. 4.20). Es ist zu vermuten, dass diese für die gezeigte Bindung von YhbJ an verschiedene RNA-Spezies verantwortlich ist, zumal eine Deletion dieser Domäne die Kontrolle der glmSExpression durch YhbJ aufhebt. In durchgeführten Analysen zeigt YhbJ eine Interaktion mit jeder der verwendeten RNAs, selbst mit einem RNA-Stück, das einem Teil der lacZ-mRNA entspricht. Obwohl diese Sequenz als „unspezifische“ RNA gewählt wurde, kann jedoch nicht ausgeschlossen werden, dass auch diese Sequenz Strukturen aufweist, die eine Bindung von YhbJ ermöglichen, beispielsweise eine Haarnadelstruktur oder ein bestimmtes Sequenzmotiv.

In dem Gram-positiven Bakterium B. subtilis, von dem bekannt ist, dass in ihm die Kontrolle der glmS-Expression durch ein cis-agierendes Ribozym gesteuert wird, ist diese RNA-Bindedomäne im YhbJ-Ortholog YvcJ nur schwach vorhersagbar, während 
sie in Organismen wie Vibiro cholerae und Staphylococcus aureus völlig zu fehlen scheint.

YhbJ aus E. coli zeigt somit zwei Eigenschaften, die darauf hinweisen, dass die Kontrolle der glmS-Expression nicht die einzige Aufgabe dieses Proteins ist: Obwohl das Walker A-Motiv in allen 125 YhbJ-Homologen konserviert ist, haben Austausche der in diesem Motiv konservierten Glycin-Reste keinen Einfluss auf die Kontrolle der glmS-Expression. Umgekehrt hebt eine Deletion des potenziellen RNA-Bindemotivs am C-Terminus des Proteins den Einfluss von YhbJ auf die $g \operatorname{lm} S$-Expression auf, aber das Motiv ist nicht universell konserviert, sondern nur in einer Untergruppe der Sequenzen vertreten.

Anhand dieser Befunde kann spekuliert werden, dass YhbJ neben der Beeinflußung der GlmZ-Prozessierung noch weitere, bislang unbekannte Funktionen ausübt.

\subsection{MicroArray Analysen eines $\Delta y h b J$-Stammes im Vergleich zum Wildtyp}

Um einen weiteren Einblick in die Funktion von YhbJ zu erlangen, sowie um mögliche weitere Ziele einer YhbJ-kontrollierten Regulation ähnlich der der glmS-Expression zu identifizieren, wurden MicroArray Analysen mit einem $\Delta y h b J-S t a m m$ und dem korrespondierenden Wildtyp durchgeführt und die Expressionsniveaus in diesen Stämmen miteinander verglichen. Berücksichtigt man nur Gene, deren Expression mindestens um einen Faktor von 2,5 zwischen Wildtyp und yhbJ-Deletionsstamm verändert ist, so erhält man einen Satz von 93 Genen, die in einer $y h b J$-Deletion stärker exprimiert werden, sowie 31 Gene, deren Expression signifikant herabgesetzt ist (siehe 4.6.)

Überraschenderweise konnte für 4 Gene (ibpA, $i b p B$, $p y r B$ und $p y r I)$ ein höherer Faktor der Aktivierung der Expression in Abwesenheit von YhbJ ermittelt werden als für glmS. Die in Abwesenheit von YhbJ verstärkt exprimierten Gene lassen sich in mehrere funktionell ähnliche Gruppen unterteilen:

1. Chaperone und Proteasen der Stressantwort (5.3.1.)

2. Enzyme der Pyrimidinsynthese (5.3.2.)

3. Komponenten von Transportkomplexen (5.3.3.)

4. Regulatorische Proteine (5.3.4.)

Ebenso können die Gene, deren Expression in einem yhbJ-Deletionsstamm herabgesetzt ist, in Gruppen zusammengefasst werden: 
1. Das Kälteschockprotein cspA (5.3.5.)

2. Gene der Lipopolysaccharid-Kernsynthese (5.3.6.)

3. Regulatorische Proteine (5.3.7.)

Diese Gruppen werden nachfolgend im Detail diskutiert.

\subsubsection{Chaperone und Proteasen der Stressantwort}

Die beiden Gene, deren Expression in Abwesenheit von YhbJ am stärksten erhöht ist, sind $i b p A$ und $i b p B$, die zusammen ein bicistronisches Operon bilden. Ihre Expression untersteht der Kontrolle durch $\sigma^{32}$, einem alternativen Sigma-Faktor, der spezifisch für Gene der Hitzeschockantwort ist, jedoch wurde auch eine basale, $\sigma^{32}$-unabhängige Expression beobachtet (Laskowska et al. 1996b). Die korrespondierenden Genprodukte IbpA und IbpB werden auch als sHsp bezeichnet (small heat shock proteins, kleine Hitzeschockpoteine). Sie sind universell konserviert und interagieren mit Aggregaten fehlgefalteter Proteine (Kuczynska-Wisnik et al. 2002). Ihre Überexpression vermittelt erhöhte Resistenz gegenüber Hitzeschock und oxidativen Stress (Kitagawa et al. 2000), führt aber gleichzeitig zu einer Retardierung des Abbaus aggregierter Proteine (Kedzierska et al. 1999). Deshalb ist die Expression dieser Gene unter normalen Wachstumsbedingungen strikt reprimiert (Mogk et al. 2003a).

Ebenfalls deutlich erhöht ist die Expression der Gene mopA und mopB, deren Produkte Untereinheiten des GroEL/GroES-Chaperon sind. Das Chaperon GroEL und seine regulatorische Untereinheit GroEL sind essentiell für die korrekte Faltung von 85 cytosolischen Proteinen, von denen 13 essentiell sind. Die Faltung weiterer 165 Proteine ist zumindest teilweise von GroEL/GroES abhängig (Kerner 2005). Die Gene werden unter allen Wachstumsbedingungen exprimiert, jedoch verstärkt nach einem Hitzeschock (Fayet et al. 1989). Eine Überexpression von GroEL/GroES verhindert die Aggregation fehlgefalteter Proteine (Gragerov et al. 1992). Dabei agiert der Komplex vornehmlich in den späten Phasen der Proteinreifung (Gaitanaris et al. 1994).

Die Gene $h s l U$ und $h s l V$ kodieren für die Untereinheiten des prokaryotischen Homologs des Proteasoms in Eukaryoten. HslV ist eine Protease mit hoher Sequenzhomologie zu den sieben Untereinheiten des Proteasoms (Rohrwild et al. 1996), während HslU ein AAA-Protein (ATPases associated with various cellular activities / ATPasen verbunden mit unterschiedlichen zellulären Aktivitäten) der Clp/Hsp100-Familie ist (Rohrwild et al. 1996; Kwon et al. 2003). Das HslUV-System ist homolog zur ClpXP-Protease 
(Gottesman et al. 1993). Es wird für das Wachstum bei hohen Temperaturen benötigt (Katayama et al. 1996) und wird ebenfalls verstärkt nach Hitzeschock exprimiert (Chuang et al. 1993).

Das DnaK/DnaJ/GrpE-System (KJE), kodiert durch die in einer $y h b J$-Deletion ebenfalls verstärkt exprimierten Genen dnaK, dnaJ und grpE, ist homolog zum eukaryotischen Hsp70-Chaperonsystem. Es assistiert bei der korrekten Faltung neusynthetisierter Peptidketten, und nimmt eine Reihe weiterer Funktionen wahr, unter Anderem im Abbau großer Proteinkomplexe (Bukau und Horwich 1998). DnaK stellt hierbei das eigentliche Chaperon dar, während DnaJ und GrpE sogenannte Ko-Chaperone sind. DnaJ stimuliert die ATPase-Aktivität von DnaK (Wall et al. 1994), während GrpE die Freisetzung von ADP + Pi reguliert (Liberek et al. 1991). Zusätzlich ist GrpE ein Thermosensor, der die Aktivität von DnaK bei hohen Temperaturen herabsetzt. Die Expression von dnaK, dnaJ und grpE ist ebenfalls $\sigma^{32}$-abhängig (Grimshaw et al. 2003). Im Gegensatz zu GroEL/GroES wirkt KJE in der frühen Phase der Proteinreifung (Gaitanaris et al. 1994).

Die Gene yrfIH kodieren für Hsp15 und Hsp33 (ㅌeat shock protein, Hitzeschockprotein). Die Expression beider Gene wird durch Hitzeschock stark erhöht. Hsp33 wird durch oxidierende Bedingungen aktiviert: Es dimerisiert durch Ausbildung einer Disulfidbrücke, wodurch es Chaperon-Aktivität entwickelt (Vijayalakshmi et al. 2001). Im Gegensatz dazu ist Hsp15 ein Protein, das unspezifisch Oligonukleotide bindet (Korber et al. 1999) und Ribosomen-Recycling durch Interaktion mit freien 50SUntereinheiten propagiert (Korber et al. 2000).

Lon ist eine ATP-abhängige Protease und dient der Degradation fehlgefalteter Proteine sowie dem Abbau einer bestimmten Gruppe regulatorischer Proteine (Nishii et al. 2005). Es verhindert die Aggregation von Proteinen (Laskowska et al. 1996a) und in Abwesenheit von Lon ist diese stark erhöht (Rosen et al. 2002). Zumindest ein Teil der Lon-spezifischen Degradation missgefalteter Proteine ist abhängig von DnaK (Sherman und Goldberg 1992).

ClpB ist Teil der Clp/Hsp100-Familie, stellt innerhalb dieser jedoch einen Sonderfall dar, da es nicht mit einem proteolytischen Partner interagiert (Mogk et al. 2003b). ClpB kooperiert mit KJE in der Resolubilisierung aggregierter (Haslberger et al. 2007). Seine Expression ist ebenfalls $\sigma^{32}$-abhängig (Kitagawa et al. 1991).

Über inaA ist wenig bekannt. Seine Expression ist durch die Anwesenheit schwacher Säuren aktiviert (Slonczewski et al. 1987) und es ist vermutlich an der Vermittlung einer Toleranz gegenüber niedrigen $\mathrm{pH}-$ Werten beteiligt (White et al. 1992). 
Die Protease Do wird durch das Gen htrA kodiert und stellt eine periplasmatische SerinProtease dar, die für das Überleben der Zelle bei hohen Temperaturen notwendig ist (Seol et al. 1991). Sie degradiert abnormale periplasmatische Proteine, darunter auch aggregierte Proteinkomplexe (Strauch und Beckwith 1988). Do weist des Weiteren eine Chaperon-Aktivität auf, die unabhängig von der Protease-Aktivität ist. Die ProteaseAktivität ist strikt temperaturabhängig und ist bei niedrigen Temperaturen stark verringert (Spiess et al. 1999). Die Expression von $h$ trA ist strikt $\sigma^{\mathrm{E}}$-abhängig (Erickson und Gross 1989).

$\mathrm{CpxP}$ ist ein Regulator der Cpx-Antwort, die Resistenz gegenüber extracytoplasmatischen Stress vermittelt (Danese und Silhavy 1998). Es ist möglich, dass das Protein Chaperon-Aktivität besitzt (DiGiuseppe und Silhavy 2003).

HspQ stellt ein Hitzeschockprotein dar, das den Abbau fehlgefalteter Proteine vermittelt, jedoch selbst keine Protease-Aktivität aufweist. Seine Expression ist ebenfalls abhängig von $\sigma^{32}$ (Shimuta et al. 2004).

Die sHsp IbpA und IbpB, das DnaK/DnaJ/GrpE-System und ClpB bilden eine proteolytische Triade zum Abbau von Protein-Aggregaten: Die sHsps interagieren mit aggregierenden Proteinen und halten diese in einer Form, in der sie zugänglich für eine Neufaltung durch DnaK sind. Während DnaK nur kleinere Proteinaggregate selbsttätig auflösen kann, ermöglicht die konzertierte Aktivität mit ClpB die effektive Auflösung großer Komplexe. In Abwesenheit von IbpAB oder ClpB ist ein Überleben der Zelle sowohl bei $37^{\circ} \mathrm{C}$ wie auch unter erhöhter Temperatur von $42^{\circ} \mathrm{C}$ nur bei artifiziell erhöhter Expression der Gene des KJE-Systems möglich (Mogk et al. 2003a).

Die erhöhte Expression von Chaperonen und Proteasen in einem $\Delta y h b J$-Hintergrund lässt mehrere Erklärungen zu. Eine simple Variante ist, dass die massive Überexpression von $g \operatorname{lm} S$ zu einer starken Bildung von Proteinaggregaten führt, die eine Stressantwort provozieren, die der auf einen Hitzeschock ähnelt. Allerdings zeigt ein $\Delta y h b J$-Stamm keinerlei Wachstumsdefekt. Falls die Zelle durch die Entkopplung der $g \operatorname{lm} S$-Expression einem derartig starken Stress ausgesetzt wäre, sollte sich dies global auf die zellulären Prozesse auswirken und es wäre ein verlangsamtes Wachstum zu erwarten.

Eine Überexpression von $g \operatorname{lm} Z$ führt zu einer erhöhten Aktivität einer glmS-lacZReporterfusion (vergleiche Abb. 4.5). Sollte es sich bei den beobachteten Effekten auf die Expression von Genen, deren Produkte an der Hitzeschockantwort beteiligt sind, um 
einen sekundären Effekt durch die ehöhte GlmS-Synthese handeln, so sollte eine Überexpression von glmZ vergleichbare Auswirkungen haben. Wie unter 4.4. diskutiert ist dies nicht der Fall. Vielmehr ist die Transkription von $i b p A B$ unter diesen Bedingungen herabgesetzt, während die anderen Gene dieser Gruppe keine signifikante Veränderung ihrer Expression aufweisen.

Ein Großteil der hier genannten Gene steht unter Kontrolle von $\sigma^{32}$, welcher eine Antwort auf Hitzeschock vermittelt, und viele der Genprodukte sind notwendig für das Überleben der Zelle unter hohen Temperaturen. Die Expression von $r p o H$ ist äußerst komplex reguliert und es sind 6 Promotoren beschrieben, von denen aus das Gen transkribiert werden kann. Darunter finden sich zwei konstitutive $\sigma^{70}$-abhängige Promotoren sowie ein $\sigma^{24}$-abhängiger und ein Hitzeschock-abhängiger Promotor (Erickson und Gross 1989; Wang und Kaguni 1989). Interessanterweise wurde der Promotor P6 vor $r p o H$ als $\sigma^{54}$-abhängig beschrieben, jedoch ist das korrespondierende Aktivatorprotein unbekannt (Janaszak et al. 2007). Das Gen unterliegt einer posttranskriptionellen Kontrolle der Translation: Eine stabile Sekundärstruktur im 5'Bereich des Transkriptes verhindert die Translation bei niedrigen Temperaturen und dient als Thermosensor (Morita et al. 1999).

Dies eröffnet die faszinierende Möglichkeit, dass YhbJ hier, parallel zu der Kontrolle der $\operatorname{glm} S$-Expression, einen direkten oder indirekten Einfluss auf die Stabilität der inhibitorischen Sekundärstruktur hat. Die Abwesenheit von YhbJ könnte eine Destabilisierung der Sekundärstruktur bewirken, die nachfolgend die Translation der $r p o H$-mRNA ermöglicht, wodurch die Expression der $\sigma^{32}$-abhängigen Gene initiiert werden kann.

Interessant in diesem Zusammenhang ist die Expression von rpoH in Abwesenheit hoher Temperaturen bei Induktion mit Ethanol und die nachfolgende Induktion von Genen der Hitzeschock-Antwort über einen unbekannten Mechanismus (VanBogelen et al. 1987) und eine Expression der $\sigma^{32}$-abhängigen Gene bei Hemmung der DNA-Gyrase (Mizushima et al. 1996), die beide einen alternativen, Hitzeschock-unabhängigen Weg der rpoH-Expression implizieren.

\subsubsection{Enzyme der Pyrimidinsynthese}

Die Expression der Gene pyrB und pyrI ist in einem yhbJ-Deletionsstamm um einen Faktor von 25 (pyrB) beziehungsweise 20 (pyrl) erhöht. Das Gen pyrB kodiert für die katalytische Untereinheit der Aspartat-Transcarbamoylase (ATCase), das Gen pyrI für 
die regulatorische Untereinheit (Neidhardt et al. 1996). Sie bilden ein gemeinsames Operon, das unter einer Attenuationskontrolle durch PyrL steht (Levin und Schachman 1985). Die Expression von pyrL ist in Abwesenheit von YhbJ ebenfalls um einen Faktor von 7,5 erhöht.

Die ATCase besteht aus je sechs katalytischen und regulatorischen Untereinheiten und katalysiert den initialen Schritt der de novo-Synthese von Pyrimidinen, die Kondensation von Carbamoyl-Phosphat und Aspartat zu Carbamoyl-L-Aspartat und Orthophosphat (Pardee und Yates 1956). Die Enzymaktivität wird durch CTP gehemmt (Gerhart und Pardee 1962) und durch ATP erhöht (Bethell et al. 1968). Beide Effektoren konkurrieren hierbei um dieselbe Bindestelle an der regulatorischen Untereinheit (Honzatko et al. 1979).

Die Expression von pyrBI erfolgt von zwei Promotoren stromaufwärts von $p y r B$ und unterliegt einer UTP-abhängigen Attenuationskontrolle: Vor dem Start-Codon von pyrB befindet sich ein Bereich, der im Transkript zwei Haarnadelstrukturen ausbildet, welchen eine Sequenz multipler Uridine folgt. Falls ausreichende Mengen UTP in der Zelle zur Verfügung stehen, ist es wahrscheinlich, dass die RNA-Poylmerase die Transkription nach der zweiten Haarnadelstruktur terminiert. Falls der intrazelluläre UTP-Spiegel gering ist, so pausiert die RNA-Polymerase an der ersten Sekundärstruktur und die beginnende Translation des PyrL-Peptides verhindert die Ausbildung der zweiten Haarnadelstruktur, so dass die Transkription fortgeführt werden kann (Christie et al. 1981). Es konnte ebenso gezeigt werden, dass die RNA-Polymerase in Abhängigkeit von der UTP-Konzentration an der ersten Haarnadelstruktur verweilt (Turnbough et al. 1983) und ein Entfernen der Sekundärstrukturen erhöht die pyrBIExpression signifikant (Levin und Schachman 1985).

Ein weiteres Gen, dessen Expression in einer $y h b J$-Deletion erhöht ist, ist carA. Das korrespondierende Genprodukt, CarA, bildet zusammen mit CarB die CarbamoylPhosphat-Synthase, welche die Bildung von Carbamoyl-Phosphat katalysiert. Dies ist wie beschrieben eines der Substrate des PyrBI-Komplexes (Thoden et al. 1999).

GlmS katalysiert den geschwindigkeitsbestimmenden Schritt in der Synthese von Peptidoglycan und Lipopolysacchariden über das zentrale Intermediat UDP-GlcNAc (Badet et al. 1987). Die erhöhte Expression der Gene für die Carbamoyl-Phosphat Synthase-Untereinheit CarA und der ATCase könnte bedeuten, dass eine Entkopplung der glmS-Expression in Abwesenheit von YhbJ zu einer Verarmung der Zelle an Pyrimidinen führt, da UTP von GlmU verbraucht wird, um UDP-GlcNAc zu synthetisieren (Mengin-Lecreulx und van Heijenoort 1994). Dies würde zu einem 
erhöhten Bedarf an Pyrimidin-Vorläufern führen was eine verstärkte Expression der entsprechenden Enzyme nach sich ziehen würde.

\subsubsection{Komponenten von Transportkomplexen}

Die Expression der Gene $m g l A B C$, welche für Bestandteile eines GalaktoseTransporters kodieren, ist in einem $\Delta y h b J$-Hintergrund um einen Faktor von 7 erhöht. Sie sind in einem gemeinsamen Operon lokalisiert (Harayama et al. 1983), welches einer komplexen Regulation unterliegt und dessen Expression durch $\sigma^{38}$ (NotleyMcRobb et al. 2002), die Regulatoren GalS und GalR(Geanacopoulos und Adhya 1997) und den Regulator FlhDC (Pruss et al. 2001) beeinflusst wird. Der MglABCTransporter gehört zur ABC-Superfamilie ( $\underline{A} T P$-b binding cassette, ATP-Bindekassette) (Wu und Mandrand-Berthelot 1995). MglA stellt die ATP-bindende Komponente dar, $\mathrm{MglB}$ ist ein periplasmatisches Galaktose-bindendes Protein und MglC ein integrales Membranprotein (GOA et al. 2001). Zusätzlich dient MglB als Chemorezeptor für Galaktose (Scholle et al. 1987).

YhdY ist Bestandteil des YhdWXYZ-ABC-Transporter. Diese Proteine sind allesamt nicht näher charakterisierte Mitglieder der ABC-Superfamilie, wobei YhdY eine membranständige Komponente darstellt. Aufgrund der Sequenz der Proteine wird angenommen, dass es sich um einen ATP-abhängigen Transporter für Aminosäuren handelt (Saurin et al. 1999). Die Expression des yhdWXYZ-Operons wird durch NtrC kontrolliert (Reitzer und Schneider 2001), dessen Gen $g \ln G$ in Abwesenheit von YhbJ ebenfalls verstärkt exprimiert wird (siehe 4.3.4.).

Das Gen tnaB kodiert für einen von drei bekannten Transportern für Tryptophan in $E$. coli und bildet zusammen mit tnaA ein Operon (Deeley und Yanofsky 1981). Es ist zu beachten, dass auch die Expression von tnaA, welches für eine Tryptophanase kodiert, in einer $y h b J$-Deletion deutlich erhöht ist. Die Transkription des tnaAB-Operons ist durch einen Tryptophan-abhängigen Antiterminationsmechanismus reguliert und unterliegt der Katabolitenrepression (Gollnick und Yanofsky 1990). TnaB ist ein Mitglied der ArAAAP-Familie der Aminosäuretransporter und seine Rolle ist hauptsächlich die Aufnahme von Tryptophan für die katabole Nutzung (Yanofsky et al. 1991).

CycA ist ein weiterer Aminosäuretransporter, dessen Gen in einem $y h b J$ Deletionsstamm verstärkt exprimiert wird. Es ist beteiligt an der Aufnahme von Glycin, Serin und Alanin (Robbins und Oxender 1973). 
Das Gen yjcG kodiert für eine Acetat/Glykolat-Permease (Gimenez et al. 2003).

BglF ist ein Protein, das die EIIA-, EIIB- und EIIC-Domäne enthält und somit einen Teil des PTS darstellt. Das korrespondierende Operon wird in Wildtyp-Zellen von $E$. coli nicht exprimiert, kann jedoch durch unterschiedliche Mechanismen aktiviert werden (Reynolds et al. 1986; Schnetz und Rak 1992; Kawula und Lelivelt 1994; Khan und Isaacson 1998). BglF ermöglicht die Aufnahme von $\beta$-Glukosiden in die Zelle (Postma et al. 1993) und übt neben dem Transport noch verschiedene regulatorische Funktionen aus (Amster-Choder 2005).

Ein weiterer Bestandteil eines Aminosäure- oder in diesem Fall OligopeptidTransporters, dessen Gen in Abwesenheit von YhbJ verstärkt exprimiert wird, ist OppA. Dieses Protein ist Teil des OppABCDF-Transportkomplexes, der ein Mitglied der ABCSuperfamilie ist (Pearce et al. 1992). Der Komplex importiert kurze Oligopeptide mit einer Länge von bis zu 5 Aminosäuren, jedoch keine freien Aminosäuren (Guyer et al. 1986)). OppA stellt hierbei die periplasmatische Bindekomponente dar, die eine hohe Affinität zu Oligopeptid-Substraten aufweist (Tame et al. 1994).

GlnH ist ein Teil des hochaffinen Glutamintransporters GlnHPQ, der ebenfalls ein Mitglied der Superfamilie der ABC-Transporter ist (Wu und Mandrand-Berthelot 1995). GlnH ist das periplasmatische Glutamin-bindende Protein des Systems (GOA et al. 2001) und untersteht der Kontrolle durch NtrC (Reitzer und Schneider 2001), dessen Gen $g \ln G$ in Abwesenheit von YhbJ ebenfalls verstärkt exprimiert wird (siehe 4.3.4.). Auch ArtP ist Teil eines ABC-Transportkomplexes, in diesem Fall des ArtPMQJITransporters für Arginin (Linton und Higgins 1998). ArtP ist die cytoplasmatische ATP-bindende Komponente des Komplexes (Wissenbach et al. 1995).

CorA ist Teil eines Transporters der MIT-Familie ( $\underline{\text { Metal }}$ ion transporter, Transporter für Metall-Ionen), welcher aus den Proteinen CorABCD besteht und für die Aufnahme von Magnesium-Ionen verantwortlich ist. CorA alleine ermöglicht den Einstrom von Magnesium-Ionen, während für einen Export von $\mathrm{Mg}^{2+}$ neben CorA auch die anderen Komponenten des Systems notwendig sind (Smith et al. 1993). Neben Magnesium kann CorA auch Nickel- und Kobalt-Ionen transportieren (Hmiel et al. 1986).

Das Gen putP kodiert für einen Natrium/Prolin-Symporter (Reizer et al. 1994b), der auch am Transport von Propionat beteiligt ist (Reed et al. 2006).

NmpC schließlich stellt ein Mitglied der GBP-Familie (General bacterial porins, allgemeine bakterielle Porine) dar (Zhai und Saier 2002). Es handelt sich wahrscheinlich um ein Wasser-gefülltes Porin der äußeren Membran (Hindahl et al. 
1984). Das Protein ist vermutlich mit Peptidoglykan assoziiert (Pugsley und Schnaitman 1978).

Die erhöhte Expression der Gene $y h d Y$ und $g \ln H$ ist vermutlich bedingt durch die 6,5fach erhöhte Expression des Gens $g \ln G$, dessen Produkt einen Aktivator der $\sigma^{54}$ abhängigen Genexpression darstellt und dessen Kontrolle des yhdWXYZ- und glnHFQOperons beschrieben ist (Reitzer und Schneider 2001).

Sechs der hier genannten Gene kodieren für Bestandteile von Transportern für Aminosäuren oder Oligopeptide. Der Grund hierfür ist jedoch unklar. Zwar würde eine stark erhöhte Aktivität der Glukosamin-6-Phosphat-Synthase GlmS der Zelle Glutamin entziehen, da sie die Bildung von Glukosamin-6-Phosphat aus Fruktose-6-Phosphat und Glutamin katalysiert, jedoch entsteht in dieser Reaktion auch Glutamat, welches unter Aufwendung von ATP wieder zu Glutamin regeneriert werden kann. Eine derart starke Aktivität von GlmS würde der Zelle weiterhin große Mengen Fruktose-6-Phosphat entziehen. Dieses kann zwar ebenfalls regeneriert werden (durch den Abbau von GlcN6-P über NagB), jedoch ist keine verstärkte Expression des nag-Operons zu beobachten und auch die Expression von Schlüsselenzymen des Energiestoffwechsels ist unverändert. Dies lässt es unwahrscheinlich erscheinen, dass die Aktivität von GlmS als sekundären Effekt die verstärkte Expression der Gene für Transportproteine verursacht.

Die Expression der Gene $m g l A$ und $m g l B$ ist in Abwesenheit von YhbJ deutlich erhöht. Unter Überexpression von $g \operatorname{lm} Z(m g l B)$ beziehungsweise von $g \operatorname{lm} Z$ oder $g \operatorname{lm} Y(m g l A)$ ist ihre Expression jedoch reprimiert (siehe 4.4.). Dies lässt darauf schließen, dass der Effekt einer $y h b J$-Deletion auf ihre Expression kein Sekundäreffekt der verstärkten glmS-Expression ist, sondern auf einem Mechanismus beruht, der diese Komponenten involviert.

\subsubsection{Gene regulatorischer Proteine mit erhöhter Expression im $\Delta y h b J$-Hintergrund}

Das Gen $y h b J$ ist mit rpoN kolokalisiert, welches für den alternativen Sigma-Faktor 54 kodiert (siehe 1.2.). Die Expression $\sigma^{54}$-abhängiger Promotoren ist strikt durch die Aktivität eines Aktivatorproteins kontrolliert. NtrC ist ein derartiges Aktivatorprotein (Reitzer 2003) und die Expression des korrespondierenden Gens ist in Abwesenheit von YhbJ um den Faktor 6,5 erhöht. NtrC ist der Response Regulator des NtrBCZweikomponentensystems, welches auf eine Limitierung verwertbaren Stickstoffs oder Kohlenstoffs reagiert (Reitzer und Magasanik 1985). Es aktiviert die Expression 
verschiedener Gene der Stickstoff-Assimilation, darunter auch $g \ln H$ und $y h d Y$ sowie seine eigene Expression.

CaiF ist ein transkriptioneller Aktivator, der unter anaeroben Bedingungen und in Anwesenheit von Carnitin die Expression der Gene des Carnitin-Stoffwechsels aktiviert, namentlich das caiTABCDE- und das fixABCX-Operon (Eichler et al. 1996). Außer in den Promotorregionen dieser beiden Operons konnten durch Computeranalysen keine weiteren CaiF-Bindestellen identifiziert werden (Buchet et al. 1999).

Im Gegensatz zu CaiF ist FrvR ein negativer transkriptioneller Regulator, der exklusiv die Expression des eigenen frv-Operons inhibiert (Reizer et al. 1994a).

RhaS ist ein transkriptioneller Aktivator, der in Anwesenheit von L-Rhamnose die Expression des rhaBAD-Operons (Egan und Schleif 1993) und rhaT-Operons (Via et al. 1996) aktiviert, deren Genprodukte dem Transport und der Degradierung von Rhamnose dienen. Die Aktivierung der Expression erfolgt kooperativ mit CRP ( $\underline{c} A M P$ receptor protein, Rezeptorpotein für zyklisches AMP) (Holcroft und Egan 2000). Zudem ist die RhaS-vermittelte Expression besonders hoch induziert, wenn der intrazelluläre Spiegel an zyklischen AMP hoch ist (Wickstrum et al. 2005).

Der negative Regulator IscR ist Teil einer interessanten Feedback-Regulation: Der aktive Regulator enthält einen $[2 \mathrm{Fe}-2 \mathrm{~S}]^{+}$-Cluster und inhibiert die Expression des eigenen iscRSUA-Operons. Wenn die Synthese solcher Cluster durch äußere Einflüsse eingeschränkt ist, entsteht eine IscR-Form, der dieser Cluster fehlt. Dadurch verliert es seine inhibierende Wirkung und das Operon wird exprimiert (Schwartz et al. 2001).

Das Cpx-System in E. coli vermittelt Resistenz gegenüber extracytoplasmatischen Stress. Seine Expression unterliegt einer negativen Regulation durch CpxP (Danese und Silhavy 1998). Dies erfolgt durch eine Inhibition der Sensor-Kinase CpxA, welche über den Response Regulator CpxR die Cpx-Antwort vermittelt (DiGiuseppe und Silhavy 2003). Die Expression von cpxP selbst unterliegt der Kontrolle durch das CpxARZweikomponentensystem, so dass es sich hier um eine Feedback-Inhibition handelt (Danese und Silhavy 1998). Eine $c p x P$-Mutante ist ferner nur eingeschränkt zur Bildung von Biofilmen fähig (Beloin et al. 2004).

Die erhöhte Expression von $g \ln G$ spiegelt sich in der ebenfalls erhöhten Expression der Gene $y h d Y$ und $g \ln H$ wieder, welche unter der Kontrolle des durch $g \ln G$ kodierten Proteins NtrC stehen. Für die anderen Regulatoren, deren Genexpression in einem yhbJDeletionshintergrund erhöht ist, ist allerdings keine gleichzeitige Erhöhung der Zielgene 
ersichtlich. Ein Grund hierfür könnte das Fehlen entsprechender externer Signale sein (beispielsweise ein hoher Spiegel zyklischen AMPs im Falle von RhaS). CpxP, IscR und FrvR wirken jedoch autoregulatorisch auf die eigene Expression, so dass eine erhöhte Expression dieser Gene höchst unerwartet ist. Der Mechanismus, der in Abwesenheit von YhbJ zu einer erhöhten Expression der korrespondierenden Gene führt, verbleibt kryptisch.

\subsubsection{Das Kälteschockprotein CspA}

In Abwesenheit von YhbJ ist die Expression von $\operatorname{csp} A$ dramatisch herabgesetzt. Das korrespondierende Protein ist ein RNA-Chaperon, das die Bildung sekundärer RNAStrukturen bei tiefen Temperaturen verhindert (Jiang et al. 1997). Das cspA-Transkript ist sehr instabil bei $37^{\circ} \mathrm{C}$ und wird durch eine RNase E-abhängige Prozessierung am 3'Ende destabilisiert (Hankins et al. 2007).

CspA aktiviert die Expression von gyrA (Brandi et al. 1994) und dient nach einem Kälteschock als transkriptioneller Aktivator von hns (La Teana et al. 1991). Es ist ein negativer Regulator seiner eigenen Expression.

Obwohl der Zusammenhang zwischen YhbJ und CspA unklar ist, so ist es doch eine interessante Beobachtung, das in Abwesenheit von YhbJ Gene der HitzeschockAntwort aktiviert (siehe 4.3.1.) und mit $\operatorname{cspA}$ und $y i h K$ (siehe 4.3.6) Gene der Kälteschock-Antwort reprimiert werden. Ein weiterer beachtenswerter Aspekt ist die Destabilisierung des $\operatorname{csp} A$-Transkriptes durch RNase E. Eine Möglichkeit, dass die Kontrolle $\operatorname{cspA-Expression~einem~Mechanismus~unterliegt,~der~von~ähnlichen~Faktoren~}$ kontrolliert wird wie die $g \operatorname{lm} S$-spezifische Expression.

\subsubsection{Gene der Lipopolysaccharid-Kernsynthese}

Neben Peptidoglykan sind Lipopolysaccharide das zweite Endprodukt des Syntheseweges, dessen initiale Reaktion die Herstellung von Glukosamin-6-Phosphat ist (vergleiche 1.3.). Der letzte gemeinsame Vorläufer ist UDP-GlcNAc.

In einem $y h b J$-Deletionshintergrund ist die Expression einiger Gene, die für Proteine der Lipopolysaccharid-Kernsynthese kodieren, erniedrigt. Den höchsten Effekt hat die Abwesenheit von YhbJ auf die Expression von rfaK. Dieses Gen kodiert für die Heptosyl-Transferase IV. RfaK ist verantwortlich für das Anfügen von Heptose IV an den Glc III-Rest des äußeren Kerns (Heinrichs et al. 1998) und möglicherweise auch für 
das Anfügen von GlcNAc an eine Heptose des inneren Kerns (Klena et al. 1992). Ebenfalls in Abwesenheit von YhbJ ist die Expression von $r f a Y$ und $r f a Z$ erniedrigt, die Bestandteil desselben Operons wie $r f a K$ sind und ebenfalls an der Synthese des Lipopolysaccharid-Kerns beteiligt sind.

Die Phosphorylierung von Heptose II des inneren Kerns wird durch die Kinase RfaY durchgeführt, während RfaZ am Hinzufügen der KDO III -Einheit an den KDO II-Rest des inneren Kerns beteiligt ist. Eine Überproduktion von RfaZ führt zu Fehlern in der Lipopolysaccharid-Biosynthese, beispielsweise verringerte Mengen O-Antigens oder unvollständige Strukturen des äußeren Kerns (Frirdich et al. 2003), während eine Deletion zu einem Defekt in der Synthese der Lipooligosaccharide der Zellhülle führt (Klena et al. 1992).

Das Gen $w b b K$ kodiert für ein Protein, von dem ebenfalls angenommen wird, dass es an der Synthese der Lipopolysaccharide beteiligt ist (GOA et al. 2001) und seine Expression ist ebenfalls in Abwesenheit von YhbJ erniedrigt.

YihK ist ein Protein, für das ebenfalls eine Rolle in der Biosynthese von Lipopolysacchariden vorhergesagt wurde, da eine Mutation des korrespondierenden Gens den Defekt einer $r f a Q$-Mutante unterdrücken kann (Moller et al. 2003). Zudem ist das Protein für das Überleben bei niedrigen Temperaturen notwendig (Pfennig und Flower 2001). In enteropathogenen E. coli-Stämmen ist YihK in die Pathogenese involviert (Grant et al. 2003).

Die verringerte Expression von Genen, deren korrespondierende Proteine eine wichtige Rolle in der Synthese von Lipopolysacchariden spielen, erscheint zunächst kontraintuitiv. In Abwesenheit von YhbJ ist die Expression von $g \operatorname{lm} S$ stark erhöht, so dass in der Zelle eine große Menge UDP-GlcNAc für die Synthese von Lipopolysacchariden zur Verfügung stehen sollte. Dies ist allerdings nur eine von vielen Komponenten, die zum Aufbau funktioneller Lipopolysaccharide benötigt werden. Ein Überschuss an UDP-GlcNAc kann sogar einen Mangel an anderen Vorläufern induzieren, indem die kontinuierliche Verfügbarkeit zu einer starken Synthese von Lipopolysacchariden führt, wodurch andere Komponenten schneller verbraucht würden, als sie nachproduziert werden können. Dies könnte zu einer verringerten Expression der Gene führen, die die Enzyme des Lipopolysaccharid-Aufbaus kodieren. Beispielsweise könnte eine Induktion der Genexpression durch ein anderes Substrat als UDP-GlcNAc wegfallen oder die Expression dieser Gene unterliegt einer Feedback-Inhibition durch das 
Endprodukt des Syntheseweges, und eine erhöhte Verfügbarkeit von UDP-GlcNAc führt zu einer Akkumulation dieser Endprodukte.

\subsubsection{Gene regulatorischer Proteine mit erniedrigter Expression im $\Delta y h b J$-Hintergrund}

Neben den unter 4.3.4. diskutierten Genen regulatorischer Proteine, deren Expression in Abwesenheit von YhbJ erhöht ist, gibt es auch ein Set an Genen regulatorischer Proteine, die unter diesen Bedingungen schwächer exprimiert werden:

TdcA ist ein transkriptioneller Aktivator, der Gene kontrolliert, deren Produkte im Abbau von Aminosäuren involviert sind. Er kontrolliert vor allem die Expression des tdcABCDEFG-Operons (Hagewood et al. 1994). Widersprüchlicherweise ist das durch TdcA kontrollierte Gen $t d c D$ in Abwesenheit von YhbJ um einen Faktor von 2,5 stärker exprimiert.

Das Protein HepA ist eine ATPase, die mit der RNA-Polymerase interagieren kann und einen generellen Aktivator der Transkription an eng spiralisierten DNA-Abschnitten darstellt (Sukhodolets et al. 2001).

Das Gen ydaR kodiert für einen nicht näher charakterisierten potenziellen transkriptionellen Regulator (Perez-Rueda et al. 2004).

MelR ist der transkriptionelle Aktivator der Expression des melAB-Operons, dessen Genprodukte am Abbau von Melibiose, einem Disaccharid, beteiligt sind. Die Regulation erfolgt in Kooperation mit CRP ( $\underline{c} A M P$ receptor protein, Rezeptorpotein für zyklisches AMP) (Belyaeva et al. 2000). MelR reprimiert in Abwesenheit von Melibiose seine eigene Expression (Tamai et al. 2000).

Auch hier, wie schon im Fall der Gene regulatorischer Proteine mit erhöhter Expression in Abwesenheit von YhbJ, können die beobachteten Veränderungen in der Expression der Regulatoren nicht mit korrelierenden Effekten auf die von ihnen kontrollierten Gene verknüpft werden. Im Falle von TdcA widersprechen die Ergebnisse der MicroArray Analyse sogar den beschriebenen Verhalten der Expression: TdcA ist ein transkriptioneller Aktivator des $t d c A B C D E F G$-Operons und seine Expression ist in Abwesenheit von YhbJ um einen Faktor von 4 erniedrigt. Trotz der anzunehmenden Reduktion der Aktivierung des tdcABCDEFG-Operons aufgrund der verringerten TdcA-Menge ist die Expression von $t d c D$ um einen Faktor von 2,5 erhöht. Es ist nicht auszuschließen, dass die Unterschiede durch Effekte stromabwärts des Promotors ausgelöst werden. Beispielsweise könnte TdcA ein sehr stabiles Protein sein, so dass 
trotz der verringerten Expression noch immer signifikante Mengen des Regulators in der Zelle vorhanden sind, und diese die Expression des von ihnen kontrollierten Operons noch immer aktivieren können. Gegen diese Theorie spricht jedoch, dass von sieben kotranskribierten Genen des Operons nur für $t d c D$ eine signifikant erhöhte Expression nachweisbar ist.

Eine weitere Möglichkeit ist eine alternative Transkription des Gens, die bislang unbekannt ist und die unabhängig von TdcA stattfindet. Um die genaue Ursache des beobachteten widersprüchlichen Effekts aufzuklären sind jedoch weitergehende Analysen notwendig.

\subsection{Vergleich der Auswirkungen einer $y h b J$-Deletion mit der Überexpression von GImY und GImZ in MicroArray Analysen}

In der AG RNA-Biologie des Max-Plack-Institutes für Infektionsbiologie wurden MicroArray Analysen mit plasmidischer Überexpression der kleinen RNAs GlmY und GlmZ durchgeführt (K. Papenfort und J. Vogel, persönliche Kommunikation). Vergleicht man die Ergebnisse dieser Analysen mit denen der in dieser Arbeit durchgeführten MicroArrays mit einem yhbJ-Deletionsstamm, so zeigt sich zunächst nur eine geringe Überlappung der beeinflussten Gene. Lediglich 25 Gene zeigen sowohl in einer $y h b J$-Deletion als auch unter Überexpression von $g \operatorname{lm} Z$ oder $g \operatorname{lm} Y$ ein verändertes Transkriptionsprofil. Noch bemerkenswerter ist jedoch, dass lediglich vier dieser Gene ein mit dem hier vorgestellten Regulationsmechanismus konsistentes Verhalten aufweisen: Die Gene $g \operatorname{lmS}$, rhaS, thiG und $y h d Y$ werden sowohl in Abwesenheit von YhbJ als auch bei Überexpression einer der kleinen sRNAs. Dies impliziert, dass die Expression dieser Gene einer ähnlichen, wenn nicht übereinstimmenden, Regulation durch YhbJ und GlmY/GlmZ unterliegen.

Die restlichen 21 Gene, deren Expression sowohl in Abwesenheit von YhbJ als auch bei Überexpression von GlmY oder GlmZ verändert ist, zeigen ein gegensätzliches Verhalten: Alle von ihnen werden im $y h b J$-Deletionsstamm verstärkt und bei Überexpression einer der kleinen RNAs verringert exprimiert.

Ein antagonistisches Verhalten von einer yhbJ-Deletion im Vergleich zur Überexpression ist unerwartet, wenn man die Ergebnisse der Untersuchung der glmSspezifischen Expression berücksichtigt: In Abwesenheit von yhbJ akkumulieren die aktiven Formen der sRNAs, prozessiertes GlmY und unprozessiertes GlmZ. Ebenso konnte gezoegt werden, dass im Falle der Überexpression von glmZ oder glmY 
ebenfalls die aktiven Formen akkumulieren (Reichenbach et al. 2008; Urban und Vogel 2008).

Unter diesem Gesichtspunkt zeigt sich, dass sowohl YhbJ wie auch GlmY und GlmZ spezifische Regulons haben. Weiterhin wurden in den MicroArray Analyse unter Überexpression von GlmY 109 Gene mit veränderter Expression identifiziert, unter Überexpression von GlmZ 60 Gene. Die Überlappung beträgt hier jedoch nur 3 Gene. Unter der Vorraussetzung, dass eine Überexpression von GlmY die Prozessierung von GlmZ verhindert, kann spekuliert werden, dass die Expression dieser Gene indirekt von GlmY über diesen Effekt gesteuert wird. Andererseits lassen diese Ergebnisse die Vermutung zu, dass GlmY unabhängig von GlmZ agieren kann, beispielsweise durch direkte Interaktion mit Ziel-mRNAs oder durch die Beeinflussung der Stabilität anderer kleiner RNAs.

Im Falle von GlmZ kann spekuliert werden, ob die prozessierte Form der sRNA ebenfalls eine regulatorische Funktion hat. Diese würde dann die Expression der Gene erklären, die nicht mit dem GlmY-Regulon überlappen.

Aus dem Vergleich der MicroArray Analysen lassen sich somit drei Schlüsse ziehen:

1. Die Gene $g \operatorname{lm} S$, thiG, rhaS und $y h d Y$ folgen in ihrer YhbJ/GlmY/GlmZ-abhängigen Expression einem gemeinsamen Muster, dass einen ähnlichen oder gleichen Mechanismus der Regulation wahrscheinlich macht.

2. Die geringe Überlappung der durch GlmY/GlmZ und YhbJ in ihrer Expression beeinflussten Gene lässt darauf schließen, dass diese unterschiedliche, spezifische Regulons besitzen und die in Abwesenheit von YhbJ beobachteten Effekte zu einem großen Teil nicht auf einem Mechanismus beruhen, an dem GlmY oder GlmZ beteiligt sind

3. Da eine die plasmidische Überexpression von $g \operatorname{lm} Y$ und $g \operatorname{lm} Z$ zu einer Aktivierung der spezifischen glmS-Expression führt (Kalamorz et al. 2007; Urban et al. 2007; Reichenbach et al. 2008; Urban und Vogel 2008), sollten unter diesen Bedingungen ähnliche Sekundäreffekte wie in Abwesenheit von YhbJ auftreten, wenn auch schwächer. Jedoch ist keine der unter 5.3. diskutierten Gruppen der durch YhbJ beeinflussten Gene durch Überexpression der kleinen RNAs signifikant beeinfluss Dies lässt vermuten, dass die beobachteten Effekte direkt auf die Abwesenheit von YhbJ zurückzuführen sind und keine sekundären Auswirkungen der Überexpression von glmS darstellen. 


\subsection{Expression des rpoN-Operons}

Die Analyse der Expression des rpoN-Operons und somit von $y h b J$ (siehe 3.5.) ergab, dass die Expression zu 80\% vom rpoN-Promotor ausgeht, während eine unvollständige Termination der Expression vom stromaufwärts gelegenen lptB-Promotor aus etwa $20 \%$ zu der Expression des rpoN-Operons beiträgt (vergleiche Abb. 4.23.).

Auffällig ist der Abfall der $\beta$-Galaktosidase Aktivität in der [lptB-yhbJ]-lacZReporterfusion, welche neben dem rpoN-Promotor auch die stromabwärts gelegenen Gene rpoN, $h p f, p t s N$ sowie ein 5'-Fragment des Gens yhbJ umfasst. Dies stimmt mit vorangegangenen Analysen der rpoN-Expression überein, in der eine ähnliche transkriptionelle Fusion $(\operatorname{lptB}(-177)$ bis $y h b J(+573))$ ebenfalls eine deutlich verringerte Aktivität aufweist (Powell et al. 1995).

Dieser Effekt kann unterschiedliche Gründe haben. Da es sich um translationale Fusionen handelt, unterliegt die $\beta$-Galaktosidase Aktivität der Reporterfusionen direkt der Translationsstärke des Genes, an das lacZ fusioniert wurde. Demnach könnte der Abfall der Aktivität durch eine geringere Translationsrate von $y h b J$ gegenüber rpoN bedingt sein. Eine weitere Erklärung könnte die Anwesenheit einer schwachen Sekundärstruktur stromabwärts von rpoN sein, die eine Termination der Translation oder auch Transkription propagiert. Eine zusätzliche Promotoraktivität innerhalb des rpoN-Operons wurde postuliert (Powell et al. 1995), jedoch zeigen Analysen verkürzter interner Fragmente des Operons keine transkriptionelle Aktivität und eine Sequenzanalyse konnte keine potenziellen Promotoren identifizieren (B. Görke, persönliche Kommunikation).

Allerdings kann ein Einfluss der sRNAs GlmY und GlmZ nicht völlig ausgeschlossen werden. Die in 4.5.3. präsentierten Ergebnisse zeigen lediglich, dass sich diese beiden kleinen RNAs nicht auf die Transkription von yhbJ auswirken, sie lassen jedoch keinen Schluss auf eine eventuellen Einfluss von GlmY und GlmZ auf die Translationseffizienz zu. Es wäre möglich, dass die Ribosomenbindestelle von $y h b J$ in der mRNA aufgrund von Sekundärstrukturen nicht zugänglich ist, und die Bindung der mRNA mit einer der kleinen RNAs nötig ist um die Expression des Gens zu ermöglichen. Umgekehrt könnte die Translation auch durch Interaktion mit einer sRNA stimuliert werden (Gottesman 2002). 


\subsection{Ausblick}

Obwohl der Start- und Ausgangspunkt der spezifischen glmS-Expression aufgeklärt werden konnten (ein Mangel an GlcN-6-Phosphat führt zur Stabilisierung einer glmSspezifischen mRNA), ist der genaue Ablauf der Regulation weiterhin unklar.

Besonders wichtig für ein weitergehendes Verständnis der Abläufe ist die Frage, wie das Signal in die regulatorische Kaskade eingespeist wird. Die Expression von $\operatorname{glm} Y$ ist von $\sigma^{54}$ abhängig, dessen Aktivität nur durch ein zusätzliches Aktivatorprotein vermittelt werden kann. Dieses potenzielle Aktivatorprotein ist ein wahrscheinlicher Kandidat für den Sensor des GlcN-6-P-Spiegels. Das Gen $g \operatorname{lm} Y$ ist in direkter Nachbarschaft der Gene des YfhAK-Zweikomponentensystems kodiert. Der Response Regulator YfhA ist ein potenzieller Aktivator für $\sigma^{54}$-abhängige Promotoren. Untersuchungen der $g \operatorname{lm} Y$-Expression und einer möglichen Verknüpfung mit YfhAK werden momentan in unserer Arbeitsgruppe durchgeführt.

Um einen weiteren Einblick in die Funktion von YhbJ zu erhalten, sind verschiedene Richtungen möglich: Durch Überexpression und Aufreinigung von YhbJ-Derivaten mit Mutationen in der potenziellen RNA-Bindedomäne und in den anderen konservierten Motiven kann die Funktion dieser Domänen weiter charakterisiert werden, besonders hinsichtlich der Bindung von RNA, der vorhergesagten Fähigkeit zur ATP/GTPHydrolyse sowie einer möglichen Dimerisierung. Eine Aufklärung der Kristallstruktur von Protein:RNA-Komplexen kann weiteren Einblick in den Vorgang der RNABindung geben. Zudem könnten mutierte Formen von GlmY und GlmZ in EMSAs mit YhbJ verwendet werden, um die RNA-Bindung des Proteins mit der Anwesenheit bestimmter Merkmale in der RNA $\mathrm{zu}$ verknüpfen (beispielsweise mit den Ausbuchtungen an den mittleren Haarnadelstrukturen der beiden sRNAs, siehe Abb.4.2.). Mittels SPINE (Herzberg et al. 2007) wäre es zudem möglich, Proteine zu identifizieren, die mit YhbJ interagieren.

Die Auswertung der MicroArray Analysen mit einem $\Delta y h b J$-Stamm wird durch die parallele Wirkung zweier artifizieller Bedingungen erschwert: Die Auswirkungen der Abwesenheit von YhbJ sind hier kombiniert mit den Auswirkungen der Überexpression von glmS. Zwar können durch eine Abgleich der MicroArray Analysen unter Überexpression von $g \operatorname{lm} Z$ und in Abwesenheit von YhbJ, wie unter 5.4. diskutiert, die Sekundäreffekte der verstärkten $g \operatorname{lm} S$-Expression subtrahiert werden, jedoch kommen hier wiederum zusätzliche Effekte und Sekundäreffekte durch die Wirkung der kleinen 
RNA hinzu. Um die potenziellen Einflüsse der Abwesenheit von YhbJ von denen einer stark erhöhten $g \operatorname{lm} S$-Expression auf die Genexpression $\mathrm{zu}$ separieren, können MicroArray-Analysen mit Wildtyp-Kulturen durchgeführt werden, in denen durch Zugabe von Nva-FMDP die Produktion von GlmS in Anwesenheit physiologischer Mengen von YhbJ erhöht ist. Umgekehrt könnte durch die Mutation der für die Stabilisierung der $g \operatorname{lm} S$-spezifischen mRNA durch GlmZ verantwortlichen Nukleotide eine Überexpression von $g \operatorname{lm} S$ in Abwesenheit von YhbJ verhindert werden, ohne eventuelle weitere Ziele von GlmZ zu beeinflussen.

Ein weiterer wichtiger Schritt in Zusammenhang mit der MicroArray Analyse der Auswirkungen der Deletion von yhbJ ist eine Verifizierung der Ergebnisse durch alternative Methoden. Beispielsweise könnte die Expression ausgewählter durch die Deletion in ihrer Expression beeinflußter Gene mittels Northern Blot Analyse oder durch Untersuchungen mit entsprechenden lacZ-Fusionen untersucht werden. Solche Analysen könnten zusätzlich auch bei gleichzeitiger Überexpression von plasmidständigen $y h b J$ durchgeführt werden. Falls in diesen Untersuchungen ein reproduzierbarer Effekt von YhbJ auf die Genexpression auftritt, könnte nachfolgend der Einfluß der in dieser Arbeit beschriebenen mutierten Formen von YhbJ untersucht werden. Dadurch könnten unter Umständen bestimmte konservierte Motive innerhalb von YhbJ mit einer Funktion verknüpft werden.

Daten aus der MicroArray Analyse des $y h b J$-Deletionsstammes eröffnen des Weiteren die Möglichkeit, dass die Abwesenheit von YhbJ eine Translation der $r p o H$-mRNA, welche für den Sigma-Faktor der Hitzeschockantwort $\left(\sigma^{32}\right)$ kodiert, bei niedrigen Temperaturen ermöglicht. Dies ließe sich schnell und einfach überprüfen, indem die Expression einer translationalen rpoH-lacZ-Fusion im Wildtyp und in einem yhbJDeletionsstamm bei $37^{\circ} \mathrm{C}$ und $42^{\circ} \mathrm{C}$ verglichen wird.

Auch hier würden die zuvor vorgeschlagenen zusätzlichen MicroArray-Analysen hilfreich sein: Falls die Induktion der Hitzeschockantwort auf der Aggregation von GlmS durch Entkopplung der Gen-Expression in Abwesenheit von YhbJ beruht, so sollte dieser Effekt bei Nva-FMDP-induzierter Überexpression auch in Anwesenheit von YhbJ eintreten. Im umgekehrten Fall, wenn die Abwesenheit von YhbJ für den Effekt verantwortlich ist, sollte dieser auch in einer Mutante eintreten, in der die Entkopplung der $g \operatorname{lm} S$-Expression nicht mehr möglich ist. 
In Verbindung mit der vorgeschlagenen rpoH-lacZ-Reporterfusion könnte auch der Effekt einer artifiziellen, plasmidgestützten Überexpression von $g \operatorname{lm} S$ auf die Translationseffizienz von rpoH geprüft werden.

YhbJ weist Eigenschaften auf, die eine weitergehende Funktion als die Kontrolle der glmS-Expression implizieren: Das hierfür notwendige potenzielle RNA-Bindemotiv ist innerhalb der Proteinfamilie nicht konserviert, während Mutationen des hochkonservierten Walker A-Motiv der P-Loop-ATPase-Domäne keine Auswirkung auf die Fähigkeit von YhbJ zur Expressionskontrolle von $\operatorname{glm} S$ hat. Dies sind starke Hinweise auf eine zusätzliche Funktion von YhbJ. Um diese Hypothese weiter zu verfolgen könnten globale Analysen der Transkription und Translation in Stämmen durchgeführt werden, die Mutationen in den konservierten Motiven von YhbJ tragen, besonders mit Mutationen des Walker A-Motivs oder der potenziellen RNABindedomäne.

Schließlich bleibt das Rätsel der unterschiedlichen $\beta$-Galaktosidase Aktivität der Reporterfusionen zur Untersuchung der Expression des rpoN-Operons. Um hier weitere Einblicke zu erlangen, sollte zunächst der Effekt einer Deletion und plasmidischer Überexpression der kleinen RNAs GlmY und GlmZ auf das Verhalten der Reportergenfusionen untersucht werden. Zudem könnte eine Fusion der intergenischen Region zwischen $h p f$ und $p t s N$ an $l a c Z$ unter Kontrolle eines konstitutiven Promotors genutzt werden, um mögliche posttranskriptionelle Regulationen zu detektieren. 


\section{Literaturverzeichnis}

Aiba, H. (2007). "Mechanism of RNA silencing by Hfq-binding small RNAs." Curr. Opin. Microbiol. 10(2): 134-139.

Aiba, H., S. Matsuyama, T. Mizuno und S. Mizushima (1987). "Function of micF as an antisense RNA in osmoregulatory expression of the ompF gene in Escherichia coli." J Bacteriol 169(7): 3007-3012.

Altschul, S. F., W. Gish, W. Miller, E. W. Myers und D. J. Lipman (1990). "Basic local alignment search tool." J Mol Biol 215(3): 403-410.

Alvarez-Anorve, L. I., M. L. Calcagno und J. Plumbridge (2005). "Why does Escherichia coli grow more slowly on glucosamine than on $\mathrm{N}$-acetylglucosamine? Effects of enzyme levels and allosteric activation of GlcN6P deaminase (NagB) on growth rates." J Bacteriol 187(9): 2974-2982.

Amster-Choder, O. (2005). "The bgl sensory system: a transmembrane signaling pathway controlling transcriptional antitermination." Curr Opin Microbiol 8(2): 127134.

Andersen, J., N. Delihas, K. Ikenaka, P. J. Green, O. Pines, O. Ilercil und M. Inouye (1987). "The isolation and characterization of RNA coded by the micF gene in Escherichia coli." Nucleic Acids Res 15(5): 2089-2101.

Argaman, L., R. Hershberg, J. Vogel, G. Bejerano, E. G. Wagner, H. Margalit und S. Altuvia (2001). "Novel small RNA-encoding genes in the intergenic regions of Escherichia coli." Curr. Biol. 11(12): 941-950.

Arluison, V., S. Hohng, R. Roy, O. Pellegrini, P. Regnier und T. Ha (2007). "Spectroscopic observation of RNA chaperone activities of Hfq in post-transcriptional regulation by a small non-coding RNA." Nucleic Acids Res 35(3): 999-1006.

Bachmann, B. J. (1972). "Pedigrees of some mutant strains of Escherichia coli K-12." Bacteriol Rev 36(4): 525-557.

Badet, B., P. Vermoote, P. Y. Haumont, F. Lederer und F. LeGoffic (1987). "Glucosamine synthetase from Escherichia coli: purification, properties, and glutamineutilizing site location." Biochemistry 26(7): 1940-1948.

Bailey, T. L., N. Williams, C. Misleh und W. W. Li (2006). "MEME: discovering and analyzing DNA and protein sequence motifs." Nucleic Acids Res 34(Web Server issue): W369-373.

Bartel, D. P. (2004). "MicroRNAs: genomics, biogenesis, mechanism, and function." Cell 116(2): 281-297.

Bearne, S. L. und C. Blouin (2000). "Inhibition of Escherichia coli glucosamine-6phosphate synthase by reactive intermediate analogues. The role of the 2-amino function in catalysis." J Biol Chem 275(1): 135-140. 
Belitsky, B. R. und A. L. Sonenshein (1999). "An enhancer element located downstream of the major glutamate dehydrogenase gene of Bacillus subtilis." Proc Natl Acad Sci U S A 96(18): 10290-10295.

Beloin, C., J. Valle, P. Latour-Lambert, P. Faure, M. Kzreminski, D. Balestrino, J. A. Haagensen, S. Molin, G. Prensier, B. Arbeille und J. M. Ghigo (2004). "Global impact of mature biofilm lifestyle on Escherichia coli K-12 gene expression." Mol Microbiol 51(3): 659-674.

Belyaeva, T. A., J. T. Wade, C. L. Webster, V. J. Howard, M. S. Thomas, E. I. Hyde und S. J. Busby (2000). "Transcription activation at the Escherichia coli melAB promoter: the role of MelR and the cyclic AMP receptor protein." Mol Microbiol 36(1): 211-222.

Bentley, R. und R. Meganathan (1982). "Biosynthesis of vitamin K (menaquinone) in bacteria." Microbiol Rev 46(3): 241-280.

Bessman, M. J., J. D. Walsh, C. A. Dunn, J. Swaminathan, J. E. Weldon und J. Shen (2001). "The gene ygdP, associated with the invasiveness of Escherichia coli K1, designates a Nudix hydrolase, Orf176, active on adenosine (5')-pentaphospho-(5')adenosine (Ap5A)." J Biol Chem 276(41): 37834-37838.

Bethell, M. R., K. E. Smith, J. S. White und M. E. Jones (1968). "Carbamyl phosphate: an allosteric substrate for aspartate transcarbamylase of Escherichia coli." Proc Natl Acad Sci U S A 60(4): 1442-1449.

Blattner, F. R., G. Plunkett, 3rd, C. A. Bloch, N. T. Perna, V. Burland, M. Riley, J. Collado-Vides, J. D. Glasner, C. K. Rode, G. F. Mayhew, J. Gregor, N. W. Davis, H. A. Kirkpatrick, M. A. Goeden, D. J. Rose, B. Mau und Y. Shao (1997). "The complete genome sequence of Escherichia coli K-12." Science 277(5331): 1453-1474.

Boël, G., I. Mijakovic, A. Maze, S. Poncet, M. K. Taha, M. Larribe, E. Darbon, A. Khemiri, A. Galinier und J. Deutscher (2003). "Transcription regulators potentially controlled by HPr kinase/phosphorylase in Gram-negative bacteria." J. Mol. Microbiol. Biotechnol. 5(4): 206-215.

Bradford, M. M. (1976). "A rapid and sensitive method for the quantification of microgram quantities of protein utilizing the principle of protein-dye binding." Anal. Biochem. 72: 248-254.

Brandi, A., C. L. Pon und C. O. Gualerzi (1994). "Interaction of the main cold shock protein CS7.4 (CspA) of Escherichia coli with the promoter region of hns." Biochimie 76(10-11): 1090-1098.

Brennan, R. G. und T. M. Link (2007). "Hfq structure, function and ligand binding." Curr. Opin. Microbiol. 10(2): 125-133.

Broschat, K. O., C. Gorka, J. D. Page, C. L. Martin-Berger, M. S. Davies, H. C. Huang Hc, E. A. Gulve, W. J. Salsgiver und T. P. Kasten (2002). "Kinetic characterization of human glutamine-fructose-6-phosphate amidotransferase I: potent feedback inhibition by glucosamine 6-phosphate." J Biol Chem 277(17): 14764-14770. 
Buchet, A., W. Nasser, K. Eichler und M. A. Mandrand-Berthelot (1999). "Positive co-regulation of the Escherichia coli carnitine pathway cai and fix operons by CRP and the CaiF activator." Mol Microbiol 34(3): 562-575.

Buck, M., M. T. Gallegos, D. J. Studholme, Y. Guo und J. D. Gralla (2000). "The bacterial enhancer-dependent sigma $(54)(\operatorname{sigma}(\mathrm{N}))$ transcription factor." J Bacteriol 182(15): 4129-4136.

Bukau, B. und A. L. Horwich (1998). "The Hsp70 and Hsp60 chaperone machines." Cell 92(3): 351-366.

Burton, E., P. V. Gawande, N. Yakandawala, K. LoVetri, G. G. Zhanel, T. Romeo, A. D. Friesen und S. Madhyastha (2006). "Antibiofilm activity of GlmU enzyme inhibitors against catheter-associated uropathogens." Antimicrob. Agents Chemother. 50(5): 1835-1840.

Casadaban, M. J. (1976). "Transposition and fusion of the lac genes to selected promoters in Escherichia coli using bacteriophage lambda and Mu." J Mol Biol 104(3): 541-555.

Castano, I. und F. Bastarrachea (1984). "glnF-lacZ fusions in Escherichia coli: studies on glnF expression and its chromosomal orientation." Mol Gen Genet 195(1-2): 228-233.

Celesnik, H., A. Deana und J. G. Belasco (2007). "Initiation of RNA decay in Escherichia coli by 5' pyrophosphate removal." Mol Cell 27(1): 79-90.

Ceyssens, P. J., K. Hertveldt, H. W. Ackermann, J. P. Noben, M. Demeke, G. Volckaert und R. Lavigne (2008). "The intron-containing genome of the lytic Pseudomonas phage LUZ24 resembles the temperate phage PaP3." Virology 377(2): 233-238.

Chmara, H., H. Zahner, E. Borowski und S. Milewski (1984). "Inhibition of glucosamine-6-phosphate synthetase from bacteria by anticapsin." J Antibiot (Tokyo) 37(6): 652-658.

Christie, G. E., P. J. Farnham und T. Platt (1981). "Synthetic sites for transcription termination and a functional comparison with tryptophan operon termination sites in vitro." Proc Natl Acad Sci U S A 78(7): 4180-4184.

Chuang, S. E., V. Burland, G. Plunkett, 3rd, D. L. Daniels und F. R. Blattner (1993). "Sequence analysis of four new heat-shock genes constituting the hslTS/ibpAB and hslVU operons in Escherichia coli." Gene 134(1): 1-6.

Cochrane, J. C. und S. A. Strobel (2008). "Catalytic strategies of self-cleaving ribozymes." Acc Chem Res 41(8): 1027-1035.

Collins, J. A., I. Irnov, S. Baker und W. C. Winkler (2007). "Mechanism of mRNA destabilization by the $g \operatorname{lm} S$ ribozyme." Genes Dev. 21(24): 3356-3368. 
Condon, C. (2003). "RNA processing and degradation in Bacillus subtilis." Microbiol Mol Biol Rev 67(2): 157-174, table of contents.

Crooks, G. E., G. Hon, J. M. Chandonia und S. E. Brenner (2004). "WebLogo: a sequence logo generator." Genome Res 14(6): 1188-1190.

Danese, P. N. und T. J. Silhavy (1998). "CpxP, a stress-combative member of the Cpx regulon." J Bacteriol 180(4): 831-839.

Datsenko, K. A. und B. L. Wanner (2000). "One-step inactivation of chromosomal genes in Escherichia coli K-12 using PCR products." Proc. Natl. Acad. Sci. U S A 97(12): 6640-6645.

Deana, A. und J. G. Belasco (2005). "Lost in translation: the influence of ribosomes on bacterial mRNA decay." Genes Dev 19(21): 2526-2533.

Deeley, M. C. und C. Yanofsky (1981). "Nucleotide sequence of the structural gene for tryptophanase of Escherichia coli K-12." J Bacteriol 147(3): 787-796.

DeLisa, M. P., C. F. Wu, L. Wang, J. J. Valdes und W. E. Bentley (2001). "DNA microarray-based identification of genes controlled by autoinducer 2-stimulated quorum sensing in Escherichia coli." J Bacteriol 183(18): 5239-5247.

Deutscher, J., C. Francke und P. W. Postma (2006). "How phosphotransferase system-related protein phosphorylation regulates carbohydrate metabolism in bacteria." Microbiol. Mol. Biol. Rev. 70(4): 939-1031.

DiGiuseppe, P. A. und T. J. Silhavy (2003). "Signal detection and target gene induction by the CpxRA two-component system." J Bacteriol 185(8): 2432-2440.

Diwa, A., A. L. Bricker, C. Jain und J. G. Belasco (2000). "An evolutionarily conserved RNA stem-loop functions as a sensor that directs feedback regulation of RNase E gene expression." Genes Dev. 14(10): 1249-1260.

Domka, J., J. Lee und T. K. Wood (2006). "YliH (BssR) and YceP (BssS) regulate Escherichia coli K-12 biofilm formation by influencing cell signaling." Appl Environ Microbiol 72(4): 2449-2459.

Edwards, R. M. und M. D. Yudkin (1982). "Location of the gene for the low-affinity tryptophan-specific permease of Escherichia coli." Biochem J 204(2): 617-619.

Egan, S. M. und R. F. Schleif (1993). "A regulatory cascade in the induction of rhaBAD." J Mol Biol 234(1): 87-98.

Eguchi, Y., T. Okada, S. Minagawa, T. Oshima, H. Mori, K. Yamamoto, A. Ishihama und R. Utsumi (2004). "Signal transduction cascade between EvgA/EvgS and PhoP/PhoQ two-component systems of Escherichia coli." J Bacteriol 186(10): 3006-3014. 
Eichler, K., A. Buchet, R. Lemke, H. P. Kleber und M. A. Mandrand-Berthelot (1996). "Identification and characterization of the caiF gene encoding a potential transcriptional activator of carnitine metabolism in Escherichia coli." $\mathrm{J}$ Bacteriol 178(5): 1248-1257.

El Qaidi, S., F. Allemand, J. Oberto und J. Plumbridge (2008). "Repression of galP, the galactose transporter in Escherichia coli, requires the specific regulator of Nacetylglucosamine metabolism." Mol Microbiol.

Erickson, J. W. und C. A. Gross (1989). "Identification of the sigma E subunit of Escherichia coli RNA polymerase: a second alternate sigma factor involved in hightemperature gene expression." Genes Dev 3(9): 1462-1471.

Fayet, O., T. Ziegelhoffer und C. Georgopoulos (1989). "The groES and groEL heat shock gene products of Escherichia coli are essential for bacterial growth at all temperatures." J Bacteriol 171(3): 1379-1385.

Frirdich, E., B. Lindner, O. Holst und C. Whitfield (2003). "Overexpression of the waaZ gene leads to modification of the structure of the inner core region of Escherichia coli lipopolysaccharide, truncation of the outer core, and reduction of the amount of $\mathrm{O}$ polysaccharide on the cell surface." J Bacteriol 185(5): 1659-1671.

Gaitanaris, G. A., A. Vysokanov, S. C. Hung, M. E. Gottesman und A. Gragerov (1994). "Successive action of Escherichia coli chaperones in vivo." Mol Microbiol 14(5): 861-869.

Galinier, A., J. P. Lavergne, C. Geourjon, S. Fieulaine, S. Nessler und J. M. Jault (2002). "A new family of phosphotransferases with a P-loop motif." J Biol Chem 277(13): 11362-11367.

Ganduri, Y. L., S. R. Sadda, M. W. Datta, R. K. Jambukeswaran und P. Datta (1993). "TdcA, a transcriptional activator of the tdcABC operon of Escherichia coli, is a member of the LysR family of proteins." Mol Gen Genet 240(3): 395-402.

Garner, M. M. und A. Revzin (1981). "A gel electrophoresis method for quantifying the binding of proteins to specific DNA regions: application to components of the Escherichia coli lactose operon regulatory system." Nucleic Acids Res 9(13): 30473060 .

Geanacopoulos, M. und S. Adhya (1997). "Functional characterization of roles of GalR and GalS as regulators of the gal regulon." J Bacteriol 179(1): 228-234.

Gerdes, S. Y., M. D. Scholle, J. W. Campbell, G. Balazsi, E. Ravasz, M. D. Daugherty, A. L. Somera, N. C. Kyrpides, I. Anderson, M. S. Gelfand, A. Bhattacharya, V. Kapatral, M. D'Souza, M. V. Baev, Y. Grechkin, F. Mseeh, M. Y. Fonstein, R. Overbeek, A. L. Barabasi, Z. N. Oltvai und A. L. Osterman (2003). "Experimental determination and system level analysis of essential genes in Escherichia coli MG1655." J Bacteriol 185(19): 5673-5684. 
Gerhart, J. C. und A. B. Pardee (1962). "The enzymology of control by feedback inhibition." J Biol Chem 237: 891-896.

Gimenez, R., M. F. Nunez, J. Badia, J. Aguilar und L. Baldoma (2003). "The gene $y j c G$, cotranscribed with the gene acs, encodes an acetate permease in Escherichia coli." J Bacteriol 185(21): 6448-6455.

GOA (2000). "Gene Ontology annotation based on Swiss-Prot keyword mapping.".

GOA, DDB, FB, MGI, ZFIN (2001). "Gene Ontology annotation through association of InterPro records with GO terms.".

Goeddel, D. V., H. L. Heyneker, T. Hozumi, R. Arentzen, K. Itakura, D. G. Yansura, M. J. Ross, G. Miozzari, R. Crea und P. H. Seeburg (1979). "Direct expression in Escherichia coli of a DNA sequence coding for human growth hormone." Nature 281(5732): 544-548.

Goldberg, A. L., T. N. Akopian, A. F. Kisselev, D. H. Lee und M. Rohrwild (1997). "New insights into the mechanisms and importance of the proteasome in intracellular protein degradation." Biol Chem 378(3-4): 131-140.

Goldblum, K. und D. Apririon (1981). "Inactivation of the ribonucleic acidprocessing enzyme ribonuclease E blocks cell division." J. Bacteriol. 146(1): 128-132.

Gollnick, P. und C. Yanofsky (1990). "tRNA(Trp) translation of leader peptide codon 12 and other factors that regulate expression of the tryptophanase operon." J Bacteriol 172(6): 3100-3107.

Görke, B., E. Foulquier und A. Galinier (2005). "YvcK of Bacillus subtilis is required for a normal cell shape and for growth on Krebs cycle intermediates and substrates of the pentose phosphate pathway." Microbiology 151: 3777-3791.

Görke, B. und B. Rak (1999). "Catabolite control of Escherichia coli regulatory protein BglG activity by antagonistically acting phosphorylations." Embo J. 18(12): 3370-3379.

Görke, B. und J. Stülke (2008). "Carbon catabolite repression in bacteria: many ways to make the most out of nutrients." Nat. Rev. Microbiol. 6: 613-624.

Görke, B. und J. Vogel (2008). "Noncoding RNA control of the making and breaking of sugars." Genes Dev. 22(21): 2914-2925.

Gottesman, S. (2002). "Stealth regulation: biological circuits with small RNA switches." Genes Dev 16(22): 2829-2842.

Gottesman, S. (2004). "The small RNA regulators of Escherichia coli: roles and mechanisms." Annu. Rev. Microbiol. 58: 303-328.

Gottesman, S. (2005). "Micros for microbes: non-coding regulatory RNAs in bacteria." Trends Genet 21(7): 399-404. 
Gottesman, S., W. P. Clark, V. de Crecy-Lagard und M. R. Maurizi (1993). "ClpX, an alternative subunit for the ATP-dependent Clp protease of Escherichia coli. Sequence and in vivo activities." J Biol Chem 268(30): 22618-22626.

Gottesman, S., C. A. McCullen, M. Guillier, C. K. Vanderpool, N. Majdalani, J. Benhammou, K. M. Thompson, P. C. FitzGerald, N. A. Sowa und D. J. FitzGerald (2006). "Small RNA regulators and the bacterial response to stress." Cold Spring Harb Symp Quant Biol 71: 1-11.

Graf, P. C. und U. Jakob (2002). "Redox-regulated molecular chaperones." Cell Mol Life Sci 59(10): 1624-1631.

Gragerov, A., E. Nudler, N. Komissarova, G. A. Gaitanaris, M. E. Gottesman und V. Nikiforov (1992). "Cooperation of GroEL/GroES and DnaK/DnaJ heat shock proteins in preventing protein misfolding in Escherichia coli." Proc Natl Acad Sci U S A 89(21): 10341-10344.

Grant, A. J., M. Farris, P. Alefounder, P. H. Williams, M. J. Woodward und C. D. O'Connor (2003). "Co-ordination of pathogenicity island expression by the BipA GTPase in enteropathogenic Escherichia coli (EPEC)." Mol Microbiol 48(2): 507-521.

Grimshaw, J. P., I. Jelesarov, R. K. Siegenthaler und P. Christen (2003). "Thermosensor action of GrpE. The DnaK chaperone system at heat shock temperatures." J Biol Chem 278(21): 19048-19053.

Gruber, T. M. und C. A. Gross (2003). "Multiple sigma subunits and the partitioning of bacterial transcription space." Annu Rev Microbiol 57: 441-466.

Guillier, M., S. Gottesman und G. Storz (2006). "Modulating the outer membrane with small RNAs." Genes Dev 20(17): 2338-2348.

Guyer, C. A., D. G. Morgan und J. V. Staros (1986). "Binding specificity of the periplasmic oligopeptide-binding protein from Escherichia coli." J Bacteriol 168(2): 775-779.

Hagewood, B. T., Y. L. Ganduri und P. Datta (1994). "Functional analysis of the tdcABC promoter of Escherichia coli: roles of TdcA and TdcR." J Bacteriol 176(20): 6214-6220.

Hajnsdorf, E., F. Braun, J. Haugel-Nielsen und P. Regnier (1995). "Polyadenylylation destabilizes the $r p s O$ mRNA of Escherichia coli." Proc. Natl. Acad. Sci. U S A 92(9): 3973-3977.

Hall, T. A. (1999). "BioEdit: a user-friendly biological sequence alignment editor and analysis program for Windows 95/98/NT." Nucl. Acids. Symp. Ser. 41: 95-98.

Hanahan, D. (1983). "Studies on transformation of Escherichia coli with plasmids." $\underline{\mathbf{J}}$ Mol Biol 166(4): 557-580.

Hand, N. J. und T. J. Silhavy (2003). "Null mutations in a Nudix gene, ygdP, implicate an alarmone response in a novel suppression of hybrid jamming." J Bacteriol 185(22): 6530-6539. 
Hankins, J. S., C. Zappavigna, A. Prud'homme-Genereux und G. A. Mackie (2007). "Role of RNA structure and susceptibility to RNase E in regulation of a cold shock mRNA, cspA mRNA." J Bacteriol 189(12): 4353-4358.

Harayama, S., J. Bollinger, T. Iino und G. L. Hazelbauer (1983). "Characterization of the mgl operon of Escherichia coli by transposon mutagenesis and molecular cloning." J Bacteriol 153(1): 408-415.

Haslberger, T., J. Weibezahn, R. Zahn, S. Lee, F. T. Tsai, B. Bukau und A. Mogk (2007). "M domains couple the ClpB threading motor with the DnaK chaperone activity." Mol Cell 25(2): 247-260.

Hayden, J. D. und S. E. Ades (2008). "The Extracytoplasmic Stress Factor, Sigma E, Is Required to Maintain Cell Envelope Integrity in Escherichia coli." PLoS ONE 3(2): e1573.

Heinrichs, D. E., J. A. Yethon und C. Whitfield (1998). "Molecular basis for structural diversity in the core regions of the lipopolysaccharides of Escherichia coli and Salmonella enterica." Mol Microbiol 30(2): 221-232.

Helmann, J. D. (2002). "The extracytoplasmic function (ECF) sigma factors." $\underline{\text { Adv }}$ Microb Physiol 46: 47-110.

Helmann, J. D. und M. J. Chamberlin (1988). "Structure and function of bacterial sigma factors." Annu Rev Biochem 57: 839-872.

Herzberg, C., L. A. Weidinger, B. Dörrbecker, S. Hübner, J. Stülke und F. M. Commichau (2007). "SPINE: a method for the rapid detection and analysis of proteinprotein interactions in vivo." Proteomics 7(22): 4032-4035.

Herzberg, M., I. K. Kaye, W. Peti und T. K. Wood (2006). "YdgG (TqsA) controls biofilm formation in Escherichia coli K-12 through autoinducer 2 transport." J Bacteriol 188(2): 587-598.

Hindahl, M. S., G. W. Crockford und R. E. Hancock (1984). "Outer membrane protein NmpC of Escherichia coli: pore-forming properties in black lipid bilayers." $\mathbf{J}$ Bacteriol 159(3): 1053-1055.

Hmiel, S. P., M. D. Snavely, C. G. Miller und M. E. Maguire (1986). "Magnesium transport in Salmonella typhimurium: characterization of magnesium influx and cloning of a transport gene." J Bacteriol 168(3): 1444-1450.

Holcroft, C. C. und S. M. Egan (2000). "Interdependence of activation at rhaSR by cyclic AMP receptor protein, the RNA polymerase alpha subunit C-terminal domain, and rhaR." J Bacteriol 182(23): 6774-6782.

Holliday, G. L., J. M. Thornton, A. Marquet, A. G. Smith, F. Rebeille, R. Mendel, H. L. Schubert, A. D. Lawrence und M. J. Warren (2007). "Evolution of enzymes and pathways for the biosynthesis of cofactors." Nat Prod Rep 24(5): 972-987. 
Honzatko, R. B., H. L. Monaco und W. N. Lipscomb (1979). "A 3.0-A resolution study of nucleotide complexes with aspartate carbamoyltransferase." Proc Natl Acad Sci U S A 76(10): 5105-5109.

Isupov, M. N., G. Obmolova, S. Butterworth, M. A. Badet-Denisot, B. Badet, I. Polikarpov, J. A. Littlechild und A. Teplyakov (1996). "Substrate binding is required for assembly of the active conformation of the catalytic site in Ntn amidotransferases: evidence from the 1.8 A crystal structure of the glutaminase domain of glucosamine 6phosphate synthase." Structure 4(7): 801-810.

Jacob, F. und J. Monod (1961). "Genetic regulatory mechanisms in the synthesis of proteins." J Mol Biol 3: 318-356.

Janaszak, A., W. Majczak, B. Nadratowska, A. Szalewska-Palasz, G. Konopa und A. Taylor (2007). "A sigma54-dependent promoter in the regulatory region of the Escherichia coli rpoH gene." Microbiology 153(Pt 1): 111-123.

Jansen, J. A., T. J. McCarthy, G. A. Soukup und J. K. Soukup (2006). "Backbone and nucleobase contacts to glucosamine-6-phosphate in the glmS ribozyme." Nat Struct Mol Biol 13(6): 517-523.

Jiang, W., Y. Hou und M. Inouye (1997). "CspA, the major cold-shock protein of Escherichia coli, is an RNA chaperone." J Biol Chem 272(1): 196-202.

Jishage, M., A. Iwata, S. Ueda und A. Ishihama (1996). "Regulation of RNA polymerase sigma subunit synthesis in Escherichia coli: intracellular levels of four species of sigma subunit under various growth conditions." J Bacteriol 178(18): 54475451.

Joanny, G., J. Derout, D. Brechemier-Baey, V. Labas, J. Vinh, P. Regnier und E. Hajnsdorf (2007). "Polyadenylation of a functional mRNA controls gene expression in Escherichia coli." Nucleic Acids Res. 35: 2494-2502.

Jones, D. H., F. C. Franklin und C. M. Thomas (1994). "Molecular analysis of the operon which encodes the RNA polymerase sigma factor sigma 54 of Escherichia coli." Microbiology 140 ( Pt 5): 1035-1043.

Kalamorz, F., B. Reichenbach, W. März, B. Rak und B. Görke (2007). "Feedback control of glucosamine-6-phosphate synthase GlmS expression depends on the small RNA GlmZ and involves the novel protein YhbJ in Escherichia coli." Mol. Microbiol. 65: $1518-1533$.

Katayama, T., T. Kubota, M. Takata, N. Akimitsu und K. Sekimizu (1996). "Disruption of the $h s l U$ gene, which encodes an ATPase subunit of the eukaryotic 26S proteasome homolog in Escherichia coli, suppresses the temperature-sensitive dnaA46 mutation." Biochem Biophys Res Commun 229(1): 219-224.

Kawula, T. H. und M. J. Lelivelt (1994). "Mutations in a gene encoding a new Hsp70 suppress rapid DNA inversion and $b g l$ activation, but not proU derepression, in hns-1 mutant Escherichia coli." J Bacteriol 176(3): 610-619. 
Kedzierska, S., M. Staniszewska, A. Wegrzyn und A. Taylor (1999). "The role of DnaK/DnaJ and GroEL/GroES systems in the removal of endogenous proteins aggregated by heat-shock from Escherichia coli cells." FEBS Lett 446(2-3): 331-337.

Kenig, M. und E. P. Abraham (1976). "Antimicrobial activities and antagonists of bacilysin and anticapsin." J Gen Microbiol 94(1): 37-45.

Khan, M. A. und R. E. Isaacson (1998). "In vivo expression of the beta-glucoside ( $b g l$ ) operon of Escherichia coli occurs in mouse liver." J Bacteriol 180(17): 4746-4749.

Khemici, V. und A. J. Carpousis (2004). "The RNA degradosome and poly(A) polymerase of Escherichia coli are required in vivo for the degradation of small mRNA decay intermediates containing REP-stabilizers." Mol. Microbiol 51(3): 777-790.

Kisselev, L. L., J. Justesen, A. D. Wolfson und L. Y. Frolova (1998). "Diadenosine oligophosphates (Ap(n)A), a novel class of signalling molecules?" FEBS Lett 427(2): 157-163.

Kitagawa, M., Y. Matsumura und T. Tsuchido (2000). "Small heat shock proteins, $\mathrm{IbpA}$ and IbpB, are involved in resistances to heat and superoxide stresses in Escherichia coli." FEMS Microbiol Lett 184(2): 165-171.

Kitagawa, M., C. Wada, S. Yoshioka und T. Yura (1991). "Expression of ClpB, an analog of the ATP-dependent protease regulatory subunit in Escherichia coli, is controlled by a heat shock sigma factor (sigma 32)." J Bacteriol 173(14): 4247-4253.

Klena, J. D., E. Pradel und C. A. Schnaitman (1992). "Comparison of lipopolysaccharide biosynthesis genes $r f a K, r f a L, r f a Y$, and $r f a Z$ of Escherichia coli K12 and Salmonella typhimurium." J Bacteriol 174(14): 4746-4752.

Korber, P., J. M. Stahl, K. H. Nierhaus und J. C. Bardwell (2000). "Hsp15: a ribosome-associated heat shock protein." Embo J 19(4): 741-748.

Korber, P., T. Zander, D. Herschlag und J. C. Bardwell (1999). "A new heat shock protein that binds nucleic acids." J Biol Chem 274(1): 249-256.

Kozak, M. (2005). "Regulation of translation via mRNA structure in prokaryotes and eukaryotes." Gene 361: 13-37.

Kuczynska-Wisnik, D., S. Kedzierska, E. Matuszewska, P. Lund, A. Taylor, B. Lipinska und E. Laskowska (2002). "The Escherichia coli small heat-shock proteins IbpA and IbpB prevent the aggregation of endogenous proteins denatured in vivo during extreme heat shock." Microbiology 148(Pt 6): 1757-1765.

Kushner, S. R. (2007). Messenger RNA Decay. Web module 4.6.4. Escherichia coli and Salmonella. Cellular and molecular biology. Web edition. G. Björk, American Society for Microbiology.

Kwon, A. R., B. M. Kessler, H. S. Overkleeft und D. B. McKay (2003). "Structure and reactivity of an asymmetric complex between HslV and I-domain deleted HslU, a prokaryotic homolog of the eukaryotic proteasome." J Mol Biol 330(2): 185-195. 
La Teana, A., A. Brandi, M. Falconi, R. Spurio, C. L. Pon und C. O. Gualerzi (1991). "Identification of a cold shock transcriptional enhancer of the Escherichia coli gene encoding nucleoid protein H-NS." Proc Natl Acad Sci U S A 88(23): 1090710911.

Larkin, M. A., G. Blackshields, N. P. Brown, R. Chenna, P. A. McGettigan, H. McWilliam, F. Valentin, I. M. Wallace, A. Wilm, R. Lopez, J. D. Thompson, T. J. Gibson und D. G. Higgins (2007). "Clustal W and Clustal X version 2.0." Bioinformatics 23(21): 2947-2948.

Laskowska, E., D. Kuczynska-Wisnik, J. Skorko-Glonek und A. Taylor (1996a). "Degradation by proteases Lon, Clp and HtrA, of Escherichia coli proteins aggregated in vivo by heat shock; HtrA protease action in vivo and in vitro." Mol Microbiol 22(3): 555-571.

Laskowska, E., A. Wawrzynow und A. Taylor (1996b). "IbpA and IbpB, the new heat-shock proteins, bind to endogenous Escherichia coli proteins aggregated intracellularly by heat shock." Biochimie 78(2): 117-122.

Lease, R. A., M. E. Cusick und M. Belfort (1998). "Riboregulation in Escherichia coli: DsrA RNA acts by RNA:RNA interactions at multiple loci." Proc Natl Acad Sci U S A 95(21): 12456-12461.

Lee, C. R., S. H. Cho, M. J. Yoon, A. Peterkofsky und Y. J. Seok (2007). "Escherichia coli enzyme IIA ${ }^{\mathrm{Ntr}}$ regulates the $\mathrm{K}^{+}$transporter TrkA." Proc. Natl. Acad. Sci. U S A 104(10): 4124-4129.

Lee, C. R., B. M. Koo, S. H. Cho, Y. J. Kim, M. J. Yoon, A. Peterkofsky und Y. J. Seok (2005). "Requirement of the dephospho-form of enzyme IIA ${ }^{\mathrm{Ntr}}$ for derepression of Escherichia coli K-12 ilvBN expression." Mol. Microbiol. 58(1): 334-344.

Levin, H. L. und H. K. Schachman (1985). "Regulation of aspartate transcarbamoylase synthesis in Escherichia coli: analysis of deletion mutations in the promoter region of the pyrBI operon." Proc Natl Acad Sci U S A 82(14): 4643-4647.

Liberek, K., J. Marszalek, D. Ang, C. Georgopoulos und M. Zylicz (1991). " Escherichia coli DnaJ and GrpE heat shock proteins jointly stimulate ATPase activity of DnaK." Proc Natl Acad Sci U S A 88(7): 2874-2878.

Linton, K. J. und C. F. Higgins (1998). "The Escherichia coli ATP-binding cassette (ABC) proteins." Mol Microbiol 28(1): 5-13.

Madhusudan, S., A. Paukner, Y. Klingen und K. Schnetz (2005). "Independent regulation of H-NS-mediated silencing of the $b g l$ operon at two levels: upstream by BglJ and LeuO and downstream by DnaKJ." Microbiology 151(Pt 10): 3349-3359.

Madigan, M., J. Martinko und J. Parker (2003). Brock - Biology of Microorganisms.

Majdalani, N., D. Hernandez und S. Gottesman (2002). "Regulation and mode of action of the second small RNA activator of RpoS translation, RprA." Mol Microbiol 46(3): 813-826. 
Maki, Y., H. Yoshida und A. Wada (2000). "Two proteins, YfiA and YhbH, associated with resting ribosomes in stationary phase Escherichia coli." Genes Cells 5(12): 965-974.

Marshall, N. J., R. Andruszkiewicz, S. Gupta, S. Milewski und J. W. Payne (2003). "Structure-activity relationships for a series of peptidomimetic antimicrobial prodrugs containing glutamine analogues." J. Antimicrob. Chemother. 51(4): 821-831.

McCarthy, T. J., M. A. Plog, S. A. Floy, J. A. Jansen, J. K. Soukup und G. A. Soukup (2005). "Ligand requirements for glmS ribozyme self-cleavage." Chem Biol 12(11): 1221-1226.

Mengin-Lecreulx, D. und J. van Heijenoort (1993). "Identification of the $g \operatorname{lm} U$ gene encoding N-acetylglucosamine-1-phosphate uridyltransferase in Escherichia coli." $\mathrm{J}$. Bacteriol. 175(19): 6150-6157.

Mengin-Lecreulx, D. und J. van Heijenoort (1994). "Copurification of glucosamine1-phosphate acetyltransferase and $\mathrm{N}$-acetylglucosamine-1-phosphate uridyltransferase activities of Escherichia coli: characterization of the $g \operatorname{lm} U$ gene product as a bifunctional enzyme catalyzing two subsequent steps in the pathway for UDP-Nacetylglucosamine synthesis." J. Bacteriol. 176(18): 5788-5795.

Mengin-Lecreulx, D. und J. van Heijenoort (1996). "Characterization of the essential gene glmM encoding phosphoglucosamine mutase in Escherichia coli." $\underline{\text { J. Biol. Chem. }}$ 271(1): 32-39.

Merrick, M. J. (1993). "In a class of its own--the RNA polymerase sigma factor sigma 54 (sigma N)." Mol. Microbiol. 10(5): 903-909.

Midelfort, C. F. und I. A. Rose (1977). "Studies on the mechanism of Escherichia coli glucosamine-6-phosphate isomerase." Biochemistry 16(8): 1590-1596.

Mikulecky, P. J., M. K. Kaw, C. C. Brescia, J. C. Takach, D. D. Sledjeski und A. L. Feig (2004). " Escherichia coli Hfq has distinct interaction surfaces for DsrA, rpoS and poly(A) RNAs." Nat Struct Mol Biol 11(12): 1206-1214.

Milewski, S. (2002). "Glucosamine-6-phosphate synthase--the multi-facets enzyme." Biochim. Biophys. Acta. 1597(2): 173-192.

Milewski, S., R. Andruszkiewicz, L. Kasprzak, J. Mazerski, F. Mignini und E. Borowski (1991). "Mechanism of action of anticandidal dipeptides containing inhibitors of glucosamine-6-phosphate synthase." Antimicrob Agents Chemother 35(1): $36-43$.

Miller, J. H. (1972). Experiments in molecular genetics. Cold Spring Harbor, New York, Cold Spring Harbor Laboratory.

Minagawa, S., H. Ogasawara, A. Kato, K. Yamamoto, Y. Eguchi, T. Oshima, H. Mori, A. Ishihama und R. Utsumi (2003). "Identification and molecular characterization of the Mg2+ stimulon of Escherichia coli." J Bacteriol 185(13): 36963702 . 
Mizushima, T., Y. Ohtsuka, H. Mori, T. Miki und K. Sekimizu (1996). "Increase in synthesis and stability of sigma 32 on treatment with inhibitors of DNA gyrase in Escherichia coli." Mol Gen Genet 253(3): 297-302.

Mogk, A. und B. Bukau (2004). "Molecular chaperones: structure of a protein disaggregase." Curr Biol 14(2): R78-80.

Mogk, A., E. Deuerling, S. Vorderwulbecke, E. Vierling und B. Bukau (2003a). "Small heat shock proteins, ClpB and the DnaK system form a functional triade in reversing protein aggregation." Mol Microbiol 50(2): 585-595.

Mogk, A., C. Schlieker, C. Strub, W. Rist, J. Weibezahn und B. Bukau (2003b). "Roles of individual domains and conserved motifs of the AAA+ chaperone ClpB in oligomerization, ATP hydrolysis, and chaperone activity." J Biol Chem 278(20): 1761517624.

Mohanty, B. K., V. F. Maples und S. R. Kushner (2004). "The Sm-like protein Hfq regulates polyadenylation dependent mRNA decay in Escherichia coli." Mol Microbiol 54(4): 905-920.

Moller, A. K., M. P. Leatham, T. Conway, P. J. Nuijten, L. A. de Haan, K. A. Krogfelt und P. S. Cohen (2003). "An Escherichia coli MG1655 lipopolysaccharide deep-rough core mutant grows and survives in mouse cecal mucus but fails to colonize the mouse large intestine." Infect Immun 71(4): 2142-2152.

Møller, T., T. Franch, P. Hojrup, D. R. Keene, H. P. Bachinger, R. G. Brennan und P. Valentin-Hansen (2002). "Hfq: a bacterial Sm-like protein that mediates RNA-RNA interaction." Mol. Cell 9(1): 23-30.

Moller, T., T. Franch, C. Udesen, K. Gerdes und P. Valentin-Hansen (2002). "Spot 42 RNA mediates discoordinate expression of the E. coli galactose operon." Genes Dev 16(13): 1696-1706.

Moralejo, P., S. M. Egan, E. Hidalgo und J. Aguilar (1993). "Sequencing and characterization of a gene cluster encoding the enzymes for L-rhamnose metabolism in Escherichia coli." J Bacteriol 175(17): 5585-5594.

Morita, M., M. Kanemori, H. Yanagi und T. Yura (1999). "Heat-induced synthesis of sigma32 in Escherichia coli: structural and functional dissection of rpoH mRNA secondary structure." J Bacteriol 181(2): 401-410.

Morita, T. und H. Aiba (2006). "[RNA silencing mediated by small RNAs in Escherichia coli]." Tanpakushitsu Kakusan Koso 51(16 Suppl): 2478-2483.

Morita, T., K. Maki und H. Aiba (2005). "RNase E-based ribonucleoprotein complexes: mechanical basis of mRNA destabilization mediated by bacterial noncoding RNAs." Genes Dev. 19(18): 2176-2186.

Mouilleron, S., M. A. Badet-Denisot und B. Golinelli-Pimpaneau (2006). "Glutamine binding opens the ammonia channel and activates glucosamine-6P synthase." J Biol Chem 281(7): 4404-4412. 
Mullis, K., F. Faloona, S. Scharf, R. Saiki, G. Horn und H. Erlich (1986). "Specific enzymatic amplification of DNA in vitro: the polymerase chain reaction." Cold Spring Harb Symp Quant Biol 51 Pt 1: 263-273.

Murooka, Y., T. Higashiura und T. Harada (1978). "Genetic mapping of tyramine oxidase and arylsulfatase genes and their regulation in intergeneric hybrids of enteric bacteria." J Bacteriol 136(2): 714-722.

Neidhardt, F. C., I. R. Curtiss, J. L. Ingraham, E. C. C. Lin, K. B. Low Jr, B. Magasanik, W. S. Reznikoff, M. Riley, M. Schaechter and H. E. Umbarger (1996). Escherichia coli and Salmonella, American Society for Microbiology, Washington, D.C.

Nishii, W., T. Suzuki, M. Nakada, Y. T. Kim, T. Muramatsu und K. Takahashi (2005). "Cleavage mechanism of ATP-dependent Lon protease toward ribosomal S2 protein." FEBS Lett 579(30): 6846-6850.

Notley-McRobb, L., S. Seeto und T. Ferenci (2002). "Enrichment and elimination of mutY mutators in Escherichia coli populations." Genetics 162(3): 1055-1062.

Opdyke, J. A., J. G. Kang und G. Storz (2004). "GadY, a small-RNA regulator of acid response genes in Escherichia coli." J Bacteriol 186(20): 6698-6705.

Pardee, A. B. und R. A. Yates (1956). "Pyrimidine biosynthesis in Escherichia coli." Biol Chem 221(2): 743-756.

Parkinson, J. S. (1993). "Signal transduction schemes of bacteria." Cell 73(5): 857871.

Pearce, S. R., M. L. Mimmack, M. P. Gallagher, U. Gileadi, S. C. Hyde und C. F. Higgins (1992). "Membrane topology of the integral membrane components, OppB and OppC, of the oligopeptide permease of Salmonella typhimurium." Mol Microbiol 6(1): 47-57.

Perez-Rueda, E., J. Collado-Vides und L. Segovia (2004). "Phylogenetic distribution of DNA-binding transcription factors in bacteria and archaea." Comput Biol Chem 28(5-6): 341-350.

Pfennig, P. L. und A. M. Flower (2001). "BipA is required for growth of Escherichia coli K12 at low temperature." Mol Genet Genomics 266(2): 313-317.

Plumbridge, J. (1995). "Co-ordinated regulation of amino sugar biosynthesis and degradation: the NagC repressor acts as both an activator and a repressor for the transcription of the glmUS operon and requires two separated NagC binding sites." Embo J. 14(16): 3958-3965.

Plumbridge, J. und A. Kolb (1991). "CAP and Nag repressor binding to the regulatory regions of the nagE-B and manX genes of Escherichia coli." J. Mol. Biol. 217(4): 661679. 
Plumbridge, J. und O. Pellegrini (2004). "Expression of the chitobiose operon of Escherichia coli is regulated by three transcription factors: NagC, ChbR and CAP." Mol. Microbiol. 52(2): 437-449.

Plumbridge, J. und E. Vimr (1999). "Convergent pathways for utilization of the amino sugars $\mathrm{N}$-acetylglucosamine, $\mathrm{N}$-acetylmannosamine, and $\mathrm{N}$-acetylneuraminic acid by Escherichia coli." J. Bacteriol. 181(1): 47-54.

Plumbridge, J. A. (1991). "Repression and induction of the nag regulon of Escherichia coli K-12: the roles of $n a g C$ and $n a g A$ in maintenance of the uninduced state." Mol. Microbiol. 5(8): 2053-2062.

Plumbridge, J. A., O. Cochet, J. M. Souza, M. M. Altamirano, M. L. Calcagno und B. Badet (1993). "Coordinated regulation of amino sugar-synthesizing and -degrading enzymes in Escherichia coli K-12." J. Bacteriol. 175(16): 4951-4956.

Postma, P. W., J. W. Lengeler und G. R. Jacobson (1993). "Phosphoenolpyruvate:carbohydrate phosphotransferase systems of bacteria." Microbiol. Rev. 57(3): 543-594.

Powell, B. S., D. L. Court, T. Inada, Y. Nakamura, V. Michotey, X. Cui, A. Reizer, M. H. Saier, Jr. und J. Reizer (1995). "Novel proteins of the phosphotransferase system encoded within the rpoN operon of Escherichia coli. Enzyme IIA ${ }^{\mathrm{Ntr}}$ affects growth on organic nitrogen and the conditional lethality of an erats mutant." J. Biol. Chem. 270(9): 4822-4839.

Prevost, K., H. Salvail, G. Desnoyers, J. F. Jacques, E. Phaneuf und E. Masse (2007). "The small RNA RyhB activates the translation of shiA mRNA encoding a permease of shikimate, a compound involved in siderophore synthesis." Mol Microbiol 64(5): 1260-1273.

Pruss, B. M., X. Liu, W. Hendrickson und P. Matsumura (2001). "FlhD/FlhCregulated promoters analyzed by gene array and lacZ gene fusions." FEMS Microbiol Lett 197(1): 91-97.

Pugsley, A. P. und C. A. Schnaitman (1978). "Outer membrane proteins of Escherichia coli. VII. Evidence that bacteriophage-directed protein 2 functions as a pore." J Bacteriol 133(3): 1181-1189.

Rabus, R., J. Reizer, I. Paulsen und M. H. Saier, Jr. (1999). "Enzyme I ${ }^{\mathrm{Ntr}}$ from Escherichia coli. A novel enzyme of the phosphoenolpyruvate-dependent phosphotransferase system exhibiting strict specificity for its phosphoryl acceptor, NPr." J. Biol. Chem. 274(37): 26185-26191.

Raivio, T. L. (2005). "Envelope stress responses and Gram-negative bacterial pathogenesis." Mol Microbiol 56(5): 1119-1128.

Raivio, T. L., D. L. Popkin und T. J. Silhavy (1999). "The Cpx envelope stress response is controlled by amplification and feedback inhibition." J Bacteriol 181(17): 5263-5272. 
Ray, P., R. J. Hall, R. D. Finn, S. Chen, A. Patwardhan, M. Buck und M. van Heel (2005). "Conformational changes of Escherichia coli sigma54-RNA-polymerase upon closed-promoter complex formation." J Mol Biol 354(2): 201-205.

Reed, J. L., T. R. Patel, K. H. Chen, A. R. Joyce, M. K. Applebee, C. D. Herring, O. T. Bui, E. M. Knight, S. S. Fong und B. O. Palsson (2006). "Systems approach to refining genome annotation." Proc Natl Acad Sci U S A 103(46): 17480-17484.

Reichenbach, B., A. Maes, F. Kalamorz, E. Hajnsdorf und B. Görke (2008). "The small RNA GlmY acts upstream of the sRNA GlmZ in the activation of $\mathrm{glmS}$ expression and is subject to regulation by polyadenylation in Escherichia coli." Nucleic Acids Res. 36(8): 2570-2580.

Reitzer, L. (2003). "Nitrogen assimilation and global regulation in Escherichia coli." Annu Rev Microbiol 57: 155-176.

Reitzer, L. und B. L. Schneider (2001). "Metabolic context and possible physiological themes of sigma(54)-dependent genes in Escherichia coli." Microbiol. Mol. Biol. Rev. 65(3): 422-444.

Reitzer, L. J. und B. Magasanik (1985). "Expression of $g \ln A$ in Escherichia coli is regulated at tandem promoters." Proc Natl Acad Sci U S A 82(7): 1979-1983.

Reitzer, L. J. und B. Magasanik (1986). "Transcription of $g \ln A$ in E. coli is stimulated by activator bound to sites far from the promoter." Cell 45(6): 785-792.

Reizer, J., V. Michotey, A. Reizer und M. H. Saier, Jr. (1994a). "Novel phosphotransferase system genes revealed by bacterial genome analysis: unique, putative fructose- and glucoside-specific systems." Protein Sci 3(3): 440-450.

Reizer, J., A. Reizer und M. H. Saier, Jr. (1994b). "A functional superfamily of sodium/solute symporters." Biochim Biophys Acta 1197(2): 133-166.

Reizer, J., A. Reizer, M. H. Saier, Jr. und G. R. Jacobson (1992). "A proposed link between nitrogen and carbon metabolism involving protein phosphorylation in bacteria." Protein Sci 1(6): 722-726.

Ren, D., L. A. Bedzyk, S. M. Thomas, R. W. Ye und T. K. Wood (2004). "Gene expression in Escherichia coli biofilms." Appl Microbiol Biotechnol 64(4): 515-524.

Reynolds, A. E., S. Mahadevan, S. F. LeGrice und A. Wright (1986). "Enhancement of bacterial gene expression by insertion elements or by mutation in a CAP-cAMP binding site." J Mol Biol 191(1): 85-95.

Rhodius, V. A., W. C. Suh, G. Nonaka, J. West und C. A. Gross (2006). "Conserved and variable functions of the sigmaE stress response in related genomes." PLoS Biol 4(1): e2.

Rice, P. W., D. A. Polayes und J. E. Dahlberg (1987). "Spot 42 RNA of Escherichia coli is not an mRNA." J Bacteriol 169(8): 3850-3852. 
Rippe, K., M. Guthold, P. H. von Hippel und C. Bustamante (1997). "Transcriptional activation via DNA-looping: visualization of intermediates in the activation pathway of $E$. coli RNA polymerase x sigma 54 holoenzyme by scanning force microscopy." J Mol Biol 270(2): 125-138.

Rivas, E., R. J. Klein, T. A. Jones und S. R. Eddy (2001). "Computational identification of noncoding RNAs in E. coli by comparative genomics." Curr Biol 11(17): 1369-1373.

Robbins, J. C. und D. L. Oxender (1973). "Transport systems for alanine, serine, and glycine in Escherichia coli K-12." J Bacteriol 116(1): 12-18.

Rohrwild, M., O. Coux, H. C. Huang, R. P. Moerschell, S. J. Yoo, J. H. Seol, C. H. Chung und A. L. Goldberg (1996). "HslV-HslU: A novel ATP-dependent protease complex in Escherichia coli related to the eukaryotic proteasome." Proc Natl Acad Sci U S A 93(12): 5808-5813.

Rosen, R., D. Biran, E. Gur, D. Becher, M. Hecker und E. Z. Ron (2002). "Protein aggregation in Escherichia coli: role of proteases." FEMS Microbiol Lett 207(1): 9-12.

Sambrook, J. und D. Russell (2001). Molecular Cloning: A Laboratory Manual. Cold Spring Harbor, Cold Spring Harbor Laboratory.

Sanger, F., S. Nicklen und A. R. Coulson (1977). "DNA sequencing with chainterminating inhibitors." Proc Natl Acad Sci U S A 74(12): 5463-5467.

Saraste, M., P. R. Sibbald und A. Wittinghofer (1990). "The P-loop--a common motif in ATP- and GTP-binding proteins." Trends Biochem Sci 15(11): 430-434.

Sasse-Dwight, S. und J. D. Gralla (1990). "Role of eukaryotic-type functional domains found in the prokaryotic enhancer receptor factor sigma 54." Cell 62(5): 945954.

Saurin, W., M. Hofnung und E. Dassa (1999). "Getting in or out: early segregation between importers and exporters in the evolution of ATP-binding cassette (ABC) transporters." J Mol Evol 48(1): 22-41.

Schnetz, K. und B. Rak (1992). "IS5: a mobile enhancer of transcription in Escherichia coli." Proc Natl Acad Sci U S A 89(4): 1244-1248.

Schnetz, K., C. Toloczyki und B. Rak (1987). "Beta-glucoside (bgl) operon of Escherichia coli K-12: nucleotide sequence, genetic organization, and possible evolutionary relationship to regulatory components of two Bacillus subtilis genes." I Bacteriol 169(6): 2579-2590.

Scholle, A., J. Vreemann, V. Blank, A. Nold, W. Boos und M. D. Manson (1987). "Sequence of the $m g l B$ gene from Escherichia coli K12: comparison of wild-type and mutant galactose chemoreceptors." Mol Gen Genet 208(1-2): 247-253.

Schultz, J., F. Milpetz, P. Bork und C. P. Ponting (1998). "SMART, a simple modular architecture research tool: identification of signaling domains." Proc Natl Acad Sci U S A 95(11): 5857-5864. 
Schumacher, J., N. Joly, M. Rappas, D. Bradley, S. R. Wigneshweraraj, X. Zhang und M. Buck (2007). "Sensor I threonine of the AAA+ ATPase transcriptional activator $\mathrm{PspF}$ is involved in coupling nucleotide triphosphate hydrolysis to the restructuring of sigma 54-RNA polymerase." J Biol Chem 282(13): 9825-9833.

Schumacher, M. A. und R. G. Brennan (2002). "Structural mechanisms of multidrug recognition and regulation by bacterial multidrug transcription factors." Mol Microbiol 45(4): 885-893.

Schwartz, C. J., J. L. Giel, T. Patschkowski, C. Luther, F. J. Ruzicka, H. Beinert und P. J. Kiley (2001). "IscR, an Fe-S cluster-containing transcription factor, represses expression of Escherichia coli genes encoding Fe-S cluster assembly proteins." Proc Natl Acad Sci U S A 98(26): 14895-14900.

Seol, J. H., S. K. Woo, E. M. Jung, S. J. Yoo, C. S. Lee, K. J. Kim, K. Tanaka, A. Ichihara, D. B. Ha und C. H. Chung (1991). "Protease Do is essential for survival of Escherichia coli at high temperatures: its identity with the htrA gene product." Biochem Biophys Res Commun 176(2): 730-736.

Serres, M. H., S. Gopal, L. A. Nahum, P. Liang, T. Gaasterland und M. Riley (2001). "A functional update of the Escherichia coli K-12 genome." Genome Biol 2(9): RESEARCH0035.

Seshasayee, A. S., P. Bertone, G. M. Fraser und N. M. Luscombe (2006). "Transcriptional regulatory networks in bacteria: from input signals to output responses." Curr Opin Microbiol 9(5): 511-519.

Sharp, J. S. und D. H. Bechhofer (2003). "Effect of translational signals on mRNA decay in Bacillus subtilis." J Bacteriol 185(18): 5372-5379.

Sherman, M. und A. L. Goldberg (1992). "Involvement of the chaperonin dnaK in the rapid degradation of a mutant protein in Escherichia coli." Embo J 11(1): 71-77.

Shiau, S. P., P. Chen und L. J. Reitzer (1993). "Effects of insertions and deletions in glnG (ntrC) of Escherichia coli on nitrogen regulator I-dependent DNA binding and transcriptional activation." J Bacteriol 175(1): 190-199.

Shimuta, T. R., K. Nakano, Y. Yamaguchi, S. Ozaki, K. Fujimitsu, C. Matsunaga, K. Noguchi, A. Emoto und T. Katayama (2004). "Novel heat shock protein HspQ stimulates the degradation of mutant DnaA protein in Escherichia coli." Genes Cells 9(12): 1151-1166.

Slonczewski, J. L., T. N. Gonzalez, F. M. Bartholomew und N. J. Holt (1987). "Mu d-directed lacZ fusions regulated by low $\mathrm{pH}$ in Escherichia coli." J Bacteriol 169(7): 3001-3006.

Smirnova, I. N., V. N. Kasho und L. D. Faller (1998). "Inferences about the catalytic domain of P-type ATPases from the tertiary structures of enzymes that catalyze the same elementary reaction." FEBS Lett 431(3): 309-314. 
Smith, R. L., J. L. Banks, M. D. Snavely und M. E. Maguire (1993). "Sequence and topology of the CorA magnesium transport systems of Salmonella typhimurium and Escherichia coli. Identification of a new class of transport protein." J Biol Chem 268(19): 14071-14080.

Sperandeo, P., R. Cescutti, R. Villa, C. Di Benedetto, D. Candia, G. Deho und A. Polissi (2007). "Characterization of lptA and $l p t B$, two essential genes implicated in lipopolysaccharide transport to the outer membrane of Escherichia coli." J Bacteriol 189(1): 244-253.

Sperandeo, P., C. Pozzi, G. Deho und A. Polissi (2006). "Non-essential KDO biosynthesis and new essential cell envelope biogenesis genes in the Escherichia coli yrbG-yhbG locus." Res Microbiol 157(6): 547-558.

Spiess, C., A. Beil und M. Ehrmann (1999). "A temperature-dependent switch from chaperone to protease in a widely conserved heat shock protein." Cell 97(3): 339-347.

Storz, G., S. Altuvia und K. M. Wassarman (2005). "An abundance of RNA regulators." Annu Rev Biochem 74: 199-217.

Strauch, K. L. und J. Beckwith (1988). "An Escherichia coli mutation preventing degradation of abnormal periplasmic proteins." Proc Natl Acad Sci U S A 85(5): 15761580 .

Studholme, D. J. und M. Buck (2000). "The biology of enhancer-dependent transcriptional regulation in bacteria: insights from genome sequences." Microbiol Lett 186(1): 1-9.

Sukhodolets, M. V., J. E. Cabrera, H. Zhi und D. J. Jin (2001). "RapA, a bacterial homolog of SWI2/SNF2, stimulates RNA polymerase recycling in transcription." Genes Dev 15(24): 3330-3341.

Sukhodolets, M. V. und S. Garges (2003). "Interaction of Escherichia coli RNA polymerase with the ribosomal protein S1 and the Sm-like ATPase Hfq." Biochemistry 42(26): 8022-8034.

Svergun, D. I., M. Malfois, M. H. Koch, S. R. Wigneshweraraj und M. Buck (2000). "Low resolution structure of the sigma54 transcription factor revealed by X-ray solution scattering." J Biol Chem 275(6): 4210-4214.

Taguchi, H. (2005). "Chaperonin GroEL meets the substrate protein as a "load" of the rings." J Biochem 137(5): 543-549.

Tamai, E., T. A. Belyaeva, S. J. Busby und T. Tsuchiya (2000). "Mutations that increase the activity of the promoter of the Escherichia coli melibiose operon improve the binding of MelR, a transcription activator triggered by melibiose." J Biol Chem 275(22): 17058-17063.

Tame, J. R., G. N. Murshudov, E. J. Dodson, T. K. Neil, G. G. Dodson, C. F. Higgins und A. J. Wilkinson (1994). "The structural basis of sequence-independent peptide binding by OppA protein." Science 264(5165): 1578-1581. 
Teplyakov, A., C. Leriche, G. Obmolova, B. Badet und M. A. Badet-Denisot (2002). "From Lobry de Bruyn to enzyme-catalyzed ammonia channelling: molecular studies of D-glucosamine-6P synthase." Nat Prod Rep 19(1): 60-69.

Teplyakov, A., G. Obmolova, M. A. Badet-Denisot, B. Badet und I. Polikarpov (1998). "Involvement of the $\mathrm{C}$ terminus in intramolecular nitrogen channeling in glucosamine 6-phosphate synthase: evidence from a 1.6 A crystal structure of the isomerase domain." Structure 6(8): 1047-1055.

Teplyakov, A., G. Obmolova, B. Badet und M. A. Badet-Denisot (2001). "Channeling of ammonia in glucosamine-6-phosphate synthase." J Mol Biol 313(5): 1093-1102.

Terribilini, M., J. D. Sander, J. H. Lee, P. Zaback, R. L. Jernigan, V. Honavar und D. Dobbs (2007). "RNABindR: a server for analyzing and predicting RNA-binding sites in proteins." Nucleic Acids Res 35(Web Server issue): W578-584.

Thoden, J. B., X. Huang, F. M. Raushel und H. M. Holden (1999). "The small subunit of carbamoyl phosphate synthetase: snapshots along the reaction pathway." Biochemistry 38(49): 16158-16166.

Thompson, J. D., D. G. Higgins und T. J. Gibson (1994). "CLUSTAL W: improving the sensitivity of progressive multiple sequence alignment through sequence weighting, position-specific gap penalties and weight matrix choice." Nucleic Acids Res 22(22): 4673-4680.

Tinsley, R. A., J. R. Furchak und N. G. Walter (2007). "Trans-acting glmS catalytic riboswitch: locked and loaded." RNA 13(4): 468-477.

Tsui, H. C., H. C. Leung und M. E. Winkler (1994). "Characterization of broadly pleiotropic phenotypes caused by an $h f q$ insertion mutation in Escherichia coli K-12." Mol. Microbiol. 13(1): 35-49.

Turnbough, C. L., Jr., K. L. Hicks und J. P. Donahue (1983). "Attenuation control of pyrBI operon expression in Escherichia coli K-12." Proc Natl Acad Sci U S A 80(2): 368-372.

Urban, J. H., K. Papenfort, J. Thomsen, R. A. Schmitz und J. Vogel (2007). "A conserved small RNA promotes discoordinate expression of the glmUS operon mRNA to activate GlmS synthesis." J. Mol. Biol. 373: 521-528.

Urban, J. H. und J. Vogel (2008). "Two seemingly homologous noncoding RNAs act hierarchically to activate glmS mRNA translation." PLoS Biol. 6(3): e64.

VanBogelen, R. A., P. M. Kelley und F. C. Neidhardt (1987). "Differential induction of heat shock, SOS, and oxidation stress regulons and accumulation of nucleotides in Escherichia coli." J Bacteriol 169(1): 26-32.

Vassilieva, I. M., M. V. Rouzanov, N. V. Zelinskaya, I. Moll, U. Blasi und M. B. Garber (2002). "Cloning, purification, and crystallization of a bacterial gene expression regulator--Hfq protein from Escherichia coli." Biochemistry (Mosc) 67(11): 1293-1297. 
Via, P., J. Badia, L. Baldoma, N. Obradors und J. Aguilar (1996). "Transcriptional regulation of the Escherichia coli rhaT gene." Microbiology 142 ( Pt 7): 1833-1840.

Viegas, S. C., V. Pfeiffer, A. Sittka, I. J. Silva, J. Vogel und C. M. Arraiano (2007). "Characterization of the role of ribonucleases in Salmonella small RNA decay." Nucleic Acids Res. 35(22): 7651-7664.

Vijayalakshmi, J., M. K. Mukhergee, J. Graumann, U. Jakob und M. A. Saper (2001). "The 2.2 A crystal structure of Hsp33: a heat shock protein with redox-regulated chaperone activity." Structure 9(5): 367-375.

Wagner, E. G., S. Altuvia und P. Romby (2002). "Antisense RNAs in bacteria and their genetic elements." Adv Genet 46: 361-398.

Walker, J. E., M. Saraste, M. J. Runswick und N. J. Gay (1982). "Distantly related sequences in the alpha- and beta-subunits of ATP synthase, myosin, kinases and other ATP-requiring enzymes and a common nucleotide binding fold." Embo J 1(8): 945-951.

Wall, D., M. Zylicz und C. Georgopoulos (1994). "The NH2-terminal 108 amino acids of the Escherichia coli DnaJ protein stimulate the ATPase activity of DnaK and are sufficient for lambda replication." J Biol Chem 269(7): 5446-5451.

Wang, Q. P. und J. M. Kaguni (1989). "A novel sigma factor is involved in expression of the rpoH gene of Escherichia coli." J Bacteriol 171(8): 4248-4253.

Wassarman, K. M., F. Repoila, C. Rosenow, G. Storz und S. Gottesman (2001). "Identification of novel small RNAs using comparative genomics and microarrays." Genes Dev. 15(13): 1637-1651.

White, R. J. (1968). "Control of amino sugar metabolism in Escherichia coli and isolation of mutants unable to degrade amino sugars." Biochem J 106(4): 847-858.

White, S., F. E. Tuttle, D. Blankenhorn, D. C. Dosch und J. L. Slonczewski (1992). "pH dependence and gene structure of inaA in Escherichia coli." J Bacteriol 174(5): 1537-1543.

Wickstrum, J. R., T. J. Santangelo und S. M. Egan (2005). "Cyclic AMP receptor protein and RhaR synergistically activate transcription from the L-rhamnose-responsive rhaSR promoter in Escherichia coli." J Bacteriol 187(19): 6708-6718.

Wigneshweraraj, S., D. Bose, P. C. Burrows, N. Joly, J. Schumacher, M. Rappas, T. Pape, X. Zhang, P. Stockley, K. Severinov und M. Buck (2008). "Modus operandi of the bacterial RNA polymerase containing the sigma54 promoter-specificity factor." Mol Microbiol 68(3): 538-546.

Wilusz, C. J. und J. Wilusz (2005). "Eukaryotic Lsm proteins: lessons from bacteria." Nat Struct Mol Biol 12(12): 1031-1036.

Winkler, W. C., A. Nahvi, A. Roth, J. A. Collins und R. R. Breaker (2004). "Control of gene expression by a natural metabolite-responsive ribozyme." Nature 428(6980): 281-286. 
Wissenbach, U., S. Six, J. Bongaerts, D. Ternes, S. Steinwachs und G. Unden (1995). "A third periplasmic transport system for L-arginine in Escherichia coli: molecular characterization of the artPIQMJ genes, arginine binding and transport." Mol Microbiol 17(4): 675-686.

Wong, C., Y. Tintut und J. D. Gralla (1994). "The domain structure of sigma 54 as determined by analysis of a set of deletion mutants." J Mol Biol 236(1): 81-90.

Wosten, M. M. (1998). "Eubacterial sigma-factors." FEMS Microbiol Rev 22(3): 127150.

Wu, L. F. und M. A. Mandrand-Berthelot (1995). "A family of homologous substrate-binding proteins with a broad range of substrate specificity and dissimilar biological functions." Biochimie 77(9): 744-750.

Xu, F., S. Lin-Chao und S. N. Cohen (1993). "The Escherichia coli pcnB gene promotes adenylylation of antisense RNAI of ColE1-type plasmids in vivo and degradation of RNAI decay intermediates." Proc. Natl. Acad. Sci. U S A 90(14): 67566760 .

Yanofsky, C., V. Horn und P. Gollnick (1991). "Physiological studies of tryptophan transport and tryptophanase operon induction in Escherichia coli." J Bacteriol 173(19): 6009-6017.

Yethon, J. A., D. E. Heinrichs, M. A. Monteiro, M. B. Perry und C. Whitfield (1998). "Involvement of waaY, waaQ, and waaP in the modification of Escherichia coli lipopolysaccharide and their role in the formation of a stable outer membrane." J Biol Chem 273(41): 26310-26316.

Yu, D. und D. L. Court (1998). "A new system to place single copies of genes, sites and lacZ fusions on the Escherichia coli chromosome." Gene 223(1-2): 77-81.

Zhai, Y. und M. H. Saier, Jr. (2002). "The beta-barrel finder (BBF) program, allowing identification of outer membrane beta-barrel proteins encoded within prokaryotic genomes." Protein Sci 11(9): 2196-2207.

Zhang, A., S. Altuvia, A. Tiwari, L. Argaman, R. Hengge-Aronis und G. Storz (1998). "The OxyS regulatory RNA represses rpoS translation and binds the Hfq (HF-I) protein." Embo J 17(20): 6061-6068.

Zhang, L., K. Zuo, F. Zhang, Y. Cao, J. Wang, Y. Zhang, X. Sun und K. Tang (2006). "Conservation of noncoding microsatellites in plants: implication for gene regulation." BMC Genomics 7: 323.

Zhang, X., M. Chaney, S. R. Wigneshweraraj, J. Schumacher, P. Bordes, W. Cannon und M. Buck (2002). "Mechanochemical ATPases and transcriptional activation." Mol Microbiol 45(4): 895-903.

Zuker, M. (2003). "Mfold web server for nucleic acid folding and hybridization prediction." Nucleic Acids Res. 31(13): 3406-3415. 


\section{Anhang}

\subsection{Stämme}

\begin{tabular}{|c|c|c|}
\hline Name & Beschreibung & Referenz/Quelle \\
\hline AM111 & MC4100 hfq1::omega & (Tsui et al. 1994) \\
\hline AM112 & MC4100 hfq $2::$ omega & (Tsui et al. 1994) \\
\hline DH5 $\alpha$ & $\begin{array}{l}\phi 80 \mathrm{~d} l a c \mathrm{Z} \Delta \mathrm{M} 15, \text { recA1, end } \mathrm{A} 1, \text { gyrA96, thi-1, hsdR17 }\left(\mathrm{r}_{\mathrm{K}}{ }^{-} \text {, }\right. \\
\left.\mathrm{m}_{\mathrm{K}}^{+}\right) \text {, supE44, relA1, deoR, } \Delta(\text { lacZYA-argF }) \mathrm{U} 169\end{array}$ & $\begin{array}{l}\text { (Sambrook und Russell } \\
\text { 2001) }\end{array}$ \\
\hline IBPC750 & $\begin{array}{l}\text { IBPC5321 } \Delta \text { glmS::tc thi-1 argG6 argE3 his-4 xyl-5 rpsL } \\
\Delta l a c X 74 \text { mlc delta glmS::tc }\end{array}$ & $\begin{array}{l}\text { (Plumbridge und Vimr } \\
\text { 1999) }\end{array}$ \\
\hline IBPC 5321 & thi-1 argG6 argE3 his-4 xyl-5 rpsL $\Delta \mathrm{lacX} 74 \mathrm{mlc} \Delta \mathrm{glmS}:: \mathrm{tc}$ & $\begin{array}{l}\text { (Plumbridge und Kolb } \\
\text { 1991) }\end{array}$ \\
\hline JVS8018 & E. coli MC4100 $\Delta y h b J:: k a n$ & $\begin{array}{l}\text { (Urban und Vogel } \\
\text { 2008) }\end{array}$ \\
\hline MC4100 & $\begin{array}{l}\mathrm{F}^{-} \text {araD139 } \Delta(\operatorname{argF}-1 \mathrm{lac}) \mathrm{U} 169 * \text { rspL150 relA1 flbB5301 } \\
\text { fruA25 }+ \text { deoC1 ptsF25 e14- }\end{array}$ & (Casadaban 1976) \\
\hline N3431 & lacZ43 (Fs), rne-3071(ts), relA1, spoTl, thi-1 & $\begin{array}{l}\text { (Goldblum und } \\
\text { Apririon 1981) }\end{array}$ \\
\hline N3433 & lacZ43 (Fs), rne+, relA1, spoT1, thi-1 & $\begin{array}{ll}\text { (Goldblum } & \text { und } \\
\text { Apririon 1981) } & \\
\end{array}$ \\
\hline R1279 & $\Delta$ (pho-bgl)201 $\Delta$ (lac-pro) ara thi & (Görke und Rak 1999) \\
\hline R2260 & R1279 $\Delta($ ptsH ptsI crr)::neo & $\begin{array}{lr}\text { Laborsammlung } & \text { B. } \\
\text { Görke, Institut für } \\
\text { Mikrobiologie und } \\
\text { Genetik, Göttingen }\end{array}$ \\
\hline $\mathrm{R} 2404$ & R1279 $\Delta p t s P$ & (Kalamorz et al. 2007) \\
\hline R2409 & $\mathrm{R} 1279 \Delta p t s P, \Delta(p t s H$ ptsI crr $):: n e o$ & (Kalamorz et al. 2007) \\
\hline R2413 & $\mathrm{R} 1279 \Delta p t s N-n p r$ & (Kalamorz et al. 2007) \\
\hline R2415 & R1279 $\Delta p t s N-n p r \Delta(p t s H$ ptsI crr $):: n e o$ & (Kalamorz et al. 2007) \\
\hline W3110 & $F-\lambda I N(r r n D-r r n E) I$ & (Bachmann 1972) \\
\hline$\overline{\mathrm{Z} 2}$ & $\begin{array}{l}\Delta(\text { ptsN-npr }) \Delta\left(\text { pho-bgl)201 } \Delta(\text { lac-pro }) \text { ara thi, strp }{ }^{R} F^{\prime} \text { laci }^{q}\right. \\
\text { lacZAM15 lacY } \text { pro }^{+}\end{array}$ & (Kalamorz et al. 2007) \\
\hline $\mathrm{Z} 3$ & $\begin{array}{l}\Delta\left(\text { pho-bgl)201 } \Delta(\text { lac-pro }) \text { ara thi, strp }{ }^{R} F^{\prime} \text { laci }{ }^{q} \text { lacZAM15 }\right. \\
\text { lacY }^{+} \text {pro }^{+}\end{array}$ & (Kalamorz et al. 2007) \\
\hline $\mathrm{Z5}$ & 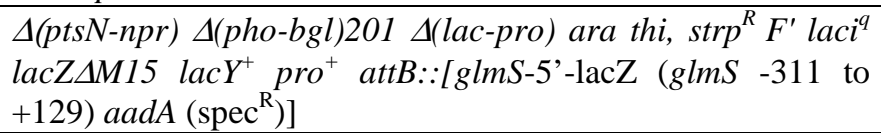 & (Kalamorz et al. 2007) \\
\hline Z6 & 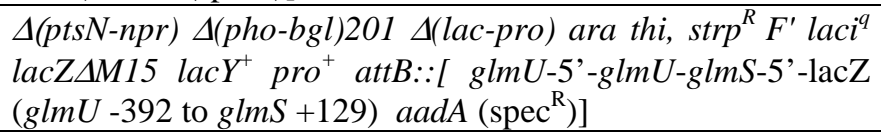 & (Kalamorz et al. 2007) \\
\hline$\overline{Z 8}$ & 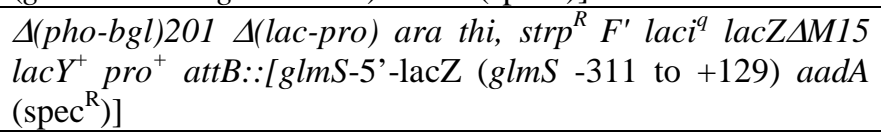 & (Kalamorz et al. 2007) \\
\hline Z9 & 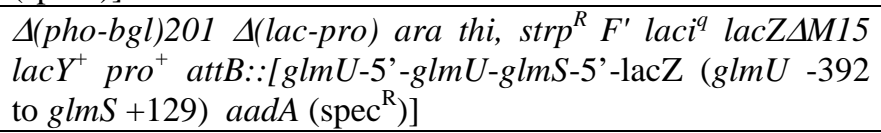 & (Kalamorz et al. 2007) \\
\hline Z10 & 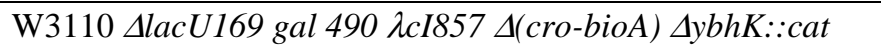 & Diese Arbeit \\
\hline Z11 & 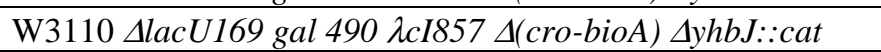 & Diese Arbeit \\
\hline $\mathrm{Z12}$ & $\Delta($ pho-bgl)201 $\Delta$ (lac-pro) ara thi $\Delta$ nagC::tc & $\begin{array}{l}\text { Laborsammlung B. } \\
\text { Görke, Institut für } \\
\text { Mikrobiologie und } \\
\text { Genetik, Göttingen } \\
\end{array}$ \\
\hline $\mathrm{Z} 24$ & R1279 yhbJ::cat & $\begin{array}{l}\text { Diese Arbeit und } \\
(\text { Kalamorz et al. 2007) }\end{array}$ \\
\hline$\overline{Z 27}$ & Z8 yhbJ::cat & $\begin{array}{l}\text { Diese Arbeit und } \\
\text { (Kalamorz et al. 2007) }\end{array}$ \\
\hline
\end{tabular}


Anhang

\begin{tabular}{|c|c|c|}
\hline Z28 & Z8 $\Delta y h b J$ & $\begin{array}{l}\text { Diese Arbeit und } \\
\text { (Kalamorz et al. 2007) }\end{array}$ \\
\hline Z29 & Z2 ybhK::cat & Diese Arbeit \\
\hline $\mathrm{Z30}$ & $\mathrm{Z} 2 \Delta y b h K$ & Diese Arbeit \\
\hline Z31 & Z3 ybhK::cat & Diese Arbeit \\
\hline $\mathrm{Z} 32$ & Z3 $\Delta y b h K$ & Diese Arbeit \\
\hline $\mathrm{Z37}$ & $\mathrm{R} 1279 \Delta y h b J$ & $\begin{array}{l}\text { Diese Arbeit und } \\
\text { (Kalamorz et al. 2007) }\end{array}$ \\
\hline Z38 & Z8 glmZ::cat & $\begin{array}{l}\text { Diese Arbeit und } \\
\text { (Reichenbach et al. } \\
\text { 2008) }\end{array}$ \\
\hline Z39 & $\mathrm{Z} 8 \Delta g \operatorname{lm} Z$ & Diese Arbeit \\
\hline $\mathrm{Z} 40$ & Z9 $\Delta$ glmZ::cat & $\begin{array}{l}\text { Diese Arbeit und } \\
\text { (Kalamorz et al. 2007) }\end{array}$ \\
\hline Z41 & $\mathrm{Z} 9 \Delta \mathrm{g} \operatorname{lm} Z$ & Diese Arbeit \\
\hline Z42 & Z5 glmZ::cat & $\begin{array}{l}\text { Diese Arbeit und } \\
\text { (Kalamorz et al. 2007) }\end{array}$ \\
\hline Z43 & $\mathrm{Z} 5 \Delta g \operatorname{lm} Z$ & $\begin{array}{l}\text { Diese Arbeit und } \\
\text { (Kalamorz et al. 2007) }\end{array}$ \\
\hline $\mathrm{Z} 44$ & R1279 glmZ::cat & $\begin{array}{l}\text { Diese Arbeit und } \\
\text { (Kalamorz et al. 2007) }\end{array}$ \\
\hline Z45 & $\mathrm{R} 1279 \Delta \operatorname{glm} Z$ & $\begin{array}{l}\text { Diese Arbeit und } \\
\text { (Kalamorz et al. 2007) }\end{array}$ \\
\hline Z46 & R2413 glmZ::cat & $\begin{array}{l}\text { Diese Arbeit und } \\
\text { (Kalamorz et al. 2007) }\end{array}$ \\
\hline Z47 & $\mathrm{R} 2413 \Delta g \operatorname{lm} Z$ & $\begin{array}{l}\text { Diese Arbeit und } \\
\text { (Reichenbach et al. } \\
\text { 2008) }\end{array}$ \\
\hline $\mathrm{Z} 52$ & N3431 $\Delta y h b J:: c a t$ & (Kalamorz et al. 2007) \\
\hline $\mathrm{Z} 53$ & N3433 $\Delta y h b J:: c a t$ & (Kalamorz et al. 2007) \\
\hline Z60 & R1279 hfql::отеga & (Kalamorz et al. 2007) \\
\hline Z61 & Z24 hfq1::omega & (Kalamorz et al. 2007) \\
\hline Z62 & R1279 hfq2::отеga & (Kalamorz et al. 2007) \\
\hline Z63 & Z24 hfq2::отеga & (Kalamorz et al. 2007) \\
\hline $\mathrm{Z79}$ & $\mathrm{R} 1279 \Delta p t s N$ & Diese Arbeit \\
\hline Z87 & R1279 dgoT::cat & Diese Arbeit \\
\hline Z88 & \begin{tabular}{|l|}
$\mathrm{R} 1279 \Delta d g o T$ \\
\end{tabular} & Diese Arbeit \\
\hline Z89 & R2413 dgoT::cat & Diese Arbeit \\
\hline Z90 & R2413 $\Delta d g o T$ & Diese Arbeit \\
\hline Z91 & $\mathrm{R} 1279$ yjiR::cat & Diese Arbeit \\
\hline Z92 & $\mathrm{R} 1279 \Delta y j i R$ & Diese Arbeit \\
\hline Z93 & R2413 yjiR::cat & Diese Arbeit \\
\hline Z94 & $\mathrm{R} 2413 \Delta y j i R$ & Diese Arbeit \\
\hline Z95 & R1279 glmY::cat & $\begin{array}{l}\text { Diese Arbeit und } \\
\text { (Reichenbach et al. } \\
\text { 2008) }\end{array}$ \\
\hline$\overline{Z 96}$ & $\mathrm{R} 1279 \Delta g \operatorname{lm} Y$ & $\begin{array}{l}\text { Diese Arbeit und } \\
\text { (Reichenbach et al. } \\
\text { 2008) }\end{array}$ \\
\hline Z97 & R2413 glmY::cat & Diese Arbeit \\
\hline Z98 & $\mathrm{R} 2413 \Delta g \operatorname{lm} Y$ & Diese Arbeit \\
\hline Z184 & R1279 $\Delta r p o N$ & $\begin{array}{l}\text { Laborsammlung B. } \\
\text { Görke, Institut für } \\
\text { Mikrobiologie und } \\
\text { Genetik, Göttingen }\end{array}$ \\
\hline
\end{tabular}




\subsection{Plasmide}

\begin{tabular}{|c|c|c|}
\hline Name & Beschreibung & Referenz / Quelle \\
\hline pBAD18 & $\begin{array}{l}\text { Expressionsplasmid; } \mathrm{P}_{\text {ara }} \text {-promoter, MCS 2, bla/cat/amp, } \\
\text { pBR322-ori }\end{array}$ & (Guzman et al. 1995) \\
\hline pBAD30 & Expressionsplasmid; $\mathrm{P}_{a r a}$-promoter, MCS 2, bla, pACYC-ori & (Guzman et al. 1995) \\
\hline pBAD33 & Expressionsplasmid; $\mathrm{P}_{a r a}$-promoter, MCS 2, cat, pACYC-ori & (Guzman et al. 1995) \\
\hline pBGG15 & $\begin{array}{l}\text { transkriptionelle Fusion von E. coli glmU-5' }(-392 \text { to }+240) \\
\text { an lacZ in pKES-15 }\end{array}$ & (Kalamorz et al. 2007) \\
\hline pBGG16 & $\begin{array}{l}\text { transkriptionelle Fusion von E. coli } g \operatorname{lm} S-5^{\prime}(\mathrm{g} \operatorname{lm} S-311 \text { to } \\
+129) \text { an lacZ in pKES-15 }\end{array}$ & (Kalamorz et al. 2007) \\
\hline pBGG17 & $\begin{array}{l}\text { transkriptionelle Fusion von E. coli } g \operatorname{lm} U-5{ }^{\prime}-g \operatorname{lm} U-g \operatorname{lm} S-5 \\
(g \operatorname{lm} U-392 \text { to } g \operatorname{lm} S+129) \text { an } \operatorname{lac} Z \text { in } \mathrm{pKES}-15\end{array}$ & (Kalamorz et al. 2007) \\
\hline pBGG56 & $\begin{array}{l}\text { E. coli glmS unter tacOP-Kontrolle. } \\
\text { Konstruktion: Ligation mit } 3 \text { Fragmenten: } \\
\text { 1. pFDX3543 } \Delta \text { XbaI/SacII (2392 bp), 2. pFDX3543 } \\
\Delta \text { SacII/BamHI (767 bp), 3. glmS + 15 bp stromaufwärts aus } \\
\text { PCR mit BG180/BG181, } \Delta \text { BamHI/XbaI. }\end{array}$ & $\begin{array}{l}\text { Diese Arbeit und } \\
\text { (Kalamorz et al. 2007) }\end{array}$ \\
\hline pBGG57 & $\begin{array}{l}\text { pBGG56, jedoch } g \operatorname{lm} S \text { ersetzt durch } g \operatorname{lm} Z \\
\text { Konstruktion: pBGG56 } \Delta \mathrm{XhoI} / \mathrm{XbaI}(3168 \mathrm{bp}) \text { ligiert mit } \\
\text { Produkt aus PCR mit BG186/BG187 } \Delta \mathrm{XhoI} / \mathrm{XbaI} \text {. }\end{array}$ & Diese Arbeit \\
\hline pBGG58 & $\begin{array}{l}\text { transkriptionelle Fusion von } E . \text { coli glmZ }+ \text { intergenische } \\
\text { Region (glmZ }-424 \text { to } g \operatorname{lm} Z+172) \text { an } l a c Z \text { in pKES-15 } \\
\text { Konstruktion: pKES15 } \Delta S a c \mathrm{I} / \mathrm{XbaI} \text { ligiert mit Produkt aus } \\
\text { PCR mit BG199/BG201 } \Delta S a c \mathrm{I} / \mathrm{XbaI}\end{array}$ & Diese Arbeit \\
\hline pBGG59 & $\begin{array}{l}\text { transkriptionelle Fusion von } E \text {. coli glmZ }+ \text { intergenische } \\
\text { Region (glmZ }-424 \text { bis } g \operatorname{lm} Z+31) \text { ) an lacZ in pKES-15 } \\
\text { Konstruktion: pKES15 } \Delta \text { SacI/XbaI ligiert mit Produkt aus } \\
\text { PCR mit BG199/BG202 } \Delta S a c \mathrm{I} / \mathrm{XbaI}\end{array}$ & $\begin{array}{l}\text { Diese Arbeit und } \\
\text { (Kalamorz et al. 2007) }\end{array}$ \\
\hline pBGG63 & $\begin{array}{l}\text { yhbJ-Gly8Ala-Mutante mit authentischer Shine-Dalgarno- } \\
\text { Sequenz unter Kontrolle des } \mathrm{P}_{a r a} \text {-Promoters in pBAD33 }\end{array}$ & $\begin{array}{l}\text { Laborsammlung B. } \\
\text { Görke }\end{array}$ \\
\hline pBGG83 & $\begin{array}{l}\text { glm } Z \text { mit den intergenischen Bereichen stromauf- und ab- } \\
\text { wärts ( } g \operatorname{lm} Z-416 \text { bis } g \operatorname{lm} Z+254 \text { ) unter Kontrolle des } \mathrm{P}_{a r a}{ }^{-} \\
\text {Promoters in pBAD30 } \\
\text { Konstruktion: pBAD30 } \Delta S a c \mathrm{I} / \mathrm{XbaI} \text { ligiert mit Produkt aus } \\
\text { PCR mit BG234/BG } 237 \Delta S a c \mathrm{I} / \mathrm{XbaI}\end{array}$ & Diese Arbeit \\
\hline pBGG84 & $\begin{array}{l}\text { glmZ mit } 100 \text { bp stromaufwärts und intergenischen Bereich } \\
\text { stromabwärts ( } g \operatorname{lmZ}-100 \text { bis } g \operatorname{lmZ}+) \text { unter Kontrolle des } \mathrm{P}_{\text {ara }}{ }^{-} \\
\text {Promoters in pBAD30 } \\
\text { Konstruktion: pBAD30 } \Delta S a c \mathrm{I} / \mathrm{XbaI} \text { ligiert mit Produkt aus } \\
\text { PCR mit BG235/BG } 237 \Delta S a c \mathrm{I} / \mathrm{XbaI}\end{array}$ & (Kalamorz et al. 2007) \\
\hline pBGG85 & $\begin{array}{l}g \operatorname{lm} Z \text { mit intergenischen Bereich stromabwärts }(g \operatorname{lm} Z+1 \text { bis } \\
g \operatorname{lm} Z+) \text { unter Kontrolle des } \mathrm{P}_{a r a} \text {-Promoters in pBAD30 } \\
\text { Konstruktion: pBAD30 } \Delta S a c \mathrm{I} / \mathrm{Xba} \text { I ligiert mit Produkt aus } \\
\text { PCR mit BG236/BG } 237 \Delta S a c \mathrm{I} / \mathrm{Xba \textrm {I }}\end{array}$ & Diese Arbeit \\
\hline pBGG88 & $\begin{array}{l}\text { glmM unter Kontrolle des } \mathrm{P}_{a r a} \text {-Promoters in pBAD18 }(a m p) \text {. } \\
\text { Konstruktion: pBAD18 } \Delta \text { SacI/XbaI ligiert mit Produkt aus } \\
\text { PCR mit BG280/BG } 281 \Delta S a c \mathrm{I} / \mathrm{Xba \textrm {I }}\end{array}$ & Diese Arbeit \\
\hline pBGG89 & $\begin{array}{l}\text { glmZ + intergenische Region stromaufwärts }(g \operatorname{lm} Z-424 \text { bis } \\
g \operatorname{lm} Z+172) \text { unter Kontrolle des } \mathrm{P}_{a r a} \text {-Promoters in pBAD18 } \\
(a m p) . \\
\text { Konstruktion: pBAD18 } \Delta S a c \mathrm{I} / \mathrm{XbaI} \text { ligiert mit Produkt aus } \\
\text { PCR mit BG234/ BG275 } \Delta S a c \mathrm{I} / \mathrm{XbaI}\end{array}$ & Diese Arbeit \\
\hline pBGG90 & 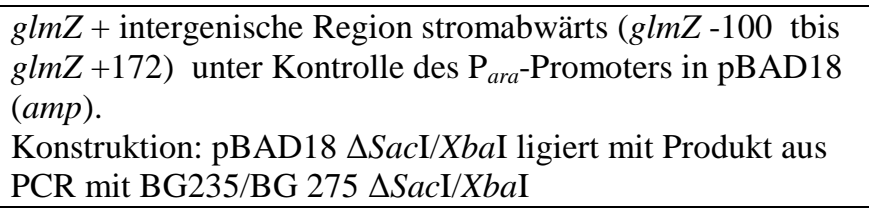 & Diese Arbeit \\
\hline pBGG91 & $\begin{array}{l}g \operatorname{lm} Z(g \operatorname{lm} Z+1 \text { bis } g \operatorname{lm} Z+172) \text { unter Kontrolle des } \mathrm{P}_{a r a^{-}} \\
\text {Promoters in pBAD18 }(a m p) . \\
\text { Konstruktion: pBAD18 } \Delta S a c \mathrm{I} / \mathrm{XbaI} \text { ligiert mit Produkt aus } \\
\text { PCR mit BG236/BG } 275 \Delta S a c \mathrm{I} / \mathrm{Xba \textrm {I }}\end{array}$ & Diese Arbeit \\
\hline
\end{tabular}




\begin{tabular}{|c|c|c|}
\hline pBGG95 & $\begin{array}{l}\text { glmM unter Kontrolle des } \mathrm{P}_{a r a} \text {-Promoters in pBAD18 (cat). } \\
\text { Konstruktion: pBAD18 } \Delta \text { SacI/XbaI ligiert } g l m M \text {-Fragment } \\
\text { aus pBGG88 } \triangle \text { SacI/XbaI }\end{array}$ & Diese Arbeit \\
\hline pBGG105 & $\begin{array}{l}\text { yhbJ mit N-terminalen Strep-Tag } \\
\text { Kostruktion: pGP172 } \Delta \text { KpnI/EcoRI ligiert mit Fragment aus } \\
\text { PCR mit BG306/BG307 } \Delta \text { KpnI/EcoRI }\end{array}$ & Diese Arbeit \\
\hline pBGG106 & $\begin{array}{l}\text { ybhK mit N-terminalen Strep-Tag } \\
\text { Kostruktion: pGP172 } \Delta \text { KpnI/EcoRI ligiert mit Fragment aus } \\
\text { PCR mit BG313/BG314 } \Delta \text { KpnI/EcoRI }\end{array}$ & Diese Arbeit \\
\hline pBGG109 & $\begin{array}{l}\text { yhbJ- } \Delta \text { AA 256- mit authentischer Shine-Dalgarno-Sequenz } \\
\text { unter Kontrolle des } \mathrm{P}_{\text {ara }} \text {-Promoters in pBAD33 } \\
\text { Konstruktion: pBAD } 33 \Delta \mathrm{SacI} / \mathrm{XbaI} \text { ligiert mit Fragment aus } \\
\text { PCR mit BG209/BG } 310 \Delta \mathrm{SacI} / \mathrm{XbaI}\end{array}$ & Diese Arbeit \\
\hline pBGG110 & $\begin{array}{l}\text { yhbJ-Gly8Ala mit authentischer Shine-Dalgarno-Sequenz } \\
\text { unter Kontrolle des } \mathrm{P}_{\text {ara }} \text {-Promoters in pBAD33 } \\
\text { Konstruktion: pBAD } 33 \Delta \mathrm{SacI} / \mathrm{XbaI} \text { ligiert mit Fragment aus } \\
\text { PCR mit BG210/BG } 310 \Delta \mathrm{SacI} / \mathrm{XbaI}\end{array}$ & Diese Arbeit \\
\hline pBGG119 & $\begin{array}{l}\text { yhbJ mit authentischer Shine-Dalgarno-Sequenz unter } \\
\text { Kontrolle des } \mathrm{P}_{\text {ara }} \text {-Promoters in pBAD33 } \\
\text { Konstruktion: Ligation mit } 3 \text { Fragmenten: } \\
\text { 1. pBAD33 } \Delta \text { SacI/XbaI, 2. Fragment aus PCR mit } \\
\text { BG209/BG324 } \Delta \text { SacI/NcoI, 3. Fragment aus PCR mit } \\
\text { BG346/BG212 } \Delta N c o I / X b a I\end{array}$ & Diese Arbeit \\
\hline pBGG120 & $\begin{array}{l}\text { yhbJ G13A mit authentischer Shine-Dalgarno-Sequenz } \\
\text { unter Kontrolle des } \mathrm{P}_{a r a} \text {-Promoters in pBAD33 } \\
\text { Konstruktion: Ligation mit } 3 \text { Fragmenten: } \\
\text { 1. pBAD33 } \Delta \text { SacI/XbaI, 2. Fragment aus PCR mit } \\
\text { BG323/BG324 } \Delta \text { SacI/NcoI, 3. Fragment aus PCR mit } \\
\text { BG346/BG212 } \Delta N c o I / X b a I\end{array}$ & Diese Arbeit \\
\hline pBGG121 & $\begin{array}{l}y h b J \Delta \text { AA164 - } 212 \text { mit authentischer Shine-Dalgarno- } \\
\text { Sequenz unter Kontrolle des } \mathrm{P}_{\text {ara }} \text {-Promoters in pBAD33 } \\
\text { Konstruktion: Ligation mit } 3 \text { Fragmenten: } \\
\text { 1. pBAD33 } \Delta \text { SacI/XbaI, 2. Fragment aus PCR mit } \\
\text { BG323/BG324 } \Delta \text { SacI/NcoI, 3. Fragment aus PCR mit } \\
\text { BG325/BG212 } \Delta N c o I / X b a I \text {. }\end{array}$ & Diese Arbeit \\
\hline pBGG122 & $\begin{array}{l}y h b J \text { F167A mit authentischer Shine-Dalgarno-Sequenz } \\
\text { unter Kontrolle des } \mathrm{P}_{a r a}-\text { Promoters in pBAD33 } \\
\text { Konstruktion: Ligation mit } 3 \text { Fragmenten: } \\
\text { 1. pBAD33 } \Delta \text { SacI/XbaI, 2. Fragment aus PCR mit } \\
\text { BG209/BG324 } \Delta \text { SacI/NcoI, 3. Fragment aus PCR mit } \\
\text { BG326/BG212 } \Delta N c o I / X b a I \text {. }\end{array}$ & Diese Arbeit \\
\hline pBGG123 & $\begin{array}{l}\text { yhbJ G168L mit authentischer Shine-Dalgarno-Sequenz } \\
\text { unter Kontrolle des } \mathrm{P}_{a r a}-\text { Promoters in pBAD33 } \\
\text { Konstruktion: } \\
\text { Konstruktion: Ligation mit } 3 \text { Fragmenten: } \\
\text { 1. pBAD33 } \Delta \text { SacI/XbaI, 2. Fragment aus PCR mit } \\
\text { BG209/BG324 } \Delta \text { SacI/Ncol, 3. Fragment aus PCR mit } \\
\text { BG327/BG212 } \Delta N c o I / X b a I\end{array}$ & Diese Arbeit \\
\hline pBGG124 & $\begin{array}{l}\text { yhbJ mit authentischer Shine-Dalgarno-Sequenz unter } \\
\text { Kontrolle des } \mathrm{P}_{a r a} \text {-Promoters in pBAD33 } \\
\text { Konstruktion: Ligation mit } 3 \text { Fragmenten: } \\
\text { 1. pBAD33 } \Delta \text { SacI/XbaI, 2. Fragment aus PCR mit } \\
\text { BG209/BG330 } \Delta \text { SacI/BamHI, 3. Fragment aus PCR mit } \\
\text { BG328/BG212 } \Delta \text { BamHI/XbaI. }\end{array}$ & Diese Arbeit \\
\hline pBGG125 & $\begin{array}{l}\text { yhbJ N188A mit authentischer Shine-Dalgarno-Sequenz } \\
\text { unter Kontrolle des } \mathrm{P}_{a r a} \text {-Promoters in pBAD33 } \\
\text { Konstruktion: Ligation mit } 3 \text { Fragmenten: } \\
\text { 1. pBAD33 } \Delta \text { SacI/XbaI, } 2 \text {. Fragment aus PCR mit } \\
\text { BG209/BG331 } \Delta \text { SacI/BamHI, 3. Fragment aus PCR mit } \\
\text { BG328/BG212 } \Delta \text { BamHI/XbaI.. }\end{array}$ & Diese Arbeit \\
\hline pBGG126 & $\begin{array}{l}\text { yhbJ P189A mit authentischer Shine-Dalgarno-Sequenz } \\
\text { unter Kontrolle des } \mathrm{P}_{a r a} \text {-Promoters in pBAD33 }\end{array}$ & Diese Arbeit \\
\hline
\end{tabular}




\begin{tabular}{|c|c|c|}
\hline & $\begin{array}{l}\text { Konstruktion:_Ligation mit } 3 \text { Fragmenten: } \\
\text { 1. pBAD33 } \Delta \text { SacI/XbaI, 2. Fragment aus PCR mit } \\
\text { BG209/BG332 } \Delta \text { SacI/BamHI, 3. Fragment aus PCR mit } \\
\text { BG328/BG212 } \Delta \text { BamHI/XbaI.. }\end{array}$ & \\
\hline pBGG127 & $\begin{array}{l}\text { yhbJ G199L mit authentischer Shine-Dalgarno-Sequenz } \\
\text { unter Kontrolle des } \mathrm{P}_{a r a} \text {-Promoters in pBAD33 } \\
\text { Konstruktion: Ligation mit } 3 \text { Fragmenten: } \\
\text { 1. pBAD33 } \Delta \text { SacI/XbaI, 2. Fragment aus PCR mit } \\
\text { BG209/BG330 } \Delta \text { SacI/BamHI, 3. Fragment aus PCR mit } \\
\text { BG329/BG212 } \Delta \text { BamHI/XbaI. }\end{array}$ & Diese Arbeit \\
\hline pBGG149 & $\operatorname{glm} Y$ unter $\mathrm{P}_{\mathrm{L}}$-Kontrolle in $\mathrm{pFDX} 1088$ & $\begin{array}{l}\text { (Reichenbach et al. } \\
\text { 2008) }\end{array}$ \\
\hline pBGG161 & $\begin{array}{l}\text { yhbJ mit C-terminalen His(10)-Tag unter } \mathrm{P}_{\text {tac }} \text { Kontrolle in } \\
\text { pKES170 } \\
\text { Konstruktion: pKES170 } \Delta \text { NdeI-XbaI ligiert mit Fragment } \\
\text { aus PCR mit BG394/BG395 } \Delta \text { NdeI-XbaI }\end{array}$ & Diese Arbeit \\
\hline pBGG162 & $\begin{array}{l}\text { yhbJ mit N-terminalen His(10)-Tag unter } \mathrm{P}_{t a c} \text { Kontrolle in } \\
\text { pKES170 } \\
\text { Konstruktion: pKES170 } \Delta \text { NdeI-PstI ligiert mit Fragment aus } \\
\text { PCR mit BG396/BG397 } \Delta \text { NdeI-PstI }\end{array}$ & Diese Arbeit \\
\hline pBGG165 & $\begin{array}{l}\text { translationale } \operatorname{lptA}(-152) \rightarrow \text { rpoN(+79)-lacZ-Fusion in } \\
\text { pKEM20 } \\
\text { Konstruktion: pKEM20 } \Delta \text { SalI-XbaI ligiert mit Fragment aus } \\
\text { PCR mit BG400/BG401 } \Delta \text { Sall-XbaI }\end{array}$ & Diese Arbeit \\
\hline pBGG166 & $\begin{array}{l}\text { translationale } l p t B(+100) \rightarrow r p o N(+79)-l a c Z \text {-Fusion in } \\
\text { pKEM20 } \\
\text { Konstruktion: pKEM20 } \Delta \text { SalI-XbaI ligiert mit Fragment aus } \\
\text { PCR mit BG402/BG401 } \Delta \text { SalI-XbaI }\end{array}$ & Diese Arbeit \\
\hline pBGG168 & $\begin{array}{l}\text { translationale } l p t B(+100) \rightarrow y h b J(+168) \text {-lacZ-Fusion in } \\
\text { pKEM20 } \\
\text { Konstruktion: pKEM20 } \Delta \text { SalI-XbaI ligiert mit Fragment aus } \\
\text { PCR mit aus PCR mit BG402/BG404 } \Delta \text { SalI-XbaI }\end{array}$ & Diese Arbeit \\
\hline pCP20 & $\begin{array}{l}\text { bla, cat; FLP Rekombinase unter Kontrolle eines } \\
\text { temperatursensitiven Promotors; ori pSC } 101^{\text {repTS }}\end{array}$ & $\begin{array}{l}\text { (Datsenko und Wanner } \\
\text { 2000) }\end{array}$ \\
\hline pFDX3453 & $b g l G$ unter $P_{t a c}$-Kontrolle, MCS hinter $b g l G$, tet, pACYC-ori & (Görke and Rak 1999). \\
\hline pFDX4291 & $\begin{array}{l}\text { pSC101-ori, cat, Operatorloses } P_{t a c}, \text { BglII, sacB-RBS, NdeI, } \\
\text { XbaI, HincII }\end{array}$ & (Kalamorz et al. 2007) \\
\hline pFDX4292 & $p t s O$ unter $P_{t a c}$-Kontrolle in pFDX4291 & (Kalamorz et al. 2007) \\
\hline pFDX4294 & $p t s N$ unter $P_{t a c}-$ Kontrolle in pFDX4291 & (Kalamorz et al. 2007) \\
\hline pFDX4296 & $p t s N, y h b J, p t s O$ unter $P_{t a c}$-Kontrolle in pFDX4291 & (Kalamorz et al. 2007) \\
\hline pFDX4320 & $y h b J, p t s O$ unter $P_{t a c}$-Kontrolle in pFDX4291 & (Kalamorz et al. 2007) \\
\hline pFDX4322 & $p t s O$ and $p t s N$ unter $P_{t a c}$-Kontrolle in pFDX4291 & (Kalamorz et al. 2007) \\
\hline pFDX4324 & $y h b J$ under $P_{t a c}-$ control in pFDX4291 & (Kalamorz et al. 2007) \\
\hline pKD3 & $\begin{array}{l}\text { cat-Kassette mit stromabwärts gelegener } \\
\text { Ribosomensbindestelle zur Vermeidung polarer Effekte, } \\
\text { siehe 3.5.3. }\end{array}$ & $\begin{array}{l}\text { (Datsenko und Wanner } \\
\text { 2000). }\end{array}$ \\
\hline pKD46 & $\begin{array}{l}\text { Helferplasmid mit } \lambda \text {-Rekombinasesystem unter } \mathrm{P}_{\text {ara }}{ }^{-} \\
\text {Kontrolle, bla; ori pSC } 101^{\text {repTS }} \text {, siehe 3.5.3. }\end{array}$ & $\begin{array}{l}\text { (Datsenko und Wanner } \\
2000)\end{array}$ \\
\hline pKEM4 & $\begin{array}{l}\text { ori p15A, neo, attP, aadA, T4gene32-Terminator, } \\
\text { promoterloses lacZ }\end{array}$ & $\begin{array}{l}\text { Laborsammlung K. } \\
\text { Schnetz, Institut für } \\
\text { Genetik, Köln }\end{array}$ \\
\hline pKEM20 & $\begin{array}{l}\text { ori p15A, neo, attP, aadA, T4gene32-Terminator, } P_{\text {prov-lacZ. }} \text {. } \\
\text { Vektor für translationale lacZ Fusionen. }\end{array}$ & $\begin{array}{l}\text { Laborsammlung K. } \\
\text { Schnetz, Institut für } \\
\text { Genetik, Köln }\end{array}$ \\
\hline pKES15 & $\begin{array}{l}\text { ori p15A, neo, attP, aadA, T4gene32-Terminator, } P_{\text {prov-lacZ. }} \text {. } \\
\text { Vektor für transkriptionale lacZ Fusionen. }\end{array}$ & $\begin{array}{l}\text { Laborsammlung K. } \\
\text { Schnetz, Institut für } \\
\text { Genetik, Köln }\end{array}$ \\
\hline pKES170 & $\begin{array}{l}\text { bla, lacI, } \mathrm{P}_{\text {tac }} \text {, SD T7 Gen 10, NdeI, XbaI, pBR322-ori. } \\
\text { Vektor für Protein-Überproduktion }\end{array}$ & $\begin{array}{l}\text { Laborsammlung K. } \\
\text { Schnetz, Institut für } \\
\text { Genetik, Köln }\end{array}$ \\
\hline pKESK18 & $\begin{array}{l}\text { Tn10-Transposase unter } \lambda \mathrm{P}_{\mathrm{R}} \text {-control, } \lambda \mathrm{cI}_{857}, \mathrm{mTn} 10:: \text { cat, } \\
\text { pSC101-rep }^{\mathrm{TS}} \text {, neo }\end{array}$ & $\begin{array}{l}\text { (Madhusudan et al. } \\
\text { 2005) }\end{array}$ \\
\hline
\end{tabular}




\subsection{Oligonukleotide}

\begin{tabular}{|c|c|c|}
\hline Name & Sequenz & Verwendung \\
\hline BG25 & GTGCTGCAAGGCGATTAAGTTGG & $\begin{array}{l}\text { Sequenzierung lacZ- } \\
\text { Fusionen }\end{array}$ \\
\hline BG80 & GGCCACGCGTCGACTAGTACNNNNNNNNNNGATC & $\begin{array}{l}\text { Degenerierter Primer } \\
\text { für 1. Schritt der ST- } \\
\text { PCR }\end{array}$ \\
\hline BG81 & GCTCTAGAGGCCACGCGTCGACTAGTAC & $\begin{array}{l}\text { 2. Schritt der ST-PCR. } \\
\text { identisch zum } \\
\text { definierten Bereich von } \\
\text { BG80 }\end{array}$ \\
\hline BG82 & TTTGCATGCTTCAAAGCCTGTCGGAATTGG & $\begin{array}{l}\text { 1.Schritt der ST-PCR, } \\
\text { paart im mTn10- } \\
\text { Transposon, rechtes } \\
\text { Ende }\end{array}$ \\
\hline BG83 & $\begin{array}{l}\text { GCTCTAGAATTCACGGTTTACCCAC } \\
\text { TTATAAACAAAAGATCGG }\end{array}$ & $\begin{array}{l}\text { 2.Schritt der ST-PCR, } \\
\text { paart im mTn10- } \\
\text { Transposon, rechtes } \\
\text { Ende }\end{array}$ \\
\hline BG84 & AAGAGCGCCCAATACGCAAACCGCC & $\begin{array}{l}\text { 1.Schritt der ST-PCR, } \\
\text { paart im mTn10- } \\
\text { Transposon, linkes } \\
\text { Ende }\end{array}$ \\
\hline BG85 & GCTCTAGACGCGTTGGCCGATTCATTAATGCAGGG & $\begin{array}{l}\text { 2.Schritt der ST-PCR, } \\
\text { paart im mTn10- } \\
\text { Transposon, linkes } \\
\text { Ende }\end{array}$ \\
\hline BG96 & TGATGCAGGAAATGGGTCTG & fwd-check $y h b K$ \\
\hline BG97 & GGCGGAGCTGCAATACGC & rev-check $y h b K$ \\
\hline BG146 & AAGTAATCGCAACATCCGCATTA & $\begin{array}{l}\text { Sequenzierung von } \\
\text { Insertionen in pKES15 }\end{array}$ \\
\hline BG155 & $\begin{array}{l}\text { CAATTTGCGCTACTGTAGCGCGGATAATCTGACTCCAGG } \\
\text { AAACTATGTGTAGGCTGGAGCTGCTTCG }\end{array}$ & $\begin{array}{l}\text { fwd-Primer zur } \\
\text { Generierung der } \\
\text { Kassette zur } \\
\text { markerlosen Deletion } \\
\text { von } y b h K\end{array}$ \\
\hline BG156 & $\begin{array}{l}\text { CACTTTGTCTTCAATAGGAAGCCGGAATTTTCCTTCGGAT } \\
\text { TTCCGTTAACATATGAATATCCTCCTTAGTTCCTATTCC }\end{array}$ & $\begin{array}{l}\text { rev-Primer zur } \\
\text { Generierung der } \\
\text { Kassette zur } \\
\text { markerlosen Deletion } \\
\text { von } y b h K\end{array}$ \\
\hline BG157 & $\begin{array}{l}\text { GTTATTCGGTAATGTCTCTTTTAGACGTTGTGAGGAGAAA } \\
\text { CAGTACGTGTAGGCTGGAGCTGCTTCG }\end{array}$ & $\begin{array}{l}\text { fwd-Primer zur } \\
\text { Generierung der } \\
\text { Kassette zur } \\
\text { markerlosen Deletion } \\
\text { von yhbJ }\end{array}$ \\
\hline BG158 & $\begin{array}{l}\text { GGCATGCATGCCCAGCTTGTTTGTGATTTCAACAGTTTGC } \\
\text { TTGACGGTCATATGAATATCCTCCTTAGTTCCTATTCC }\end{array}$ & $\begin{array}{l}\text { rev-Primer zur } \\
\text { Generierung der } \\
\text { Kassette zur } \\
\text { markerlosen Deletion } \\
\text { von yhbJ }\end{array}$ \\
\hline BG159 & GTTTGTAGGCCGGATAAGGC & fwd-check-ybhK \\
\hline BG160 & CGTGCATCGTCCTTTAGAGG & rev-check $y b h K$ \\
\hline BG161 & GGATACCGAAGGTACTCCGG & fwd-check-yhbJ \\
\hline BG162 & CGTAAGAGCACTTCAGCGTC & rev-check $y h b J$ \\
\hline BG163 & CGTGGTATTCACTCCAGAGCG & fwd-check cat (pKD3) \\
\hline BG164 & GCTGGTGATATGGGATAGTG & rev-check cat (pKD3) \\
\hline BG180 & $\begin{array}{l}\text { GCGGGATCCTCGAGAAATCGGAATCAAAAACTATGTGT } \\
\text { GG }\end{array}$ & fwd-glmS BamHI/XhoI \\
\hline
\end{tabular}


Anhang

\begin{tabular}{|c|c|c|}
\hline BG181 & GCGTCTAGATTACTCAACCGTAACCGATTTTGCC & rev-glmS XbaI \\
\hline BG182 & $\begin{array}{l}\text { CGGGCATACAGGTTGACCGACAACGATATAAATCGGAAT } \\
\text { CAAAAACTGTGTAGGCTGGAGCTGCTTCG }\end{array}$ & $\begin{array}{l}\text { fwd-Primer zur } \\
\text { Generierung der } \\
\text { Kassette zur } \\
\text { markerlosen Deletion } \\
\text { von } \mathrm{glmS}\end{array}$ \\
\hline BG183 & $\begin{array}{l}\text { CAGGAAGAAAAATGCCCCGCTTACGCAGGGCATCCATTT } \\
\text { ATTACATATGAATATCCTCCTTAGTTCCTATTCC }\end{array}$ & $\begin{array}{l}\text { rev-Primer zur } \\
\text { Generierung der } \\
\text { Kassette zur } \\
\text { markerlosen Deletion } \\
\text { von } g \operatorname{lm} S\end{array}$ \\
\hline BG184 & $\begin{array}{l}\text { GGGATGTTATTTCCCGATTCTCTGTGGCATAATAAACGAG } \\
\text { TGTAGGCTGGAGCTGCTTCG }\end{array}$ & $\begin{array}{l}\text { fwd-Primer zur } \\
\text { Generierung der } \\
\text { Kassette zur } \\
\text { markerlosen Deletion } \\
\text { von } g l m Z\end{array}$ \\
\hline BG185 & $\begin{array}{l}\text { CACCCGGAGGCAAGCACCTCCGGGGCCTTCCTGATACAT } \\
\text { CATATGAATATCCTCCTTAGTTCCTATTCC }\end{array}$ & $\begin{array}{l}\text { rev-Primer zur } \\
\text { Generierung der } \\
\text { Kassette zur } \\
\text { markerlosen Deletion } \\
\text { von } \text { glmZ }\end{array}$ \\
\hline BG186 & $\begin{array}{l}\text { GCGCTCGAGGTAGATGCTCATTCCATCTCTTAT } \\
\text { TTCGCC }\end{array}$ & fwd-glmZ XhoI \\
\hline BG187 & GCGTCTAGAGCACCTCCGGGGCCTTCCTGATACAT & rev-glmZ-XbaI \\
\hline BG188 & GTGTAGGATCAAGCTCAGG & fwd-check $g \operatorname{lm} Z$ \\
\hline BG189 & CAGCTATGCGTCGCGACG & rev-check $g \operatorname{lm} Z$ \\
\hline BG190 & GCGGGATCCGCAAAATGCTCCGGTTTCATGTCATC & fwd-glmZ-BamHI \\
\hline BG191 & GCGCTCGAGTTCCTTCTCACCCGGAGGCAAGCA & rev-glmZ-XhoI \\
\hline BG197 & CTTACAAGACGAACACGTTAAGC & fwd-check $r p o N$ \\
\hline BG198 & GTCTTCCTTATCGGTTGGGTC & rev-check rpoN \\
\hline BG199 & GCACGCGTCGACGCAAAATGCTCCGGTTTCATG & fwd-glmZ (-421) SalI \\
\hline BG200 & GCACGCGTCGACGATGCTGTTTTTAGTTTTAACGGC & fwd-glmZ (-207) SalI \\
\hline BG201 & GCGTCTAGAAAAACAGGTCTGTATGACAACAAGTGGG & rev- $g \operatorname{lm} Z(+172) X b a \mathrm{I}$ \\
\hline BG202 & GCGTCTAGAGGCGAACATAAGAGATGGAATGAGC & rev-glmZ $(+30) X b a \mathrm{I}$ \\
\hline BG203 & $\begin{array}{l}\text { GCATGAGAGGAAATCAGGCGCTTCGCCGCTATTTCGAAT } \\
\text { GTGTAGGCTGGAGCTGCTTCG }\end{array}$ & $\begin{array}{l}\text { fwd-Primer zur } \\
\text { Generierung der } \\
\text { Kassette zur } \\
\text { markerlosen Deletion } \\
\text { von yjiR }\end{array}$ \\
\hline BG204 & $\begin{array}{l}\text { CCGGTTTTTCTCTCTGTATGGTCCACATAAGGAATACAGC } \\
\text { CATATGAATATCCTCCTTAGTTCCTATTCC }\end{array}$ & $\begin{array}{l}\text { rev-Primer zur } \\
\text { Generierung der } \\
\text { Kassette zur } \\
\text { markerlosen Deletion } \\
\text { von yjiR }\end{array}$ \\
\hline BG205 & CCTGGTCAGGCGTTCACATGGCATCC & fwd-check yjiR \\
\hline BG206 & CCTCATCTTTCAGAGGCTTCATCATCCACC & rev-check yjiR \\
\hline BG229 & AGATTAGCGGATCCTACCTG & $\begin{array}{l}\text { Sequenzierung } \\
\text { pBAD18/30/33 (fwd) }\end{array}$ \\
\hline BG232 & TGATTTAATCTGTATCAGGCTG & $\begin{array}{l}\text { Sequenzierung } \\
\text { pBAD18/30/33 (rev) }\end{array}$ \\
\hline BG233 & CGGACGCCTACGATTACGC & rev-check-glm $Z$ \\
\hline BG234 & GGCGAGCTCGCAAAATGCTCCGGTTTCATGTC & $\begin{array}{l}\text { fwd-glmZ Position }-424 \\
\text { SacI }\end{array}$ \\
\hline BG235 & GGCGAGCTCTCAGGAAGTTATTACTCAGGAAGC & $\begin{array}{l}\text { fwd- } g \operatorname{lm} Z \text { Position }-100 \\
\text { SacI }\end{array}$ \\
\hline BG236 & GGCGAGCTCGTAGATGCTCATTCCATCTCTTATGTTCG & fwd-glmZ SacI \\
\hline BG237 & GGCTCTAGATTCCTTCTCACCCGGAGGCAAGCACC & $\begin{array}{l}\text { rev-glmZ Position }+254 \\
X b a I\end{array}$ \\
\hline BG244 & $\begin{array}{l}\text { GCGCAGTGGTGTGGCACATATTCCACAGTTGAAGGAGTG } \\
\text { TAGGCTGGAGCTGCTTCG }\end{array}$ & $\begin{array}{l}\text { fwd-Primer zur } \\
\text { Generierung der } \\
\text { Kassette zur }\end{array}$ \\
\hline
\end{tabular}


Anhang

\begin{tabular}{|c|c|c|}
\hline & & $\begin{array}{l}\text { markerlosen Deletion } \\
\text { von } d g o T\end{array}$ \\
\hline BG245 & $\begin{array}{l}\text { CGGCTTCGCTATGCCCAAAATCTGGAGAAAGCTCGCTCA } \\
\text { TATGAATATCCTCCTTAGTTCCTATTCC }\end{array}$ & $\begin{array}{l}\text { rev-Primer zur } \\
\text { Generierung der } \\
\text { Kassette zur } \\
\text { markerlosen Deletion } \\
\text { von } d g o T\end{array}$ \\
\hline BG246 & GCCTTTCTGATTGGTGAAGCGG & fwd-check-dgoT \\
\hline BG247 & CGTAAGCCCCTCATCGGGC & rev-check-dgoT \\
\hline BG248 & $\begin{array}{l}\text { CAACAAAGCCGGGAATTACCCGGCTTTGTTATGGAAGTG } \\
\text { TAGGCTGGAGCTGCTTCG }\end{array}$ & $\begin{array}{l}\text { fwd-Primer zur } \\
\text { Generierung der } \\
\text { Kassette zur } \\
\text { markerlosen Deletion } \\
\text { von } g \operatorname{lm} Y\end{array}$ \\
\hline BG249 & $\begin{array}{l}\text { CTATTTTCTTTATTGGCACAGTTACTGCATAATAGTAACC } \\
\text { CATATGAATATCCTCCTTAGTTCCTATTCC }\end{array}$ & $\begin{array}{l}\text { rev-Primer zur } \\
\text { Generierung der } \\
\text { Kassette zur } \\
\text { markerlosen Deletion } \\
\text { von } g \operatorname{lm} Y\end{array}$ \\
\hline BG250 & GGTGTTACTCTCGTCAGACGCG & fwd-check- $g \operatorname{lm} Y$ \\
\hline BG251 & GTCTCTTTTTAGCGACACAGTGGC & rev-check-glm $Y$ \\
\hline BG254 & AAAGTCAGCGAAGGAAATG & $\begin{array}{l}\text { rev-sraC } \mathrm{r} / \mathrm{c} \text { für in vitro } \\
\text { Transkription }\end{array}$ \\
\hline BG255 & $\begin{array}{l}\text { CTAATACGACTCACTATAGGGAGATCACCAGAACGGGCG } \\
\mathrm{G}\end{array}$ & $\begin{array}{l}\text { fwd-sraC r/c mit T7- } \\
\text { Promotor für in vitro } \\
\text { Transkription }\end{array}$ \\
\hline BG275 & GGCTCTAGAAAAACAGGTCTGTATGACAACAAGTGG & $\begin{array}{l}\text { rev-glmZ prozessiert } \\
X b a I\end{array}$ \\
\hline BG276 & $\begin{array}{l}\text { GCGACAATCGCCGCCTTTTTAGCCAGTTATCTAACGCTGT } \\
\text { GTAGGCTGGAGCTGCTTCG }\end{array}$ & $\begin{array}{l}\text { fwd-Primer zur } \\
\text { Generierung der } \\
\text { Kassette zur } \\
\text { markerlosen Deletion } \\
\text { von } \operatorname{glm} M\end{array}$ \\
\hline BG277 & $\begin{array}{l}\text { GGAAGCCACTCTGTCTGCAAAGGAAAACAAACGCTCATA } \\
\text { TGAATATCCTCCTTAGTTCCTATTCC }\end{array}$ & $\begin{array}{l}\text { rev-Primer zur } \\
\text { Generierung der } \\
\text { Kassette zur } \\
\text { markerlosen Deletion } \\
\text { von } \operatorname{glm} M\end{array}$ \\
\hline BG278 & GCTTCAACCAATAAAGCGGG & fwd-check-glmM \\
\hline BG279 & GCGGTAGTCTGGCCTGTGCG & rev-check-glmM \\
\hline BG280 & GGCGAGCTCATGAGTAATCGTAAATATTTCGG & fwd-glmM SacI \\
\hline BG281 & GGCTCTAGATTAAACGGCTTTTACTGCATCGGCG & rev-glmM XbaI \\
\hline BG306 & TCCGAATTCTATGGTACTGATGATCGTCAGCGGACG & fwd-yhbJ EcoRI \\
\hline BG307 & AGGGGTACCTGGTTTACGTTTTTCCAGCGTACGATGGCG & rev-yhbJ KpnI \\
\hline BG310 & $\begin{array}{l}\text { GGCTCTAGAGGTACCATACACCGAACGGTGCTTCCCGCC } \\
\text { GG }\end{array}$ & $\begin{array}{l}\text { rev-yhbJ Position } 765 \\
\text { KpnI }\end{array}$ \\
\hline BG323 & $\begin{array}{l}\text { TCCCCCGGGAGCTCGTGAGGAGAAACAGTACATGGTACT } \\
\text { GATGATCGTCAGCGGACGTTCAGGㅡTCAGG }\end{array}$ & fwd-yhbJ G13A SacI \\
\hline BG324 & CAAAGACCATGGTCAGTTCGCGTTCAC & $\begin{array}{l}\text { rev-yhbJ Position } 493 \\
\text { NcoI }\end{array}$ \\
\hline BG325 & AACTGACCATGGTCACAGAAGTACACAATTTTATCTACC & $\begin{array}{l}\text { fwd-yhbJ Position } 636 \\
\text { NcoI }\end{array}$ \\
\hline BG326 & $\begin{array}{l}\text { GAACTGACCATGGTCTTTGAGTCTGCCGGCTTCAAACAC } \\
\text { GGT }\end{array}$ & $\begin{array}{l}\text { fwd-yhbJ Position } 475 \\
\text { F167A NcoI }\end{array}$ \\
\hline BG327 & $\begin{array}{l}\text { GAACTGACCATGGTCTTTGAGTCTTTCCTCTTCAAACACG } \\
\text { GT }\end{array}$ & $\begin{array}{l}\text { fwd-yhbJ Position } 475 \\
\text { G168L NcoI }\end{array}$ \\
\hline BG328 & CGCACTGGGATCCGAAACTGCGTCCAATGACAGGT & $\begin{array}{l}\text { fwd-yhbJ Position } 566 \\
\text { BamHI }\end{array}$ \\
\hline BG329 & $\begin{array}{l}\text { CGCACTGGGATCCGAAACTGCGTCCAATGACACTTC } \\
\text { TTGA }\end{array}$ & $\begin{array}{l}\text { fwd-yhbJ Position } 566 \\
\text { G199L BamHI }\end{array}$ \\
\hline
\end{tabular}


Anhang

\begin{tabular}{|c|c|c|}
\hline BG330 & CAGTTTCGGATCCCAGTGCGGGTTCGGCAAGAAG & $\begin{array}{l}\text { rev-yhbJ Position } 585 \\
\text { BamHI }\end{array}$ \\
\hline BG331 & CAGTTTCGGATCCCAGTGCGGGGCCGGCAAGAAG & $\begin{array}{l}\text { rev-yhbJ Position } 585 \\
\text { P189A BamHI }\end{array}$ \\
\hline BG332 & CAGTTTCGGATCCCAGTGCGCGTTCGGCAAGAAG & $\begin{array}{l}\text { rev-yhbJ Position } 585 \\
\text { N188A BamHI }\end{array}$ \\
\hline BG346 & $\begin{array}{l}\text { GAACTGACCATGGTCTTTGAGTCTTTCGGCTTCAAACAC } \\
\text { GGT }\end{array}$ & $\begin{array}{l}\text { fwd-yhbJ Position } 475 \\
\text { NcoI }\end{array}$ \\
\hline BG349 & GAGCCCGAAGTGGCGAG & $\begin{array}{l}\text { Sequenzierung } \\
\text { pKES170 (fwd) }\end{array}$ \\
\hline BG350 & GACCCGTTTAGAGGCCC & $\begin{array}{l}\text { Sequenzierung } \\
\text { pKES170 (rev) }\end{array}$ \\
\hline BG351 & CGTCATATGGTACTGATGATCGTCAGC & fwd-yhbJ NdeI \\
\hline BG352 & ATCCTCGAGTCATGGTTTACGTTTTTCCAG & rev-yhbJ XhoI \\
\hline BG353 & CCACCATACCCACGCCG & $\begin{array}{l}\text { Sequenzierung } \\
\text { pET16B (fwd) }\end{array}$ \\
\hline BG354 & CCCTGGATGCTGTAGGC & $\begin{array}{l}\text { Sequenzierung } \\
\text { pET16B (rev) }\end{array}$ \\
\hline BG367 & GCACGCGTCGACGATCCAACGGTTTGATCCG & $\begin{array}{l}\text { fwd-rpoN Position } 542 \\
\text { Sall für lacZ-Fusionen }\end{array}$ \\
\hline BG368 & GCGTCTAGAGATCCCAGTGCGGGTTCGGC & $\begin{array}{l}\text { rev-yhbJ Position } 576 \\
\text { XbaI für lacZ-Fusionen }\end{array}$ \\
\hline BG369 & TCCGAGCTCTATGGTACTGATGATCGTCAGCG & fwd-yhbJ SacI \\
\hline BG370 & TCCGAGCTCTATGCGCAATCGTACGCTGGC & fwd-ybhK SacI \\
\hline BG371 & AGGGGTACCTTATGGTTTACGTTTTTCCAGCGTACG & rev-yhbJ KpnI \\
\hline BG394 & CTCGTACTCATATGGTACTGATGATCGTCAGC & fwd-yhbJ NdeI \\
\hline BG395 & CGCTCTAGATGGTTTACGTTTTTCCAGCG & rev-yhbJ XbaI \\
\hline BG396 & $\begin{array}{l}\text { CTCGTACTCATATGCATCATCATCATCATCATCATCATCAT } \\
\text { CATGCTAGCATGGTACTGATGATCGTCAG }\end{array}$ & fwd-His(10)-yhbJ NdeI \\
\hline BG397 & $\begin{array}{l}\text { TGGCTGCAGTCTAGATTATCATGGTTTACGTTTTTCCAGC } \\
\text { G }\end{array}$ & rev-yhbJ PstI \\
\hline BG400 & GCCCTCGAGGGTCCGTAAAAGCAGATAAAGCC & $\begin{array}{l}\text { fwd-lptB für lacZ- } \\
\text { Fusionen XhoI }\end{array}$ \\
\hline BG401 & GCCTCTAGACAACAGACGAATTGCCT & $\begin{array}{l}\text { rev-rpoN für lacZ- } \\
\text { Fusion } X b a \mathrm{I}\end{array}$ \\
\hline BG402 & GCCTCGAGTGCTGGGGCCAAACGG & $\begin{array}{l}\text { fwd-lptA für lacZ- } \\
\text { Fusion XhoI }\end{array}$ \\
\hline BG404 & GCCTCTAGAAAAACCCATATCTTCCAGCGC & $\begin{array}{l}\text { rev-yhbJ für lacZ- } \\
\text { Fusion } X b a \mathrm{I}\end{array}$ \\
\hline BG407 & $\begin{array}{l}\text { ATGAAGCAAGGTTTGCAACTCAGGCGTGTAGGCTGGAGC } \\
\text { TGCTTCG }\end{array}$ & $\begin{array}{l}\text { fwd-Primer zur } \\
\text { Generierung der } \\
\text { Kassette zur } \\
\text { markerlosen Deletion } \\
\text { von rpoN }\end{array}$ \\
\hline BG408 & $\begin{array}{l}\text { AACGAGTTGTTTACGCTGGTTTGACGGCATATGAATATCC } \\
\text { TCCTTAGTTCCTATTCC }\end{array}$ & $\begin{array}{l}\text { rev-Primer zur } \\
\text { Generierung der } \\
\text { Kassette zur } \\
\text { markerlosen Deletion } \\
\text { von } r p o N\end{array}$ \\
\hline BG409 & CGCGTTGGCCGATTCATTAATGC & $\begin{array}{l}\text { Sequenzierung } \\
\text { pKES170 (fwd) }\end{array}$ \\
\hline BG410 & Ccatcggcgctacggcgtttc & $\begin{array}{l}\text { Sequenzierung } \\
\text { pKES170 (rev) }\end{array}$ \\
\hline BG425 & CGAGTCACCAGAAATATTCGAAC & $\begin{array}{l}\text { fwd-yhbJ } \\
\text { (Sondenherstellung für } \\
\text { Northern Blot Analyse) }\end{array}$ \\
\hline BG426 & $\begin{array}{l}\text { CTAATACGACTCACTATAGGGAGAGGTTGTTGGTTTCCA } \\
\text { GCATAGG }\end{array}$ & $\begin{array}{l}\text { rev-yhbJ mit T7- } \\
\text { Promotor } \\
\text { (Sondenherstellung für } \\
\text { Northern Blot Analyse) }\end{array}$ \\
\hline
\end{tabular}


Anhang

\begin{tabular}{|c|c|c|}
\hline BG427 & CAAAGACCATGGTCAGTTCGCGTTCACGTTTAC & $\begin{array}{l}\text { rev-yhbJ Position } 493 \\
\text { NcoI }\end{array}$ \\
\hline BG428 & $\begin{array}{l}\text { GAACTGACCATGGTCTTTGAGTCTTTCCTCTTCAAACACG } \\
\text { GTATCC }\end{array}$ & $\begin{array}{l}\text { fwd-yhbJ Position } 475 \\
\text { G168L NcoI }\end{array}$ \\
\hline BG429 & CCTGGTGAAAGAGCAGAAAATGC & fwd-check $l p t B$ \\
\hline BG430 & GCCAGTTGTTGGCTAAGCC & rev-check lptB \\
\hline BG431 & GAACAAGGTATCATGGTGGC & fwd-check $h p f$ \\
\hline BG432 & CCACTCAAACAGTGGAACAG & rev-check $h p f$ \\
\hline BG444 & $\frac{\text { CTAATACGACTCACTATAGGGAGA }}{\text { GTAGATGCTCATTCCATCTCTTATG }}$ & $\begin{array}{l}\text { fwd- } g \operatorname{lm} Z \text { mit T7- } \\
\text { Pomotor (in vitro } \\
\text { Transkription }\end{array}$ \\
\hline BG445 & AAAAAAACGCCTGCTCTTATTACGGAGC & $\begin{array}{l}\text { rev-glmZ unprozessiert } \\
\text { für in vitro } \\
\text { Transkription }\end{array}$ \\
\hline BG446 & $\begin{array}{l}\text { CTAATACGACTCACTATAGGGAGAAGTGGCTCATTC } \\
\text { ACCGACTTATGTC }\end{array}$ & $\begin{array}{l}\text { fwd- } g \operatorname{lm} Y \text { mit T7- } \\
\text { Pomotor (in vitro } \\
\text { Transkription }\end{array}$ \\
\hline BG447 & AACAAAGCCGGGAATTACCCGGC & $\begin{array}{l}\text { rev- } g \operatorname{lm} Y \text { unprozessiert } \\
\text { für in vitro } \\
\text { Transkription }\end{array}$ \\
\hline BG448 & AAGGCGGTGCCTAACTCGACG & $\begin{array}{l}\text { rev-glmY prozessiert } \\
\text { für in vitro } \\
\text { Transkription }\end{array}$ \\
\hline BG449 & $\begin{array}{l}\text { CTAATACGACTCACTATAGGGAGAATTGTGAGCGG } \\
\text { ATAACAATTTCAC }\end{array}$ & $\begin{array}{l}\text { fwd-lacZ mit T7- } \\
\text { Pomotor (in vitro } \\
\text { Transkription }\end{array}$ \\
\hline BG450 & CGCCATTCAGGCTGCGCAACTGTTG & $\begin{array}{l}\text { rev-lac } Z \text { (in vitro } \\
\text { Transkription) }\end{array}$ \\
\hline BG458 & GCCAAACGGTGCCGGTAAGA & $\begin{array}{l}\text { fwd-lptB } \\
\text { (Sondenherstellung für } \\
\text { Northern Blot Analyse) }\end{array}$ \\
\hline BG459 & $\begin{array}{l}\text { CTAATACGACTCACTATAGGGAGAGATCAAATGCC } \\
\text { CCTGACTGAC }\end{array}$ & $\begin{array}{l}\text { rev-lptB mit T7- } \\
\text { Promotor (Sonden- } \\
\text { herstellung für } \\
\text { Northern Blot Analyse) }\end{array}$ \\
\hline BG460 & AGGATTACCTGATGTGGCAGG & $\begin{array}{l}\text { fwd-rpoN (Sonden- } \\
\text { herstellung für } \\
\text { Northern Blot Analyse) }\end{array}$ \\
\hline BG461 & $\begin{array}{l}\text { CTAATACGACTCACTATAGGGAGATACCGTCCAGTG } \\
\text { ACCGTTATGC }\end{array}$ & $\begin{array}{l}\text { rev-rpoN mit T7- } \\
\text { Promotor (Sonden- } \\
\text { herstellung für } \\
\text { Northern Blot Analyse) }\end{array}$ \\
\hline BG471 & CAACAAGTGGGTGCTTCACTC & $\begin{array}{l}\text { rev- } g \operatorname{lm} Z \text { prozessiert } \\
\text { für in vitro } \\
\text { Transkription }\end{array}$ \\
\hline BG472 & CCGAGGGGAAGTTCAGATAC & $\begin{array}{l}\text { rev-glmZ unprozessiert } \\
\text { für in vitro } \\
\text { Transkription }\end{array}$ \\
\hline BG473 & ATCATGCTAGCATGGTACTGATGATCGTCAGC & fwd-yhbJ NheI \\
\hline BG474 & $\begin{array}{l}\text { GGCTCTAGATTATCATGGTTTACGTTTTTCCAGCGT } \\
\text { ACGATGGCGTGACTGGACGTTTGCACCGCGCGAG }\end{array}$ & rev-yhbJ K270A XbaI \\
\hline BG475 & $\begin{array}{l}\text { GGCTCTAGATTATCATGGTTTACGTTTTTCCAGCGT } \\
\text { ACGAGCGCGTGACTGG }\end{array}$ & rev-yhbJ H276A XbaI \\
\hline BG476 & GCTTAGCAGTGTTCTTAACAGG & $\begin{array}{l}\text { fwd-ptsN } \\
\text { (Sondenherstellung für } \\
\text { Northern Blot Analyse) }\end{array}$ \\
\hline BG477 & $\begin{array}{l}\text { CTAATACGACTCACTATAGGGAGACCGTAATGATTT } \\
\text { GATACAGCTC }\end{array}$ & $\begin{array}{l}\text { rev-pts } N \text { mit T7- } \\
\text { Promotor } \\
\text { (Sondenherstellung für } \\
\text { Northern Blot Analyse) }\end{array}$ \\
\hline
\end{tabular}


Anhang

\begin{tabular}{|l|l|l|}
\hline BG527 & $\begin{array}{l}\text { CTAATACGACTCACTATAGGGAGAAAGTCAGCGAA } \\
\text { GGAAATG }\end{array}$ & $\begin{array}{l}\text { fwd-sraC mit T7- } \\
\text { Pomotor (in vitro } \\
\text { Transkription }\end{array}$ \\
\hline BG528 & ATCACCAGAACGGGCGG & $\begin{array}{l}\text { rev-sraC (in vitro } \\
\text { Transkription) }\end{array}$ \\
\hline BG529 & CTAATACGACTCACTATAGGGAGGCAAAGGGGAGT & $\begin{array}{l}\text { fwd-sraF mit T7- } \\
\text { Pomotor (in vitro } \\
\text { Transkription }\end{array}$ \\
\hline BACTTC 530 & AAAAAACGGCCAACGTCG & $\begin{array}{l}\text { rev-sraF (in vitro } \\
\text { Transkription) }\end{array}$ \\
\hline
\end{tabular}

Schnittstellen der genannten Enzyme sind fett gedruckt, Sdequnzen komplementär zur pKD3Rsistzenzkassette in rot. T7-Promotorsequenzen sind unterstrichen. Alle Sequenzen sind 5' $-3^{\prime}$ geschrieben.

\subsection{Zusätzlich verwendete Materialien}

\subsubsection{Chemikalien}

Neben den an den an den entsprechenden Stellen genannten Substanzen wurden folgende weitere Chemikalien benutzt:

$\begin{array}{ll}\text { Acrylamid } & \text { Fa. Roth, Karlsruhe } \\ \text { Agar } & \text { Fa. Roth, Karlsruhe } \\ \text { Agarose } & \text { Fa. Peqlab, Erlangen } \\ \text { Antibiotika } & \text { Fa. Sigma, München } \\ \text { Blocking-Reagenz } & \text { Fa. Roche, Mannheim } \\ \text { Bromphenolblau } & \text { Fa. Serva, Heidelberg } \\ \text { CDP* } & \text { Fa. Roche, Mannheim } \\ \text { dNTPs } & \text { Fa. Fermentas, St. Leon-Rot } \\ \text { Ethidiumbromid } & \text { Fa. Merck, Darmstadt } \\ \text { Imidazol } & \text { Fa. Serva, Heidelberg } \\ \text { IPTG } & \text { Fa. Peqlab, Erlangen } \\ \text { Magermilchpulver } & \text { Fa. BD, Sparks, USA } \\ \text { Ni2+-Agarose Superflow } & \text { Fa. Quiagen, Hilden } \\ \text { ONPG } & \text { Fa. Sigma, München } \\ \text { TEMED } & \text { Fa. Merck, Darmstadt } \\ \text { Tween 20 } & \text { Fa. Sigma, München }\end{array}$

Alle sonstigen allgemeinen Chemikalien wurden von Merck, Serva, Fluka, Sigma oder Roth in p.a. Qualität bezogen. 
7.4.2. Antikörper, Enzyme und Oligonukleotide

Zusätzlich zu den bereits genannten wurden folgende Enzyme verwendet:

Lysozym aus Hühnereiweiß

Polyklonaler Antikörper gegen E. coli

GlmS

Polyklonaler Antikörper gegen E. coli

YhbJ

Oligonukleotide

Restriktionsendonukleasen

\subsubsection{Hilfsmittel}

Folgende Hilfsmittel fanden Verwendung :

Dialyseschläuche

Einmalspritzen $(5 \mathrm{ml}, 10 \mathrm{ml})$

Gene Amp Reaction Tubes (PCR)

Glaspipetten

Halbmikroküvetten aus Kunststoff

Kunststoffpetrischalen

Küvetten aus Kunststoff

Mikroliterpipetten

$(2 \mu 1,20 \mu 1,200 \mu 1,1000 \mu 1)$

Pipettenspitzen

Polyethylenröhrchen

Poly-Prep Chromatography Columns

Polyvinylidendifluorid (PVDF)-

Membran

Reaktionsgefäße (1,5 ml; $2 \mathrm{ml})$

Zentrifugenbecher
Fa. Merck, Darmstadt

erhalten von Bernard Badet

Fa. SeqLab, Göttingen

Fa. Operon, Köln

Fa. Fermentas, St. Leon-Rot
Fa. Roth, Karlsruhe

Fa. Terumo Medical Corporation,

Somerset, USA

Fa. Perkin Elmer, Weiterstadt

Fa. B.Brand, Wertheim

Fa. Sarstedt, Nümbrecht

Fa. Greiner, Nürtingen

Fa. Greiner, Nürtingen

Fa. Gilson, Düsseldorf

Fa. Eppendorf, Hamburg

Fa. Greiner, Nürtingen

Fa. Eppendorf, Hamburg

Fa. Sarstedt, Nümbrecht

Fa. Greiner, Nürtingen

Fa. Bio-Rad, München

Fa. Bio-Rad, München

Fa. Greiner, Nürtingen

Fa. Beckmann, München 


\subsubsection{Geräte}

Für diese Arbeit wurden folgende allgemeine Geräte genutzt:

\author{
Biofuge 15 \\ Biofuge fresco \\ Biofuge primo $\mathrm{R}$ \\ Blotting-Apparatur VacuGene XI \\ Dampfsterilisator LTA32/25 \\ Feinwaage Sartorius CP64 \\ French Press \\ Horizontalschüttler 3006 \\ Kulturschüttler Innova 2300 \\ Kulturschüttler Lab-Shaker Modell \\ „Kühne“" \\ Kulturschüttler RO 106 \\ Magnetrührer REO basic C \\ pH-Meter 766 Calimatic \\ PowerPack Basic \\ Sterilbank HeraSafe \\ Sorvall RC5B plus
}

Spektralphotometer UltraSpec 2000

TE70 Semiphor Semi-Dry Transfer

Unit

Thermoblock 1.0

Ultrazentrifuge Sorvall Ultra pro 80

Waage Sartorius CP22025

Wasserbad Typ 3047

Wasservollentsalzungsanlage
Fa. Heraeus Christ, Osterode

Fa. Heraeus Christ, Osterode

Fa. Heraeus Christ, Osterode

Fa. Amersham, Freiburg

Fa. Zirbus, Bad Grund

Fa. Sartorius, Göttingen

Spectonic Unicam, England

GFL, Burgwedel

Fa. New Brunswick, Neu-Isenburg

Fa. B. Braun, Melsungen

Fa. Infors, Basel, Schweiz

Fa. JAK Werk, Staufen

Fa. Knick, Berlin

Fa. Bio-Rad, München

Fa. Heraeus Christ, Osterode

Fa. Kendro Laboratory Products,

Langenselbold

Fa. Amersham, Freiburg

Fa. Amersham, Freiburg

Fa. Waasetec, Göttingen

Fa. Beckman, München

Fa. Sartorius, Göttingen

Fa. Küttermann Labortechnik, Uetze-

Hänigsen

Fa. Millipore, Schwalbach 


\subsubsection{Computerprogramme}

Zusätzlich zu den bisher genannten Computerprogramme wurde zum Erstellen dieser Arbeit das Office XP-Paket (Fa. Microsoft, Redmond, USA) sowie für die Literaturrecherche und -verwaltung EndNote X.2 (Fa. Thomson ISI ResearchSoft, Philadelphia, USA)

\subsection{Rohdaten der $\beta$-Galaktosidase-Messungen}

Mittelwerte und Abweichungen beruhen auf mindestens 3 unabhängigen Messungen

Abb. 4.3.

$\begin{array}{lrr}\text { Stamm } & \text { Mittelwert } & \text { Abweichung } \\ \text { Wildtyp } & 4,7 & 1,3 \\ \Delta[\text { ptsN-npr } & 139,2 & 14,7 \\ \Delta \text { yhbJ } & 105,6 & 9,1 \\ -88 & 4,61 & 0,8 \\ -59 & 4,5 & 0,7 \\ -1 & 14,5 & 3,5 \\ 6 & 4,5 & 0,7 \\ 10 & 6,33 & 1,5 \\ 12 & 3,5 & 0,7 \\ 16 & 4,5 & 0,7 \\ 30 & 8,5 & 2,1 \\ 74 & 5 & 0 \\ 83 & 7 & 1,4 \\ 84 & 5,3 & 0,57\end{array}$

Abb. 4.5.:

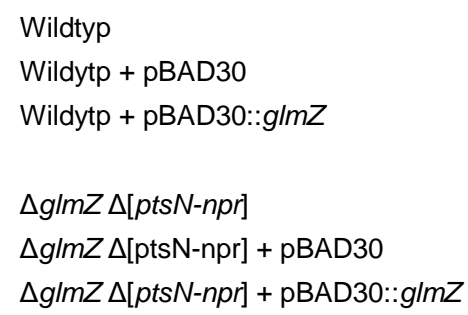

Abb. 4.6.:

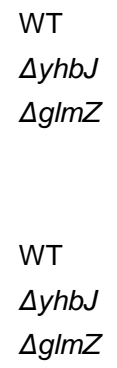

WT
$\Delta y h b J$
$\Delta g I m Z$

$\begin{array}{rrr}\text { Mittelwert } & & \\ \text { Leervektor } & \text { glmZ'-lacZ } & \text { PlacUv-lacZ } \\ 300,02 & 7426,65 & 21055,35 \\ 145,75 & 8658,05 & 21117,35 \\ 107 & 8217 & 21374,5 \\ \text { Abweichung } & & \\ \text { Leervektor } & \text { glmZ'-lacZ } & \text { P lacUv-lacZ } \\ 1,767 & 577,21 & 300,72 \\ 12,09 & 854,25 & 1167,92 \\ 11,73 & 375,76 & 1149,04\end{array}$


Abb. 4.9.A

\begin{tabular}{|c|c|c|c|c|c|c|}
\hline Stamm & $\begin{array}{l}\text { Mittel- } \\
\text { wert }\end{array}$ & Abweichung & $\begin{array}{c}+g l n \\
\text { Mittel- } \\
\text { wert }\end{array}$ & $\begin{array}{l}\text { Z auf Plasmid } \\
\text { Abweichung }\end{array}$ & $\begin{array}{l}\text { Mittel- } \\
\text { wert }\end{array}$ & $\begin{array}{l}+1 \% \text { GlcNAc } \\
\text { Abweichung }\end{array}$ \\
\hline Wildtyp & 8 & 3,5 & 9 & 0,7 & 4 & 0,7 \\
\hline$\Delta[p t s N-n p r]$ & 154 & 1,4 & 146 & 13,4 & 123 & 12,7 \\
\hline$g / m S(-7):: m \operatorname{m} 10$ & 30 & 0 & 6 & 0,7 & 6 & 0 \\
\hline$g \operatorname{lmS}(+5):: m \operatorname{m} 10$ & 60 & 10,6 & 10 & 1,4 & 7 & 1,4 \\
\hline$g \operatorname{lmS}(-63):: m \operatorname{m} 10$ & 62 & 5,7 & 13 & 2,8 & 20 & 4,9 \\
\hline
\end{tabular}

Abb. 4.10.

[h]

\section{Mittelwert}

0
1
2
3
4
5
6

$\mathrm{t}[\mathrm{h}]$

0
1
2
3
4
5
6

Abweichung

$\Delta g / m S$

2

53,3

25,2

58,7

98,7

68,8

944

$\mathrm{OD}_{600}$

$\mathrm{t}[\mathrm{h}]$

$\Delta g I m S$

0,39

0,99

2,9

3,26

1,67

0,73

0,73

6
$\Delta g l m S+1 \%$ GlcNAc

71

52,4

46

104,5

90,9

85,2

78,2

$\Delta g / m S+1 \%$ GlcNAc

4,1

3,4

2,2

1,6

4,6

6,2

3,3

$\Delta g l m S+1 \%$ GlcNAc

0,41
1,11
3,57
4,77
6,68
7,79
8,08

0,41

1,11

3,57

4,77

6,68

8,08

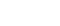

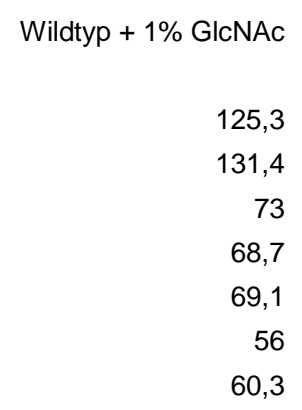

66,3

$\begin{array}{rr}\text { Wildtyp } & \text { Wildtyp }+1 \% \text { GlcNAc } \\ 4,8 & 3,7 \\ 3,9 & 3 \\ 2,5 & 4,1 \\ 2 & 3,4 \\ 2,1 & 2,7 \\ 5,6 & 3,3 \\ 4,9 & 4,3\end{array}$

Wildtyp Wildtyp $+1 \%$ GlcNAc

$\begin{array}{ll}0,50 & 0,45 \\ 1,58 & 1,41 \\ 3,27 & 2,63 \\ 5,78 & 5,22 \\ 7,07 & 7,64 \\ 7,25 & 7,43 \\ 7,08 & 7,16\end{array}$


Abb.4.12.

Fosfomycin

Konzentration

[mg/ml]

Zeit [h]

$\begin{array}{rrrrrrrrr} & 0 & 1 & 2 & 5 & 10 & 25 & 50 & 100 \\ 0 & 0,34 & 0,34 & 0,34 & 0,34 & 0,34 & 0,34 & 0,34 & 0,34 \\ 1 & 0,74 & 0,75 & 0,71 & 0,55 & 0,28 & 0,09 & 0,10 & 0,09 \\ 2 & 1,8 z & 2,10 & 1,69 & 1,31 & 0,08 & 0,07 & 0,07 & 0,06 \\ 3 & 2,28 & 2,54 & 1,69 & 0,15 & 0,06 & 0,08 & 0,06 & 0,05 \\ 4 & 2,92 & 3,56 & 2,54 & 0,07 & 0,06 & 0,08 & 0,05 & 0,04 \\ 5 & 3,72 & 3,53 & 2,85 & 0,07 & 0,05 & 0,07 & 0,05 & 0,04 \\ 6 & 3,88 & 4,25 & 3,11 & 0,07 & 0,05 & 0,07 & 0,05 & 0,04 \\ 7 & 4,12 & 4,48 & 3,76 & 0,08 & 0,06 & 0,04 & 0,04 & 0,04 \\ 8 & 4,24 & 4,32 & 3,87 & 0,09 & 0,06 & 0,05 & 0,04 & 0,04\end{array}$

Ampicillin

Konzentration

[mg/ml]

Zeit [h]

$\begin{array}{rrrrrrrrr} & 0 & 1 & 2 & 5 & 10 & 25 & 50 & 100 \\ 0 & 0,36 & 0,36 & 0,36 & 0,36 & 0,36 & 0,36 & 0,36 & 0,36 \\ 1 & 0,75 & 0,68 & 0,76 & 0,71 & 0,487 & 0,40 & 0,11 & 0,10 \\ 2 & 1,72 & 1,91 & 1,58 & 1,37 & 0,28 & 0,08 & 0,07 & 0,07 \\ 3 & 2,59 & 2,07 & 1,89 & 1,20 & 0,13 & 0,06 & 0,06 & 0,05 \\ 4 & 2,88 & 2,11 & 2,09 & 1,32 & 0,09 & 0,06 & 0,05 & 0,05 \\ 5 & 4,56 & 1,93 & 2,74 & 1,28 & 0,09 & 0,06 & 0,05 & 0,04 \\ 6 & 4,13 & 2,90 & 3,01 & 1,27 & 0,09 & 0,06 & 0,05 & 0,04 \\ 7 & 4,68 & 2,79 & 3,08 & 1,26 & 0,10 & 0,06 & 0,05 & 0,04 \\ 8 & 4,42 & 3,22 & 3,16 & 1,34 & 0,11 & 0,07 & 0,05 & 0,04\end{array}$

$\mathrm{N}$-Ethylmaleimid

Konzentration

[mg/ml]

Zeit [h]

$\begin{array}{rrrrrrrr}0 & \text { DMSO } & 0,1 & 1 & 5 & 10 & 50 & 100 \\ 0,31 & 0,31 & 0,31 & 0,31 & 0,31 & 0,31 & 0,31 & 0,31 \\ 0,73 & 0,63 & 0,73 & 0,71 & 0,38 & 0,32 & 0,29 & 0,28 \\ 2,31 & 1,81 & 2,04 & 2,11 & 0,58 & 0,34 & 0,27 & 0,26 \\ 2,70 & 3,12 & 3,46 & 2,77 & 0,96 & 0,48 & 0,25 & 0,25 \\ 3,16 & 2,86 & 3,27 & 3,08 & 2,82 & 0,73 & 0,24 & 0,25 \\ 5,46 & 3,64 & 4,51 & 3,75 & 3,00 & 1,27 & 0,24 & 0,24 \\ 4,62 & 3,74 & 4,62 & 4,34 & 4,09 & 3,24 & 0,23 & 0,23 \\ 5,25 & 3,99 & 5,49 & 4,60 & 4,32 & 4,24 & 0,22 & 0,23 \\ 4,82 & 4,13 & 5,44 & 4,80 & 4,39 & 3,59 & 0,21 & 0,21\end{array}$

Nva-FMDP

Konzentration

$[\mu \mathrm{g} / \mathrm{ml}]$

Zeit [h]

$\begin{array}{rrrrrrrrr} & 0 & 1 & 5 & 10 & 20 & 50 & 100 & 300 \\ 0 & 0,31 & 0,31 & 0,31 & 0,31 & 0,31 & 0,31 & 0,31 & 0,31 \\ 1 & 0,78 & 0,78 & 0,77 & 0,78 & 0,77 & 0,78 & 0,77 & 0,71 \\ 2 & 2,22 & 2,70 & 2,45 & 2,23 & 2,20 & 2,16 & 1,95 & 1,90 \\ 3 & 2,33 & 2,20 & 2,70 & 2,78 & 2,89 & 2,82 & 2,75 & 2,55 \\ 4 & 3,24 & 3,45 & 3,39 & 3,38 & 3,29 & 3,42 & 3,33 & 2,99 \\ 5 & 4,61 & 3,23 & 4,25 & 4,22 & 4,16 & 4,23 & 4,01 & 3,95 \\ 6 & 4,65 & 3,88 & 4,24 & 4,31 & 5,17 & 4,56 & 4,79 & 4,50 \\ 7 & 4,45 & 3,58 & 4,45 & 4,40 & 4,58 & 4,66 & 4,67 & 4,28 \\ 8 & 4,77 & 4,31 & 4,80 & 4,752 & 4,87 & 5,35 & 4,63 & 4,52\end{array}$


Abb. 4.13.

Messwert

$\begin{array}{r}\text { Konzentration } \\ {[\mathrm{mg} / \mathrm{ml}]}\end{array}$
Zeit [h]

$\begin{array}{rrrrrrrr} & \text { w/o } & \text { DMSO } & \text { EtOH } & \text { Amp 2 } & \text { Amp 50 } & \text { Fos 2 } & \text { Fos 50 } \\ 0 & 216,3 & & & & & & \\ 1 & 370,6 & 399,6 & 407,7 & 409,3 & 385,7 & 422,9 & 340,9 \\ 3 & 236,8 & 172,5 & 158,4 & 192,7 & 335,4 & 185,3 & 352,9 \\ 5 & 172,5 & 159,4 & 142,5 & 131,8 & 426,1 & 147,8 & 529,3\end{array}$

\begin{tabular}{rrrrr}
\multicolumn{5}{c}{$\begin{array}{r}\text { Konzentration } \\
{[\mathrm{mg} / \mathrm{ml}]}\end{array}$} \\
Zeit [h] & NVA-FMDP 3,3 & NVA-FMDP 100 & NEM & \\
1 & 584,2 & 10 & NEM 50 \\
3 & 359,9 & 2220,5 & 139,4 & 165,5 \\
5 & 175 & 1389,6 & 240,5 & 111,1 \\
& & & &
\end{tabular}

$\mathrm{OD}_{600}$
Konzentration
$[\mathrm{mg} / \mathrm{ml}]$

Zeit [h]

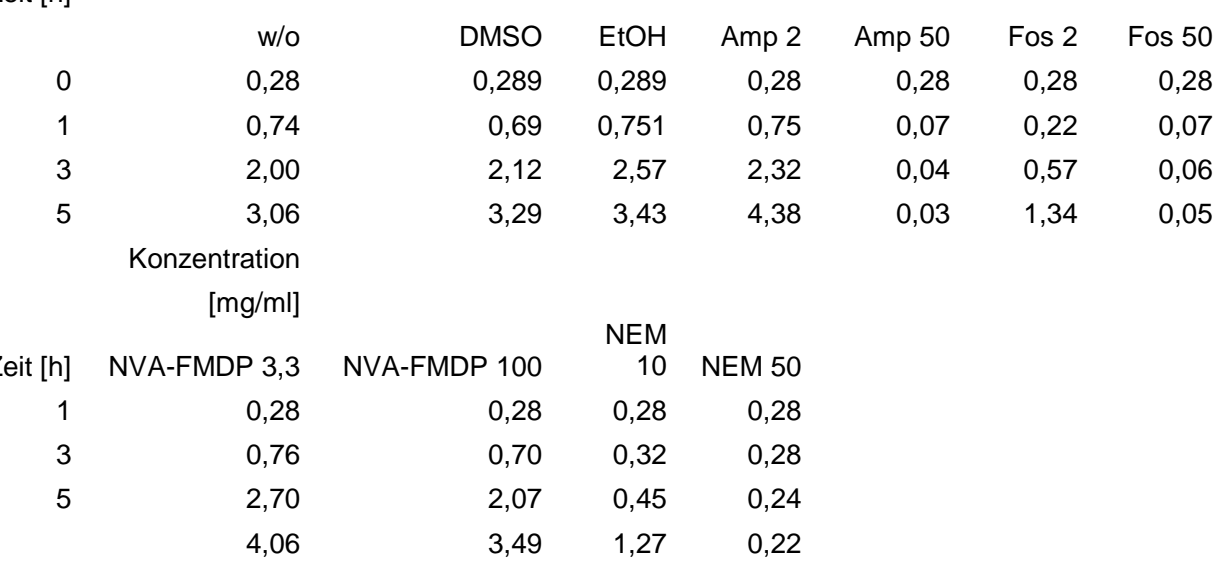

Abb.4.14.

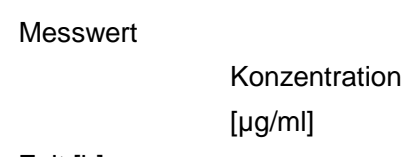

Zeit [h]

$\begin{array}{rrrrrrrrr} & 0 & 1 & 5 & 10 & 20 & 50 & 100 & 300 \\ 0 & 251,4 & & & & & & & \\ 1 & 300,7 & 312 & 354,1 & 401,1 & 511,1 & 740,1 & 1077,5 & 1538 \\ 2 & 203 & 136,4 & 182,3 & 227,4 & 392,4 & 683,7 & 1180,8 & 1516,5 \\ 3 & 270 & 306,4 & 257,7 & 335,6 & 396 & 669,9 & 943,8 & 1841,4 \\ 4 & 221,5 & 185,4 & 198,6 & 242 & 304,7 & 547,8 & 779,1 & 1694\end{array}$




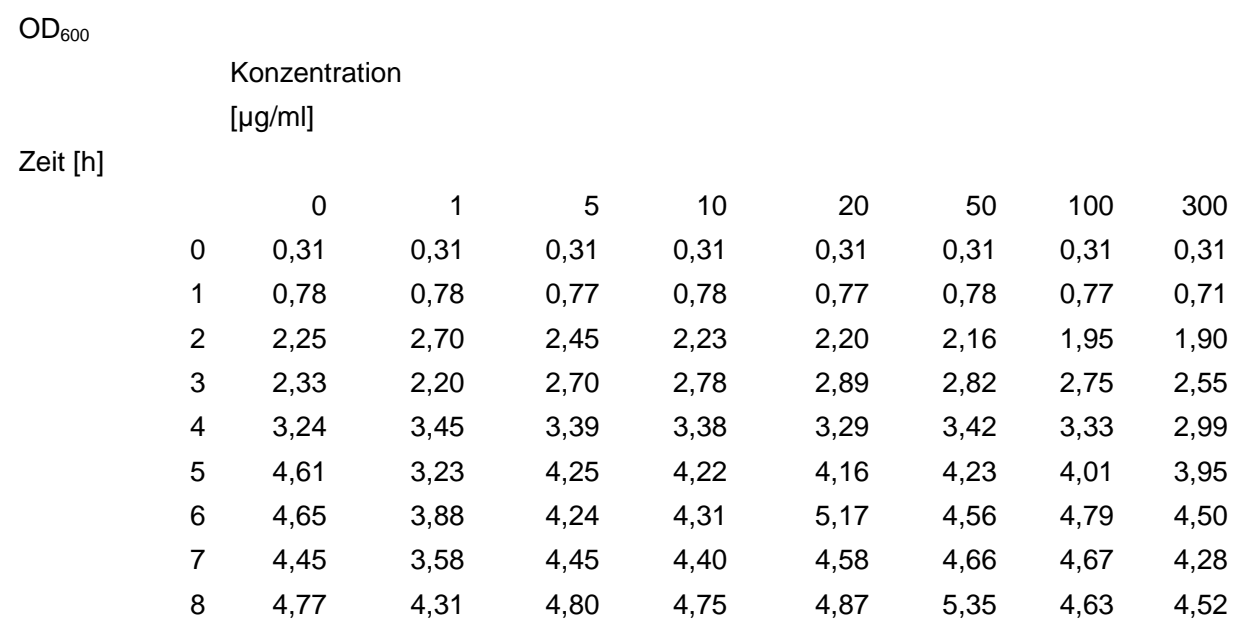

Abb. 4.15.

\begin{tabular}{|c|c|c|c|c|}
\hline $\mathrm{t}[\mathrm{h}]$ & 0 & 1 & 3 & 5 \\
\hline \multicolumn{5}{|l|}{ Stamm } \\
\hline Wildtyp & 216,3 & 370,6 & 236,8 & 172,5 \\
\hline Wildtyp + FMDP 100 & & 1210 & 2220,5 & 1389,6 \\
\hline Wildtyp + FMDP100 + 1\% GlcNAc & & 183 & 161,9 & 130,5 \\
\hline
\end{tabular}

Abb 4.17.

Messwert

Stamm
$\Delta g / m Z$
$\Delta g I m Z+$ Nva-FMDP 100
$\Delta g / m Z+$ Nva-FMDP $100+1 \%$ GlcNAc
$\Delta g I m Z+$ NEM 10

$\mathrm{t}[\mathrm{h}]$

$\begin{array}{rrrr}0 & 1 & 3 & 5 \\ 263,7 & 343,5 & 221,5 & 179,8 \\ & 386,7 & 241 & 216 \\ & 165 & 122,9 & 124,7 \\ 108,3 & 361,8 & 213,7\end{array}$

$\mathrm{OD}_{600}$

Stamm

$\mathrm{t}[\mathrm{h}]$

$\Delta g I m Z$

$\begin{array}{rrrrrr}0 & 1 & 2 & 3 & 4 & 5 \\ 0,522 & 1 & 2,87 & 4,59 & 5,41 & 6,1 \\ 0,522 & 1 & 1,56 & 2,04 & 2,34 & 2,63 \\ 0,522 & 1 & 4,22 & 6,26 & 6,5 & 6,78\end{array}$

$\Delta g / m Z+$ Nva-FMDP100 + $1 \%$ GlcNAc

Abb. 4.24.

Stamm

Wildtyp

$\triangle y h b J$

$\triangle y h b J$ pBAD 33

$\triangle y h b J$ pBAD 33::yhbJ WT

$\triangle y h b J$ pBAD 33::yhbJ G8A

$\triangle y h b J$ pBAD 33::yhbJ G13A

$\triangle y h b J$ pBAD 33::yhbJ F167A

$\triangle y h b J$ pBAD 33::yhbJ G168L

$\triangle y h b J$ pBAD 33::yhbJ N188A

$\triangle y h b J$ pBAD 33::yhbJ P189A

$\triangle y h b J$ pBAD 33::yhbJ G199L

$\triangle y h b J$ pBAD 33::yhbJ $\triangle$ AA164 - 212

$\triangle y h b J$ pBAD 33::yhbJ $\triangle$ AA256 - 284

$\triangle y h b J$ pBAD 33::yhbJ G8A $\triangle \mathrm{AA} 256-284$

\begin{tabular}{|c|c|c|c|}
\hline $\begin{array}{l}\text { Mittelwert } \\
\text { ohne } \\
\text { Arabinose }\end{array}$ & $\begin{array}{l}\text { mit } \\
\text { Arabinose }\end{array}$ & $\begin{array}{l}\text { Abweichung } \\
\text { ohne Arabinose }\end{array}$ & mit Arabinose \\
\hline 7,54 & 8,01 & 1,27 & 1,41 \\
\hline 71,45 & 69,11 & 5,39 & 3,95 \\
\hline 67,10 & 67,28 & 4,52 & 1,20 \\
\hline 29,00 & 7,88 & 4,61 & 3,31 \\
\hline 55,25 & 23,33 & 0,63 & 2,25 \\
\hline 30,05 & 9,18 & 2,33 & 3,21 \\
\hline 74,81 & 74,04 & 0,42 & 1,17 \\
\hline 72,73 & 74,87 & 4,66 & 1,65 \\
\hline 64,65 & 65,25 & 1,34 & 2,04 \\
\hline 62,75 & 65,51 & 4,31 & 7,78 \\
\hline 61,64 & 66,56 & 6,92 & 7,88 \\
\hline 73,12 & 76,07 & 8,90 & 7,28 \\
\hline 70,96 & 70,17 & 4,36 & 1,61 \\
\hline 71,32 & 74,21 & 1,73 & 2,66 \\
\hline
\end{tabular}


Anhang

Abb. 4.25.

Wildtyp

$\triangle y h b J$

$\triangle y h b J$ pKES170

$\triangle y h b J$ pKES170::yhbJ

$\mathrm{His}(10)$

$\Delta y h b J$ pKES170::His(10)-

yhbJ

\begin{tabular}{rrrr} 
Mittelwert & \multicolumn{3}{r}{ Abweichung } \\
ohne IPTG & mit IPG & ohne IPTG & mit IPTG \\
4,65 & 5,27 & 1,33 & 1,08 \\
105,62 & 108,97 & 8,31 & 0 \\
97,65 & 88,50 & 4,10 & 7,35 \\
3,55 & 3,65 & 1,62 & 1,90 \\
3,25 & 3,35 & 0,63 & 0,63
\end{tabular}

Abb. 4.30.

\begin{tabular}{|c|c|c|}
\hline Stamm & Mittelwert & Abweichung \\
\hline Wildtyp $+[$ IptA-rpoN']-lacZ & 1805 & 192 \\
\hline Wildtyp $+\left[/ p t B-r p o N^{\prime}\right]-l a c Z$ & 1538 & 54 \\
\hline Wildtyp $+[r p o N-y h b J ']-l a c Z$ & 607 & 87 \\
\hline$\Delta y h b J+\left[/ p t A-r p o N^{\prime}\right]-l a c Z$ & 2079 & 48 \\
\hline$\Delta y h b J+\left[/ p t B-r p o N^{\prime}\right]-l a c Z$ & 1858 & 89 \\
\hline$\Delta y h b J+[r p o N-y h b J ']-l a c Z$ & 840 & 128 \\
\hline$\Delta p t s N+\left[/ p t A-r p o N^{\prime}\right]-l a c Z$ & 1580 & 652 \\
\hline$\Delta p t s N+\left[/ p t B-r p o N^{\prime}\right]-l a c Z$ & 1866 & 90 \\
\hline$\Delta p t s N+[r p o N-y h b J ']-l a c Z$ & 749 & 77 \\
\hline$\Delta r p o N+\left[/ p t A-r p o N^{\prime}\right]-l a c Z$ & 1359 & 62 \\
\hline$\Delta r p o N+\left[/ p t B-r p o N^{\prime}\right]-l a c Z$ & 1367 & 117 \\
\hline$\Delta r p o N+[r p o N-y h b J ']-l a c Z$ & 645 & 7 \\
\hline
\end{tabular}

Abb. 4.31.

\begin{tabular}{|c|c|c|}
\hline \multicolumn{3}{|l|}{ Stamm } \\
\hline \multicolumn{3}{|l|}{ Wildtyp + [IptA-rpoN']-lacZ } \\
\hline \multicolumn{3}{|l|}{ Wildtyp $+[$ lptB-rpoN']-lacZ } \\
\hline \multicolumn{3}{|l|}{ Wildtyp $+[r p o N-y h b J ']-l a c Z$} \\
\hline \multicolumn{3}{|l|}{$\Delta y h b J+\left[/ p t A-r p o N^{\prime}\right]-l a c Z$} \\
\hline \multicolumn{3}{|l|}{$\Delta y h b J+\left[/ p t B-r p o N^{\prime}\right]-l a c Z$} \\
\hline \multicolumn{3}{|l|}{$\Delta y h b J+[r p o N-y h b J ']-l a c Z$} \\
\hline \multicolumn{3}{|c|}{ Wildtyp + [IptA-rpoN']-lacZ + pBAD33::yhbJ } \\
\hline \multicolumn{3}{|c|}{ Wildtyp $+[$ lptB-rpoN']-lacZ + pBAD33::yhbJ } \\
\hline \multicolumn{3}{|c|}{ Wildtyp $+[r p o N-y h b J ']-l a c Z+p B A D 33:: y h b J$} \\
\hline \multicolumn{3}{|c|}{ Wildtyp $+[$ IptA-rpoN']-lacZ + pBAD33::yhbJ + Arabinose } \\
\hline \multicolumn{3}{|c|}{ Wildtyp $+[$ [lptB-rpoN']-lacZ + pBAD33::yhbJ + Arabinose } \\
\hline \multicolumn{3}{|c|}{ Wildtyp $+[r p o N-y h b J ']-l a c Z+p B A D 33:: y h b J+$ Arabinose } \\
\hline \multicolumn{3}{|l|}{ Abb.4.32. } \\
\hline Stamm & Mittelwert & Abwecihung \\
\hline Wildtyp $+[$ IptA-rpoN']-lacZ & 1805 & 192 \\
\hline Wildtyp $+[$ lptB-rpoN']-lacZ & 1538 & 54 \\
\hline Wildtyp $+[$ lptB-yhbJ']-lacZ & 607 & 87 \\
\hline$\Delta n a g C:: t c+\left[l p t A-r p o N^{\prime}\right]-l a c Z$ & 978 & 236 \\
\hline$\Delta$ nagC::tc $+[$ lptB-rpoN']-lacZ & 931 & 130 \\
\hline$\Delta n a g C:: t c+[l p t B-y h b J ']-l a c Z$ & 915 & 101 \\
\hline
\end{tabular}


Anhang

Abb. 4.33

$\begin{array}{lrr}\text { Stamm } & \text { Mittelwert } & \text { Abweichung } \\ \text { Wildtyp + [lptA-rpoN']-lacZ } & 1291 & 52 \\ \text { Wildtyp + [lptB-rpoN']-lacZ } & 1370 & 40 \\ \text { Wildtyp + [lptB-yhbJ']-lacZ } & 578 & 15 \\ & & \\ \text { Wildtyp + [lptA-rpoN']-lacZ + 1\% GlcNAc } & 1574 & 16 \\ \text { Wildtyp + [lptB-rpoN']-lacZ + 1\% GlcNAc } & 1331 & 1 \\ \text { Wildtyp + [lptB-yhbJ']-lacZ + 1\% GlcNAc } & 613 & 8\end{array}$

\subsection{Rohdaten zur Charakterisierung von YhbJ (siehe 4.3)}

\subsubsection{Verwendete Proteinsequenzen}

AciSP. = Acinetobacter sp.

ActSuc = Actinobacillus succinogenes

AerSal = Aeromonas salmonicida

AltBac $=$ Alteromonadales bacterium

AzoSp. = Azoarcus Sp.

BacCer = Bacillus cereus

BacCoa = Bacillus coagulans

BacLic = Bacillus licheniformis

BacThu = Bacillus thuringiensis

BifLon = Bifidobacterium longum

CarHyd = Carboxydothermus hydrogenoformans

CloBei $=$ Clostridium beijerincki

CloTet $=$ Clostridium tetani

ColPsy = Colwellia psychrerythraea

DesbHaf = Desulfitobacterium hafniense

EntSp. = Enterobacter sp.

EntcFaec = Enterococcus faecium

EscCol = Escherichia coli

FusNuc = Fusobacterium nucleatum

GeoThe = Geobacillus thermodenitrificans

HaeDuc = Haemophilus ducreyi

HaeSom = Haemophilus somnus

IdiBal = Idiomarina baltica

KlePne = Klebsiella pneumoniae

LacCas = Lactobacillus casei

LacGas = Lactobacillus gasseri

LacPla = Lactobacillus plantarum

LacSak = Lactobacillus sakei

LactLac $=$ Lactococcus lactis

LisInn = Listeria innocua

LisWel = Listeria welshimeri

MarAqu = Marinobacter aquaeolei

MycSme = Mycobacterium smegmatis

NitEur = Nitrosomas europea

Ocelhe = Oceanobacillus iheyensis

PedPen = Pediococcus pentosaceus

PhorLum = Photorhabdus luminescens

PseAtl = Pseudoalteromonas atlantica

PseTun = Pseudoalteromonas tunicata

SalTyp = Salmonella typhimurium

SheBal = Shewanella baltica

SheFri = Shewanella frigidimarina

SheOne $=$ Shewanella oneidensis

SheWoo = Shewanella woodyi

SodGlo = Sodalis glossinidius

StaEpi = Staphylococcus epidermidis

StaSap = Staphylococcus saprophyticus

StrMut = Streptococcus mutans

StrPyo = Streptococcus pyogenes

StrSui = Streptococcus suis

StpAve $=$ Streptomyces avermitilis

TheThe = Thermus thermophilus

TherTen = Thermoanaerobacter tengcongensis

VibAlg = Vibrio alginolyticus

VibCho = Vibrio cholerae

VibHar = Vibrio harveyi

VibSpl = Vibrio splendidus

YerBer $=$ Yersinia bercovieri
ActPle =Actinobacillus pleuropneumoniae AerHyd = Aeromonas hydrophila

AlkMet = Alkaliphilus metalliredigenes

AlteMac $=$ Alteromonas macleodii

BacAnt $=$ Bacillus anthracis

BacCla $=$ Bacillus clausii

BacHal $=$ Bacillus halodurans

BacSub $=$ Bacillus subtilis

BacWei = Bacillus weihenstephanensis

CalSac $=$ Caldicellulosiruptor saccharolyticus

CloAce $=$ Clostridium acetobutylicum

CloPer $=$ Clostridium perfringens

CloThe $=$ Clostridium thermocellum

CorEff = Corynebacterium effescens

DesRed $=$ Desulfotomaculum reducens

EntcFae $=$ Enterococcus faecalis

ErwCar = Erwinia carotovor

ExiSib = Exiguobacterium sibiricum

GeoKau = Geobacillus kaustophilus

GloVio = Gloeobacter violaceus

Haelnf = Haemophilus influenzae

HalOre = Halothermothrix orenii

IdiLoi = Idiomarina loihiensis

LacAci = Lactobacillus acidophilus

LacDel = Lactobacillus delbrueckii

LacJoh = Lactobacillus johnsonii

LacReu = Lactobacillus reuteri

LacSal = Lactobacillus salivarius

LeiXyl = Leifsonia $x y l i$

LisMon = Listeria monocygotes

ManSuc = Mannheimia succiniciproducens

MooThe $=$ Moorella thermoacetica

MycTub = Mycobacterium tyberculosis

NocFar = Nocardia farcinica

PasMul = Pasteurella multocida

PhoPro = Photobacterium pofundum

ProMir = Proteus mirabilis

PseHal $=$ Pseudoalteromonas haloplanktis

SalEnt = Salmonella enterica serovar

SerPro = Serratia proteamaculans

SheDef = Shewanella denitrificans

SheLoi = Shewanella loihica

ShePut = Shewanella putrefaciens

ShiFle = Shigella flexneri

StaAur = Staphylococcus aureus

StaHae = Staphylococcus haemolyticus

StrAlg = Streptococcus agalactiae

StrPne = Streptococcus pneumoniae

StrSan = Streptococcus sanguinis

StrThe = Streptococcus thermophilus

SymThe = Symbiobacterium thermophilum

TherEth = Thermoanaerobacter ethanolicus

ThesCar $=$ Thermosinus carboxydivorans

VibAng = Vibrio angustum

VibFis = Vibrio fischeri

VibPar = Vibrio parahaemolyticus

VibVul = Vibrio vulnificus

YerEnt $=$ Yersinia enterolitica 


\section{Anhang}

YerFre = Yersinia frederksenii

YerPes $=$ Yersinia pestis

ZymMob = Zymomonas mobilis

$>$ ACISP ACIAD3059

MKRILIVTGQSGSGKSSALQVLEDLGYYCIDNLPLALLPEIVAKLDHENNLEQLALGVDVRSTRADMQEFDLVFEQLQKHGTVDVIYLTTQDQELIARFSASRRPHPL MKRILIVTGQSGSGKSSALQVLEDLGYYCIDNLPLALLPEIVAKLDHENNLEQLALGVDVRSTRADMQEFDLVFEQLQKHGTVDVIYLTTQDQELIARFSASRRPHPL ASRFKSLNECIQEEKQLLLPIQFRSTVHIDTTDKSVHDLKHTLLSKLGQSDKLILILQSFGYKHGIPLDADYV
EMFDDIFHFLDKWLPVFAEGHRHYMTVSIGCTGGQHRSVYIVDRLKKALEAKWSIQVLHREMKHWS

$>$ ACTPLE ZP 00133926

MELIIISGRSGSGKSVALRALEDVGYYCVDNLPLPLIPELAGFLSNSGRSAVVSLDIRNIPENPESIEALLEQLSKLTIQTKIIFLDCERNTLIRRYSDTRRLHPLSNKDLS LESAIDLENTLLEPLYQQANYIIDTTNISSHELAENLRGILRGSTDKALKIVFESFGFKYGLPADADYVFDVRFLPNPHWNPELRPMTGLEQPVIDFLERQTEVHNFIYQ TRNYLEMWLPMLEKNNRSYLTIAIGCTGGKHRSVFIAEQLAKYFQSRDKDVQIRHRSLEKHHKK

>ACTSUC_ZP_00733020

MELIIISGRSGAGKSVALRALEDIGYYCVDNLPIDLLPQLADILSQSQASAAISLDIRNLPNSSQHLDEILTELENKHQIKIIFLDADRSTLIRRYSDSRRLHPLSVQNQDL SLEAAIDAEQIQLDPLIQHANLIIDTAVLSTHELAERLREFLRGNSDKELKIVVESFGFKYGLPLDADYVFDVRFLPNPHWNPSLRPMTGLEQPVIDFLSKYEDVANFIY TTRNYIETWLPMLERNNRSYLTIAIGCTGGKHRSVYIAQQLGEYFQDKGKHVKIQHKSLEKHKNR

$>$ AERHYD_AHA_3920

MQLIVVSGRSGSGKTVALRVLEDLGYYCVDNLPVNLLPQLIVSVESQYDKLAVSIDVRNLPASPDKLETLLAQVRNEGRVEFSSFFFDAENSTLLKRYGESRRLHPL SRNQLSLDEAIREETHLLAPLSSTADLRIDTTNLSIHDLSELIKTRVLGKKENELVLVFESFGFKYGIPKDADFVFDARFLPNPHWIPELKPFTGKDEPVARYLSSQPDV MQFILQIENMLATWLPHLERNNRSYVTVGIGCTGGQHRSVFIAEQLAGAFRLLGKNVQIRHRTLDKSAPQF

$>$ AERSAL ABO88502

MQLIVVSGRSGSGKTVALRVLEDLGYYCVDNLPVNLLPQLIVSVESQYDKLAVSIDVRNLPVSADKLETLLAQVRNEGRVEFSSFFFDAENSTLLKRYGESRRLHPL SRKQLSLDEAIREETNLLAPLSSTADLRIDTTSLSIHDLSELIKTRVLGKKENELVLVFESFGFKYGIPKDADFVFDARFLPNPHWIPELKPFTGKDEPVARYLSSQPDV MQFILQIENMLATWLPHLERNNRSYVTVGIGCTGGQHRSVFIAEQLAGAFRLLGKNVQIRHRTLDKSTPQH

$>$ ALKMET UPF0042

MKFVIITGLSGAGKSQTVKSMEDFGFYCVDNLPPALIPKFAELCHQSQGVISRAALVIDIRGGMFFDDLFESLKELEHLGHQYEILFLDADDEVLMKRFKETRRSHPL NVDGSIENGITRERELLQELKDRASHIIHTTKLIPAQLKEELRNIYVEGNQMNNLMISIASFGFKHGIPLDSDLVFDVRFLPNPFYIEELKDFTGNDVKVRNYVMNSPIS VEFSNKLHDIVSFLIPHYVQEGKNQLVISIGCTGGRHRSVTIAHVLYHQLKDKGHRVTLSHR DSGETRERKK ES

$>$ ALTBAC_ATW7_18740

MELIIISGRS GSGKKSVALRVVEDLGYYCVD NIPVNLLPSLVRSVSDNYDKIAVSIDVRNLPKEQDEFNHIIEYLPGFTKPTLFYLDSEDQTLIKRFSETR RLHPLSIDSL PLDLAIKKEKELLDVLITRADYMIDTSELSVHQLAESIREKILGKKDKQLIVTFESFGFKHGIPKEADYVFDARFLPNPHWEPELKPLNGLDQPVKDYLA SHSIVQKFTW QIQTFVQTWLPHLERNNRSYLTIAIGCTGGQHRSVYLAQTIGESFAVTHPNVKIRHREQE K

$>$ ALTEMAC MADE 14619

MKLIIISGRSGSGKS VALRALEDLGYYCVDNIPVNLLPTLTHTVVDEYDQVAVSIDVRNLPKNPDDLVEILDYLPSSWSMTIVYIDASDDVLVKRFSETRRLHPLAKLNK SLSEAIRAESALLAPIAERADLYLDTDKLTIHQLAELIRERILGKKSSRLVLVFESFGFKHGIPKDADYVFDARFLPNPHWEPDLKHLTGLDAPVEVFLGSQPVVTKFIW QIQNLITTWLPHLERNNRSYVTVAIGCTGGQHRSVYIAQTLSKTFSEIHPDVQIRHRELN Q

$>$ AZOSP. EBA3650

MQIVLISḠLSGSGKSIALKVLEDVGYYAVDNLPATLLPELVAELSDTGHERVAIAVDVRSGASLLALPQQVEHLHALASDLRLIFLDARDDTLIARFSETRRRHPLASE DVSLAEAIQSERDALASIAELGHRIDTSELHANTLRAWIKDFLAIEATEGLTLMFQSFGFKYGIPLDADLVFDVRCLPNPHYDLRLRPFTGKDQPVIEFLDSFPEVGRM CEDIRRFVATWLPSYARDNRSYLTVAIGCTGGQHRSVYIAEWLGRHFSDTLRVLVRHRSAARRIVDHGADMA DK

$>$ BACANT GBAA5384

MTENNDIKMVIITGMSGAGKTVALQSFEDLGYFCVDNLPPMLLPKFIELMADSKGKMNKVALGVDLRGREFFEHLWGALDDLSERTWIIPHILFLDAKDSTLVTRYKE TRRSHPLAPTGLPLKGIEIERSLLTDMKARANIVLDTSDLKPKELREKIVHLFSTETEQAFRVNVMSFGFKYGIPIDADLVFDVRFLPNPYYIPHMKPLTGLDEEVSSYV LKFNETHKFLEKLTDLITFMLPHYKREGKSQLVIAIGCTGGQHRSVTLTEYLGKHLKPEYSVHVSHRDVEKRKGH

>BACCER_UPF0042

MTENNDIKMVIITGMSGAGKTVALQSFEDLGYFCVDNLPPMLLPKFVELMADSKSKMNKVALGIDLRGREFFEHLWGALDDLSERTWIIPHILFLDAKDSTLVTRYKE TRRSHPLAPTGLPLKGIEAERGLLTDMKARANIVLDTSDLKPKELREKIVQLFSTETEQAFRVNVMSFGFKYGIPIDADLVFDVRFLPNPYYIPHMKPLTGLDEEVSSY VLKFNETHKFLEKLTDLITFMLPHYKREGKSQLVIAIGCTGGQHRSVTLAEYLGKHLKPDYSVHVSHRDVEKRKGH

$>$ BACCLA ABC3036

MNQSEVEIVIITGMSGAGKSVAVRSFEDLGYYCIDNLPPVLLPKFIELIEGGIDKVTKVALVMDLRGQSFFDELFKAIDELNETPASRLKIQILYLDAKDSKLVQRYKETR RTHPLAKGGLPLEGIQKERNLLEEIKGRAQQIIDTTELKPLQLREKIMQRFAGNDRQAFAVHFVSFGFKYGIPIDADLVFDVRFLPNPHYVEDLRPKTGLQTEVSSYVL KWKETKQFVEKLTDLFDFMLPHYKREGKSQVVIGIGCTGGQHRSVTLAEYFCAHYEAKYDAYTSHRDINKRKANSR

$>$ BACCOA UPF0042

MGLEGNQMQFVIITGMSGAGKTVAIQSLEDLGFFCVDNLPPTLLPKFLELMKDASNKMNKVALVMDLRGREFFDDLFRALDELDKSSWVTPTILFLDADDSVLVRRY MGLEGNQMQFVIITGMSGAGKTVAIQSLEDLGFFCVDNLPPTLLPKFLELMKDASNKMNKVALVMDLRGREFFDDLFRALDELDKSSWVTPTILFLDADDSVLVRRY
KETRRSHPLSPDGTPLEGIQQERKILEELKGRAQLILNTSNLKPRELREKIVMEFSANKQSFFTVNVLSFGFKNGIPIDCDLVFDVRFLPNPFYIEHMRPKTGLDEEVY KETRRSHPLSPDGTPLEGIQQERKILEELKGRAQLILNTSNLKPRELREKIVMEFSANKQSFFTVNVLSFGFKNGIPIDCD
TYVLKWNETQKFLEKLTDLLAFMLPHYKREGKSQLVIGIGCTGGQHRSVALAEYIGHFFEKDYHTTISHRDIKRKERKP

$>$ BACHAL BH3569

MNVKEEIDIVIITGMSGAGKTVAVQSLEDLGYFCVDNLPPALIPKFIELIESSSGKMNKLALVIDLRGQTFFDQLFESIDLLDQSSLSKYNIQILFLDAKDAKLVQRYKET RRSHPLAKHGLPLDGIKKERELLEDLKGRAQQIIDTTDLKPIQLREKIIQRFSCEEHHSFTVNMMSFGFKYGIPIDADLVFDVRFLPNPHYVDHLRPKTGLEGEVSSYV LKWTETQQFIEKLEDLLSFMLPQYKREGKSQVVIGIGCTGGKHRSVTLAEHFAKVFANEYMMHVSHRDVEKGKER

$>$ BACLIC_YVCJ

MNANGGHDIQLVIITGMSGAGKTVAIQSFEDLGFFCVDNLPPSLLPKFLELMKESSSKMSKVALVMDLRGREFFDSLIEALDEIGETSWITPRILFLDAKDSVLVSRYK ETRRSHPLATTGLPLEGIQTERELLEELKGRSQIIYDTSDMKPKDLREKIVQHFAADHGHTFTVNVMSFGFKYGLPIDADLVFDVRFLPNPYYIDSMRPLTGKDQEVS SYVMKWNETQKFLEKLTELLSFMLPSYKREGKSQLVIAIGCTGGQHRSVTLAEYLADYFKKDYYTHVTHRDIE KKSRK

$>$ BACSUB YVCJ

MSVSESHDIQLVIITGMSGAGKTVAIQSFEDLGYFCVDNLPPSLLPKFLELMKESNSKMSKVALVMDLRGREFFDRLIEALDEMAENPWITPRILFLDAKDSILVTRYK ETRRSHPLAATGLPLEGIALERELLEELKGRSQIIYDTSDMKPRDLREKIVKHFATNQGETFTVNVMSFGFKYGIPIDADLVFDVRFLPNPYYIESMRPLTGKDKEVSS YVMKWNETQKFNEKLIDLLSFMLPSYKREGKSQVVIAIGCTGGQHRSVTLAENLADYFKKDYYTHVTHRDIEKRSRK

>BACTHU_ZP_00739740

MTENNDIKMVIITGMSGAGKTVALQSFEDLGYFCVDNLPPMLLPKFIELMADSKGKMNKVALGIDLRGREFFEHLWGALDDLSERTWIIPHILFLDAKDSTLVTRYKE MTENNDIKMVIITGMSGAGKTVALQSFEDLGYFCVDNLPPMLLPKFIELMADSKGKMNKVALGIDLRGREFFEHLWGALDDLSERTWIIPHILFLDAKDSTLVTRYKE VLKFNETHKFLEKLTDLITFMLPHYKREGKSQLVIAIGCTGGQHRSVTLTEYLGKHLKPEYSVHVSHRDVEKRKGH

$>$ BACWEI_UPF0042

MTENNDIKMVIITGMSGAGKTVALQSFEDLGYFCVDNLPPMLLPKFIELMADSKGKMNKVALGIDLRGREFFEYLWGALDDLSERTWIIPHILFLDAKDSTLVTRYKE TRRSHPLAPTGLPLKGIEAERGLLTDMKARANIVLDTSDLKPKELREKIVHLFSTETEQAFRVNVMSFGFKYGIPIDADLVFDVRFLPNPYYIPHMKPLTGLDEEVSSY VLKFNETHKFLEKLTDLITFMLPHYKREGKSQLVIAIGCTGGQHRSVTLTEYLGKHLKPEYSVHVSHRDVEKRKGH

$>$ BIFLON_BL0705

MNQQTTNRDTGEAAATNAPANSATSTSTPDNQPTPLDAFEVLLITGMSGAGRSHAADCVEDMGWYVVDNLPPKLLIPLVDMMTTSGSGSESGVHKLAAVIDVRSS YFDELAAVLGHLDDLGVKTRILFLDASNEVLIKRYESVRRPHPLQHGNRLIDGILEERHLLEDLKERADWVIDTSSLSIHQLSTKLYEAMLGSGPTTVAVHIFSFGFKY GMPIDADFVADVRFLPNPFWVPSLRELTGRDKPVADYVLSSKGAKEFLDAYEKAIEIALEGYAQEDKHYVTIAVGCTGGQHRSVAMSEELARRLRA HGLNVTVSAR EQHKRHSS

$>$ CALSAC_ZP 00884966

MILLETVIVTGMSGAGKSLAIRAFEDMGFFCIDNLPPQFLPKIAELASASNDKISRIAAVIDIRGGELFDDFKDVLNDLKKGTYNFKVLFLDAHDNVLVQRYKETRRKHP LSFESDGSILEAIQKEREKLEDIKRYADFIIDTSTLSPRDLKEKLFEIFSAQRSRETMLITVMSFGFKYGLPLDADLVFDVRFIPNPFYVEELKHKTGKEKEVKEYVLKW DVTKEFLKKLFDLILFLIPNYAEEGKAQLVIAIGCTGGKHRSVTIAEELFELIKNNGYKASIFHRDIEKDIKG 
$>$ CARHYD_YP 359144

>CARHYD_YP_359144 LGVRGSQILDNIKKERKFLENLRARADKVIDTSDLQPADLRNEILNYYGEEQKRSKISINIVTFGYKYGLPLDADLIMDVRFLPNPFYVKELRPLSGSDKPVYDYVFNY EVTKKFTEKFLDLIEFLMPFYQKEGKSNLVIAIGCTGGRHRSVAIANFLARTLEEKNYEVYLRHRDLEKHREE

$>$ CLOACE_CAC0511

MRFVIVTGLSGAGKTQAIRSLEDLGYFCIDNLPPALIPKFAQVCYESESKINKIALVIDIRGGEFFDNLFESLKYLKEAGYKYEILFLDADNEVLIKRFKESRRKHPLAPN GRILNGIQMERKKLKTLYNMANNVIDTSKLATRELREKINSIYQEEGQIESKLIVTVVSFGFKYGIPVDSDLVFDVRFLPNPFYIPELKRFSGIEKPVKDYVMSFDQTKE FVNKIEQLLKFLIPNYLKEGKRQLIVSIGCTGGRHRSVTIANEIYERLKNDGETVNIDHRDIEEDINKGGKKL

$>$ CLOBEI_ZP_00909349

MRFVIVTGLSGAGKTQATRTLEDLGYFCVDNLPPKLISKFAEVCTQSGGNIEKVALVIDIRGGIFFDDFFEALNYLKKNEFKYEILFLEATDEVLIKRFKETRRSHPLSP DGRVLTGITQEREKLREVKNIADIIIDTSKYEIRHLREKINKNYGDHTYPEKQLSITVLSFGFKYGIPVDSDLVFDVRFIPNPFYIPELKQYSGNDEPVKDYVLKQEETVN FIEKLVDMLRYLIPNYIKEGKSQLIISIGCTGGRHRSVAIANEVYERLNKENYNSKIEHRDVAEDLHKGEKKL

$>$ CLOPER_CPE0354

MRFVIVTGLSGAGKTEATRSLEDLGYFCVDNLPPKLIPKFAEACVQSEGKIDKIALVIDIRGGIFFDDLFESIEYLKANDFNYEILFLEASDEVLVKRFKETRRSHPLSPD GRIITGISEERMRLRELKDRADNIIDTSNYPIRNLREKINLLYGDGKPVEQNLSITVLSFGFKYGIPSDSDLVFDVRFIPNPFYIPELKPFSGEDEPVKNYVLAQEETKGF LSRLSDMAEFLIPNYIKEGKRQLIISIGCTGGRHRSVAIANALYKDLLCKNFHVTLEHRDINEDINRGDRKL

$>$ CLOTET_CTC02495

MRFVIVTGLSGAGKTQAIRSLEDLGYFCVDNLPPTLIPKFAEACYKTDGRINKIALVIDIRGGEFFDNLFESLNYIKDQNYKYEILFLEASDEVLVKRFKETRRNHPLSS GGRILNGIALERSRLKEVKDVASNIINTSKFTNMDLRQEITRIYGDGDQVEAQLTITVVSFGFKYGIPLDSDLLFDVRFLPNPYYIPELRNFSGNDKPVYDYVLEFNQTK EFIGKLNDILEFLIPHYTEEGKRQLIVAIGCTGGRHRSVSIANSIYKLLEEKGHKVNIDHRDIHEDNNKGGKKL

$>$ CLOTHE_UPF0042

MRLLIITGISGAGKSLVVKYLEDIGFFCVDNLPPLLIGKFAEICLKSRGKISKVALVIDIRGGELFNDLVPELNALKESGIDYEILFLEASDQVLIKRYK

ESRRIHPLAPEGRLIKGIKTEREILSQIRKNATYIIDTSNLTPRQLKEEILAIFVEGRKFDGMIVNIISFGFKYGIPIECDLVFDVRFIPNPYYIESMKYKTGKDEEVRNYVM SFAETAEFMTKLKDLVDFLIPNYIKEGKSQLVIGVGCTGGRHRSVAISEALFSYLCGREHRVFIDHRDIDKDGRSNRR

$>$ COLPSYCPS 4546

MKLIIVSGRSGSGKSVALRVLEDLGYYCVDNIPINLLPALTHTVINDYENVAVSLDVRNLPKDPEDIPEIIAYLPKAVDVNTLFLDADDNDLIRRFSETRRLHPLIKENMA MKLIIVSGRSGSGKSVALRVLEDLGYYCVDNIPINLLPALTHTVINDYENVAVSLDVRNLPKDPEDIPEIIAYLPKAVDVNTLFLDADDNDLIRRFSETRRLHPLIKENMA LDQAIALEKSLLEPISTNADLYINTSQLSPHQLADLVRERILGKKTGSMVLVFESFGFKHGIPVDADY
QINSFMMTWLPHLERNNRSYVTIAIGCTGGKHRSVYIAEMLAKNFRKERDDIQTHHRDIDIKST

$>$ COREFF CE1710

MNQTPGSTVPETATPVTSPASSPSAPETTFTPVIITGMSGAGLSTAARVLEDLGWFVTHNLPPQMILPLVEMCAREDSPVDKVAVVCDVRSREFRGGLRETITELEE KNLAPTVLFLDARDDELIRRFDNVRRTHPLQGSQTLQVGIERERQMLSDLKEEADVVIDTSELSVHDLRRAIESSFRTIAKRVQHVTIESFGFKHGSPRDADFIIDARF LPNPFWVPELRPFRGVDKPVSDYVLSQKGAGEFLDNFIAMLDDMLPGYRHEGKNFITVGIGCTGGHHRSVAVSEELARRLGERPDLDVSVVHRDINRN

$>$ DESBHAF_DSY4845

MLSKQVRLLVITGLSGAGKTQALQSLEDQGYFCVDNLPPSLILKFAELCTQSQGKVTRAAIVCDLRGGEFFSSLAEALGDLHREGFHYEILFLEASDEVLVGRYKES RRRHPLSPSGGILEGIQMERQMLTELRGVAHKIMDTSNLSSQQLRHQVAESFGNEQASGHLAVSVVSFGFKYAIPLDVDLLIDVRFLPNPFYVAELRPLTGEHPQV QDYIFSNPVAQEFVDKYLGLLEFILPYYVKEGKRHLVIGVGCTGGQH RSVAIAERIG LFLQERSYMMSVKHRDAARNRKGDKSK

$>$ DESRED UPF0042

MSDSEGGVEVSSPRLLIVTGMSGAGKTQAVQSLEDLGYFCVDNLPPALIPKFAELVSQSNGKVEKVALVVDIRGGAFFHQAIEVLHDLGEQGYRFEVLFLEASDETL VRRYKESRRRHPLDNHGEVLKVIQEERELLREIRGRATKVIDTSNVSNNQLKEQIITQYGGDKENSNRLLITVISFGYKYGIPMDSDLVLDVRFLPNPYYIPELRCLTG NDEPVQQHVMSQDVTKEFMEKLIDFVQFLVPHYQREGKATLMIAIGCTGGMHRSVTLTNKLGEVLSEKGYRVNVRHRDIMRV

>ENTSP. ZP 01590769

MVLMIVSGRSGSGKSVALRALEDMGFYCVDNLPVVLLPELARTLADRQISAAVSIDVRNMPESPEVFEQAMSSLPETFTPQLLFLDADRNTLIRRYSDTRRLHPLSS KNLSLESAIDEESDLLEPLRSRADLIVDTSEMSVHELAEMLRTRLLGKRERELTMVFESFGFKHGIPIDADYVFDVRFLPNPHWDPKLRPMTGLDKPVAAFLDRHTE VHNFIYQTRSYLELWLPMLETNNRSYLTVAIGCTGGKHRSVYIAEQLADYFRSRGKNVQSRHRTLEKRKT

$>$ ENTCFAE EF0766

MPENLQLVIITGMSGAGKTVAVQSFEDMGYFCIDNLPPSLIPKFWELIKESGKVTKIALVIDLRSRTFFREIQDMLVELENTNFIDTTILFLDATDEELVSRYKETRRAHP MAMDGLVTEGIRKERAMLEEIKADAQLVIDTTDLSPRQLRERLNKELATRETHEFRVEMVSFGFKYGLPIDADIVMDVRFLPNPHYIDELRPLTGMDQPVYDYVMGF PETDEFYTKFIDLLRTVLPGYKKEGKSSVTIAIGCTGGQHRSVALTERVGAELKEEDYHVNITHRDRLKRKETVNRS

$>$ ENTCFAEC_UPF0042

MTDNLQLVIITGMSGAGKTVAIQSFEDMGYFCIDNMPPRLIPKFWELIKESGKVTKMALGVDLRSRSFFEEIQNMLIEIENTNFIDTSILFLDASDEELVARYKETRRAH PMAMDGLITEGIRKERAILDDLKAQASVIIDTTTLTPRQLREKINESFKSKGDQGFRIEFVSFGFKYGLPIDSDIVMDVRFLPNPHYIPELRPLTGKDQPVYDYVMSFDE TQSFYHKFLDLLETVLPGYIKEGKSSLTVAIGCTGGQHRSVALTERLANALGKNYKVNVTHRDKDKRKETVNRS

$>$ ERWCAR ECA0285

MVLMIVSGRSGSGKSVALRALEDMGFYCVDNLPVVLLPELANTLAARNISAAVSIDVRNMPESPEIFEHAMEQLPPSFSPQLLFLDADRNTLIRRYSDTRRLHPLSSK NLSLESAIDEESDLEPLRSRADLIIDTSEMSVHELAEMLRTRLLGKERELTMVFESFGFKHGIPIDADYVFDVRFLPNPHWDPKLRPMTGLDKPVASFLDRHTEVH NFIYQTRSYLELWLPMLETNNRSYLTVAIGCTGGKHRSVYVAEQ LADYFRSRGKNVQSRHRTLEKRKPS

$>$ ESCCOLSP._YHBJ

MVLMIVSGRSGSGKSVALRALEDMGFYCVDNLPVVLLPDLARTLADREISAAVSIDVRNMPESPEIFEQAMSNLPDAFSPQLLFLDADRNTLIRRYSDTRRLHPLSS KNLSLESAIDKESDLLEPLRSRADLIVDTSEMSVHELAEMLRTRLLGKRERELTMVFESFGFKHGIPIDADYVFDVRFLPNPHWDPKLRPMTGLDKPVAAFLDRHTE KNLSLESAIDKESDLLEPRSRADLIVDTSEMSVHELAEMLRTRLLGKRERELTMVFESFGFKHGIPIDADYVI
VHNFIYQTRSYLELWLPMLETNNRSYLTVAIGCTGGKHRSVYIAEQLADYFRSRGKNVQSRHRTLEKRKP

$>$ EXISIB UPF0042

MEQNQPQLLVIITGMSGAGKTVAMNSFEDLGYFCVDNLPPTLLPQLIEVIGQVRPKIAVAIDTRARDFIDSFFVVYEDLKKTNLQIRMLYLDARNDVLVRRYKESRRSH MEQNQPQLVIITGMSGAGKTVAMNSFEDLGYFCVDNLPPTLLPQLIEVIGQVRPKIAVAIDTRARDFIDSFVYELLKTLQRIRLYLARNDVLVRYKESRRSH EAKLFYKKLVDMLEFLIPQYEREGKSQLVVALGCTGGKHRSIT FAEAISKEFK NQYHIVTNHRDYVHAKEEK

$>$ FUSNUC_FN1089

MKTKHIIIVTGLSGAGKTTALNILEDMSYYTIDNLPLGLEKSLLDTEIEKLAVGIDIRTFKNTKDFFTFINYIKESGVKMDIIFIEAHEAIILGRYTLSRRAHPLKEVTLLRSILK EKKILFPIREIADLVIDTTEIKTVELEKRFKKFILAKDGENTDININIHIQSFGYKYGIPTDSDLMFDVRFIPNPYYIEKLKELNGFDEEVKEYVLSQKESKEFYFKLLPLLEF LIPQYIKEGKKHLTISIGCSGGQHRSVTFVNKLAEDLKNSKVLEYINVYVSHREKELGHW

$>$ GEOKAU GK3066

MGQNGALQPIQLVIITGMSGAGKTVAIQSFEDLGFFCIDNLPPTLLPKFLELVKESGNKMNKVALVMDLRSRDFFDHLFAALDELAEQAWVIPQVLFLDAQDSTLVAR YKETRRTHPLAPNEPPLEGIRLERKLLEELKGRAQIIYDTTGLKPRELREKIIRQFSSHAQSGFTINVMSFGFKYGIPIDADLVFDVRFLPNPHYIEHMRPKTGLDDDVS SYVLKWGETQKFLEKLIDLLSFMLPYYQREGKSQLVIAIGCTGGQHRSVALAEYIARHFSDDYKTVVSHRDMERRKDIHR

$>$ GEOTHE_GTNG_3015

MGQNGTVQPTQLVIITGMSGAGKTVAIQSFEDLGFFCVDNLPPTLLPKFLELVKESGNKMNKVALVMDLRSRDFFDHLFVALDELAEQEWIVPQILFLDAQDSTLVA RYKETRRTHPLAPNEPPLEGIRLERQLLEEIKGRAQIIYDTTGLKPRELREKIVRQFSVHAQSGFTVNVMSFGFKYGIPIDADLVFDVRFLPNPYYIEHMRPKTGLDDE RYKETRRTHPLAPNEPPLEGIRLERQLLEEIKGRAQIIYDTTGLKPRELREKIVRQFSVHAQSGFTVNVMSFGFKYGIPIDADLV
VSSYVLKWGETQKFLEKLLDLLAFMLPYYQREGKSQLVIAIGCTGGQHRSVALAEYIARHFSADYKTVVSHRDMERRKEAHR

$>$ GLOVIO GLR4163 MTSFSAPGSPVDTVLLTSPAGAGRTEAIRIFEDLGYLCLNHVWPELVPTFLKHYAPIAPRLVLCLASRPEADAQAGLIAARVALRSLARTTVHVHLDCPEGVLLSRYA
LTRRPHPWFDHGKGLLAAIRAERTALEPVRALADEVVDTGPLELAQLRVHLGALVGGRPTELPVTVMSFGFKRGVPADAQFVLIRFLPNPYYESALKPLTGLDVG VAEYVFASEQSQATYRSLLEFLRFLLHQYRQDRRSQLLIAIGCTGGQHRSVAFVERLSGDLAAEGFACRPSHRDLAVNRLQELSR

$>$ HAEDUC_HD0584

MELVIISGRSGSGKSVALRALEDVGYYCVDNLPFPLIAELASFLLASDCSAVVSLDIRNFPENLTRIDELLHQLSQLTINTKMIFLDCESATLIRRYSDSRRLHPLSNQD LSLASAIELENTLLDPLRQQADYLIDTTHSSPHELAANLRHILRGSTEKELNIVFESFGFKYGLSADADYVFDVRFLPNPHWHAELRAMTGLEQPVIDFLERQTEVHN FIYQTRNYLETWLPMLEKNNRSYLTIAFGCTGGKHRSVFITEQLAKYFQSRGKNVKIRHRSLEKYHKKT 
$>$ HAEINF_AAC22801

MGKLMEIIIISGRSGAGKSVALRALEDAGYYCVDNIPLDLLPQLTDILSQSQSSVAISLDIRNIPNSAHSLKQTLSTLQKHHQIKIIFLEADRATLIRRYSDSRRLHPLSLK DLSLEAAIDEEYRYLEPLIQHANLILDTTHLSTHSLAERLREFLRGNSEKELKIIVESFGFKYGIPLDADYVFDVRFLPNPHWDPTLRPMTGLEAPVAEFLNSHTEVNEF IYLTRHYIDTWLPMLEKNNRSYLTIAIGCTGGKHRSVYIAQQLGEYFQAKGKTVKIQHKSLERNKKI

$>$ HAESOM_ZP_00132582

MEIIIISGRSGAGKSVALRALEDIGYYCVDNLTMDLVPQLVDMLENKQHLVAISLDIRNLPQEPETLDHILNLLQEKYPVKIIFLDTDRNTLIRRYSDSRRLHPLSVQNLS LEAAIAAEKEHLEPLVQHANVIIDTTPLSPHELAERLREFLRGNTEKELQIIVESFGFKYGIPLDADYVFDVRFLPNPHWNQELRPMTGLEKPVIEFMQKHIEVDNFIYQ TRNYIENWLPMLEKNNRSYLTIAIGCTGGKHRSVYIAQQIGEYFRAKGKKVQIQHKSLEKHTQNK

$>$ HALORE_UPF0042

MQFLIVTGMSGAGKSVALNFFEDMGFFCIDNLPPALISKFAELCLHSELDKIAVVSDIRGREFFNALFSELSSLEKRGIDYEILFLEASDEVLIRRYKETRRRHPLDEEG MQFLIVTGMSGAGKSVALNFFEDMGFFCIDNLPPALISKFAELCLHSELDKIAVVSDIRGREFFNALFSELSSLEKRGIDYEILFLEASDEVLIRRYKETRRRHPLDEEG RVLDAIRKERHLLEEIKGKANKIIDTSKLSKQELNHELKKVYSSYFIGKQSMSVTIISFGYKYGIP
YKRFFDMMDFLLPEYSREGKSHFTIAIGCTGGKHRSVTTAIKLKEFLLSKGYHVVVEHKDISK

$>$ IDIBAL_OS145_05430

MQLIIVSGRSGSGKTIALRVLEDLGFYCVDNLPIALLSTLVHSVLAQYDRVAISIDVRNLPEDSQELLESIDFLPAEVDIEVLFIDADDQTLLQRFGETRRLHPLSQKQLP LLEALQLENRLLDPIAVRATWRIDSSHLSLHQLSEEVSARVLGKASKQVVIVFQSFGFKHGVPKDADFVFDARILPNPHWNPELKLLTGQDEDVKQFFRKESLVTKY LLQVENFLATWLPYFRRSNRSYLTIAMGCTGGQHRSVYLAETLAEQFRSEGTHVQVRHRELS K

$>$ IDILOI_IL0393

MQLIIVSTGRSGSGKTIALRVLEDLGFYCVDNLPISLLPTLVHAVIEQYQKIAISIDVRNLPEHSEELLDSLSFLPKGVEPEILFIDSDDNTLLKRFGETRRLHPLSQKELPL LEALQAEHKMLEPIMERATWRLDSSDLSLHQLSEQVTERVLGRADKKLIIVFQSFGFKYGLPKDADFVFDARILPNPHWQPELKLLTGLDTDVQIFFRQEPLVTKFIY QLENFLDTWLPHFQRSNRSYLTIATGCTGGQHRSVYISQQLAERFEQKAVKVQVRHRELKTHG

$>$ KLEPNE_P17163

MVLMIVSGRSGSGKSVALRALEDMGFYCVDNLPVVLLPELARSLADRNISAAVSIDVRNMPESPEIFEQAMKNLPAEFSPQLLFLDADRNTLIRRYSDTRRLHPLSS KNLSLESAIDEESDLLEPLRSRADLIVDTSEMSVHELAEMLRTRLLGKRERELTMVFESFGFKHGIPIDADYVFDVRFLPNPHWDPKLRPMTGLDKPVAAFLDRHTE VHNFIYQTRSYLELWLPMLETNNRSYLTVAIGCTGGKHRSVYIAEQLADYFRSRGKNVQSRHRTLEKRKS

$>$ LACACI LBA069

MADEKKO RRLPPLANNGKGRLLDGIQEERRILTPIKNRSNYIVDTSNLSTKELKQKLINTFSDKKROPFSIEVMSFGFKYGMPIDADIVMDVRFLPNPFYIPELRPFTGLDKRVFDY VMNKEETQVFYKKLLDMLETAIPGYIKEGKEKLTIAIGCTGGQHRSVSIAQQLARDLSKKYPVDITHREISRYIRK

$>$ LACBRE_YP 794827

MTEDIRLVIITGMSGAGKTVAMQSFEDLGYFCIDNMPPSLLPKFWDLVRESGKLSKIALVIDLRSRAFYDEIVRMLNDVAVHGTMNAQVLFLDASDAELVSRYKETRR SHPLARNGRVLEGISRERELLAPIRQAAQLVIDTTKLSPRKLREEIFHNYETETTQAFHIELMSFGFKYGLPIDADIVMDVRFLPNPYYLPELRNQTGMDQPVYDYVM NQPQTEEFYQRFLGLLTTIVPGYKQEGKSSLTIAIGCTGGQHRSVALTQRLGQALGNTYPVHVTHRDIEKRKESANRS

>LACCAS_YP_806200

MTESLDLVIITGMSGAGKTVAMQAFEDLGYFCVDNMPPALLPKFWELVKESGKITKVALVVDLRSRAFYDQIIDMLANLDNNAYVHSRILFLDATDEELVSRYKETRR SHPLAMEGRLMDGIKKERALLTELRNRAQVVIDTTTLSPRQLREKIFLNFKESGSQPAFHIEVMSFGFKYGLPIDADIVMDVRFLPNPFYIKDYRPKTGLDPEVYNYV MDNEDAESFYNKFYDLLSEIMPKYKAEGKTSVTIAIGCTGGQHRSVAFAERIGKAFSDAYAVDITHRDIKKHKE TVNRS

$>$ LACDEL_YP_618706

MIEFNVLWEQYGIMHEKYKKQLLILTGMSGAGKTVAAHSLEDVGYFVVDNLPPELLGNFWDLMNTSEDFEKVAVVIDLRVKSFYKDLIDEINSLEDSGQTQATIVFLE ASDDTLVARYKETRRLPPLAENGRLLDGIRDERRILTPVRNRSNYILDTSKMTTKELKQKLQSKFGELHKPKFGIEVMSFGFKYGMPIDADIVMDVRFLPNPFYIPELR PFTGLDKRVFNYVMDKDETKVFYGKLLDLLLTAIPGYIDEGKEKLTIAIGCTGGQHRSVSIAQQLARDLSEKYPVDITHREISRYLRK

>LACGAS_YP_815115

MAEQKKQLLIVTTGMSGAGKTVAIKALEDMGYFVVDNLPPELLGSFWELINNSSDFSKAAVVVDLRVKSFYKDLVDEIKSLEDSQNVQSTVLFLDASDDVLVSRYKET RRLPPLAHTGRLLDGIQEERAILSRTKNISNIIIDTSRLTTKELKAKLVDKFGDNQTRTFSIEVMSFGFKYGIPIDADIVMDVRFLPNPFYIPQLKPFTGLDR RVFDYVMSKKETKKFYAKFLDMLETAIPGYIAEGKEKLTIAIGCTGGQHRSVSIARQLAVDLAKKYPVDISHREISRYIGQ

$>$ LACJOH LJ0866

MAEQKKQLLIVTGMSGAGKTVAIKALEDMGYFVVDNLPPELLGSFWELINNSSDFSKAAVVVDLRVKSFYKDLVDEIKSLEDSQNVQSTVLFLDASDDVLVSRYKET RRLPPLAHTGRLLDGIQEERNILSRTKNISNIIIDTSHLSTKELKTKLVDKFGDNRTRTFSIEVMSFGFKYGIPIDADIVMDVRFLPNPFYIPQLKPFTGLDRRVFDYVMS KKETKEFYAKFLDMLETAIPGYIAEGKEKLTIAIGCTGGQHRSVSIARQLAVDLAKKYPVDISHREISRYIGQ

$>$ LACPLA_LP_0779

MAESLQLVIISGMSGAGKTVAVQSFEDLGYFCIDNMPPALLPKFSELVEESGKIKKVALVIDLRSRAFYDEIMDMLANLDNTDFVSTRILFLDASNEELVSRYKETRRS HPLAMEGRVMDGVRKERELLAPLKDRASYVIDTSTLTPRELRESIFDKFETDQDETFHIEMLSFGFKYGLPIDADIVMDVRFLPNPYYIPELKKLTGLDKPVADYVMQ QPATEAFYQQFLSMLESIMPGYEAEGKSSLTIAIGCTGGQHRSVALTQRIGEALAKHYKVHISHRDIEKRKETVNRS

>LACREU ZP_ 01164767

MRKEELVMVDKKLKVVIITGMSGAGKTVAVHSLEDLGYFVIDNMLPGLAERFVDVIEDSREFDKIAMVMDMRSRGFYDEVLPNFEKLKKRADLDVKLLFLDANDVTL SRYKETRRSHPLSPQGRILDGVELERKLSTDLKSQADIVIDTTNVTPRNLKLRLNKLFGHGEGNDFYVEVMSFGFKYGLPLDADIVMDVRFLPNPFYIPELKHLTGND PAVQ NYVMQSPLAKEFYQHLRSLLEIALPGYIKEGKSSLTIAIGCTGGQHRSVTIANKLSADLKEKGYKVNTYHRDIEKAK

$>$ LACSAK YP 395138

MTDTLNLVVI TGMSGAGKTV AMQSFEDLGY FCVDNMPPSL LPKFWELVKE SGKVTKIALV

IDLRSRAFYD GIIEMLSGLD NTQFVTTKIL FLDASDEELV SRYKETRRSH PLARNGRLMD

IDLRSRAFYD GIIEMLSGLD NTQFVTTKIL FLDASDEELV SRYKETRRSH PLARNGRLMD

GIHKERELLT EIRNQSQMVV NTSMLSPREL REQIFRVFKT SDNPSFHIEV MSFGFKYGLP

KEGKTSVTIA IGCTGGQHRS VALAQRLADD LAVDYPVDVT HRDMKKRKES VNRS

$>$ LACSAL YP 536062

MFMSALQLVIVTGMSGAGKTVAVQSFEDLGYFCVDNMPPKLLPKFYELVKESGKITKIALVVDLRSRAFYDEIVEMVRELDENEFNSSRILFLDASDEELVARYKETR RSHPLAMEGRILDGIHLERELLAPIKSNAQIIIDTSKLSPRQLREEIFKNFEARDTKTFHIEVMSFGFKYGLPIDADIVMDVRFLPNPYYVSELRNKTGKDDAVYEYVMK SEKTEEFYQKFVSLLKYVIPGYIAEGKSNVTIAIGCTGGQHRSVALAERIGNELSKEYPVHMSHRDMNKRKETVNRS

>LACTLAC_L188550

MENKLNIVIITGMSGAGKTVAIQSFEDMGYFTVDNMPPNLIEKFVGLLNTPDNKIDKVALVVDMRSRAFFEDIQSIVTELTDNGSVNFKLLFLDANDTELVSRYKETRR SHPLAIDGRTLDGITKEREILADLKNLSEVVIDTSELTPRNLRARILQKFASSTESTFRIEVMSFGFKYGLPLDADLVFDVRFLPNPHYITELRDKNGTDKEVYDYVMEH PQSEEFYENLMKMLVPILPAYKKEGKSVLTIAFGCTGGQHRSVAFAERVSAALKDKWHLNVSHRDKDRRKETVNRS

$>$ LEIXYL LXX11490

MTSDVETTAEQQEVLIVTGMSGAGRSTVANALEDLDWYVVDNLPPQMLRPLIELANRAESGLPRIAAVVDVRGRNFFADLQEMIQSLREGTKVRVLFLEAADVTLV RRFEQVRRPHPLQGNGTLLDGITAERARLREIRESSDIIVDTSDLNIHQLATRITDIFADENTADVQVTVMSFGFKYGLPADADLVADARFLPNPFWKPELRPYTGLD EVVRNDVLQQNGAEEFIESYLEALRPIFAGYQRENKRHATIAVGCTGGKHRSVAIAEELAARLRSLPGLAVSIKHRDLGRE

$>$ LISINN LIN2617

MASKQLKLVIITGMSGAGKTVAMQSLEDLGYFCVDNLPPSLLPKFWELMKESDKMDKIALVMDLRGREFFDSIEPALDELDNTNFITTKILFLEADDKVLVSRYKETR MASKQLKLVITGMSGAGKTVAMQSLEDLGYFCVDNLPPSLLPKFWELMKESDKMDKIALVMDLRGREFFDSIEPALDELDNTNFITTILFLEADKVLVSRYKETR
RHHPLEPNGSVLDGINAERELLSDLKGRSQLVINTSNMAPRELRERINNEFQTEDKDVFNVQLMSFGFKYGIPIDADLVFDVRFLPNPHYIDKMRPLTGLDEDVYEY VMKWP ETMAFLDKLVDLLMFTLPFYKREGKTQLVIAIGCTGGQHRSVALTEYVGKAIQQKYETTISHRDMKRRKER

$>$ LISMON SP.

MASKQLKLVIITGMSGAGKTVAMQSLEDLGYFCVDNLPPSLLPKFWELMKESDKMDKIALVMDLRGREFFDSIEPALDELDNTNFITTKILFLEADDKVLVSRYKETR RHHPLEPNGSVLDGINAERELLSDLKGRSQLVINTSNMAPRELRERINNEFQTEDKDIFNVQLMSFGFKYGIPIDADLVFDVRFLPNPHYIDKMRPLTGLDEDVYEYV MKWPETQTFLDKLVDLLMFTLPFYKREGKTQLVIAIGCTGGQHRSVALTEFVGKAIQQKYETTISHRDMKRRKGR

>LISWEL_LWE2422 


\section{Anhang}

MASKQLKLVIITGMSGAGKTVAMQSLEDLGYFCVDNLPPSLLPKFWELMKESDKMDKIALVMDLRGREFFDSIEPALDELDNTNFITTKILFLEADDKVLVSRYKETR RHHPLEPNGSVLDGINAERELLSDLKGRSQLVINTSNMAPRELRERINNEFQTEDKDVFNVQLMSFGFKYGIPIDADLVFDVRFLPNPHYIDKMRPLTGLDKDVYEY VMKWP ETGAFLDKLIDLLMFTLPFYKREGKTQLVIAIGCTGGQHRSVALTEYVGKAIQQKYETTISHRDMKRRKGR

$>$ MANSUC_MS1718

MRQFMELIIISGRSGAGKSVALRALEDMGYYCVDNLPINLLPELADILSTSQQSAAVSLDIRNLPHSPETLDTLLQQLADAQHQVRIIFLEADRSTLIRRYSDSRRLHPL SMQDLSLEAAIEAEAGYLEPLLQNAELVINTSEISTHELAQRLREFLKGKPDKELKIVVESFGFKYGLPLDADYVFDVRFLPNPHWNPDLRPMTGLDQPVIDFLGKYS EV NNFIYSTRNYLETWLPMLEQNNRSYLTIAIGCTGGKHRSVYIAQQLGEYFQAKGKKVKIQHKSLEKHHKKNSA

$>$ MARAQU_UPF0042

MKLIIVSGRSGSGKSTALHVLEDLGFYCIDNLPIGLLFPLTREAATQEAPGRLKKMAVSIDARNLSAELANFETIYQQLKQTGVELEIIFLDADEQSLLQRFHATRRKHP LSDDKTSLREAITNEKQLLEPLSKLADLYVNTTGLSMYELRDMIKORVAGRKDQFLALLFQSFGFKHGVPVDSDYVFDVRCLPNPYWDTSLRKHTGVDQPVIDFLE REPLTRQMVDDLTGFLNTWLPSFADSNRSYMTISIGCTGGQHRSVYVCEQLGRYFRDNYRNVQVRHTELPHLQARGEI

$>$ MOOTHE YP 429136

MPETKYPRLVIVTGLSGAGKTQAVRCLEDLGFFCVDNLPPSLIPGLVDLLGHPGKEGEGITKVALVMDIRGGEFFSGLDAALNYLDGLGIPYEILFLEAADEVLVRRY KETRRRHPLSSGGQILEGIIEERRRLEELRGRASKIIDTSELTPRQLKEQVSELFGSSQRRLIVSIISFGYKYGIPLDADLVMDVRFLPNPYYVPALRPFTGHDRCVEEF VMASPVTRQFIEQFAALLRFLIPHYLQEGKSHLVVAIGCTGGQHRSVTLANKLGELLQGENYSVTVKHRDVVRYLSTGNRR

$>$ MYCSME_MSMEG3088

MSEMMRNSSSGVSSGGASEKDGVESHEGIDVVLVTGLSGAGRGTAAKVLEDLGWYVADNLPPELIARMVDLGLAAGSRITQLAVVMDVRSKGFTGDLDWVRNEL ATRNIAPRVLFMEASDDILVRRYEQNRRSHPLQGTQTLAEGIAAERAMLAPVRAAADLVIDTSTLPVPALRESIERAFGGETVAYTNVTVESFGYKYGLPMDADTVM DVRFLPNPHWVDELRPHSGQHPDVRDYVLGQPGALEFLDTYHRLLDVVIDGYRREGKRYMTVAIGCTGGKHRSVAIAEALAERLEGGDGLTVRVLHRDLGRE

$>$ MYCTUBCDC1551 MT1464

MMNHARGVENRSEGGGIDVVLVTGLSGAGRGTAAKVLEDLGWYVADNLPPQLITRMVDFGLAAGSRITQLAVVMDVRSRGFTGDLDSVRNELATRAITPRVVFME ASDDTLVRRYEQNRRSHPLQGEQTLAEGIAAERRMLAPVRATADLIIDTSTLSVGGLRDSIERAFGGDGGATTSVTVESFGFKYGLPMDADMVMDVRFLPNPHWV DELRPLTGQHPAVRDYVLHRPGAAEFLESYHRLLSLVVDGYRREGKRYMTIAIGCTGGKHRSVAIAEALMGLLRSDQQLSVRALHRDLGRE

$>$ MYCTUBH37RV_RV1421

MMNHARGVENRS̄EGGGIDVVLVTGLSGAGRGTAAKVLEDLGWYVADNLPPQLITRMVDFGLAAGSRITQLAVVMDVRSRGFTGDLDSVRNELATRAITPRVVFME ASDDTLVRRYEQNRRSHPLQGEQTLAEGIAAERRMLAPVRATADLIITSTLSVGGLRDSIERAFGGDGGATTSVTVESFGFKYGLPMDADMVMDVRFLPNPHWV DELRPLTGQHPAVRDYVLHRPGAAEFLESYHRLLSLVVDGYRREGKRYMTIAIGCTGGKHRSVAIAEALMGLLRSDQQLSVRALHRDLGRE

$>$ NITEUR NE1849

MQVIIISGLSGSGKSIALKVLEDSGYYCVDNLPASLLVVLINHLOTQQHAYVAVAIDMRSGENITVLPWQLKMIDKSIQIKFIFLEARTETLMQRFSETRRRHPLSDKNIT LEEAIRREREALATLTGLGHHIDTSSLRPNVLRAFIKDFIADSRSPSQLTLLFQSFGYKHGIPLDADLVFDIRCLPNPFYDPQLKELTGHDPEVIRFMESQPDASKMLR DISSFLGTWLPAYIRDNRAYLTVAIGCTGGQHRSVYFAEKLALHFHDSAHVLVRHRGLAEYKPHYARR

$>$ NOCFAR_NFA358930

MTRVESNNTASQAPPSGAGTLEQQVEVVIVTGLSGAGRGTAAKVLEDLGWYVADNLPPELIGRMVELGAAADPPIRRLALVMDVRSRFFTGDLSVVADQLRALGL RTRVLFLEASDDVLIRRFGFARRRHPLQSESADGTLSAGIAVERVRLAGVKAAADLVIDTTELSIHQLHRKLEEAYGGGAPAALQLTVQSFGFKYGVPLDADMVLDV RFLPNPHWIPELREHSGQETVVSEYVLSRPGAQDYLHTCHHLVDLTTSGYRQEGKRYMTVAVGCTGGKHRSVAIAEALGELIGADTSAESADVVRVVHRDLGRE

$>$ OCEIHE OB2468

MNQEQETKLVIITGMSGAGKTVAIQSFEDLGYYCVDNLPPALLPKFLDLMKDATNNIQKVALVMDLRGREFFDSLFEALDVLAKENWLEDHILFLDAKDEALVTRYKE TRRSHPLATDGLDGIKQEREILDELRGRAQRIIDTTSLKPRNLREKILKVYKEEKQEVFSVHFVSFGFKYGLPIDADLVFDVRFLPNPHYVSNLQPLTGLNPDVSSYVF KWSDTQTFIDKVTDLLTFMLPQYKKEGKSQLVVAIGCTGGQHRSVALAEHFSKVLSNGYTTHVSHRDIDKRKVL

$>$ PASMUL PM0169

MEIIIISGHSGAGKSVALRCLEDIGYYCVDNLPLDLLPQLASILSTNQQSVAISLDIRNLPHSSKTLENLLTEVQQQHQIKLIFLDADRGTLIRRYSDSRRLHPLSTQDLSL EAAIDAERKYLDPLTQHADLIIDTTRLSTHELAERLRDFLCEKSDKALKIIFQSFGFKYGLPLDADYVFDVRFLPNPHWIPELRPLTGLDAPVAEFLNKQNEVNHFIYLT RNYIETWLPMLEQNNRSYLTIAIGCTGGKHRSVYITEQLGEYFQAKGKNVQIQHKSLAKHKKANTQ

$>$ PEDPEN YP 803988

MNERLQFVVVTGMSGAGKTVAMQSFEDLGFFCVDNMPPALLPKFWELIKENGKISKVALVVDLRSRGFYDQILGLLTGEEEQHNIKTDVVFLDATDEELVARYKET RRAHPLAMDGRVADGVRKERELLSPIKSEAQIVIDTTNMTPRELRSDIFGHFSTNKTIPKFHIEVVSFGYKYGSPIDADIIMDVRFLPNPYYVTELKNKIGTDPAVYDYV MNQPATEEFYTDYLKLLMDIMPGYQKEGKSNLTIAIGCTGGQHRSVAIAERLAKDLSKKYVTNISHRDAHKRKETVNRS

$>$ PHOPRO PLU4044

MQLMVVSGRSGSGKSVALRVLEDLGYYCVDNLPVTLLPQFISTVENNEQDIAVSIDVRNMPSESGVIQKTLNSLDDKLDINVIFIDADDKELVKRYSETRRLHPLSKH DMSLEQAIQSESAIVADIKEHADLVIDTTNKSIHDLSETVRARVLGRESRKLILVFESFGFKHGLPTDADYVFDVRFLPNPHWVPELKPQTGLDQEVKEFLVGHAEVN KLIYQIRNFIETWLPLLEKNNRSYLTVAIGCTGGQHRSVYVAQQLADHFLHDGQQVQIRHRTLE SK

$>$ PHORLUM_PLU4044

MVLMIVSGRSGSGKSVALRALEDMGFYCVDNLPVVLLPELANTLADRDISAAVSIDVRNMPESPEVFEEALTKLPASFSPQLLFLDAERNTLIRRYSDTRRLHPLSSK NLSLESAIDQESDLLEPLRSRADLIIDTSEMSVHELAEMLRTRLLGKRERELTMVFESFGFKHGIPIDADYVFDVRFLPNPHWDPKLRPMTGLDRPVAAFLDRHTEVH NFIYQTRSYLELWLPMLETNNRSYLTVAIGCTGGKHRSVYVAEQLADYFRSRGKNVQSRHRTLEKRK

$>$ PROMIR AAC64575

MVLMIVSGGRSGSGKSVALRALEDMGFYCVDNLPVDLLPELAKTLAERDAAAAAVSIDVRNMPESPEIFEKALESLPAEYSPQLLFLDADRNTLIRRYSDTRRLHPLST KNLSLEMAIDTESDLLEPIRSRDVWIIDTSEMSVHELAEMLRTRLLGKRERELTMVFESFGFKHGIPIDADYVFDVRFLPNPHWDPKLRPMTGLDRPVAAFLDRHTEV HNFIYQTRSYLELWPMLETNNRSYLTVAIGCTGGKHRSVYVAEQLADYFRSRGKNVQSRHRTLEKRK

$>$ PSEATL_UPF0042

MKLIIISGRSGSGKSIVLRSLEDLGYYCVDNIPVNLLPTLTHTVADEYDQVAVSIDVRNLPKDPNELVEILDYLPSTWEMTILYLDASDDVLIKRFSETRRLHPLSKQNK SLSGAIQAESQLLAPIAERADLYIDTDQLSIHQLAELVRERILGKKSSRLVLVFESFGFKHGIPKDADYVFDARFLPNPHWEPDLKPLTGLDSPVEIFLGSQPIVTKFIW QIQNLISTWLPHLERNNRSYVTIAIGCTGGQHRSVYVVEMLAKTFSTSHPDVQIRHRELNR

$>$ PSEHAL PSHAA2554

MELIIISGRSGSGKSVALRVVEDLGYYCVDNIPVNLLPSLVRSVSDNYDKIAVSIDVRNLPKDQQQFNDILEYLPDFAKPTLFYLDSDDQTLIRRYSETRRLHPLSIDSL PLDLAIKKEKELLDVLVTRADHVIDTTDLSVHQLAESMRETILGKKDKQLIITFESFGFKHGIPKGADYVFDARFLPNPHWEPELKPLTGLDQPVKDYLASHSIVQKFT WQIQTFVQTWLPHLERNNRSYLTIAIGCTGGQHRSVYLAQTIGESFAMSHPNVKIRHREQEK

>PSETUN PTD2 17262

MQLIIISGRSGSGKSVALRVLEDLGYYAVDNIPVNLLPSLVRSVSDSYDKIAVSIDVRNLPKIQQEFNEILEYLPEFAKPTLFYLDSDDNTLIRRFSETRRLHPLSINSQP LDAAIKEEKILLDVLVSRADIIIDTSDLSVHQLAEAIRARVLGKKDNQLIITFESFGFKHGIPKNADYVFDARFLPNPHWEPLLKPLTGLDQPVKDFLASHSIVHKFTWQI QTFLQTWLPHLERNNRNYLTIAIGCTGGQHRSVYLAQTLADNFSRSHKNVKVHHREQEK

$>$ SALENTATCC9150_YHBJ

MVLMIVSGRSGSGKSVALRALEDMGFYCVDNLPVVLLPDLARTLADRQISAAVSIDVRNMPESPEIFEQAMNNLPGAFSPQLLFLDADRNTLIRRYSDTRRLHPLSS KNLSLESAIDKESDLLEPLRSRADLIVDTSEMSVHELAEMLRTRLLGKRERELTMVFESFGFKHGIPIDADYVFDVRFLPNPHWDPKLRPMTGLDKPVAAFLDRHTE VHNFIYQTRSYLELWLPMLETNNRSYLTVAIGCTGGKHRSVYIAEQLADYFRSRGKNVQSRHRTLEKRKT

$>$ SALENTTY2 T3240

MVLMIVSGRSGSGKSVALRALEDMGFYCVDNLPVVLLPDLARTLADRQISAAVSIDVRNIPESPEIFEQAMNNLPGAFSPQLLFLDADRNTLIRRYSDTRRLHPLSSK NLSLESAIDKESDLLEPLRSRADLIVDTSEMSVHELAEMLRTRLLGKRERELTMVFESFGFKHGIPIDADYVFDVRFLPNPHWDPKLRPMTGLDKPVAAFLDRHTEV HNFIYQTRSYLELWLPMLETNNRSYLTVAIGCTGGKHRSVYIAEQLADYFRSRGKNVQSRHRTLEKRKT

$>$ SALTYP YHBJ

MVLMIVSGRSGSGKSVALRALEDMGFYCVDNLPVVLLPDLARTLADRQISAAVSIDVRNMPESPEIFEQAMNNLPGAFSPQLLFLDADRNTLIRRYSDTRRLHPLSS KNLSLESAIDKESDLLEPLRSRADLIVDTSEMSVHELAEMLRTRLLGKRERELTMVFESFGFKHGIPIDADYVFDVRFLPNPHWDPKLRPMTGLDKPVAAFLDRHTE VHNFIYQTRSYLELWLPMLETNNRSYLTVAIGCTGGKHRSVYIAEQLADYFRSRGKNVQSRHRTLEKRKT

>SERPRO_ZP_01538297 


\section{Anhang}

MVLMIVSGRS GSGKSVALRA LEDMGFYCVD NLPVVLLPQL ANTLAERNSS AAVSIDVRNM

PESPEVFEYA MTQLPDSFSP QLLFLDADRN TLIRRYSDTR RLHPLSSKNL SLESAIDEES

DLLEPLRSRA DLIIDTSEMS VHELAEMLRT RLLGKREREL TMVFESFGFK HGIPIDADYV

FDVRFLPNPH WDPKLRPMTG LDKPVASFLD RHTEVHNFIY QTRSYLEQWL PMLETNNRSY

LTVAIGCTGG KHRSVYVAEQ LADYFRSRGK NVQSRHRTLE KRKQ

$>$ SHEAMA SAMA 3091

MKLVIVSGRSGSGKSVALRVLEDLGYYCVDNLPLQLIGPLLAQLKGNNDKVAISIDIRNMPEQEKALEKELARLPEGVELTSFFLNSSDKVLLKRYSETRRLHPLSRS KVSLQEAIKLEGKMLAPISNMVDHFIDTSNLNVYELADAVRQILLGRTDKELVIIFESFGFKHGMPTEADFMFDARFLPNPHWEPELRPLTGLDEPVKLFLERQVLVN KYIWQIENLLETWLPHLERNNRSYLTIAIGCTGGQHRSVYIAEQLAKRFANSHHKVEARHRELNAKA

$>$ SHEBAL UPF0042

MKLVIVSGRSGSGKSVALRVLEDLGYYCVDNLPLPLIGSLLEQLKGSNDLVAISVDVRNMPEQDKVLVKQLASLPPDTELTSFFLNSSDKILLKRYSETRRLHPLSKS QVSLQEAIKLEGKLLEPMSKLVDHYIDTSNLNIYDLSDQVRQILLGSVDKELVINFESFGFKHGMPTEADFMFDVRFLPNPHWELALRPLTGLDEPVAEFLNRQPLVN QVSLQEAIKLEGKLLEPMSKLVDHYIDTSNLNIYDLSDQVRQILLGSVDKELVINFESFGFKHGMPTEADF
KFIWQIENLLETWLPHLERNNRSYLTVAIGCTGGQHRSVYVAEQLAKRFSNGKHKVYARHRELNNAKA

$>$ SHEDEF_UPF0042

MKLVIVSGRSGSGKSVALRVLEDLGYYCVDNLPLPLIGSLLAQLKSSNDLVAISVDVRNIAEQGKVLEQQLALLPPETEISSFFLNSSDKVLLKRFSETRRLHPLSRSQ MSLQEAIKLEGRLLEPIAKMVDHHIDTSLLNVYELSDQVRQILLGSVDKELVINIESFGFKHGMPTEADFMFDVRFLPNPHWETELRPLTGLDVPVQEFLARQPLVHK LIWQIENLFETWMPHLERNNRSYLTIAIGCTGGQHRSVYIADQLAKRFANGKHVVNARHRELGDVKA

$>$ SHEFRI UPF0042

MKLVIVSGRSGSGKSVALRVLEDLGYYCVDNLPLPLIGTLLAQLKGSNDLVAISVDVRNIAEQGKVLQDQLALLENDTEIISFFLNSNDKVLLKRYSETRRLHPLSKNHI SLQEAIKLEGRLLEPIAKIVDHYIDTSALNIYELSDQVRQILLGSVDKELVINFESFGFKHGMPTEADFMFDVRFLPNPHWEIELRPFTGLDEPVQEFLGRQPLVNKFIW QIENLFETWMPHLERNNRSYLTIAIGCTGGQHRSVYIADQLAKRFRQGSKHTVNARHRELNISDTNN

$>$ SHELOI UPF0042

MKLVLVSGRSGSGKSVALRVLEDLGYYCVDNLPLQMMESLLEQLKGRSDLVAISVDVRNMPSEEIQLEKQLAKLPKDTEILSFFLNSSDNVLLKRYSETRRLHPLSR SKVSLKEAIOLEGKLDPIAKLVDHYIDTSNLNIYELSDKVREILLGTVDKELVINFESFGFKYGMPTEADFMFDVRFLPNPHWETELRPLTGLDEPVQQFLSQQPLVN KFIWQIENLLETWLPHLERNNRSYLTIAIGCTGGQHRSVYVTDQLAKLFNKGKHKVQARHRELKHD

\section{$>$ SHEONE SO3964}

MKLVIVSGRSGSGKSVALRVLEDLGYYCVDNLPLPLIGSLLEQLKGSNDLVAISVDVRNLPEQDKVLVKQLASLPEGTELTSFFLNSSDKVLLKRYSETRRLHPLSKS RVSLQEAIKLEGKLLEPLSQQMDHYIDTSNLNIYELSDQVRQILLGSVDKELVINFESFGFKHGMPTEADFMFDVRFLPNPHWEPELRPLTGLDEPVAEFLNRQPLV NKFIWQIENLLETWLPHLERNNRSYLTIAIGCTGGQHRSVYVAEQLAKRFSNGKHKVNARHRELSHAKA

$>$ SHEPUT UPF0042

MKLVIVSGRSGSGKSVALRVLEDLGYYCVDNLPLPLIGSLLEQLKGSNDLVAISVDVRNMPEQDKVLVQQLSNLPAGTEITSFFLNSSDKVLLKRYSETRRLHPLSKS RVSLQEAIKLEGKLLEPMSKLVDHYIDTSNLNIYDLSDQVRQILLGSVDKELVIYFESFGFKNGMPTEADFMFDVRFLPNPHWELALRPLTGLDEPVAEFLNRQPLVN KFIWQIENLLETWLPHLERNNRSYLTIAIGCTGGQHRSVYVAEQLAKRFSNGKHKVNVRHRELDNAKA

$>$ SHEWOO_UPF0042

MKLVMVSGRSGSGKSVALRVLEDLGYYCVDNLPLPLMDTLLEQLKDSTELVAISVDVRNMHETELDKQLSNLPEGTELLSFFLNSSDEVLLKRYSETRRLHPLSRSK TSLKEAIDHERILLEPVSKLVDHYIDTSNLNIYDLSNQVREILLGSVDKELVINFESFGFKHGMPAEADFMFDVRFLPNPHWEPELRPMTGLDEPVQLFLSQQPTVNK FIWQIENLLETWLPHLERNNRSYLTIAIGCTGGQHRSVYVTEQLAKLFSQSKHTVQARHRELSND

$>$ SHIFLE_YHBJ

MVLMIVSGRSGSGKSVALRALEDMGFYCVDNLPVVLLPDLARTLADREISAAVSIDVRNMPESPEIFEQAMSNLPDAFSPQLLFLDADRNTLIRRYSDTRRLHPLSS KNLSLESAIDKESDLLEPLRSRADLIVDTSEMSVHELAEMLRTRLLGKRERELTMVFESFGFKHGIPIDADYVFDVRFLPNPHWDPKLRPMTGLDKPVAAFLDRHTE VHNFIYQTRSYLELWLPMLETNNRSYLTVAIGCTGGKHRSVYIAEQLADYFRSRGKNVQSRHRTLEKRKP

>SODGLO_SG0196

MVLMIVSGRSGSGKSVALRALEDMGFYCVDNLPVVLLPQLASALAASNISAAVSIDVRNMPESPEIFEQAMDNLPQAFAPQLLFLDADRNTLIRRYSDTRRLHPLSA LNLSLESAIDEEDSLLEPLRSRADLVIDTSEMSVHELAEMLRTRMLGKRERELTMVFESFGYKHGIPIDADYVFDVRFLPNPHWDPKLRPMTGLDRPVAAFLDRHTE VHNFIYQTRSYLELWLPMLETNNRSYLTVAVGCTGGKHRSVYIAEQLADYFRSRGKNAQSRHRTLEKSKS

$>$ STAAUR SP

MDNNEKEKSKSELLVVTGLSGAGKSLVIQCLEDMGYFCVDNLPPVLLPKFVELMEQGNPSLRKVAIAIDLRGKELFNSLVAVVDKVKSESDVIIDVMFLEASTEKLISR YKETRRAHPLMEQGKRSLINAINDEREHLSQIRSIANFVIDTTKLSPKELKERIRRYYEDEEFETFTINVTSFGFKHGIQMDADLVFDVRFLPNPYYVVDLRPLTGLDK DVYNYVMKWKETEIFFEKLTDLLDFMIPGYKKEGKSQLVIAIGCTGGQHRSVALAERLGNYLNEVFEYNVYVHHRDAHIESGEKK

$>$ STAEPI_SE0548

MTSNEKEMGKSELLVVTGMSGAGKSLVIQSLEDMGFFCVDNLPPVLLPKFVELMAQGNPSLQKVAIAIDLRGKELFKSLVKEIDIIKSRNDVILDVMFLEAKTEKIISRY KESRRAHPLNEQGQRSLIDAINEEREHLSEIRSIANYVIDTTKLKPKELKQRISKFYLDENFETFTINVTSFGFKHGIQMDADLVFDVRFLPNPYYVEELRPFTGLDEPV YNYVMKWKETQIFFDKLTDLLKFMIPGYKKEGKSQLVIAIGCTGGQHRSVALAKRLAEYLNEIFEYNVYVHHRDAHIESGER

$>$ STAHAE SH2124

MTNHKENEMSKSELLVVTGLSGAGKSVVIQCLEDIGYFCVDNLPPILLPKFVELMEQGNPSLQKVAIAIDLRGKELFKSLVEEIDAIKSRNDVIVDVMFLEAETEKLISR YKESRRAHPLNENGQMSLMDSILEEKQLLSNIRTIANYIVDTTOLTTKELKARVKEKFEDENFKSFSINVSSFGFKHGIOKDADLVFDVRFLPNPYYVEDLRPMTGED EPVYHYVMKWKETEIFFEKLMDLLKFMIPGYKKEGKSQLVIAIGCTGGQHRSVALAKRIGEELTEIFDYNVYVHHRDAHIESGVRK

$>$ STASAP_SSP1952

MQPDEKEIVKSELLVVTGLSGAGKSVVIQSLEDIGYFCVDNLPPILLPKFVELMGQGNPSLQKVAIAIDLRGKELFKSLIHEMDLIKSNSDVIVDMMFLEASNERLISRY KETRRAHPLNGNGQRSLIESINEERELITEIKSLANYTIDTTOMKPKELRKRIGDYFNKSNVQTFNINVTSFGFKHGIQMDADLVFDVRFLPNPHYVDELRPLTGEDE AVYKYVMKWKETNIFYEKLIDLLKFMVPGYKKEGKSQLVIAIGCTGGQHRSVALAKRIGAELNESFDYNVYVHHRDAHVESGVKHKDEKN

$>$ STRAGA GBS0576

MSDEQIKLVIVTGMSGAGKTVAIQSFEDLGYFTIDNMPPTLVPKFLELAAQSGDTSKIAMVVDMRSRLFFREINSILDSLEINDNINFKILFLDATDTELVSRYKETRRS HPLAADGRVLDGISLERELLAPLKSMSQNVVDTSELTPRQLRKVISKEFSNQDSQSSFRIEVMSFGFKYGIPLDADLVFDVRFLPNPYYKPELRDKTGLDTEVYDYV MSFDESDDFYDHLLALIKPILPGYQNEGKSVLTVAIGCTGGQHRSTAFAHRLSEDLKADWTVNESHRDKNKRK ETVNRS

>STRMUT_SMU 1306 C

MSEKKIDLVIVTGMSGAGKTVAIQSFEDLGYFTIDNMPPALVPKFLELVESSGENDKVALVVDMRSRLFFKEVSSILDKIDLNETINFRILFLDATDSELVSRYKETRRS HPLATTGRVLDGIALERELLAPLKNLSQNVVDTTDLTPRQLRKTISDQFSVEKSQTSFRLEVVSFGFKYGLPLDADLVFDVRFLPNPYYKPELRDKTGLDKDVSDYV MQHQESEEFYQHLLALLAPILPGYQKEGKSVLTIAIGCTGGQHRSVAFAHRLAQDLGQNWTVNESHRDKNRRKETVNRS

$>$ STRPNE SP1566

MTKKQLHLVIVTGMSGAGKTVAIQSFEDLGYFTIDNMPPALLPKFLQLVEIKEDNPKLALVVDMRSRSFFSEIQAVLDELENQDGLDFKILFLDAADKELVARYKETRR SHPLAADGRILDGIKLERELLAPLKNMSQNVVDTTELTPRELRKTLAEQFSDQEQAQSFRIEVMSFGFKYGIPIDADLVFDVRFLPNPYYLPELRNQTGVDEPVYDYV MNHPESEDFYQHLLALIEPILPSYQKEGKSVLT IAMGCTGGQH RSVAFAKRLA QDLSKNWSVN EGHRDKDRRK ETVNRS

>STRPYO_SP.

MSDKHINLVIVTGMSGAGKTVAIQSFEDLGYFTIDNMPPALVPKFLELIEQTNENRRVALVVDMRSRLFFKEINSTLDSIESNPSIDFWILFLDATDGELVSRYKETRRS HPLAADGRVLDGIRLERELSPLKSMSQHVVDTTKLTPRQLRKTISDQFSEGSNQASFRIEVMSFGFKYGLPLDADLVFDVRFLPNPYYQVELREKTGLDEDVFNYV HPLAADGRVLDGIRLERELLSPLKSMSQHVVDTTKLTPRQLRKTISDQFSEGSNQASFRIEVMSFGFKYGLPLDADLVFDVR
MSHPESEVFYKHLLNLIVPILPAYQKEGKSVLTVAIGCTGGQHRSVAFAHCLAESLATDWSVNESHRDQNRRKETVNRS

>STRSAN YP 001034791 MSEKKIQLVIVTGMSGAGKTVAIQSFEDLGYFTIDNMPPTLVPKFLQLVEGTTDNDKLALVVDMRSRSFFLQIQNVLDELEQNENIDFKILFLDAADKELVARYKETRR
SHPLAADGRILDGIKLERELLAPLKNLSQNVVDTTDLTPRELRKTISEQFSNQADMHSFRIEVMSFGFKYGLPLDADLVFDVRFLPNPYYKPELRNQTGLDKDVFDYV SHPLAADGRILDGIKLERELLAPLKNLSQNVVDTTDLTPRELRKTISEQFSNQADMHSFRIEVMSFGFKYGLPLDADLVFDV
MNHAESEEFYKNLLGLIEPILPGYQKEGKSILTIAVGCTGGQHRSVAFAQRLA DDLAKNWPVN SSHRDKNRRK ETVNRS

>STRSUI_UPF0042

MSDKLHLVIVTGMSGAGKTVAIQSFEDLGYFTIDNMPPTLLPKFLELIRHSQDNNKIALVVDMRSRSFFSEIREVLDEIEGAEDLDFKVLFLDATDNELVARYKETRRS HPLAADGRVLDGIQLERELLAPLKNMSQNIIDTTELTPRNLRKAISEQFASQDNQPSFRIEVMSFGFKYGLPLDADLVFDVRFLPNPYYKLELRNLTGLDAPVFDYVM EHQESEEFYSHLLGLIEPILPGYQKEGKSILTIAVGCTGGQHRSVAFAKRLADDLEKNWNVNRSHRDKDRRKETVNRS 
>STRTHE_STR0831

MKTKIINLVVVTGMSGAGKTVAIQSFEDIGYFTIDNIPPSLVPKVIELLKHSEETDKIALVVDMRSRVFFDEINDILDQLESNEKLNFKILFLDATDGELVSRYKETRRSH PLAADGRVLDGIKLERELLSPLKSLSQNVVDTTKLTPRQLRKAISEQFSSKQDQSSFRIEVLSFGFKYGLPLDADLVFDVRFLPNPYYDPTLRNLTGLDKEVYDFVMT HKESEDFYKNLNHLIKPILPGYQKEGKSVLTIAVGCTGGQHRSVAFAHRLAQDLKNDWTVNETHRDKDRRKETVNRS

>STPAVE SAV6292

MTEHEERQEERSAQGQEAHKESGEDQAPQQAAQENGAQVSTGIETAGVPDAVIPELVIISGMSGAGRSTAAKCLEDLGWFVVDNLPPALIPTMVELGARSQGNVA RIAVVVDVRGRRFFDNLRESLADLESKNVTRRIVFLESSDEALVRRFESVRRPHPLOGDGRIVDGIDAERELLRELRGDADLVIDTSSLNVHELRAKMDAOFAGDEE PELRATVMSFGFKYGLPVDADLVVDMRFLPNPHVPELRPFTGLNEEVSAYVFNQPGAKEFLDRYAELLLIAAGYRREGKRYVTIAVGCTGGKHRSVATSEKLAA RLAAEGVETVVVHRDMGRE

$>$ SYMTHE STH186

MMDVDRSIRLVIVTGMSGAGKTQALKYLEDLGFFCVDNLPPSLMPKLAELFGQTEGKVSRLALGIDIRGGRFFHEILGALRQIAEIGVAYQILFMDASDEVLVRRYKE TRRRHPLAAQGRVLDGIQRERRLLQELRGLATFIIDTTHMTPADLRKELNRRFGQDRESPHFHVNVVSFGFKHGAVLDADLVFDVRFLPNPHYVPDLQPLTGEDPA VVEYVMKWNVTQQFYRRLTGLIGFLLPHYVAEGKSLLTIAIGCTGGKHRSVCLANRLAHWIRERGYSVSVEHRDMPRPADRSDEEEQP

$>$ THETHE TTHA0319

MRFLVLTGLSGAGKTTARGFLEDLGYFMVDNLPPRLWLPLLQEAAARGLARVGVVVDARALAFFQDLEEVLEALRPTVVYLEARPEVLLRRYNLTRRVHPLGAGNL MREIAEERRALAGLRGRAHLVVDTSELSPRGLKEALARFLGEEGGFLLRLVSFGFKWGPPQEADLVLDVRPLPNPHYDPALRPRTGLDPEVRRYVFSEAAEPYYR ALLAVAGLAAEGARAEGRAFYTVAVGCTGGRHRSVAVAERLAEELSGRFAVEVVHRDVE REG

$>$ THERETH_UPF0042

MRFVIITGLSGAGKTQALKAMEDMGFFCIDNFPPALLPKLADLFYHSKNVDKVALGMDLRGGQFFEDIYSSLEFLKKNNYDYEIVFLEASDEVLIKRFKETRRKHPLS EEGRIVDGINEERKRLAEIRKIANSIIDTSNLTSSQLKEELSNIFLKGKKFKGIIIDIMSFGYKYGIPLDADLVFDVRFLPNPFYIEELRPLTGNDDKVKEYVMKWEEAKEF LKKLGDMIKFLIPYYIREGKSQLVIAIGCTGGKHRSVTIANALYEFLKKEDYSVILHHRDIGEE

$>$ THERTEN_TTE1834

MRFVIITGLSGAGKTQALKAMEDMGFFCIDNFPPALIPKLADLFYQSKNIDKVALGMDLRGGQFFEDIYSSLDFLKKNNYDYEIVFLEASDEVLIKRFKETRRRHPLSE EGRIVDGINEERKRLSDIRKIANYIIDTSNLTSSQLKEELSNIFLKGKKFKGIIIDVMSFGYKYGIPLEADLVFDVRFLPNPFYIDELRPLTGNDEKVKEYVMKWEEAKEFL KKLGDMIKFLIPYYVREGKSQLVIAIGCTGGKHRSVAIANALYDLLKKEDYSVVVNHRD IGEE

$>$ THESCAR_UPF0042

MEDLRLVIITGMSGAGKSQVARAMEDLGYFCVDNLPPALIPKFAELCAQSAGRVRKIALVVDIRGGEFFDTLVQVLEDMEKQGFFYEILFLEAADETLIRRYKETRRR HPMAPHGRISEGISRERDRLEHIRGRATHIIDTSDLSTAQLKDKIAALFAGEREYERMTITVVSFGFKYGIPLDADMVFDVRFLPNPFYVESLRKKSGETPEVSEYIWK WPITQQFMEKLGGLVDFLVPNYIKEGKSQLIIAVGCTGGLHRSVFVANKIYEGLRNKGYKVNVEHRDIKHNIVEPC

$>$ VIBALG_V12G01_14314

MRLIVVSGHSGAGKSIALRVLEDLGYYCVDNLPVNLLDAFVHSVADSKQNVAVSIDIRNIPKKLKELTSTLEQLKTELDVTVLFLDANKETLLKRYSETRRIHPLSLGGT SLSLDQAIEREKQILTPLKAHADLVLNSSGQSLHELSETVRMRVEGRDRKGLVMVFESFGFKYGLPSDADYVFDVRFLPNPHWEPALRPLTGLDAPIAAFLEQHQS VLSLKYQIESFIENWLPLLEKNNRSYLTVAIGCTGGKHRSVYLTQQIGEYFANKGHQVQIRHTSLEKNAKE

$>$ VIBANG_VAS14_19686

MMLMVVSGRSGSGKSVALRVLEDLGYYCVDNLPVNLLPQFVKDIAHTEQDIAVSIDVRNMPQQPGEIQRILKSLENDVDVNVVFLDADDKELVKRYSETRRLHPLS RQNMTLEQAITSESAILGDLKEHADLVIDTTNKSIHDLSETVRARVLGREAKELILVFESFGFKHGLPSDADYVFDVRFLPNPHWVPELKPQTGLDQGVKDFLSSQSE VNQLNYQIRNFIESWLPMLEKNNRSYVTVAIGCTGGQHRSVYIAQSLADYFEHQGQQVQVRHRTLEEKQ

$>\mathrm{VIBCHO}$ VC2532

MRLIVVSGQSGAGKSVALRVLEDLGYYCVDNLPVSLLTAFIQSVQGSQQNVAVSIDIRNLPKEPSLVQDVLDQLKQNNDVSMLFLDASKETLLKRYSETRRIHPLSLS QSKPSLAQAIELEKQLLGPLKEQADLLLDSSNQSLHELSETVRMRIEGRERKDLVMVFQSFGFKYGLPTDADYVFDVRFLPNPHWEPDLRPLTGLDAPIKSFLEGHS EVMELKQQIQKFFEYWLPMLEKNNRSYLTIAIGCT GGKHRSVYLT QQLGEYFAQL GHQVQLRHTS LEKQQS

$>$ VIBFIS_VF0384

MKLMVVSGSSGAGKSVALRVLEDLGYYCVDNLPIDLLTQFVESIQHSSQNVAVSVDIRNLPKDPALLKNTLALLKKTHDVTVIFLDAEDKELIKRYSETRRLHPLSLIG MKLMVVSGSSGAGKSVALRVLEDLGYYCVDNLPIDLLTQFVESIQHSSQNVAVSVDIRNLPKDPALLKNTLALLKKTHDVTVIFLDAEDKELIKRYSETRRLHPLSLIG
EQCSLEQAVTLEKSILSDYREEADLVLDTTTKSIHDLSETLRSRILGRESKELVMVFESFGFKHGLPTDADYVFDVRFLPNPHWEPSLRPMTGLDKPVADYLAKHTE VIQLKEQIQQFLTTWLPALEKNNRSYLTVAIGCTGGQHRSVYITQQLGEYFKQQGKQVQIRHKTLERH

$>$ VIBHAR_AAF72890

MRLIVVSGHSGAGKSVALRVLEDLGYYCVDNLPVNLLDAFVQSVSESKQNVAVSIDIRNIPKKLKELNTTLEKLKAELDVTVLFLDANKETLLTRYSETRRIHPLSLDS QSLSLDQAIELEQEILMPLKAHADLVLNSSGQSLHDLSETVRMRVEGRERKDLVMVFESFGFKYGLPSDADYVFDVRFLPNPHWEPALRPLTGLDGPIGAFLEQHQ SVLDLKYQIESFIETWLPLLEKNNRSYLTVAIGCTGGKHRSVYLTQKIGEFFADKGHQVQIRHTSLEKNVKE

$>$ VIBPAR VP2673

MRLIVVSGHSGAGKSIALRVLEDLGYYCVDNLPVNLLDAFVHSIADSKQNVAVSIDIRNIPKKLKELTGTLEQLKTELDVTVLFLDANKETLLKRYSETRRIHPLSLGGQ SLSLDQAIEREKEILTPLKAHADLILNSSGQSLHELSETVRMRVEGRDRKGLVMVFESFGFKYGLPSDADYVFDVRFLPNPHWEPALRPLTGLDAPIAAFLEQHQSV LSLKYQIESFIETWLPLLEKNNRSYLTVAIGCTGGKHRSVYLTQQIGEYFADKGHQVQIRHTSLEKNAKE

$>$ VIBSPL_V12B01 07423

MRLIVVSGQSGAGKSVALRVLEDLGYYCVDNLPVNLLSDFVESVREINQNVAVSIDIRNLPKEPQLVTETLEQLEAATDIDVNVLFLDASKQTLLKRYSETRRIHPLSI GQEKLSLEQAIDLEKTLLTPLAEQASIVIDSSDCNLYELSEKVRFKVEGKEKQELIIVFQSFGFKYGLPSDADYVFDVRFLPNPHWEPALRPLTGLDAPIHSFLEKHSE VLELKQQIQGFVEQWLPMLEKNNRSYLTVAIGCTGGKHRSVYLTQKIGEYFEQLGHQVQIRHASLEKHQQG

$>$ VIBVUL_VV0445

MRLIVVSGHSGAGKSVALRVLEDMGYYCVDNLPVNLLESFIQSVSESKQNVAVSIDVRNIPKKLKELTTTLQKLKSSIDLSILFLDADKATLLKRYSETRRVHPLSLSD MRLIVVSGHSGAGKSVALRVLEDMGYYCVDNLPVNLLESFIQSVSESKQNVAVSIDVRNIPKKLKELTTTLQKLKSSIDLSILFLDADKATLLKRYSETRRVHPLSLSD ECHTLDQAIDLEKKMLKPLKEIADILLNSSNQSLHDLSEDVRYRIEGKERNKLIMVFESFGFKFGLPTDA
ELKRQIQTFIEHWLPLLEKNNRSYLTVAIGCTGGKHRSVYLTQQIGEYFAAMGHTVKIRHTTLEKRNKE

$>$ YERBER_ZP_00821539

MVLMIVSGRSG GSKSVALRALEDMGFYCVDNLPVVLLPQLANTLAGRNISAAVSIDVRNMPESPEVFEHAMTQLPDSFSPQLLFLDADRNTLIRRYSDTRRLHPLSA KNLSLESAIDEESILLEPLRSRADLVIDTSEMSVHELAEMLRTRLLGKRERELTMVFESFGFKHGIPIDADYVFDVRFLPNPHWDPKLRPMTGLDKPVISFLDRHTEVH NFVYQTRSYLEQWLPMLETNNRSYLTVAIGCTGGKHRSVYVAEQLADYFRARGKNVQSRHRTLEKRKQ

>YERENT_ZP_00834134

MVLMIVSGRSGSGKSVALRALEDMGFYCVDNLPVVLLPQLASTLADRNISAAVSIDVRNMPESPEVFEHAMTQLPDSFSPQLLFLDADRNTLIRRYSDTRRLHPLST KNLSLESAIDEESDLLEPLRSRADLIIDTSEMSVHELAEMLRTRLLGKRERELTMVFESFGFKHGIPIDADYVFDVRFLPNPHWDPKLRPMTGLDKPVISFLDRHTEV HNFIYQTRSYLELWLPMLETNNRSYLTVAIGCTGGKHRSVYVAEQLADYFRARGKNVQSRHRTLEKRK

>YERFRE_ZP_00828963

MVLMIVSGRSGSGKSVALRALEDMGFYCVDNLPVVLLPQLASTLAERNISAAVSIDVRNMPESPEVFEHAMTQLPDSFSPQLLFLDADRNTLIRRYSDTRRLHPLST KNLSLESAIDEESVLLEPLRSRADLIIDTSEMSVHELAEMLRTRLLGKRERELTMVFESFGFKHGIPIDADYVFDVRFLPNPHWDPKLRPMTGLDKPVISFLDRHTEVH NFVYQTRSYLELWLPMLETNNRSYLTVAIGCTGG KHRSVYVAEQ LADYFRARGK NVQSRHRTLE KRK

$>$ YERMOL_ZP_00827279

MVLMIVSGRSGSGKSVALRALEDMGFYCVDNLPVVLLPQLASTLADRNISAAVSIDVRNMPESPEVFEHAMTQLPDSFSPQLLFLDADRNTLIRRYSDTRRLHPLST

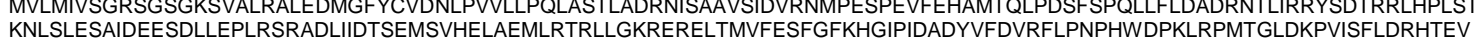
HNFVYQTRSYLELWLPMLETNNRSYLTVAIGCTGGKHRSVYVAEQLADYFRARGKNVQSRHRTLEKRKQ

$>$ YERPES SP.

MVLMIVSGRSGSGKSVALRALEDMGFYCVDNLPVVLLPQLASTLADRNISAAVSIDVRNMPESPEVFEHAMTQLPDSFSPQLLFLDADRNTLIRRYSDTRRLHPLSA KNLSLESAIDEESDLLEPLRSRADLIIDTSEMSVHELAEMLRTRLLGKRERELTMVFESFGFKHGIPIDADYVFDVRFLPNPHWDPKLRPMTGLDKPVISFLDRHTEV HNFIYQTRSYLEQWLPMLETNNRSYLTVAIGCTGG KHRSVYVAEQ LADYFRARGK NVQSRHRTLE KRKQ 
>YERPSE_YPTB3529

MVLMIVSGRSGSGKSVALRALEDMGFYCVDNLPVVLLPQLASTLADRNISAAVSIDVRNMPESPEVFEHAMTQLPDSFSPQLLFLDADRNTLIRRYSDTRRLHPLSA KNLSLESAIDEESDLLEPLRSRADLIIDTSEMSVHELAEMLRTRLLGKRERELTMVFESFGFKHGIPIDADYVFDVRFLPNPHWDPKLRPMTGLDKPVISFLDRHTEV HNFIYQTRSYLEQWLPMLETNNRSYLTVAIGCTGGKHRSVYVAEQLADYFRARGKNVQSRHRTLEKRKQ

>ZYMMOB_ZMO1325

MSRNDLSSAPSSSAAPPARILLVTGLSGAGKSTALRTFEDMGWETVDNLPLSLLERLILTPPSSVAAYKGRPLALGIDSRTRGFTVDAFLKGVEQLRQHHSQPIDILF LDCSDSELMRRFDTTRRRHPLALDRPMEDGISEERAFLAPVREIADFLIDTTTTSSHSLQSELRQQFAPENSVAPNVSILSFGFSRGIPRNCDLLFDMRFLQNPYWE EALRPLTGLDPEIADYIEQDPSFLPAVTKIKDLLLFLLPRYIDTGKSYIVIAFACTGGRHRSVYVAEWIAARLRQAHFSLTITHRDLKLPLLESQSNRIRAGKAYQGG

\subsubsection{Clustal W-Analyse}

\section{CLUSTAL W (1.83) multiple sequence alignment}

LeiXy1_Lxx11490 StpAve_SAV6292 MYCTubCDC1551_MT146 MycTubH37Rv_RV1421 MycSme_MSMEG3088 NocFar_nfa358930 CorEff_CE1710 BifLon_BL0705 ActPle_ZP 00133926 HaeDuc_HD0584 Act Suc

ManSuc_MS1718

HaeInf_AAC2280

PasMul_PM0169

HaeSom_ZP_00132582

EscColsp._YhbJ

ShiFle_YhbJ

SalEntATCC9150_YhbJ

SalTyp_YhbJ

SalEntTY2_T3240

KlePne_.

YertSp._-ZP_00834134

YerEnt_ZP_00834134

YerMol_ZP_00827279

YerFre_ZP_-

YerPse_YPTB 3529

YerBer

SerPro_ZP_01538297

ErwCar_ECA0285

Phorlum_plu4044

ProMir_AAC64575

SodGlo_SG0196

PhoPro_PLU4044

VibAng

VibAlg

VibPar_VP2673

VibHar_AAF72890

VibVul_VV0445

VibCho_vC2532

VibSpl_V12B01_07423

VibFis_VF0384

AerHyd_AHA_3920

AerSal_ABO88502

IdiLal_OS1035_II0393

AltBac_ATW7_18740

AltBac_ATW7_18740

PseHal_PSHAa2554

AlteMac_MADE_14619

PseAt 1_UPF 0042

ColPsy_CPS_4546

SheBal UPF0042

ShePut_UPF0042

SheOne_SO3964

SheDef_UPF0042

SheFri_UPF0042

SheAma_Sama_3091

SheLOi_UPF0042

SheWoo_UPF0042

MarAqu_UPF0042

AzoSp._ebA3650

NitEur_NE1849

ACiSp._ACIAD 305

ZymMob_ZMO1325

DesRed_UPF0042

ThesCar_UPF004

HalOre_UPF 0042

DesbHaf_DSY4845

MooThe_YP_429136

CarHyd_YP_359144

SymThe_STH186

ClOAce_CAC0511

CloTet_CTC02495

CloBei_ZP_00909349

CloPer_CPE0354

AlkMet_UPF0042

TherEth_UPF0042

TherTen_TTE1834

CloThe_UPF0042

CalSac_zP_00884966

BacWei_UPF0042

BacWei_UPF0042

BacAnt_GBAA5384
----10 MTEHEERQEERSAQGQEAHKESGEDQAPQQAAQENGAQVSTGIETAGVPDAVIPELVIIS 60 -MMNHARGVEN--RSEGG------GIDVVLVT 23

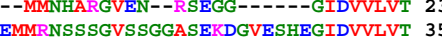

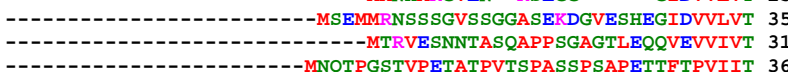
---------------------MNQTPGSTVPETATPVTSPASSPSAPETTFTPVIIT 36

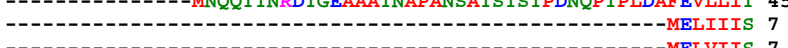
--------MELVIIS 7

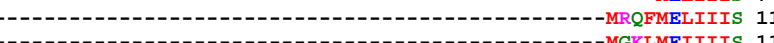
-------------------------------------MGKLMEIIIIS 11 -----------------------------------------MEIIIIS 7 -

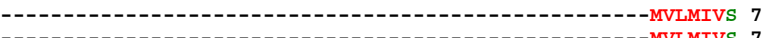

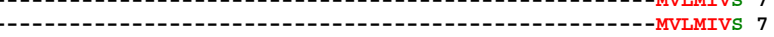

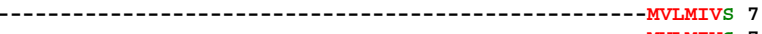
------MVLMIVS 7

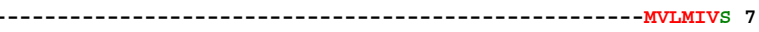

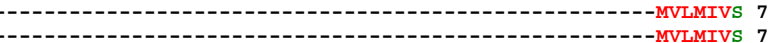

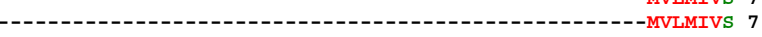

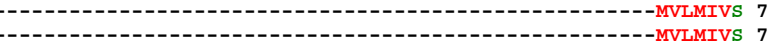

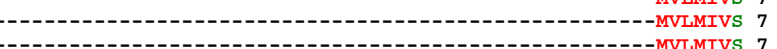

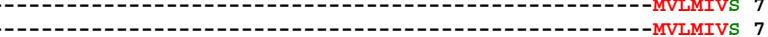
------------------------------------------------------MQLMVVS 7

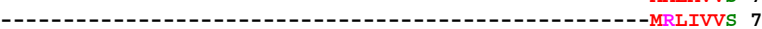

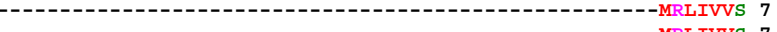
-

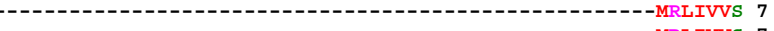
-

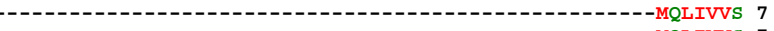
-

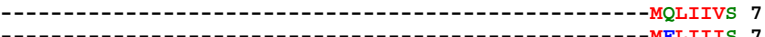
---------------------------------------------------------------MQIIIIS 7

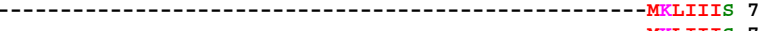

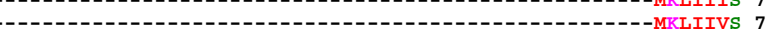

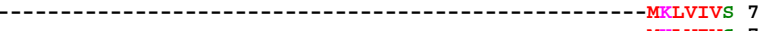

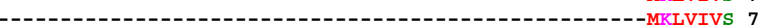

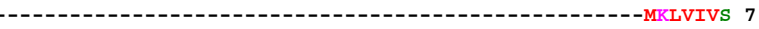

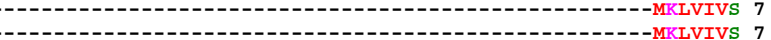

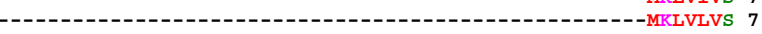
-------------------------------------------------------MKLVMVS 7 --------------------------------------------------------MQIVIIS 7

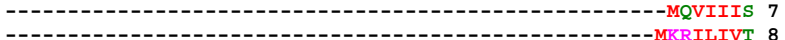
------------------------------------MSRNDLSSAPSSSAAPPARILIVT 24

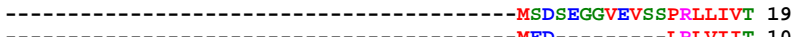

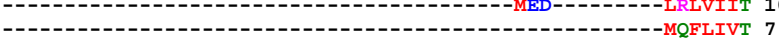

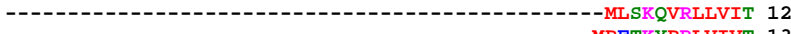
--------------------------------------MPETKYPRLVIVT 13

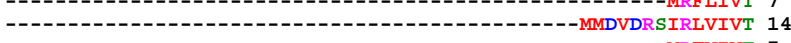

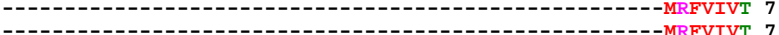

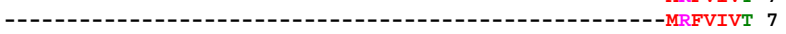

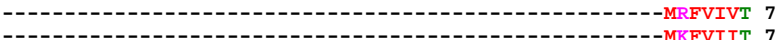
----------19 7 $------1-0$

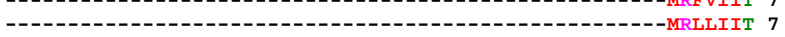

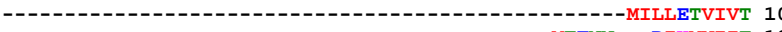

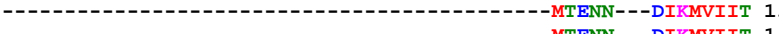

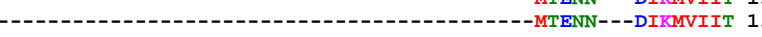


Anhang

GeoKau_GK3066
GeoThe_GTNG_3015
BacCoa_UPF0042
BacLic_YvCJ
BacSub_YvCJ
BacCla_ABC3036
BacHal_BH3569
OceIhe_OB2468
LisInn_lin2617
LisWel_lwe2422
LisMon_Sp.
ExiSib_UPF0042
EntcFae_EF0766
EntcFaec_UPF0042
LacPla_lP_0779
LacSak_YP_395138
LacCas_YP_806200
LacSal_YP_536062
LacBre_YP_794827
PedPen_YP_803988
StrMut_Smu_1306c
StrPyo_Sp.
StrAga_gbs0576
StrThe_str0831
StrPne_SP1566
StrSan_YP_001034791
StrSui_UPF0042
LactLac_L188550
LacReu_ZP_01164767
LacAci_LBA0691
LacDel_YP_618706
LacGas_YP_815115
LacJoh_IJ0866
StaAur_Sp.
StaEpi_SE0548
StaHae_SH2124
StaSap_SSP1952
FusNuc_FN1089
GloVio_glr4163
TheThe_TTHA0319

LeiXy1_Lxx11490
StpAve_SAV6292

MycTubCDC1551_MT1464

MycTubH37Rv_RV1421

MYCSme_MSMEG3088

NocFar_nfa3589

CorEff_CE1710

BifLon_BL0705
ActPle_ZP_00133926

ActPle_ZP_00133926
HaeDuc_HD0584

ActSuc_

ActSuc_-

HaeInf_AAC22801

PasMul_PM0169

HaeSom_ZP_00132582

EscColsp._YhbJ

ShiFle_Yhb

SalEntATCC9150_YhbJ

SalTyp_YhbJ

SalEntTy2_T3240

KlePne_P17163

EntSp.

YerEnt_ZP_00834134

YerMol_ZP_00827279

YerFre_ZP_00828963

YerPes_Sp.

YerPse_YPTB3529

YerBer

SerPro_ZP_01538297

ErwCar_ECA0285

PhorLum plu4044

PhorLum_plu4044

SodGlo_SG0196

PhoPro_PLU4044

VibAng_

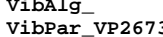

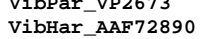

VibVul_VV0445

VibVuI_VV0445

VibSpl_V12B01_07423

VibSpl_V12B01_

VibFis_VF0384

AerHyd_AHA_3920

AerSal_ABO88502

IdiBal_OS145_0

AltBac_ATW7_18740

PseHal_PSHAa2554

PseTun_PTD2_17262

AlteMac_MADE_14619

PseAt1_UPF 0042

ColPsy_CPS_4546

SheBal_UPF0042

ShePut_UPF0042

SheOne_SO3964

SheDef_UPF0042

SheFri_UPF0042

SheAma_Sama_3091

SheLoi_UPF0042

SheWoo_UPF0042

MarAqu_UPF0042

AzOSP

NitEur_NE1849

AciSp._ACIAD3059

ACiSp._ACIAD 3059

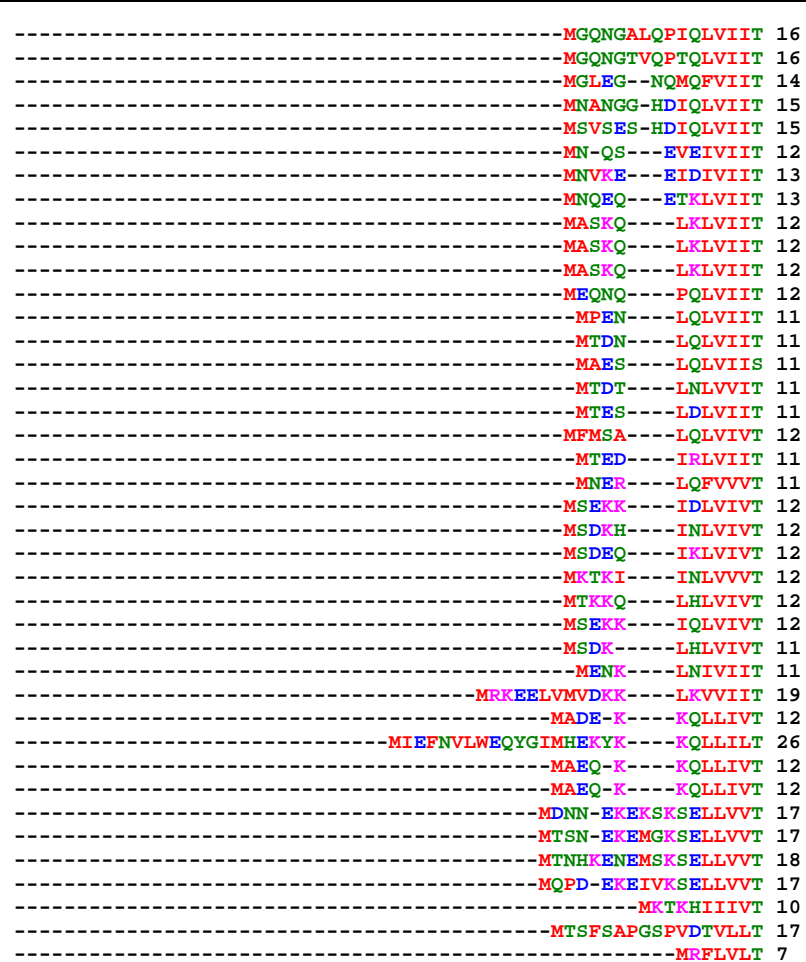

$\therefore::$

GMSGAGRSTVANALEDLDWYVVDNLPPQMLRPLIELANRA----ES--GLPRIAAVVDVR 72 GMSGAGRSTAAKCLEDLGWFVVDNLPPALIPTMVELGARS----QG--NVARIAVVVDVR 114 GLSGAGRGTAAKVLEDLGWYVADNLPPQLITRMVDFGLAA----GS--RITQLAVVMDVR 77 GLSGAGRGTAAKVLEDLGWYVADNLPPQLITRMVDFGLAA----GS--RITQLAVVMDVR 77 GLSGAGRGTAAKVLEDLGWYVADNLPPELIARMVDLGLAA----GS--RITQLAVVMDVR 89 GLSGAGRGTAAKVLEDLGWYVADNLPPELIGRMVELGAAA----DP--PIRRLALVMDVR 85 GLSGAGRGTAAKVLEDLGWYVADNLPPELIGRMVELGAAA----DP--PIRRLALVMDVR 85
GMSGAGLSTAARVLEDLGWFVTHNLPPOMILPLVEMCARE----DS--PVDKVAVVCDVR 90 GMSGAGRSHAADCVEDMGWYVVDNLPPKLIIPLVDMMTTSGSGSES--GVHKLAAVIDVR 103 GMSGAGRSHAADCVEDMGWYVVDNLPPKLLIPLVDMMTTSGSGSES--GVHKLAAVIDVR 103
GRSGSGKSVALRALEDVGYYCVDNLPLPLIPELAGFLSNSGRS---------AVVSLDIR 58 GRSGSGKSVALRALEDVGYYCVDNLPLPLIPELAGFLSNSGRS----------AVVSLDIR 58 GRSGAGKSVALRALEDIGYYCVDNLPIDLLPQLADILSOSOAS---------AAISLDIR 58 GRSGAGKSVALRALEDIGYYCVDNLPIDLLPQLADILSOSQAS---------AAISLDIR 58 GRSGAGKSVALRALEDMGYYCVNLPINLLPELADILSTSQQS--------AAASLDIR 62 GRSGAGKSVALRALEDAGYYCVDNIPLDLLPQLTDILSOSQSS----------VAISLDIR 62 GHSGAGKSVALRCLEDIGYYCVDNLPLDLLPQLASILSTNQQS----------VAISLDIR 58 GRSGAGKSVALRALEDIGYYCVDNLTMDLVPQIVDMLENKQHL---------VAISLDIR 58 GRSGSGKSVALRALEDMGFYCVDNLPVVLLPDLARTLADREIS----------AAVSIDVR 58 GRSGSGKSVALRALEDMGFYCVDNLPVVLLPDLARTLADREIS---------AAVSIDVR 58
GRSGSGKSVALRALEDMGFYCVDNLPVVLLPDLARTLADROIS-------AAVSIDVR 58 GRSGSGKSVALRALEDMGFYCVDNLPVVLLPDLARTLADRQIS----------AAVSIDVR 58 GRSGSGKSVALRALEDMGFYCVDNLPVVLLPDLARTLADRQIS----------AAVSIDVR 58 GRSGSGKSVALRALEDMGFYCVDNLPVVLLPELARSLADRNIS----------AAVSIDVR 58 GRSGSGKSVALRALEDMGFYCVDNLPVVLLPELARTLADRQIS----------AAVSIDVR 58 GRSGSGKSVALRALEDMGFYCVDNLPVVLLPQLASTLADRNIS----------AAVSIDVR 58 GRSGSGKSVALRALEDMGFYCVDNLPVVLLPQLASTLADRNIS----------AAVSIDVR 58 GRSGSGKSVALRALEDMGFYCVDNLPVVLLPQLASTLAERNIS----------AAVSIDVR 58 GRSGSGKSVALRALEDMGFYCVDNLPVVLLPQLASTLADRNIS----------AAVSIDVR 58 GRSGSGKSVALRALEDMGFYCVDNLPVVLLPQLASTLADRNIS----------AAVSIDVR 58 GRSGSGKSVALRALEDMGFYCVDNLPVVLLPQLANTLAGRNIS----------AAVSIDVR 58 GRSGSGKSVALRALEDMGFYCVDNLPVVLLPOLANTLAERNSS----------AAVSIDVR 58 GRSGSGKSVALRALEDMGFYCVDNLPVVLLPELANTLAARNIS----------AAVSIDVR 58 GRSGSGKSVALRALEDMGFYCVDNLPVVLLPELANTLADRDIS----------AAVSIDVR 58 GRSGSGKSVALRALEDMGFYCVDNLPVDLLPELAKTLAERDAA---A------AAVSIDVR 59 GRSGSGKSVALPAIEDMGFYCVDNIPVVILIPOLASALAASNIS----------AAVSIDVR 58 GRSGSGUVALVIDDIGYYCVDNUPVTLPQFTSTVEVIO GRSGSGKVAINVD GRSGSGKVATV GHSGAGKSIALRVLEDLGYYCVNLPVILDAFVHSVADSKQN----------VAVSIDIR 58 GHSGAGKIALA GHSGAGKSVALRVLEDLGYYCVDNLPVNLLDAFVQSVSESKQN---------VAVSIDIR 58 GHSGAGKSVALRVLEDMGYYCVDNLPVNLLESF IQSVSESKQN---------VAVSIDVR 58 GQSGAGSVALVLEDLGYYCVDNPVILLTAFIQSVQGSQQNGQSGAGKSVALRVLEDLGYYCVDNLPVNLLSDFVESVREINQN---------VAVSIDIR 58 GSSGAGKSVALRVLEDLGYYCVDNLPIDLLTQFVESIQHSSQN----------VAVSVDIR 58 GRSGSGKTVALRVLEDLGYYCDNLPVNLLPQLIVSVESOYDK--------LAVSIDVR 58 GRSGSGKTVALRVLEDLGYYCVDNLPVNLIPQLIVSVESQYDK---------LAVSIDVR 58 GRSGSGKTIALRVLEDLGFYCVDNLPIALLSTLVHSVLAQYDR---------VAISIDVR 58 GRSGSGKTIALRVLEDLGFYCVDNLPISLLPTLVHAVIEQYQK---------IAISIDVR 58 GRSGSGKSVALRVVEDLGYYCVDNIPVNLLPSLVRSVSDNYDK-------IAVSIDVR 58 GRSGSGKSVALRVVEDLGYYCVDNIPVNLLPSLVRSVSDNYDK--------IAVSIDVR 58 GRSGSGKSVALRVLEDLGYYAVDNIPVNLLPSLVRSVSDSYDK----------IAVSIDVR 58 GRSGSGKSVALRALEDLGYYCVDNIPVNLLPTLTHTVVDEYDQ----------VAVSIDVR 58 GRSGSGKSIVLRSLEDLGYYCVDNIPVNLLPTLTHTVADEYDQ----------VAVSIDVR 58 GRSGSGKSVALRVLEDLGYYCVDNIPINLLPALTHTVINDYEN----------VAVSLDVR 58 GRSGSGKSVALRVLEDLGYYCVDNLPLPLIGSLIEQLKGSNDL----------VAISVDVR 58 GRSGSGKSVALRVLEDLGYYCVDNLPLPLIGSLIEQLKGSNDL----------VAISVDVR 58 GRSGSGKSVALRVLEDLGYYCVDNLPLPLIGSLIEQLKGSNDL----------VAISVDVR 58 GRSGSGKSVALRVLEDLGYYCVDNLPLPLIGSLLAQLKSSNDL----------VAISVDVR 58 GRSGSGKSVALRVLEDLGYYCVDNLPLPLIGTLLAQLKGSNDL----------VAISVDVR 58 GRSGSGKSVALRVLEDLGYYCVDNLPLQLIGPLIAALLKGNNDK-----------VAISIDIR 58 GRSGSGKSVALRVLEDLGYYCVDNLPLQMMESLLEQLKGRSDL--------VAISVDVR 58 GRSGSGKSVALRVLEDLGYYCVDNLPLPLMDTLLEQLKDSTEL----------VAISVDVR 58 GRSGSGKSTALHVLEDLGFYCIDNLPIGLLFPLTREAATQEAP---G-RLKKMAVSIDAR 63 GLSGSGKSIALKVLEDVGYYAVDNLPATLLPELVAELSDTGHE---R-----VAIAVDVR 59 GLSGSGKS IALKVLEDSGYYCVDNLPASLLVVLINHLQTQQHA---Y-----VAVAIDMR 59 GLSGAGKSTALRTFEDMGWETVDNLPLSLLERLILTPPSSVAA---Y-KGRPLALGIDSR 80 
Anhang

\begin{tabular}{|c|c|c|}
\hline 42 & -GKVEKVAI & \\
\hline ThesCar_UPF0042 & GAGKSQVARAMEDLGYFCVDNLPPALIPKFAELCAQSA------GRVRKIALVVDIR & \\
\hline HalOre_UPF0042 & MSGAGKSVALNFFEDMGFFCIDNLPPALISKFAELCLHS---------ELDKIAVVSDIR & \\
\hline DesbHaf_DSY4845 & GLSGAGKTQALQSLEDQGYFCVDNLPPSLILKFAELCTQS--Q---GK-VTRAAIVCDLR & \\
\hline MooThe_YP_429136 & GLSGAGKTQAVRCLEDLGFFCVDNLPPSLIPGLVDLLGHPGKE---GEGITKVALVMDIR & \\
\hline CarHyd_YP_359144 & GLSGAGKTQAMRALEDLGYFCVDNLPPVLMPKFAELVAHA--E---NK-IEKVALVVDVR & \\
\hline SymThe_STH186 & GMSGAGKTQALKYLEDLGFFCVDNLPPSLMPKLAELFGQT--E---GK-VSRLALGIDIR & \\
\hline ClOACe_CAC0511 & GLSGAGKTQAIRSLEDLGYFCIDNLPPALIPKFAQVCYESES------KINKIALVIDIR & \\
\hline CloTet_CTC02495 & GLSGAGKTQAIRSLEDLGYFCVDNLPPTLIPKFAEACYKTDG------RINKIALVIDIR & \\
\hline CloBei_ZP_00909349 & GLSGAGKTQATRTLEDLGYFCVDNLPPKLISKFAEVCTQSGG------NIEKVALVIDIR & \\
\hline CloPer_CPE0354 & GLSGAGKTEATRSLEDLGYFCVDNLPPKLIPKFAEACVQSEG------KIDKIALVIDIR & \\
\hline AlkMet_UPF0042 & GLSGAGKSQTVKSMEDFGFYCVDNLPPALIPKFAELCHOSQG------VISRAALVIDIR & \\
\hline TherEth_UPF0042 & GLSGAGKTQALKAMEDMGFFCIDNFPPALLPKLADLFYHSK-------NVDKVALGMDLR & \\
\hline TherTen_TTE1834 & GLSGAGKTQALKAMEDMGFFCIDNFPPALIPKLADLFYQSK-------NIDKVALGMDLR & \\
\hline CloThe_UPF0042 & GISGAGKSLVVKYLEDIGFFCVDNLPPLLIGKFAEICLKSRG------KISKVALVIDIR & \\
\hline CalSac_ZP_00884966 & GMSGAGKSLAIRAFEDMGFFCIDNLPPQFLPKIAELASASND------KISRIAAVIDIR & \\
\hline BacThu_ZP_00739740 & GMSGAGKTVALQSFEDLGYFCVDNLPPMLIPKF IELMADSKGK------MNKVALGIDLR & \\
\hline BacWei_UPF0042 & GMSGAGKTVALQSFEDLGYFCVDNLPPMLLPKF IELMADSKGK------MNKVALGIDLR & \\
\hline BacAnt_GBAA5384 & GMSGAGKTVALQSFEDLGYFCVDNLPPMLIPKFIELMADSKGK------MNKVALGVDLR & \\
\hline BacCer_UPF0042 & GMSGAGKTVALQSFEDLGYFCVDNLPPMLIPKFVELMADSKSK------MNKVALGIDLR & \\
\hline GeoKau_GK3066 & GMSGAGKTVAIQSFEDLGFFCIDNLPPTLLPKFLELVKESGNK------MNKVALVMDLR & \\
\hline GeoThe_GTNG_3015 & GMSGAGKTVAIQSFEDLGFFCVDNLPPTLLPKFLELVKESGNK------MNKVALVMDLR & \\
\hline BacCoa_UPF0 042 & GMSGAGKTVAIQSLEDLGFFCVDNLPPTLLPKFLELMKDASNK------MNKVALVMDLR & \\
\hline BacLic_YvcJ & GMSGAGKTVAIQSFEDLGFFCVDNLPPSLLPKFLELMKESSSK------MSKVALVMDLR & \\
\hline BacSub_YvcJ & GMSGAGKTVAIQSFEDLGYFCVDNLPPSLLPKFLELMKESNSK------MSKVALVMDLR & \\
\hline BacCla_ABC3036 & GMSGAGKSVAVRSFEDLGYYCIDNLPPVLLPKFIELIEGGIDK------VTKVALVMDLR & \\
\hline BacHal_BH3569 & GMSGAGKTVAVQSLEDLGYFCVDNLPPALIPKFIELIESSSGK------MNKLALVIDLR & \\
\hline OceIhe_OB2468 & GMSGAGKTVAIQSFEDLGYYCVDNLPPALLPKFLDLMKDATNN------IQKVALVMDLR & \\
\hline LisInn_lin2617 & GMSGAGKTVAMQSLEDLGYFCVDNLPPSLLPKFWELMKES-DK------MDKIALVMDLR & \\
\hline LisWel_lwe2422 & GMSGAGKTVAMQSLEDLGYFCVDNLPPSLLPKFWELMKES-DK------MDKIALVMDLR & \\
\hline LisMon_Sp. & GMSGAGKTVAMQSLEDLGYFCVDNLPPSLLPKFWELMKES-DK------MDKIALVMDLR & \\
\hline UUPF0042 & GMSGAGKTVAMNSFEDLGYFCVDNLPPTLLPQLIEVIGQV----------RPKIAVAIDTR 6 & \\
\hline EntcFae_EF 0766 & GMSGAGKTVAVQSFEDMGYFCIDNLPPSLIPKFWELIKESGK--------VTKIALVIDLR & \\
\hline EntcFaec_UPF0042 & GMSGAGKTVAIQSFEDMGYFCIDNMPPRLIPKFWELIKESGK-------VTKMALGVDLR & \\
\hline LacPla_lp_0779 & GMSGAGKTVAVOSFEDLGYFCIDNMPPALLPKF SELVEESGK--------IKKVALVIDLR & \\
\hline LacSak_YP_39 & GMSGAGKTVAMOSFEDLGYFCVDNMPPSLLPKFWELVKESGK-------VTKIALVIDLR & \\
\hline LacCas_YP_ & GMSGAGKTVAMQAFEDLGYFCVDNMPPALLPKFWELVKESGK--------ITKVALVVDLR & \\
\hline LacSal_YP_5 & GMSGAGKTVAVQSFEDLGYFCVDNMPPKLLPKFYELVKESGK-------ITKIALVVDLR & \\
\hline LacBre_YP_794827 & GMSGAGKTVAMOSFEDLGYFCIDNMPPSLLPKFWDLVRESGK-------LSKIALVIDLR & \\
\hline PedPen_YP_803988 & GMSGAGKTVAMQSFEDLGFFCVDNMPPALLPKFWELIKENGK- & \\
\hline StrMut_Smu_1306c & GMSGAGKTVAIQSFEDLGYFTIDNMPPALVPKFLELVESSGE-- & \\
\hline StrPyo_Sp. & GMSGAGKTVAIQSFEDLGYFTIDNMPPALVPKFLELIEQTNE- & \\
\hline StrAga_gbs 0576 & GMSGAGKTVAIQSFEDLGYFTIDNMPPTLVPKFLELAAQSGD-------TSKIAMVVDMR & \\
\hline StrThe_str0831 & GMSGAGKTVAIQSFEDIGYFTIDNIPPSLVPKVIELLKHSEE- & \\
\hline StrPne_SP1566 & GMSGAGKTVAIQSFEDLGYFTIDNMPPALLPKFLQLVEIKED--- & \\
\hline StrSan_YP_001034791 & GMSGAGKTVAIQSFEDLGYFTIDNMPPTLVPKFLQLVEGTTD-------NDKLALVVDMR & \\
\hline StrSui_UPF0042 & GMSGAGKTVAIQSFEDLGYFTIDNMPPTLLPKFLELIRHSQD-------NNKIALVVDMR & \\
\hline LactLac_L188550 & GMSGAGKTVAIQSFEDMGYFTVDNMPPNLIEKFVGLLNTPDNK------IDKVALVVDMR & \\
\hline LacReu_ZP_01164767 & GMSGAGKTVAVHSLEDLGYFVIDNMLPGLAERFVDVIEDSRE-------FDKIAMVMDMR & \\
\hline LaCACi_LBA0691 & GMSGAGKTVVAHDLEDMGYFVVDNLPPTLLGSFWDLINNSND-------FHKVAVVIDLR & \\
\hline LacDel_YP_618706 & GMSGAGKTVAAHSLEDVGYFVVDNLPPELLGNFWDLMNTSED-------FEKVAVVIDLR & \\
\hline LacGas_YP_815115 & GMSGAGKTVAIKALEDMGYFVVDNLPPELLGSFWELINNSSD-- & \\
\hline LacJoh_LJ0866 & GMSGAGKTVAIKALEDMGYFVVDNLPPELLGSFWELINNSSD-------FSKAAVVVDLR & \\
\hline StaAur_Sp. & GLSGAGKSLVIQCLEDMGYFCVDNLPPVLLPKFVELMEQGNPS-------LRKVAIAIDLR & \\
\hline StaEpi_SE0548 & GMSGAGKSLVIQSLEDMGFFCVDNLPPVLLPKFVELMAQGNPS------LQKVAIAIDLR & \\
\hline StaHae_SH2124 & GLSGAGKSVVIQCLEDIGYFCVDNLPPILIPKFVELMEQGNPS-------LQKVAIAIDLR & \\
\hline StaSap_SSP1952 & GLSGAGKSVVIQSLEDIGYFCVDNLPPILLPKFVELMGQGNPS-------LQKVAIAIDLR & \\
\hline FusNuc_FN1089 & GLSGAGKTTALNILEDMSYYTIDNLPLGLEKSLLDT- & \\
\hline GloVio_glr4163 & SPAGAGRTEAIRIFEDLGYLCLNHVWPELVPTFLKHYA & \\
\hline \multirow[t]{2}{*}{ TheThe_TTHA0319 } & GLSGAGKTTARGFLEDLGYFMVDNLPPRLWLPLLQEAA & \\
\hline & & \\
\hline
\end{tabular}

LeiXy1_Lxx11490

StpAve_SAV6292 MycTubCDC1551_MT146

MycTubH37Rv_RV1421

MycSme_MSMEG3088

NocFar_nfa358930

CorEff_CE1710

BifLon_BL0705

ActPle_ZP_00133926

HaeDuc_HD0584

Act Suc

ManSuc_MS1718

ManSuc_MS1718
HaeInf_AAC22801

HaeSom_ZP_00132582

EscColsp. YhbJ

SalEntATCC9150_YhbJ

SalTyp_YhbJ

SalEntTy2_T3240

KlePne_P17163

EntSp.

YerEnt_ZP_00834134

YerMol_ZP_0082727

YerFre_ZP_00828963

YerPes_Sp.

YerPse_YPTB3529

YerBer

SerPro_ZP_01538297

ErwCar_ECA0285

Phorlum_plu4044

ProMir_AAC64575

SodGlo_SG0196

PhoPro_PLU4044

VibAng_

Vibalg

VibPar_VP2673

VibHar_AAF72890

VibVul_VV0445

VibCho_vC2532

VibSpl_v12B01_07423

VibFis_VF0384

AerHyd_AHA_3920

IdiBal_OS145_05430 GRR-FFDNLRESLADLES----KNVTRRIVFLESSDEALVRRFESVRRPHPLQGD---GR 166 SRG-FTGDLDSVRNELAT----RAITPRVVFMEASDDTLVRRYEQNRRSHPLQGE---OT 129 SRG-FTGDIDSVRNELAT----RAITPRVVFMEASDDTLVRRYEQNRRSHPLQGE---OT 129 SKG-FTGDLDWVRNELAT-----RNIAPRVLFMEASDDILVRRYEQNRRSHPLQGT---QT 141 SRF-FTGDLSVVADOLRA----LGLRTRVLFLEASDDVLIRRFGFARRRHPLOSESADGT 140 SRE-FRGGLRETITELEE----KNLAPTVLFLDARDDELIRRFDNVRRTHPLOGS---OT 142 S-S-YFDELAAVLGHLDD----LGVKTRILFLDASNEVLIKRYESVRRPHPLQHG---NR 154 NIPENPES IEALLEQLSKL----TIQTKI IFLDCERNTLIRRYSDTRRLHPLSNK--DLS 112 NFPENLTRIDELLHQLSQL----TINTKMIFLDCESATLIRRYSDSRRLHPLSNQ--DLS 112 NLPNSSOHLDEILTELEN-----KHQIKI IFLDADRSTLIRRYSDSRRLHPLSVQNODLS 113 NLPHSPETLDTLLQQLADA----QHQVRI IFLEADRSTLIRRYSDSRRLHPLSMQ--DLS 116 NIPNSAHSLKQTLSTLQK-----HHQIKIIFLEADRATLIRRYSDSRRLHPLSLK--DLS 115 NLPHSSKTLENLLTEVQQ-----OHQIKLIFLDADRGTLIRRYSDSRRLHPLSTQ--DLS 111 NLPQEPETLDHILNLLQE-----KYPVKI IFLDTDRNTLIRRYSDSRRLHPLSVQ--NLS 111

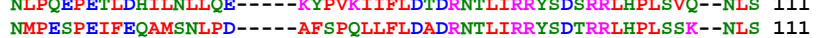

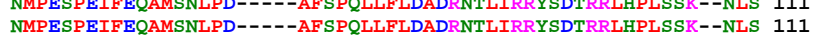
NMPESPEIFEOAMNNLPG-----AFSPOLLFLDADRNTLIRRYSDTRRLHPLSSK--NLS 111 NMPESPEIFEQAMNNLPG-----AFSPOLLFLDADRNTLIRRYSDTRRLHPLSSK--NLS 111

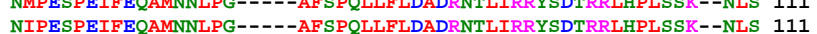
NMPESPEIFEOAMKNLPA-----EF SPOLLFLDADRNTLIRRYSDTRRLHPLSSK--NLS 111 NMPESPEVFEOAMSSLPE-----TFTPOLLFIDADRNTLIRRYSDTRRLHPLSSK--NLS 111 NMPE NMPESPEVFEHAMTOLPD-----SFSPOLLFIDADRNTLIRRYSDTRRLHPLSTK--NLS 111

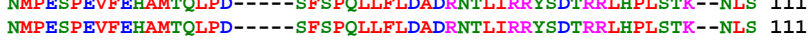

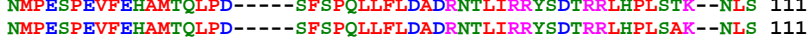
NMPESPEVFEHAMTQLPD----SFSPLLFLDADRNTLIRRYSDTRRLLHPLSAK--NLS 11 NMPESPEVFEHAMTQLPD-----SF SPQLLFLDADRNTLIRRYSDTRRLHPLSAK--NLS
NMPESPEVFEHAMTQLPD-----SF SPQLLFLDADRNTLIRRYSDTRRLHPLSAK--NLS 111 NMPESPEVFEYAMTQLPD-----SFSPQLLFLDADRNTLIRRYSDTRRLHPLSSK--NLS 111 NMPESPEIFEHAMEQLPP------SFSPQLLFLDADRNTLIRRYSDTRRLHPLSSK--NLS 111 NMPESPEVFEEALTKLPA-----SFSPQLLFLDAERNTLIRRYSDTRRLHPLSSK--NLS 111 NMPESPEIFEKALESLPA-----EYSPQLLFLDADRNTLIRRYSDTRRLHPLSTK--NLS 112 NMPESPEIFEQAMDNLPQ-----AFAPQLLFLDADRNTLIRRYSDTRRLHPLSAL--NLS 111 NMP SESGVIQKTLNSLDDKL-----DINVIF IDADDKELVKRYSETRRLHPLSK--HDMS 111 NMPQQPGEIQRILKSLENDV-----DVNVVFLDADDKELVKRYSETRRLHPLSR--QNMT 111 NIPKKLKELTSTLEOLKTEL-----DVTVLFLDANKETLLKRYSETRRIHPLSLGGTSLS 113 NIPKKLKELTGTLEQLKTEL-----DVTVLFLDANKETLLKRYSETRRIHPLSLGGQSLS 113 NIPKKLKELNTTLEKLKAEL-----DVTVLFLDANKETLLTRYSETRRIHPLSLDSQSLS 113 NIPKKLKELTTTLQKLKSSI-----DLSILFLDADKATLLKRYSETRRVHPLSLSDECHT 113 NLPKEPOLVTETLEOLEAAT---DIDVNVLFLDASKOTLLKRYSETRRIHPLSIGOEKLS 115 NLPKDPALLKNTLALLKKTH-----DVTVIFLDAEDKELIKRYSETRRLHPLSLIGEOCS 113 NLPASPDKLETLIAOVRNEG---RVEFSSFFFDAENSTLLKRYGESRRLHPLSRN--OLS 113 NLPASPDKLELIAQR

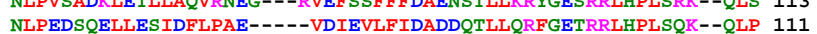


Anhang

IdiLoi_I10393

AltBac_ATW7_18740

PseHal_PSHAa2554

PseTun_PTD2_17262

AlteMac_MADE_14619

PseAt1_UPF0042

ColPsy_CPS_4546

SheBal_UPF0042

ShePut_UPF0042

SheOne_SO3964

SheDef_UPF0042

SheFri_UPF0042

SheAma_Sama_3091

SheLoi_UPF0 042

SheLOi_UPF0042

SheWoo_UPF0042

MarAqu_UPF0042

AzoSp._ebA3650

AciSp._ACIAD3059

ACiSp._ACIAD 3059

ThesCar_UPF0042

HalOre_UPF0042

HesbHaf_DSY484

MooThe_YP_429136

CarHyd_YP_359144

SymThe_STH186

ClOAce_CAC0511
CloTet_CTC02495

CloBei_ZP_00909349

CloPer_CPE0354

AlkMet_UPF 0042

TherEth_UPF0042

TherTen_TTE1834

CloThe_UPF 0042

CalSac_ZP_00884966

BacThu_ZP_00739740

BacWei_UPF0042

BacAnt_GBAA5384

BacCer_UPF0042

GeoKau_GK3066

GeoThe_GTNG_3015

BacCoa_UPFO

BacLic_YvcJ

BacCla_ABC3036

BacHal_BH3569

BacHal_BH3569

OceIhe_OB2468

LisWel_lwe2422

LisMon_SP.

LisMon_Sp.

ExiSib_UPF0042

EntCFae_EF0766

LacPla_lp_0779

LacPla_lp_0779

LacSak_YP_395138

LacCas_YP_806200

LacSal_YP_536062

LacBre_YP_794827

PedPen_YP_803988

StrPyo_SP.

StrAga_gbs 0576

StrThe_str0831

StrPne_SP1566

StrSan_YP_001034791

StrSui_UPF0042

LactLac_L188550

LacReu_ZP_01164767

LacAci_LBA0691

LacDel_YP_618706

LacGas_YP_815115

LacJoh_LJ0866

StaAur_Sp.

StaEpi_SE0548

StaHae_SH2124

StaSap_SSP1952

FusNuc_FN1089

FusNuc_FN1089

TheThe_TTHA0319

LeiXY1_Lxx11490

StpAve_SAV6292

MycTubCDC1551_MT1464

MycTubH37Rv_RV142

MycSme_MSMEG3088

NocFar_nfa358930

CorEff_CE1710

BifLon_BL0705

ActPle_ZP_00133926

HaeDuc_HD0584

ActSuc

ManSuc_MS1718

HaeInf_AAC2280

PasMul_PM0169

HaeSom_ZP_00132582

EscColsp._YhbJ

ShiFle_YhbJ

SalEntATCC9150_YhbJ

SalTyp_YhbJ

SalEntTy2_T324

KlePne 17163

EntSp.

YerEnt_ZP_00834134

YerMol_ZP 00827279

YerFre_ZP_00828963
NLPEHSEELIDSLSFLPKG-----VEPEILFIDSDDNTLLKRFGETRRLHPLSOK--ELP 111 NLPKEQDEFNHIIEYLPGF-----TKPTLFYLDSEDQTLIKRF SETRRLHPLSID--SLP 111 NLPKDQQQFNDILEYLPDF-----AKPTLFYLDSDDQTLIRRYSETRRLHPLSID--SLP 111 NLPKIQOEFNEILEYLPEF-----AKPTLFYLDSDDNTLIRRFSETRRLHPLSIN--SQP 111 NLPKNPDDLVEILDYLPSS-----WSMTIVYIDASDDVLVKRF SETRRLHPLAKL--NKS 111 NLPKDPNELVEILDYLPST------WEMTILYLDASDDVLIKRF SETRRLHPLSKO--NKS 111 NLPKDPEDIPEI IAYLPKA-----VDVNTLFLDADDNDLIRRF SETRRLHPLIKE--NMA 111 NMPEODKVLVKOLASLPPD-----TELTSFFLNSSDKILLKRYSETRRLHPLSKS--OVS 111 NMPEODKVLVOOLSNLPAG-----TEITSFFLNSSDKVLLKRYSETRRLHPLSKS--RVS 111 NLPEODKVLVKOLASLPEG-----TELTSFFLNSSDKVLLKRYSETRRLHPLSKS--RVS 111 NIAEOGKVLEQQLALLPPE-----TEISSFFLNSSDKVLLKRFSETRRLHPLSRS--QMS 111 NIAEQGKVLQDQLALLEND-----TEIISFFLNSNDKVLIKRYSETRRLHPLSKN--HIS 111 NMPEOEKALEKELARLPEG-----VELTSFFLNSSDKVLLKRYSETRRLHPLSRS--KVS 111 NMP SEE IQLEKQLAKLPKD-----TEILSFFLNSSDNVLLKRYSETRRLHPLSRS--KVS 11 NMH--ETELDKOLSNLPEG-----TELLSFFLNSSDEVLLKRYSETRRLHPLSRS--KTS 109 NLSAELANFETIYQQLKQT----GVELEI IFLDADEQSLLQRFHATRRKHPLSDD--KTS 117 SGA-SLLALPQQVEHLHAL----ASDLRLIFLDARDDTLIARF SETRRRHPLASE--DVS 112 SGA-SLLALPQQ SGE-NITVLPQLKMIDK----SIQIKF IFLEARTEIM STRAD TRGF GGAGGE-FFDTLVQVLDMEK----QGFYEILFLAADETLIRRYKETRRRAPMAP-H-G-R 116 GRE-FTNALF SELSSLEK---RGIDYEILFLEASDEVLIRRYKETRRRHPLDE-E-G-R 111 GGE-FFSSLAEALGDLHR----EGFHYLILFLEASDEVLVGRYKESRRRHPLSP-S-G-G 118 GGE-FFSLLDAALNYLDG----LGIPYEILFLEAADEVLVRRYKETRRRHPLSS-G-G-Q 122 GQK-FFQDLDWALGELTK----LGIKYEILFLEARDEVLLKRFKANRRGHPLGV-R-GSQ 114 GGR-FFHEILGALRQIAE----IGVAYQILFMDASDEVLVRRYKETRRRHPLAA-Q-G-R 120 GGE-FFDNLFESLKYLKE----AGYKYEILFLDADNEVLIKRFKESRRKHPLAP---NGR 113 GGE-FFDNLFESLNYIKD----QNYKYEILFLEASDEVLVKRFKETRRNHPLSS---GGR 113 GGI-FFDDFFEALNYLKK----NEFKYEILFLEATDEVLIKRFKETRRSHPLSP---DGR 113 GGI-FFDDLFESIEYLKA----NDFNYEILFLEASDEVLVKRFKETRRSHPLSP---DGR 113 GGM-FFDDLFESLKELEH----LGHQYEILFLDADDEVLMKRFKETRRSHPLNV---DGS 113 GGQ-FFEDIYSSLEFLKK----NNYDYEIVFLEASDEVLIKRFKETRRKHPLSE---EGR 112 GGQ-FFEDIYSSLDFLKK----NNYDYEIVFLEASDEVLIKRFKETRRRHPLSE---EGR 112 GGE-LFNDLVPELNALKE----SGIDYEILFLEASDQVLIKRYKESRRIHPLAP---EGR 113 GGE-LFDDFKDVLNDLKK----GTYNFKVLFLDAHDNVLVQRYKETRRKHPLSFES-DGS 118 GRE-FFEHLWGALDDLSE---RTWIIPHILFLDAKDSTLVTRYKETRRSHPLAPT---GL 120 GRE-FFEYLWGALDDLSE---RTWI IPHILFLDAKDSTLVTRYKETRRSHPLAPT---GL 120 GRE-FFEHLWGALDDLSE---RTWIIPHILFLDAKDSTLVTRYKETRRSHPLAPT---GL 120 GRE-FFEHLWGALDDLSE---RTWIIPHILFLDAKDSTLVTRYKETRRSHPLAPT---GL 120 SRD-FFDHLFAALDELAE---QAWVIPQVLFLDAODSTLVARYKETRRTHPLAPN---EP 123 SRD-FFDHLFVALDELAE---QEWIVPQILFLDAQDSTLVARYKETRRTHPLAPN---EP 123 GRE-FFDDLFRALDELDK---SSWVTPTILFLDADDSVLVRRYKETRRSHPLSPD---GT 121 GRE-FFDSLIEALDEIGE---TSWITPRILFLDAKDSVLVSRYKETRRSHPLATT---GL 122 GRE-FFDRLIEALDEMAE---NPWITPRILFLDAKDSILVTRYKETRRSHPLAAT---GL 122 GQS-FFDELFKAIDELNET-PASRLKIQILYLDAKDSKLVQRYKETRRTHPLAKG---GL 121 GQT-FFDQLFES IDLLDQS-SLSKYNIQILFLDAKDAKLVQRYKETRRSHPLAKH---GL 122 GRE-FFDSLFEALDVLAR---ENWLEDHILFLDAKDEALVTRYKETRRSHPLATD---GL 120 GRE-FFDSIEPALDELDN---TNFITTKILFLEADDKVLVSRYKETRRHHPLEPN---GS 118 GRE-TDSIEAR GRE-FFDSIEPALDELDN---TNFITTKILFLEADDKVLVSRYKETRRHHPLEPN---GS 118 ARD-FIDSFF VYEDLKK----TNLQIRMLYLDARNDVLVRRYKESRRSHPLAPT---AS 115 SRT-FFREIQDMLVELEN---TNFIDTIILFDAIDEELVSRYKETRRAHPMAMD---GL 117 SRS-FFEIQNMLIEIEN-CONFIDISILFDASDEELVARYKETRRAHPMAMD---GL 117 SRA-FYDEIMDMLANLDN---TDFVSTRILFLDASNEELVSRYKETRRSHPLAME---GR 117 SRA-FYDGI IEMLSGLDN---TQFVTTKILFLDASDEELVSRYKETRRSHPLARN---GR 117 SRA-FYDQI IDMLANLDN---NAYVHSRILFLDATDEELVSRYKETRRSHPLAME---GR 117 SRA-FYDEIVEMVRELDE---NEFNSSRILFLDASDEELVARYKETRRSHPLAME---GR 118 SRA-FYDEIVRMLNDVAV----HGTMNAQVLFFLDASDAELVSRYKETRRSHPLARN---GR 117 SRG-FYDQILGLLTGEEE---OHNIKTDVVFLDATDEELVARYKETRRAHPLAMD---GR 117 SRL-FFKEVSSILDKIDL---NETINFRILFLDATDSELVSRYKETRRSHPLATT---GR 118 SRL-FFKEINSTLDSIES---NPSIDFWILFLDATDGELVSRYKETRRSHPLAAD---GR 118 SRL-FFREINSILDSLEI---NDNINFKILFLDATDTELVSRYKETRRSHPLAAD---GR 118 SRV-FFDEINDILDQLES---NEKLNFKILFIDATDGELVSRYKETRRSHPLAAD---GR 118 SRS-FFSEIQAVLDELEN---QDGLDFKILFLDAADKELVARYKETRRSHPLAAD---GR 118 SRS-FFLQIQNVLDELEQ---NENIDFKILFLDAADKELVARYKETRRSHPLAAD---GR 118 SRS-FFSEIREVLDEIEG---AEDLDFKVLFLDATDNELVARYKETRRSHPLAAD---GR 117 SRA-FFEDIOSIVTELTD---NGSVNFKLLFLDANDTELVSRYKETRRSHPLAID---GR 118 SRG-FYDEVLPNFEKLKK---RADLDVKLIFLDANDVTLISRYKETRRSHPLSPQ---GR 125 VKA-FYTDLIDEVNSLED---NGNVQATILYLDASDDVLVARYKETRRLPPLANNG-KGR 120 VKS-FYKDLIDEINSLED---SGOTOATIVFLEASDDTLVARYKETRRLPPLAEN---GR 132 VKS-FYKDLVDEIKSLED---SQNVQSTVLFLDASDDVLVSRYKETRRLPPLAHT---GR 118 VKS-FYKDLVDEIKSLED---SQNVQSTVLFLDASDDVLVSRYKETRRLPPLAHT---GR 118 GKE-LFNSLVAVVDKVKS---ESDVI IDVMFLEASTEKLISRYKETRRAHPLMEOG-KRS 126 GKE-LFKSLVKE IDIIKS---RNDVILDVMFLEAKTEKI ISRYKESRRAHP LNEQG-QRS 126 GKE-LFKSLVEEIDAIKS---RNDVIVDVMFLEAETEKLISRYKESRRAHPLNENG-OMS 127 GKE-LFKSLIHEMDLIKS---NSDVIVDMMFLEASNERLISRYKETRRAHPLNGNG-QRS 126 $\begin{array}{ll}\text { GKE-LFKSLIHEMDLIKS---NSDVIVDMMFLEASNERLISRYKETRRAHP LNGNG-QRS } & 126 \\ \text { TFK-NTKDFFTF INYIKE----SGVKMDI IF IEAHEAIIIGRYTLSRRAHP LKEV----T } 109\end{array}$ AQA-GLIAARVALRSLARTT-------VHVHLDCPEGVLISRYALTRRPHPWFDHG--KG 122
ALA-FFODLEEVLEALRPT----------VVYLEARPEVLIRRYNLTRRVHP-LGAG--N- 105 $:: *: * * *$

LLDGITAERARLREIRESSDIIVDTSDLNIHQLATRITDIFADEN----TADVQVTVMSF 179 IVDG IVDGIDAERELLRELRGDADLVIDTSSLNVHELRAKMDAQFAGDE----EPELRATVMSF 222 LAEGIAAERRMLAAPVRATADLIIDTSTLSVGGLRDSIERAFGGDG----GATTSVTVESF 185 LAEGIAAERRMLAPVRATADLIIDTSTLSVGGLRDSIERAFGGDG----GATTSVTVESF 185 LAEGIAAERAMLAPVRAAADLVIDTSTLPVPALRESIERAFGGET----VAYTNVTVESF 197 LSAGIAVERVRLAGVKAAADLVIDTTELS IHQLHRKLEEAYGGGA----PAALQLTVQSF 196 LQVGIERERQMLSDLKEEADVVIDTSELSVHDLRRAIESSFRTIA----KRVQHVTIESF 198 LIDGILEERHLLEDLKERADWVIDTSSLS IHQLSTKL YEAMLGSG----PTTVAVHIFSF 210 LESAIDLENTLLEPLYQQANYIIDTTNISSHELAENLRGILR-GS---TDKALKIVFESF 168 LASAIELENTLLDPLRQQADYLIDTTHSSPHELAANLRHILR-GS---TEKELNIVFESF 168

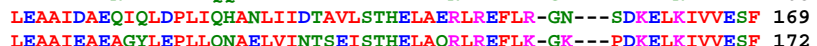
LEAAIEAEAGYLEPLIQNAELVINTSEISTHELAQRLREFLK-GK---PDKELKIVVESF 172 LEAAIDEEYRYLEPLIQHANLILDTTHLSTHSLAERLREFLR-GN---SEKELKI IVESF 171 LEAAIDAERKYLDPLTQHADLIIDTTRLSTHELAERLRDFLC-EK---SDKALKIIFQSF 167 LEAAIAAEKEHLEPLVQHANVI IDTTPLSPHELAERLREFLR-GN---TEKELQIIVESF 167 LESAIDKESDLLEPLRSRADLIVDTSEMSVHELAEMLRTRLI-GK---RERELTMVFESF 167 LESAIDKESDLLEPLRSRADLIVDTSEMSVHELAEMLRTRLL-GK---RERELTMVFESF 167 LESAIDKESDLLEPLRSRADLIVDTSEMSVHELAEMLRTRLL-GK---RERELTMVFESF 167 LESAIDKESDLLEPLRSRADLIVDTSEMSVHELAEMLRTRLI-GK---RERELTMVFESF 167 LESAIDKESDLLEPLRSRADLIVDTSEMSVHELAEMLRTRLL-GK---RERELTMVFESF 167 LESAIDEESDLLEPLRSRADLIVDTSEMSVHELAEMLRTRLL-GK---RERELTMVFESF 167 LESAIDEESDLLEPLRSRADLIVDTSEMSVHELAEMLRTRLI-GK---RERELTMVFESF 167 LESAIDEESDLLEPLRSRADLIIDTSEMSVHELAEMLRTRLL-GK---RERELTMVFESF 167 LESAIDEESDLLEPLRSRADLIIDTSEMSVHELAEMLRTRLI-GK---RERELTMVFESF 167 LESAIDEESVLLEPLRSRADLI IDTSEMSVHELAEMLRTRLL-GK---RERELTMVFESF 167 
Anhang

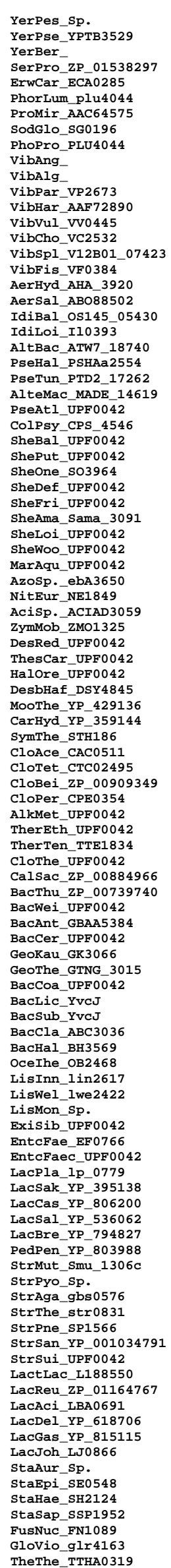

LeiXY1_Lxx11490 StpAve_SAV6292 MYCTubCDC1551_MT1464 MYCTubH37Rv_RV142
LESAIDEESDLLEPLRSRADLIIDTSEMSVHELAEMLRTRLL-GK---RERELTMVFESF 167 LESAIDEESDLLEPLRSRADLIIDTSEMSVHELAEMLRTRLL-GK---RERELTMVFESF 167 LESAIDEESILLEPLRSRADLVIDTSEMSVHELAEMLRTRLL-GK---RERELTMVFESF 167 LESAIDEESDLIEPLRSRADIIIDTSEMSVHELAEMLRTRLI-GK---RERELTMVFESF 167 LESAIDEESDLLEPLRSRADLIIDTSEMSVHELAEMLRTRLI-GK---RERELTMVFESF 167 LESAIDQESDLLEPLRSRADLI IDTSEMSVHELAEMLRTRLL-GK---RERELTMVFESF 167 LEMAIDTESDLLEP IRSRDVWI IDTSEMSVHELAEMLRTRLL-GK---RERELTMVFESF 168 LESAIDEEDSLLEPLRSRADLVIDTSEMSVHELAEMLRTRML-GK---RERELTMVFESF 167 LEQAIQSESAIVADIKEHADLVIDTTNKS IHDLSETVRARVL-GR---ESRKLILVFESF 167 LEQA ITSESAILGDLKEHADLVIDTTNKS IHDLSETVRARVL-GR---EAKELILVFESF 167 LDQAIEREKQILTPLKAHADLVLNSSGQSLHELSETVRMRVE-GR---DRKGLVMVFESF 169 LDQAIEREKEILTPLKAHADLILNSSGOSLHELSETVRMRVE-GR---DRKGLVMVFESF 169 IDOA TRI LDOA ID LAOA IETEKOLLGPLKEOADILLDSSNOSLHELSETVRMRIE-GR---ERKDLVMVESS 169

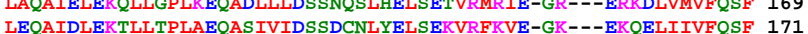
LEATDLEK LEAVILEKILSDYREEADLVDDTIKSIHDLSETLRSRIL-GR---ESKELVMVFESF 169 LDEAIREE HLLAPLSSTADLRIDTTNLSIHDLSELIKTRVL-GK---KENELVLVFESF 169 LDEAIREETNLLAPLSSTADLRIDTTSLS IHDLSELIKTRVL-GK--CENELVLVFESF 169 LLEALQLENRLLDP IAVRATWRIDSSHLSLHQLSEEVSARVL-GK---ASKQVVIVFQSF 167 LLEALAEH LDLAIKKEKELLDVLITRADYMIDTSELSVHQLAESIREKIL-GK---KDKQLIVIFESF 167 LDLAIKKEKELLDVLVTRADHVIDTTDLSVHQLAESMRETIL-GK---KDKQLIITFESF 167 LDAAIKEEKILIDVLVRADIIIDISDLSVHQLAEAIRARVL-GK---KDNQLIITFESF 167 LSEAIRAESALLAP IAERADLYLDTDKLTIHQLAELIRERIL-GK---KSSRLVLVFSF 167 LSGAIQAESQLLAPIAERADLYIDTDQLSIHQLAELVRERIL-GK---KSSRLVLVFESF 167 IDQAIALEKSLLEP IS TNADLY INTSQLSP HQLADLVRERIL-GK---KTGSMVLVFESF 167 LQEAIKLEGKLLEPMSKLVDHYIDTSNLNIYDLSDQVRQILL-GS---VDKELVINFESF 167
LOEAIKLEGKLIEPMSKLVDHYIDTSNLNIYDLSDOVROIL-GS---VDKELVIYFESF 167 LQEAIKLEGKLIEPMSKLVDHY IDTSNLNIYDLSDQVRQILL-GS---VDKELVIYFESF 167
LQEAIKLEGKLIEPLSQQMDHYIDTSNLNIYELSDQVRQILI-GS---VDKELVINFESF 167 LQEAIKLEGRLLEP IAKMVDHHIDTSLLNVYELSDQVRQILL-GS---VDKELVINIESF 167 LQEAIKLEGRLLEP IAKIVDHYIDTSALNIYELSDQVRQILL-GS---VDKELVINFESF 167 LQEAIKLEGKMLAP ISNMVDHF IDT SNLNVYELADAVRQILL-GR---TDKELVI IFESF 167 LKEAIQLEGKLIDP IAKLVDHYIDTSNLNIYELSDKVREILL-GT---VDKELVINFESF 167 LKEAIDHERILLEPVSKLVDHYIDTSNLNIYDLSNQVREILL-GS---VDKELVINFESF 165 LREAITNEKQLLEPLSKLADLYVNTTGLSMYELRDMIKQRVA-GR---KDOELALLFQSF 173 LAEAIQSERDALASIAELG-HRIDTSELHANTLRAWIKDFLAIEA---TEG-LTLMFQSF 167 LEEAIRREREALATLTGLG-HHIDTSSLRPNVLRAFIKDFIADSR---SPSOLTLLFOSF 167 LNECIQEEKQLLLPIQFRSTVHIDTTDKSVHDLKHTLLSKLG------OSDKLILILQSF 168 MEDGISEERAFLAPVREIADFLIDTTTTSSHSLQSELROOFA-PE---NSVAPNVSILSF 190 VLKVIOEERELLREIRGRATKVIDTSNVSNNOLKEOIITOYGGDKE--NSNRLIITVISF 183 ISEGISRERDRLEHIRGRATHIIDTSDLSTAQLKDKIAALFAGERE---YERMTITVVSF 173 VLDAIRKERHLLEEIKGKANKIIDTSKLSKOELNHELKKVYSSYFI--GKOSMSVTIISF 169 ILEGIQMERQMLTELRGVAHKIMDTSNLSSQQLRHOVAESFG-NEQ--ASGHLAVSVVSF 175 ILEGI IEERRRLEELRGRASKI IDTSELTPRQLKEQVSELFG-SSQ--RR--LIVSIISF 177 ILDNIKKERKF LENLRARADKVIDTSDLQPADLRNEILNYYG-EEQ--KRSKISINIVTF 171 VLDGIQRERRLIOELRGLATF I IDTTHMTPADLRKELNRRFG-QDR--ESPHFHVNVVSF 177 $\begin{array}{lll}\text { VLDGIQRERRLLQELRGLATF IDTTHMTPADLRKELNRRFG-QDR--ESPHFHVNVVSF } & 177 \\ \text { ILNGIQMERKKLKTLYNMANNVIDTSKLATRELREKINSIYQEEGQ--IESKLIVTVVSF } & 171\end{array}$ $\begin{array}{lll}\text { ILNGIQMERKKLKTLYNMANNVIDTSKLATRELREKINSIYQEEGQ--IESKLIVTVVSF } & 171 \\ \text { ILNGIALERSRLKEVKDVASNIINTSKFTNMDLROEITRIYGDGDQ--VEAQLTITVVSF } & 171\end{array}$ $\begin{array}{lll}\text { ILNGIALERSRLKEVKDVASNI INTSKFTNMDLRQEITRIYGDGDQ--VEAQLTITVVSF } & 171 \\ \text { VLTGITOEREKLREVKNIADII IDTSKYEIRHLREKINKNYGDHTY--PEKOLSITVLSF } 171\end{array}$ $\begin{array}{lll}\text { VLTGITQEREKLREVKNIADII IDTSKYEIRHLREKINKNYGDHTY--PEKQLSITVLSF } & 171 \\ \text { IITGISEERMRLRELKDRADNI IDTSNYP IRNLREKINLIYGDGKP--VEQNLSITVLSF } 171\end{array}$

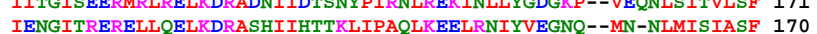
IVDGINEERKRLAEIRKIANSI IDTSNLTSSOLKEELSNIFLKGKK--FK-GIIIDIMSF 169 $\begin{array}{lll}\text { IVDGINEERKRLAEIRKIANSI IDTSNLTSSQLKEELSNIFLKGKK--FK-GIIIDIMSF } & 169 \\ \text { IVDGINEERKRLSD IRKIANYIIDTSNLTSSOIKEEISNIFLKGKK--FK-GIIIDVMSF } & 169\end{array}$ IVDGINEERKRLSDIRKIANYIIDTSNLTSSQLKEELSNIFLKGKK--FK-GIIIDVMSF 169 LIKGIKTEREILSQIRKNATYIIDTSNLTPRQLKEEILAIFVEGRK--FD-GMIVNIISF 170 ILEAIQKEREKLEDIKRYADFIIDTSTLSPRDLKEKLFEIFSAQRS--RE-TMLITVMSF 175 PLKGIEAERDLLTDMKARANIVLDTSDLKPKELREKIVHLFSTE----TEQAFRVNVMSF 176 PLKGIEAERGLLTDMKARANIVLDTSDLKPKELREKIVHLFSTE----TEQAFRVNVMSF 176 PLKGIEIERSLLTDMKARANIVLDTSDLKPKELREKIVHLFSTE----TEQAFRVNVMSF 176 PLEGIRLERKLLEELKGRAQI IYDTTGLKPRELREKIIRQFSSH----AQSGFTINVMSF 179 PLEGIRLERQLLEEIKGRAQI IYDTTGLKPRELREKIVRQF SVH----AQSGFTVNVMSF 179 PLEGIQQERKILEELKGRAQLILNTSNLKPRELREKIVMEFSAN----KQSFFTVNVLSF 177 PLEGIQTERELLEELKGRSQIIYDTSDMKPKDLREKIVQHFAAD----HGHTFTVNVMSF 178 PLEGIALERELLEELKGRSOIIYDTSDMKPRDLREKIVKHFATN----OGETFTVNVMSF 178 PLEGIOKERNLLEEIKGRAQQI IDTTELKPLQLREKIMORFAGN----DRQAFAVHFVSF 177 PLDGIKKERELLEDLKGRAQQI IDTTDLKPIQLREKI IQRF SCE----EHHSFTVNMMSF 178 PLDGIKQEREILDELRGRAQRI IDTTSLKPRNLREKILKVYKEE----KOEVFSVHFVSF 176 VLDGINAERELLSDLKGRSOLVINTSNMAPRELRERINNEFQTE----DKDVFNVQLMSF 174 VLDGINAERELLSDLKGRSOLVINTSNMAPRELRERINNEFOTE----DKDVFNVQLMSF 174 VLDGINAERELLSDLKGRSOLVINTSNMAPRELRERINNEFOTE----DKDIFNVQLMSF 174 PLIGIERERTLLEGFRDKAQLLMDTSDIKPLALKERILKEFTEG----ERIPFTVNVMSF 171 VTEGIRKERAMLEEIKADAQLVIDTTDLSPRQLRERLNKELATR----ETHEFRVEMVSF 173 ITEGIRKERAILDDLKAQASVIIDTTTLTPRQLREKINESFKSK----GDQGFRIEFVSF 173 VMDGVRKERELLAPLKDRASYVIDTSTLTPRELRESIFDKFETD----ODETFHIEMLSF 173 $\begin{array}{lll}\text { LMDGIHKERELLTEIRNOSOMVVNTSMLSPRELREOIFRVFKTS----DNP SFHIEVMSF } & 173\end{array}$ $\begin{array}{lll}\text { LMDGIHKERELLTEIRNQSQMVVNTSMLSPRELREQIFRVFKTS----DNPSFHIEVMSF } & 173 \\ \text { LMDGIKKERALLTELRNRAQVVIDTTTLSPRQLREKIFLNFKESG---SOPAFHIEVMSF } & 174\end{array}$ $\begin{array}{lll}\text { LMDGIKKERALLTELRNRAQVVIDTTTLSPRQLREKIF LNFKESG---SQPAFHIEVMSF } & 174 \\ \text { ILDGIHLERELLAPIKSNAQIIIDTSKLSPRQLREEIFKNFEAR----DTKTFHIEVMSF } & 174\end{array}$

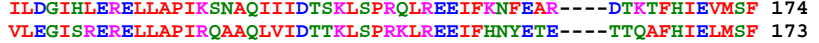
VLEGISRERELIAP IRQAAQLVIDTTKLSPRKLREEIFHNYETE----TTQAFHIELMSF 173
VADGVRKERELISP IKSEAOIVIDTTTMTPRELRSDIFGHFSTNK---TIPKFHIEVVSF 174 VADGRARELISPIKSEAQIVIDTTNMTPRELRSDIFGHFSTNK---TIPKFHIEVVSF 174 VLDGIALERELLAPLKNLSQNVVDTTDLTPRQLRKTISDQF SVEK---SQTSFRLEVVSF 175 VIGIRLERLLSPLKSMQHVDIKLIPRQLRKTISDQFSEGS-LOAFIEVMS 175 VLDGISLERELLAPLKSMSQNVVDTSELTPRQLRKVISKEFSNQD---SOSSFRIEVMSF 175 VLDGIKLERELLSPLKSLSQNVVTTKLTPRQLRKAISEQFSSKQ---DQSSFRIEVLSF 175 ILDGIKLERELLAPLNMSQNVDTIELTPRELRKTLAEQF SDQE---OAQSFRIEVMSF 175 ILDGIKLERELLAPLKNLSONVVDTTDLTPRELRKTISEOFSNQA---DMHSFRIEVMSF 175 VLDGIQLERELLAPLKNMSQNIIDTTELTPRNLRKAISEQFASOD---NQPSFRIEVMSF 174 TLDGITKEREILADLKNLSEVVIDTSELTPRNLRARILQKFAS-S---TESTFRIEVMSF 174 ILDGVELERKLSTDLKSQADIVIDTTNVTPRNLKLRLNKLFGHG----EGNDFYVEVMSF 181 LLDGIQEERRILTP IKNRSNYIVDTSNLSTKELKQKLINTFSDK----KRQPFSIEVMSF 176 LLDGIRDERRILTPVRNRSNYILDTSKMTTKELKOKLQSKFGEL----HKPKFGIEVMSF 188 LIDGIQEERAILSRTKNISNI IIDTSRLTTKELKAKLVDKFGDN----QTRTFSIEVMSF 174 LIDGIQEERNILSRTKNISNIIIDTSHLSTKELKTKLVDKFGDN----RTRTFSIEVMSF 174 LINAINDEREHLSOIRS IANFVIDTTKLSPKELKERIRRYYEDE----EFETFTINVTSF 182 LIDAINEEREHLSEIRSIANYVIDTTKLKPKELKORISKFYLDE----NFETFTINVTSF 182 LMDSILEEKQLLSNIRTIANYIVDTTQLTTKELKARVKEKFEDE----NFKSFSINVSSF 183 LIESINEERELLTEIKSLANYTIDTTQMKPKELRKRIGDYFNKS----NVQTFNINVTSF 182 LLRSILKEKKILFP IRE IADLVIDTTEIKTVELEKRFKKF ILAKDGENTDININIHIQSF 169 LLAAIRAERTALEPVRALADEVVDTGPLELAQLRVHLGALVGG-----RPTELPVTVMSF 177 LMREIAEERRALAGLRGRAHLVVDTSELSPRGLKEALARFLG-------EEGGFLLRLVSF 159

GFKYGLPADADLVADARFLPNPFWKPELRPYTGLDEVVRNDVLQQNGAEEFIESYLEALR 239 GFKYGLPVDADLVVDMRF LPNP HWVPELRPFTGLNEEVSAYVFNQPGAKEFLDRYAELLR 282 GFKYGLPMDADMVMDVRFLPNPHWVDELRPLTGQHPAVRDYVLHRPGAAEFLESYHRLLS 245 GFKYGLPMDADMVMDVRFLPNP HWVDELRPLTGQHPAVRDYVLHRPGAAEFLESYHRLIS 245 GYKYGLPMDADTVMDVRFLPNP HWVDELRPHSGQHPDVRDYVLGQPGALEFLDTYHRLID 257 
Anhang

NocFar_nfa358930

CorEff_CE1710

BifLon_BL0705

ActPle_ZP_00133926

HaeDuc_HD0584

Act Suc

ManSuc_MS1718

PasMul_PM0169

HaeSom_ZP_00132582

EscColsp._YhbJ

ShiFle_YhbJ

SalEntATCC9150_YhbJ

SalTyp_YhbJ

SalEntTY2_T3240

KlePne_.

YerEnt_zP_00834134

YerEnt_ZP_00834134

YerMol_ZP_00827279

YerFre_zP_O

YerPes_Sp.

YerBer_

SerPro_ZP_01538297

ErWCar_ECA0285

PhorLum_plu4044

ProMir_AAC6457

PhoPro_PLU4044

Vibang

VibAlg

VibPar_VP2673

VibHar_AAF72890

VibVuI_vv0445

VibCho_VC2532

VibSpl_V12B01_07423

VibFis_VF0384

AerHyd_AHA 3920

AerSal_ABO88502

IdiBal_os145_05430

IdiLoi_I10393

AltBac_ATW7_18740

PseHal_PSHAa2554

PseTun_PTD2_17262

AlteMac_MADE_14

ColPsy_CPS_4546

SheBal_UPF0042

SheBal_UPF0042

ShePut_UPF0042

SheOne_SO3964

SheDef_UPF0042

SheAma_Sama_3091

SheAma_Sama_30

SheLOi_UPF0042

SheWoO_UPF0042

MarAqu_UPF0042

AzoSp._ebA3650

NitEur_NE1849
ACiSp._ACIAD3059

ZymMob_ZMO1325

DesRed_UPF 0042

ThesCar_UPF0042

HalOre_UPF0042

DesbHaf_DSY4845

MooThe_YP_429136

SymThe_STH186

ClOACe_CAC0511

CloTet_CTC02495

CloBei_ZP_00909349

CloPer_CPE 0354

AlkMet_UPF0042

TherEth_UPF0042

TherTen_TTE1834

TherTen_TTE1834

CalSac_ZP_00884966

BacThu_ZP_00739740

BacWei_UPF0042

BacAnt_GBAA538

BacCer_UPF00

GeoKau_GK3066

GeoThe_GTNG_301

BacClic_YveJ

BacLic_YvcJ

BacSub_YvCJ

BacCla_ABC3036

BacHal_BH3569

OceIhe_OB2468

LisInn_lin2 617

LisWel_lwe2

LisMon_Sp.

ExiSib_UPF0042

EntCFae_EF0766

EntCFaec_UPF 0042

LacPla_lp_0779

LacSak_YP_395138

LacCas_YP_806200

LacSal_YP_536062

LacBre_YP_794827

PedPen_YP_803988

StrMut_Smu_1306c

StrPyo_Sp.

StrAga_gbs 0576

StrThe_str0831

StrPne_SP1566

StrSan_YP_001034791

StrSan_YP_0010347
GFKYGVPLDADMVLDVRFLPNPHWIPELREHSGQETVVSEYVLSRPGAQDYLHTCHHLVD 256 GFKHGSPRDADFIIDARFLPNPFWVPELRPFRGVDKPVSDYVLSOKGAGEFLDNFIAMLD 258 GFKYGMP IDADFVADVRFLPNPFWVPSLRELTGRDKPVADYVLSSKGAKEFLDAYEKAIE 270 GFKYGLPADADYVFDVRFLPNPHWNPELRPMTGLEQPVIDFLERQTEVHNFIYQTRNYLE 228 GFKYGLSADADYVFDVRFLPNPHWHAELRAMTGLEQPVIDFLERQTEVHNFIYQTRNYLE 228 GFKYGLPLDADYVFDVRFLPNP HWNPSLRPMTGLEOPVIDFLSKYEDVANFIYTTRNYIE 229 GFKYGLPLDADYVFDVRFLPNP HWNPDLRPMTGLDQPVIDFLGKYSEVNNF IYSTRNYLE 232 GFKYGIPLDADYVFDVRFLPNPHWDPTLRPMTGLEAPVAEFLNSHTEVNEFIYLTRHYID 231 GFKYGLPLDADYVFDVRFLPNPHWIPELRPLTGLDAPVAEFLNKONEVNHFIYLTRNYIE 227 GFKYGIPLDADYVFDVRFLPNPHWNQELRPMTGLEKPVIEFMOKHIEVDNFIYQTRNYIE 227 GFKHGIPIDADYVFDVRFLPNPHWDPKLRPMTGLDKPVAAFLDRHTEVHNFIYOTRSYLE 227 GFKHGIPIDADYVFDVRFLPNP HWDPKLRPMTGLDKPVAAFLDRHTEVHNFIYOTRSYLE 227 GFKHGIPIDADYVEDVRELPNPHWDPKLPPMTGLDKPVAAFLDRHTEVHNE IYOTRSYL 227 GFKHGIPIDADYVFEVRFIPNPHWDPKLRPMTGIDKPVAAFLDRHTEVHNFIYOTRSYIE 227 GFKHGIPIDADYVFDVRFIPNPHWDPKLRPMTGLDKPVAAFIDRHTEVHNF IYOTRSYLE 227

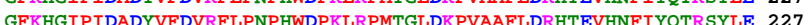
GKH 227 GF 227 GF 227 GFKHIPIDADYVVRFLNPHDPKLRPMTGLKPVISFLDRHEVHF 227 GF GKHGIPIDADVEDELPNHWPKRPMGLDKPISELDRHE 227 GFKHGIPIDADYVDVRF LPNPHWPKLRPMTGLDKPVISFLDRHTEHNVTOTRSYL 227 GFHGIPIDADYVDVFLPNPHDPKLRPMTLDKPVASFLDRHEVHNFIYQTSYLE 227 GFKHGIP IDADVEDVRLPNPHWDKLRPMIGLDKPVASFLDRHTEVHNTYQRSYLE 227 GFKHGIPIDADYVFDVRFLPNPHWDPKLRPMTGLDRPVAAFLDRHTEVHNFIYQTRSYLE 227 GFKHGIPIDADYVFVRFLPNPHWDPKLRPMTGLDRPVAAFLDRHTEVHNFIYQTRSYLE 228 GYKHGIPIDADYVDVRFLPNPHWDPKLRPMTLDRPVAAFLDRTEVHNFIYQTRSYLE 227 GFKHGLPIDADYVDVRFLPNPHWPELKPQTLDQEVKE GFKHGLPSDADYVFDVRFLPNPHWVPELKPQTGLDQGVKDFLSSQSEVNQLNYQIRNFIE 227 GFKYGLPSDADYVFDVRFLPNPHWEPALRPLTGLDAPIAAFLEQHQSVLSLKYQIESFIE 229 GFKYGLP SDADYVFDVRFLPNP HWEPALRPLTGLDAPIAAFLEOHQSVLSLKYQIESFIE 229 GFKYGLPSDADYVFDVRFLPNPHWEPALRPLTGLDGP IGAFLEOHOSVLDLKYOIESFIE 229 GFKFGLPTDADYVFDVRFLPNP HWEPALRPMTGLDAPIKTFLESHDEVLELKRQIQTFIE 229 GFKYGLPTDADYVFDVRFLPNPHWEPDLRPLTGLDAP IKSFLEGHSEVMELKOQIQKFFE 229 GFKYGLP SDADYVFDVRFLPNPHWEPALRPLTGLDAP IHSFLEKHSEVLELKOOIOGFVE 231 GFKHGLPTDADYVFDVRFLPNPHWEP SLRPMTGLDKPVADYLAKHTEVIQLKEOIOOFLT 229 GFKYGIPKDADFVFDARFLPNPHWIPELKPFTGKDEPVARYLSSOPDVMOFILOIENMLA 229 GFKYGIPKDADFVFDARFLPNPHWIPELKPFTGKDEPVARYLSSQPDVMQFILQIENMLA 229 GFKHGVPKDADFVFDARILPNP HWNPELKLLTGQDEDVKOFFRKESLVTKYLLOVENELA 227 GFKYGLPKDADFVFDARILPNP HWOPELKLLTGLDTDVQIFFROEPLVTKFIYQLENFLD 227 GFKHGIPKEADYVFDARFLPNPHWEPELKPLNGLDQPVKDYLASHSIVQKFTWQIQTFVQ 227 GFKHGIPKGADYVEDARELPNPHWEPEITPLTGLDOPVKDYLASHSIVOKETWOIOTFVO 227 GFKHGIPKNADYVFDARFLPNPHWEPLLKPITGLDOPVKDFIASHSIVHKFTWOIOTELO 227 GFKHGIPKDADYVFDARFLPNPHWEPDLKHLTGLDAPVEVFLGSOPVVTKF IWOIONI 227 GFKHGIPKDADYVIF 227 GFKHIXDAD 227 GF 227 GFK GrK 227 GFKH GFKHMP GKKH 227 GFKGMP GFYM TEAD DVR LPN HWELRPLTGLDEPVQ LSQLNKIWQIENLLE 227 GFKHMMAEADFMIDVR LPNPHWPELRPMHELDEPVQLFLSQP IVNKF IWQIENLLE 225 GFKHGVPVDSDYVFDVRCLPNPYWDTSLRKHTGVDOPVIDFLEREPLTROMVDDLTGF LN 233 GFKYGIPLDADLVFDVRCLPNPHYDLRLRPFTGKDQPVIEFLDSFPEVGRMCEDIRRFVA 227 GYKHGIPLDADLVFIRCLPNPFYDQLKELTGHDEVIRFMESOPDASKMLRDISSFLG 227 GYKHGIPLDADYVEVRHLPNPHDLELRRESGLDEPVRRLLSSDQTNEMEDIEHELD 228 GFSRGIPRNCDLLFDMRFLQNPYWEEALRPLTGLDPEIADYIEQDPSFLPAVTKIKDLLL 250 GYKYGIPMDSDLVLDVRFLPNPYYIPELRCLTGNDEPVQQHVMSQDVTKEFMEKLIDFVQ 243 GFKYGIPLDADMVFDVRFLPNPFYVESLRKKSGETPEVSEYIWKWPITQQFMEKLGGLVD 233 GYKYGIPMDADLVFDVRFLPNPYYVRSLKERTGEETVVODYILKWPVTOKFYKRFFDMMD 229 GFKYAIPLDVDLLIDVRFLPNPFYVAELRPLTGEHPQVQDYIF SNPVAOEFVDKYLGLLE 235 GYKYGIPLDADLVMDVRF LPNPYYVPALRPFTGHDRCVEEFVMASPVTROFIEOFAALLR 237 GYKYGLPLDADLIMDVRFLPNPFYVKELRPLSGSDKPVYDYVFNYEVTKKFTEKFLDLIE 231 GFKHGAVLDADLVFDVRFLPNP HYVPDLQPLTGEDPAVVEYVMKWNVTQQFYRRLTGLIG 237 GFKYGIPVDSDLVFDVRFLPNPFYIPELKRFSGIEKPVKDYVMSFDOTKEFVNKIEOLLK 231 GFKYGIPLDSDLLFDVRFLPNPYYIPELRNF SGNDKPVYDYVLEFNQTKEFIGKLNDILE 231 GFKYGIPVDSDLVFDVRF IPNPFYIPELKOYSGNDEPVKDYVLKOEETVNF IEKLVDMLR 231 GFKYGIP SDSDLVFDVRFIPNPFYIPELKPFSGEDEPVKNYVLAOEETKGFLSRLSDMAE 231 GFKHGIPLDSDLVFDVRFLPNPFYIEELKDFTGNDVKVRNYVMNSPISVEFSNKLHDIVS 230 GYKYGIPLDADLVFDVRFIPNDFYIEELRPITGNDDKVVEYVMKWEEAKEFLKKICDMTK 229 GYKYGIPI ADIVEDVRFIPNPFYIDELRPLTGNDEKVKEYVMKWEFAKEFLKKLGDMIK 229 GFKYGIP IECDIVEDVRF IPNPYYIESMKYKTGKDEFVRNYVMSFAETAFFMTKLKDIVD 230

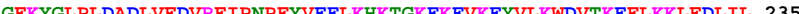
GFY GYIP 236 GFY 236 GHY 236 GTYGIPIDADA 236 GFKYIP IDADLVDVRF LPNPHYIEHMRPKGLDDDVSSYVLKGETQKFLEKLIDLLS 239 GRYGIDADLVEDVRELPNPYIE GFNGIPIDCDLVFDVRELPNPFYIEHMRPKIGLDEEVYTYLKWEIQKFLELIDLLA 237

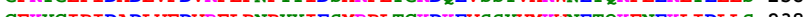
GFKYGIPIDADLVEDVR LPNPYYESMRPLTGKDKEVSSYMKWNETQKFNEKLIDLLS 238 GFKYGIP IDADLVF'DVRF LPNP HYVEDLRPKTGLQTEVSSYVLKWKETKQFVEKLTDLFD 237 GFKYGIPIDADLVFDVRFLPNPHYVHLRPKTGLEGEVSSYVLKWTETQQFIEKLEDLLS 238 GFKYGLPIDADLVFDVRFLPNPHYVSNLOPLTGLNPDVSSYVFKWSDTQTFIDKVTDLLT 236 GFKYGIPIDADLVIDVRFLPNPHYIDKMRPLTGLDEDVYEYVMKWPEMMAFLDKLVDLLM 234 GFKYGIPIDADLVFDVRFLPNPHYIDKMRPLTGLDKDVYEYVMKWPETGAFLDKLIDLLM 234 GFKYGIPIDADLVFDVRFLPNPHYIDKMRPLTGLDEDVYEYVMKWPETQTFLDKLVDLLM 234 GFKHGLPLDADLVFDLRFLPNPFYIPELRPKTGLDLEVSSYVMQWPEAKLFYKKLVDMLE 231 GFKYGLPIDADIVMDVRFLPNPHYIDELRPLTGMDQPVYDYVMGFPETDEFYTKFIDLLR 233 GFKYGLPIDSDIVMDVRFLPNPHYIPELRPLTGKDQPVYDYVMSFDETQSFYHKFLDLLE 233 GFKYGLPIDADIVMDVRFLPNPYYIPELKKLTGLDKPVADYVMOOPATEAFYOQFLSMLE 233 GFKYGLP IDADIVMDVRFLPNPYYVAEFKALNGLDKPVRDYVMEQPATEKFYQQLTALLK 233 GFKYGLPIDADIVMDVRFLPNPFYIKDYRPKTGLDPEVYNYVMDNEDAESFYNKFYDLLS 234 GFKYGLPIDADIVMDVRFLPNPYYVSELRNKTGKDDAVYEYVMKSEKTEEFYOKFVSLLK 234 GFKYGLPIDADIVMDVRFLPNPYYLPELRNQTGMDQPVYDYVMNQPQTEEFYQRFLGLLT 233 GYKYGSP IDADI IMDVRFLPNPYYVTELKNKIGTDPAVYDYVMNQPATEEFYTDYLKLLM 234 GFKYGLPLDADLVFDVRFLPNPYYKPELRDKTGLDKDVSDYVMOHOESEEFYOHLLALIA 235 GFKYGLPLDADLVFDVRFLPNPYYOVELREKTGLDEDVFNYVMSHPESEVFYKHLLNLIV 235 GFKYGIPIDADLVEDVRFLPNPYYKPELRDKTGLDTEVYDYVMSEDESDDFYDHLTAI 235 GFKYGLPIDADLVEDVRFIPNPYYDPTLRNLTGLDKEVYDFVMTHKESEDFYKNLNHLIK 235 GFKYGIPIDADLVFDVRFIPNPYYLPELRNOTGVDEPVYDYVMNHPESEDFYOHLIALIE 235 GFKYGIPIDADIVEDVFIPNPYYKPELRNQTGLDKDVFDYVMNHAESEFTYKNT GFKYGLPLDADLVFDVRFLPNPYYKLELRNLTGLDAPVFDYVMEHOESEEFYSHLLGLIE 234 
Anhang

LactLac_L188550

LacReu_ZP_01164767

LaCACi_LBA0691

LacDel_YP_618706

LacGas_YP_815115

LacJoh_LJ0866

StaAur_Sp.

StaEpi_SE0548

StaHae_SH2124

StaSap_SSP1952

FusNuc_FN1089

GloVio_glr4163

TheThe TTHA0319

LeiXy1_LXx11490

StpAve_SAV6292

MycTubCDC1551_MT1464

MycTubH37Rv_RV1421

MYCSme_MSMEG3088

NocFar_nfa358930

CorEff_CE1710

BifLon_BL0705

HaeDuc_HD0584

Act Suc

ManSuc_MS1718

HaeInf_AAC2280

PasMul_PM0169

HaeSom_ZP_00132582

EscColsp._YhbJ
ShiFle_YhbJ

SalEntATCC9150_YhbJ

SalTyp_YhbJ

SalEntTy2_T3240

EntSp.

YerEnt_ZP_00834134

YerMol_ZP_00827279

YerPes_Sp.

YerPse_YPTB3529

YerBer

SerPro_ZP_01538297

ErwCar_ECA0285

PhorLum_ECA 285044

ProMir_AAC64575

ProMir_AAC64575

PhoPro_PLU4044

VibAng_

VibAlg

VibPar_VP2 673

VibHar_AAF72890

VibVul_VV044

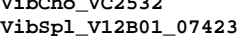

VibFis_VF0384

AerHyd_AHA_3920

AerSal_ABO88502

IdiBal_os145_05430

IdiLoi_I10393

AltBac_ATW7_18740

PseHal_PSHAa2554

PseTun_PTD2_17262

PseAt1_UPF0042

ColPsy_CPS_4546

SheBal_UPF0042

ShePut_UPF0042

SheOne_SO3964

SheDef_UPF0042

SheFri_UPF0042

SheAma sama 3091

SheAma_Sama_30

SheLOi_UPF0042

SheWoo_UPF0042

MarAqu_UPF0042

AzOSp._ebA3650

ACiSp._ACIAD 3059

ZymMob_ZMO1325

DesRed_UPF0042

HalOre_UPF0042

Halore_UPFO042

MesbHaf_DSY4845

MooThe_YP_429136

SymThe_STH186

ClOAce_CAC0511

ClOTet_CTC02495

CloBei_ZP_00909349

CloPer_CPE0354

AlkMet_UPF0042

TherEth_UPF0042

TherTen_TTE1834

CloThe_UPF0042

CalSac_ZP_00884966

BacThu_ZP_00739740

BacWei_UPF0042

BacAnt_GBAA5384

BacCer_UPF0042

GeoKau_GK3066

GeoThe_GTNG 3015

BacCoa_UPF0 042

BacLic_YvcJ

BacSub_YvcJ

BacCla_ABC3036

GFKYGLPLDADLVFDVRFLPNPHYITELRDKNGTDKEVYDYVMEHPQSEEFYENLMKMLV 234 GFKYGLPLDADIVMDVRFLPNPFYIPELKHLTGNDPAVONYVMOSPLAKEFYOHLRSLLE 241 GFKYGMP IDADIVMDVRFLPNPFYIPELRPFTGLDKRVFDYVMNKEETQVFYKKLLDMLE 236 GFKYGMPIDADIVMDVRFLPNPFYIPELRPFTGLDKRVFNYVMDKDETKVFYGKLLDLLL 248 GFKYGIP IDADIVMDVRFLPNPFYIPQLKPFTGLDRRVFDYVMSKKETKKFYAKFLDMLE 234 GFKYGIPIDADIVMDVRFLPNPFYIPQLKPFTGLDRRVFDYVMSKKETKEFYAKFLDMLE 234 GFKHGIQMDADLVFDVRFLPNPYYVVDLRPLTGLDKDVYNYVMKWKETEIFFEKLTDLLD 242 GFKHGIOMDADLVFDVRFLPNPYYVEELRPFTGLDEPVYNYVMKWKETQIFFDKLTDLLK 242 GFKHGIQKDADLVFDVRFLPNPYYVEDLRPMTGEDEPVYHYVMKWKETEIFFEKLMDLLK 243 GFKHGIOMDADLVFDVRFLPNP HYVDELRPLTGEDEAVYKYVMKWKETNIFYEKLIDLIK 242 GYKYGIPTDSDLMFDVRF IPNPYYIEKLKELNGFDEEVKEYVLSOKESKEFYFKLLPLIE 229 GFKRGVPADAOFVLDIRFLPNPYYESALKPLTGLDVGVAEYVFASEOSOATYRSLLEFLR 237 GFKWGPPOEADIVIDVRPPINPHYDPALPPRTGLDPEVRRYVES-

PIFAGYORENKRHATIAVGCTGGKHRSVAIAEELAARLRSLPGLA-----VSIKHR----D 291 LIAAGYRREGKRYVTIAVGCTGGKHRSVATSEKLAARL-AAEGVE----TVVVHR----D 333 LVVDGYRREGKRYMTIAIGCTGGKHRSVAIAEALMGLIRSDQQLS-----VRALHR-----D 297 LVVDGYRREGKRYMTIAIGCTGGKHRSVAIAEALMGLIRSDQQLS----VRALHR----D 297 VVIDGYRREGKRYMTVAIGCTGGKHRSVAIAFALAERIEGGELT----VRVIHR----D 309 LTTSGYROEGKRYMTVAVGCTGGKHRSVAIAEALGELIGADTSAESADVVRVVHR-----D 312 DMLPGYRHEGKNF ITVGIGCTGGHHRSVAVSEELARRLGERPDID----VSVVHR----D 310 IALEGYAOEDKHYVTIAVGCTGGOHRSVAMSEETARRIRAH-GLN----VTVSAR----E 321 MWLPMI TWLPMLEKNNRSYLTIAFGCTGGKHRSVFITEQLAKYFQSR------GKNVKIRHR----S 279 TWLPMLERNNRSYLTIAIGCTGGKHRSVYIAQQLGEYFQDK------GKHVKIQHK----S 280 TWLPMLEQNNRSYLTIAIGCTGGKHRSVYIAQQLGEYFQAK-----GKKVKIQHK----S 283 TWLPMLEKNR SYIAICCIGGKHRSYIAQQLGEYF QAK----GKIVKIQHK---S 282 TWLPMLEQNNRSYLTIAIGCTGGKHRSVYITEQLGEYFQAK------GKNVQIQHK----S 278 NWLPMLEKNNRSYLTIAIGCTGGKHRSVYIAQQIGEYFRAK------GKKVQIQHK-----S 278 LWLPMLETNNRSYLTVAIGCTGGKHRSVYIAEQLADYFRSR-----GKNVQSRHR----T 278 LWLPMLETNNRSYLTVAIGCTGGKHRSVYIAEQLADYFRSR-----GKNVQSRHR----T 278 LWLPMLETNNRSYLTVAIGCTGGKHRSVYIAEQLADYFRSR-----GKNVQSRHR----T 278 LWLPMLETNNRSYLTVAIGCTGGKHRSVYIAEQLADYFRSR-----GKNVQSRHR----T 278 LWLPMLETNNRSYLTVAIGCTGGKHRSVYIAEOLADYFRSR------GKNVOSRHR----T 278 LWLPMLETNNRSYLTVAIGCTGGKHRSVYIAEQLADYFRSR-----GKNVQSRHR----T 278 LWLPMLETNNRSYLTVAIGCTGGKHRSVYIAEQLADYFRSR------GKNVQSRHR----T 278 LWLPMLETNNRSYLTVAIGCTGGKHRSVYVAEQLADYFRAR-----GKNVQSRHR----T 278 LWLPMLETNNRSYLTVAIGCTGGKHRSVYVAEOLADYFRAR------GKNVOSRHR----T 278 LWLPMLETNNRSYLTVAIGCTGGKHRSVYVAEOLADYFRAR-----GKNVOSRHR----T 278 QWLPMLETNNRSYLTVAIGCTGGKHRSVYVAEQLADYFRAR------GKNVQSRHR----T 278 OWLPMLETNNRSYITVAIGCTGGKHRSVYVAEOLADYFRAR-----GKNVOSRHR----T 278 OWLPMLETNNRSYLTVAIGCTGGKHRSVYVAEOLADYFRAR-----GKNVOSRHR----T 278 OWLPMLETNNRSYLTVAIGCTGGKHRSVYVAEOLADYFRSR-----GKNVOSRHR----T 278 LWLPMIETNNRSYLTVAIGCTGGKHRSVYVAEOLADYFRSR------GKNVOSRHR----T 278 WTPTI WWPMLE LWLPMLETNNRSLTVAIGCTGGKHRSVVAEQLADYFRSR-----GKNVQSRHR----T 279 LWLPT 278 TWLPLIE SWLPMLEKNRSYVAT WWPLIEKR

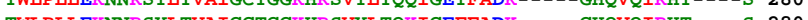
TWPLLEKMRYLVICCTG HWPLLEKNNRS YWLPMLEKNNRSYLTIAIGCTGGKHRSVYLTQQLGEYFAQL------GHQVQLRHT-----S 280 QWLPMLEKNNRSYLTVAIGCTGGKHRSVYLTQKIGEYFEQI-----GHOVOIRHA----S 282 TWLPALEKNNRSYLTVAIGCTGGQHRSVYITQQLGEYFKQQ-----GKQVQIRHK----T 280 TWLPLERNARSYTVGIGCIGGQHRSVF IAEQLAGAFRLL-L TWLPHLERNNRSYVTVGIGCTGGQHRSVF IAEQLAGAFRLI-----GKNVQIRHR----T 280 TWLPYFRRSNRSYLTIAMGCTGGQHRSVYLAETLAEQFRSE-----GTHVQVRHR-----E 278 TWLPHFQRSNRSYLTIATGCTGGQHRSVYISQQLAERFEQK-----AVKVQVRHR----E 278 TWLPHLERNNRSYLTIAIGCTGGOHRSVYLAOTIGESFAVT------HPNVKIRHR----E 278 TWLPHLERNNRSYLTIAIGCTGGOHRSVYLAQTIGESFAMS------HPNVKIRHR-----E 278 TWLPHLERNNRNYLTIAIGCTGGOHRSVYLAQTLADNFSRS-----HKNVKVHHR----E 278 TWLPHLERNNRSYVTVAIGCTGGOHRSVYIAQTLSKTFSEI------HPDVQIRHR----E 278 TWLPHLERNNRSYVTIAIGCTGGOHRSVYVVEMLAKTFSTS------HPDVQIRHR----E 278 TWLPHLERNNRSYVTIAIGCTGGKHRSVYIAEMLAKNFRKE------RDDIOTHHR----D 278 TWLPHLERNNRSYLTVAIGCTGGOHRSVYVAEQLAKRFSNG------KHKVYARHR----E 278 TWLPHLERNNRSYLTIAIGCTGGOHRSVYVAEOLAKRFSNG-----KHKVNVRHR----E 278 TWLPHLERNNRSYLTIAIGCTGGOHRSVYVAEOLAKRFSNG------KHKVNARHR----E 278 TWMP HLERNNRSYLTIAIGCTGGOHRSVYIADOLAARR ANG-----KHVVNARHR----E 278 TWMP HLERNNRSYLTIAIGCTGGOHRSVYIADOLAKRFROGS----KHTVNARHR----E 279 TWLPHLERNNRSYLTIAIGCTGGOHRSVYIAEOLAKRFANS------HHKVEARHR-----E 278 TWLPHLERNNRSYLTIAIGCTGGOHRSVYVTDOLAKLFNKG-----KHKVOARHR----- 278 TWIPUT

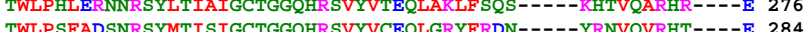
TWLSE TWLPSYADNA TWLPAYIRDNAYLIVAICII KW FLLPRYIDTEST FLVPHYREGRATMIAIGCIGGMRSVILTNKLGEVLSE-C-K-GYRVNVRR---D 294 FLVNYIKEGKSDIIAVGCIGGLHRSVFANKIYEGLRN----K-GYKVNVEHR----D 284 FLLPEYSREGKSH FILP Y VKEGKRHVIGVGIGGORSVAIAERIGLFLQE----R-SYMMSVRHR----D 286 FLIPHYLQEGKSHLVVAIGCTGGQHRSVTLANKLGELIQG----E-NYSVTVKHR----D 288 FLMPFYQKEGKSNLVIAIGCTGGRHRSVAIANF LARTLEE----K-NYEVYLRHR----D 282 FLLPHYVAEGKSLLTIAIGCTGGKHRSVCLANRLAHWIRE-----R-GYSVSVEHR----D 288 FLIPNYLKEGKRQLIVSIGCTGGRHRSVTIANEIYERLKN----D-GETVNIDHR----D 282 FLIPHYTEEGKRQLIVAIGCTGGRHRSVS IANS IYKLLEE----K-GHKVNIDHR----D 282 YLIPNYIKEGKSQLI ISIGCTGGRHRSVAIANEVYERLNK----E-NYNSKIEHR----D 282 FLIPNYIKEGKRQLI ISIGCTGGRHRSVAIANALYKDLLC----K-NFHVTLEHR----D 282 FLIPHYVQEGKNQLVISIGCTGGRHRSVTIAHVLYHOLKD----K-GHRVTLSHR----D 281 FLIPYYIREGKSOLVIAIGCTGGKHRSVTIANALYEFLKK----E-DYSVILHHR-----D 280 FLIPYYVREGKSOLVIAIGCTGGKHRSVAIANALYDLLKK----E-DYSVVVNHR----D 280 FLIPNYIKEGKSOLVIGVGCTGGRHRSVAISEALF SYLCG----R-EHRVF IDHR----D 281 FLIPNYAEEGKAOLVIAIGCTGGKHRSVTIAEELFELIKN----N-GYKASIFHR----D 286 FMLPHYKREGKSOLVIAIGCTGGOHRSVTLTEYLGKHLK-----P-EYSVHVSHR----D 286 FMLPHYKREGKSOLVIAIGCTGGOHRSVTLTEYLGKHLK-----P-EYSVHVSHR----D 286 FMLPHYKREGKSOLVIAIGCTGGOHRSVTLTEYLGKHLK-----P-EYSVHVSHR----D 286 FMLPHYKREGKSOLVIAIGCTGGOHRSVTLAEYLGKHLK-----P-DYSVHVSHR----D 286 FMLPYYQREGKSQLVIAIGCTGGQHRSVALAEYIARHFS-----D-DYKTVVSHR----D 289 FMLPYYOREGKSOLVIAIGCTGGOHRSVALAEYIARHFS-----A-DYKTVVSHR----D 289 FMLP HYKREGKSOLVIGIGCTGGQHRSVAL_AEYIGHFFE-----K-DYHTTISHR----D 287 FMLPSYKREGKSOLVIAIGCTGGOHRSVTLAEYLADYFK------K-DYYTHVTHR----D 288 FMLP SYKREGKSOVVIAIGCTGGOHRSVTIAYNADYK-----K-DYYTHVTHR----D 288 FMLPHYKREGKSQVVIGIGCTGGOHRSVTLAEYFCAHYE------A-KYDAYTSHR----D 287 
Anhang

BacHal_BH3569
OceIhe_OB2468
LisInn_lin2617
LisWel_lwe2422
LisMon_Sp.
ExiSib_UPF0042
EntcFae_EF0766
EntCFaec_UPF0042
LacPla_IP_0779
LacSak_YP_395138
LacCas_YP_806200
LacSal_YP_536062
LacBre_YP_794827
PedPen_YP_803988
StrMut_Smu_1306c
StrPyo_Sp.
StrAga_gbs0576
StrThe_Str0831
StrPne_SP1566
StrSan_YP_001034791
StrSui_UPF0042
LactLac_L188550
LacReu_ZP_01164767
LacAci_LBA0691
LacDel_YP_618706
LacGas_YP_815115
LacJoh_LJ0866
StaAur_Sp.
StaEpi_SE0548
StaHae_SH2124
StaSap_SSP1952
FusNuc_FN1089
GloVio_g1r4163
TheThe_TTHA0319

LeiXy1_Lxx11490 StpAve_SAV6292 MyCTubCDC1551_MT1464 MycTubH37Rv_RV1421 MYCSME_MSMEG3088 NocFar_nfa358930 BifLon_BL0705 ActPle_ZP_00133926 HaeDuc_HD0584 HaeDuc_

ManSuc_MS1718 HaeInf_AAC22801 HaeInf_AAC22801 PasMul_PM0169 EscColsp._YhbJ SalEntATCC9150_YhbJ SalTyp_YhbJ SalEntTy2_T3240

KlePne_P17163

EntSp.

YerEnt_ZP_00834134

YerMol_ZP_0082727

YerFre_ZP_00828963

YerPes_Sp.

YerPse_YPTB3529

YerBer

SerPro_ZP_01538297

ErwCar_ECA0285

Phorlum plu4044

ProMir_AAC64575

SodGlo_SG0196

PhoPro_PLU4044

Vibang

VibAlg

VibPar_VP2673

VibHar_AAF72890

VibVul_Vv0445

VibCho_vc2532

VibSpl_v12B01_074

ibris_

AerHyd_AHA_3920

AerSal_ABO88502

IdiBal_os145_I10393

IdiLB__I10393

PseHal_PSHAa2554

PseHal_PSHAa2554

PseTun_PTD2_17262

AlteMac_MADE_1

PseAt1_UPF 0042

ColPsy_CPS_454

SheBal_UPF0042

ShePut_UPF0042

SheOne_SO3964

SheDef_UPF0042

SheFri_UPF0042

SheAma_Sama_3091

SheLoi_UPF0042

SheWoo_UPF0042

MarAqu_UPF0042

AzoSp._ebA3650

NitEur_NE1849

ACISP._ACIAD3059

ZymMob_zMO1325

DesRed_UPF0042

ThesCar_UPF0042

HalOre_UPF 0042

DesbHaf DSY4845

MooThe_YP_429136
FMLPQYKREGKSQVVIGIGCTGGKHRSVTLAAEHFAKVFA------N-EYMMHVSHR----D 288 FMLPQYKKEGKSOLVVAIGCTGGOHRSVALAEHF SKVLS-----N-GYTTHVSHR----D 286 FTLPFYKREGKTQLVIAIGCTGGQHRSVALTEYVGKAIQ------Q-KYETTISHR----D 284 FTLPFYKREGKTQLVIAIGCTGGQHRSVALTEYVGKAIQ-----Q-KYETTISHR----D 284 FTLPFYKREGKTQLVIAIGCTGGOHRSVALTEFVGKAIQ-----Q-KYETTISHR----D 284 FLIPQYEREGKSQLVVALGCTGGKHRS ITFAEAISKEFK------N-QYHIVTNHR----D 281 TVLPGYKKEGKSSVTIAIGCTGGOHRSVALTERVGAELKE----E-DYHVNITHR----D 284 TVLPGYIKEGKSSLTVAIGCTGGOHRSVALTERLANALG-----K-NYKVNVTHR----D 283 SIMPGYEAEGKSSLTIAIGCTGGOHRSVALTQRIGEALA-----K-HYKVHISHR----D 283 SIMPGYLKEGKTSVTIAIGCTGGOHRSVALAORLADDLA------V-DYPVDVTHR----D 283 EIMPKYKAEGKTSVTIAIGCTGGOHRSVAFAERIGKAFS-----D-AYAVDITHR----D 284 YVIPGYIAEGKSNVTIAIGCTGGOHRSVALAERIGNELS-----K-EYPVHMSHR----D 284 TIVPGYKOEGKSSITIATCCTGGOHRVATTQRIOAL---N-TYPVHVTHR---DD 283 DIMPGYOKEGKSNITIAIGCTGGOHRSVAIAFRAKDI----K-KYVTNISHR---D 283 DIIPGYO PIIPAYO DIV PILPAY PILPG PILPSYREGKS PILPGYKEGKSILTIAVGCIGGQHRSVAFARLADDLA-----K-NWPVNSSHR----D 285 PILP PILPAYKKEGKSVLIAAFGCIGGQHRSAFAERVSAALK-----D-KWHLNVSHR---D 284 IALPGYIKEGKSSTIAIGCIGGQHRSVIIANKLSADLKE----K-GYKVNTYHR----D 292 TAIPGYIKEGKEKLTIAIGCIGGQHRSVSIAQQLARDLS-----K-KYPVDITHR----E 286 TAIPGYIDEGKERLIAIGCIGGQHRVSIAQQLARDLS---E-KYPVDITHR-L-E 298 TAIPGYIAEGKEKLTIAIGCTGGQHRSVSIARQLAVDLA-----K-KYPVDISHR----E 284 TAIPGYIAEGKELTIAIGCTGGQHRSVSIARQLAVDLA----K-KYPVDISHR----E 284 FMIPGYKKEGKSOLVIAIGCTGGOHRSVALAERLGNYLNEV---F-EYNVYVHHR----D 294 FMIPGYKKEGK FMIPGYKKEGKSQLVIAIGCTGGQHRSVALAKRIGEELTEI---F-DYNVYVHHR----D 295 FMVPGYKKEGKSQLVIAIGCTGGQHRSVALAKRIGAELNES---F-DYNVYVHHR-----D 294 FLIPQYIKEGKKHLTISIGCSGGQHRSVTFVNKLAEDLKNSKVLE-YINVYVSHR----E 284 FLLHQYRQDRRSQLIIAIGCTGGQHRSVAFVERLSGDLAAEG-----FACRPSHR----D 288 LAAEGARAEGRAFYTVAVGCTGGRHRSVAVAERLAEELSGR-------FAVEVVHR-----D 268

\begin{tabular}{|c|c|}
\hline & \\
\hline GRE & \\
\hline GRE- & 30 \\
\hline GRE- & $3 c$ \\
\hline SRE- & \\
\hline SRE- & 31 \\
\hline RN--- & \\
\hline KRHSS------ & 32 \\
\hline KK------ & \\
\hline KT----- & 28 \\
\hline IR----- & \\
\hline KNSA---- & 29 \\
\hline RNKKI-C-C- & \\
\hline INTQ---- & 28 \\
\hline NK------ & \\
\hline EKRKP-- & 28 \\
\hline----- & \\
\hline$---\infty$ & 28 \\
\hline ------ & \\
\hline [------ & 28 \\
\hline ----- n & \\
\hline ------- & 28 \\
\hline -------- & \\
\hline--- & 28 \\
\hline ------ & \\
\hline-4 & 28 \\
\hline & \\
\hline 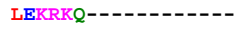 & 28 \\
\hline 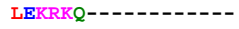 & \\
\hline s-- & 28 \\
\hline & 28 \\
\hline-- & 28 \\
\hline 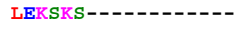 & 28 \\
\hline 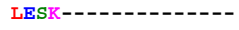 & 28 \\
\hline & 28 \\
\hline E-- & 28 \\
\hline & 28 \\
\hline-- & 28 \\
\hline & 28 \\
\hline---- & 28 \\
\hline & \\
\hline- & 28 \\
\hline & \\
\hline- & 2 \\
\hline & \\
\hline-- & 2 \\
\hline . & \\
\hline--- & 28 \\
\hline & \\
\hline--- & 28 \\
\hline & \\
\hline & 2 \\
\hline & \\
\hline & 2 \\
\hline & \\
\hline & 2 \\
\hline --- & \\
\hline & 28 \\
\hline 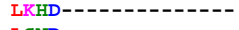 & \\
\hline & 28 \\
\hline & \\
\hline & \\
\hline--- & \\
\hline & \\
\hline$Y_{Q}$ & \\
\hline & \\
\hline & \\
\hline & \\
\hline re- & \\
\hline
\end{tabular}




\begin{tabular}{|c|c|c|}
\hline CarHyd_YP_359144 & LEK--HREE- & 289 \\
\hline SymThe_STH186 & MPRPADRSDEEEQP---- & 302 \\
\hline ClOACe_CAC0511 & IEEDINKGGKKL---- & 294 \\
\hline CloTet_CTC02495 & IHEDNNKGGKKL------ & 294 \\
\hline CloBei_ZP_00909349 & VAEDLHKGEKKL- & 294 \\
\hline CloPer_CPE 0354 & INEDINRGDRKL------ & 294 \\
\hline AlkMet_UPF0042 & SGETRERKKES------- & 292 \\
\hline TherEth_UPF0042 & IGEE-- & 284 \\
\hline TherTen_TTE1834 & IGEE--------- & 284 \\
\hline CloThe_UPF0042 & IDKDGRSNRR---- & 291 \\
\hline CalSac_ZP_00884966 & IEKDIKG--- & 293 \\
\hline BacThu_ZP_00739740 & VEKRKGH----------- & 293 \\
\hline BacWei_UPF 0042 & VEKRKGH------------ & 293 \\
\hline BacAnt_GBAA5384 & VEKRKGH----------- & 293 \\
\hline BacCer_UPF0042 & VEKRKGH---------- & 293 \\
\hline GeoKau_GK3066 & MERRKDIHR--------- & 298 \\
\hline GeoThe_GTNG_3015 & MERRKEAHR--------- & 298 \\
\hline BacCoa_UPF 0042 & IKRKEERKP--------- & 296 \\
\hline BacLic_YvcJ & IEKKSRK------------ & 295 \\
\hline BacSub_YvcJ & IEKRSRK----------- & 295 \\
\hline BacCla_ABC3036 & INKRKANSR--------- & 296 \\
\hline BacHal_BH3569 & VEKGKER----------- & 295 \\
\hline OceIhe_OB2468 & IDKRKVL--------- & 293 \\
\hline LisInn_lin2 617 & MKRRKER----------- & 291 \\
\hline LisWel_lwe2422 & MKRRKGR----------- & 291 \\
\hline LisMon_Sp. & MKRRKGR----------- & 291 \\
\hline ExiSib_UPF0042 & YVHAKEEK---------- & 289 \\
\hline EntcFae_EF0766 & RLKRKETVNRS------- & 295 \\
\hline EntcFaec_UPF0042 & KDKRKETVNRS------- & 294 \\
\hline LacPla_lp_0779 & IEKRKETVNRS------- & 294 \\
\hline LacSak_YP_395138 & MKKRKESVNRS------ & 294 \\
\hline LacCas_YP_806200 & IKKHKETVNRS-- & 295 \\
\hline LacSal_YP_536062 & MNKRKETVNRS-- & 295 \\
\hline LacBre_YP_794827 & IEKRKESANRS--- & 294 \\
\hline PedPen_YP_803988 & AHKRKETVNRS--- & 295 \\
\hline StrMut_Smu_1306c & KNRRKETVNRS-- & 296 \\
\hline StrPyo_Sp. & QNRRKETVNRS------ & 296 \\
\hline Straga_gbs 0576 & KNKRKETVNRS------- & 296 \\
\hline StrThe_str0831 & KDRRKETVNRS------- & 296 \\
\hline StrPne_SP1566 & KDRRKETVNRS------- & 296 \\
\hline StrSan_YP_001034791 & KNRRKETVNRS------- & 296 \\
\hline StrSui_UPF0042 & KDRRKETVNRS-------- & 295 \\
\hline LactLac_L188550 & KDRRKETVNRS------- & 295 \\
\hline LacReu_ZP_01164767 & IEKAK------------ & 297 \\
\hline LacACi_LBA0691 & ISRYIRK----------- & 293 \\
\hline LacDel_YP_618706 & ISRYLRK----------- & 305 \\
\hline LacGas_YP_815115 & ISRYIGQ-- & 291 \\
\hline LacJoh_LJ0866 & ISRYIGQ---------- & 291 \\
\hline StaAur_Sp. & AHIESGEKK-------- & 303 \\
\hline StaEpi_SE0548 & AHIESGER--------- & 302 \\
\hline StaHae_SH2124 & AHIESGVRK------- & 304 \\
\hline StaSap_SSP1952 & AHVESGVKHKDEKN--- & 308 \\
\hline FusNuC_FN1089 & KELGHW-- & 290 \\
\hline GloVio_glr4163 & LAVNRLOELSR-------- & 299 \\
\hline heThe_TTHA0319 & $\mathrm{V}$ & 273 \\
\hline
\end{tabular}

\subsubsection{RNABindR-Vorhersagen}

\section{Dargestellt ist die optimal prediction.}

„+“" zeigen potenziell an der Bindung von RNA beteiligte Aminosäuren an.

$>$ ActSuc_ZP_00733020

MELI I ISGRSGAGKSVALRALED I GYYCVDNLP IDLLP QLAD I LSQSQASAA I S LD IRNLPNSSQHLDE I LTELE NKHQ IKI IFLDADRSTLIRRYSDSRRLHP LSVQNQDLSLEAA IDAEQIQLDP L IQHANLI IDTAVLSTHELAERL REF LRGNSDKELKIVVESF GFKYGLP LDADYVFDVRF LPNP HWNP S LRP MT GLEQPVIDF LSKYEDVANF IYTTR NYIETWLPMLERNNRSYLTIAIGCTGGKHRSVYIAQQLGEYFQDKGKHVKIQHKSLEKHKNR $---------------------------++++-+---+---+-++++++-+-+++++++--++$

>BaCSub_YvCJ

MSVSESHDIQLVI ITGMSGAGKTVAIQSFEDLGYFCVDNLPP SLLP KF LELMKESNSKMSKVALVMDLRGREFFD RLIEALDEMAENPWITPRI LF LDAKDS I LVTRYKETRRSHP LAATGLP LEGIALERELLEELKGRSQI IYDTSDM KPRDLREKIVKHFATNQGETFTVNVMSF GFKYGIP IDADLVFDVRF LPNPYYIESMRP LTGKDKEVSSYVMKWNE

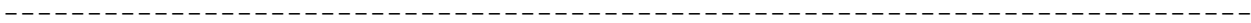
TQKFNEKLIDLLSFMLP SYKREGKSQVVIAIGCTGGQHRSVTLAENLADYFKKDYYTHVTHRD IEKRSRK >ClOPer_CPE0354

MRFVIVTGLSGAGKTEATRSLEDLGYFCVDNLPPKLIPKFAEACVQSEGKIDKIALVIDIRGGIFFDDLFES IEY LKANDFNYE I LF LEASDEVLVKRFKETRRSHP LSP DGRI I TGISEERMRLRELKDRADN I ID T SNYP IRNLREKI $-----------------------------------+-+-------------------------------------$ NLLYGDGKPVEQNLSI TVLSFGFKYGIP SD SDLVFDVRF IPNPFY IPELKPF S GEDEPVKNYVLAQEETKGF LSR LSDMAEF LIPNYIKEGKRQLI IS IGCTGGRHRSVA IANALYKDLLCKNF HVTLEHRD INED INRGDRKL 


\section{Anhang}

$>$ CorEff_CE1710

MNQTPGSTVPETATPVTSPASSP SAPETTFTPVI I TGMSGAGLSTAARVLEDLGWFVTHNLPPQMI LP LVEMCAR EDSPVDKVAVVCDVRSREFRGGLRET ITELEEKNLAP TVLF LDARDDEL I RRFDNVRRTHP LQGSQTLQVG IERE -- - - - - - - - - - - - - - - RQMLSDLKEEADVVIDTSELSVHDLRRAIESSFRT IAKRVQHVT IESFGF KHGSPRDADF I IDARF LPNPFWVPE LRPFRGVDKPVSDYVLSQKGAGEF LDNF IAMLDDMLP GYRHEGKNF I TVGIGCTGGHHRSVAVSEELARRLGERP -- - - - - - - - - - - - - - - - - - - - - - - - - - - - - - - - - - - - - - + +++++++++-- - - - - - - - - + + DLDVSVVHRDINRN

$-----------+-$

$>$ EntcFaec_UPF0042

MTDNLQLVIITGMSGAGKTVAIQSFEDMGYFCIDNMPPRLIPKFWELIKESGKVTKMALGVDLRSRSFFEEIQNM LIEIENTNF IDTS I LF LDASDEELVARYKETRRAHPMAMD GLI TEGIRKERA I LDDLKAQASVI IDTTTLTP RQL -- - - - - - - - - - - - - - - - - - - - - - - - - - - - - - - - - - - - - - - - - - - - - - - - - - - - + REKINESFKSKGDQGFRIEFVSFGFKYGLP IDSD IVMDVRF LPNP HY IPELRP LTGKDQPVYDYVMSFDETQSFY HKF LDLLETVLPGYIKEGKSSLTVAIGCTGGQHRSVALTERLANALGKNYKVNVTHRDKDKRKETVNRS $---------------------------+++++++-----+--++++++++++-+++++++++++++++$

>EntSp._ZP_01590769

MVLMIVSGRSGSGKSVALRALEDMGFYCVDNLPVVLLPELARTLADRQISAAVS IDVRNMPESPEVFEQAMSSLP ETFTPQLLFLDADRNTLIRRYSDTRRLHP LSSKNLSLESA IDEESDLLEP LRSRADLIVDTSEMSVHELAEMLRT

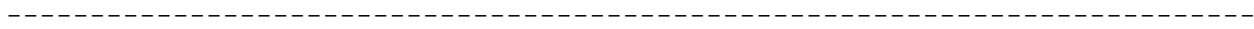
RLLGKRERELTMVFESFGF KHGIP IDADYVFDVRF LPNP HWDP KLRPMTGLDKPVAAF LDRHTEVHNF IYQTRSY LELWLPMLETNNRSYLTVAIGCTGGKHRSVYIAEQLADYFRSRGKNVQSRHRTLEKRKT

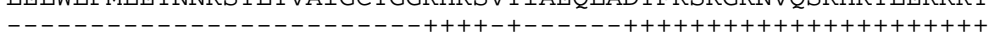

$>$ ErwCar_ECA0285

MVLMIVSGRSGSGKSVALRALEDMGFYCVDNLPVVLLPELANTLAARNISAAVS IDVRNMPESPE IFEHAMEQLP P SF SP QLLF LDADRNTLIRRYSDTRRLHP LSSKNLSLESA IDEESD LLEP LRSRADL I IDTSEMSVHELAEMLRT RLLGKRERELTMVFESFGFKHGIP IDADYVFDVRF LP NP HWDP KLRPMTGLDKPVASF LDRHTEVHNF IYQTRSY - - - - - - - - - - - - - - LELWLPMLETNNRSYLTVAIGCTGGKHRSVYVAEQLADYFRSRGKNVQSRHRTLEKRKPS $-------------------------++++-+---+--++++++++++++++++--+++++$

$>$ EscColsp._YhbJ

MVLMIVSGRSGSGKSVALRALEDMGFYCVDNLPVVLLPDLARTLADREISAAVS IDVRNMPESPE IFEQAMSNLP DAF SP QLLF LDADRNTLIRRYSDTRRLHP LS SKNLSLESA IDKESDLLEP LRSRADL IVD TSEMSVHELAEMLRT - - - - - - - - - - - - - - - - - - - - - - - - - - - - - - - - - - - - - - - - - - - - - - - - - - - - - RLLGKRERELTMVFESFGFKHGIP IDADYVFDVRF LP NP HWDP KLRPMTGLDKPVAAF LDRHTEVHNF IYQTRSY LELWLPMLETNNRSYLTVAIGCTGGKHRSVYIAEQLADYFRSRGKNVQSRHRTLEKRKP - -------------------++++-+------+++++++++-++++++--++++ $>$ HaeInf_AAC22801

MGKLMEI I I ISGRSGAGKSVALRALEDAGYYCVDNIP LDLLPQLTD ILSQSQSSVAISLDIRNIPNSAHSLKQTL STLQKHHQIKI IF LEADRATLIRRYSDSRRLHP LS LKD LS LEAAIDEEYRYLEP LIQHANLI LDT THLSTHS LAE STLQKHHQIKIIFLEADRATLIRRYSDSRRLHP LSLKDLSLEAAIDEEYRY LEP LIQHANLILDTIHLSTHSLAE RLREF LRGNSEKELKI IVESFGFKYGIP LDADYVFDVRF LPNP HWDP TLRPMTGLEAPVAEF LNSHTEVNEF IYL TRHYIDTWLPMLEKNNRSYLTIAIGCTGGKHRSVYIAQQLGEYFQAKGKTVKIQHKSLERNKKI $-----------------------------++++-+---++---++++++++-+-++++--+--+-$

$>$ KlePne_P17163

MVLMIVSGRSGSGKSVALRALEDMGFYCVDNLPVVLLPELARSLADRNISAAVS IDVRNMPESPEIFEQAMKNLP

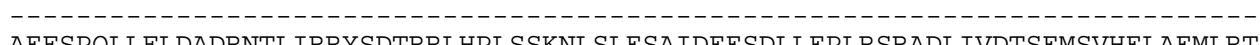
AEFSPQLLFLDADRNTLIRRYSDTRRLHP LSSKNLSLESA IDEESDLLEP LRSRADLIVDTSEMSVHELAEMLRT RLLGKRERELTMVFESFGFKHGIP IDADYVFDVRF LP NP HWDP KLRPMTGLDKPVAAF LDRHTEVHNF IYQTRSY

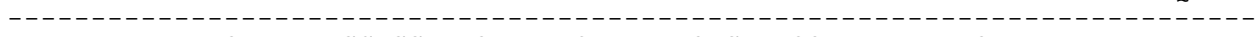
LELWLPMLETNNRSYLTVAIGCTGGKHRSVYIAEQLADYFRSRGKNVQSRHRTLEKRKS --- - - - - - - - - - - - - - - - ++++-+---- ++++++++++++++++++++++

$>$ LacCas_YP_806200

MTESLDLVI ITGMSGAGKTVAMQAFEDLGYFCVDNMP PALLP KFWELVKESGKI TKVALVVDLRSRAFYDQI IDM LANLDNNAYVHSR I LF LDATDEELVSRYKETRRSHP LAMEGRLMDGIKKERALLTELRNRAQVVIDTT TLSPRQL REKIFLNFKESGSOPAFHIEVMSFGFKYGLPIDADIVMDVRFLPNPFYIKDYRPKTGLDPEVYNYVMDNEDAESF YNKFYDLLSEIMP KYKAEGKTSVTIAIGCTGGQHRSVAFAERIGKAF SDAYAVDITHRD IKKHKETVNRS - 
$>$ LisMon_Sp.

MASKQLKLVI ITGMSGAGKTVAMQSLEDLGYFCVDNLPP SLLPKFWELMKESDKMDKIALVMDLRGREFFDS IEP ALDELDNTNF I TTKI LF LEADDKVLVSRYKETRRHHP LEPNGSVLD G INAERELLSDLKGRSQLVINT SNMAPRE

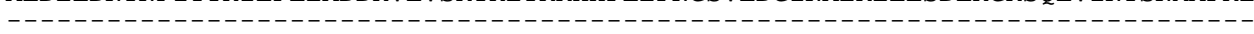
LRERINNEF QTEDKD IFNVQLMSFGFKYGIP IDADLVFDVRF LPNP HY IDKMRP LTGLDEDVYEYVMKWPETQTF LDKLVDLLMFTLPFYKREGKTQLVIAIGCTGGQHRSVALTEFVGKAIQQKYETT ISHRDMKRRKGR -

$>$ MycTubCDC1551_MT1464

MMNHARGVENRSEGGGIDVVLVTGLSGAGRGTAAKVLEDLGWYVADNLPPQLITRMVDFGLAAGSRITQLAVVMD --+--------+---++++-+-----++-++---+-----------------------------------------------VRSRGFTGDLDSVRNELATRAITPRVVFMEASDDT LVRRYEQNRRSHP LQGEQTLAEGIAAERRMLAPVRATADL I IDTSTLSVGGLRDS IERAFGGD GGATTSVTVESFGF KYGLPMDADMVMDVRF LPNP HWVDELRP LTGQHPAVRD I IDTSTLSVGGLRDS IERAFGGDGGATTSVTVESFGFKYGLPMDADMVMDVRF LPNP HWVDE LRP LTGQHPAVRD YVLHRP GAAEF LESYHRLLSLVVDGYRREGKRYMT IAIGCTGGKHRSVAIAEALMGLLRSDQQLSVRALHRDLGR -----------------------------+--++++-+------+++++++-------------+----------------$\mathrm{E}$

$>$ NitEur_NE1849

MQVI I ISGLSGSGKS IALKVLEDSGYYCVDNLPASLLVVL INHLQTQQHAYVAVA IDMRSGENITVLPWQLKMID KSIOIKF IFLEARTETLMORFSETRRRHPLSDKNITLEEAIRREREALATLTGLGHHIDTSSLRPNVLRAF IKDF KSIQIKF IFLEARTETLMQRFSETRRRHP LSDKNITLEEAIRREREALATLTGLGHHIDTSSLRPNVLRAF IKDF IADSRSP SQLTLLFQSFGYKHGIP LDADLVFD IRCLPNPFYDP QLKELTGHDPEVIRFMESQPDASKMLRDISSF

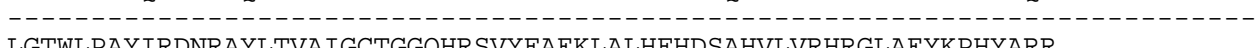
LGTWLPAYIRDNRAYLTVAIGCTGGQHRSVYFAEKLALHFHDSAHVLVRHRGLAEYKPHYARR

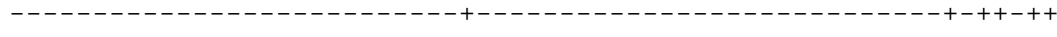

$>$ PhorLum_plu4044

MVLMIVSGRSGSGKSVALRALEDMGFYCVDNLPVVLLPELANT LADRDISAAVS IDVRNMPESPEVFEEALTKLP ASFSPQLLFLDAERNTLIRRYSDTRRLHP LSSKNLSLESAIDQESDLLEPLRSRADLI IDT SEMSVHELAEMLRT RLLGKRERELTMVFESFGF KHG IP IDADYVFDVRF LPNP HWDP KLRPMT GLDRPVAAF LDRHTEVHNF IYQTRSY - - - - - - - - - - - LELWLPMLETNNRSYLTVAIGCTGGKHRSVYVAEQLADYFRSRGKNVQSRHRTLEKRK $-----------------------++++-+---+--+++++++++++++++++++++$

>ProMir_AAC64575

MVLMIVSGRSGSGKSVALRALEDMGFYCVDNLPVDLLPELAKTLAERDAAAAAVS IDVRNMPESPEIFEKALESL PAEYSPQLLF LDADRNTLIRRYSDTRRLHP LSTKNLSLEMAIDTESDLLEP IRSRDVWI IDT SEMSVHELAEMLR

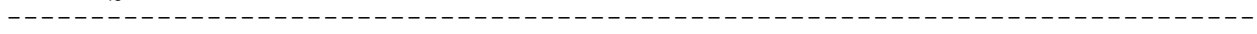
TRLLGKRERELTMVFESFGFKHG IP IDADYVF DVRF LPNP HWDP KLRPMT GLDRPVAAF LDRHTEVHNF IYQTRS YLELWLPMLETNNRSYLTVAIGCTGGKHRSVYVAEQLADYFRSRGKNVQSRHRTLEKRK -

>SalEntATCC9150_YhbJ

MVLMIVSGRSGSGKSVALRALEDMGFYCVDNLPVVLLPDLARTLADRQISAAVS IDVRNMPESPE IFEQAMNNLP GAF SP QLLF LDADRNTLIRRYSDTRRLHP LS SKNLSLESA IDKESDLLEP LRSRADL IVD TSEMSVHELAEMLRT RLLGKRERELTMVFESF GF KHG IP IDADYVFDVRF LPNP HWDP KLRPMT GLDKPVAAF LDRH TEVHNF I YQTRSY LELWLPMLETNNRSYLTVAIGCTGGKHRSVYIAEQLADYFRSRGKNVQSRHRTLEKRKT -

$>$ SalEntTy2_T3240

MVLMIVSGRSGSGKSVALRALEDMGFYCVDNLPVVLLPDLARTLADRQISAAVS IDVRNIPE SPE IFEQAMNNLP GAFSP QLLF LDADRNTLIRRYSDTRRLHP LSSKNLSLESA IDKESDLLEP LRSRADL IVDT SEMSVHELAEMLRT

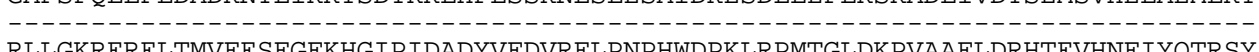
RLLGKRERELTMVEESEGEKHGIPIDADYVTDVRELPNPHWDPKLRPMTGLDKPVAAFLDRHTEVHN IYQTRSY LELWLPMLETNNRSYLTVAIGCTGGKHRSVYIAEQLADYFRSRGKNVQSRHRTLEKRKT -

>SalTyp_YhbJ

MVLMIVSGRSGSGKSVALRALEDMGFYCVDNLPVVLLPDLARTLADRQISAAVS IDVRNMPESPE IFEQAMNNLP GAF SP QLLF LDADRNTLIRRYSDTRRLHP LS SKNLSLESAIDKESDLLEP LRSRADLIVDTSEMSVHELAEMLRT GAF RLLGKRERELTMVFESFGF KHGIP IDADYVFDVRF LP NP HWDP KLRPMTGLDKPVAAF LDRH TEVHNF IYQTRSY LELWLPMLETNNRSYLTVAIGCTGGKHRSVYIAEQLADYFRSRGKNVQSRHRTLEKRKT 


\section{Anhang}

>SerPro_ZP_01538297

MVLMIVSGRSGSGKSVALRALEDMGFYCVDNLPVVLLPQLANTLAERNSSAAVS IDVRNMPESPEVFEYAMTQLP DSF SPQLLF LDADRNTLIRRYSDTRRLHP LSSKNLSLESA IDEESDLLEP LRSRADLI IDTSEMSVHELAEMLRT

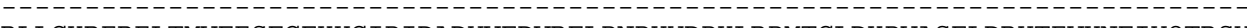
RLLGKRERELTMVFESFGFKHGIP IDADYVFDVRF LP NP HWDP KLRPMTGLDKPVASF LDRHTEVHNF IYQTRSY LEQWLPMLETNNRSYLTVAIGCTGGKHRSVYVAEQLADYFRSRGKNVQSRHRTLEKRKQ -

>SheFri_UPF0042

MKLVIVSGRSGSGKSVALRVLEDLGYYCVDNLPLP LIGTLLAQLKGSNDLVA I SVDVRNIAEQGKVLQDQLALLE NDTEI I SF F LNSNDKVLLKRYSETRRLHP LSKNH I SLQEA I KLEGRLLEP IAKIVDHY IDTSALNIYELSDQVRQ I LLGSVDKELVINFESF GF KHGMP TEADFMF DVRF LP NP HWE I ELRP F T GLDEPVQEF LGRQP LVNKF IWQ I ENL FETWMP HLERNNRSYLTIAIGCTGGQHRSVYIADQLAKRFRQGSKHTVNARHRELNISDTNN $-----------------------++++++-++-++++++++++++++++-+-+--+------$

>ShiFle_YhbJ

MVLMIVSGRSGSGKSVALRALEDMGFYCVDNLPVVLLPDLARTLADREISAAVS IDVRNMPESPEIFEQAMSNLP

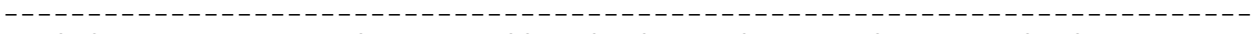
DAF SP QLLF LDADRNTLIRRYSDTRRLHP LSSKNLSLESAIDKESDLLEP LRSRADLIVDTSEMSVHELAEMLRT RLLGKRERELTMVFESFGFKHGIP IDADYVFDVRF LP NP HWDP KLRPMTGLDKPVAAFLDRHTEVHNF IYQTRSY LELWLPMLETNNRSYLTVAIGCTGGKHRSVYIAEQLADYFRSRGKNVQSRHRTLEKRKP >SOdGlo_SG0196

MVLMIVSGRSGSGKSVALRALEDMGFYCVDNLPVVLLPQLASALAASNISAAVS IDVRNMPESPE IFEQAMDNLP QAFAP QLLFLDADRNTLIRRYSDTRRLHP LSALNLSLESA IDEEDS LLEP LRSRADLVIDTSEMSVHELAEMLRT

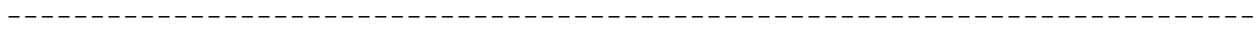
RMLGKRERELTMVFESFGYKHGIP IDADYVFDVRF LP NP HWDP KLRPMTGLDRPVAAF LDRHTEVHNF IYQTRSY LELWLPMLETNNRSYLTVAVGCTGGKHRSVYIAEQLADYFRSRGKNAQSRHRTLEKSKS --- - - - - - - - - - - - - - + ++++-+---+ -++++++++++-+++++---+-++

$>$ StaAur_Sp.

MDNNEKEKSKSELLVVTGLSGAGKSLVIQCLEDMGYFCVDNLPPVLLPKFVELMEQGNP SLRKVAIAIDLRGKEL

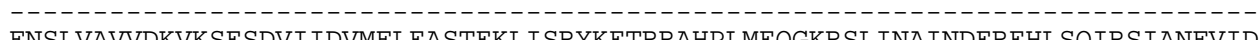
FNSLVAVVDKVKSESDVI IDVMF LEASTEKLI SRYKE TRRAHP LMEQGKRSLINA INDEREHLSQ IRS IANFVID TTKLSPKELKERIRRYYEDEEFETFT INVTSFGFKHG I QMDADLVFDVRFLPNPYYVVDLRP LTGLDKDVYNYVM KWKETEIFFEKLTDLLDFMIPGYKKEGKSOLVIAIGCTGGOHRSVALAERLGNYINEVFEYNVYVHHRDAH IESG KWKETEIFEEKLTDLLDFMIPGYKKEGKSQLVIAIGCTGGQHRSVALAERLGNYLNEVEEYNVYVHHRDAHIESG $\mathrm{EK}$

$--$

$>$ StrPyo_Sp.

MSDKHINLVIVTGMSGAGKTVAIQSFEDLGYFTIDNMPPALVPKFLELIEQTNENRRVALVVDMRSRLFFKEINS TLDS IESNP S IDFWILF LDATD GELVSRYKETRRS HP LAAD GRVLDG IRLERELLSP LKSMSQHVVDTTKLTPRQ --- - - - - - - - - - - - - - - - - - - - - - +- - - - - - - - - - - - - - - - - - - - - - - - - - - - - - - LRKT I SDQF SEGSNQASFRIEVMSF GFKYGLP LDADLVFDVRF LPNPYYQVELREKTGLDEDVFNYVMS HP ESEV FYKHLLNLIVP ILPAYQKEGKSVLTVAIGCTGGQHRSVAFAHCLAES LATDWSVNESHRDQNRRKETVNRS $-------------------------------+++++--------------------------+------+-$

$>$ VibCho_VC2532

MRLIVVSGQSGAGKSVALRVLEDLGYYCVDNLPVSLLTAF IQSVQGSQQNVAVS ID IRNLPKEP SLVQDVLDQLK QNNDVSMLFLDASKETLLKRYSETRRIHP LSLSQSKP S LAQA IELEKQLLGP LKEQADLLLDSSNQSLHELSETV RMRIEGRERKDLVMVEQSFGFKYGLP TDADYVFDVRF LPNP HWEPDLRP LTGLDAP I KSF LEGHSEVMELKQQIQ KFFEYWLPMLEKNNRSYLTIAIGCTGGKHRSVYLTQQLGEYFAQLGHQVQLRHTSLEKQQS --- - - - - - - - - - - - - - - - - - + +- - - - - - - - - - - - - - - - - - - - -

>YerBer_ZP_00821539

Optimal Predictions

MVLMIVSGRSGSGKSVALRALEDMGFYCVDNLPVVLLPQLANTLAGRNISAAVS IDVRNMPESPEVFEHAMTQLP DSFSPOLLFLDADRNTLIRRYSDTRRLHPISAKNLSLESA IDFESILIEPLRSRADLVIDTSEMSVHELAEMLRT

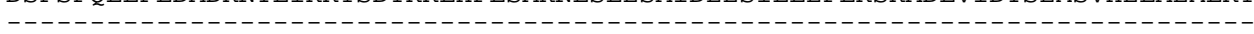
RLLGKRERELTMVFESFGFKHGIP IDADYVFDVRF LP NP HWDP KLRPMTGLDKPVISF LDRHTEVHNFVYQTRSY $--------------------------------------------------------------------------1$ LEQWLPMLETNNRSYLTVAIGCTGGKHRSVYVAEQLADYFRARGKNVQSRHRTLEKRKQ 
>YerEnt_ZP_00834134

MVLMIVSGRSGSGKSVALRALEDMGFYCVDNLPVVLLPQLASTLADRNISAAVS IDVRNMPESPEVFEHAMTQLP DSF SPQLLF LDADRNTLIRRYSDTRRLHP LSTKNLSLESA IDEESDLLEP LRSRADL I IDT SEMSVHELAEMLRT RLLGKRERELTMVF ESF GF KHGIP IDADYVFDVRF LP NP HWDP KLRPMTGLDKPVISF LDRHTEVHNF IYQTRSY LELWLPMLETNNRSYLTVAIGCTGGKHRSVYVAEQLADYFRARGKNVQSRHRTLEKRK $-------------------------++++-+---+--+++++++++++++++++++++$

>YerFre_ZP_00828963

MVLMIVSGRSGSGKSVALRALEDMGFYCVDNLPVVLLPQLASTLAERNISAAVS IDVRNMPESPEVFEHAMTQLP DSFSPQLLFLDADRNTLIRRYSDTRRLHP LSTKNLSLESAIDEESVLLEP LRSRADLI IDTSEMSVHELAEMLRT RLLGKRERELTMVFESF GFKHGIP IDADYVFDVRF LP NP HWDP KLRP MTGLDKPVISF LDRHTEVHNFVYQTRSY LELWLPMLETNNRSYLTVAIGCTGGKHRSVYVAEQLADYFRARGKNVQSRHRTLEKRK $-------------------------++++-+---+--+++++++++++++++++++++$

>YerMol_ZP_00827279

MVLMIVSGRSGSGKSVALRALEDMGFYCVDNLPVVLLPQLASTLADRNISAAVS IDVRNMPESPEVFEHAMTQLP DSFSPQLLFLDADRNTLIRRYSDTRRLHP LSTKNLSLESA IDEESDLLEP LRSRADL I IDTSEMSVHELAEMLRT

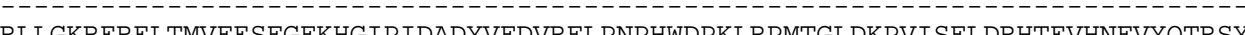
GLDKPVISFLDRHTEVHNFVYOTRSY

LELWLPMLETNNRSYLTVAIGCTGGKHRSVYVAEQLADYFRARGKNVQSRHRTLEKRKQ $-----------------------++++-+---+--++++++++++++++++++++++$

>YerPes_Sp.

MVLMIVSGRSGSGKSVALRALEDMGFYCVDNLPVVLLPQLASTLADRNISAAVS IDVRNMPESPEVFEHAMTQLP DSF SPQLLF LDADRNTLIRRYSDTRRLHP LSAKNLSLESAIDEESDLLEP LRSRADLI IDTSEMSVHELAEMLRT RLLGKRERELTMVFESFGFKHGIP IDADYVFDVRF LP NP HWDP KLRPMTGLDKPVISF LDRHTEVHNF IYQTRSY LEQWLPMLETNNRSYLTVAIGCTGGKHRSVYVAEQLADYFRARGKNVQSRHRTLEKRKQ $------------------------++++-+---+--++++++++++++++++++++++$

>YerPse_YPTB3529

MVLMIVSGRSGSGKSVALRALEDMGFYCVDNLPVVLLPQLASTLADRNISAAVS IDVRNMP ESPEVFEHAMTQLP DSFSPQLLF LDADRNTLIRRYSDTRRLHP LSAKNLSLESA IDEESDLLEP LRSRADL I IDTSEMSVHELAEMLRT RLLGKRERELTMVFESFGFKHGIP IDADYVFDVRF LP NP HWDP KLRPMT GLDKPVISF LDRHTEVHNF IYQTRSY LEQWLPMLETNNRSYLTVAIGCTGGKHRSVYVAEQLADYFRARGKNVQSRHRTLEKRKQ LEQWLPMLETNNRSYLTVAIGCTGGKHRSVYVAEQLADYFRARGKNVQSRHRT LEKRKQ

>ZymMob_ZMO1325

MSRNDLSSAPSSSAAPPARI LLVTGLSGAGKSTALRTFEDMGWETVDNLPLSLLERLILTPP SSVAAYKGRP LAL GIDSRTRGF TVDAF LKGVEQLRQHHSQP ID I LF LDCSD SELMRRFD T TRRRHP LALDRP MEDGISEERAF LAPVR

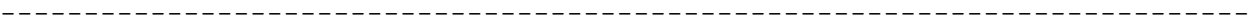
EIADF LIDTTTTSSHSLQSELRQQF AP ENSVAPNVS I LSFGF SRGIPRNCDLLFDMRF LQNPYWEEALRP LTGLD PEIADYIEQDP SF LPAVTKIKDLLLF LLPRY IDTGKSYIVIAFACTGGRHRSVYVAEWIAARLRQAHF S LT ITHR

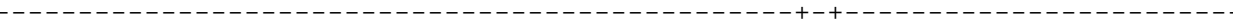
DLKLPLLESQSNRIRAGKAYQGG

$--------------+--+-++--$

\subsection{Rohdaten der MicroArray Analyse}

\begin{tabular}{|c|c|c|c|c|c|c|c|c|c|c|}
\hline Sequence ID & Venn & $\begin{array}{l}\text { Fold } \\
\text { Change }\end{array}$ & P-value & Int1 & Int2 & $\begin{array}{l}\text { Fold } \\
\text { Change }\end{array}$ & P-value & Int1 & Int2 & $\begin{array}{l}\text { Sequence } \\
\text { Code }\end{array}$ \\
\hline 1555628 & IX & 3,84 & $9,07 \mathrm{E}-08$ & 922 & 4023 & 85,01 & 0 & 211 & 20618 & ibpA \\
\hline 1555629 & IX & 4,28 & 0,00021 & 721 & 3757 & 61,11 & $4,27 \mathrm{E}-41$ & 273 & 21284 & ibpB \\
\hline 1554953 & III & $-1,29$ & 0,11263 & 7312 & 5185 & 25,82 & 0 & 633 & 16024 & pyrB \\
\hline 1554960 & III & $-1,21$ & 0,12283 & 1848 & 1437 & 20,20 & 0 & 192 & 4019 & pyrl \\
\hline 1555678 & IX & 8,93 & $7,76 \mathrm{E}-32$ & 2139 & 21832 & 12,25 & 0 & 5493 & 66905 & glmS \\
\hline 1556250 & III & $-1,01$ & 0,94071 & 12093 & 13800 & 11,90 & $1,40 \mathrm{E}-45$ & 2056 & 25427 & carA \\
\hline 1555315 & III & 1,57 & 0,00184 & 951 & 1623 & 11,69 & 0 & 1142 & 13522 & mopA \\
\hline 1555572 & III & 2,17 & 0,00864 & 1340 & 3985 & 10,88 & $4,33 \mathrm{E}-35$ & 1925 & 22435 & hsIV \\
\hline 1555911 & III & 1,50 & 0,05055 & 529 & 695 & 10,08 & 0 & 376 & 3795 & dnaK \\
\hline 1552813 & III & 1,46 & 0,29162 & 407 & 787 & 10,01 & $4,71 \mathrm{E}-16$ & 513 & 5871 & yrfG \\
\hline 1555316 & III & 2,18 & 0,00003 & 12845 & 32637 & 9,33 & 0 & 7263 & 67957 & mopB \\
\hline
\end{tabular}


Anhang

\begin{tabular}{|c|c|c|c|c|c|c|c|c|c|c|}
\hline 1554517 & III & 1,25 & 0,05212 & 10279 & 12072 & 8,67 & 0 & 6846 & 58528 & tnaA \\
\hline 1554518 & III & $-1,03$ & 0,7082 & 1020 & 991 & 7,67 & 0 & 343 & 2715 & tnaB \\
\hline 1554961 & III & 1,30 & 0,15827 & 827 & 1239 & 7,45 & $3,48 \mathrm{E}-26$ & 889 & 7032 & pyrL \\
\hline 1554501 & IX & 6,22 & $8,14 \mathrm{E}-30$ & 356 & 2315 & 7,18 & 2,19E-35 & 297 & 2120 & thiG \\
\hline 1555272 & III & $-1,18$ & 0,04639 & 338 & 287 & 7,12 & $1,62 \mathrm{E}-41$ & 240 & 1698 & $\mathrm{mglA}$ \\
\hline 1555273 & III & 1,09 & 0,42777 & 777 & 891 & 7,09 & 0 & 1069 & 7716 & $\mathrm{mglB}$ \\
\hline 1555274 & III & 1,16 & 0,46541 & 145 & 162 & 6,86 & 0 & 132 & 953 & $\mathrm{mglC}$ \\
\hline 1552814 & III & 1,75 & 0,01413 & 1443 & 2988 & 6,81 & 0 & 1347 & 9167 & yrfH \\
\hline 1555684 & III & 1,16 & 0,28457 & 2489 & 2931 & 6,55 & 0 & 617 & 4049 & $g \ln G$ \\
\hline 1556106 & IX & 3,94 & $9,38 \mathrm{E}-06$ & 272 & 1449 & 6,45 & $1,09 \mathrm{E}-27$ & 615 & 3807 & cysH \\
\hline 1557026 & III & 1,03 & 0,84607 & 2714 & 2662 & 6,36 & $5,34 \mathrm{E}-18$ & 796 & 5122 & ampD \\
\hline 1556197 & III & 1,72 & 4,57E-07 & 2688 & 4613 & 6,30 & 0 & 972 & 6241 & b4140 \\
\hline 1555910 & III & $-1,08$ & 0,89756 & 294 & 225 & 6,12 & 0,00009 & 212 & 1197 & dnaJ \\
\hline 1553230 & III & $-1,41$ & 0,00612 & 780 & 553 & 6,05 & $1,87 \mathrm{E}-21$ & 102 & 625 & yjaB \\
\hline 1552991 & III & 1,17 & 0,42472 & 134 & 159 & 5,86 & $1,57 \mathrm{E}-30$ & 126 & 771 & yjcH \\
\hline 1555571 & III & 1,59 & 0,06901 & 159 & 278 & 5,75 & $3,15 \mathrm{E}-18$ & 187 & 1135 & hslU \\
\hline 1553509 & IX & 4,78 & $2,26 \mathrm{E}-11$ & 398 & 1981 & 5,41 & $2,42 \mathrm{E}-15$ & 321 & 1648 & yhdY \\
\hline 1555460 & IX & 2,53 & $8,42 \mathrm{E}-07$ & 1081 & 3218 & 5,27 & $8,74 \mathrm{E}-31$ & 1818 & 10104 & Ion \\
\hline 1556248 & III & $-1,07$ & 0,47832 & 613 & 576 & 5,25 & $5,84 \mathrm{E}-15$ & 237 & 1242 & caiF \\
\hline 1555858 & III & 2,07 & 0,03109 & 171 & 412 & 5,02 & $3,06 \mathrm{E}-17$ & 98 & 478 & frvR \\
\hline 1556298 & III & 1,02 & 0,93835 & 157 & 164 & 4,86 & $6,07 \mathrm{E}-18$ & 119 & 588 & clpB \\
\hline 1555888 & III & $-1,33$ & 0,015 & 410 & 300 & 4,68 & $4,65 \mathrm{E}-31$ & 263 & 1234 & fumC \\
\hline 1556985 & III & $-1,06$ & 0,59992 & 239 & 231 & 4,54 & $1,07 \mathrm{E}-37$ & 206 & 954 & acs \\
\hline 1554758 & IX & 4,43 & $6,53 \mathrm{E}-25$ & 125 & 571 & 4,38 & $1,28 \mathrm{E}-28$ & 102 & 445 & rhaS \\
\hline 1556107 & III & 1,82 & 0,00004 & 86 & 163 & 4,36 & $8,83 \mathrm{E}-25$ & 72 & 313 & cysl \\
\hline 1555504 & III & 1,29 & 0,3946 & 166 & 251 & 4,22 & $5,52 \mathrm{E}-22$ & 128 & 542 & $\mathrm{mcrC}$ \\
\hline 1555139 & III & $-1,01$ & 0,98257 & 5339 & 3791 & 4,07 & $6,38 \mathrm{E}-08$ & 6307 & 24608 & ndk \\
\hline 1553071 & III & 1,36 & 0,05631 & 748 & 989 & 4,05 & 0 & 237 & 981 & yjhH \\
\hline 1556086 & III & 1,12 & 0,61925 & 238 & 274 & 4,03 & $1,40 \mathrm{E}-45$ & 211 & 877 & сусA \\
\hline 1554111 & III & 1,53 & 0,01378 & 439 & 600 & 4,00 & $1,05 \mathrm{E}-41$ & 502 & 1984 & ybeY \\
\hline 1556102 & III & 3,10 & 0,01397 & 128 & 592 & 3,90 & $1,16 \mathrm{E}-07$ & 332 & 1368 & cysC \\
\hline 1555386 & III & 1,55 & 0,00016 & 506 & 794 & 3,79 & $1,35 \mathrm{E}-39$ & 241 & 906 & inaA-r \\
\hline 1554955 & III & $-1,27$ & 0,3314 & 1473 & 931 & 3,77 & $5,13 \mathrm{E}-08$ & 781 & 2814 & pyrD \\
\hline 1552990 & III & 1,13 & 0,5085 & 152 & 169 & 3,63 & $4,58 \mathrm{E}-27$ & 141 & 509 & yjcG \\
\hline 1554460 & III & $-1,11$ & 0,62547 & 3396 & 2634 & 3,59 & $1,63 \mathrm{E}-10$ & 3447 & 12333 & sucC \\
\hline 1556218 & III & 1,47 & 0,12888 & 372 & 505 & 3,54 & 0 & 244 & 870 & bglF \\
\hline 1552815 & III & 1,32 & 0,20591 & 170 & 232 & 3,53 & $1,37 \mathrm{E}-11$ & 231 & 834 & yrfl \\
\hline 1555250 & III & 1,78 & 0,00337 & 399 & 669 & 3,48 & $2,48 \mathrm{E}-21$ & 428 & 1532 & menA \\
\hline 1554112 & III & 1,37 & 0,3048 & 200 & 247 & 3,45 & $7,13 \mathrm{E}-18$ & 303 & 1000 & ybez \\
\hline 1553798 & III & 1,20 & 0,26154 & 423 & 506 & 3,40 & $1,04 \mathrm{E}-28$ & 278 & 949 & $y c j X$ \\
\hline 1555009 & III & $-1,10$ & 0,75775 & 637 & 451 & 3,37 & $6,23 \mathrm{E}-16$ & 931 & 3054 & oppA \\
\hline 1554339 & III & $-1,26$ & 0,01932 & 921 & 727 & 3,37 & $1,02 \mathrm{E}-10$ & 597 & 2107 & upp \\
\hline 1555685 & III & 1,18 & 0,18521 & 579 & 655 & 3,34 & $2,48 \mathrm{E}-35$ & 1146 & 3947 & $\mathrm{glnH}$ \\
\hline 1553184 & III & 2,48 & 0,00021 & 333 & 836 & 3,29 & $5,52 \mathrm{E}-16$ & 314 & 1039 & yigU \\
\hline 1554319 & III & $-1,03$ & 0,76799 & 2750 & 2731 & 3,25 & $4,65 \mathrm{E}-18$ & 2263 & 7386 & udhA \\
\hline 1556070 & III & 1,13 & 0,24774 & 9060 & 10099 & 3,25 & $6,25 \mathrm{E}-37$ & 7577 & 24685 & cspE \\
\hline 1553892 & III & 1,09 & 0,52364 & 1250 & 1386 & 3,25 & $9,74 \mathrm{E}-13$ & 701 & 2314 & yeaD \\
\hline 1553988 & III & 1,78 & 0,0076 & 1098 & 2383 & 3,19 & $4,28 \mathrm{E}-14$ & 1454 & 4875 & yceP \\
\hline 1556347 & III & 1,38 & 0,00037 & 961 & 1302 & 3,12 & $8,58 \mathrm{E}-23$ & 1355 & 4331 & b2531 \\
\hline 1555744 & III & 1,22 & 0,56782 & 210 & 309 & 3,12 & 1,06E-09 & 233 & 755 & grpE \\
\hline 1556874 & III & 1,55 & 0,00005 & 374 & 568 & 3,11 & $1,07 \mathrm{E}-16$ & 633 & 2026 & artP \\
\hline 1556193 & III & $-1,56$ & 0,0001 & 513 & 339 & 3,08 & 1,22E-21 & 341 & 1075 & b3913 \\
\hline 1556108 & IX & 1,91 & 1,66E-09 & 211 & 394 & 3,06 & $6,72 \mathrm{E}-06$ & 432 & 1254 & cysJ \\
\hline 1555240 & III & $-1,15$ & 0,56325 & 2254 & 1608 & 3,06 & $6,27 \mathrm{E}-08$ & 2872 & 8646 & mdh \\
\hline 1555576 & III & 1,47 & 0,02941 & 368 & 492 & 3,00 & $2,53 \mathrm{E}-25$ & 636 & 1936 & htrA \\
\hline 1555505 & III & $-1,23$ & 0,01905 & 382 & 311 & 2,99 & $2,72 \mathrm{E}-23$ & 141 & 421 & $\mathrm{mcrD}$ \\
\hline 1554435 & III & 1,06 & 0,78046 & 3194 & 3505 & 2,98 & $1,09 \mathrm{E}-18$ & 1178 & 3529 & yadD \\
\hline 1557015 & III & 1,02 & 0,8296 & 564 & 559 & 2,97 & 1,79E-32 & 533 & 1593 & aldA \\
\hline 1555909 & III & 1,37 & 0,06073 & 1000 & 1514 & 2,96 & $2,26 \mathrm{E}-23$ & 1297 & 3851 & dnaG \\
\hline 1554070 & III & 1,67 & 0,21751 & 4129 & 11552 & 2,94 & 0,00021 & 9209 & 29815 & ybcU \\
\hline 1555263 & III & 2,22 & 0,03016 & 80 & 197 & 2,94 & $9,44 \mathrm{E}-17$ & 103 & 303 & metF \\
\hline 1556194 & III & 1,06 & 0,87553 & 1236 & 1896 & 2,92 & 0,00012 & 1636 & 5176 & b3914 \\
\hline 1555241 & III & $-1,13$ & 0,4899 & 1848 & 1401 & 2,92 & 4,04E-07 & 2990 & 8481 & mdh-r \\
\hline 1556987 & III & 1,05 & 0,79163 & 351 & 406 & 2,90 & $2,79 \mathrm{E}-11$ & 409 & 1202 & add \\
\hline
\end{tabular}


Anhang

\begin{tabular}{|c|c|c|c|c|c|c|c|c|c|c|}
\hline 1553148 & III & 1,32 & 0,0378 & 327 & 420 & 2,87 & 1,93E-10 & 180 & 510 & yidY \\
\hline 1555287 & III & 1,20 & 0,1141 & 4920 & 5611 & 2,87 & 1,09E-06 & 5819 & 15967 & miaA \\
\hline 1553958 & III & 1,56 & 0,04539 & 2789 & 5284 & 2,87 & 4,07E-12 & 3971 & 11764 & $y c c V$ \\
\hline 1553731 & III & 1,45 & 0,01552 & 98 & 145 & 2,85 & 0,0001 & 124 & 377 & yeic \\
\hline 1556779 & III & $-1,03$ & 0,78803 & 490 & 479 & 2,84 & $1,78 \mathrm{E}-19$ & 168 & 463 & b1397 \\
\hline 1555432 & III & 1,86 & 0,01504 & 105 & 217 & 2,80 & 0,00001 & 239 & 721 & IdhA \\
\hline 1553285 & III & $-1,11$ & 0,72937 & 1206 & 891 & 2,79 & 0,00051 & 2011 & 5471 & yhgl \\
\hline 1556045 & III & $-1,23$ & 0,18131 & 304 & 264 & 2,78 & $1,39 \mathrm{E}-17$ & 308 & 871 & corA \\
\hline 1554340 & III & 1,00 & 0,97713 & 420 & 423 & 2,76 & 9,34E-06 & 403 & 1171 & uraA \\
\hline 1553201 & III & 1,28 & 0,28732 & 245 & 342 & 2,76 & 1,15E-31 & 130 & 354 & yinR \\
\hline 1554950 & III & $-1,34$ & 0,38496 & 155 & 126 & 2,76 & 1,49E-06 & 110 & 285 & putP \\
\hline 1555086 & III & 1,35 & 0,12484 & 364 & 475 & 2,75 & 1,43E-18 & 135 & 371 & phnO \\
\hline 1553165 & III & $-1,32$ & 0,13897 & 893 & 598 & 2,74 & $2,43 E-29$ & 387 & 1066 & yifE \\
\hline 1553097 & III & 1,22 & 0,14896 & 567 & 683 & 2,59 & $1,36 \mathrm{E}-07$ & 318 & 814 & yjiU \\
\hline 1554110 & III & 1,76 & 0,01476 & 176 & 283 & 2,58 & $5,97 \mathrm{E}-11$ & 289 & 718 & ybeX \\
\hline 1554484 & III & 1,27 & 0,424 & 208 & 254 & 2,52 & 6,44E-09 & 287 & 738 & $\operatorname{tdcD}$ \\
\hline 1554956 & III & 1,13 & 0,60999 & 159 & 182 & 2,50 & $8,80 \mathrm{E}-06$ & 143 & 379 & pyrE \\
\hline 1555164 & III & 1,10 & 0,54283 & 1097 & 1069 & 2,50 & $3,24 \mathrm{E}-19$ & 3036 & 7518 & $\mathrm{nmpC}$ \\
\hline 1555689 & III & 1,04 & 0,85109 & 506 & 491 & 2,47 & $9,68 \mathrm{E}-13$ & 701 & 1735 & $g \ln Q$ \\
\hline 1555503 & III & 1,11 & 0,70274 & 304 & 407 & 2,44 & $4,75 \mathrm{E}-08$ & 510 & 1307 & $\mathrm{mcrB}$ \\
\hline 1555401 & III & 1,01 & 0,9639 & 888 & 865 & 2,43 & 3,44E-07 & 706 & 1587 & ivbL \\
\hline 1554628 & III & 1,28 & 0,43954 & 188 & 237 & 2,37 & 0,00003 & 163 & 387 & sbp \\
\hline 1553096 & III & 1,27 & 0,44327 & 166 & 258 & 2,35 & $9,79 \mathrm{E}-08$ & 325 & 781 & yjiт \\
\hline 1555010 & III & 1,05 & 0,6125 & 267 & 275 & 2,35 & 1,83E-24 & 584 & 1373 & oppB \\
\hline 1553540 & III & 1,48 & 0,06255 & 579 & 1005 & 2,34 & $2,16 \mathrm{E}-17$ & 2052 & 4809 & yfhO \\
\hline 1554705 & III & 1,23 & 0,15144 & 3500 & 4756 & 2,34 & 1,39E-12 & 4709 & 11299 & speE \\
\hline 1553431 & III & 1,08 & 0,50168 & 561 & 617 & 2,33 & 2,82E-22 & 227 & 535 & ygjO \\
\hline 1555869 & III & 1,22 & 0,03481 & 436 & 536 & 2,32 & $8,03 \mathrm{E}-12$ & 530 & 1267 & $\mathrm{ftsJ}$ \\
\hline 1555886 & III & $-1,04$ & 0,81886 & 498 & 514 & 2,32 & $8,88 \mathrm{E}-20$ & 694 & 1642 & fumA \\
\hline 1555483 & III & $-1,26$ & 0,15092 & 207 & 168 & 2,31 & $7,73 \mathrm{E}-11$ & 177 & 411 & malK \\
\hline 1555859 & III & 1,49 & 0,05403 & 396 & 574 & 2,28 & 6,82E-06 & 216 & 502 & frvX \\
\hline 1555774 & III & 1,43 & 0,00939 & 310 & 432 & 2,28 & $3,71 \mathrm{E}-06$ & 175 & 390 & fimc \\
\hline 1554954 & III & 1,05 & 0,84566 & 438 & 370 & 2,27 & $2,56 \mathrm{E}-15$ & 525 & 1175 & pyrC \\
\hline 1556787 & III & $-1,09$ & 0,5495 & 531 & 526 & 2,26 & 0,00001 & 377 & 888 & b1422 \\
\hline 1553501 & III & 1,29 & 0,09676 & 277 & 375 & 2,25 & 1,10E-09 & 373 & 867 & yhdN \\
\hline 1554540 & III & $-1,07$ & 0,60663 & 1497 & 1333 & 2,25 & 5,30E-09 & 5365 & 12146 & treC \\
\hline 1552853 & III & 1,25 & 0,33845 & 962 & 931 & 2,25 & $3,26 \mathrm{E}-07$ & 836 & 1905 & ykfE \\
\hline 1555088 & III & 1,21 & 0,37185 & 332 & 391 & 2,22 & 1,69E-06 & 145 & 325 & phnQ \\
\hline 1554040 & III & $-1,31$ & 0,04427 & 797 & 617 & 2,20 & $1,41 \mathrm{E}-08$ & 334 & 762 & yciH \\
\hline 1555276 & III & 1,12 & 0,66272 & 321 & 420 & 2,20 & $5,97 \mathrm{E}-10$ & 427 & 946 & mgtA \\
\hline 1554457 & III & 1,05 & 0,66373 & 355 & 376 & 2,19 & 5,15E-08 & 197 & 439 & $\operatorname{stp} A$ \\
\hline 1556872 & III & 1,16 & 0,12701 & 757 & 872 & 2,19 & 5,52E-09 & 1038 & 2330 & artl \\
\hline 1554770 & III & 1,14 & 0,51918 & 510 & 671 & 2,18 & 2,73E-16 & 1454 & 3198 & ribB \\
\hline 1556233 & III & 1,30 & 0,32665 & 1381 & 1752 & 2,17 & 1,04E-06 & 805 & 1753 & brnQ \\
\hline 1555688 & III & 1,29 & 0,23277 & 204 & 242 & 2,16 & $3,23 E-15$ & 479 & 1065 & $g \ln P$ \\
\hline 1553114 & III & $-1,05$ & 0,65424 & 669 & 618 & 2,15 & $3,54 \mathrm{E}-20$ & 880 & 1915 & yibN \\
\hline 1554459 & III & $-1,01$ & 0,98015 & 2300 & 1851 & 2,13 & $3,44 \mathrm{E}-10$ & 4629 & 9785 & sucB \\
\hline 1553747 & III & 1,25 & 0,12593 & 300 & 385 & 2,09 & 8,82E-09 & 232 & 474 & yejF \\
\hline 1555666 & III & $-1,07$ & 0,48868 & 382 & 355 & 2,04 & $2,16 \mathrm{E}-07$ & 430 & 899 & glcF \\
\hline 1555597 & III & $-1,21$ & 0,12081 & 186 & 154 & 2,02 & $2,09 \mathrm{E}-07$ & 152 & 308 & hycA \\
\hline 1555070 & III & $-1,45$ & 0,00053 & 3655 & 2509 & 2,02 & $2,14 \mathrm{E}-11$ & 1005 & 2043 & pheP \\
\hline 1556116 & III & 1,12 & 0,63185 & 176 & 206 & 2,00 & 4,63E-13 & 299 & 600 & cysW \\
\hline 1555830 & III & 1,31 & 0,15955 & 333 & 473 & 1,96 & 1,63E-13 & 596 & 1176 & fliY \\
\hline 1554859 & III & $-1,50$ & 0,00003 & 1810 & 1202 & 1,95 & $3,12 \mathrm{E}-16$ & 610 & 1191 & potG \\
\hline 1556883 & III & $-1,43$ & 0,01191 & 342 & 232 & 1,93 & 8,33E-15 & 409 & 793 & asnA \\
\hline 1555979 & III & 1,13 & 0,53141 & 115 & 129 & 1,91 & 1,22E-07 & 133 & 249 & exbB \\
\hline 1555707 & III & $-1,10$ & 0,28842 & 3030 & 2749 & 1,85 & $4,04 \mathrm{E}-13$ & 5668 & 10740 & gltA \\
\hline 1556944 & 1 & 2,49 & $2,15 \mathrm{E}-10$ & 128 & 302 & 1,69 & $6,02 \mathrm{E}-07$ & 342 & 574 & b0831 \\
\hline 1555773 & IV & $-1,03$ & 0,8888 & 220 & 219 & $-1,87$ & $1,36 \mathrm{E}-11$ & 783 & 417 & hemA \\
\hline 1555321 & IV & $-1,15$ & 0,23529 & 1046 & 903 & $-1,89$ & $2,76 \mathrm{E}-14$ & 2983 & 1596 & $\mathrm{mrcB}$ \\
\hline 1553108 & IV & $-1,18$ & 0,2649 & 434 & 364 & $-1,89$ & $8,99 \mathrm{E}-11$ & 767 & 408 & yjjN \\
\hline 1553027 & IV & $-1,01$ & 0,94739 & 158 & 159 & $-1,90$ & $9,45 \mathrm{E}-15$ & 879 & 463 & yjeR \\
\hline 1554362 & IV & $-1,31$ & 0,07979 & 554 & 386 & $-1,91$ & $2,10 \mathrm{E}-10$ & 2389 & 1239 & wbbl \\
\hline 1554940 & IV & $-1,24$ & 0,37575 & 141 & 120 & $-1,94$ & 4,81E-09 & 356 & 183 & purF \\
\hline
\end{tabular}


Anhang

\begin{tabular}{|c|c|c|c|c|c|c|c|c|c|c|}
\hline 1552810 & IV & 1,16 & 0,40898 & 576 & 629 & $-2,02$ & $6,23 \mathrm{E}-10$ & 1294 & 632 & yrfD \\
\hline 1554814 & IV & $-1,31$ & 0,02045 & 567 & 428 & $-2,02$ & $1,81 \mathrm{E}-16$ & 2700 & 1336 & $\mathrm{rplQ}$ \\
\hline 1554965 & IV & $-1,16$ & 0,33782 & 775 & 721 & $-2,08$ & $1,40 \mathrm{E}-08$ & 5112 & 2439 & $\operatorname{radC}$ \\
\hline 1553489 & IV & $-1,14$ & 0,49355 & 328 & 296 & $-2,10$ & $1,32 \mathrm{E}-16$ & 781 & 369 & yhcN \\
\hline 1554450 & IV & 1,06 & 0,82895 & 250 & 319 & $-2,12$ & $3,18 \mathrm{E}-07$ & 1898 & 909 & srlR \\
\hline 1553040 & IV & 1,01 & 0,93918 & 188 & 197 & $-2,12$ & $9,41 \mathrm{E}-17$ & 908 & 428 & yjfN \\
\hline 1553756 & IV & $-1,00$ & 0,98479 & 103 & 103 & $-2,17$ & $1,91 \mathrm{E}-13$ & 352 & 163 & yfaE \\
\hline 1555008 & IV & $-1,10$ & 0,69427 & 466 & 386 & $-2,18$ & $2,64 \mathrm{E}-17$ & 2337 & 1056 & ompX \\
\hline 1556143 & IV & $-1,08$ & 0,63856 & 173 & 161 & $-2,18$ & 1,30E-08 & 455 & 207 & deaD \\
\hline 1555138 & IV & $-1,16$ & 0,63849 & 150 & 124 & $-2,21$ & $3,41 \mathrm{E}-06$ & 673 & 301 & ndh \\
\hline 1554605 & IV & 1,05 & 0,85839 & 143 & 160 & $-2,26$ & 0,00002 & 573 & 255 & rstB \\
\hline 1557011 & IV & 1,31 & 0,30492 & 214 & 243 & $-2,26$ & 1,37E-06 & 1458 & 635 & ahpF \\
\hline 1556448 & IV & $-1,08$ & 0,48388 & 141 & 127 & $-2,28$ & $2,84 \mathrm{E}-10$ & 681 & 295 & b1837 \\
\hline 1555358 & IV & 1,23 & 0,56793 & 122 & 119 & $-2,28$ & $4,65 \mathrm{E}-06$ & 538 & 230 & mviN \\
\hline 1554363 & IV & $-1,31$ & 0,02318 & 468 & 339 & $-2,30$ & $2,03 \mathrm{E}-11$ & 3989 & 1729 & wbbJ \\
\hline 1554595 & IV & $-1,74$ & 0,00002 & 2287 & 1365 & $-2,36$ & $3,55 \mathrm{E}-09$ & 15862 & 7025 & rpsS \\
\hline 1556889 & IV & 1,05 & 0,79922 & 184 & 199 & $-2,38$ & $6,95 \mathrm{E}-14$ & 721 & 305 & aspS \\
\hline 1554808 & IV & $-1,12$ & 0,47793 & 2926 & 2370 & $-2,40$ & $3,81 \mathrm{E}-07$ & 25279 & 10019 & rplL \\
\hline 1554566 & IV & $-1,48$ & 0,28973 & 398 & 252 & $-2,42$ & 0,00008 & 1921 & 714 & tsf \\
\hline 1554820 & $x$ & $-1,99$ & 1,37E-09 & 1797 & 873 & $-2,46$ & $3,02 \mathrm{E}-20$ & 10730 & 4441 & rplV \\
\hline 1554847 & IV & $-2,05$ & 0,00271 & 1788 & 768 & $-2,50$ & $9,24 \mathrm{E}-08$ & 5695 & 2290 & rpsC \\
\hline 1552841 & IV & $-1,11$ & 0,50174 & 628 & 572 & $-2,52$ & 3,88E-07 & 1770 & 718 & yjjP \\
\hline 1553194 & IV & $-1,12$ & 0,53849 & 1602 & 1653 & $-2,53$ & 1,47E-09 & 11898 & 4809 & yihK \\
\hline 1555167 & IV & $-1,01$ & 0,95992 & 181 & 187 & $-2,56$ & $5,40 \mathrm{E}-06$ & 962 & 375 & nrdA \\
\hline 1556989 & IV & $-1,08$ & 0,74196 & 275 & 281 & $-2,57$ & $2,66 \mathrm{E}-10$ & 2275 & 902 & adhE \\
\hline 1554422 & IV & 1,00 & 0,98809 & 259 & 262 & $-2,57$ & 5,77E-06 & 758 & 297 & yabO \\
\hline 1554617 & IV & 1,10 & 0,74523 & 131 & 140 & $-2,61$ & $1,42 \mathrm{E}-07$ & 934 & 354 & sapA \\
\hline 1555255 & IV & 1,12 & 0,62822 & 184 & 217 & $-2,63$ & 2,61E-08 & 1131 & 442 & menF \\
\hline 1552948 & IV & $-1,08$ & 0,62186 & 186 & 179 & $-2,65$ & $5,71 \mathrm{E}-11$ & 755 & 283 & yojL \\
\hline 1555183 & IV & $-1,02$ & 0,86822 & 213 & 212 & $-2,66$ & $2,45 \mathrm{E}-15$ & 1299 & 478 & ntpA \\
\hline 1554615 & IV & $-1,04$ & 0,74295 & 177 & 170 & $-2,67$ & 4,31E-24 & 435 & 162 & ruvC \\
\hline 1555109 & IV & $-1,07$ & 0,75344 & 276 & 295 & $-2,74$ & $2,03 E-16$ & 2081 & 751 & pmrD \\
\hline 1554012 & IV & 1,78 & 0,00001 & 135 & 243 & $-2,80$ & $1,93 \mathrm{E}-24$ & 986 & 354 & $y c g E$ \\
\hline 1553443 & IV & $-1,04$ & 0,82107 & 287 & 265 & $-2,84$ & 2,33E-21 & 691 & 243 & yhaG \\
\hline 1554744 & IV & $-1,52$ & 0,00028 & 402 & 270 & $-2,86$ & 1,93E-19 & 1180 & 412 & rfaY \\
\hline 1554440 & IV & 1,25 & 0,51168 & 160 & 184 & $-2,96$ & $3,27 \mathrm{E}-10$ & 772 & 262 & yadl \\
\hline 1554027 & IV & 1,05 & 0,80371 & 124 & 130 & $-2,99$ & 5,61E-22 & 982 & 333 & ychH \\
\hline 1555249 & IV & 1,48 & 0,26999 & 113 & 155 & $-3,15$ & $2,08 \mathrm{E}-07$ & 907 & 302 & melR \\
\hline 1554364 & IV & $-1,01$ & 0,96367 & 654 & 720 & $-3,19$ & 5,37E-29 & 6620 & 2081 & wbbK \\
\hline 1554935 & IV & $-1,44$ & 0,00035 & 408 & 279 & $-3,19$ & 1,30E-09 & 2686 & 806 & purA \\
\hline 1553809 & IV & 1,37 & 0,45718 & 268 & 453 & $-3,22$ & 2,13E-07 & 2487 & 812 & ydaR \\
\hline 1556476 & IV & $-2,05$ & 0,00146 & 209 & 99 & $-3,25$ & $3,14 \mathrm{E}-18$ & 392 & 122 & b2001 \\
\hline 1554745 & IV & $-1,11$ & 0,5115 & 181 & 165 & $-3,38$ & $6,53 \mathrm{E}-22$ & 1293 & 387 & rfaZ \\
\hline 1553455 & IV & $-1,05$ & 0,8154 & 109 & 108 & $-3,45$ & 4,26E-31 & 561 & 164 & yhaU \\
\hline 1556971 & IV & $-1,06$ & 0,85561 & 388 & 322 & $-3,47$ & $1,08 \mathrm{E}-11$ & 3220 & 916 & aceF \\
\hline 1553442 & IV & 1,13 & 0,71801 & 109 & 113 & $-3,56$ & 1,94E-22 & 991 & 276 & yhaF \\
\hline 1553463 & IV & $-1,07$ & 0,74854 & 1280 & 1478 & $-3,63$ & 4,94E-41 & 14953 & 4152 & yhbM \\
\hline 1555519 & IV & 1,05 & 0,8487 & 216 & 230 & $-3,68$ & $1,23 \mathrm{E}-06$ & 1146 & 285 & hepA \\
\hline 1554481 & IV & $-1,34$ & 0,30019 & 102 & 83 & $-3,98$ & 4,74E-06 & 485 & 112 & $\operatorname{tdc} A$ \\
\hline 1554739 & IV & $-1,27$ & 0,49882 & 513 & 515 & $-4,74$ & 6,11E-07 & 4355 & 994 & rfaK \\
\hline 1553461 & $x$ & $-2,36$ & 0,00086 & 247 & 102 & $-8,28$ & 0 & 923 & 108 & yhbJ \\
\hline 1556067 & IV & 1,12 & 0,63171 & 1117 & 1552 & $-15,31$ & 0 & 44565 & 2964 & $\operatorname{csp} A$ \\
\hline
\end{tabular}




$\begin{array}{ll}\text { Name: } & \text { Kalamorz, Falk } \\ \text { Geburtsdatum: } & 06.02 .1981 \\ \text { Geburtsort: } & \text { Bad Lauterberg } \\ \text { Nationalität: } & \text { Deutsch }\end{array}$

Bildung und berufliche Laufbahn:

1987-1991

1991-1993

1993-1997

$1997-2000$

2000-2005

2005

2006-bis heute
Grundschule Bad Lauterberg

Orientierungsstufe der Kooperative Gesamtschule Bad Lauterberg

Gymnasialzweig an der Kooperative Gesamtschule Bad Lauterberg

Sekundardstufe 2 am Ernst-Moritz-Arndt-Gymnasium Herzberg/Harz, Erlangen der Allgemeinen Hochschulreife Studium der Biologie (Diplom) an der Georg-AugustUniversität Göttingen

Abschluß mit Diplom

Dktorarbeit am Institut für Allgemeine Mikrobiologie und Genetik, Georg-August-Universität Göttingen 